Abbas Poya,

Maurus Reinkowski (Hg.)

Das Unbehagen in

der Islamwissenschaft

Ein klassisches Fach

im Scheinwerferlicht

der Politik und der Medien

[transcript] global | local Islam 
Abbas Poya, Maurus Reinkowski (Hg.)

Das Unbehagen in der Islamwissenschaft 

Abbas Poya, Maurus Reinkowski (Hg.)

\section{Das Unbehagen in der Islamwissenschaft}

Ein klassisches Fach im Scheinwerferlicht

der Politik und der Medien

[transcript] 


\section{Bibliografische Information der Deutschen Bibliothek}

Die Deutsche Bibliothek verzeichnet diese Publikation in der Deutschen Nationalbibliografie; detaillierte bibliografische Daten sind im Internet über http://dnb.ddb.de abrufbar.

(C) 2008 transcript Verlag, Bielefeld

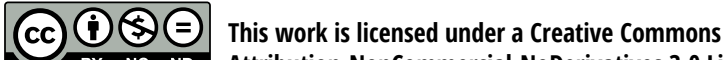 BY NC ND Attribution-NonCommercial-NoDerivatives 3.0 License.}

Umschlaggestaltung: Kordula Röckenhaus, Bielefeld Lektorat \& Satz: Abbas Poya Druck: Majuskel Medienproduktion GmbH, Wetzlar ISBN 978-3-89942-715-8

Gedruckt auf alterungsbeständigem Papier mit chlorfrei gebleichtem Zellstoff. Besuchen Sie uns im Internet: http://www.transcript-verlag.de

Bitte fordern Sie unser Gesamtverzeichnis und andere Broschüren an unter: info@transcript-verlag.de 


\section{Inhalt}

Einführung: Was soll Islamwissenschaft bedeuten?

ABBAS POYA/MAURUS REINKOWSKI

\section{TEIL I}

\section{SELBSTVER(UN)SiCHERUNGEN}

Islamwissenschaft und relevante Redundanz

MAURUS REINKOWSKI

Islamwissenschaft:

Globalisierung einer philologischen Disziplin

BENJAMIN JOKISCH

Historismus versus Orientalismus?

Oder: Zur Geschichte einer Wahlverwandtschaft

BIRGIT SCHÄBLER

Islamwissenschaft aus der Sicht eines

außer-universitären Forschungsinstituts: Orient als Islam?

ULRIKE FREITAG

\section{TEIL II}

\section{AN DEN ANGEBLICHEN RÄNDERN}

,Die Mauer muss weg!', oder: Alles für sich ist singulär.

Gedanken zur islamwissenschaftlichen Beschäftigung mit Südasien in Deutschland

JAN-PETER HARTUNG

Iranistik zwischen brennender Aktualität und

exotischer Abseitigkeit - Gedanken zur Positionierung

eines ,kleinen' orientalistischen Faches

BERT G. FRAGNER

Afrika in der deutschen Islamwissenschaft

ROMAN LOIMEIER

Islamische Kunstgeschichte und Archäologie:

Letztes Fach der Orientalistik? 
Gender Studies - eine Herausforderung zur

Standortbestimmung der Islamwissenschaft

BIRGIT KRAWIETZ

TEIL III

Mediale Und politische Ambivalenzen

Auf dem Marktplatz der Islamgespenster.

Die Islamwissenschaft in Zeiten des Erklärungsnotstandes

MANFRED SING

Die Islamwissenschaft und der 11. September

GUIDO STEINBERG

Von der „Islampolitik“ zum „Dialog mit der islamischen Welt“" Anmerkungen zum Verhältnis zwischen Orientalistik und deutscher (Außen-)politik

TIM EPKENHANS

Die Täter zu Opfern, die Opfer zu Tätern machen -

Räume und Grenzen islamwissenschaftlicher Politikdeutung

UDO STEINBACH

\section{TEIL IV \\ REORIENTIERUNGEN}

Ist das Tor des ,Iğtihād‘ in der Islamwissenschaft geschlossen?

ABBAS POYA

Unterscheiden und Verstehen: Über Nutzen und

Missbrauch der Islamwissenschaft

GUDRUN KRÄMER

Islamwissenschaften: Ein Fächer von Fächern im

Wettbewerb um Mittel und Macht

LUDWIG AMMANN

Gaze - Jenseits vom Orient und von Zivilisierungsmissionen

MARIAM POPAL

Zur Zukunft der Islamwissenschaft

NAVID KERMANI

Bibliographie 


\section{Danksagung}

Die Idee zum vorliegenden Band entstand im Wintersemester 2005/06. Wir veranstalteten damals ein Kolloquium zum Thema „Was soll uns Islamwissenschaft bedeuten?". Vor dem Hintergrund der immer noch andauernden Orientalismusdebatte und der neuen medialen und politischen Herausforderungen für die Islamwissenschaft in Folge des 11. Septembers luden wir Vortragende aus Freiburg und außerhalb dazu ein, ihre Ansichten über das Fach, seine Geschichte sowie seine Methodik zu präsentieren und Vorschläge vorzubringen, wie sich das Fach in Zukunft positionieren solle. Die Resonanz auf das Kolloquium war so positiv gestimmt, dass wir beschlossen, die Vorträge im Rahmen des Kolloquiums als Sammelband zu veröffentlichen.

Von denen, die während des Kolloquiums Vorträge hielten, haben nur einige ihre Beiträge verschriftlichen können. Es war daher sehr erfreulich, als wir viele andere davon überzeugen konnten, mit uns ins anfangs schwankende Boot zu steigen. Wir möchten aber auch nicht vergessen, diejenigen Vortragenden lobend hervorzuheben, die in diesem Band leider nicht vertreten sind, die aber mit ihren wertvollen Gedanken die Grundlagen zu diesem Band legen halfen.

Wir bedanken uns bei Miriam Younes und Diana Schwarz für die tatkräftige Unterstützung beim Korrekturlesen und bei der Erstellung der Bibliographie. Jens Rosenmeyer sind wir für die technische Erstellung des Buches zu Dank verpflichtet. 



\title{
Einführung:
}

\section{Was soll Islamwissenschaft bedeuten?}

\author{
ABBAS POYA UND MAURUS REINKOWSKI
}

Lebendigkeit und Kreativität in den Geisteswissenschaften geht mit einem Krisenbewusstsein einher. Man könnte sogar sagen, dass sich die Geisteswissenschaften seit dem 19. Jahrhundert unter anderem durch regelmäßig wiederkehrende Sinnkrisen konstituieren. ${ }^{1}$ Die Sinnfrage wurde in den letzten Jahrzehnten durch die Herausforderung verschärft, sich gegenüber einer Öffentlichkeit rechtfertigen zu müssen, die Auskünfte über den Nutzen der Geisteswissenschaften einholen will. Geisteswissenschaftlerinnen und Geisteswissenschaftlern, die solchen Anfragen und Anforderungen gegenüberstehen, fällt es schwer, deutliche Aussagen zu den Aufgaben ihrer eigenen Wissenschaft zu treffen. Sie können das Aufgabengebiet ihrer Einzeldisziplinen umreißen, weitergehenden Fragen weichen sie aber eher aus. Geisteswissenschaftliche Selbstkritik und Selbstversicherung zeigen dabei ein typisches Muster: Kritik am Fach wird geübt, um dann doch Zweifel an der Existenzberechtigung des Faches auszuschließen. Begleitet wird diese Rede (die Rede, die immer in der Rede von der letztlich doch sinnvollen Disziplin mündet) von einem unheilschwangeren Raunen über die späteren hohen (wissenschaftlichen und sozialen) Folgekosten, hätte das betreffende Fach Stellenstreichungen hinzunehmen. ${ }^{2}$

1 Siehe Jürgen Kaube: „Das Unbehagen in den Geisteswissenschaften. Empire und überempirische Krisen“, in: Florian Keisinger/Roland Berger (Hg.), Wozu Geisteswissenschaften? Kontroverse Argumente für eine überfällige Debatte, Frankfurt/M, New York: Campus 2003, S. 17-28, hier S. 17: „,Krise“ wäre dann für die Geisteswissenschaften das, was für Naturwissenschaftler der ,Fortschritt' ist: eine ebenso festliche wie überempirische Formel für den sonntäglichen Außenverkehr und die Begegnung mit Massenmedien.“

2 Siehe als Beispiel: Jörg Rüpke: „Altertumswissenschaft“, in: F. Keisinger/R. Berger (Hg.), Wozu Geisteswissenschaften, S. 117-123, hier S. 120: „Wer die relevante Vergangenheit erst 1917 oder 1789 oder 1517 beginnen lässt, bedarf der Altertumswissenschaft nicht und muss sie auch nicht finanzieren. Eine solche Wahl überlässt Früheres der Mythenbildung. Und haftet für die Folgen“; ebenso auch Friedrich Wilhelm Graf: „Theologie“, in: F. Keisinger/R. Berger (Hg.), Wozu Geisteswissenschaften, S. 109-116, hier S. 116. 
Diese Beobachtungen gelten auch für die Islamwissenschaft. Dennoch scheint dieses Fach von dem Gefühl der Ortlosigkeit und Orientierungslosigkeit in besonderem Maße betroffen zu sein. Warum dies? Die Islamwissenschaft ist doch ein beeindruckend interdisziplinär arbeitendes Fach; sie ist eine große Teile der Welt umspannende Disziplin, die umfangreiche Sprachkenntnisse voraussetzt und Entscheidendes zum Verständnis einer der großen monotheistischen Religionen beiträgt. Besonders seit dem 11. September 2001 steht das Fach im Scheinwerferlicht der Öffentlichkeit und wird um so mehr in seiner Bedeutung wahrgenommen. Genauso aber ließe sich sagen, dass die Islamwissenschaft ein Fach ist, das keine eigenständige Methode aufweist, das sich in der Vielzahl seiner selbstgestellten Aufgaben verheddert und gegenüber anderen geisteswissenschaftlichen Fächern ein deutliches Theoriedefizit aufweist. In der Zwiesprache mit anderen Fächern ist es in Gefahr, zum Stichwortgeber für das gänzlich ,Andere' degradiert zu werden - und die immer größer werdenden Erwartungen der Politik und der Medien wird es ohnehin nicht gänzlich erfüllen können.

Versuchen wir also besser zu verstehen, worin die besonderen Probleme der Islamwissenschaft bestehen könnten. $\mathrm{Zu}$ tun hat dies mit den geänderten Arbeitsbedingungen der Islamwissenschaft im Rahmen der Geisteswissenschaften. Die Verpflichtung der Geisteswissenschaften zu ihnen eigentlich fremden Arbeitsverbünden führt die Islamwissenschaft in Forschungszusammenhänge, die von ihr oft gar nicht gewollt sind, in denen sie wenig Mitspracherecht zu haben scheint, und in denen Islamwissenschaftler ihre Kräfte leicht verzetteln. Zu tun hat das Unbehagen in der Islamwissenschaft auch mit den Erwartungen der politischen Klasse und der Medien, die in der Islamwissenschaft die zuständige Instanz für jene amorphe und doch so schwarz am politischen Gewitterhimmel stehende Wolke sehen, die nur durch die gemeinsame Bezeichnung, der Islam` zusammengehalten wird.

Ein Unbehagen hat sich also der deutschen Islamwissenschaft bemächtigt und inzwischen viele Vertreterinnen und Vertreter des Faches erfasst, egal welcher Ausrichtung der Islamwissenschaft sie anhängen oder welche Begründung dieses Faches sie verfechten. Wie dieses Unbehagen gedeutet werden soll, ist jedoch umstritten: Ist es ein Zeichen der Modernisierung des Faches und seiner allmählichen Herauslösung aus einer traditionell eher isoliert betriebenen Wissenschaft? Handelt es sich um die Folgen einer allgemeinen Wissenschaftsglobalisierung oder erklärt es sich aus der Überbeanspruchung eines Faches, das für die vielfältigen politischen und medialen Erwartungen, die an es herangetragen werden, gar nicht gerüstet ist? Liegt es daran, dass der/die Islamwissenschaftler/in hin- und hergerissen ist zwischen seinem/ihrem Wunsch nach kontemplativem Schaffen und einer in die Öffentlichkeit hinein wirkenden, wissenschaftlich aber eher nicht anerkannten Sichtbarkeit? Oder handelt es sich vielmehr um das Unbehagen, das manchen beschleicht angesichts unnötiger Selbstgeißelungen?

Oder glauben wir nur fälschlich daran, dass jenes Unbehagen uns seit neuester Zeit begleitet, obwohl es doch von Anbeginn dazugehört? Und sagt es nicht 
sehr viel mehr über die Befindlichkeit des Beobachters aus als über das beobachtete Objekt? Wenn Sigmund Freud feststellt, „daß wir uns in unserer heutigen Kultur nicht wohl fühlen, aber es sehr schwer [ist], sich ein Urteil darüber zu bilden, ob und inwieweit die Menschen früherer Zeit sich glücklicher gefühlt haben“, 3 so lässt sich Ähnliches für die deutsche Universität vermuten. In der Tat: Waren die früheren Zeiten wirklich so viel glücklicher?

Die Islamwissenschaft ist ein Abkömmling der Philologie. Diese Disziplin war und ist die genuine Methode der Islamwissenschaft. Eine solide Kenntnis der Quellensprachen und der philologischen Methoden - darüber ist man sich einig ist unverzichtbar. Das erklärte Ziel der Islamwissenschaft ist nach wie vor die Rekonstruktion des unermesslichen Textkorpus, das in der islamischen Welt in den letzten 14 Jahrhunderten entstanden ist.

Von der Bezeichnung des Faches ,Islam-Wissenschaft ' her wiederum müsste die Islamwissenschaft eigentlich religionswissenschaftlich ausgerichtet sein. Es ist aber bemerkenswert, dass die meisten Islamwissenschaftler heute sich weder ihrer Herkunft (nämlich der Philologie) noch ihrer naheliegenden Aufgabe (nämlich der religionswissenschaftlichen Betrachtung des Islams) verpflichtet sehen. Die Masse der Islamwissenschaftler begreift sich vor allem als Historiker oder zumindest als Geisteswissenschaftler, die mit historischen Methoden arbeiten.

Der historisch arbeitenden Islamforschung ist jedoch niemals die Eingliederung in die Geschichtswissenschaft gelungen; sie ist in die nur schwer zugängliche Gildenordnung der deutschen Historiker niemals eingelassen worden, so wie auch die islamische Geschichte niemals als Schnittmenge mit der europäischen Weltgeschichte angenommen wurde. Aber warum sollte auch die Islamwissenschaft von der Geschichtswissenschaft akzeptiert werden? Die Islamwissenschaft sieht sich nämlich selbst als interdisziplinär ausgerichtet. Im wissenschaftlichen Alltag wirkt sich jedoch diese Interdisziplinarität sehr oft in der Weise aus, dass die Islamwissenschaft eklektisch arbeitet; sie wählt sich aus der Fülle der geistesund sozialwissenschaftlichen Methoden die ihr jeweils dienlichen und scheinbar passenden Elemente aus.

Wenn also die Islamwissenschaft kein Fach mit eigenständiger Methodik ist und sich auch im Grunde keiner Disziplin gänzlich anschließen darf/kann/will, kann sie dann eine Aussage darüber treffen, was ihr eigentliches Anliegen ist? Verfügt sie zumindest über einen Kern? Die meist sehr allgemein gehaltenen Definitionen von Islam und Islamwissenschaft, die von Vertreterinnen und Vertretern des Faches selbst gegeben werden, kreisen jedoch nicht um einen solchen angenommenen Kern, sondern wollen eher die äußeren Konturen beschreiben. Meist heben diese Selbstbeschreibungen auf einen ,islamischen Halo ' ab, also die Gesamtheit dessen, was Marshall Hodgson in seinem The Venture of Islam ,is-

3 Sigmund Freud: Das Unbehagen in der Kultur. Und andere kulturtheoretische Schriften, Frankfurt/M: Fischer 1996, S. 55. 
lamicate" nannte und das jenseits von Norm und Ritual die Vielfalt der islamischen Kulturen ausmacht. Aber gerade diese vielfältigen Emanationen der islamischen Zivilisationen können eigentlich auch von Historikern, Architekturhistorikern, vergleichenden Literaturwissenschaftlern, Politologen usw. untersucht und beschrieben werden.

Gibt es also überhaupt einen Bereich, der als alleiniges Kompetenzreservat der Islamwissenschaft zu gelten hätte? Gerne behaupten die Vertreterinnen und Vertreter des Faches (vor allem gegenüber den Medien), dass es ,den Islam‘ nicht gibt. In der Verteidigung ihres Faches gegenüber anderen Disziplinen operieren sie aber meist mit der Auffassung eines Islams. In einem engeren Bereich, den man vielleicht Islamkunde nennen könnte, ${ }^{4}$ wird versucht, genau diesen Kern zu erfassen. Könnte es also die Aufgabe der Islamwissenschaft sein, jenseits falscher Essentialismen den „,keimträchtigen Kern“活 der islamischen Kulturen zu erkennen? Wenn der Halo des Islams auch von anderen Fächern (Regionalstudien, Geschichte, Literaturwissenschaft) untersucht werden kann, besteht dann die Existenzberechtigung des Faches in seiner Kompetenz für einen solchen islamischen Kern? Wäre dieser Kern unter Umständen mit dem identisch, was die Islamwissenschaft für sich selbst als Grundlagenwissenschaft reklamiert?

Diese Fragen sind nicht nur heuristischer Luxus, sondern sie bedeuten viel für die Zukunft des Faches, ihre Stellung in den Geisteswissenschaften und ihre Wirkung hinein in die Öffentlichkeit. Benachbarte Fächer werden immer mehr in die Domänen der Islamwissenschaft eindringen. Die Kompetenz, die die Islamwissenschaft bis heute bei sich selbst sieht, ist die profunde Kenntnis einer oder mehrerer islamischer Sprachen. Angesichts einer zunehmend globalisierten Studentenschaft wird der Vorsprung der Islamwissenschaft, wenn er nur auf ihrer sprachlichen Kompetenz beruhen sollte, immer mehr schrumpfen. So wird es immer mehr Studierende der Geschichte oder der Politikwissenschaft geben, die über solche Sprachkenntnisse schon aufgrund ihrer Herkunft verfügen. Was diesen Studierenden allein fehlt, ist die Fähigkeit, das über Jahrhunderte angesammelte Textkorpus der islamischen Hauptsprachen sichten und verstehen zu können. Wird die natürliche Folge sein, dass die Islamwissenschaft sich um so mehr auf ihre ureigenste Domäne zurückzieht, nämlich die mühe- und verdienstvolle Lektüre von Handschriften bzw. ganz allgemein von klassischen islamischen Texten - eine Fähigkeit, die in westlichen Gesellschaften nur im Rahmen eines islamwissenschaftlichen Studiums vermittelt wird?

Das Gegenstück zum wissenschaftlichen Experiment in den Naturwissenschaften ist in den Geisteswissenschaften das Schaffen von Redundanz - Redun-

4 Heute ist übrigens der Begriff ,Islamkunde“ eher bekannt als Bezeichnung für den islamischen Religionsunterricht an den öffentlichen Schulen.

5 Ludwig Ammann: „Islamwissenschaften“, in: Klaus E. Müller (Hg.), Phänomen Kultur: Perspektiven und Aufgaben der Kulturwissenschaften, Bielefeld: transcript 2003, S. 82. 
danz im Sinne eines Potentials an Deutungen und Thesen. Diese Redundanz wird benötigt, um in langwierigen Prozessen aus einer großen Auswahl die richtigen Lösungsvorschläge herauszufinden. Für die Islamwissenschaft stellt sich die spezifische Frage, wie sie weiterhin Redundanz, auch ihre ganz eigene, schaffen kann, ohne selbst redundant zu werden; d.h. welche Formen von ,relevanter Redundanz' kann die Islamwissenschaft in den und für die Geisteswissenschaften zur Verfügung stellen?

Dass die Islamwissenschaft in der Wissenschaftslandschaft eigentlich mehr als eine Nebenrolle spielen könnte, sieht man an den zukünftigen Aufgabenbereichen der Geisteswissenschaften: „Es genügt, öffentlich gängige Problem-Labels wie nine-eleven, EU-Beitritt der Türkei, Globalisierung, Multikulti, clash of civilizations, Bürgerkrieg in Ex-Jugoslawien, religiöser Fundamentalismus, Umweltverschmutzung, Handy-Sucht, Pandemien, demographische Entwicklung oder Aufstände von Jugendlichen in ghetto-ähnlichen Vorstädten“ aufzuzählen, ${ }^{6}$ um zu erkennen, dass bei nahezu jeder Fragestellung auch die Islamwissenschaft gefragt sein könnte.

Die öffentliche Nachfrage nach Islamwissenschaft und die islamwissenschaftlichen Wachstumsschmerzen, die damit verbunden sind, sind Auslöser für die Entstehung des vorliegenden Bandes, aber nicht alleiniger Gegenstand der folgenden Beiträge. Es wird auch um innerdisziplinäre Selbstbefragungen und Selbstversicherungen gehen: Wie soll das Fach auf den Anspruch der Politik und der Öffentlichkeit antworten, dass es immer das genuin ,Islamische“ von all dem zu erklären habe, was in der islamischen Welt oder unter Muslimen geschieht? Ist vielleicht dieses Missverständnis der Außenstehenden, was die Islamwissenschaft angeblich leisten soll - nämlich den ,wahren Kern' des Islams zu benennen -, einer der Gründe für die argumentative Lähmung des Faches? Wenn es aber solche Missverständnisse gibt, warum kann sie die Islamwissenschaft nicht ausräumen und ihre wirklichen Potentiale offensiv vertreten? Verfestigt sie durch ihre traditionelle Beschäftigung mit normativen Texten und durch ihre dementsprechende Darstellung des Islams nicht vielmehr die in der europäischen Öffentlichkeit vorherrschende Auffassung, dass Muslime im Durchschnitt die religiösen und dogmatischen Inhalte des Islams mit größerem Nachdruck als andere Religionen verfechten und deswegen ein weitaus strengeres religiöses Verhalten zeigen? Ist es dem Fach überhaupt gelungen, sich von den Paradigmen des Orientalismus des 19. und 20. Jahrhunderts zu entfernen? Was bedeutet die wachsende Präsenz von jungen muslimischen deutschen Wissenschaftlerinnen und Wissenschaftlern für die Zukunft der Islamwissenschaft? Kann das Fach - jenseits seiner philologischen Tradition - neue methodische Wege einschlagen?

6 Jochen Hörisch: Die ungeliebte Universität. Rettet die Alma mater!, München, Wien: Hanser 2006, S. 91. 
Es gibt bereits beeindruckende Abhandlungen zur Geschichte der Islamwissenschaft, etwa von Ulrich Haarmann, Josef van Ess und Baber Johansen. ${ }^{7}$ An all diesen Arbeiten fällt aber auf, dass sie immer wieder um Carl Heinrich Becker (1876-1933) als zentrale Figur und Begründer der Islamwissenschaft kreisen, ${ }^{8}$ dass sie aber etwa über die Zeit des Nationalsozialismus wenig sagen können ${ }^{9}$ und auch für das mittlerweile halbe bundesrepublikanische Jahrhundert kaum über schiere Bestandsaufnahmen hinauskommen. ${ }^{10}$ Diese Lücke, nämlich das Fehlen eines tieferen Verständnisses der deutschsprachigen Islamwissenschaft in den letzten fünfzig Jahren, kann dieser Band nicht schließen, denn die Geschichte des Faches lässt sich nur durch Forschungsarbeit im Detail rekonstruieren. ${ }^{11}$

Noch einmal daher die Frage: Wozu dieses Buch? Es geht hier in diesem Band zuerst einmal darum, das sich aus unterschiedlichsten Quellen speisende, aber allgemein spürbare Unbehagen innerhalb des Faches zu artikulieren und den aktuellen Diskussionsstand in diesem Zusammenhang zu dokumentieren. Es geht aber doch auch zugleich um mehr: Man könnte sich nämlich an den letzten Satz in Voltaires Candide halten („Cela est bien dit, répondit Candide, mais il faut cultiver notre jardin.") und argumentieren, dass die Islamwissenschaft nur durch

7 Ulrich Haarmann: „Die islamische Moderne bei den deutschen Orientalisten“, in: Friedrich H. Kochwasser/Hans R. Roemer (Hg.), Araber und Deutsche. Begegnungen in einem Jahrtausend, Tübingen u.a.: Erdmann 1974, S. 56-91; Josef van Ess: „From Wellhausen to Becker: The Emergence of ,Kulturgeschichte“ in Islamic Studies", in: Malcolm H. Kerr (Hg.), Islamic Studies: A Tradition and its Problems, Malibu: Undena Publications 1980, S. 27-51; Baber Johansen: „Politics and Scholarship: The Development of Islamic Studies in the Federal Republic of Germany“, in: Tareq Y. Ismael (Hg.), Middle East Studies. International Perspectives on the State of the Art, New York u.a.: Praeger 1990, S. 71-130.

8 Neuerdings auch Gegenstand gleich zweier islamwissenschaftlicher Monographien: Alexander Haridi: Das Paradigma der ,islamischen Zivilisation ' - oder die Begründung der deutschen Islamwissenschaft durch Carl Heinrich Becker (1876-1933): Eine wissenschaftsgeschichtliche Untersuchung, Würzburg: Ergon 2005; Giovanni Morrone: Incontro di civiltà. L'Islamwissenschaft di Carl Heinrich Becker, Napoli: Liguori 2006.

9 Siehe nun aber Ekkehard Ellinger: Deutsche Orientalistik zur Zeit des Nationalsozialismus 1933-1945, Edingen-Neckarhausen: deux-mondes-Verlag 2006.

10 Reine Bestandsaufnahmen hat es immer wieder gegeben, siehe zum Beispiel Rainer Büren: Gegenwartsbezogene Orientforschung in der Bundesrepublik Deutschland. Gegenstand, Lage und Förderungsmöglichkeiten, Göttingen 1974 (Schriftenreihe der Stiftung Volkswagenwerk); Angelika Hartmann (Hg.), Angewandte interdisziplinäre Orientforschung: Stand und Perspektiven im westlichen und östlichen Deutschland; Ergebnisse eines Kolloquiums an der Universität Würzburg im Juni 1990, Hamburg: Deutsches Orient-Institut 1991; Ekkehard Rudolph (Hg.), Bestandsaufnahme: Kultur- und sozialwissenschaftliche Forschung über die muslimische Welt in der Bundesrepublik Deutschland, Hamburg: Deutsches Orient-Institut 1999.

$11 \mathrm{Zu}$ dieser würde auch die in diesem Band bereits völlig untergegangene Tradition der DDR gehören. 
ihre alltägliche und an der Sache orientierte Arbeit beweisen könne, was sie wirklich leistet. Das wird sie natürlich tun können und müssen, aber langfristig wird ihr dies eher gelingen, wenn sie lernt, sich zugleich über sich selbst als Fach zu verständigen.

Dieser Band schreibt nicht vor, wie sich das Fach Islamwissenschaft in $\mathrm{Zu}-$ kunft entwickeln soll, reflektiert jedoch kritische Ansätze, die dem Fach neue Perspektiven eröffnen könnten. Auch wenn der Sammelband nicht den Anspruch erheben will, alle Stimmen der Islamwissenschaft eingefangen zu haben, so erhält man doch einen lebendigen Eindruck von der Vielfalt der in diesem Fach vertretenen Positionen. Meinungen und Argumentationen, die die Herausgeber nicht teilen, wurden mit Bedacht belassen. Rein sachlich betrachtet, hätten zudem manche Passagen in den Beiträgen wegen Überlappungen und Wiederholungen getilgt werden müssen. Auch hier entschieden wir uns dafür, in die Beiträge möglichst wenig einzugreifen, um ein Bild davon zu vermitteln, in welchen Fragen (und manchmal auch: Antworten) die Beitragenden sich am ehesten nahe kommen. Der Band versteht sich als ein Plädoyer: Für eine Öffnung, die nicht bedeutet, dass man anderes ausschließen müsste; für eine Debatte, die nicht abgeschlossen werden kann, sondern offen bleiben muss; für den unbefangenen Umgang mit Widersprüchen und Widersprüchlichkeiten. 

TEIL I

SelbstVer(Un)Sicherungen 



\section{Islamwissenschaft und relevante Redundanz}

MAURUS REINKOWSKI (FREIBURG)

\section{Orientalistik und Islamwissenschaft}

Der Orient war nicht die einzige Welt, die außerhalb Europas lag, aber er war schon seit langem das Gegenüber par excellence, das eigentliche Andere. Die akademische Disziplin, die sich seit dem 19. Jahrhundert diesem hauptsächlichen Anderen (nur die beiden Amerikas, Australien und das südliche Afrika waren ausgenommen) widmete, war und ist die Orientalistik. Den Orient erforschende wissenschaftliche Gesellschaften, wie die Société Asiatique (gegr. 1822), Royal Asiatic Society (gegr. 1824), American Oriental Society (gegr. 1842) oder Deutsche Morgenländische Gesellschaft (gegr. 1845), wurden ins Leben gerufen. Bis weit in das 20. Jahrhundert hinein pflegten die Orientalisten einen umfassenden Anspruch: Die Gelehrten sollten die Gesamtheit des Orients zu erfassen und umfassen imstande sein. So wurde 1949 mit Oluf Krückmann (1904-1984) ein Wissenschaftler an das Orientalische Seminar der Universität Freiburg berufen, „der in seiner Person noch die ganze Welt des Vorderen Orients vereinte: Die Keilschriftsprachen ebenso wie die Ägyptologie und die Islamwissenschaft “ ${ }^{1}$ Carl Heinrich Becker (1876-1933), der die Islamwissenschaft als reguläres Fach in Deutschland mitbegründete, aber bereits im Alter von etwa 40 Jahren in die Wissenschaftspolitik wechselte, interessierte sich ,,neben orientalischer Sprache, Literatur, Geschichte und Religion für Archäologie und Kunstgeschichte, für Geschichte der Mathematik, Medizin und Chemie, für Papyrusforschung, für islamisches Recht, für modernen orientalischen Volksaberglauben, für Geschichte Zentralafrikas, für die Kolonial- und Islampolitik der Großmächte, für orientalisches Pressewesen, für die Auseinandersetzung des Orients mit dem vordringen-

1 Horst Steible: „Geschichte des Orientalischen Seminars“, http://www.orient.unifreiburg.de/geschichte.html vom 5. April 2007. - Der Koranforscher Josef Horovitz (1874-1931) wird 1914 auf eine Professur nach Frankfurt/M berufen, deren Stifter als Aufgabengebiete semitische Philologie mit Berücksichtigung der targumischen und talmudischen Literatur sowie Islamkunde festgelegt hatte; Shlomo Dov Fritz Goitein: „Nachruf auf Josef Horovitz“, in: Der Islam 22 (1935), S. 122-127, hier S. 126. 
den Okzident.“2 Die Gründe für diese enzyklopädische Ausrichtung lagen zum einen an der damals noch geringeren Fächerdifferenzierung innerhalb der Orientalistik und zum anderen an einer oft der orientalistischen Spezialisierung vorausgehenden Ausbildung in Fächern wie Theologie und klassische Philologie. ${ }^{3}$

Die Islamwissenschaft wurde immer auch als Teil der Orientalistik verstanden, und in der Tat: Die Ähnlichkeiten zwischen diesen beiden sind bemerkenswert - allein schon in der Hinsicht, dass sie weniger Disziplinen ähneln als konglomerierten Wissenschaftstraditionen.

Beide, Islamwissenschaft und Orientalistik, agieren und argumentieren in ihrer Eigenschaft als geisteswissenschaftliche Fächer, bei denen - wie schon in der Einführung zum Sammelband angesprochen wurde - das Krisenbewusstsein ein grundlegendes Merkmal ihrer Selbstbefindlichkeit ist. Klagen gehört zum akademischen Handwerk und zu einer erfolgreichen geisteswissenschaftlichen Wissenschaftspolitik. So bemängelte Hans Robert Roemer (1915-1997), der vielleicht erfolgreichste orientalistische und islamwissenschaftliche Wissenschaftslobbyist der Nachkriegszeit, in den 1970er Jahren die fehlende Ausstattung mit Personal - eine Dekade, die nach heutigem Verständnis als eher noch angenehm gelten muss. ${ }^{4}$ Gemeinsam ist auch Islamwissenschaft und Orientalistik ein schon

2 Hellmut Ritter: „Nachruf auf Carl Heinrich Becker“, in: Der Islam 24 (1937), S. 175-185, hier S. 180. - Siehe als weiteres anschauliches Beispiel wiederum den Nachruf von Fritz Meier auf Hellmut Ritter (1892-1971), in: Der Islam 48 (1972), S. 193-205, hier S. 199f: „Ritters gelehrte hinterlassenschaft ist eine der reichsten und markantesten, die die geschichte seines faches aufzuweisen hat. Sie ist keinesweges spezialisiert, sondern umfasst das arabische, persische, türkische, kurdische und aramäische sprachgebiet, reicht von arbeiten über grammatik, dialektologie, rhetorik über geschichte, wirtschaftsgeschichte, geschichte der naturwissenschaften und technik, magie, literaturgeschichte, handschriftenkunde, filosofie, theologie, mystik, volkskunde, dichtung, theater bis zur musik und ruht auf einer allgemeinbildung, die weit über das gewohnte mass hinausreicht." Siehe auch den Nachruf von Albrecht Noth auf den breit aufgestellten Orientalisten cum Islamwissenschaftler cum promovierten Juristen Otto Spies (1901-1981), in: Der Islam 59 (1982), S. 185188, hier S. 186.

3 Johann W. Fück (1894-1974) unterrichtete zuerst im Schuldienst klassische Philologie und Hebräisch, Nachruf von Werner Ende, in: Der Islam 53 (1976), S. 193; Richard F. Kreutel (1916-1981) hatte eine abgeschlossene Ausbildung als Gymnasiallehrer für Klassische Philologie, Nachruf von Karl Teply, in: Der Islam 59 (1982), S. 190-194, hier S. 190; Rudi Paret (1901-1983), prominenter Koranübersetzer und -interpret, studierte zuerst Evangelische Theologie in Tübingen; siehe Nachruf von Josef van Ess, in: Der Islam 61 (1984), S. 1-7, hier S. 2.

4 „Mit der Stagnation der Haushalte hat auch schon der Abstieg begonnen, in der Orientalistik noch ehe der ohnehin erst zu Beginn der sechziger Jahre begonnene Ausbau einen Abschluß gefunden und Dauerregelungen an die Stelle von Provisorien und Improvisationen getreten wären.", Eröffnungsansprache des Ersten Vorsitzenden der Deutschen Morgenländischen Gesellschaft, Hans Robert Roemer, zum Orientalistentag 1975 in Freiburg, in: Wolfgang Voigt (Hg.), XIX. Deutscher Orienta- 
nicht mehr ganz neues nagendes Gefühl des Unbehagens angesichts der Zukunft des Faches. ${ }^{5}$

Ähnlichkeiten solcher Art dürfen mit Recht trivial genannt werden: Sie könnten auch für viele andere Fächer ausgemacht werden. Aber es gibt noch weit bedeutendere Hinweise auf eine tiefgehende Verwandtschaft von Orientalistik und Islamwissenschaft: Die Orientalistik ist für die Islamwissenschaft nicht nur von Bedeutung, weil diese institutionell noch sehr oft in orientalistischen Arbeitseinheiten angesiedelt ist; die Islamwissenschaft ist in vielen ihrer Eigenschaften noch ein zutiefst orientalistisches Fach. Folgt man den Selbstdarstellungen der Orientalistik oder Islamwissenschaft, so lassen sich in den meisten Selbstbeschreibungen die Begriffe ,orientalistisch “ und ,islamwissenschaftlich ' mühelos austauschen. Die Islamwissenschaft scheint so eine Orientalistik im kleineren Format zu sein; sie praktiziert eine ähnliche generell-umfassende Sicht ihres Aufgabenbereichs wie dies die Orientalistik tut. So heißt es in einer Selbstdarstellung des Faches Islamwissenschaft: „Als Kulturwissenschaft auf philologisch-historischer Grundlage beschäftigt sie sich prinzipiell mit allen Kulturen und Gesellschaften, in denen Muslime in Geschichte und Gegenwart, also etwa seit 600 nach Christus, entweder die Mehrheit oder jedenfalls eine aktive Minderheit gestellt haben." ${ }^{6}$ Beiden, Islamwissenschaft und Orientalistik, ist der Hinweis auf die große Breite des Faches gemein - in Gestalt eines unermesslichen geographischen Raumes und einer enormen Vielfalt von Sprachen (neben den klassischen Sprachen der Islamwissenschaft, Arabisch, Persisch und Türkisch bzw. Osmanisch, können unter anderen Suaheli, Urdu, Dari, Kurdisch, Paschto und Bahasa Melayu/Indonesia genannt werden). ${ }^{7}$

Beiden, Orientalistik und Islamwissenschaft, ist auch gemeinsam, dass trotz dieser Breite und Fülle von Forschungsfeldern und internen Unterdisziplinen ein-

listentag vom 28. September bis 4. Oktober 1975 in Freiburg im Breisgau, Wiesbaden: Steiner 1977, S. XV.

5 So sinniert Franz Rosenthal in seinem Beitrag „Die Krise der Orientalistik“, in: Fritz Steppat (Hg.), XXI. Deutscher Orientalistentag vom 24. bis 29. März 1980 in Berlin. Vorträge, Wiesbaden: Steiner 1983, S. 10-21, hier S. 13: „So müssen wir uns denn fragen, woher das Gefühl des Unbehagens kommt, das wir häufig haben, wenn wir an die Zukunft unseres Studienbereichs denken“.

6 Lutz Richter-Bernburg: „Islamwissenschaft“, in: Florian Keisinger/Roland Berger (Hg.), Wozu Geisteswissenschaften? Kontroverse Argumente für eine überfällige Debatte, Frankfurt/M, New York: Campus 2003, S. 124-130, hier S. 126f. - Extrem weit gespannt ist die Aufgabenbeschreibung der Islamwissenschaft in Tübingen, http://www.uni-tuebingen.de/orientsem/islampl.htm\#de vom 14.10.2007.

7 Man vergleiche auch die Darstellung der geographischen und thematischen Weite der Islamwissenschaft auf den Seiten der Freiburger Islamwissenschaft: „Der geographische Rahmen erstreckt sich von der Atlantikküste Nordafrikas über die Arabische Halbinsel, Südosteuropa und die Türkei, Iran, Mittel- und Zentralasien bis nach Indonesien. Der inhaltliche Rahmen umspannt Religion, Geschichte, Sprachen und Literatur ebenso wie Recht, Philosophie, Kunst, Gesellschaft, Wirtschaft und historische Landeskunde.“, http://www.orient.uni-freiburg.de/islam vom 14.10.2007. 
zelne Forschungsfelder hervorstechen. In der Orientalistik sind dies die Sinologie, Indologie und Islamwissenschaft. Im Fall der deutschsprachigen Islamwissenschaft dominieren diejenigen Regionen, die im weitesten Sinne als die Geburtsländer der monotheistischen Religionen gelten können, also der Nahe Osten. Nimmt man die gesamte islamische Welt als Maßstab, so erscheinen Gebiete wie Israel, Palästina und Syrien stark vergrößert, währenddessen bereits Länder wie Iran in dieser Matrix übermäßig klein geraten, ganz zu schweigen von so ,fernen * Gebieten wie Südostasien. Aus dieser Perspektive erscheint - überspitzt ausgedrückt - der Islam im subsaharischen Afrika, in Südasien oder Südostasien als eine Art asiatischer Restislam. ${ }^{8}$

Es kann auch nicht nur Zufall sein, dass der Islamwissenschaft jede eigentliche Standesvertretung fehlt: Weder die, die gesamte Orientalistik umfassende Deutsche Morgenländische Gesellschaft noch die 1993 gegründete und nur auf die Moderne bezogene Deutsche Arbeitsgemeinschaft Vorderer Orient für gegenwartsbezogene Forschung und Dokumentation können als ideale Lobbyisten des islamwissenschaftlichen Fächerverbundes gelten. Oder ist nicht doch die Islamwissenschaft mit ihren - ähnlich wie in der Orientalistik - undefinierten Fachgrenzen am besten in einer orientalistischen Interessenorganisation aufgehoben? Die Frage stellt sich ohnehin: Wer ist eigentlich Islamwissenschaftler bzw. wer wird eigentlich von anderen Islamwissenschaftlern als Islamwissenschaftler angesehen? Eine Umfrage unter deutschen Islamwissenschaftlerinnen und Islamwissenschaftlern würde hier höchst disparate Ergebnisse zeitigen.

Orientalistik und Islamwissenschaft teilen sich nicht nur die enorme geographische Breite und thematische Vielfalt, sondern auch die Betonung der historischen Tiefe: „Es ist das Besondere der Orientalistik - zumindest in der Tradition der Deutschen Morgenländischen Gesellschaft, und dies gilt es auch in jedem Fall zu bewahren -, dass sie sich mit jeweils zeitgenössischen Fragen nur aus einer - eben gerade auch sprachlich-philologisch - fundierten Kenntnis vorausgegangener Epochen heraus auseinanderzusetzen bereit ist. “9 Während das Argument einer historischen Tiefe orientalischer oder islamischer Zivilisationen kaum von der Hand zu weisen ist, so ist die Vorstellung, dass Geschichte und Gegenwart unauflösbar ineinander verschränkt sind und eine institutionalisierte Trennung in moderne und historische Studien weitgehend sinnlos wäre ,in einer Welt, wo uralt verwurzelte Traditionen noch heute wirksam sind“" ${ }^{10}$ doch nicht

8 Zur marginalen Stellung Afrikas und Südasiens im Rahmen der Islamwissenschaft siehe die Beiträge von Roman Loimeier und Jan-Peter Hartung in diesem Band.

9 Eröffnungsansprache des Ersten Vorsitzenden der Deutschen Morgenländischen Gesellschaft, Herrmann Jungraithmayr, auf dem XXV. Orientalistentag 1991 in München, in: Cornelia Wunsch (Hg.), XXV. Deutscher Orientalistentag, vom 8. bis 13.4.1991 in München. Vorträge, Stuttgart: Steiner 1994, S. 1-7, hier S. 5.

10 Eröffnungsansprache des Ersten Vorsitzenden der Deutschen Morgenländischen Gesellschaft auf dem XVII. Orientalistentag 1968 in Würzburg, in: Wolfgang Voigt (Hg.), Deutscher Orientalistentag: Vorträge. Vom 21. bis 27. Juli 1968 in Würzburg, 
ungefährlich: Heutige Gesellschaften werden in Haftung genommen für vergangene Kulturen.

\section{Zwischen philologischer Verankerung und disziplinärer Verunsicherung}

Die Selbstverteidigungstechniken und -argumente der islamwissenschaftlichen und orientalistischen Fachtraditionen sind bis in die unmittelbare Gegenwart ähnlich gewesen. Beiden ist gemein, dass sie jahrzehntelang zwischen der Scylla übermäßiger philologischer Selbstzufriedenheit und der Charybdis disziplinärer Verunsicherung - angesichts der Herausforderung durch methodisch besser verankerte und wissenschaftspolitisch stärker gerüstete Fächer wie Geschichte, Politikwissenschaft und Soziologie - gesegelt sind.

Wenn die große und auch heroische Zeit der Orientalistik das späte 19. und das frühe 20. Jahrhundert war, so lässt sich für die zweite Hälfte des 20. Jahrhundert ein Bedeutungsverfall des Orients festhalten: Der Orient, auch in den Orientwissenschaften, wird nur noch als ein Hilfskonstrukt verstanden, ja sogar als ein höchst problematischer Begriff - auch infolge der schneidenden Kritik, die an den Konzepten des Orients, des Orientalismus und der Orientalistik geäußert wurde.

1978 erschien Edwards Said Orientalism. In diesem Buch, das die Diskussionen der letzten dreißig Jahre geprägt hat, ${ }^{11}$ unternimmt Said seine Beweisführung im Wesentlichen anhand europäischer Reiseliteratur und westlicher orientalistischer Werke. Orientalismus bedeutet ihm dabei Verschiedenes, das dennoch eng ineinander verwoben ist: (a) die akademische Wissenschaft der Orientalistik; (b) eine Denkweise, die den Unterschied zwischen West und Ost zur Voraussetzung ihrer Argumentation macht; (c) ein Medium der Dominanz und Kontrolle über ,den Orient'. Der Orient ist also nicht nur eine Idee, sondern dient als Objekt zur Ausübung realer Macht: Europäischer Kolonialismus und westlicher Imperialismus stützen den Orientalismus und stehen hinter dessen Projektionen. Und natürlich helfen die Projektionen des Orientalismus wiederum die Machtverhältnisse zu zementieren. Der Orientalismus ist demnach eine sehr stabile und zähe Konstruktion, die nicht einfach aufgebrochen werden kann, und die sich durchaus immer wieder an neue Umstände anpassen kann.

Zwar weiß man heute genug über die Schwächen und Einseitigkeiten von Saids Darstellung, ${ }^{12}$ aber trotzdem sind wir in der Debatte über die Orientalistik

Teil 1. 1969, Zeitschrift der Deutschen Morgenländischen Gesellschaft: Supplement; 1, S. XXXI.

11 Der Ruhm von Saids Buch ist gerechtfertigt, aber doch auch einseitig. Bereits 1963 hatte Anouar Abdel-Malek (,L'orientalisme en crise“, Diogène 44/1983, S. 103140) alle wesentlichen Elemente der Orientalismuskritik formuliert.

$12 \mathrm{Zu}$ einer ausgewogenen und rezenten Zusammenfassung der Thesen Saids, seiner Kritiker und Nachfolger siehe Zachary Lockman: Contending Visions of the Middle 
noch kaum über Orientalism hinausgedrungen. ${ }^{13}$ Man wird wohl erst dann von einem wirklichen Fortschritt in der Orientalismuskritik sprechen können, wenn nicht in jedem Beitrag zur orientalistischen und islamwissenschaftlichen Wissenschaftsgeschichte (wie es auch in diesem Band der Fall ist) immer wieder Said erwähnt wird.

In anglo-amerikanischen Ländern wird jedenfalls heute all dasjenige, was sich mit ,dem Orient" beschäftigen will, ihn also als solchen als gegeben annimmt, als Orientalismus verworfen. ${ }^{14}$ Jemand anderen einen ,great Orientalist ${ }^{*}$ zu nennen, kann dann nichts anderes mehr als eine gewollte Beleidigung sein. In deutschsprachigen Ländern dagegen gibt es noch zahlreiche ,Orientalische Seminare': Angefangen von Wien, Zürich, und Basel über Freiburg, Tübingen, Frankfurt, Gießen, Bonn, Köln, bis nach Halle und Leipzig. ${ }^{15}$

Das ist also die eine Seite: Wir sehen vor uns eine - angeblich - machtvolle Geschichte der Deutungshoheit über den Orient, ausgeübt von wissenschaftlichen Hohepriestern, die zwar selbst unentrinnbar in ihren Diskursen gefangen sind, die aber auch allen anderen ihre Rede vom Orient aufzwingen können. Aber haben wir - im Gegensatz zur Rede der deutungsmächtigen Islamwissenschaft als einer der letzten großen Bastionen eines wissenschaftlichen Orientalismus - haben wir nicht auf der anderen Seite ganz andere, viel verhaltenere und auch kleinmütigere Töne im Ohr? ${ }^{16}$ Wie steht es eigentlich mit dem Selbstbewusstsein der Islamwissenschaft und der Orientalistik?

East. The History and Politics of Orientalism, Cambridge: Cambridge University Press 2004, Kap. 6: „Said's Orientalism: A Book and its Aftermath“.

13 Bemerkenswert ist die Vermutung von Baber Johansen: „Politics and Scholarship: The Development of Islamic Studies in the Federal Republic of Germany“, in: Tareq Y. Ismael (Hg.), Middle East Studies. International Perspectives on the State of the Art, New York u.a.: Praeger 1990, S. 71-130, hier S. 73, dass der Erfolg von Saids Buch sich seiner einseitigen Denunziation der Orientalistik zu verdanken habe. Entlastet von ihren Schuldgefühlen, hätten alle anderen Teile der westlichen Öffentlichkeit auf den Sündenbock Orientalistik als angeblichen Hauptverantwortlichen für die Entstehung des Orientalismus zeigen können.

14 Anlässlich des 30. Internationalen Orientalistenkongresses von 1976 (deren erster 1873 in Paris stattgefunden hatte) war die UNESCO zu keiner weiteren finanziellen Unterstützung des Kongresses bereit, wenn die Konferenz sich nicht in „International Conference of Asian and North African Studies“ (ICANAS) umbenennen würde. Die Forderung wurde erfüllt. Im September 2007 fand übrigens in Ankara die 38. ICANAS-Konferenz statt.

15 Daneben existieren zurückhaltendere Bezeichnungen, wie etwa „Seminar für Sprachen und Kulturen des Vorderen Orients“ (Heidelberg) oder „Seminar für Orientalistik“ (Kiel und Marburg). Eine Umbenennung der Seminare ist nicht leicht möglich, denn es ist eben ,der Orient", der die in diesen Seminaren vertretenen Fächer (wie auch immer) verbindet.

16 Siehe den altbekannten - schon bei Said angelegten - Widerspruch in den Polemiken gegen die Orientalistik bzw. den Orientalismus: Einerseits schrumpft die antiquierte Orientalistik, eine der wesentlichen Trägerinnen des Orientalismus, in ihrem Geltungsbereich und verliert zusehends an Ansehen, andererseits ist aber der Orien- 
Islamwissenschaft und Orientalistik teilen die Auffassung, dass sie letztlich in der Philologie verankert sind, und verteidigen die ,philologische Primärmethode“17 als ihr grundlegendes Kapital. Eugen Wirths Feststellung aus den 1970er Jahren, die Orientalistik sei konzentrisch angeordnet ,vom Allerheiligsten (Philologie, Literaturwissenschaft und Beschäftigung mit den schriftlichen Quellen) hin zu den Rändern der Orientalistik mit Feldern wie Sozial- und Wirtschaftsgeschichte" hatte und hat wohl auch immer noch für die Islamwissenschaft Gültigkeit. ${ }^{18}$ Der Grund für die so nachhaltige Bindung an die Philologie, und zwar im Sinne einer über die pure Sachnützlichkeit hinausgehenden emotionalen Verpflichtung, ${ }^{19}$ muss auch in der Erfahrung der Orientalistik liegen, sich unter Berufung auf ihre philologische Kompetenz erfolgreich von übergeordneten Fachtraditionen losgelöst zu haben. Der Orientalistik war es (mitsamt der damals als eigenes Fach noch nicht existierenden Islamwissenschaft) im frühen 19. Jahrhundert gelungen, sich von ihrer Rolle als Magd der Theologie zu emanzipieren, und zwar dadurch, dass sie sich auch als Expertin für lebende orientalische Sprachen zu empfehlen begann.

Wenn in dieser Geschichte der Emanzipation ein Grund für die starke Bindung an die Philologie liegt, so ist darin auch der Keim der Selbstüberschätzung enthalten: Die Philologie wird mitunter zu einer Art Totem erhoben: Ende der 1990er Jahre führte der damalige Vorsitzende der Deutschen Morgenländischen Gesellschaft die Erfolglosigkeit der deutschen Entwicklungshilfe auf den falschen Ansatz zurück, zur Entwicklung fremder Kulturen beizutragen zu wollen, ohne von ihnen eine genauere innere Kenntnis zu besitzen. Deswegen seien Forschungszentren einzurichten, ,in denen auf streng philologischer Grundlage die Besonderheit der fremden Kultur und ihrer inhärenten Wertmaßstäbe Gegenstand der Forschung sein müßte. “ ${ }^{20}$ Man darf vermuten, dass diese Ermahnung bei dem

talismus weiterhin so wirkungsmächtig, dass er nach wie vor den orientalischen und insbesondere den muslimischen Anderen problemlos fehl-repräsentieren und fehlkonstruieren kann. Ich verdanke diesen wichtigen Hinweis Manfred Sing.

17 Walter Slaje: „Was ist und welchem Zweck dient Indologie? Tractatus irae“, in: ZDMG 153 (2003), S. 311-331, hier S. 321: „Die philologische Primärmethode [Heraushebung im Original] aber schließt uns die geistige Welt dieser Zivilisation als dafür notwendige Grundlage zunächst über ihre sprachlichen Dokumente - von den chiffriert überlieferten Gedanken her - auf.“

18 Eugen Wirth: „Orientalistik und Orientforschung. Aufgaben und Probleme aus der Sicht der Nachbarwissenschaften“, in: W. Voigt (Hg.), XIX. Deutscher Orientalistentag, S. LVII.

19 Auffallend ist immer wieder der beschwörende Ton, wenn an die Unbedingtheit der philologischen Grundlagen erinnert wird. Siehe als ein Beispiel die Schlusssätze in Josef van Ess: „,The Emergence of ,Kulturgeschichte“ in Islamic Studies“, in: Malcolm H. Kerr (Hg.), Islamic Studies: A Tradition and its Problems, Malibu: Undena Publications 1980, S. 27-51, hier S. 51: „There is no valid historical research withouth philology. We need Herder as well as Hegel.“

20 Eröffnungsansprache des Ersten Vorsitzenden der Deutschen Morgenländischen Gesellschaft, Hermann Jungraithmayr, am 28.9.1998, in: Stefan Wild/Hartmut 
damaligen Bundesminister für Finanzen und der damaligen Bundesministerin für Zusammenarbeit und Entwicklung nicht zu tiefer innerer Einkehr geführt haben wird.

In ihrer öffentlichen Sichtbarkeit und Repräsentanz in den Universitäten unterscheiden sich allerdings die orientalistischen Fächer heute erheblich. ${ }^{21}$ Fächer wie Indologie und Semitistik, die eine starke Forschungstradition in Deutschland aufweisen, aber in der derzeitigen Wahrnehmung der Wissenschaftsverwaltungen als antiquiert gelten, ${ }^{22}$ werden abgebaut, währenddessen andere Fächer wie die Islamwissenschaft oder Sinologie angesichts der Bedeutung, die den entsprechenden Regionen (islamische Welt bzw. China) zugesprochen wird, in ihrem Bestand belassen werden. Die Sinologie darf als ,Wirtschaftsgewinnlerin' bezeichnet werden, während die Islamwissenschaft wenn nicht als ,Kriegsgewinnlerin', so doch zumindest als ,Konfliktgewinnlerin“ gelten muss.

Die zunehmende Antiquiertheit des Begriffes und der gemeinsamen Fächertradition ,Orientalistik' ist den orientalistischen Fächern selbst bekannt. Eine der möglichen Antworten wäre, sich von dieser Tradition zu distanzieren bzw. sich schlicht von ihr loszusagen. So haben sich aus den letzten Orientalistentagen (dem etwa alle drei Jahre stattfindenden Fachkongress der deutsprachigen Orientalistik) einzelne Fächer wie die Ägyptologie vollständig und andere wie die Afrikanistik, Indogermanistik, Japanologie, Judaistik und Südostasienkunde weitgehend verabschiedet. $^{23}$

Jedoch würde es nicht gelingen und wohl auch schädlich für einzelne Fächer sein, die Orientalistik kurzerhand für abgeschafft zu erklären. Denn aufgelöst

Schild (Hg.), Norm und Abweichung. Akten des 27. Deutschen Orientalistentages (Bonn, 28. September bis 2. Oktober 1998), Würzburg: Ergon 2001, S. 3-9, hier S. 5.

21 Zum Kanon der Orientalistik gehören die Fächer Ägyptologie, Afrikanistik, Alter Orient, Arabistik, Christlicher Orient/Byzanz, Indogermanistik, Indologie, Iranistik, Islamwissenschaft, Japanologie, Judaistik, Kunst und Archäologie des Orients, Moderner Orient, Orientalische Kunstgeschichte, Orientgeographie, Semitistik, Sinologie, Südostasienkunde, Turkologie/Osmanistik, Zentralasienkunde. Dieser Fächerkanon ist übrigens an keiner Stelle autoritativ festgelegt. In ihren verschiedenen Satzungen legt die Deutsche Morgenländische Gesellschaft als ihr Ziel die Erforschung des Morgenlandes fest, ohne dieses näher zu beschreiben; siehe z.B. die Satzung vom Oktober 1903: „Die Kenntnis des Morgenlandes (im weitesten Sinne)“, in: ZDMG 67 (1913), S. LXXI.

22 Man kann davon ausgehen, dass sich die Haltung gegenüber der Indologie in den nächsten Jahren rasch verändern wird; fraglich hingegen ist, ob die Semitistik, obwohl noch vor wenigen Jahrzehnten nahezu ein deutsches Wissenschaftsoligopol, mehr Anteilnahme in den Wissenschaftsverwaltungen finden wird.

23 Als Hinweis hierfür können die Veranstaltungsprogramme der Orientalistentage in den Jahren 2001 (web.uni-bamberg.de/split/dot), 2004 (www.dot2004.de) und 2007 (www.dot2007.de) dienen. Diese und der Orientalistentag von 1998 in Bonn wurden von Islamwissenschaftlern organisiert und waren dementsprechend von deren Interessen geprägt. 
würden mit den Orientalischen Seminaren in erster Linie die Fächer und nicht ,der Orient', auf den vor allem auch die Nicht-Orientalistik nur schwer wird verzichten wollen. Der Orient, auch wenn er von der Liste der korrekten wissenschaftlichen Begrifflichkeiten getilgt worden sein mag, macht sich als unterdrücktes Unbewusstes immer wieder geltend.

Was also könnte heute die Aufgabe der Orientalistik sein? Ist sie ein Konglomerat von regional- bzw. kulturwissenschaftlich orientierten Fächern mit einer stark philologischen Prägung? Sollte sich eine wissenschaftliche Organisation wie die Deutsche Morgenländische Gesellschaft vor allem als Vereinigung verstehen, die die gemeinsamen Interessen ,kleiner' kulturwissenschaftlich ausgerichteter Fächer an deutschen Universitäten vertritt? Darüber hinaus gehend aber stellt sich die Frage: Welches Anliegen können - über die gemeinsame Herkunft und über das gemeinsame wissenschaftspolitische Anliegen in der deutschen Universitätslandschaft hinausgehend - diese Fächer miteinander teilen? Die Orientalistik spiegelt nach wie vor die Vielfalt der darin vertretenen Disziplinen und Philologien wider; sie scheint aber nicht fähig, eine Auseinandersetzung der orientalistischen Disziplinen (aber auch innerhalb der einzelnen Disziplinen) ${ }^{24}$ darüber zustande zu bringen, in welcher Weise Orientalistik noch ein sinnvoller Wissenschaftsverbund sein könnte. ${ }^{25}$ Es ist auch bezeichnend, dass nicht die Orientalistik, sondern die Geschichtswissenschaft als „zankende Zunft“ tituliert wurde. ${ }^{26}$ In dieser Bezeichnung ist auch eine gewisse Anerkennung für die lebendige Streitkultur in der Geschichtswissenschaft enthalten: Offensichtlich haben weder Historikerstreit noch Historikerstreitigkeiten dem Fach Geschichte geschadet, sondern seinen Stand in der Öffentlichkeit eher befestigt.

Ohnehin schrumpft der Geltungsbereich der Orientalistik oder das, was als Orientalistik verstanden wird. Den meisten Außenstehenden käme es heute nicht

24 Hans-Wilm Schütte: Die Asienwissenschaften in Deutschland. Geschichte, Stand und Perspektiven, Hamburg: IFA 2002, S. 251; zur fehlenden Suche der Indologie nach einer Verständigung über das Wesen ihres Faches: „Aber haben sich die Indologen je zu Tagungsserien getroffen, um ihr Selbstverständnis zu diskutieren? Nahmen entsprechende Debatten auf den deutschen Orientalistentagen breiten Raum ein? Davon ist nichts bekannt."

25 Symptomatisch für ,Glanz und Elend' der Orientalistik ist die Zeitschrift der Deutschen Morgenländischen Gesellschaft, die für Beiträge aus allen orientalistischen Disziplinen ein höchst bewährtes Publikationsforum bietet, aber zugleich ernüchternd ist in der Zusammenhangs- und Kommunikationslosigkeit der unterschiedlichen Beiträge. Siehe eine ähnliche Einschätzung der Problematik bereits bei Carl Brockelmann: „Die morgenländischen Studien in Deutschland“, in: ZDMG 76 (1922), S. 1-17, hier S. 14: „So konnte es schließlich nicht ausbleiben, daß unsere Zeitschrift, da sie im Gegensatz zu den Fachorganen auf zufällig ihr zufließende Beiträge aus allen Gebieten der Orientforschung angewiesen blieb, jeden organischen Aufbau vermissen ließ.“

26 Klaus Große Kracht: Die zankende Zunft. Historische Kontroversen in Deutschland nach 1945, Göttingen: Vandenhoeck \& Ruprecht 2005. 
mehr in den Sinn, die Sinologie als genuin orientalistisches Fach zu verstehen. An manchen Standorten findet sich noch die Sinologie im Verbund von Orientalischen Seminaren, aber die Islamwissenschaft ist meist das dominierende, manchmal sogar das einzige darin vertretene Fach - vor allem, wenn man nicht nur die Disziplin Islamwissenschaft selbst berücksichtigt, sondern auch zahlreiche weitere, der Islamwissenschaft nahe stehende Fächer wie Turkologie, Arabistik und Iranistik, die sich mit den jeweils behandelten Kulturen in ihrer islamischen Überprägung auseinandersetzen. Man möchte also vermuten, dass die heute stärkste und weithin unangefochtene Spielart der Orientalistik die Islamwissenschaft ist. Gerade die letzten Jahre vermitteln auch den Eindruck, als sei der Islam in der Wahrnehmung der westlichen Öffentlichkeit anstelle des Orients in den Part des grundsätzlich Anderen eingetreten. Wenn man also die Existenz eines ,harten Kern Orients ' heute noch vermuten will, dann muss es sich wohl um den Islam handeln. Diese Erwartung der Öffentlichkeit ist höchst bedenklich auch für die Islamwissenschaft.

\section{Erst Überforderung und dann Marginalisierung?}

„Vor zwei oder drei Generationen war der Anspruch der Orientalisten, kraft ihrer philologischen Fähigkeiten exklusiv für die Erkenntnis, Interpretation und Vermittlung zuständig zu sein, gesellschaftlich anerkannt und garantiert. In diesem Bewusstsein verwalteten wir Generationen hindurch das Exotische, Außergewöhnliche und Fremde und konnten uns dank unserer bisweilen zu höchsten Höhen der Kunst zugespitzten philologischen Kenntnisse auch der allgemeinen Wertschätzung sicher sein. Fragen nach jeweils zeitgenössischen, gegenwärtigen Verhältnissen setzten wir oft erfolgreich den höherrangigen Wert des Alten, des Historischen, des Klassischen entgegen und waren uns der Akzeptanz derartiger Thesen sicher. ${ }^{\prime 27}$

Ein solches Verharren in den olympischen Höhen der Orientalistik ist für die Islamwissenschaft längst nicht mehr möglich. Wiederholt wurde an der Islamwissenschaft als Fach bemängelt, dass sie sich nicht als Gesprächspartner der Öffentlichkeit und der Politik bewiesen hat. Es scheint aber derzeit trotzdem so, als wolle man angesichts des kulturalistisch und identitätspolitisch geprägten Konflikts mit der islamischen Welt die Islamwissenschaft noch einmal zur Bewährung in den Rang eines Generalbevollmächtigten für das Andere einsetzen. Aber wird ihr dieser Status wegen erwiesener Inkompetenz und Untätigkeit nicht bald wieder entzogen werden? Dieser Überforderung nicht gerecht zu werden und da-

27 Ansprache des Ersten Vorsitzenden der Deutschen Morgenländischen Gesellschaft, Bert Fragner, bei der Eröffnung des XXVIII. Deutschen Orientalistentags, 26.-30. März 2001: „Orientalistik zwischen Philologie und Sozialwissenschaft“, http://web. uni-bamberg.de/split/dot/reden_fragner vom 5.4.2007. 
für die Strafe der Marginalisierung gewärtigen zu haben, mit dieser Sachlage steht die deutsche Islamwissenschaft nicht alleine da. So konnten die zahlreichen think tanks in den USA in der öffentlichen Meinungsbildung die Vertreter der Universitäten vor allem deswegen an den Rand drängen, weil sie eher dazu fähig waren, Sachverhalte verständlich und in Kürze darzustellen, aber auch das ,nationale Interesse “ in den Vordergrund zu stellen. ${ }^{28}$ In den Vereinigten Staaten gibt es ohnehin eine längere Tradition der unmittelbaren Einbindung von akademischen Ressourcen für sicherheitsdienstliche Belange, etwa in Gestalt des ,Camelot'-Programms (eines Vorhabens der US-amerikanischen Armee in den 1960er Jahren), nach dem die in den US-amerikanischen Universitäten verankerten Area Studies, unter anderen auch die für den Nahen Osten, für die Entwicklung einer effektiven Politik der counter insurgency herangezogen werden sollten. ${ }^{29}$

Auch wenn bisher solche unmittelbar sicherheitsrelevanten Erwartungen nicht an die deutsche Islamwissenschaft herangetragen worden sind (wohl weniger aus wissenschaftlicher Pietät als aus der Überzeugung, dass dies ohnehin keinen Sinn hätte), so scheint sie auch nicht dazu in der Lage zu sein, allgemeine Erklärungsmodelle zum ,Problemfall Islam“ anbieten zu können. ${ }^{30}$ Mittelfristig steht die Islamwissenschaft in Gefahr, von den Mühlen einer an sie herangetragenen übermäßigen Erwartung und einer (aus dieser enttäuschten Erwartung heraus begründeten) Geringschätzung und Marginalisierung zermahlen zu werden.

Die Islamwissenschaft sieht sich dem grundsätzlichem Problem gegenüber, dass ihre Selbstbezeichnung Erwartungen weckt, die sie nicht einlösen kann. Es geht hier weniger um die im Wort ,Islamwissenschaft‘ enthaltene Ankündigung, zur Gesamtheit der islamischen Welt in historischer Tiefe und geographischer Breite Auskunft geben zu können. Weitaus schwerer wiegt die Erwartung der Öffentlichkeit, dass die Islamwissenschaft den unauflösbaren, nicht zu greifenden Kern ,Islam‘ erklären soll: Die Islamwissenschaft soll sagen, worin das Geheimnis des eigentlichen Orients, der heute der Islam ist, liegt, aber eben nicht, um sich einem fremden kulturellen Mysterium zu nähern, sondern um zu erläutern, wie der Muslim als solcher ,tickt ${ }^{31}$

28 Martin Kramer: Ivory Towers on Sand: The Failure of Middle Eastern Studies in America, Washington, D.C.: The Washington Institute for Near Eastern Policy 2001, S. 106f.

29 Ebd., S. 86; zu späteren Vorstößen von Regierungsorganisationen siehe S. 87-90.

30 Siehe hierzu auch die Anmerkung von Jacques Waardenburg: „The Study of Islam in German Scholarship“, in: Azim Nanji (Hg.), Mapping Islamic Studies. Genealogy, Continuity and Change, Berlin, New York: Mouton de Gruyter 1997, S. 1-32, hier S. 21: „The situation is the more astonishing since German culture has always had a speculative bent and German scholarship is reputed for its creative theoretical thought. Why precisely this German genius has been largely absent in the field of Islamic studies is a problem."

31 Dass auch Bomben ticken, ist hier ein nicht ganz zufälliges Zusammentreffen des Wortsinns. 
Aus ihrer philologischen Tradition heraus ist die Islamwissenschaft stark, wenn es um die Beschreibung von Normativitäten geht, die sie aus der Lektüre von Texten gewinnt. Texte, sakrale Texte vor allem, legen auch - so der eigene Anspruch der Muslime - religiöses Verhalten fest. Das ist nicht ohne Fallstricke: Weil Muslime in der Weise wahrgenommen werden, dass sie die religiösen und dogmatischen Inhalte des Islams mit größerem Nachdruck als säkularisierte Christen verfechten, wird von ihnen ein solches streng religiöses Verhalten dann auch als zwingend vorausgesetzt. Die deutsche Öffentlichkeit, so ließe sich überspitzt ausdrücken, erwartet von den Muslimen ,eben diese Übereinstimmung [ihres] Verhaltens mit ihren eigenen Normen“32 und von der Islamwissenschaft erwartet sie nur noch die Bestätigung dieser Erwartungen. Den als Muslimen erzogenen Menschen wird ihre religiöse Identität geradezu aufgedrängt - und den Islamwissenschaftlern ihre angebliche Identität als Bewahrer des Schlüssels zum eigentlichen Verständnis des Islams.

Das Dilemma der Islamwissenschaft ist, dass viele Vertreter dieser Disziplin selbst der Ansicht sind, bei den meisten politischen Entwicklungen unter Muslimen und in der islamischen Welt handle sich nicht um nur dem Islam zueigene Charakteristika, sondern viel eher um bestimmte gesellschaftliche Strukturen oder der um spezifische Antworten auf die Herausforderung der Moderne. Die islamische Welt, enttäuscht von falschen europäischen Versprechungen wie dem Liberalismus und Marxismus, versuche, die Moderne durch eine islamisierende Überformung für sich verstehbar und bewältigbar zu machen. Auf die Spitze getrieben bedeutet dies, dass die Islamwissenschaft sich gewissermaßen als nicht zuständig erklärt für alles Islamische, da es ja nur scheinbar islamisch sei. Worin könnte also der Sinn eines Faches liegen, das - so stellt sich das dem Außenstehenden dar - sich vor allem berufen sieht, gerade das als irrelevant zu bezeichnen, was es erklären soll?

Hierin könnte auch einer der Gründe dafür liegen, warum die Islamwissenschaft in der Öffentlichkeit als so stumm erscheint. Die Islamwissenschaft weiß vielleicht, was man nicht sagen kann, indem sie das Einspruchsrecht der Fakten kennt. Sie weiß aber nicht, was man sagen kann; dazu müsste sie selbst erst gelernt haben, über Muslime und Islamisches reden zu können, ohne dass diese Rede immer letztlich ,den Islam' meinen würde.

Das Fach Islamwissenschaft muss sich nicht notwendigerweise selbst beschädigen, wenn es ihm gelingen sollte, im Sinne des von Odo Marquardt auf die Philosopie gemünzten Begriffes der ,Inkompetenzkompensationskompetenz', auf diese Dilemmata hinzuweisen und verständlich zu machen, dass die falschen Erwartungen an die Islamwissenschaft Teil eines größeren Missverständnisses sind.

32 Peter Heine: Kulturknigge für Nichtmuslime. Ein Ratgeber für alle Bereiche des Alltags, Freiburg: Herder 2001, S. 158. 
Worin also könnte die Antwort der Islamwissenschaft auf - jenseits all ihrer unbestrittenen Kompetenzen - ihre spezifische Inkompetenz sein, die Frage „Nun sagen Sie uns doch einmal gute Frau/guter Mann, was ist denn der Islam eigentlich?" nicht befriedigend beantworten zu können oder genauer vielleicht, nicht die Fähigkeit zu haben, diese Frage in überzeugender Weise als unzulässig abzuwehren.

\section{Was kann die Islamwissenschaft tun?}

„Aus den Stürmen der kurz zuvor über ganz Europa hereingebrochenen politischsocialen Bewegung, die auch mein Vaterland so mächtig ergriffen hatte, sah ich mich plötzlich in die durch nichts gemilderte Einförmigkeit des orientalischen Lebens versetzt. Während ich daheim alles hatte wanken sehen, stand hier alles unerschütterlich, unbeweglich und jeden Zweifel ausschliessend. Nichts störte die tiefe Ruhe. “33

Man könnte diese Passage auch als ein Gleichnis auf die Islamwissenschaft der ersten Nachkriegsjahrzehnte lesen, als sie noch weitgehend unberührt von innenund außenpolitischen Stürmen in sich und ihren Traditionen ruhte. In den gemütlichen islamwissenschaftlichen Seminaren waren deutsche Studierende und Dozierende unter sich; gemeinsam sprach man über den zeitlich und räumlich so fernen Islam. Mit dieser Gemütlichkeit scheint es erst einmal vorbei zu sein.

Dabei wäre eigentlich das Streben nach einer akademischen vita contemplati$v a,{ }^{34}$ vulgo das Pochen auf Ruhe als oberstem Wissenschaftlerrecht, nicht nur eine wohlfeile Ausrede - dies zeigen Plädoyers zur Rettung der deutschen Universität, in denen die Forderung nach Kontemplativität an oberster Stelle steht: „Was die Universität heute braucht, ist Ruhe.“35

Dennoch: Die Islamwissenschaft wird in den nächsten Jahren nicht - jedenfalls nicht mit Erfolg - das Privileg der Ruhe einfordern können. Viele Herausforderungen warten auf sie, anregende, aber auch einfach unangenehme. Um auf diese Herausforderungen antworten zu können, wird die Islamwissenschaft eine Gratwanderung unternehmen müssen: Sie darf nicht ihre Kompetenzen verlieren und muss zugleich versuchen, spezifische Formen einer islamwissenschaftlichen ,Inkompetenzkompensationskompetenz' zu schaffen.

Manches von dem, was zum Abschluss dieses Beitrags über den möglichen Auftrag der Islamwissenschaft in der Zukunft gesagt wird, ist handhabbar, man-

33 Alfred von Kremer: Geschichte der herrschenden Ideen des Islams. Der Gottesbegriff, die Prophetie und Staatsidee, Hildesheim: Georg Olms 1961. Nachdruck der Ausgabe von 1. Auflage, Leipzig 1868, S. X.

34 L. Richter-Bernburg: Islamwissenschaft, S. 126.

35 Jochen Hörisch: Die ungeliebte Universität. Rettet die Alma mater! München, Wien: Hanser 2006, S. 134. 
ches geht über allerlei Wolkiges nicht hinaus. Beim Blick in die vermeintlich wichtigsten Zukunftsaufgaben der Islamwissenschaft tun sich aber auch intellektuell so bestechende Autoren wie Baber Johansen schwer. Johansen sah es 1990 als eine hauptsächliche Aufgabe der Islamwissenschaft an, sich einem „,neuen Orientalismus“ zu widersetzen, der den Nahen Osten nur als politisches Gebilde und als wirtschaftlichen Faktor sehen könne (heute müsste natürlich an erster Stelle die Reduzierung der Muslime und des Islams auf ein Sicherheitsproblem stehen). Um dies leisten zu können, müsse erstens die Islamwissenschaft ihre Tradition bewahren, das Textuniversum der islamischen Welt zu erforschen und verstehen zu wollen, zweitens eine engere Vertrautheit mit den Sprachen und Traditionen ihrer eigenen (also der europäischen) Kultur und ihrer Abbildung in den verschiedenen akademischen Traditionen erwerben, und drittens ein weitaus sensibleres Sensorium für die kulturellen Strömungen und emotionalen Zustände in der islamischen Welt entwickeln. Darüber hinaus plädiert er dafür, dass die Islamwissenschaft für die Zwecke ihrer Analysen einen ,theoretischen, empirischen und historischen Bezugsrahmen" entwickeln solle. ${ }^{36}$ Es scheint wohl so, als ob niemand der Islamwissenschaft einen klaren Weg in die Zukunft weisen könne.

Die Islamwissenschaft in Deutschland ist in den letzten Jahrzehnten zu sehr Handwerk gewesen: Philologische Überlastung, unter anderem durch die nur sehr selten wirklich eingelöste Verheißung, mehrere islamische Sprachen (vorzugsweise Arabisch, Persisch und Türkisch) zu erlernen, kann schon während des Studiums zu einem Defizit an intellektueller Ausbildung beitragen. Zudem besteht ein Missverständnis sowohl auf Seiten der Islamwissenschaftler als auch der Außenstehenden: Islamwissenschaftler sollten sich als Intellektuelle zu Fragen äußern können, die den Islam und die Muslime in den Gesellschaften der Gegenwart betreffen, ohne allesamt zu sich mit der unmittelbaren Moderne beschäftigenden Sozialwissenschaftlern mutieren zu müssen. Man kann und sollte über - für andere - entlegene Themen und Dinge forschen und trotzdem dazu fähig sein, sich im öffentlichen Raum zu behaupten.

Die Deutungshoheit der Islamwissenschaft, wenn es jemals eine solche gegeben haben sollte, ist auch durch die Migration von Muslimen nach Europa erodiert worden. Orientalistik als Disziplin setzte ein klar definiertes Eigenes voraus - und dieses klar definierte Eigene war auch im Fall der Islamwissenschaft immer Europa mit seiner spezifisch christlich-abendländischen Kultur. Schon 1983 beklagte der 1938 aus Deutschland emigrierte und in den USA lehrende Islamwissenschaftler Franz Rosenthal (1914-2003), der Orientalistik sei das Fremde abhanden gekommen: Die muslimischen Migranten nach Europa würden ,an den

36 B. Johansen: Politics and Scholarship, S. 115: „Islamic studies ought to have a theoretical, empirical, and historical frame of reference that enables it to analyze cultures in terms of interactions between individuals, groups, and classes [...]“. 
ererbten Grundlagen der Orientalistik rütteln und sie zu zerstören drohen. Es sieht so aus, als ob der Reiz des Fremden nicht mehr existieren könne und die Suche nach dem Eigenen in diesem einst Fremden nicht mehr möglich sei, da das Fremde eben allzu vertraut und alltäglich geworden zu sein scheint. “37

So leicht aber geht das Fremde nicht verloren. Der Begriff ,Muslim“ hat in Europa bereits teilweise eine neoethnische oder pseudoethnische Konnotation angenommen, indem man dem Muslim nicht nur eine religiöse Zugehörigkeit, sondern gewissermaßen eine ethnisch-rassische zuweist. Abhilfe lässt sich womöglich unter anderem durch die Schaffung von Räumen bewerkstelligen, in denen Muslime und Nicht-Muslime eben nicht als Parlamentäre verfeindeter Formationen aufeinandertreffen (was übrigens ein Grundproblem aller ,Dialog 'Bemühungen ist), ja, in denen solche Zuordnungen einem gar nicht mehr in den Sinn kommen. Unter anderen könnte die Islamwissenschaft Ort eines solchen Austauschs sein, in dem Muslime und Nicht-Muslime eben nicht mehr als Muslime und Nicht-Muslime, sondern als gemeinsam arbeitende Studierende, Lehrende und Forschende aufeinandertreffen. ${ }^{38}$

Notwendig ist auch eine klarere Vermittlung des Faches im Unterricht. Es ist eine Illusion zu glauben, die enorme fachliche Breite der Islamwissenschaft könne in der Lehre eins zu eins wiedergegeben werden. Die Herausforderung für die geisteswissenschaftlichen Fächer, nämlich ,das Studium in eine Sequenz klar bestimmter Schritte so zu zerlegen, dass die Studenten einen Studiengang erleben, in dem Geleistetes aufeinander aufbaut und sich nicht nur impressionistisch zu einem Bild fügt“" ${ }^{39}$ lässt sich besonders als Aufgabe für die islamwissenschaftlichen Studiengänge verstehen.

Eine weitere Herausforderung für die Islamwissenschaft ist, sich in Zukunft zu einzelnen politischen Entwicklungen und Fragestellungen deutlich zu äußern. Dass Islamwissenschaftler in der deutschen Islamkonferenz kaum vertreten sind, muss man als Schicksal hinnehmen. Manches in der Zukunft Liegende könnte aber noch von der Islamwissenschaft beeinflusst werden: So braucht die Islamwissenschaft nicht Anspruch darauf zu erheben, die Lehrer für den islamischen Religionsunterricht auszubilden, aber sie muss darauf bestehen, dass die Dozenten, die diese Lehrer ausbilden (werden), einen festen Anteil ihrer Ausbildung

37 F. Rosenthal: Krise der Orientalistik, S. 15.

38 Das wird nicht immer einfach sein: Eine der Stärken westlicher Wissenschaft, nämlich wissenschaftliche Kritik, können manche der muslimischen Studierenden nur als Kritik an ihrer eigenen Religion verstehen. - Die Sinologie und die Slavistik mit einer zunehmenden Zahl von chinesischen bzw. russischen Muttersprachlern/innen unter ihren Studierenden kennen in den letzten beiden Jahrzehnten eine ähnliche Entwicklung; im Fall der Islamwissenschaft aber treten die religiös-kulturellen Trennlinien wohl noch deutlicher hervor.

39 Jürgen Kaube: „Das Unbehagen in den Geisteswissenschaften. Empirie und überempirische Krisen“, in: F. Keisinger/R. Berger (Hg.), Wozu Geisteswissenschaften, S. 17-28, hier S. 23. 
nicht nur in Studiengängen der islamischen Theologie erhalten, sondern auch in der Islamwissenschaft. Es geht hier nicht darum, dass Dozenten des islamischen Religionsunterrichts eine distanzierte Sicht auf ihre Religion einüben sollen, sie sollen aber zumindest die Haltung einer kritischen Distanz kennenlernen, die in der islamischen Theologie und Wissenschaftstradition nicht sehr ausgeprägt ist.

Über allem mea culpa soll aber auch nicht das tua culpa vergessen werden. Es ist ein Zeichen für den Orientalismus und Provinzialismus der deutschen Gesellschaft, dass sie erwartet, jeweils eine Handvoll von Fachvertretern könne eine Region in allen ihren Aspekten erklären, die weitaus größer ist als Westeuropa und Nordamerika zusammengenommen. Wie würde gelacht werden, wenn jemand den Vorschlag wagte, in Zukunft die Theologie, Geschichte, Philosophie, Soziologie, Politik-, Religions- und Literaturwissenschaft an einer Universität durch ein, zwei ,Okzidentalisten “ vertreten zu lassen? Es geht hier nicht um Lobbyismus, nämlich dass Gedanken zur Lage der Islamwissenschaft in Deutschland zwangsläufig in der Forderung nach mehr Stellen für die Islamwissenschaft münden müssen, sondern darum, dass an der Erklärung der ungeheuer großen und vielfältigen, islamischen Welt' auch andere, bisher abseits stehende Fächer wie die Geschichtswissenschaft teilhaben sollten. Warum sollte nicht etwa das Fach Geschichte in zumindest einigen Universität dazu in die Lage gebracht werden, eine Generation von auf die Gebiete der islamischen Welt spezialisierten und zugleich historisch arbeitenden Wissenschaftlern aufzunehmen - die schon in der nächsten Generation Historiker und eben nicht Islamwissenschaftler hervorbrächten $?^{40}$

Die Islamwissenschaft wird wegen ihrer ausgeprägten philologischen Orientierung und wegen ihrer nicht leicht zu behebenden Tradition einer, oft eklektizistischen Anleihe bei verschiedensten Disziplinen in absehbarer Zukunft keine für die allgemeinen Geisteswissenschaften wegweisenden Pfade beschreiten. Die Islamwissenschaft kann und soll auch kein Methodenfach werden. Es wäre unfruchtbar zu verlangen, dass jeder Islamwissenschaftler sich in Zukunft nur als Religionswissenschaftler, nur als Soziologe, nur als Literaturwissenschaftler, nur als Historiker, nur als Anthropologe usw. zu verstehen hätte. Das methodisch Chaotische oder - positiv gefasst - der disziplinäre Kosmopolitismus der Islamwissenschaft sind durchaus bewahrenswert. Dennoch ist die Konzentrierung auf ein, höchstens aber zwei methodische Schwerpunkte und sehr wenige inhaltliche

40 Die bisherige Bilanz (auch wenn in dieser Übersicht ein, zwei Professuren übersehen worden sein mögen) lässt eher vermuten, dass die eurozentrischen Beharrungskräfte der deutschen Geschichtswissenschaft die Oberhand behalten werden. Bisher gab es im Fach Geschichte an deutschen Universitäten nur folgende Professuren mit einer auf die islamische Welt bzw. den Nahen Osten bezogenen Ausrichtung: Helmut Mejcher in Hamburg (keine Nachfolge), Dan Diner in Essen (beim Nachfolger ersetzt durch einen anderen Schwerpunkt), Fikret Adanır in Bochum (Nachfolge noch unklar), Birgit Schäbler (Erfurt), Alexander Schölch, später Thomas Philipp in Erlangen (Nachfolge noch unklar). 
Felder notwendig. Nur so kann die Islamwissenschaft im besten Sinne eine Disziplin von ,Universal-Spezialisten ' bleiben. ${ }^{41}$ Das Fach kann jedoch versuchen, aus dem Gespräch mit anderen Disziplinen und dem intensiven Nachdenken über das eigene Fach eigenständig Fragestellungen entwickeln - also ein Fach mit einem spezifischen Gewicht und Gehalt sein. Noch zu oft argumentiert die Islamwissenschaft mit dem Hinweis auf ein Arkanum Islamwissenschaft, das sich nur dem mitteilbar machen könne, der selbst auch Islamwissenschaft studiert habe.

Es gilt, dass sowohl klassische Islamwissenschaft als auch Gegenwartsbezogenheit in der Islamwissenschaft ihren Platz haben. Auch ist das Fach nicht dazu da, ,kurzfristig verwertbare, pragmatische Ergebnisse oder gar nur Entscheidungshilfen für Politik und Wirtschaft zu liefern“. ${ }^{42}$ Das Fach hat das Recht, auf seinen Wissenschaftstraditionen zu beharren, auf seiner ihm eigenen Art der ,relevanten Redundanz" ${ }^{43}$ Die Islamwissenschaft muss sich aber zugleich der Ungeduld stellen, die ihr gegenüber gezeigt wird. ,Aristokratische' Selbstrechtfertigungen, dass man sich eigentlich nicht rechtfertigen und nicht zeitgemäß sein müsse, gehören zur unverzichtbaren Folklore der Universität und sind für das Überleben der Universität vielleicht sogar unverzichtbar - sofern sie allerdings produktive Wirkung entfalten. Die Islamwissenschaft wird bestehen können, wenn sie ihren Wert für andere, aber vor allem für sich selbst erweist.

41 H.-W. Schütte: Asienwissenschaften, S. 292, bezieht sich hier auf das Fach Sinologie.

42 Das Zitat bezieht sich im Originalkontext nicht auf die Islamwissenschaft, sondern auf die Orientalistik insgesamt; Lother Ledderose: „Begrüssungsansprache“, in Werner Diem/Abdoldjavad Falaturi (Hg.), XXIV. Deutscher Orientalistentag, vom 26. bis 30. September 1988 in Köln. Ausgewählte Vorträge, Stuttgart: Steiner 1990, S. 1-6, hier S. 6.

43 Siehe zum Begriff der ,relevanten Redundanz die Einleitung zum Sammelband. 



\section{Islamwissenschaft: \\ Globalisierung einer philologischen Disziplin}

BENJAMIN JOKISCH (HAMBURG)

Historisch gesehen haben sich Inhalte, Methoden und Aufgaben der Wissenschaften stets geändert. Wissenschaften, so lautet die Prämisse, sind nicht statisch, sondern definieren sich in ihrem jeweiligen historischen Kontext. Dies gilt auch für die Islamwissenschaft, die als eigenständige Disziplin zwar noch relativ jung ist, in ihren Wurzeln aber bis ins Mittelalter zurückreicht. Angesichts bedeutsamer globaler Veränderungen vor allem im 20. und 21. Jahrhundert stellt sich die Frage, wie die traditionell philologisch ausgerichtete Islamwissenschaft in der Gegenwart zu definieren ist und wie eine solche Disziplin im Wettkampf der Wissenschaften bestehen kann. ${ }^{1}$

Die vorliegende Studie versteht sich als ein Plädoyer für die Islamwissenschaft als einer substantiell philologischen Disziplin, ${ }^{2}$ die aber keinesfalls auf der philologischen Stufe stehen bleiben darf, sondern inhaltlich und methodisch in hohem Maße auf benachbarte, relevante Disziplinen übergreifen muss. ${ }^{3}$ Neben dem sprachlichen Grundbestand, d.h. der Beschäftigung mit der Koransprache Arabisch und einigen weiteren Islamsprachen, sowie, darauf aufbauend, der Un-

1 Philologie wird hier nicht im engeren Sinne als Wortphilologie, d.h. die „Kunst, die literarische Tradition zu verstehen, zu erklären und wiederherzustellen“ "verstanden, sondern im weiteren Sinne - gemäß A. Boeckh - als Sachphilologie definiert. Siehe Axel Horstmann: Antike Theoria und moderne Wissenschaft. August Boeckhs Konzeption der Philologie, Frankfurt/M: Peter Lang 1992, S. 101-115.

2 Dies ist im Grunde die Auffassung vieler namhafter Islamwissenschaftler. Vgl. Muhammad Arkoun: „The study of Islam in French scholarship“, in: Azim Nanji (Hg.), Mapping Islamic studies. Genealogy, continuity and change, Berlin, New York: de Gruyter 1997, S. 41; Josef van Ess: „From Wellhausen to Becker: The emergence of Kulturgeschichte in Islamic studies", in: Malcolm Kerr (Hg.), Islamic studies: A tradition and its problems, Malibu: Undena 1980, S. 51; Udo Steinbach: „Neuere Entwicklungen in der deutschen gegenwartsbezogenen Islamwissenschaft“, in: Angelika Hartmann u.a. (Hg.), Angewandte interdisziplinäre Orientforschung. Stand und Perspektiven im westlichen und östlichen Deutschland, Hamburg: Deutsches OrientInstitut 1991, S. 41-42; Jacques Waardenburg: „The study of Islam in German scholarship“, in: A. Nanji (Hg.), Mapping Islamic studies, S. 16.

3 J. Waardenburg: „Art. Mustashrikūn“, in: Encyclopedia of Islam VII, S. 751. 
tersuchung der wesentlichen Phänomene des Islam als Kultur und Religion, ${ }^{4}$ die eine unabdingbare Voraussetzung für alle islamkundlichen Studien bilden und eben deshalb dem Fach seine Besonderheit verleihen, weist die Islamwissenschaft nach dieser Konzeption ein weites Spektrum an Variablen auf, die sich nach Art und Intensität der Vernetzung mit angrenzenden Wissenschaften bestimmen. Die Öffnung der Disziplin gegenüber neuen Fächern, Methoden und Fragestellungen dürfte im Hinblick auf die zunehmende Globalisierung der Welt genauso notwendig sein wie die Bewahrung ihrer philologischen Tradition.

Die frühesten, gezielten Auseinandersetzungen europäischer Gelehrter mit dem Islam waren noch nicht im engeren Sinne wissenschaftlich intendiert, legten aber den Grundstein für das, was später einmal eine Wissenschaft werden sollte. Als der christliche Kleriker Petrus Venerabilis im 12. Jahrhundert und nach ihm verschiedene Dominikaner und Franziskaner - darunter der berühmte und orienterfahrene Raimundus Lullus (st. 1316) ${ }^{5}$ - begannen, Schriften über den Islam zu verfassen $^{6}$, ging es primär um eine mehr oder weniger vernunftbegründete, nach dem Scheitern der Kreuzzüge nunmehr verbale Widerlegung des Islam. Doch im Zuge dieser Polemik vertieften und systematisierten die Gelehrten die sprachlichen Studien und gelangten dabei zu neuen Erkenntnissen, die teilweise frühere Fehleinschätzungen korrigierten. ${ }^{7}$ Höchstwahrscheinlich stehen die religiös motivierten Studien der christlichen Gelehrten in Verbindung mit den zahlreichen, lateinischen Übersetzungen arabischer, profaner Texte, die ebenfalls in jener Zeit einsetzten und die eine neue, später als ,Frühe Renaissance“ bezeichnete Epoche in Europa einleiteten. Die Untersuchung und Vermittlung orientalischer Sprachen wird nun zunehmend institutionalisiert. Anfang des 14. Jahrhunderts empfahl das Konzil von Vienne die Einrichtung orientalischer Sprachkurse an fünf europäischen Universitäten ${ }^{8}$ und betonte damit die Bedeutung eines sprachlichen $\mathrm{Zu}$ gangs zur anderen Religion. Aufgrund dieser Aktivitäten, ob nun religiös oder humanistisch begründet, kam es zu einer systematischen Auseinandersetzung mit der arabischen Grammatik und zur Erstellung von Wörterbüchern, dem wesentlichen Rüstzeug einer Philologie. Ohne diese Voraussetzungen wäre die Einrich-

4 Im Einzelnen gehören dazu sicherlich Teilbereiche des Islam wie Geschichte, Theologie, Geographie, Recht, Hadīt, Philosophie oder Mystik.

5 Helmut Riedlinger: „Art. Raimundus Lullus“, in: Lexikon für Theologie und Kirche, Freiburg 1999, Bd. 8, S. 810-811.

6 Dazu gehören in erster Linie die gegen den Islam gerichteten Streitschriften. In diesem Kontext entstand aber auch die erste lateinische Koranübersetzung. Eine ausführliche Darstellung zu diesem frühen Stadium islamkundlicher Studien findet sich in: Hartmut Bobzin: Der Koran im Zeitalter der Reformation. Studien zur frühen Geschichte der Arabistik und Islamkunde in Europa, Stuttgart: Steiner 1995.

7 Gerhard Endreß: Einführung in die islamische Geschichte, München: C. H. Beck 1982, S. 15.

8 Ekkehard Rudolph: Westliche Islamwissenschaft im Spiegel muslimischer Kritik. Grundzüge und aktuelle Merkmale einer innerislamischen Diskussion, Berlin: Klaus Schwarz 1991, S. 68. 
tung arabistischer Lehrstühle im 16. und 17. Jahrhundert an mehreren europäischen Universitäten kaum vorstellbar. ${ }^{9}$ Interessant ist, dass die in jener Zeit als eigenständige Disziplin hervortretende Semitistik oder Arabistik ${ }^{10}$ ihre Anbindung an die Theologie mehr und mehr verliert und sich damit das Forschungsinteresse erweitert. Während es einerseits nach wie vor christliche Tendenzen gab, die Arabistik etwa für die alttestamentliche Wissenschaft zu instrumentalisieren, finden sich andererseits immer mehr europäische Gelehrte, die ihr Augenmerk auf nicht-religiöse Aspekte des Islam legten. Literatur unterschiedlichster Art wie Historiographien, Prosopographien und sogar arabische Gedichte werden seit der Zeit der Aufklärung ediert, übersetzt und durch die Möglichkeit des Buchdrucks einer breiteren Öffentlichkeit zugänglich gemacht. ${ }^{11}$ Die philologische Arbeit jener Gelehrten steht noch heute - auch in der muslimischen Welt - in gutem Ruf. Hinzu treten in jener Zeit Feldforschungen - etwa durch den französischen Reisenden Volney (1757-1820) - die die reine Textlektüre durch direkte Beobachtungen vor Ort ergänzen. ${ }^{12}$ Im 19. Jahrhundert wird die Orientalistik mit der Schaffung spezieller Einrichtungen und der Herausgabe orientalistischer Fachzeitschriften weiter institutionalisiert und verwissenschaftlicht. In Frankreich entstand 1821 die Societé Asiatique und zwei Jahre später in England die Royal Asiatic Society. ${ }^{13}$ Als es um die Wende zum 20. Jahrhundert durch die Ablösung von der Semitistik/Arabistik zur Begründung der Islamwissenschaft im engeren Sinne kommt, ${ }^{14}$ bleibt die Philologie ein wesentliches Element der Disziplin. Doch der Akzent liegt nun in viel höherem Maße auf gesellschaftlichen Aspekten des Islam, was nicht zuletzt auf die durch den Kolonialismus bedingten Interessenlagen zurückzuführen ist. Gegenstand der Islamwissenschaft ist in jener Zeit zumindest für den herausragenden Hamburger Orientalisten C. H. Becker - Kulturgeschichte im weitesten Sinne. ${ }^{15}$

9 So wurde z.B. der erste Lehrstuhl für Arabistik in Frankreich im Jahre 1539 im Collège de France eingerichtet und mit Guillaume Postel besetzt. Vgl. M. Arkoun: The study of Islam in French scholarship, S. 33.

10 Innerhalb der Semitistik nahm die Arabistik den größten Raum ein. Vgl. Ludmila Hanisch: Die Nachfolger der Exegeten: deutschsprachige Erforschung des Vorderen Orients in der ersten Hälfte des 20. Jahrhunderts, Wiesbaden: Harrassowitz 2003, S. 66.

11 Herausragende Beispiele sind die Übersetzungen von „Tausend und eine Nacht“ oder der berühmten „Utopia“ von Ibn Țufayl, die in Europa sehr weite Verbreitung fanden. Zur Rezeption des letzteren Werkes in Europa siehe Lawrence Conrad (Hg.), The world of Ibn Ṭufayl. Interdisciplinary perpectives on Hayy Ibn Yaqzān, Leiden: Brill 1996.

12 M. Arkoun: The study of Islam in French scholarship, S. 34.

13 Clifford E. Bosworth: The study of Islam in British scholarship, in: A. Nanji (Hg.), Mapping Islamic studies, S. 57.

14 L. Hanisch: Die Nachfolger der Exegeten, S. 68.

15 C. H. Becker leugnet nicht Vorzüge einer kritischen Philologie, distanziert sich aber von der reinen philologischen Arbeitsweise eines Arabisten wie etwa H.L. Fleischer 
Die sich damit andeutende Aufteilung in Semitistik/Arabistik und Islamwissenschaft markiert den Beginn eines Spezialisierungsprozesses, in dessen Verlauf Teilgebiete des Islam immer deutlicher fokussiert werden. Bereits vor dem 2. Weltkrieg sind Forscher anzutreffen, die ihren Schwerpunkt jeweils in der Geschichte, Theologie, Mystik, Philosophie, dem Traditionswesen oder dem Recht sehen. Diese Tendenz setzt sich in der 2. Hälfte des 20. Jahrhunderts mit rasanter Geschwindigkeit fort, sodass Islamwissenschaft heute für ein Kaleidoskop von Spezialgebieten steht, die in ihrer Gesamtheit von keinem Islamwissenschaftler mehr beherrscht werden können. Parallel zu dieser Entwicklung entstehen in den USA die sogenannten area studies bzw. - mit speziellem Bezug zu einzelnen Regionen des Islam - die Middle Eastern Studies. Sie stehen weniger in der philologischen Tradition der europäischen - vor allem deutschen und französischen - Orientalistik, bringen aber mit ihrem strengen Gegenwartsbezug und der regionalen Eingrenzung eine zeitliche und räumliche Spezialisierung. Das Fehlen der philologischen Basis in den area studies wird mitunter auch kritisch gesehen, und es gibt Stimmen, die mehr historische Tiefe auf philologischer Grundlage einfordern, um zukünftige Entwicklungen in der Region präziser prognostizieren zu können. ${ }^{16}$

Insbesondere im 20. Jahrhundert hat sich die Islamwissenschaft nicht nur in hohem Maße spezialisiert, sondern auch ,globalisiert‘. Mit letzterem Vorgang sind neben dem verstärkten Gegenwartsbezug vor allem zwei eng miteinander verknüpfte Phänomene gemeint:

1) Interdisziplinarität

2) Betrachtung des Islam als Teil eines globalen Kontextes, an dem der betrachtende Islamwissenschaftler und seine Kultur selbst partizipieren

Durch die erheblich erweiterten Möglichkeiten der Mobilität und Kommunikation wird die geographische Distanz zwischen der muslimischen und der westlichen Welt stark verkürzt. Weltweiter Handel, Tourismus, Migration, globale militärische Operationen, moderne Kommunikatiosmittel und die allgegenwärtigen Medien haben für eine soziale Denationalisierung, ${ }^{17}$ d.h. enge Verflechtung und

(1801-88). Vgl. J. v. Ess: From Wellhausen to Becker, S. 39-40. Zur Begründung der deutschen Islamwissenschaft durch C. H. Becker siehe Alexander Haridi: Das Paradigma der ,,islamischen Zivilisation“ - oder die Begründung der deutschen Islamwissenschaft durch Carl Heinrich Becker (1876-1933), Würzburg 2005, S. 13.

16 Martin Kramer: Ivory towers on sand. The failure of Middle Eastern Studies in America, Washington: Washington Institute for Near East Policy 2001, S. 122.

17 Unter ,sozialer Denationalisierung 'ist hier der Prozess der Ausdehnung der verdichteten sozialen Handlungszusammenhänge über die Grenzen der Nationalstaaten hinaus zu verstehen (Martin Beck: „Globalisierung als Bedrohung. Die Globalisierungsresistenz des Vorderen Orients als Ausdruck rationaler Reaktionen der politischen Eliten auf die neuen Entwicklungen im internationalen System“, in: Henner 
eine direkte Konfrontation der Kulturen gesorgt, ${ }^{18}$ die mitunter negativ als „,clash of civilizations" empfunden wird. ${ }^{19}$ Vor diesem Hintergrund ist es vielleicht nicht überraschend, dass kulturelle und religiöse Unterschiede deutlicher hervortreten und gelegentlich für Konflikte sorgen wie etwa die Salman Rushdie Affäre und die anschließende Auseinandersetzung mit der Islamwissenschaftlerin Annemarie Schimmel,${ }^{20}$ die Kopftuch-Debatte in Deutschland und Frankreich, ${ }^{21}$ der Fall des ägyptischen Literaturwissenschaftlers Nașr Ḥāmid Abū Zayd ${ }^{22}$ oder jüngst der Karikaturenstreit. Medial gestützt erreichen Konflikte dieser Art eine breite Öffentlichkeit und provozieren Grundsatzdebatten über Vereinbarkeit oder Unvereinbarkeit islamischer und westlicher Werte. In deutlich verstärktem Maße lassen sich in der jüngsten Vergangenheit Initiativen zum interreligiösen bzw. interkulturellen Dialog beobachten. ${ }^{23}$

Im Rahmen dieser Auseinandersetzungen dominiert aber nach wie vor ein eher schemenhaftes, unvollkommenes Islambild, das nicht zuletzt durch die Islamwissenschaft selbst gefördert wurde. Trotz der vorangeschrittenen Spezialisierung und der dadurch bedingten Erschließung von Detailwissen ist der Islam ein einheitliches Objekt wissenschaftlicher Betrachtung geblieben, das zum Vergleich anregt und dem Westen als Ganzes gegenübergestellt wird. Pauschalisierendes Denken in Gegensatzkategorien wie modern - veraltet, rechtsstaatlich despotisch, fortschrittlich - rückständig etc. lässt sich bis ins 20. Jahrhundert hinein im orientalistischen Schrifttum zurückverfolgen. Es ist wohl erst die von Edward Said vollends ausgelöste, unter dem Schlagwort Orientalism geführte Debatte, die mit aller Deutlichkeit auf diese Problematik Bezug nimmt und der es spätestens seit den 90er Jahren des 20. Jahrhunderts gelang, sowohl in der westlichen wie in der muslimischen Welt eine bewusste Reflexion über das Verhältnis

Fürtig (Hg.), Islamische Welt und Globalisierung. Aneignung, Abgrenzung, Gegenentwürfe, Würzburg: Ergon 2001, S. 54.

18 Über den Islam in einer globalisierten Welt siehe z.B. Olivier Roy: Globalized Islam: the search for a new ummah, London: Hurst 2004.

19 Der Artikel „Clash of civilizations?”, in: Foreign Affairs 72 (1993), S. 22-49 sowie das etwas später erschienene Buch ,The clash of civilizations and the remaking of world order', New York: Simon \& Schuster 1996 von Samuel Huntington hat auch in der Orientalistik eine heftige Kontroverse ausgelöst.

20 Siehe dazu Stefan Wild: „Der Friedenspreis und Annemarie Schimmel. Eine Nachlese“, in: Die Welt des Islams 36 (1996), S. 107-122.

21 Carola May: Die Kopftuchdebatte in Frankreich, Hamburg: Magisterarbeit 2005.

22 Baudouin Dupret: „A propos de l'affaire Abu Zayd, universitaire poursuivi pour apostasie; le procès: l'argumentation des Tribunaux“, in: Maghreb-Mashrek (1996), S. 18-22; Kilian Bälz: ,Submitting faith to judicial scrutiny through the family trial: the Abū Zayd case“, in: Die Welt des Islams 37 (1997), S. 135-155.

23 Die jüngere Literatur über den islamisch-christlichen, arabisch-europäischen etc. Dialog ist höchst umfangreich. Siehe z.B. Wolfgang Jäger: Die islamische Welt und Europa: Begegnung - Zusammenprall - Dialog?, zur Geschichte des islamischen und des christlichen Kulturkreises, Berlin 2002. 
von Orient und Okzident in Gang zu setzen. ${ }^{24}$ Dass sich E. Said als palästinensischer Migrant in den USA erweist - in einer Zeit, in der der Globalisierungsprozess und damit die direkte Begegnung der Kulturen sehr intensiv wahrgenommen werden -, ist bezeichnend. Zweifellos steht die Debatte in einem engen Zusammenhang mit der westlichen wie östlichen Reaktion auf das neu erkannte Phänomen der Globalisierung. ${ }^{25}$

Die Bewusstmachung und das Überdenken des westlich-islamischen Verhältnisses - nicht nur in seiner politischen, sondern auch in seiner kulturellen Dimension - hatte immense Auswirkungen auf die weitere Entwicklung der Islamwissenschaft, die sich nun noch stärker gezwungen sah, aus ihrem ,Elfenbeinturm ' herauszutreten und sich der globalisierten Realität zu öffnen. Während sich erste Ansätze einer gegenwartsbezogenen Orientforschung bereits in den 70er Jahren konstatieren lassen, ${ }^{26}$ erhält die Forschung in diesem Bereich in den 90er Jahren deutliche, weitere Impulse - und dies sicherlich nicht zuletzt aufgrund der Orientalismus-Debatte, in der die traditionelle Fokussierung auf den vormodernen Islam heftig kritisiert wurde.

In engem Zusammenhang mit der zeitlichen Akzentverschiebung steht die nun verstärkt zu beobachtende Vernetzung der Islamwissenschaft mit angrenzenden Disziplinen wie Soziologie, Politologie, Rechtswissenschaft oder Geographie. $^{27}$ Die primär philologischen Methoden der Islamwissenschaft reichen nicht mehr aus, um den modernen Erscheinungen des Islam gerecht $\mathrm{zu}$ werden und müssen durch neuere Forschungsmethoden ergänzt werden. Eine Debatte innerhalb der Disziplin über die Kompatibilität bzw. den Vorrang der verschiedenen Methoden ist nach wie vor im Gange, ${ }^{28}$ wird aber den endgültigen Einzug neuer Forschungsmethoden in die Islamwissenschaft kaum verhindern können. Andererseits wäre es unangemessen, den philologischen Charakter der Islamwissenschaft als überholt anzusehen, da die philologische Arbeit - sozusagen als Grundlagenforschung - bis zu einem gewissen Grade nach wie vor die Basis für neuere, nicht minder auf Quellen angewiesene, geschichts- und sozialwissenschaftliche Studien bilden kann. Hinzu kommt, dass Erkenntnisse über den vor-

24 Es ist sein 1978 erschienenes Buch ,Orientalism‘, das die Kontroverse auslöste, repräsentiert durch eine sehr umfangreiche, auf den Orientalismus Bezug nehmende Literatur.

$25 \mathrm{Zu}$ muslimischen Reaktionen, die zwischen kritischer Ablehnung und vorsichtiger Akzeptanz schwanken, siehe H. Fürtig: „Muslime in der Globalisierung. Wahrnehmungen und Reaktionen“, in: H. Fürtig (Hg.), Islamische Welt und Globalisierung, S. 41-80.

26 Der Begriff ,Orientforschung' beinhaltet hier nicht den o.g. Bereich der area studies.

27 U. Steinbach: Neuere Entwicklungen in der deutschen gegenwartsbezogenen Islamwissenschaft, S. 41-42.

28 Siehe z.B. den Disput zwischen R. Schulze und B. Radtke. Vgl. Reinhard Schulze: „Was ist die islamische Aufklärung?“, in: Die Welt des Islams 36 (1996), S. 291294. 
modernen Islam, die in höherem Maße philologisch gestützt sind, nicht ohne Auswirkung auf Studien über den modernen Islam bleiben können. Beschreibt man den Islam als „Erinnerungskultur“ ${ }^{29}$ in der mehr als anderswo Rückbezug auf die Vergangenheit genommen wird, erweist sich eine strikte Trennung in historische und gegenwartsbezogene Forschung als nicht sachdienlich. In diesem speziellen, nicht essentialistisch zu verstehenden Sinne lässt sich in Einschränkung des oben Gesagten vielleicht doch von einem Islam als einer Einheit ausgehen, die eine Abgrenzung gegenüber anderen Kulturen und Religionen rechtfertigt. Ohne den Anspruch auf innere Differenzierung aufzugeben, wäre es dennoch nicht erstrebenswert, den Islam als Forschungsobjekt zeitlich und noch in anderer Hinsicht in seine Bestandteile zu zerlegen und diese zum Gegenstand jeweils unterschiedlicher, voneinander unabhängiger Disziplinen $\mathrm{zu}$ machen. Vielmehr wäre es die interdisziplinäre Aufgabe der Islamwissenschaft - die zudem als einzige Disziplin die notwendigen sprachlichen Grundlagen vermitteln kann - die verschiedenen Disziplinen in den für den Islam relevanten Bereichen zusammenzuführen und damit die Möglichkeit zu schaffen, den Islam in seiner Komplexität besser zu verstehen. Dies gilt unabhängig von der Frage, ob eine ,islamische Identität' tatsächlich besteht oder nur konstruiert ist. ${ }^{30}$

Neben der Interdisziplinarität charakterisiert ein zweites Kriterium die moderne Islamwissenschaft, nämlich die Neubestimmung der Position des Islamwissenschaftlers gegenüber seinem Forschungsobjekt. Es resultiert ebenfalls aus der Orientalismus-Debatte und hängt eng mit der zuvor genannten Frage nach der islamischen bzw. westlichen Identität zusammen. Um eine objektive, wertfreie Erschließung des Phänomens Islam oder seiner Teilaspekte zu ermöglichen - bis ins 20. Jahrhundert hinein wurde der Orient in der westlichen Orientalistik als ein uniformer und statischer Chronotopos konstruiert ${ }^{31}$ - wird u.a. auf die Diskursanalyse verwiesen, die der den Kulturwissenschaften immanenten Problematik der Hermeneutik begegnen soll. ${ }^{32}$ Ausgehend von einer fremden Welt, die von der eigenen Welt grundsätzlich verschieden ist, wird nach der Möglichkeit des Verstehens gefragt, das dazu neigt, das Fremde in den Kategorien des Vertrauten

29 Ulrich Marzolph: „Islamische Kultur als Gedächtniskultur. Fachspezifische Überlegungen anhand des Fallbeispiels Iran“, in: Der Islam 75 (1998), S. 296-317.

30 Der nicht nur für die Islamwissenschaft relevante Streit zwischen Anhängern und Gegnern der „Volksgeisttheorie“ ist nicht neu. Im 19. Jahrhundert stehen sich europäische Gelehrte wie Thibaut und Savigny in dieser Frage unversöhnlich gegenüber. Vgl. J. v. Ess: From Wellhausen to Becker, S. 38.

31 Jan Loop: „Kontroverse Bemühungen um den Orient. Johann Jacob Reiske und die deutsche Orientalistik seiner Zeit“, in: Hans-Georg Ebert u.a.. (Hg.), Johann Jacob Reiske - Leben und Wirkung. Ein Leipziger Byzantinist und Begründer der Orientalistik im 18. Jahrhundert, Leipzig: Evangelische Verlagsanstalt 2005, S. 47. Eine interessante Ausnahme bildet der deutsche Orientalist und Byzantinist J. Reiske (idem 77).

32 Siehe z.B. Marco Schöller: Methode und Wahrheit in der Islamwissenschaft. Prolegomena, Wiesbaden: Harrassowitz 2000. 
zu erschließen. Im Rahmen der Diskursanalyse ist die Gefahr einer solchen Fehldeutung weitgehend gebannt, doch dafür ist diese Analyse eher deskriptiv und ermöglicht nur ein eingeschränktes Verstehen. Hinzu kommt das Problem der vorausgesetzten Wesensverschiedenheit. Was ist, wenn sich bei der Untersuchung des Gegenstandes Islam herausstellt - etwa durch einen interkulturellen Ansatz, der den Islam in einem engen Kontext mit anderen Religionen oder Kulturen sieht - dass der Islam gar nicht jene Identität besitzt, die ihm nach dem äuBeren Anschein zugeschrieben wird? In der modernen globalisierten Welt stellt sich diese Frage zwangsläufig, da schon eine räumliche Trennung der Kulturen kaum noch möglich ist. Mehr oder weniger große muslimische Minderheiten bilden längst Teil zahlreicher nicht-muslimischer Gesellschaften und lösen unweigerlich einen - oftmals kritisch beäugelten - Prozess gegenseitiger Anpassung aus. ${ }^{33}$ Umgekehrt sind natürlich auch die Auswirkungen des Westens auf die muslimische Welt unübersehbar. Wissenschaftliche Beschreibungen und Analysen des Islam können folglich nur aus einer Lage heraus geschehen, in der Subjekt und Objekt der Forschung Teil ein und desselben Kontextes sind, sozusagen im selben Boot sitzen. Aufgrund dieser engen Verflechtung bedeuten Erkenntnisse über den Islam bis zu einem gewissen Grade immer auch Erkenntnisse über die Kultur des westlichen Islamwissenschaftlers selbst.

Was die Erforschung des Islam in der Gegenwart angeht, so dürfte die ,Betroffenheit' des Islamwissenschaftlers außer Frage stehen. Man könnte aber noch einen Schritt weiter gehen und das Kriterium der Betroffenheit auf den Islam in seiner historischen Dimension beziehen. Globalisierung im engeren Sinne ist sicherlich eine Erscheinung der Neuzeit. Soweit man dem Phänomen überhaupt eine besondere historische Dimension zubilligt, datiert man die Globalisierung im Allgemeinen auf die Entdeckung Amerikas durch Columbus im Jahre 1492 oder die spektakuläre Weltumsegelung Magellans im Jahre 1519/20. Erst diese Form europäischer Expansion und die damit einhergehende Herausbildung einer ,Weltwirtschaft' schaffte nach diesem Verständnis das Bewusstsein von der ,einen ' Welt. ${ }^{34}$ Im weiteren Sinne aber hat es die Globalisierung - was insbesondere das Verhältnis der drei monotheistischen Religionen Islam, Christentum und Judentum und die damit verknüpften Kulturen angeht - schon lange vorher gegeben. ${ }^{35}$ Demgegenüber hat die durch die islamkundliche Philologie bedingte Fixie-

33 Bryan Turner: Orientalism, postmodernism and globalism, London: Routledge 1994, S. 9. Zum Eindringen islamrechtlicher Elemente in das deutsche Recht siehe Mathias Rohe: Der Islam - Alltagskonflikte und Lösungen, Freiburg u.a.: Herder 2001.

34 H. Fürtig: Muslime in der Globalisierung, S. 17-18.

35 Interessanterweise datieren auch einige muslimische Wissenschaftler den Beginn der Globalisierung auf jene frühe Zeit, als zwischen dem achten und zwölften Jahrhundert ein intensiver wissenschaftlicher, wirtschaftlicher und kultureller Austausch die damals bekannte Welt umfasste (H. Fürtig: Muslime in der Globalisierung, S. 19). 
rung auf das Arabische und andere islamische Sprachen die Vorstellung von getrennten Welten über Jahrhunderte hinweg gefestigt. Islamische Kultur wurde fast ausschließlich aus islamischen Quellen und damit aus sich selbst heraus erklärt. ${ }^{36}$ Dass der Islam schon seit dem frühesten Mittelalter auf vielfältige Weise mit benachbarten Kulturen und Religionen verflochten war, wurde zwar nie grundsätzlich bestritten, hat aber in der philologischen Arbeit der Islamwissenschaftler keinen entsprechenden Niederschlag gefunden. Erst die Anwendung des neueren, interdisziplinären Ansatzes der connected histories ${ }^{37}$ auf die Beziehungen zwischen Islam und Christentum in der Vormoderne öffnet den Weg für die Hypothese, dass der Islam auch in seiner frühesten historischen Entwicklung viel enger mit Europa verknüpft war, als beide Seiten es eingestehen wollen. Dieser Hypothese Nachdruck zu verleihen würde aber bedeuten, islamische Quellen (Arabisch, Persisch etc.) in sehr enger Verbindung mit Quellen anderer Religionen und Kulturen zu analysieren and damit die philologische Arbeit der Islamwissenschaftler zu erweitern. ${ }^{38}$ Globalisierung einer philologischen Disziplin würde hier bedeuten, dass die Auswahl und vergleichende Analyse der Quellen in Hinblick auf einen übergeordneten historischen Kontext ${ }^{39}$ erfolgt, der über die engeren Grenzen einer bestimmten Kultur - in diesem Falle der islamischen - hinausgeht. Soweit sich im Zuge solcher kontextuellen Untersuchungen, die oftmals nur durch interdisziplinäre Zusammenarbeit zu bewältigen sind, interkulturelle $\mathrm{Ab}$ hängigkeiten feststellen lassen, sind historische Ereignisse oder Prozesse u.U. neu zu interpretieren. Wie z.B. würde man die mittelalterliche europäische Rechtsentwicklung, die bis dato in einem engeren europäischen Kontext beschrieben wird, vor dem Hintergrund der islamischen oder jüdischen Rechtsentwicklung beurteilen? Oder welcher Zusammenhang besteht zwischen dem Aufkommen neuer ökonomischer Konzeptionen im Europa des 11. Jahrhunderts und

36 Eine Ausnahme bildet die Rezeption antiken Gedankengutes durch arabische Gelehrte. Doch dieser Bereich der islamischen Kultur wird in der Forschung recht deutlich von anderen Bereichen der islamischen Kultur (Recht, Hadīt etc.) getrennt.

$37 \mathrm{Zu}$ diesem Ansatz siehe Sanjay Subrahmanyam: „Connected histories: notes towards a reconfiguration of early modern Eurasia", in: Modern Asian Studies 31 (1997), S. 735-762. Einen ähnlichen Ansatz hat bereits Gustave E. von Grunebaum vertreten: „The problem of cultural influence“, in: Dunning S. Wilson (Hg.), Islam and medieval Hellenism: social and cultural perpectives, London: Variorum Reprints 1976, S. 86-99; siehe auch Lawrence Conrad u.a. (Hg.), The Byzantine and early Islamic Near East, Princeton: Darwin Press 1992.

38 Der Nachweis genetischer Abhängigkeiten von Texten als wichtiger Bestandteil der philologischen Arbeit würde sich in diesem Falle auf Quellen verschiedener Religionen und Kulturen beziehen.

39 Dieser übergeordnete Kontext kann sich neben verschiedenen Kulturen auch auf verschiedene Teilbereiche ein und derselben Kultur beziehen wie z.B. Recht, Theologie und Philosophie. 
sehr ähnlichen Konzeptionen im Islam zur selben Zeit? ${ }^{40}$ Diese und ähnliche Fragestellungen, die eine ,globale“ Sichtweise voraussetzen, hätten Auswirkungen auf die Arbeit der Philologen und all derjenigen, die sich wiederum auf die Arbeit der Philologen stützen. Ein konkretes, auf das byzantinisch-islamische Wechselwirkungsverhältnis bezogenes Beispiel soll diesen Ansatz näher verdeutlichen:

Mehrfach ist in islamwissenschaftlichen, aber auch byzantinistischen Studien der Hinweis auf weitergehende, d.h. über den militärisch-politischen Bereich hinausgehende Interaktionen zwischen Byzanz und Kalifat zu finden. So betrachtet P. Crone ${ }^{41}$ den Synchronismus von byzantinischem und islamischem Bilderverbot Anfang des 8. Jahrhunderts als nicht zufällig. Verbindungen wurden auch zwischen dem frühen byzantinischen und islamischen Humanismus im 8. und 9. Jahrhundert gesehen. Sogar die Mu'tazila scheint - zumindest nach A. Vasiliev ${ }^{42}$ und Haddad $^{43}$ - auffällige Gemeinsamkeiten mit der zeitgleichen ikonoklastischen Bewegung in Byzanz zu haben. Weitere Beispiele für punktuelle Parallelen zwischen den beiden Religionsstaaten lassen sich hinzufügen. Aber dennoch gehen all diese Studien, die noch weit von der vollständigen Erfassung gleichartiger, synchroner Phänomene in Byzanz und Kalifat entfernt sind, von Einzelerscheinungen aus, die eben nicht als Teil eines organischen, über die Grenzen der jeweiligen Religion und Kultur hinausgehenden Entwicklungsprozesses betrachtet werden. Um der Grundannahme von der Verflechtung der Kulturen, wie sie C. H. Becker und viele andere bereits vertreten haben, Nachdruck zu verleihen, müssten die Hintergründe all dieser Parallelerscheinungen auf der Basis des relevanten Schrifttums näher beleuchtet werden. Im Einzelnen wäre etwa zu fragen: Welche kausale Beziehung besteht zwischen dem monotheletischen Konflikt in Byzanz (7.-8. Jh.), der sich im Kern um die Frage des freien Willens dreht und mit der Herausbildung einer ,grotesk' traditionalistischen Bewegung verknüpft war $^{44}$ und dem qadaritisch-murği'itischen Konflikt im Kalifat zur selben Zeit ebenfalls begleitet von einer traditionalistischen Bewegung ${ }^{45}$ Inwieweit bildet der byzantinische Ikonoklasmus eine Reaktion auf das kurz zuvor staatlich verordnete Bilderverbot im Kalifat? Lässt sich die gängige These von P. Lemerle,

$40 \mathrm{Zu}$ dieser Thematik siehe die jüngste Studie von Gene W. Heck: Charlemagne, Muhammad and the roots of capitalism, Berlin: de Gruyter 2006.

41 Patricia Crone: „Islam, Judeo-Christianity and Byzantine iconoclasm“, in: Jerusalem Studies in Arabic and Islam 2 (1980), S. 70.

42 Aleksandr A. Vasil'ev: Byzance et les Arabes, Bd.1: La Dynastie d’Amorium, Brüssel: Inst. de Philologie et d'Histoire Orientales 1935.

43 Robert M. Haddad: „Iconoclasts and Mu'tazila”, in: Greek Orthodox Theological Review 27 (1982), S. 287-305.

44 Hier ist anzumerken, dass dieser bedeutende Konflikt in der Islamwissenschaft kaum zur Kenntnis genommen wurde.

45 Prosopographische Untersuchungen legen nahe, dass die frühe Hadīt-Bewegung in besonderem Maße im Qadarismus verankert ist. 
dass der byzantinische Humanismus ein eigenständiges, vom islamischen Humanismus unabhängiges Phänomen darstelle, angesichts der Tatsache halten, dass sich eben diese These in Bezug auf den Islam ausschließlich auf Sekundärquellen stützt? Welche Verbindung ist zwischen der Mihna und dem 2. Ikonoklasmus in Byzanz sowie dem anschließenden Triumph der Orthodoxie in den beiden Religionsstaaten zu sehen? Betrachtet man all diese synchronen Erscheinungen nicht nur als jeweils interdependent, sondern auch diachron als Teile eines längeren, byzantinisch-islamischen Entwicklungsprozesses, in dem Bewegungen, Institutionen oder Einzelpersonen als Träger bestimmter Konzepte in die jeweils andere Kultur hineinwirken und damit einen Mechanismus von Wirkung und Gegenwirkung in Gang setzen, ergibt sich ein äußerst komplexes Bild, das sich aus einem rein byzantinischen oder rein islamischen Kontext heraus nicht erklären lässt. Vieles weist darauf hin, dass Teile der byzantinischen Zirkusparteien, insbesondere der Benetoi (= die Blauen), im Zuge der arabischen Eroberungen in das Kalifat einsickerten und dort nach der Konversion islamische Ableger bildeten. Die hāriğitische Bewegung der Azraqiten (= die Blauen), die neben der Bezeichnung dieselbe Militanz und eine sehr ähnliche theologische Konzeption aufweist (radikale Form der Frei-Willens-Doktrin i.V.m. einem strengen Traditionalismus), ist nach arabischen Quellen von einem Byzantiner (Nāfi` b. al-Azraq) begründet worden. Die prekäre, da politische Verantwortlichkeit implizierende Doktrin des Qadarismus brachte zusätzliches Konfliktpotenzial in die innerislamische Auseinandersetzung um die Legitimität von Herrschaft. Umgekehrt ist zu berücksichtigen, dass die Polarisierung der byzantinischen Gesellschaft bis hin zur Spaltung der Reichskirche Mitte des 7. Jahrhunderts nicht zuletzt auf die arabische Expansion zurückzuführen ist. Der Dyotheletismus ist Produkt jener Krise im byzantinischen Rumpfstaat, in der immer mehr Menschen die Lösung in der Rückkehr zum wahren Glauben, d.h. zur Tradition, sahen. In der weiteren Entwicklung kann das Bilderverbot Yazīd II. - das bis Ende des 7. Jahrhunderts im Islam ganz offensichtlich keine Rolle spielte - als Reaktion auf den politisch gefährlichen Dyotheletismus gesehen werden, der im Zuge des Trullanischen Konzils (692) eine enge Verbindung mit der Bilderverehrung eingegangen ist und somit äußerlich sichtbar wurde. Obwohl die genauen Hintergründe des wenig später eingeführten byzantinischen Ikonoklasmus im Dunkeln bleiben, lässt sich vermuten, dass Leo III. angesichts seiner cäsaropapistischen Ambitionen dieselben Maßnahmen ergriff wie sein Kollege in Damaskus, um sich unter dem Deckmantel des Ikonoklasmus der dyotheletischen Dissidenten zu entledigen. Schließlich standen sich Kaiser und Kalif im selben Konflikt derselben Opposition gegenüber.

Ende des 8. Jahrhunderts wurde der Ikonklasmus durch eine kurze Phase der Orthodoxie unter der Kaiserin Irene abgelöst. Auch diese Phase hat mit der orthodoxen Politik Hārūn ar-Rašīds in seiner frühen Regierungszeit ein Pendant im Kalifat. Das Freidenkertum am Kalifenhof in Bagdad weicht einem traditionalistisch gefärbten Konformismus. Das, was die Ikone in Konstantinopel ist, - und 
diese bildet nach orthodox-christlichem Verständnis die Alternative zur $\mathrm{Hl}$. Schrift - wird der Qur'ān in Bagdad. Der politische Background mag die Parallelität der neuen Orthodoxie erklären: Sowohl Irene als auch Hārūn ar-Raš̄ìd und die einflussreichen Barmakiden, die miteinander in Kontakt standen, stützten sich auf die traditionalistische Opposition als neue Machtbasis, während der Einfluss der Militärs stark reduziert wurde. Byzanz und Kalifat verfolgten in jener Zeit eine defensive Politik. Gleichzeitig kommt es in Bagdad zu einer Art Kulturexplosion, eingeleitet durch die von der Regierung geförderte systematische Übersetzungstätigkeit. Allein schon die Tatsache, dass die Zugpferde des byzantinischen Humanismus Johannes Grammatikos, Photios oder Choirophaktes sich zumindest zeitweilig in Bagdad aufhielten, macht eine Verbindung zwischen byzantinischem und islamischem Humanismus mehr als wahrscheinlich.

Nach dem Sturz von Irene (802) und der Barmakiden (803) kehrte die Lage sich wieder um. In Byzanz bekam der Ikonoklasmus erneuten Auftrieb, wobei das Argument von der „Erschaffenheit des Bildes“ im Vordergrund stand. Etwa zur gleichen Zeit begann in Bagdad die Doktrin von der „Erschaffenheit des Qur'ān" zu kursieren, um schließlich von Ma'mūn zur Staatsdoktrin erklärt zu werden. Dieser stand eine wachsende Gruppe von Traditionalisten gegenüber, die sich zur „Unerschaffenheit des Qur'ān“ bekannte - in den Reihen der Bilderverehrer, die bereits während des 1. Ikonoklasmus ihren Schwerpunkt im Kalifat hatten, sprach man von Bildern, die ,nicht von Menschenhand gemacht“ sind. Dass die Traditionalisten im Kalifat schließlich triumphierten, wird nicht zuletzt daran liegen, dass vom vorausgehenden Triumph der Bilderverehrer in Byzanz starke Impulse ausgingen. Unmittelbar nach der offiziellen Widerrufung des Ikonoklasmus in Konstantinopel kam es in Bagdad zu gewaltsamen Ausschreitungen der Traditionalisten gegenüber Vertretern der halq al-Qur'ān-Doktrin. Die sich seit Mitte des 9. Jahrhunderts formierende Orthodoxie in Bagdad gibt sich mit ahl as-sunna wa'l-ğamā'a eine Bezeichnung, die als direkte Übersetzung von ecclesia apostolica et catolica interpretiert werden kann, die seit Ende des 8. Jahrhunderts gängige Bezeichnung für die Orthodoxie in Byzanz.

Wie sich an diesem Beispiel zeigt, können sich die Forschungsperspektiven je nach vorausgesetztem Kontext - innerislamisch oder byzantinisch-islamisch verschieben und jeweils zu verschiedenen Ergebnissen führen. Ein solcher über einzelne Kulturen hinausgehender und letztlich auf Globalisierung basierender Ansatz birgt wissenschaftsorganisatorische Probleme. Auch wenn Interdisziplinarität ein Schlagwort in der gegenwärtigen Forschung ist, so fehlen doch in vielen Disziplinen immer noch die organisatorischen Voraussetzungen für eine effektive Zusammenarbeit. Ein richtiger Schritt in diese Richtung ist sicherlich die Errichtung von Forschungszentren, in denen verschiedene, bisher separate Disziplinen unter einem Dach vereinigt und mitunter durch besondere Koordinatoren miteinander vernetzt werden. Interdisziplinäre Forschungsprojekte lassen sich im Rahmen solcher Institutionen eher verwirklichen und ermöglichen eine differenziertere Erforschung interkultureller Phänomene. Es bleibt zu hoffen, dass Er- 
gebnisse auf dieser Ebene auf die Inhalte und Methoden der jeweiligen Disziplinen zurückwirken und die Zahl jener Spezialisten zunimmt, die sozusagen zwischen den Stühlen sitzen.

Betrachtet man also die jüngsten Entwicklungen der Islamwissenschaft unter dem Aspekt der Globalisierung, erscheint die Disziplin eher in einem Prozess der Auflösung oder Verschmelzung mit anderen, angrenzenden Disziplinen. Der ,Islam' als Forschungsgegenstand sui generis wird nicht zuletzt aufgrund der Orientalismus-Debatte - ihrerseits ein Produkt der Globalisierung - längst nicht mehr mit der Eindringlichkeit betont wie dies etwa C. H. Becker noch Anfang des 20. Jahrhunderts getan hatte. Andererseits erweist sich die islamkundliche Philologie nach wie vor als unabdingbare Voraussetzung für viele islamrelevante Forschungen und auch die innere historische Vernetzung des Islam - ob konstruiert oder nicht - erlaubt neben den zweifellos notwendigen Spezialuntersuchungen eine Gesamtsicht. Die Islamwissenschaft wird im Kern wohl eine philologische Disziplin bleiben, aber eben in vielen verschiedenen konkreten Ausprägungen. 



\section{Historismus versus Orientalismus? \\ Oder: Zur Geschichte einer Wahlverwandtschaft}

BIRGIT SCHÄBLER (ERFURT)

Im Jahre 2008 feiert ein Buch mit einer These als Titel 30-jähriges Jubiläum: Edward Saids Orientalismus. In diesen 30 Jahren ist die Debatte um die Rolle der Orientalistik nicht abgerissen - zumindest was die USA betrifft, wo Saids Buch, die Welle der Foucault-Rezeption einerseits reitend und sie andererseits befördernd, die weiteste wissenschaftliche Verbreitung erfuhr. Obwohl in Orientalismus zahlreiche Widersprüche zur Diskurs-Theorie Foucaults bestanden, auf die wiederholt hingewiesen worden ist, etablierte das Buch dort beinahe ein eigenes Forschungsfeld in den Kulturwissenschaften. Seine Hauptthese ist, dass der Westen den Orient gewissermaßen als Objekt des Wissens nach seinem Gegenbilde erschaffen hätte, als negative Folie seiner Identität und mit dem klaren Ziel, ihn zu beherrschen. Während Europa sich also rational, politisch wohlgeordnet und entwicklungsfähig (auch: männlich) sah, wurde der Orient als irrational, ungeordnet, stagnierend und weiblich dargestellt.

Aber auch in den orientalischen Studien zeigte das Buch Wirkung. In den USA spaltete es die Nah-Ost- und Islamstudien nachhaltig. Bernard Lewis, ein Orientalist und Historiker an der Universität Princeton kritisierte Orientalismus als ein falsches, geradezu absurdes Argument. Laut Lewis bewies Said einen „,beunruhigenden Mangel an Kenntnis darüber, was Gelehrte täten und was Gelehrsamkeit eigentlich sei“. Er sprach Said das Recht ab, sich zu Fragen des Orients zu äußern, da er seine akademischen Abschlüsse in keinem einzigen einschlägigen Fach sondern in englischer und vergleichender Literaturwissenschaft erworben habe. ${ }^{1}$ Für Edward Said wiederum war und blieb Bernard Lewis ein Intimfeind, der ihn als unliebsamen Eindringling aus des Professors „kleinem wissenschaftlichem Herrschaftsgebiet" vertreiben wolle. Die Kontroverse war bitter.

1 Bernard Lewis: „Orientalism. An Exchange“, in: New York Review of Books 29, Nr. 13 (1993), S. 46-48 und ders.: „The Question of Orientalism“, in: New York Review of Books 29, Nr. 11 (1993), S. 49-56. (Übersetzung B.S.). 
Bis heute kann in den USA die Erwähnung eines dieser beiden Kontrahenten im falschen Kontext für junge Wissenschaftler/innen ein Karriere-Killer sein. ${ }^{2}$

Nicht nur im Vergleich zur amerikanischen Rezeption fiel die deutsche Auseinandersetzung mit Said eher mager aus. Auch hier wurde er vor allem in den Literaturwissenschaften rezipiert. Dies ist eigentlich erstaunlich, hatte Said doch die deutschen Orient-Studien aus seinem Argument weitgehend ausgenommen. Unter den deutschen Orientalisten und Islamwissenschaftlern setzte sich vor allem Baber Johansen mit dem Orientalismus auseinander.

Johansen stellte 1990 unter anderem die viel beachtete These auf, dass nicht die deutsche Orientalistik einen Orientalismus im Saidschen Sinne betrieben habe. Dazu sei sie, als (zu) kleines Fach, gar nicht in der Lage gewesen. Es sei vielmehr die Geschichtswissenschaft, die sich eines solchen Orientalismus schuldig gemacht habe. Der Historismus im Allgemeinen, und Ranke und vor allem Troeltsch im Besonderen dienen ihm hier als die hauptsächlichen Übeltäter.

Ernst Troeltsch (im Text durchgehend als „Max Troeltsch“ bezeichnet, wahrscheinlich in Verschmelzung mit einem weiteren Gelehrten seiner Zeit, Max Weber) habe, so Johansen, eine „Kulturkreistheorie“ entwickelt, die die ,realen Machtbeziehungen zwischen Europa und Amerika, Asien und Afrika in eine kulturelle Beziehung transformiert" hätte, was ihm eine dreifache Trennung, nämlich eine kulturelle, historische und politische, von Europa und dem Rest der Welt erlaubt habe. ${ }^{3}$ Die deutschen Orientalisten Carl Heinrich Becker (und Hans Heinrich Schaeder) seien dem gefolgt und hätten somit den ,historistischen Orientalismus“ nur reproduziert. ${ }^{4}$ Da Geschichte, wie auch Recht, als höherwertige Disziplinen galten, hatten sie mehr Einfluss als die orientalischen Studien. Diese müssten, so Johansen, im Lichte ihrer „,methodischen Abhängigkeit“ von ideologisch höher eingeschätzten Disziplinen und ihrer „praktischen Abhängigkeit“ von Staat und Gesellschaft gesehen werden.

„Until the end of the Weimar Republic it is historicism and not Islamic Studies that defines the Orient in terms of cultural essentialism [...]. It is Troeltsch and not Becker who is the theoretical and ideological authority of this type of Orientalism. ${ }^{\text {" } 5}$

2 Siehe hierzu Birgit Schäbler: „Konstruktionen des Selbst als Wissenschaft. Anmerkungen einer Nahost-Historikerin zu Leben und Werk Edward Saids“, in: Alf Lüdtke/Rainer Prass (Hg.), Gelehrtenleben. Wissenschaftspraxis in der Neuzeit, Göttingen: Böhlau 2007 (im Druck).

3 Baber Johansen: „Politics and Scholarship: The Development of Islamic Studies in the Federal Republic of Germany“, in: Tareq Y. Ismael (Hg.), Middle East Studies. International Perspectives on the State of the Art, New York: Praeger 1990, S. 71130, hier S. 84f.

4 Ebd., S. 85.

5 Ebd., S. 86. 
Baber Johansen, dies muss hier mit Achtung festgehalten werden, war einer der wenigen auf dem Felde der deutschen Islamwissenschaft, der sich überhaupt der Herausforderung, die durch Saids Buch entstanden war, stellte. Seine Thesen, die jedoch einer Exkulpation des Faches gleich kommen, haben bis in die jüngste Zeit Wirkung gezeigt. ${ }^{6}$

Dieser Beitrag hält es für wichtig, Troeltsch und Becker in den Kontext ihrer Zeit einzuordnen und ihr Denken und politisches Handeln von dieser Warte zu verstehen und zu bewerten. Wichtiger noch gilt es aber auch, eine Ebene tiefer zu graben und Hinweise auf die Wurzeln von Historismus und Orientalismus zu finden.

\section{Der Historismus}

Der „deutsche Historismus“, so Johansen, betrachte erstens das politische Leben und die Beziehung zwischen Staat und Religion als höchsten Ausdruck der Individualität eines Volkes. Er gehe, zweitens, davon aus, dass eine Geschichte der Menschheit nicht existieren könne. Für den Historismus existiere die Weltgeschichte als Geschichte der Beziehungen zwischen Völkern, Nationen, Staaten, Kulturen und Religionen. Nur einige Völker seien Teil einer Weltgeschichte. Diese These führt Johansen auf Ranke bzw. Ernst Schulin zurück. ${ }^{7}$ Der Historismus definiere, drittens, historische Entwicklung als die Entwicklung von Individuen, seien dies Personen, Völker oder Kulturen. Und viertens erkenne der Historismus keinen menschlichen Fortschritt in der Geschichte an. Ranke lehne die Idee des Fortschritts ab, da jede Epoche unmittelbar zu Gott, ,also zum Historiker", so Johansen, sei. ${ }^{8}$

Zunächst bedarf es an dieser Stelle also eines Wortes zum Historismus. Johansen ordnet sich ein in die Kritik am Historismus, wie sie in den 1970er und 1980er Jahren fast schon obligatorisch geworden war. Wer etwas auf sich hielt, allen voran die sich als ,kritisch“ verstehenden Historiker selbst, brandmarkte den Historismus als eine konservative, gar reaktionäre Haltung. Vor allem diejenigen, die die Geschichtswissenschaft als historische, gar systematische Sozialwissenschaft neu konstituieren wollten, distanzierten sich vom Historismus. Das Misstrauen gegenüber dem Fach und den Historikern war gewaltig. Kein geringerer als Hans-Ulrich Wehler befürchtete:

6 Sie beeinflussten noch die kritische Studie Haridis stark. Alexander Haridi: Das Paradigma der ,islamischen Zivilisation“ - oder die Begründung der deutschen Islamwissenschaft durch Carl Heinrich Becker (1876-1933), Würzburg: Ergon 2005.

7 Ernst Schulin: Die weltgeschichtliche Erfassung des Orients bei Hegel und Ranke, Göttingen: Vandenhoeck \& Ruprecht 1958.

8 B. Johansen: Politics and Scholarship, S. 80f. 
„Die Gefahren [der Ausbildung des Historikers] sind allerdings auch deutlich zu erkennen, denn viel zu oft ist bei den Historikern das behutsame Verstehenwollen zur schieren konservativen Bewegungslosigkeit und reaktionären Vergangenheitsidealisierung erstarrt". 9

Es waren eher die ,allgemeinen“ Wissenschaftstheoretiker, die in dieser Zeit darauf hinwiesen, dass man zwischen den erkenntnistheoretischen Prinzipien des Historismus und dem, was Wissenschaftler, die dem Historismus zugerechnet werden, tatsächlich geschrieben haben, unterscheiden müsse. ${ }^{10}$ Der ,Historismus “ ist eine von verschiedenen Definitionen, Missverständnissen und Kontroversen begleitete Angelegenheit. ${ }^{11}$ Eine neuere, und in den Augen dieser Autorin brauchbare ,Definition“ des Historismus besagt folgendes:

„Historismus ist eine bestimmte Weise des historischen Denkens und eine ihr entsprechende Konzeption von Geschichtswissenschaft. Es ist ein Denken, dem es um die Erkenntnis der Eigenart vergangener Zeiten im Unterschied zur Gegenwart und dem es zugleich um einen übergreifenden Zusammenhang verschiedener Zeiten geht: Deren Aufeinanderfolge erscheint als einheitliche und durchgängige Entwicklung eigentümlicher menschlicher Lebensformen. ,Individualität" und ,Entwicklung ' sind die dafür charakteristischen Kategorien. Dieses so ausgerichtete historische Denken erfolgt in der Form einer fachwissenschaftlich organisierten Forschung: die für diese Forschung maßgebliche Methode ist hermeneutisch definiert: Historische Erkenntnis ist Verstehen von zeitlichen Zusammenhängen durch Einsicht in handlungsleitende Absichten (oder, wie es in einer älteren Terminologie formuliert wurde: in den ,Geist ' der Handelnden). Historismus, wie er sinnvoll definiert werden kann, ist also eine verstehende Geisteswissenschaft." $" 12$

Der Historismus weist des weiteren eine Verengung des historischen Interesses auf den Staat auf, die treffend als „deutsche Andacht zum Staate“ (Iggers) beschrieben worden ist, ebenso wie eine Engführung auf die Nation.

Wenn Historismus jedoch heißt, das Vergangene oder allgemeiner das Fremde in seiner Eigenart zu verstehen, dann gehört dazu auch, dass man das Andere gerade als Anderes, von der eigenen Lebenswelt des Erkennenden Abweichendes verstehen lernt. ${ }^{13}$ Dass die Historisten sich aber mehr mit der jeweils eigenen Nation, dem jeweils eigenen Staat oder den Wurzeln der abendländischen Kultur

9 Hans Ulrich Wehler: Geschichte und Soziologie, Köln: Kiepenheuer \& Witsch, 1976, S. 17.

10 Helmut Seiffert: Einführung in die Wissenschaftstheorie, 2. Bd., München: C.H. Beck 1970, S. 216.

11 Annette Wittkau: Historismus. Zur Geschichte des Begriffs und des Problems, 2. Aufl., Göttingen: Vandenhoeck \& Ruprecht 1994.

12 Friedrich Jäger/Jörn Rüsen: Geschichte des Historismus. Eine Einführung, München: Beck 1992.

13 H. Seiffert, Wissenschaftstheorie, S. 217. 
beschäftigten, zeichnet jeden Historismus aus, sei es nun der deutsche, der französische oder der englische. Alle sind sie faktisch eurozentrisch, obwohl der Historismus theoretisch die außereuropäische Welt nicht ausschließt. Man könnte dies ein historistisches Paradox nennen. ${ }^{14}$ Dass Ranke sich auf die germanischromanischen Völker beschränkt, die Slawen ausschließt und den Orient von vorneherein ,als Gegensatz Europas‘ konstruiert, ist seiner Person und seinen Interessen als Historiker in seiner Zeit geschuldet. Wolfgang Reinhard hat den Historismus als „Denkgewohnheit“ der deutschen Historiker auf Martin Luther zurückgeführt, womit er freilich die Formen von dessen Denken, nicht den Inhalt meinte. ${ }^{15}$ Aber immerhin lässt sich in diesem Zusammenhang feststellen, dass schon Martin Luther den Orient als das Andere, die „Türcken“ und ihre Siege als Bedrohung gesehen hatte, interessanterweise aber auch als gerechte Strafe für die verderbte Christenheit unter der Herrschaft des päpstlichen Antichristen, der die größere Gefahr darstellte. ${ }^{16}$

Dass der Historismus den Fortschrittsgedanken ablehnt, machte ihn zwar dem Marxismus und der von ihm beeinflussten intellektuellen Kultur der 1960er und 1970er Jahre suspekt, ist aber faktisch ein großer historischer Fortschritt gegenüber den früheren historischen Weltbildern und Theorien (Fortschrittsglaube, Verfallsglaube und Zyklentheorien) gewesen. Dieser Punkt macht den Historismus erkenntnistheoretisch, d.h. jenseits seiner Verkürzungen, in der heutigen Debatte, nach dem Ende der großen Meistererzählungen, eher wieder interessant.

$\mathrm{Zu}$ der Zeit, als Ernst Troeltsch und C. H. Becker schrieben, befand sich der Historismus in der Krise. Schon einige Jahrzehnte davor hatte Friedrich Nietzsche in der 1873 erschienenen zweiten seiner „Unzeitgemäßen Betrachtungen: Vom Nutzen und Nachteil der Historie für das Leben“ gegen den Historismus als Kulturerscheinung polemisiert, ohne das Wort zu gebrauchen: $\mathrm{Zu}$ viel Historie mache den Menschen schwach. Das Individuum versinke ins Innerliche, in den „Zusammen gehäuften Wust des Erlernten, das nicht nach außen wirkt, der Belehrung, die nicht Leben wird.“ Die „Austreibung der Instincte durch Historie“ habe die Menschen (er meint die Deutschen) ,fast zu lauter abstractis und Schatten umgeschaffen“. 17

Um 1920, am Ende des ersten Großen Krieges, der bekanntlich auch als ein Kulturkrieg, ein ,Krieg der Geister“ geführt worden war, erhielt dieser alte Be-

14 Angelika Epple: „,Global History“ und ,Area History‘. Plädoyer für eine weltgeschichtliche Perspektivierung des Lokalen“, in: Birgit Schäbler (Hg.), Area Studies und die Welt. Weltregionen und neue Globalgeschichte, Wien: Mandelbaum Verlag 2007, S. 90-116.

15 Wolfgang Reinhard: „Martin Luther und der Ursprung der historistischen Geschichtswissenschaft in Deutschland", in: ders. Ausgewählte Abhandlungen, Berlin: Duncker \& Humblot 1997, S. 311-344.

16 Hartmut Bobzin: Der Koran im Zeitalter der Reformation, Stuttgart: Steiner 1995.

17 Nietzsche, zitiert nach der Auswahl von Rüdiger Safranski: Nietzsche, München: dtv 1997, S. 188. 
fund über die deutsche Bildungslandschaft eine neue Dringlichkeit, da die beileibe nicht ausgetriebenen „Instincte“ im politischen Leben an die Oberfläche kamen. Die Überwindung des Historismus, so Troeltsch, erfordere eine „Überwindung der Geschichte durch Geschichte“. Die ,praktisch-kulturelle Aufgabe der Gegenwart“ lautet für ihn: „Aus dem Schmelztiegel des Historismus muß die Geschichte des Abendlandes in neuer Geschlossenheit und Vereinheitlichung hervor gehen“. ${ }^{18}$

\section{Ernst Troeltsch und der Historismus}

Ernst Troeltsch, dessen Werk im Auftrag der Bayerischen Akademie der Wissenschaften in einer neuen kritischen Gesamtausgabe herausgegeben wird, war ein Vertreter des Kulturprotestantismus und der Religionssoziologie, Sozialwissenschaftler und praktischer Philosoph. Er wandte sich sowohl gegen den Historismus als auch gegen den Zynismus des Machtstaatsdenkens der deutschen Geschichtswissenschaft und bemühte sich um eine europäische Kultursynthese, die allerdings sehr westeuropäisch angelegt war. Dies tat er bereits in seinem berühmten Buch Der Historismus und seine Probleme von 1922, dessen letztes Kapitel wiederum sein Nachdenken „Ueber den Aufbau der europäischen Kulturgeschichte“ enthält. Dieses Kapitel ist es, in dem er sich mit Becker auseinandersetzt und das von Johansen etwas irreführend als „Kulturkreistheorie“ bezeichnet wird. Denn Troeltsch greift hier auf längst formulierte Ideen zurück, und entwirft in keiner Weise eine neue Theorie. Schon zu Beginn des 20. Jahrhunderts war die „Kulturkreislehre“, deren prominentester Vertreter wohl Oswald Spengler war, ausformuliert. $^{19}$

Nach den Verheerungen des Ersten Weltkrieges geschrieben, zeigt das Buch Troeltschs das Bemühen, den Bruch zwischen Deutschland und Westeuropa zu überwinden. Noch mehr aber tun dies seine letzten Schriften, die er für eine Vortragsreise nach England verfasst hatte. ${ }^{20}$ Vor allem der deutsch-britische Kultur-

18 Ernst Troeltsch: Der Historismus und seine Probleme, Tübingen: Mohr 1922, Kapitel IV, „Über den Aufbau der europäischen Kulturgeschichte“, S. 694-772, hier S. 771. Alle Seitenzahlen im Text beziehen sich auf dieses Kapitel. Es wurde zuerst, 1918, als Vortrag gehalten und dann, 1921, im 3. Heft von Schmollers Jahrbuch (XLIV) veröffentlicht, bevor Troeltsch es als Abschlusskapitel für Der Historismus und seine Probleme verwandte.

19 Vgl. Heinz Dieter Kittsteiner: „Zum Aufbau der europäischen Kulturgeschichte in den Stufen der Moderne“, in: Friedrich Wilhelm Graf (Hg.), „Geschichte durch Geschichte überwinden“. Ernst Troeltsch in Berlin, Gütersloh: Gütersloher Verl.-Haus 2006, S. 21-47.

20 Gangolf Hübinger/Andreas Terwey: „Ernst Troeltsch: Fünf Vorträge zu Religion und Geschichtsphilosophie für England und Schottland. Der Historismus und seine Überwindung (1924)/Christian Thought. Its History and Application (1923)“, Berlin, New York: Walter de Gruyter 2006 (Troeltsch Gesamtausgabe Band 17). Siehe 
kontakt, der trotz wachsender Rivalitäten das 19. Jahrhundert überdauert hatte, war mit dem August 1914 abrupt unterbrochen worden. Troeltsch war einer der wenigen deutschen Wissenschaftler, die nach dem Krieg wieder nach England eingeladen wurden. 1923 sollte er fünf Vorträge zur Religion und Geschichtsphilosophie halten. Sie sollten eine erneute „Gewinnung geistiger Beziehungen“ bewirken. Troeltsch starb jedoch, bevor er die Reise antreten konnte.

Ziel dieser Schriften war es, auf religiösem Fundament Wertmaßstäbe einer politischen Ethik zu liefern, um dem „Europäertum“ zu neuem „Gemeingeist“ zu verhelfen und so den Aufbau einer zukunftsfähigen Nachkriegsordnung zu ermöglichen. Seine Ehefrau, Maria Troeltsch, gab den posthum erschienen Schriften dann den beziehungsreichen (und geschäftsträchtigen) Titel Der Historismus und seine Überwindung. Die Titelgebung sorgte für Verstimmung bei den Verlegern, die „Die Absolutheit des Christentums“ für einen wesentlich besseren Titel hielten, und den Verdacht nicht loswurden, dass ersterer nicht ganz ohne Hintergedanken an den Absatz des Buches ausgedacht worden war. ${ }^{21}$

Für unseren Zweck der historischen Kontextualisierung macht aber der Titel „Der Historismus und seine Überwindung“ durchaus Sinn, denn er zeigt noch einmal, wie eng die Texte an Troeltschs vorheriges Buch anschließen. Sie zeigen auch, dass es für ihn geradezu logisch zwingend war, in seinem Bemühen um eine westgebundene Nachkriegsordnung die islamische Welt aus dem europäischen Kulturkreis auszuschließen. Eben weil er im (protestantischen) Christentum den einzig verbliebenen Garanten im Aufbauprozess des neuen Europas sieht, muss die islamische Welt draußen bleiben. Dass es ihm dabei eindeutig um Westeuropa ging, zeigt die Tatsache, dass auch das orthodox-christlich-slavische Osteuropa außen vor blieb. Dieser Autorin geht es hier in keiner Weise um eine Verteidigung von Troeltschs Ansichten und Thesen. Wichtig ist vielmehr, sie in den historischen Kontext zu stellen. Da es der „Aufbau der europäischen Kulturgeschichte" ist, in dem Troeltsch sich explizit mit Becker auseinandersetzt, noch einmal eine kurze Darstellung des „Aufbaus“:

Zwei Hauptthemen bewegen Troeltsch: Die „Kultursynthese“ und die Universalgeschichte. Die Kultursynthese bildet dabei die ,subjektive Voraussetzung und das Ideal der Universalgeschichte", denn nach ihr treffe sie ihre Auswahl. Die Universalgeschichte bilde den objektiven Hintergrund und das Material der Kultursynthese (S. 700). Troeltsch sieht es als notwendig an, die Universalgeschichte auf das Europäertum zu beschränken, denn es geht ihm um den „Europäismus“, bestimmt durch die beiden Kulturwelten der modernen abendländischen und der antiken mittelmeerischen Welt. Obwohl sich der „Europäismus“ mit den großen angelsächsischen und lateinischen Expansionen über den größten

auch die Rezension von Benedikt Stuchtey in der Süddeutschen Zeitung vom 1. März 2007, S. 14.

21 E. Troeltsch: Fünf Vorträge, S. 61f. 
Teil der Erde ausgebreitet habe, sei er in dieser Zusammensetzung allein eine „Sinneinheit wenn wir nach dem unsere eigene Existenz tragenden historischen Zusammenhang und Sinnganzen fragen“. Die Philologien und Historien der anderen Kulturgebiete stünden mit einem dauernden Übergewicht des Philologischen etwas exotisch daneben, merkt Troeltsch richtig zur Wissenschaftslandschaft (nicht nur) seiner Zeit an.

„Abendland, näheres und ferneres Morgenland, Kulturvölker, Halbkulturvölker und Primitive sind derart verschieden, dass von einem gemeinsamen Kulturgehalt der heutigen Menschheit nicht im entferntesten die Rede sein kann. [...] In diesem Umstand ist auch die übliche Verschiebung der Begriffe begründet, durch die allein man Universalgeschichte, Menschheit und Fortschritt zustande bringt, nämlich dass man sich in Wahrheit lediglich an die abendländische, europäisch-amerikanische Entwicklung hält, deren Menschenmasse für die Menschheit und deren Entwicklung für die Weltgeschichte oder Weltentwicklung ausgibt. Man mag dann einige Seitenblicke auf den Orient, meist nur den vorderen Orient, damit verbinden und die europäische Entwicklung an die Anthropologie anknüpfen. Oder man mag sagen, dass es sich nicht um den biologischen Begriff der Menschheit handle und dieses eben vom Abendland bestimmungsgemäß herausentwickelt worden sei oder - einfacher - nur dort sich tatsächlich verwirklicht finde. Aber alles das ist nur naiver oder verfeinerter Europäerhochmut, begünstigt durch gewisse Begriffe der christlichen Dogmatik, die auch bei Feinden und Nichtkennern des Christentums noch recht kräftig sind. Palästina, Rom, Wittenberg und Genf sind die Erdmittelpunkte, und von da entsteht eine Herde mit dem einen Hirten, das Reich der absoluten Wahrheit und Erlösung, das die Moderne in das Reich der alleinigen Kultur, Vernunft und Wissenschaft verwandelt hat. Der Eroberer, der Kolonisator, und der Missionar steckt in allem europäischen Denken. Das ist eine Quelle seiner praktischen Kraft und Fruchtbarkeit, aber auch vieler theoretischen Irrtümer, und Übertreibungen“ (S. 707).

Aus diesen Erkenntnissen zieht Troeltsch nun nicht die Konsequenz, eine andere Weltgeschichte jenseits des ,naiven oder verfeinerten Europäerhochmuts“ zu fordern und zu befördern. Ihm geht es um etwas anderes, nämlich um den (Wieder-) Aufbau des West-Europäertums, und darum, den ,deutschen Sonderzug in einen europäischen Zentralbahnhof zu dirigieren“. ${ }^{22}$ Deshalb gibt es für ihn nur eine Weltgeschichte des Europäertums. Der alte Gedanke der Weltgeschichte, so sagt er, müsse neue und bescheidenere Formen annehmen. Es gibt verschiedene Kulturkreise: den vorderasiatischen, den ,schließlich in der islamischen Kultur sich

22 Gangolf Hübinger: Gelehrte, Politik und Öffentlichkeit. Eine Intellektuellengeschichte, Göttingen: Vandenhoeck \& Rupprecht 2006, S. 190, unter Bezug auf Bernd Sösemann: „Das ,erneuerte Deutschland‘. Ernst Troeltschs politisches Engagement im Ersten Weltkrieg“, in: Horst Renz/Friedrich Wilhelm Graf (Hg.), Troeltsch-Studien, Bd. 3, Protestantismus und Neuzeit, Gütersloh: Gütersloher Verlagshaus 1984, S. 120-144. 
einigenden“, den ägyptischen, den hinduistischen, den chinesischen und schließlich den mittelmeerisch-europäisch-amerikanischen. Nur in solchen Kulturkreisen liegt nach Troeltsch ein einheitliches Kulturergebnis von jedes Mal völlig eigenem und einzigartigem Sinn vor, mit einer eigenen individuellen Entwicklungsgeschichte. Nun sei es aber völlig unmöglich, diese auf sehr verschiedenen Entwicklungshöhen befindlichen Kulturkreise sämtlich geistig zu beherrschen. Wie sie sich untereinander nur schwer verstehen, so könne niemand sie alle zugleich verstehen und könnte man es, so würde dieses Verständnis zwar interessant sein und die „Möglichkeiten des Menschentums“ lehrreich beleuchten, aber doch zugleich praktisch für die eigene Stellungnahme und positive Kulturarbeit (sic!) schlechterdings nichts nützen. Dieses letztere aber ist der einzige Sinn, den Troeltsch der Geschichtsphilosophie zuschreiben kann.

Troeltschs Glaubensbekenntnis lautet: „Wir kennen in Wahrheit nur uns selbst und verstehen nur unser eigenes Sein und deshalb auch nur unsere eigene Entwicklung. Nur deren Erkenntnis ist uns praktisches Bedürfnis und Notwendigkeit, Voraussetzung des eigenen, Kultur gestaltenden Handelns und Zukunftwollens.“ Worum es ihm geht ist nichts weniger als die ,brennend wichtige Aufgabe der Formulierung des europäischen Wesens und der Herausarbeitung der europäischen Zukunft“. Dies sei an einem sichtlichen Wendepunkt der europäischen Geschicke dringender als je und verhelfe der Historie „,trotz allen Seufzens über Historismus und Gedächtnisüberlastung heute zu einer zentralen philosophischen Bedeutung“" (S. 711).

Doch er sichert sich ab: Man würde ihn nun aber auch wieder falsch verstehen, wenn man argumentieren würde, es solle gar keine Ausbreitung des historischen Wissens und Denkens über den erreichbaren Gesamtumfang des menschlichen Lebens geben. „Das wäre doch eine falsche Nutzanwendung des gesagten. Nur die Kultursynthese ist auf den angegebenen Gegenstand zu beschränken. Aber selbstverständlich ist es nützlich und notwendig, Geschichten von Indien, China, Japan usw. zu schreiben, soweit ein Europäer dazu imstande ist, und diese Geschichten entweder selbständig nebeneinander erscheinen zu lassen oder sie mit anderen Geschichten unentwickelter Völker nach geographischer Reihenfolge aneinanderzureihen, wie es etwa die Helmholtsche Weltgeschichte getan hat.“ (S. 711). Das sei dann aber kein historischer Zusammenhang und keine Entwicklung, sondern gehöre in das Gebiet der „Buchbindersynthese“ oder der ,gelehrten Fabrik und Kooperation“. Diesen enzyklopädischen Erkenntnissen könne man keinen philosophischen Geist einhauchen. Hier spricht die Hybris des Geschichtsphilosophen, der offensichtlich (noch) keinen Sinn hat für Fragen, die die Welt als ganze, also über Westeuropa hinausgehend, betreffen. Auch dies ein Erbe, das es der Geschichte des Orients in der Folge in Deutschland schwer gemacht hat, sich zu etablieren.

Mit der Geschichte „,der anderen“ setzt Troeltsch sich nicht auseinander, hat auch keine Kenntnis von ihr. Denn wie sonst könnte er die leider immer noch gängige Behauptung aufstellen, den Gedanken der Entwicklung gebe es nur in 
der europäisch-atlantischen Weltgeschichte; die arabische Historie sei über das erzählende und erklärende Stadium nicht hinausgekommen. Von Ibn Khaldun hat er offenbar noch nichts gehört, wie auch C. H. Becker feststellt. ${ }^{23}$

Auf Becker bezieht sich Troeltsch in einer langen Fußnote. Er setzt sich mit dessen beiden zentralen Aufsätzen „Der Islam als Problem“ und vor allem „Der Islam im Rahmen einer allgemeinen Kulturgeschichte" auseinander. Er könne, so schreibt er, der höchst interessanten Studie nur zustimmen. Aber: Der Standpunkt des „reinen Historikers“, als welchen er also Becker offensichtlich sieht, sei etwas anderes als der der Geschichtsphilosophie. Der Historiker Becker achte auf die „Gemeinsamkeit der Ursprünge“, er aber auf die Gemeinsamkeit der Ergebnisse (S. 727).

Becker habe ,um der von der Urzeit her bestehenden Gemeinsamkeit zwischen Europa und dem vorderen Orient willen die Einbeziehung der islamischen Welt gefordert, die verwandte Wurzeln im hebräischen Prophetismus und in der hellenistischen Kultur habe und lange Zeit hindurch als die Europa überlegene Kulturmacht das letztere gefördert und durchwirkt habe, auch heute noch als nächster Nachbar und relativ verwandtestes Kulturprinzip uns einen Teil unserer wesentlichsten Lebensprobleme stelle“ (S. 726). Aber Troeltsch bleibt dabei: Es sind die Griechen, die die Grundlagen des Europäismus bereiten, und deren enger Zusammenhang mit dem Orient verschwindet nun einmal.

Vom Orient sei dem Europäertum als selbständig wirkende Kraft nur der hebräische Prophetismus und seine Folge, das Christentum, eingepflanzt worden. Denn seine Persönlichkeitsidee sei eben gerade nicht dem Orient, sondern dem Hellentum verwandt. Die Art, wie der Orient das letztere ins Ich aufnehmen konnte, zeige der Islam, der Judentum und Christentum arabisiert und die daraus entstehende Religion zu einem militärisch-politischen Prinzip gemacht habe. Auch fehle dem Orient die römische Tradition mit ihrem ,praktischadministrativen Geiste“. Hier ist das schlichte Nichtwissen über den ,praktischadministrativen' Geist des Osmanischen Reiches zu konstatieren, dessen penible Steuerkataster noch nicht ins Wissen der historischen Zunft eingedrungen waren. Und einen Hammer-Purgstall nahm man in diesen Kreisen wenig zur Kenntnis.

Troeltsch kann sich dem Hellentum nicht entziehen: Die Verschmelzung der islamischen Religion und der griechischen Kultur sei nicht entfernt so innerlich und wesenhaft wie im Abendlande. Der Hellenismus sei vielmehr lediglich reines Kultur-Prinzip geblieben, und die Humanisierung des Islam kam eher aus der persischen Mystik als aus dem Hellenentum. Vor allem handelt es sich aber doch nur um verwandte Grundlagen, und nicht um verwandte Ziele und Lebenszusammenhänge. Die Ziele der islamischen Welt seien niemals wie in Europa die

23 Carl Heinrich Becker: „Der Islam im Rahmen einer allgemeinen Kulturgeschichte“, entstanden 1921, zuerst veröffentlicht in: ZDMG, Jg. 76 (N.F. 1), und in Carl Heinrich Becker: Islamstudien, Leipzig: Quelle \& Meyer 1924, S. 32. 
eines autonomen, frei und grenzenlos aus sich selber schaffenden Menschentums geworden (S. 726f.).

Deshalb habe der Islam eine Spezialgeschichte für sich, so zahlreich und eng seine Beziehungen zum Europäismus auch seien, und gehöre nicht in die Universalgeschichte des Europäertums. Es gebe keine gemeinsame Kultursynthese für beide Welten, außer etwa den Gedanken der gegenseitigen Toleranz und der Verständigung sehr verschiedenartiger geistiger Welten, wozu aber ein sehr modernisierter und europäisierter Islam nötig wäre, ,wie ihn vielleicht die heutigen Ägypter wollen“ (S. 727). Vielmehr sei umgekehrt bei der relativen Gemeinsamkeit der Voraussetzungen die Auseinanderentwicklung beider Welten lehrreich für die Triebkräfte des Europäertums.

Troeltsch will für die praktische Lebensbildung den Historismus überwinden. Man müsse unterscheiden zwischen Kulturgehalten und praktisch-soziologischer Lebensordnung. Die Erstere muss man aus der Historie seit Hebräern und Griechen verstehen, die Letztere vor allem in ihrer modernen Einzigartigkeit praktisch-anschaulich erfassen. Und dazu bedürfe es keiner Geschichte, die weiter zurückgeht ,als auf die Bildungsgeschichte unserer Gesellschaft seit dem 16. Jahrhundert“ (S. 770). Also: Auf den Humanismus.

Troeltschs Überlegungen zum Wesen West-Europas, die nach außen auf Ausschluss, nach innen auf Neu-Ausrichtung und Intensivierung (,Umschmelzung“) beruhen, haben eine ungeheure Aktualität. Kritiklos übernommene Versatzstücke seiner Argumentation tauchen durchaus noch in den heutigen Europa-Debatten auf. Weltweit ist eine Selbstvergewisserung über westliche Werte zu beobachten. $\mathrm{Zu}$ Beginn des 21. Jahrhunderts, in einer Zeit der globalen Herausforderung durch Migrationen, neue Kriege und globalen Terrorismus setzt das Nachdenken über die Wurzeln europäischer Identität erneut ein. Es kann sich heute jedoch nicht mehr in den altbekannten Pfaden des Ausschlusses alles Fremden bewegen, sondern muss Europa als ,Provinz der Welt‘ anerkennen.

\section{H. Becker und der Orientalismus}

C. H. Becker, der gemeinhin als der Begründer der Islamwissenschaft gilt, war Troeltsch, auf den er sich explizit bezog, in vielem ähnlich. Stärker noch als Troeltsch war er Kulturpolitiker, denn er nahm zur Umsetzung seiner Pläne hohe politische Ämter ein. Während Troeltsch nur Unterstaatssekretär im Preußischen Kultusministerium war (1920 schied er aus diesem Amt aus), ebenso wie auch Becker 1919, brachte es Becker 1921 und von 1925-1930 zum Kultusminister, zu einer Zeit als Troeltsch mit seinem letzten Werk in die Wissenschaft zurück kehrte.

Alfred Weber, der mit Troeltsch zusammen die Gründungsphase der Deutschen Demokratischen Partei prägte, beschreibt in einem Brief 1920 seinen Besuch bei Troeltsch und seine Haltung zum aufstrebenden Becker: 
„[...] ich amüsierte mich, dass [Troeltsch] mit typischer Nonchalance eigentlich alles, was ihm nicht in den Kram paßte: schwierige finanzielle Lage der Hochschulen und Professoren u. dgl., bei Seite schob, obgleich es ihn als preußischen Unterstaatssekretär im Unterrichtsministerium doch eigentlich recht nahe anging. - Wir sprachen viel über Becker (Du weißt!) - Auch dessen Zweifelswürdigkeit (- er ist ja im Grund ein einfacher, vielgeschäftiger und strebsamer Macher geworden -) wollte er erst nicht zugeben $[\ldots] .{ }^{، 24}$

Becker und Troeltsch kannten sich bereits aus Heidelberger Universitätszeiten. Beide bewegten sich nun auf der turbulenten Hauptstadt-Bühne Berlins, aber in unterschiedlichen Rollen. Während Troeltsch mehr in die Rolle des Intellektuellen schlüpfte, der die politische Meinung durch geistige, publizistische Interventionen $\mathrm{zu}$ beeinflussen suchte und auch politische Posten nicht ausschlug, wurde Becker Wissenschaftspolitiker.

Auch C. H. Becker suchte nach den geistigen Verheerungen des Ersten Weltkriegs eine Erneuerung der deutschen Gesellschaft. 1918/19 leitete er seine „Gedanken zur Hochschulreform“ folgendermaßen ein:

„Der furchtbare Zusammenbruch, dessen Zeugen wir sind, macht alles problematisch, was wir bisher für unantastbaren materiellen oder geistigen Besitz gehalten haben. Wir sind nicht nur mit den Waffen geschlagen, wir sind in unserer geistigen und moralischen Struktur erschüttert. [...] versagt haben die maßgebenden Faktoren unseres geistigen Seins". 25

Versagt hatte auch die deutsche Wissenschaft:

„Gewiß folgten wir den Gesetzen voraussetzungsloser, selbstverleugnender Arbeit; aber wir trieben das Form- und Zwecklose der Wissenschaft wohl etwas weit, und darüber ging uns der Sinn für das Ganze, der Überblick und das letzte Ziel der Wissenschaft, Auswahl und Synthese verloren“. ${ }^{26}$

Der Weg aus der Krise, den Becker vorschlägt, erinnert an Troeltsch: Es müsse der Wille zur Synthese wieder erwachen. Hierfür will Becker interessanterweise die Soziologie in Dienst nehmen, die dem deutschen Denken eigentlich nicht entspreche, weil sie überhaupt nur aus Synthese bestehe. Dabei denkt er an „Soziologie im weitesten Sinne, einschließlich der Politikwissenschaft und der Zeitge-

24 Alfred Weber an Else Jaffé, 30.4.1920, zitiert aus G. Hübinger: Gelehrte, S. 191f.

25 Carl Heinrich Becker: „Gedanken zur Hochschulreform (1918/19) (Auszüge)“, in: Guido Müller (Hg.), Carl Heinrich Becker. Internationale Wissenschaft und nationale Bildung, Köln: Böhlau 1997, S. 181.

26 C. H. Becker: Hochschulreform, S. 184. 
schichte“ “27 Die ersten Lehrstühle in Preußen wurden auch von Becker durchgesetzt. $^{28}$

Auch C. H. Becker, der Mann der Tat, beklagt den ,merkwürdigen historischen Sinn des Deutschen“. Das vorige Jahrhundert sei für die deutsche Geisteswissenschaft ein Zeitalter der Historie gewesen. Noch heute litte die Gesellschaft unter den Folgen. Überall in der Wissenschaft hätte Historisches im Vordergrund gestanden. Auch in der Philologie, aus der er ja herkam: Die Sprachgeschichte, der „historische Lautwandel“ habe das gelehrte Interesse beherrscht. „Der Historizismus war unsere Stärke und unser Verhängnis, denn der Deutsche nimmt die Geschichte ernst. “29 Becker macht diesen „,wissenschaftlich-historischen Sinn, eine Denkgewöhnung, die leider nach rückwärts eingestellt war, statt nach vorwärts", für die Randständigkeit verantwortlich, in der das Bildungsbürgertum und die akademischen Kreise verharrten. „Gerade die Tüchtigkeit für das Fach wurde zum Verhängnis für das Staatsbürgertum der Professoren. “30

Wissenschaftlich bezieht sich Becker ebenfalls stark auf Troeltsch, vor allem auf dessen „Aufbau der europäischen Kulturgeschichte“. Dieser Aufsatz war ihm der unmittelbare Anlass, sich mit dem „Islam im Rahmen einer allgemeinen Kulturgeschichte" zu befassen.

Becker stimmt der Einteilung der Welt in Kulturkreise zu. Jeder dieser Kreise habe seine „gesonderte Eigenentwicklung und entsprechend seine eigene Geschichte“. Wolle man sie zusammenfassen, so käme, ,wenn der Abendländer als Geschichtsschreiber auftritt, doch nur eine Vergewaltigung der anderen Kulturkreise zugunsten der Verherrlichung der entscheidenden abendländischen Entwicklungsmomente dabei heraus“. .31

Der einzige Punkt, in dem er Troeltsch nicht zustimmt, ist dessen Beschränkung des europäischen Kulturkreises auf Westeuropa. „Für den Orientalisten“, so argumentiert er, stelle sich hier „das Grundproblem jeder tieferen Geschichtsbetrachtung“. Welches nicht darin bestehe, dass ,,von orientalistischer Seite die entscheidende Einzigartigkeit des hellenischen Denk- und Formwillens und des europäischen Tatwillens bestritten werden sollte“, sondern dass „in Anerkennung des wirklichen geschichtlichen Ablaufs mit gewissen Einschränkungen die Einbeziehung der vorderasiatisch-islamischen Welt in die europäische" gefordert werden müsse. ${ }^{32}$

Solcherart vorsichtig einschränkend fordert Becker also, die Grenze zwischen Europa und Asien weiter nach Osten zu verschieben, so dass ,der Islam` zu Eu-

27 Ebd., S. 189f.

28 Cornelia Essner/Gerd Winkelhane: „Carl Heinrich Becker (1876-1933), Orientalist und Kulturpolitiker“, in: Die Welt des Islams 28 (1988), S. 163.

29 C. H. Becker: Hochschulreform, S. 192.

30 Ebd.

31 C. H. Becker: Kulturgeschichte, S. 25.

32 Ebd., S. 26. 
ropa gehört. Denn der Islam stellt für ihn das Bindeglied zwischen Europa und Asien dar, und ist als solches ,,aus der asiatischen Geschichte“ herauszulösen.

Dazu musste er auch den Islam aus der entstehenden Religionsgeschichte bzw. der Religionswissenschaft herauslösen, denn für Beckers Ehrgeiz war der Islam weit mehr als nur eine Religion. Diese Herauslösung hatte er in seinem programmatischen Aufsatz „Der Islam als Problem“ unternommen, in dem er die zukünftige Islamwissenschaft bzw. deren Existenzberechtigung begründete (mit dem programmatischen allerersten Satz „Die Wissenschaft vom Islam braucht ihre Existenzberechtigung nicht erst zu erweisen“): „Wie die alte Geschichte neben die klassische Philologie ist sie seit langem als historische (Hervorhebung B. S.) Disziplin neben die Philologien der von Muhammedanern gesprochenen Sprachen getreten“" 33

Der Islam ist nach Becker also weit mehr als nur eine Religion, er ist ebenso ein „Weltreich“, ungeachtet der ,,zahllosen Einzelstaaten die auf seinen Trümmern erwuchsen“. Aber auch dies ist noch nicht ausreichend. Nicht nur eine Religion, oder banale reale Staaten, nein, ,ein viel Größeres nennen wir so: eine politische Theorie, mag sie sich nun auf staatsrechtlicher oder eschatologischer Lehre aufbauen“. Doch auch dies genügt Becker noch nicht: ,das Staat und Religion umfassende Kulturganze“, gefasst als „Zivilisation“, auch dies sei der Islam. ${ }^{34}$ Eine derart umfassende ,fundamentale“, wenn nicht gar fundamentalistische Sicht des Islams bedurfte folgerichtig einer eigenen Wissenschaftsdisziplin; an die relativ kleine Religionswissenschaft jedenfalls sollte der Islam offensichtlich nicht fallen. ${ }^{35}$ Dann schon eher, bei allem Seufzen über den Historismus, in die Leitwissenschaft des 19. Jahrhunderts: in die Geschichtswissenschaft. Becker etablierte die Islamwissenschaft als historische Disziplin, aber ohne sich selbst durch ein großes historisches Werk als Historiker hervorzutun. Dazu war er auch zu interessiert an soziologischen und Gegenwartsfragen.

Das in seinem gigantischen Anspruch letztlich Eklektische an Beckers Konstituierung der Islamwissenschaft wirkt bis heute nach. So war es ein Dreivierteljahrhundert später einem rührigen jungen Islamwissenschaftler, der kurz darauf zu einem der stärksten Kritiker des Faches werden sollte, möglich, die Islamwissenschaft in Vorträgen als „Integrationswissenschaft“, die eben beispielsweise die Disziplinen der Geschichts-, Politik- und Literaturwissenschaft umfassen würde, anzupreisen. Abgesehen vom normativen Anspruch, die Islamwissen-

33 Carl Heinrich Becker: „Der Islam als Problem“. Zuerst veröffentlicht (als Eröffnungsaufsatz) in: Der Islam, Zeitschrift für Geschichte und Kultur des islamischen Orients, hg. von Carl Heinrich Becker, (seit 1916 mit R. Tschudi, seit 1920 mit H. Ritter), Straßburg: Karl J. Trübner, später Berlin: de Gruyter, 1 (1910), S. 1-21; Nachdruck in C. H. Becker: Islamstudien, S. 1.

34 Ebd., S. 2.

35 Zur Entstehung der Religionsgeschichte siehe Hans Kippenberg: Die Entdeckung der Religionsgeschichte, München: C.H. Beck 1997. 
schaft zu einer „Integrationswissenschaft“ erhöhen $\mathrm{zu}$ wollen, entspricht diese Beschreibung durchaus noch der Realität.

Analog zu Troeltsch sieht Becker „drei Urgewalten“, auf denen die islamische Zivilisation beruht: Erstens den alten Orient, besonders in Bezug auf semitischen Prophetismus, jüdische Gesetzesreligion, persischen Dualismus und Eschatologie, babylonisch-magisches Weltbild und bürokratisch-absolutistische Staatsform, zweitens die klassische Antike in der Form des Hellenismus besonders im täglichen Leben, in Wissenschaft und Kunst, und drittens das Christentum in seiner dogmatischen, kultischen und mystischen Ausprägung. ${ }^{36}$ Die Ursprünge des Morgen- und des Abendlandes, so folgert er, seien also identisch. Doch kann er nicht anders als auf tiefen, gar biologisch konstruierten Unterschieden zu bestehen: „Man mag von Hellenisierung oder Europäisierung des Orients sprechen, es ist ein und derselbe Prozess der Auseinandersetzung des männlichen Elementes Europa mit dem weiblichen Element vorderer Orient"“. 37

Schon bei dieser klassischen, im Saidschen Sinne zutiefst orientalisierenden Haltung muss man die Frage stellen, ob sie wirklich, wie Johansen behauptet, einer ,methodischen Abhängigkeit' von der Leitwissenschaft der Geschichtswissenschaft geschuldet ist. Ein geschlechtlicher Unterschied begründete zu Beckers Zeit einen biologischen Unterschied zwischen Europäern und Westasiaten. Denn vom Konstruktionscharakter von gender hatte Becker sicherlich noch nichts gehört. Das Machtgefälle, auf das er mit seinem Vergleich abhebt, ist eindeutig.

Die grundsätzliche Verschiedenheit wird weiter betont: „Das große unterscheidende Erlebnis des Abendlandes ist eben der Humanismus [i.O. hervorgehoben]. Im Abendland lebt die Antike nicht nur weiter wie im Islam, nein, sie wird dort neu geboren. Und mit ihr wird der vom Orientalen grundsätzlich verschiedene [Hervorhebung B.S.], orientalische Mensch geboren“. ${ }^{38}$ Denn: „Im Islam lebte die Antike [...] einfach weiter, aber nicht die Antike des Sophokles oder Plato oder des echten Aristoteles, nein, hier herrschten die Epigonen, die zwar auch griechisch sprechende und schreibende, aber im Grund schon orientalisierte (sic!) Antike. “39

\section{Historismus und Orientalismus}

Becker, so Baber Johansens Argument, habe wenigstens eine ungleiche gemeinsame Geschichte (von ,Europa und Islam‘) gewollt, während Troeltsch die Idee der geteilten Geschichte ablehnte. ${ }^{40}$ Haridi sieht den Unterschied zwischen ,den

36 C. H. Becker: Kulturgeschichte, S. $28 f$.

37 Ebd., S. 29.

38 Ebd., S. 34.

39 Ebd., S. 35.

40 B. Johansen: Politics and Scholarship, S. 86. 
beiden Geschichtsphilosophen des beginnenden 20. Jahrhunderts" nur als einen „technischen“. Beiden sei gemeinsam, dass sie darauf abzielten, die Besonderheit der europäischen Moderne werttheoretisch zu begründen. So könne Troeltsch den Islam in den europäischen Kulturkreis nicht einbeziehen, und so müsse Becker seinerseits den Islam aus der Moderne ausschließen. ${ }^{41}$

Diese Einschätzung kommt der Sache schon näher, wenn auch Becker auf keinen Fall als ,Geschichtsphilosoph“ bezeichnet werden kann und auch nicht das Kaliber von Troeltsch erreicht. Die Konzepte der ,geteilten“ oder auch ,verwobenen' Geschichte sind heute neue historische Konzepte, die eine Geschichtsschreibung jenseits des Eurozentrismus ermöglichen sollen. Von so einer Vorstellung ist Becker Lichtjahre entfernt, auch wenn er, wahrscheinlich aus wissenschaftspolitischen Gründen, aus der ungenügenden orientalischen Aneignung des Hellenismus ein Argument für den Einschluss des islamischen Westasiens (oder des Islams? - Die Verwirrung der Begriffe bei Becker ist nicht zu übersehen) machen will. Mit eben diesem Argument übrigens schließt Troeltsch diese Region aus. Die Logik ist da wohl auf seiner Seite.

Troeltschs Interesse liegt, wie oben diskutiert, darin, in einer Kulturtheorie den tief gehenden Unterschied zwischen westeuropäischer und deutscher Historie zu überwinden. In gewisser Weise denkt er hier spätere Westbindungen Deutschlands vorweg, und in dieser $\mathrm{Ab}$ - und Eingrenzung wird nicht nur der Islam, sondern auch das orthodoxe Christentum, nicht nur Westasien, sondern auch Osteuropa ausgegrenzt.

Becker hingegen, auf Grund seiner intimeren Kenntnis des Islams und der islamischen Welt hätte die Bestrebungen mittlerweile klassischer muslimischer Reformer, eine islamische Moderne vorzudenken, ernst nehmen können. Er selbst stellte fest:

„Moderne Muhammedaner haben sogar die Empfindung, dass der stark rationalistische Charakter des Islam, v.a. seine schroffe Betonung der Einheit Gottes, besonders gut in die moderne Welt passe, und dass eine innere Verwandtschaft bestehe zwischen dem Islam und so ausgeprägt neuzeitlichen Produkten wie dem Haeckelschen Monismus. Auch ist es kein Zufall, dass so naturwissenschaftlich gerichtete Lehren, wie die von August Comte, in der islamischen Bildungsschicht [...] weite Verbreitung gefunden haben, wie überhaupt die moderne Naturwissenschaft ohne weiteres vom Islam aufgenommen werden kann. “42

Becker schreibt die islamische Welt jedoch grundsätzlich aus der Moderne heraus. Man kann durchaus den Eindruck gewinnen, dass es ihm mit seinen Schriften eher um die Etablierung eines neuen wissenschaftlichen Faches geht, und er

41 A. Haridi: Paradigma, S. 108f.

42 C. H. Becker: „Der Islam als Weltanschauung“, in: ders. (Hg.), Islamstudien, S. 4053, hier S. 51f. 
deshalb ,seiner Region“ eine Sonderrolle zuschreiben will. An der Anerkennung des Rechts dieser Region, aus sich selbst heraus verstanden zu werden (ein historistisches Prinzip) aber ist er durch die Scheuklappen des (Neu-)Humanismus gehindert.

Die Johansen-These, dass es die Historiker in der Tradition des Historismus gewesen seien, die den Orientalismus vertreten hätten, während die Orientalisten in Abhängigkeit zu ihnen gestanden seien, kann so nicht stehen bleiben. Becker orientalisiert den Orient stärker als Troeltsch. Und dessen Konstruktion eines dezidierten ,Europäismus` Eurozentrik vorzuwerfen, ist ein Vorwurf, der letztlich ins Leere läuft.

Trotzdem ist die Auseinandersetzung zwischen Troeltsch und Becker heute in dreierlei Hinsicht interessant. Erstens sind beide durch ihre Bindung an den (Neu)Humanismus daran gehindert, das Andere wahrhaft ernst zu nehmen. Zu tief sitzt das neuhumanistische Bildungsideal, den Europäer als den wahren Erben einer verklärten Antike zu sehen, als den einzig modernen Menschen. Der Neuhumanismus als (gymnasiales) Bildungsideal, das den originalen Renaissance-Humanismus verkürzte und trotz des weiter fortgeschrittenen Wissens normativ festschrieb, hat keine europäische Entsprechung. Er müsste für die deutsche Entwicklung in der Tat weiter untersucht werden.

Historismus und Orientalismus sind verwandte Systeme. Die Wissenschaft von der Geschichte ignorierte die Geschichte der Anderen, weil sie eben nicht als wichtig galt. (Ausnahmen waren die populären Weltgeschichten, und eben Ranke und Hegel, deren Orient-Darstellung bereits in den 1950er Jahren vom Historiker Ernst Schulin durchaus kritisch betrachtet wurde). Als zuständig für das Andere erklärte man andere Fächer, wie die Philologien (z.B. die Orientalistik), die Geographie und die Völkerkunde. Die Wissenschaft vom islamischen Orient hatte das Andere genuin zum Thema. Doch sie ist Teil derselben Kultur, die auch den Historismus hervorbrachte, einer Kultur, die sich an der Antike orientierte. ${ }^{43}$ Dies hat in unserem Falle beim Orientalisten Becker verhindert, dass er den Orient aus sich selbst, aus eigenem Recht heraus verstehen konnte, was der historischphilologischen Methode zufolge eigentlich seine Aufgabe gewesen wäre. Hier liegt also eine echte Verständnisgrenze der Wissenschaft vom Orient, zumindest im Falle Beckers. Das Argument wird noch bestätigt, vergegenwärtigt man sich

43 Auch Josef van Ess weist darauf hin, dass Becker es nicht vermochte, den „Alpdruck des Humanismus" abzuschütteln. Kein anderer aber habe dies klarer ausgedrückt als Nöldeke: „Aber auf alle Fälle habe ich fürs echte Hellenentum - ehe es sich mit dem Orient in zum Teil mir wenig sympathischer Weise mischte - sehr viel mehr übrig, als für den ganzen Orient, wenigstens soweit er regelrecht fromm war“. Josef van Ess: „The Emergence of Kulturgeschichte in Islamic Studies“, in: Malcolm H. Kerr (Hg.), Islamic Studies. A Tradition and its Problems, Malibu: Undena Publications 1980, S. 27-52, hier S. 47. 
des liebenden Enthusiasmus, dessen sich Indien, Heimat des Indo-Europäischen, in der europäischen Wissenschaft erfreute.

Der Begriff der Wahlverwandtschaft geht auf Goethe zurück, der ihn wiederum aus dem chemischen Wissen seiner Zeit entlehnte: Verwandte Stoffe verbinden sich je nach Stärke der Verwandtschaft „,wahlverwandtschaftlich“. So sind schon Orientalismus und Historismus verwandt, beide verbanden sich aber mit dem (stärkeren) Neuhumanismus. Dabei sind die Folgen für den Orientalismus schwerwiegender.

Der Historismus sucht das Vergangene aus sich selbst heraus zu verstehen. Dass die Historisten sich übertrieben auf das Eigene, den (National-)Staat kaprizierten, und das Andere ausschlossen, ist zumindest erkenntnistheoretisch nicht zwingend. Der Orientalismus sucht das Andere zu verstehen. Dass er sich dieses Andere durch Abgrenzung schuf und damit eine Wissensschöpfung betrieb, in der sich auch europäische Überlegenheitsgefühle und Beherrschungswille manifestierten, ist eine traurige Tatsache. Der Orientalismus, so wie der Begriff geprägt wurde, ist die dunkle Seite des europäischen Wissensdranges. Das SichAneignen, Beherrschen und Herabwürdigen des Anderen fand zweifelsohne statt. Doch diese dunkle ist nicht die einzige Seite der europäischen ,Lust am Wissen “. ${ }^{44}$ Dies muss in Zukunft stärker herausgearbeitet werden. Mit dem Orientalismus hat die Orientalistik insofern zu tun, als Orientalisten, wie auch Historiker (Ranke mehr als Troeltsch), Künstler und Literaten (diesen, zumindest den deutschen, ist die dunkle Seite am wenigsten vorzuwerfen) daran beteiligt waren.

Mögen die Antworten beider Autoren heute veraltet bzw. den Anforderungen der Gegenwart nicht mehr angemessen sein, die von ihnen aufgeworfenen Fragestellungen sind außerordentlich aktuell: Wie lässt sich das Verhältnis von Europa zur islamischen Welt, der außereuropäischen Welt im Ganzen, bestimmen? Welchen Platz hat die europäische Geschichte in der Weltgeschichte?

Zwei neuere Antworten auf diese Frage gilt es hier anzuführen: Eine bahnbrechende Weise, über die Denkfalle der als normativ gesetzten Universalisierung der europäischen Moderne hinaus zu denken, die die Modernisierungstheorie (womöglich im Anschluss an neuhumanistische Bildungsideale, Historismus und Orientalismus?) formuliert hat, stammt von Shmuel N. Eisenstadt. Er schlug das Paradigma der „multiple modernities“ vor, das seitdem in den Kultur- und Sozialwissenschaften weite Verbreitung gefunden hat. Die deutsche Übersetzung „Vielfalt der Moderne“ ist besser als das englische Original, weil sie der Gefahr erneuter hermetischer Grenzbildung durch den Singular vorbeugt. ${ }^{45}$ Es wird heute also versucht, Begriffe, Konzepte und Modelle neu zu denken und die ,Entwestlichung der Moderne' weiter voran zu treiben. Diese Autorin arbeitet am

44 Der Begriff ist abgewandelt von Robert Irwin übernommen, der damit aber ein radikales Gegenargument zu Said macht: Robert Irwin: The Lust for Knowing. The Orientalists and their Enemies, London: Penguin, 2006.

45 Shmuel N. Eisenstadt: Die Vielfalt der Moderne, Göttingen: Velbrück 2000. 
Konzept einer ,globalen Moderne‘. ${ }^{46}$ Dies wird auch außerhalb Europas getan. Der in dieser Hinsicht vielleicht einflussreichste Text, der die europäische Moderne (zu der auch der Marxismus zählt) von einer anderen Weltregion ausgehend dekonstruiert und Europa ,provinzialisiert" hat, ist Dipesh Chakrabartys „Provincialising Europe“ ${ }^{47}$ Doch vor ihm sprach bereits ein deutscher Historiker, nicht zufällig ein Althistoriker, 1988 von der ,Welt der Geschichte und der Provinz des Historikers“. ${ }^{48}$ Die Wege der anderen, so sagte er, könnten heute vernünftigerweise nicht mehr als „evolutionäre Sackgassen“ aufgefasst werden. Christian Meier distanzierte sich von den alten Konzepten, wie sie noch Troeltsch und Becker vertraten. Wer heute noch die „Welt der Geschichte“ auf das Antik-Abendländische beschränkt sehe, sei nicht mehr einfach in den natürlichen Begrenzungen und Akzentuierungen einer Gesellschaft (oder eines Kreises von Gesellschaften) befangen, in einem sinnvoll gegebenen Horizont historischer Betrachtung, sondern er habe schlicht Scheuklappen auf. ${ }^{49}$

In der Gegenwart, drittens, die die Globalisierung spüren lässt wie nie zuvor, und vor den Herausforderungen einer verbundenen und vernetzten Welt (von der Ökologie zum globalen Terror) sind die Sozial- und Kulturwissenschaften gefordert, Wissen zu generieren, das das Verstehen zwischen den Gesellschaften der Welt fördert. Dafür müssen sie sich selbst und ihre Traditionen kritisch überdenken. Das gilt auch für die Islamwissenschaft. Dieser Band ist ein wichtiger Schritt in diese Richtung.

Gerade den Fächern, die das Wissen um nicht-europäische Gesellschaften und Kulturen zum Gegenstand haben, kommt hier eine besondere Bedeutung zu. Sie sind gefordert, dieses Wissen in die ,allgemeinen“ Disziplinen einzuspeisen, um das Projekt der ,Entwestlichung der Moderne“ und der Globalisierung des Wissens voranzutreiben. ${ }^{50}$ Allerdings hat hier die Islamwissenschaft das Problem, von der Disziplin, in die sie eigentlich gehört, und von der sie C. H. Becker fern gehalten hat, die Religionswissenschaft, nun weit entfernt zu sein. Sie ver-

46 Birgit Schaebler: „Civilizing Others: Global Modernity and the Local Boundaries (French/German, Ottoman, and Arab) of Savagery“, in: ders./Leif Stenberg (Hg.), Globalization and the Muslim World. Culture, Religion and Modernity, Syracuse, New York: Syracuse University Press 2004, S. 3-29.

47 Dipesh Chakrabarty: Provincializing Europe: Postcolonial Thought and Historical Difference, Princeton u.a.: Princeton University Press 2000.

48 Siehe hierzu Birgit Schäbler: „Vorwort“, in ders. (Hg.), Area Studies und die Welt: Weltregionen und neue Globalgeschichte, Wien: mandelbaum 2007, S. 7-11.

49 Christian Meier: Die Welt der Geschichte und die Provinz des Historikers. Drei Überlegungen, Berlin: Wagenbach 1989, S. 14.

50 Birgit Schäbler: „Das Studium der Weltregionen (Area Studies) zwischen Fachdisziplinen und der Öffnung zum Globalen: Eine wissenschaftsgeschichtliche Annäherung", in: diess., Area Studies und die Welt. Weltregionen und neue Globalgeschichte, Wien: mandelbaum 2007, S. 11-44, am Beispiel der Nah-Ost-Studien in den USA und Deutschland. 
steht sich heute wohl am ehesten als den Kulturwissenschaften zugehörig. Mit diesen sollte sie den Dialog suchen. 


\section{Islamwissenschaft aus der Sicht eines außer-universitären Forschungsinstituts: Orient als Islam? ${ }^{1}$}

ULRIKE FREITAG (BERLIN)

Aus der Sicht eines Forschungsinstituts, das den Titel ,Zentrum Moderner Orient" (ZMO) trägt, stellt die deutsche Islamwissenschaft in mancherlei Hinsicht eine Herausforderung dar. Dies hängt teils mit der Geschichte dieses Zentrums, teils mit seiner strukturellen und finanziellen Verortung und teils mit unterschiedlichen nationalen Wissenschaftskulturen zusammen.

Der Begriff ,Moderner Orient" wurde und wird in der Öffentlichkeit oft mit jenen Gegenden gleichgesetzt, die auch zum Hauptarbeitsfeld von Islamwissenschaftlern in Deutschland gehören, nämlich mit der Region, die als ,Naher und Mittlerer Osten“ (in der Regel unter Einschluss Nordafrikas) bezeichnet wird oder, neuerdings auch häufiger, als ,Westasien“ und Nordafrika. Damit hat er einen zumindest impliziten Bezug zu der Region, die in der deutschen Islamwissenschaft im Zentrum der Aufmerksamkeit steht.

Es bedarf immer gesonderter Erklärungen, dass der ,Orient'-Begriff im Zentrum Moderner Orient ein anderer ist als der Begriff, der regional den Arbeitsbereich der deutschen Islamwissenschaft bestimmt. Da der Wandel der Begriffe auch immer einen Blick auf die sich wandelnden Vorstellungen erlaubt, sei hier nur kurz daran erinnert, dass 1912 an der damaligen Königlich Preußischen Akademie der Wissenschaften in Berlin die Orientalische Kommission geschaffen worden war. Ihre Aufgabe bestand darin, die deutsche Orientarchäologie zu befördern und bei der wissenschaftlichen Auswertung ihrer Funde zu unterstützen. ${ }^{2}$ Der hier zugrunde gelegte Orientbegriff war geographisch bereits sehr weit gefasst, konzentrierte sich die Arbeit doch auf Regionen, die drei verschiedenen

1 Für Unterstützung bei der Materialsammlung und Textdurchsicht danke ich Leyla von Mende, für zusätzliche Kritik, Anregungen und Ergänzungen Bettina Gräf, Sarah Jurkiewicz, Achim von Oppen und Margrit Pernau.

2 http://www.bbaw.de/bbaw/Forschung/Forschungsprojekte/turfanforschung/de/Turfanforschung vom 14.9.2007. 
Kontinenten zugerechnet werden können: Ägypten, Mesopotamien und Turfan in Zentralasien.

Diese Arbeit wurde an der Deutschen Akademie ab 1947 fortgesetzt, wobei neben die Beschäftigung mit der alten Geschichte die Forschung zum modernen Asien und Afrika trat. 1969 wurde die Struktur der Akademie (nun AdW der DDR) grundlegend verändert und die Mitarbeiter der orientalischen Kommission auf verschiedene historische Akademieinstitute verteilt. Für diejenigen, die sich mit der modernen Geschichte und Gegenwart Asiens, Afrikas und des Nahen Ostens befassten, also einer Region, die man zwischenzeitlich an der Akademie ebenfalls ,Orient" nannte, wurde 1981 am Zentralinstitut für Geschichte ein Bereich „Geschichte der Entwicklungsländer“ eingerichtet. ${ }^{3}$ Unmittelbar nach der ,Wende', schon im Dezember 1989, setzten sich die Mitarbeiter dafür ein, dass eine „Arbeitsgemeinschaft für Asien- und Afrikaforschung“ geschaffen werde, die einen Rahmen für stärker interdisziplinäre Forschung bilden sollte, ab April 1990 kam der Name „Orientforschung“ für das zu gründende Institut auf (einen Institutsnamen von vor 1969 aufgreifend). ${ }^{4}$,Orient" wurde unter anderem deshalb gewählt, weil der Begriff kurz war und ausreichend vage, dass man - anknüpfend an das frühere Verständnis - neben Süd- und Westasien auch Nordafrika und das subsaharische Afrika darunter subsumieren konnte. Damit entspricht der Begriff regional (nicht aber inhaltlich) eher demjenigen, was traditionell unter ,Orientalistik' verstanden wurde und der sich auch heute noch - zumindest im Prinzip - auf den Orientalistentagen wieder findet, nämlich die Forschung zu Asien, manchmal auch zu Afrika. ${ }^{5}$

\section{Islamwissenschaft und Interdisziplinarität}

Aufgrund der mittlerweile gängigen Gleichsetzung von ,Orient“ mit Vorderer Orient bzw. Islam wird in aller Regel angenommen, dass die Beschäftigung mit dem Islam im Zentrum der Forschung am ZMO steht. Häufig sind Besucher enttäuscht zu hören, dass das ZMO primär ein Ort interdisziplinärer Forschung ist,

3 Kai Hafez/Gerhard Höpp: „Gegenwartsbezogene Orientwissenschaft in der DDR und in den neuen Bundesländern: Kontinuität oder Neubeginn?““ in: Wolf-Hagen Krauth/Ralf Wolz (Hg.), Wissenschaft und Wiedervereinigung. Asien- und Afrikawissenschaften im Umbruch. Studien und Materialien der Interdisziplinären Arbeitsgruppe Wissenschaften und Wiedervereinigung, Berlin: Akademie-Verlag 1998, S. 95-163, hier S. 126 und Gerhard Höpp: Bereich Orientforschung im Institut für Allgemeine Geschichte, Typoskript, Berlin 1991, S. 1; ZMO, Nachlass Höpp, Karton 5.9.

4 K. Hafez/G. Höpp: Gegenwartsbezogene Orientwissenschaft, S. 125f.

5 So auch bei Hans-Robert Roemer: Deutsche Orientalistik der siebziger Jahre. Thesen, Zustandsanalyse, Perspektiven, Deutsche Morgenländische Gesellschaft 1972, S. 3 und passim. 
dem zwar auch einige Religionswissenschaftler angehören, ohne dass diese jedoch die Mehrzahl bilden. Auch wird ,Moderne“ am ZMO historisch als eine mehrere hundert Jahre umfassende Entwicklung verstanden. Insofern sind keineswegs alle Forschungen gegenwartsorientiert, und auch jene, welche es sind, berücksichtigen historische Dimensionen. Insgesamt könnte man das Profil so beschreiben, dass am Zentrum Moderner Orient Grundlagenforschung vor allem, aber nicht ausschließlich zu muslimisch geprägten Gesellschaften zwischen Südostasien und Mauretanien, zwischen Europa und Südafrika betrieben wird, und zwar eine Forschung, bei der sozial- und geisteswissenschaftliche Ansätze miteinander verknüpft und international eingebunden werden. Dies gehört zu den methodischen Grundaufträgen des Zentrums. ${ }^{6}$

Es ist also unter dem Aspekt der engeren disziplinären bzw. thematischen Verortung nicht so, dass man das ZMO als ein ,islamwissenschaftliches Zentrum“ beschreiben kann. ${ }^{7}$ Dennoch beschäftigen sich die meisten Forscher mit einer Region, die überwiegend muslimisch bevölkert ist. Auch trägt das nächste Forschungsprogramm den Titel „Muslimische Welten - Welt des Islam?“. Ist die Distanzierung von der (regional auf Asien und Afrika ausgedehnten) Islamwissenschaft also eine Chimäre?

Es gibt eine Reihe von wissenschaftlichen Gründen, die bisherigen ZMOForschungen zur Frage der Translokalität, also den räumlichen Ausprägungen der Zirkulation von Menschen, Waren und Ideen im Hinblick auf das genannte künftige Forschungsthema zu fokussieren. Eines der wichtigsten Ziele des neuen Forschungsprogramms ist dabei, die häufig angenommene kulturelle Zusammengehörigkeit der ,muslimischen Welt' kritisch zu beleuchten, indem reale Verflechtungen - historische wie gegenwärtige - zwischen muslimischen Gesellschaften ebenso wie mit nicht dominant muslimischen untersucht werden. Inwieweit ,Islam“ als zentrales kulturbildendes Element auch jenseits des Vorderen Orients $\mathrm{zu}$ verstehen ist und wie weit eine solche Sicht trägt, ist eine Frage, die zu problematisieren sich gerade in einer Zeit lohnt, in der eo ipso vorausgesetzt wird, dass Länder mit einer muslimischen Mehrheitsbevölkerung einen religiös wie kulturell mehr oder minder homogenen Block bilden. Insofern erscheint es sinnvoll, systematisch und unter Einbeziehung unterschiedlicher Regionalwissenschaften und Disziplinen zu untersuchen, wie sich dies aus der Perspektive unterschiedlicher muslimischer Gesellschaften selbst darstellt. Deshalb haben Forschungen, die sich nicht mit Kultur oder Religion beschäftigen, sondern beispielsweise mit Fragen nach wirtschaftlichen Handlungsräumen, transregionalen Migrationsströmen oder Stadtgeschichte befassen, am ZMO nicht nur ihren Platz,

6 Wissenschaftsrat: Empfehlungen zur Förderung Geisteswissenschaftlicher Zentren, Stuttgart, 11.11.1994 (Drs. 1751/94), S. 45.

7 So z.B. der Wissenschaftsrat in seinem Bewertungsbericht zum ,Zentrum Moderner Orient“, Berlin, 27.1.2006, S. 27, http://www.wissenschaftsrat.de/texte/6789-05.pdf vom 10.9.2007. 
sie sind sogar von zentraler Bedeutung für das Gesamtprogramm. Und auch inhaltlich erlaubt dies, die vieldiskutierte ,Rückkehr der Religionen“ einmal nicht unter dem von vornherein angenommenen Primat der Religion zu kontextualisieren und kritisch zu beleuchten.

Hierfür ist das Zentrum mit seinem langjährigen Forschungsprogramm, das nicht entlang der traditionellen regionalwissenschaftlichen Trennlinien organisiert war, geradezu prädestiniert. Die Perspektive auf nichtmuslimische Gesellschaften erlaubt dabei nicht nur den Vergleich, sondern dient auch immer wieder als ein Korrektiv, um Fragen anders zu stellen oder neue Verbindungen zu entdecken.

Dies ist keineswegs trivial, wenn man sich vergegenwärtigt, welche unterschiedlichen Entwicklungen die historische Forschung über die verschiedenen Weltregionen genommen hat. So hat beispielsweise die Geschichtsforschung zum Vorderen Orient lange die einheimische, d.h. die arabische, persische und osmanische historiographische Tradition zu ihrer Grundlage gemacht, während sowohl osmanische als auch arabische Archive erst in jüngerer Zeit zugänglich und als Quellen entdeckt wurden. Demgegenüber ist die wissenschaftliche Beschäftigung mit afrikanischer Geschichte lange stark von der Ethnologie und den Quellenbeständen der kolonialen Archive geprägt worden. Für Indien hingegen dominiert die Geschichtsschreibung auf der Basis vor allem der britischen Kolonialakten und der kritischen Auseinandersetzung damit, welche Bereiche der Geschichte damit überhaupt erschlossen werden können. Einheimische Quellen wurden, sofern es nicht um die alte Geschichte geht, erst seit den 1970er Jahren in die Analysen einbezogen. Auch in anderen Disziplinen finden sich solche regional unterschiedlichen Entwicklungen, beispielsweise hat die ,klassische " anthropologische Beschäftigung mit illiteraten Gesellschaften lange Zeit dazu geführt, dass städtische, schriftkundige oder gar technisierte Gesellschaften nicht als Gegenstände des Faches galten. Es wäre einmal eine lohnende Aufgabe, diese verschiedenen Methoden und Ansätze der verschiedenen regionalwissenschaftlichen Wissenschaftskulturen zu vergleichen - ein Unterfangen allerdings, das in diesem Rahmen nicht geleistet werden kann. ${ }^{8}$

\section{Philologie und Orientwissenschaft}

In gewisser Weise greift der Ansatz des ZMO kulturgeschichtliche Traditionen auf, die in der Entwicklung der Islamwissenschaft im späten 19. Jahrhundert ge-

8 Einen zwangsläufig vergröbernden Eindruck von den unterschiedlichen Entwicklungen in den afrikanischen, nahöstlichen und lateinamerikanischen Geschichtsschreibungen geben die Beiträge von Andreas Eckert, Ulrike Freitag und Jochen Meissner in: Wolfgang Küttler/Jörn Rüsen/Ernst Schulin (Hg.), Geschichtsdiskurs, Band 5, Frankfurt/M: Fischer-Taschenbuch-Verlag 1999. 
wisse Vorbilder haben, auch wenn sich diese ,Modernisierung ' der Orientalistik primär auf den Vorderen Orient richtete und damit regional anders ausgerichtet war als die ,Orientalistik' insgesamt. Dennoch ist es lohnend, sich kurz auf Wissenschaftler wie Carl Heinrich Becker und Martin Hartmann zu besinnen, die unter dem Einfluss von Jacob Burckhardt eine kulturhistorische Perspektive entwickelten. ${ }^{9}$ Diese Islamwissenschaft setzte sich bewusst von der philologischen Orientierung der Vorgänger $a b$ und wandte sich gegenwartsbezogenen Themen zu. Teilweise geschah dies durchaus polemisch, etwa in Georg Kampffmeyers Einleitung zur neu gegründeten Die Welt des Islams. Die Zeitschrift wurde von der „Deutschen Gesellschaft für Islamkunde“ getragen, einer Vereinigung, die sich die gegenwartsorientierte Forschung über Ethnologie, Kultur, Religion und Wirtschaft zum Ziel gesetzt hatte. ${ }^{10}$ Ihr Publikum sollten nicht nur Wissenschaftler sein, sondern auch Deutsche, die im Orient arbeiteten, ,die sich für Fragen des Hamza oder der Imāla im Arabischen nicht sonderlich erwärmen, auch altarabischen Dichtern nicht viel Geschmack abzugewinnen vermögen, die aber an den sie umgebenden lebendigen Verhältnissen wohl Interesse nehmen, die offenen Auges um sich schauen und Befähigung und Neigung durchaus besitzen, das Studium solcher Verhältnisse zu vertiefen und über sie zu berichten. “11

Das Ziel dieser neuen Islamwissenschaft war ein synthetisierender Blick auf den Orient im Kontext des Ringens um eine universale Geschichte, nicht unähnlich heutigen Bestrebungen, regionalwissenschaftliche Erkenntnisse in die neuerdings populäre Global- oder transnationale Geschichte zu integrieren. Dabei dominierte allerdings im frühen 20. Jahrhundert in Anlehnung an Ernst Troeltsch die Vorstellung von Kulturkreisen, welche als eigene Einheiten gesehen wurden, während heute im Gegenteil Verflechtungen und Begegnungen im Zentrum der Aufmerksamkeit von Globalhistorikern stehen. Interessanterweise widersprach der Islamwissenschaftler Becker dem Historiker Troeltsch in einem wichtigen Punkt: Für ihn gehörten die islamische und europäische Zivilisation im Grunde zu einem gemeinsamen Kulturkreis, innerhalb dessen sich unterschiedliche Entwicklungen abgespielt hatten. Damit kam er im Endeffekt zu dem auch von Troeltsch vertretenen Ergebnis, dass Europa in seiner Entwicklung der muslimischen Welt letztlich überlegen war. ${ }^{12}$ Dabei vereinte ihn mit Max Weber, mit dem Be-

9 Dazu und im Folgenden vgl. Sabine Mangold: Eine ,weltbürgerliche Wissenschaft“ - Die deutsche Orientalistik im 19. Jahrhundert, Stuttgart: Steiner 2004, S. 256-273.

10 Vgl. Peter Heine: „,Nur wer Hafiz liebt und kennt...' Berliner Islamwissenschaft. Ein wissenschaftsgeschichtlicher Überblick“, in: Höpp/Norbert Mattes (Hg.), Berlin für Orientalisten, Berlin: Klaus Schwarz 2002, S. 45-58, hier S. 52f.

11 Georg Kampffmeyer: „Plane perspicere“, in: Die Welt des Islams 1 (1913), S. 1-6, hier S. 4.

12 Baber Johansen: „Politics and Scholarship: The Development of Islamic Studies in the Federal Republic of Germany“, in: Tareq Y. Ismael (Hg.), Middle East Studies. International Perspectives on the State of the Art, New York u.a.: Praeger 1990, S. 71-130, hier S. 84f. 
cker ebenfalls regen Austausch pflegte, die Suche nach den Gründen für die Entwicklung der europäischen Moderne. ${ }^{13}$ Es scheint, dass damals wie heute die intensive Beschäftigung mit der außereuropäischen Geschichte zwar nicht immer zu einer gewissen Sympathie, wohl aber zumindest zu einem besseren Verständnis nicht nur der Unterschiede, sondern auch der Gemeinsamkeiten zwischen verschiedenen Regionen geführt hat.

Allerdings war zumindest für Becker noch eine Erkenntnis zentral, die in der heutigen globalgeschichtlichen Debatte gelegentlich unterzugehen droht, nämlich die Unerlässlichkeit der philologischen Grundbildung. Für Becker war diese nicht mehr Selbstzweck, sondern im Wesentlichen Mittel zum Zweck der „Kenntnis der gesamten Kulturverhältnisse des betreffenden Gebietes [...] mögen sie gegenwärtige oder vergangene sein. “14 Beckers Schüler Schaeder freilich konnte Rankes Beschäftigung mit der osmanischen Geschichte durchaus etwas abgewinnen, auch ohne Kenntnisse des Osmanischen, da er die europäischen Archive den osmanischen Chroniken für überlegen hielt. ${ }^{15}$ Es wäre interessant zu wissen, ob Schaeder diese Position nach der Öffnung der osmanischen Archive aufrechterhalten hätte.

Auch die heutige Beschäftigung mit dem modernen Orient ist kaum denkbar ohne solide philologische Grundkenntnisse. Dies gilt natürlich für die Beschäftigung mit der Geschichte und Gegenwart jeglicher Region, nur tendiert die reale Globalgeschichte dazu, sich auf die Rezeption von Literatur in der hegemonialen Sprache Englisch zu beschränken, vielleicht noch mit Beigaben aus anderen westlichen Sprachen. Auf die Fehleinschätzungen, die dies bewirken kann, hat neulich Margrit Pernau hingewiesen. ${ }^{16}$ Dabei geht es nicht nur um die Frage von Quellenkenntnis, mindestens ebenso zentral, wenn nicht im Kern der Problematik, steht die Frage nach den Begriffen, welche wir den Analysen von Verflechtungen, Einflüssen und globalen Entwicklungen zugrundelegen. ${ }^{17}$ Hier liegt die

13 Hierzu ausführlich Alexander Haridi: Das Paradigma der ,islamischen Zivilisation“ - oder die Begründung der deutschen Islamwissenschaft durch Carl Heinrich Becker (1876-1933), Würzburg: Ergon 2005; vgl. die Rezension von Stephan Conermann in: sehepunkte 6;12 (15.12.2006), http://www.sehepunkte.de/2006/12/10569.html vom 20.9.2007.

14 Carl Heinrich Becker: „Die orientalischen Wissenschaften. A. Der vordere Orient und Afrika“, in: Siegfried Körte/Friedrich Wilhelm von Loebel (Hg.), Deutschland unter Kaiser Wilhelm II., Bd. 3, Berlin: Hobbing 1914, S. 1183-1188, hier S. 1184.

15 B. Johansen: Politics and Scholarship, S. 85.

16 Margrit Pernau: „Global history - Wegbereiter für einen neuen Kolonialismus“, in: geschichte-transnational 2004, http://geschichte-transnatinal.clioonline.net/forum/id $=572 \&$ count $=26 \&$ recno $=25 \&$ type $=$ diskussionen $\&$ sort $=$ datum $\&$ order $=$ down $\&$ seg ment $=16$ vom 16.9.2007.

17 Hierzu Ulrike Freitag: „Herausforderungen an die Geschichtswissenschaft im Zeitalter der Globalisierung“, in: Lothar Gall (Hg.), 25 Jahre Historisches Kolleg, Rückblick - Bilanz - Perspektiven, München: Oldenbourg 2006, S. 271-275 und Margrit Pernau: „Transkulturelle Geschichte und das Problem der universalen Begriffe. 
eigentliche Herausforderung für die transnationale Geschichte, aber auch für die Regionalstudien im weiteren Sinne. Denn es ist nicht zu übersehen, dass sie nach wie vor einer doppelten Anforderung standhalten müssen: Unabhängig von der jeweiligen Disziplin, in der sie sich auf der Höhe der Zeit befinden müssen, was theoretische und methodische Ansprüche betrifft, sind Regionalstudien ohne Sprach- und Kulturkenntnisse von vornherein zum Scheitern verurteilt. Leider zeigt gerade die Erfahrung in den Sozialwissenschaften, dass dies oft nicht besonders ernst genommen wird, d.h. dass immer wieder davon ausgegangen wird, dass sich Politik oder Wirtschaft einer Region auch ohne Kenntnis der lokalen Sprache und Kultur analysieren lassen. ${ }^{18}$

Die Anknüpfungspunkte der Forschungen am Zentrum Moderner Orient an eine so verstandene Islamwissenschaft dürfen allerdings nicht überstrapaziert werden, nicht nur aufgrund der anderen regionalen Orientierung. Vielmehr ist der Ausgangs- und Angelpunkt bei interdisziplinärer Forschung eben nicht mehr die Religion und die auf sie bezogenen kulturellen Äußerungen, sondern es können beliebige andere Ausprägungen menschlichen Handelns sein. ${ }^{19}$

\section{Der außerwissenschaftliche Kontext der Orientforschung}

Die Beschäftigung mit der jüngeren Vergangenheit und Gegenwart des Orients, wo immer dieser liegen möge, kann nicht von dem gesellschaftspolitischen Interesse an Fragen der Orientwissenschaften gelöst werden. Dies gilt nicht nur für Großbritannien und Frankreich, wenn auch in deutlich stärker zu differenzierender Form, als sie beispielsweise Said in seiner Kritik des Orientalismus vorgebracht hat. ${ }^{20}$ Sowohl Becker als auch Hartmann lehrten an neuartigen Einrichtungen, dem Hamburger Kolonialinstitut (gegr. 1908, heute das Asien-Afrika Institut der Universität Hamburg) und am Berliner Seminar für Orientalische Sprachen (gegr. 1887 nach dem Vorbild der Pariser École spéciale des langues orientales vivantes). Das Seminar sollte dazu dienen, Diplomaten und all jenen offenzustehen, ,welche der hier vertretenen Sprachen für den Verkehr mit den Eingeborenen bedürfen. ${ }^{\text {21 }}$ Selbst wenn betont werden muss, dass sich die Vorstellun-

Muslimische Bürger im Delhi des 19. Jahrhunderts“, in: Birgit Schäbler (Hg.), Area Studies und die Welt. Weltregionen und neue Globalgeschichte, Wien: Mandelbaum 2007 (im Druck).

18 Vgl. in jüngerer Zeit auch die Diskussion über die deutsche Afrikawissenschaft in: afrika spectrum 38 (2003).

19 Für die Rolle der Religion in der Islamwissenschaft s.a. Dietrich von Denffer: „Theoretischer Ansatz und Methode in der Islamwissenschaft", in: XIX DOT, ZDMG Supl. III 1 Wiesbaden 1977, S. 342-345.

20 Edward Said: Orientalism, New York: Pantheon Books 1978.

21 Eröffnungsrede von Goßlers am 27.10.1887, in: Eduard Sachau: Bericht über die Eröffnung des Seminars für Orientalische Sprachen an der königlichen Friedrich- 
gen vieler der an diesen Institutionen tätigen Wissenschaftler nicht mit derartigen Erwartungen deckten, so waren ihnen doch Überlegungen nicht fremd, dass ihre wissenschaftliche Tätigkeit deutsche Wirtschaft und Politik befördern könnten. „Die Zeiten, da es dem Deutschen gleichgültig sein konnte, wenn ,hinten, fern in der Türkei die Völker aufeinanderschlugen“, sind endgültig vorbei“, schrieb Becker 1914, ${ }^{22}$ und diese Auffassung war nicht auf den Vorderen Orient beschränkt, sondern ließ sich auch auf Afrika, wo Deutschland koloniale Interessen verfolgte, übertragen. Auch Kampffmeyer betonte die Hinwendung zu aktuellen, auch kolonialpolitisch relevanten Themen, selbst wenn er im gleichen Atemzug kategorisch versicherte: „Politik treiben wir nicht“. ${ }^{23}$ Dies änderte sich allerdings mit dem Krieg, als Becker es sich zur Aufgabe machte, Islamwissenschaft in den Dienst des Deutschen Reiches zu stellen, während Kampffmeyer als Mitarbeiter des Deutschen Auslandsinstituts in Stuttgart an der ,Überprüfung' des Briefwechsels muslimischer Kriegsgefangener mitwirkte. ${ }^{24}$

Allerdings blieben Hartmann und Becker über lange Zeit eher die Ausnahmen als die Regel der deutschen Orientalistik. Nach dem Ersten Weltkrieg wie auch während des Nationalsozialismus wandte sich das Gros der Orientalisten unabhängig von der regionalen Ausrichtung eher philologischen Fragen zu. ${ }^{25} \mathrm{Zu}$ dem hatte der Kriegsausgang zur Folge, dass kolonial- und außenpolitisch relevantes Expertenwissen kaum mehr nachgefragt wurde. Im Nationalsozialismus wurden einige Orientalische Institute geschlossen und eine Reihe von Orientalisten ihrer Ämter enthoben, vertrieben oder ermordet. ${ }^{26}$ Politisch relevante Forschung fand ab 1936 zunächst an dem in eine Auslandshochschule an der Berliner Universität umgewandelten Seminar für Orientalische Sprachen statt, ab 1940 wurde diese mit der Hochschule für Politik vereint und als „Auslandswis-

Wilhelms-Universität zu Berlin und einige auf das Seminar bezügliche Schriftstücke, Berlin: Im Comm.-Verlag bei A. Asser 1888, S. 4, zit. nach S. Mangold: Eine „,weltbürgerliche Wissenschaft", S. 232.

22 C. H. Becker: „Die orientalischen Wissenschaften. A. Der Vordere Orient und Afrika“, S. 1183; für eine zusammenfassende Darstellung vgl. S. Mangold: Eine ,weltbürgerliche Wissenschaft", S. 273-278.

23 G. Kampffmeyer: Plane perspicere, S. 5.

24 B. Johansen: Politics and Scholarship, S. 89, Erich Pritsch: „Georg Kampffmeyer“, in: Die Welt des Islams 18 (1936), S. 1-11, Peter Heine: „C. Snouck Hurgronje vs. C. H. Becker“, in: Die Welt des Islams (n.S.) 23f. (1984), S. 378-387.

25 Hierfür und im Folgenden Udo Steinbach: „Neuere Entwicklungen in der deutschen gegenwartsbezogenen Nahost-Wissenschaft“, in: Marion Gebhardt (Hg.), Institutionen der gegenwartsbezogenen Orient-Forschung und -Information in der Bundesrepublik Deutschland und Berlin (West), Hamburg: Deutsches Übersee-Institut 1991, S. IV-XXIV.

26 Ludmilla Hanisch: „Akzentverschiebung - Zur Geschichte der Semitistik und Islamwissenschaft während des ,Dritten Reichs““, in: Berichte zur Wissenschaftsgeschichte 18 (1995), S. 217-226 u. B. Johansen: Politics and Scholarship, S. $90 f$. 
senschaftliche Fakultät" geführt. ${ }^{27}$ Orientalistik spielte hierin keine führende Rolle mehr, und es scheint, dass Orientalisten unter dem Verdacht standen, den Überlegenheitsanspruch der Arier in Frage zu stellen. Von wenigen Ausnahmen abgesehen, widmeten sich die verbleibenden Orientalisten bevorzugt Feldern, die als unpolitisch galten, während ideologisch besetzte Felder nach Möglichkeit ausgeklammert wurden. ${ }^{28}$

Forschung zur Moderne im ,Orient' fand in breiterem Rahmen erst in den späten 1960ern und 1970ern in der westdeutschen Wissenschaftslandschaft ihren Platz. Dies stand im Kontext der wissenschaftlichen Entwicklungen in den USA und Großbritannien, aber eben auch der politischen Öffnung gegenüber dem Vorderen Orient. In der DDR waren schon in den 1950er Jahren vergleichende Regionalwissenschaften an der Akademie, ab Mitte der 1960er Jahre dann in Leipzig das Orientalische Institut die Zentren dieser Art von Forschung. Diese ,Praxis- und Gegenwartsbezogenheit" ergab sich aus der Sicht der Regionalstudien als einem außen- und gesellschaftspolitischen Gestaltungsinstrument von Partei und Staat. ${ }^{29}$

Auch heute steht eine auf die Moderne bezogene Grundlagenforschung im Kontext der politischen Entwicklungen. Dies gilt gerade, aber keineswegs ausschließlich für Forschungen, die sich auf muslimische Gesellschaften beziehen, insbesondere nach dem 11. September 2001. In einer Zeit, in der Forschungseinrichtungen nicht mehr institutionell, sondern auf Programmbasis befristet finanziert werden, spielt natürlich die Frage nach der Finanzierbarkeit von Forschungsprogrammen eine gewisse Rolle. Während viele der kleineren Regionalwissenschaften am Rande des Überlebens stehen, hat es für islambezogene Forschung eine Art Boom gegeben, ebenso wie dies beispielsweise aus wirtschaftlichen Gründen in den letzten Jahren für Chinastudien zu beobachten ist. Dies gilt nicht nur für das studentische Interesse und die Nachfrage nach Absolventen, sondern eben auch für Wissenschaft in der Weise, dass es verhältnismäßig leicht ist, derartige Forschung zu finanzieren. Dessen muss man sich bewusst sein, selbst wenn die Ziele einer Einrichtung auf Grundlagenforschung und nicht auf Politikberatung gerichtet sind. Für ein Zentrum wie das ZMO bedeutet dies auch die stete Mahnung, den gewählten Fokus regelmäßig anhand der Entwicklung wissenschaftlicher wie gesellschaftlicher Debatten zu überdenken und auf keinen Fall jene Fragen und Regionen, die weniger öffentliche Aufmerksamkeit erregen, automatisch zu marginalisieren.

Was nun die Aufgaben dieser Grundlagenforschung anbelangt, so hat sie Hans Robert Roemer 1972 fast exemplarisch formuliert. Er stellt in den Vordergrund die „Vertiefung - ja oft erst Begründung - unseres Verständnisses der

27 P. Heine: Berliner Islamwissenschaft, S. 51.

28 L. Hanisch: Akzentverschiebung, S. 219f. und B. Johansen, Politics and Scholarship, S. 91.

29 K. Hafez/G. Höpp, Gegenwartsbezogene Orientwissenschaft, S. 99f. 
Völker Asiens und Afrikas, deren Gewicht für Europa ständig wächst“, und die Überwindung des herkömmlichen eurozentrischen Denkens. Die von ihm geforderten Untersuchungen, sowohl einzeln als auch im Vergleich, zu Gegenwartsproblemen und zur Rolle der Religionen im Kulturwandel, aber auch die Sicherung gefährdeten Materials und Quellenerschließung wie auch die Übersetzung bedeutender Werke sind bis heute zentrale Aufgaben. Bereits Roemer betonte die Notwendigkeit der außeruniversitären Institutionalisierung einer solchen - auch gegenwartsbezogenen - Orientforschung für Aufgaben, ,deren Kontinuität Arbeitskraft und Lebensdauer eines einzelnen Gelehrten übersteigt. “30

Hinzugekommen ist allerdings ein Aspekt, der zu Roemers Zeiten noch nicht ganz dieselbe Rolle spielte: Es wird von Wissenschaftlern zunehmend erwartet, eine öffentliche Rolle bei der Vermittlung ihrer Ergebnisse zu spielen und auch so - und nicht nur in Denkschriften und durch Beratungstätigkeit - die Relevanz ihrer Forschungen immer wieder unter Beweis zu stellen. Wie ernst Universitäten dies nehmen, zeigt sich etwa daran, dass manche Universitäten heute beispielsweise Medienauftritte in der Leistungsbilanz berücksichtigen, auf deren Grundlage Institute einen Teil ihrer Mittel erhalten. Um wie viel wichtiger ist die öffentliche Sichtbarkeit erst für Einrichtungen, deren Finanzierung regelmäßig auf dem Prüfstand steht. Während Politiker in der Regel wenig Zeit für die Erkenntnisse von Kulturwissenschaftlern haben, sieht dies bei Medien, Bildungseinrichtungen, aber in letzter Zeit auch bei entwicklungs-, sicherheits- und wirtschaftspolitischen Einrichtungen teilweise ganz anders aus. Wie aber positionieren sich Wissenschaftler, wenn sie regelmäßig Forschungsinteressen und Nachfrage miteinander verbinden müssen? Es geht bei dieser Frage weniger um die - teilweise erhebliche - zeitliche Belastung, sondern vielmehr um die kritische Reflektion dessen, was eine solche Nachfrage für die inhaltliche Ausrichtung von Forschung bedeutet - individuell wie institutionell. Und welche Rückwirkungen hat dies auf das Verhältnis zwischen im Westen angestellten Wissenschaftlern und Kollegen in den Regionen, über die geforscht wird? Nicht nur die Politik, auch die Öffentlichkeit zeigt regelmäßig ein größeres Interesse an möglichst verwertbaren und auf Tagesaktualität gerichteten Informationen über ,den Islam‘, was eine mögliche Verkürzung der Perspektiven und Verschiebung von Forschungsinteressen durchaus befördern kann.

Aber auch die Forschungsbedingungen haben sich nach dem 11. September erheblich verändert. Mehr noch als anderswo bestehen bei muslimischen Kollegen nicht nur hohe Erwartungen an ihre Kollegen, das Bild der Region im Westen zu korrigieren, sondern auch die Sorge, durch die gesammelten Informationen in ein falsches Licht gerückt zu werden. Dies beeinflusst die Lektüre von dem,

30 H. R. Roemer: Deutsche Orientalistik der siebziger Jahre, S. 4f., 29. 
was über muslimische Gesellschaften publiziert wird; es stellt Forscher vor komplizierte Fragen und kann in bestimmten Umständen ihre Sicherheit gefährden. ${ }^{31}$

Insofern erscheint es an der Zeit zu sein, dass eine offene Debatte über das Verhältnis von Wissenschaft, Politik und Öffentlichkeit beginnt, denn die Versuchungen einer Medienorientierung liegen ebenso auf der Hand wie die Einsicht, dass die Elfenbeinturmexistenz von Wissenschaftlern wohl der Vergangenheit angehört. Gerade für jene, die sich mit muslimischen Gesellschaften befassen, erscheint dies aufgrund des öffentlichen Interesses von besonderer Bedeutung zu sein.

31 Caroline B. Brettell: „Introduction Fieldwork, Text, and Audience”, in: dies. (Hg.), When They Read what We Write. The Politics of Ethnography, Westport u.a.: Bergin \& Garvey 1993, S. 1-24; zu aktuellen Fragen vgl. Farish A. Noor: Writings on the War on Terror, New Delhi: Global Media Publications 2006, S. 17-32. 

TEIL II

AN DEN ANGEBLICHEN RÄNDERN 



\section{,Die Mauer muss weg!', oder: Alles für sich ist singulär. Gedanken zur islamwissenschaftlichen Beschäftigung mit Südasien in Deutschland ${ }^{1}$}

JAN-PETER HARTUNG (LONDON)

Im Juni 1907 unterbrach ein 30jähriger indischer Muslim seine Studien am Trinity College der University of Cambridge und reiste nach Heidelberg, um dort seine bisher lediglich rudimentären Deutschkenntnisse zu verbessern, hatte er doch in den Jahren zuvor in zunehmendem Maße eine Passion für die Philosophie des deutschen Idealismus entwickelt. Nur wenig später erwarb er an der Philosophischen Fakultät der Ludwig-Maximilians-Universität zu München beim Semitisten Friedrich Hommel (gest. 1936) den akademischen Grad eines doctor philosophice $^{2}$ und kehrte nur ein Jahr später in die britische Kronkolonie zurück. Zu diesem Zeitpunkt war wohl kaum jemandem bewusst, dass dieser junge Mann zu einem der originellsten muslimischen Denker des 20. Jahrhunderts werden sollte, der Zeit seines Lebens produktiv von den Erfahrungen in Deutschland gezehrt hatte. Ebenso wenig war abzusehen, dass gerade über seine Person und sein Werk ein Tor zur Beschäftigung deutscher OrientalistInnen mit dem muslimischen Südasien aufgestoßen werden sollte. Sein Name war Muhammad Šāh Iqbāl (gest. 1938), der philosophische Poet/poetische Philosoph und Vordenker des heutigen Staates Pakistan.

Man könnte nun annehmen, dass der Bezug eines namhaften Vertreters des damals zeitgenössischen muslimischen Denkens zu Deutschland und seiner Wissenschaftstradition unmittelbar ein deutlich wahrnehmbares Interesse innerhalb

1 Ich danke von Herzen all denjenigen KollegInnen und FreundInnen, die frühere Entwürfe dieses Beitrages mit ihren kritischen Kommentaren versehen haben, oder aber auch Informationen mit mir geteilt haben.

2 Dies geschah unter interessanten Umständen: Zum einen wurde dem Aspiranten aus undurchsichtigen Gründen das reguläre Promotionsstudium in München erlassen, zum anderen wird vielfach gemunkelt, die Dissertation sei in Cambridge aus ebenso dunklen Motiven nicht angenommen worden. 
der deutschen Islamwissenschaft an der Beschäftigung mit demjenigen kulturellen Kontext geweckt hätte, aus dem der prominente Gast stammte. Dem war allerdings nicht so. Woher rührt es also, dass noch gegen Ende der 1980er Jahre sowohl international als auch innerhalb der deutschen Orientalistik beanstandet wurde, die gegenwärtige wissenschaftliche Beschäftigung mit dem muslimischen Südasien wäre allenfalls als ,stiefmütterlich` zu bezeichnen und würde der Bedeutung der Region auch für die ,traditionellen` Untersuchungsgegenstände der Islamwissenschaft keinesfalls gerecht ${ }^{3}$ Es ist meines Erachtens durchaus sinnvoll, dieser Frage offensiv nachzugehen. Insbesondere angesichts der in den letzten Jahren vorgelegten grundlegenden Arbeiten, die das ,muslimische Südasien * verstärkt ins Bewusstsein aufgeschlossener IslamwissenschaftlerInnen in Deutschland gerückt haben, scheint es mir beileibe nicht mehr nötig, diesen Untersuchungskontext gesondert zu rechtfertigen: Auf die in diesem Zusammenhang beispielsweise häufig Bezug genommene hohe Zahl an Muslimen auf dem Subkontinent, die diejenige der einzelnen arabophonen Länder um einiges übertrifft, muss meiner Ansicht nach ebenso wenig verwiesen werden wie auf die anzuerkennenden indischen Beiträge zu einer globalen muslimischen Kulturgeschichte im weitesten Sinne. Eine solch defensive Haltung hat zwar ihre Geschichte, führt - nach meinem Dafürhalten - letztlich aber nicht unbedingt zu mehr Verständnis innerhalb der akademischen Zunft, zu einem Abbau der verhärteten gegenseitigen Vorurteile, und so zu einem angemessenen Umgang mit dem Gegenstand. Vielmehr besteht die Gefahr, dass sie ihrerseits ein neues Schisma erzeugt, das sich in der Umkehrung der bisherigen ,stiefmütterlichen“ Behandlung des muslimischen Südasien durch die vor allem semitistisch orientierte deutsche Islamwissenschaft manifestiert, nämlich in der Überprivilegierung einer als besonders bedeutsam essentialisierten Region mit ihren dazugehörigen Konstituenten, wie beispielsweise der indo-muslimischen Literatursprache Urdu.

Nichtsdestotrotz ist das Unbehagen derjenigen IslamwissenschaftlerInnen, die sich in der Vergangenheit mit dem muslimischen Südasien beschäftigt haben, durchaus ernst zu nehmen und, um einer künftig konstruktiveren Auseinandersetzung mit dem Gegenstand innerhalb der deutschen Islamwissenschaft willen, in seiner Genese eingehender zu untersuchen. Erst dann wird - und einen solchen Versuch werde ich abschließend unternehmen - die Möglichkeit zu einer Neubestimmung des Standortes des Forschungsgegenstandes ,muslimisches Südasien“ eröffnet, ganz im Sinne des alten und oft gescholtenen historistischen Credo von der historia magistra vitce.

3 Vgl. z.B. J.M.S. Baljon: Religion and Thought of Shāh Wal̄ Allāh Dihlawī, 17031762, Leiden: Brill 1986, S. vii; Bert G. Fragner: „Aktuelle Fragen der historischen Erforschung der islamischen Welt", in: Sæculum 40 (1989), S. 161-165, hier S. 161f.; Helmut Reifeld: „Preface“, in: ders./Imtiaz Ahmad (Hg.), Lived Islam in South Asia. Adaption, Accomodation \& Conflict, New Delhi: Social Science Press 2004, S. vii. 


\section{Wem gehört Südasien? - Abgrenzungsprobleme I}

Die mangelhafte islamwissenschaftliche Beschäftigung mit dem indischen Subkontinent mag zu nicht geringem Teil daran liegen, dass wir es hier - trotz des bemerkenswert hohen muslimischen Anteils an der Gesamtbevölkerung - eben doch mit einer religiösen Minderheit zu tun haben, die gegenüber der Mehrheit von über $70 \%$ Hindus auch vor der Teilung der britischen Kronkolonie im Jahre 1947 recht gering wirkte. So mag man heute zwar gegen eine heuristische Taxonomie von ,Majorität-Minorität‘ oder ,Zentrum-Peripherie“ wettern, vom Standpunkt der frühen orientalistischen Wissenschaften des 19. Jahrhunderts ist die Konzentration der Islamwissenschaft auf den nahöstlichen Raum durchaus nachvollziehbar. Schließlich, und dies ist meines Erachtens eines derjenigen Probleme, aufgrund derer die Islamwissenschaft sich auch noch in jüngerer Zeit mit Forschungen zur Region Südasien schwer tut, institutionalisierte sich nahezu parallel zu ihr eine andere philologische Disziplin, deren regionaler Fokus ganz ausschließlich auf Indien lag und liegt: die Indologie.

Im Jahre 1818 wurde August Wilhelm von Schlegel (gest. 1845), Bruder des namhaften romantischen Philosophen Friedrich von Schlegel (gest. 1829), zum Professor für Literatur an die gerade erst etablierte Rheinische FriedrichWilhelms-Universität zu Bonn berufen. Dies gilt als Beginn der akademischen Indienforschung in Deutschland und begründete damit eine Wissenschaftstradition, der sich die universitäre Indologie hierzulande bis heute maßgeblich verpflichtet fühlt: ${ }^{4}$ Diejenige der philologischen Veda- und Sanskrit-Forschung. Eine solch bewusste Einengung des Untersuchungsgegenstandes ,Indien“ unterliegt einer bestimmten ideologischen Färbung, die sich nicht zuletzt den von der imperialen britischen Gelehrsamkeit des 19. Jahrhunderts hervorgebrachten Orientalismen verdankt. Dies belegt in beispielhafter Weise die 1882 erschienene und breit rezipierte Schrift India. What Can It Teach Us des bis heute in Indien wohlgelittenen Sanskrit-Philologen und Religionshistorikers Friedrich Max Müller (gest. 1900):

„Wahrlich, es gibt viele Dinge, welche Indien von uns zu lernen hat; aber es gibt andere und in einem Sinne sehr wichtige Dinge, welche auch wir von Indien lernen können. [...] Deshalb möchte ich es meinen Freunden, welche vielleicht Jahre lang in Indien gelebt haben, als Civilbeamte oder Offiziere oder Missionäre [sic] oder Kaufleute, und welche ein gut Teil mehr von jenem Lande kennen müssen, als einer, der niemals seinen Fuß auf den Boden von Âryâvarta gesetzt hat, auf einmal klar machen, dass wir von zwei ganz verschiedenen Indien reden. Ich denke besonders an Indien, wie es vor tausend, zweitausend, mag sein dreitausend Jahren war; sie denken an das Indien von heu-

4 Vgl. Ernst Windisch: Geschichte der Sanskrit-Philologie und Indischen Altertumskunde, Reprint von 1917-21, Berlin, New York: de Gruyter 1992, S. 75; HansWilm Schütte: Die Asienwissenschaften in Deutschland. Geschichte, Stand und Perspektiven, Hamburg: IFA 2002, S. 30f. 
te. Und wiederum, wenn sie an das Indien von heute denken, so erinnern sie sich hauptsächlich an das Indien von Calcutta, Bombay oder Madras, an das Indien in der Stadt. Ich blicke auf das Indien der Dorfgemeinden, das wahre Indien der Inder. ${ }^{~} 5$

Von Muslimen auf dem indischen Subkontinent, die zu Schlegels Zeiten bis zur Absetzung des Mogulmonarchen Bahādur Šāh Zafar im Zuge der Niederschlagung des Sepoy-Aufstandes von 1857/8 dort noch die nominelle Herrschaft ausübten, war hier nirgends die Rede; in der orientalistischen Diktion der Vordenker britischer Kolonialpräsenz in Indien konstituiert der Beginn muslimischer Gegenwart im Jahre 92/711 auch den Beginn des Mittelalters. Dieses ,Mittelalter “ ähnlich negativ konnotiert wie in der europäischen Periodisierung, nämlich als Epoche der Dunkelheit zwischen Antike und deren Wiederbelebung in der sogenannten ,Neuzeit ${ }^{6}$ - dauerte bis zur erwähnten Abschaffung der Mogulmonarchie in der Mitte des 19. Jahrhunderts an; ${ }^{7}$ für das Anknüpfen an die von Max Müller konstatierte ,klassische' Zeit ist die gründliche Untersuchung dieses Mittelalters allemal zu ignorieren. Folgerichtig waren denn auch eine Reihe der neuen indologischen Lehrstühle in Deutschland v.a. durch britische Gelder finanziert. $^{8}$ Die Sponsoren durften dafür eine bestimmte Ausrichtung in Forschung und Lehre erwarten und sie wurden nicht enttäuscht: Es galt das indische Altertum für die anbrechende ,neue Zeit' wiederzubeleben, und dieses bestand nun in der essentialistischen Wahrnehmung der frühen Indologen v.a. in der vedischen Kultur, dem Herzstück dessen, was als ,Hinduismus' die Diktion oftmals bis in die heutige Zeit bestimmt. ${ }^{9}$

Natürlich hat sich auch die deutsche Indologie in den vergangenen Dekaden wandeln müssen, nicht zuletzt aufgrund der unrühmlichen Rolle, die eine Reihe ihrer Vertreter während der Zeit des Nationalsozialismus gespielt und mit der sie ihre vorgeblich wertfreie, da rein philologische Wissenschaft erheblich diskreditiert hatten. ${ }^{10}$ Die Nachkriegszeit stellte neue politisch und wirtschaftlich bestimmte Anforderungen an die Indien-bezogene Forschung, was zumindest in ei-

5 Friedrich Max Müller: Indien in seiner weltgeschichtlichen Bedeutung. Vorlesungen gehalten an der Universität Cambridge, übers. v. C. Capeller, Leipzig: Engelmann 1884, S. 4-6 (Kursiva: JPH). Vgl. auch: E. Windisch: Geschichte der SanskritPhilologie, S. 293-8.

6 Vgl. Reinhart Koselleck: Vergangene Zukunft. Zur Semantik geschichtlicher Zeiten, Frankfurt/M: Suhrkamp 1979, S. 304-6.

7 Vgl. Ronald Inden: Imagining India, Oxford u.a.: Basil Blackwell 1990, S. 54f., $186 f$.

8 Vgl. H.-W. Schütte: Die Asienwissenschaften, S. 39.

9 Vgl. R. Inden: Imagining India, S. 85-127.

10 Vgl. Sheldon Pollock: „Deep Orientalism? Notes on Sanskrit and Power beyond the Raj“, in: Carol Breckenridge/Peter van der Veer (Hg.), Orientalism and the Postcolonial Predicament. Perspectives on South Asia, Philadelphia: Univ. of Pennsylvania Press 1993, S. 76-133, hier S. 86-96; H.-W. Schütte: Die Asienwissenschaften, S. 133-8. 
nem Fall auch institutionelle Konsequenzen nach sich zog: An der RuprechtKarls-Universität zu Heidelberg wurde 1962 mit dem Südasien-Institut (SAI) ein bis heute in der Bundesrepublik einzigartiges multidisziplinäres Hochschulzentrum geschaffen, das mit dem Auftrag versehen war - ausgehend vom Erbe der Indologie - erstmals auch neuindische Philologien fest zu verankern und zudem eine Reihe sozialwissenschaftlicher Fächer mit klarem Regional- und auch Gegenwartsbezug zu integrieren. ${ }^{11}$ Innerhalb dieser Disziplinen, die im Übrigen der anglophonen Südasienforschung der Nachkriegszeit entsprechen, fand nun auch erstmals das muslimische Indien eine - wenn auch bis heute noch zaghafte Würdigung.

Die etablierte Indologie allerdings, die mit 14 Lehrstühlen die deutsche Forschungslandschaft zur Region bis heute dominiert, war und ist von dieser Entwicklung nur mäßig beeindruckt. Noch 1979 waren Heinz Bechert, einstiger Ordinarius für Indologie an der Georg-August-Universität Göttingen, und Georg von Simson, zuletzt Professor an der Universität Oslo, in ihrer Einführung in die Indologie - diese wird Studierenden übrigens bis heute als Handreichung empfohlen - auf der Basis ,, allgemein anerkannter Konventionen darüber [einig], was als notwendiger Teil eines Studiums der Indologie zu gelten hat" ${ }^{\text {"12 }}$ : Es bleibt hier beim Althergebrachten, die Beschäftigung mit all den anderen möglichen Feldern der Südasien-bezogenen Forschung gilt auch heutigen IndologInnen - selbstverständlich mit einigen wenigen Ausnahmen - nicht als dem Fach zugehörig und wird nur allzu oft mit einem Naserümpfen bedacht. Dass mittlerweile an den Indologischen Seminaren der Bundesrepublik auch neuindische Sprachen, hierunter in wenigstens fünf Fällen nun sogar die Islamsprache Urdu, ${ }^{13}$ gelehrt werden, scheint lediglich ein dem Zeitgeist geschuldetes notwendiges Übel zu sein und wird von den führenden FachvertreterInnen denn auch eher en passant und allenfalls mit recht begrenztem Enthusiasmus betrieben. Studien zum muslimischen Indien sind hier jedenfalls auch weiterhin nicht hervorzubringen, zumal auch Urdu eher als eine in arabisierten Lettern geschriebene Variante des Hindi verstanden wird. $^{14}$

Anders scheint die Lage am Heidelberger SAI - allerdings leider nur auf den ersten Blick. Auch hier wird Urdu - wenn auch kontinuierlich schon über Jahre -

11 Vgl. ebd., S. 192-9.

12 Heinz Bechert/Georg von Simson (Hg.), Einführung in die Indologie. Stand - Methoden - Aufgaben, Darmstadt: WUG 1979, S. 5.

13 Vgl. Christina Oesterheld: „Problems of Teaching Urdu in Germany: A Foreigner's Reflections on the Status of Urdu“, in: The Annual of Urdu Studies 17 (2002), S. 125-137, hier S. 126.

14 Vgl. ebd., 126f. Interessanterweise wurde dieses Verständnis lange selbst von den wenigen islamwissenschaftlichen FachvertreterInnen transportiert, die bis Mitte des 20. Jahrhunderts eine begrüßenswerte Offenheit für das Urdu bewiesen haben. Vgl. Otto Spies/Ernst Bannerth: Lehrbuch der Hindūstānī-Sprache, Leipzig, Wien: Harrassowitz 1945, S. 1f. 
im Bereich Moderne Indologie in vergleichsweise geringem Umfang und zudem mit einem klaren literaturwissenschaftlichen Impetus gelehrt; die Islam-bezogene Komponente wird lediglich durch Urdu-sprachige und eher landeskundliche Texte bedient. Die für ein gründliches Studium des südasiatischen Islam relevanten Sprachen Arabisch und Persisch werden auch am SAI nicht unterrichtet, der Schwerpunkt liegt vielmehr auf einer Lese- und Kommunikationskompetenz, die zuvorderst auf ein Verständnis gegenwärtiger Entwicklungen vor allem in Pakistan abzielt, ohne auch hier den religionsbezogenen Faktor in allzu großer Tiefe würdigen zu können. Zwar wurden in den letzten Jahren vor allem in den Fachbereichen Geschichte Südasiens und Politikwissenschaften einzelne Lehrveranstaltungen mit Islam-Bezug abgehalten, diese hatten aber eher den Charakter von Überblicksveranstaltungen ohne eine ersichtliche Möglichkeit der Vertiefung in anschließenden Kursen. Eine angestrebte engere Kooperation mit der Heidelberger Orientalistik - immerhin ist Urdu dort als Zweitsprache anrechenbar, gleiches gilt vice versa für das Persische - scheiterte in der Praxis bisher insbesondere an den hohen Studienpensa in beiden Fachbereichen, was sich allerdings mit der Modularisierung der Studienpläne im Zuge des Bologna-Prozesses bald ändern könnte. Für den Moment bleibt jedoch zu konstatieren, dass auch am SAI Studien zum muslimischen Südasien bisher nicht in der Breite und vor allem Tiefe betrieben werden, wie es geboten wäre, um diesem wichtigen Bereich der Südasienforschung auch nur annähernd gerecht zu werden.

Der Fachbereich Südasienwissenschaften, der innerhalb des Instituts für Indologie und Südasienwissenschaften der Martin-Luther-Universität HalleWittenberg den neuindischen Bereich vertritt, ist der einzige mir derzeit bekannte, der sowohl in Lehre als auch Forschung auf die defizitäre Beachtung des muslimischen Südasiens reagiert hat. Dies spiegelt bereits die Möglichkeit der formalen Anerkennung von Prüfungsleistungen in relevanten Lehrveranstaltungen am Institut für Orientalistik - hier auch den Erwerb von Persisch-Sprachkenntnissen - wider. Darüber hinaus wird der Eindruck der disziplinären Offenheit auch durch die fächerübergreifende Gremien- und Herausgebertätigkeit des gegenwärtigen Lehrstuhlinhabers Rahul Peter Das gestützt, ${ }^{15}$ letztlich aber auch durch die meines Wissens in Deutschland einzigartige Forschung zum muslimischen Bengalen, die zu einer soliden Sprachausbildung im Bengali tritt. Ein in gewisser Weise ähnliches Modell wird am erst im April 2005 an der Rheinischen Friedrich-Wilhelms-Universität gegründeten ,Institut für Orient- und Asienwissenschaften“ (IOA) getestet, auf das später noch en detail eingegangen wird.

15 In diesem Zusammenhang ist das aus sechs Mitgliedern bestehende Direktorium des Orientwissenschaftlichen Zentrums der Martin-Luther-Universität Halle-Wittenberg (vgl. http://www.owz.uni-halle.de vom 24. Februar 2007), sowie die im Würzburger Ergon-Verlag erscheinende Schriftenreihe „Mitteilungen zur Sozial- und Kulturgeschichte der islamischen Welt“ (MISK) zu nennen. 
Als kleines Zwischenfazit lässt sich zunächst feststellen, dass der Bereich des muslimischen Südasien - trotz des Monopolanspruches der Indologie/Südasienwissenschaften auf die Region als Forschungsgegenstand - gar nicht, oder höchstens mangelhaft abgedeckt wird. Hinzu tritt ein Sprachproblem, denn eine seriöse Islam-bezogene Untersuchung auch des indischen Subkontinents kommt - wie oben bereits gesagt - ohne die Kenntnis des Arabischen und Persischen nicht aus; beide Sprachen wiederum gehören aber nicht zum Repertoire der südasienkundlichen Ausbildung. Hierfür würde wiederum die Islamwissenschaft verantwortlich zeichnen, doch, so die oft geäußerte Kritik, ermangelt ihr sowohl Kompetenz als auch Interesse für den indischen Subkontinent.

\section{Wem gehört der Islam? - Abgrenzungsprobleme II}

Es ist bemerkenswert, wie stark in den Darstellungen der Geschichte der deutschen Orientalistik eine Synonymie von Arabistik und Islamwissenschaft herzustellen versucht wurde. ${ }^{16}$ Dieser Umstand verweist nach meinem Dafürhalten letztlich auf eine grundlegende Denkfigur, die die Beschäftigung mit Islambezogenen Themen auf die arabophonen Traditionen beschränkt. Nun mag dies für ein Studium des frühen Islam sicher angehen, bereits aber für die Zeit der Expansion der frühen Kalifate in perso- und turkophone Regionen und die damit verbundenen kulturellen Amalgamierungsprozesse stellt sich die Frage, ob eine Kongruenz von Islam und arabischer Sprache grundsätzlich aufrechtzuerhalten ist. Die Arabistik scheint sich hier zunächst damit beholfen zu haben, dass der Fokus der Untersuchungen auf arabische, genauer sogar ,klassische“ arabische Texte gelegt wurde und vielfach auch heute noch wird. Nachbardisziplinen wie die Iranistik und die Turkologie (einschließlich der Osmanistik) erhoben, soweit ich zu sehen vermag, keinen Anspruch darauf, ebenfalls Islamwissenschaft zu sein, sondern verstanden sich insbesondere als Sprach- und Regionalwissenschaften, ${ }^{17}$ die - insbesondere im literaturwissenschaftlichen Bereich - zwar IslamBezogenes mit behandelten, allerdings keineswegs exklusiv.

Die akademische „Orientalistik (und mit ihr als wesentlicher Bestandteil die arabische Philologie)“"18 verengte also über lange Zeit hinweg den Gegenstands-

16 Vgl. z. B. Johann Fück: Die arabischen Studien in Europa bis in den Anfang des 20. Jahrhunderts, Leipzig: Harrassowitz 1955, S. 1; Hartmut Bobzin: „Geschichte der Arabischen Philologie in Europa bis zum Ausgang des achtzehnten Jahrhunderts“, in: Wolfdietrich Fischer (Hg.), Grundriß der Arabischen Philologie, Bd. 3, Wiesbaden: Reichert 1992, S. 155-187.

17 Vgl. Annemarie von Gabin (Hg.), Turkologie, Leiden, Köln: Brill 1963; Bert Fragner: ,Iranistik in Europa: Gestern, heute und morgen“, in: Heiner Eichner u.a. (Hg.), Iranistik in Europa: Gestern, heute, morgen, Wien: Verlag der Österreichischen Akademie der Wissenschaften 2006, S. 7-25.

18 H. Bobzin: Geschichte der Arabischen Philologie, S. 155. 
bereich einer Islamwissenschaft auf einen nahezu ausschließlich über arabische Texte vermittelten Islam, was meiner Überzeugung nach symptomatisch dadurch ausgedrückt wird, dass von Philosophie, Theologie, Mathematik etc. als den „,arabischen Wissenschaften“ gesprochen wird. ${ }^{19}$ Indien, um zum Kernproblem zurückzukehren, scheint für die Orientalistik und die sich aus ihr herauskristallisierende Islamwissenschaft nur insofern eine Rolle gespielt zu haben, als es insbesondere arabische Texte für die philologische Auseinandersetzung lieferte; in diesem Zusammenhang kamen denn auch südasiatische Handschriftensammlungen zu einiger Prominenz, wie sich aus Brockelmanns voluminöser Geschichte der arabischen Litteratur (1937-49) ersehen lässt. Dass Südasien lediglich als Reservoir für Arabica verschiedenster Couleur dienen sollte, die zudem nicht einmal in demjenigen lokalen Kontext verortet wurden, in dem sie gesammelt, kopiert und archiviert worden waren, rief wohl zurecht den Unmut derer hervor, die die Region stärker innerhalb der Islam-bezogenen Forschung etabliert wissen wollten. Studien über das muslimische Südasien zu fördern bedeutete ihnen nämlich auch die Förderung orientalischer Literatursprachen wie des Urdu, die der Aufnahme in den orientalistischen Kanon durch die VertreterInnen der ,klassischen Islamwissenschaft' für nicht unbedingt würdig, oder doch, wie es scheint, als höchstens nachgeordnet befunden worden waren. Dieser Umstand, der nicht zuletzt zum oben erwähnten Unbehagen gegenüber einem als absolut dominant empfundenen Arabozentrismus in der deutschen Islamwissenschaft geführt hat, konnte zunächst auch nicht durch die Wenigen getilgt werden, die das muslimische Südasien zu ihrem Gegenstand in Forschung und/oder Lehre gemacht hatten. Nichtsdestotrotz müssen gerade jene als WegbereiterInnen für die Erschließung des muslimischen Südasien als Untersuchungsgegenstand der Islamwissenschaft gelten und bedürfen deshalb einer zumindest kursorischen Betrachtung, denn in der Mehrzahl spiegelt auch ihr akademischer Werdegang die Anerkennungsproblematik dieses Gegenstandes durch die etablierte und bevorzugt um die arabische Philologie kreisende Islamwissenschaft innerhalb der deutschen Hochschullandschaft wider.

\section{Die WegbereiterInnen}

Einer der Ersten, wenn nicht der Erste überhaupt, der innerhalb der deutschen Islamwissenschaft dem muslimischen Indien ernsthafte Aufmerksamkeit schenkte, gehörte allerdings noch nicht zu den akademisch eher Marginalisierten innerhalb der islamwissenschaftlichen Zunft, sondern war im Gegenteil anerkannter Professor für Semitische Philologie und Islamkunde in Bonn. Die Rede ist von Otto Spies (gest. 1981), einem Schüler des damaligen Ordinarius für „Morgenländi-

19 Vgl. J. Fück: Die arabischen Studien, S. 322-5. 
sche Sprachen“ an der Eberhard-Karls-Universität Tübingen Enno Littmann (gest. 1958), und späterem Assistenten von Paul E. Kahle (gest. 1964) in Bonn. Als ausgewiesener Kenner des Arabischen wurde er 1932 an die Muslim University im nordindischen Aligarh berufen, ${ }^{20}$ jener namhaften Institution, die 1875 auf maßgebliche Initiative von Sir Sayyid Aḥmad Huān (gest. 1898) als „Muhammadan Anglo-Oriental College" gegründet worden war. Spies weilte vier Jahre in Indien, während derer er bereits mehrere seiner dortigen Forschungsergebnisse - insbesondere im Bereich der islamischen Geistesgeschichte - sowohl in indischen als auch deutschen Periodika publizierte. ${ }^{21}$ In Aligarh war der deutsche Gelehrte auf einen reichen arabischen und persischen Handschriftenfundus gestoßen; diese Entdeckung begann wohl die bis dahin vorherrschende islamwissenschaftliche Attitüde gegenüber dem muslimischen Subkontinent zu verändern und eine erste Sensibilität für dortige Forschungsressourcen $\mathrm{zu}$ entwickeln: Schließlich konnten diese Bestände nicht zuletzt auch zur Klärung nicht ausschließlich auf die Region bezogener Problemstellungen beitragen. ${ }^{22}$ Auch nach seinem Fortgang aus Aligarh blieb Spies ein aufmerksamer Beobachter dortiger für die deutsche Islamwissenschaft relevanter Entwicklungen, wie nicht zuletzt sein Aufsatz zu den „Arabische[n] Neuerscheinungen in Indien während der Kriegsjahre“ (Der Islam 28 (1948), S. 106-10) belegt.

Spies' Zugang zum indischen Islam war nichtsdestotrotz in allererster Linie derjenige eines arabistischen Philologen; darauf deuten auch spätere Veröffentlichungen wie Ibn Fadlallāh al-'Omarī's Bericht über Indien (1943), Indische Handschriften von Ibn Hazm's Ğamharat ansāb al-'arab (1952) oder Ein Investiturschreiben des abbasidischen Kalifen in Kairo an einen indischen König (1955) hin. Hierin ist wohl auch der Grund dafür zu suchen, dass er allzeit als Islamwissenschaftler respektiert wurde. Nichtsdestotrotz betrat Spies aber auch auf philologischem Gebiet Neuland: Unmittelbar nach Kriegsende publizierte er gemeinsam mit dem Wiener Islamwissenschaftler und Urdu-Lektor Ernst Bannerth (gest. 1976), der sich schon während des Krieges - aus welcher Motivation heraus auch immer - mit dem indischen Subkontinent auseinander gesetzt hatte, ${ }^{23}$

$20 \mathrm{Zu}$ den Umständen der Berufung von Spies nach Indien konnte ich weder im Bonner Universitätsarchiv, noch in seinem allerdings völlig ungeordneten Nachlass aufschlussreiche Informationen finden. Dies mag nicht zuletzt auch damit in Verbindung stehen, dass das Universitätsgebäude gegen Kriegsende nahezu völlig zerstört worden war und zudem Aktenbestände systematisch vernichtet wurden.

21 Vgl. Wilhelm Hoenerbach: Der Orient in der Forschung. Festschrift für Otto Spies zum 5 April 1966, Wiesbaden: Harrassowitz 1967, S. $743 f$.

22 Inwiefern Spies diesbezüglich Einfluss auf Brockelmanns Arbeit an der Geschichte der Arabischen Litteratur hatte, konnte nicht geklärt werden, ist aber durchaus vorstellbar, zumal Spies nach seiner Rückkehr aus Aligarh vorgeblich auf Wunsch Brockelmanns als Nachfolger auf dessen Lehrstuhl in Breslau berufen worden war.

$23 \mathrm{Zu}$ Bannerth vgl. die unbefriedigend kurze biographische Notiz in Ludmilla Hanisch: Die Nachfolger der Exegeten. Deutschsprachige Erforschung des Vorderen 
bei Harrassowitz das Lehrbuch der Hindūstānī-Sprache, das erste und meines Wissens bisher einzige seiner Art in Deutschland. ${ }^{24}$

Mit diesem Buch wirkte Otto Spies, der zwischen 1945 und 1952 den kriegsbedingt verwaisten Bonner orientalistischen Lehrstuhl verwaltete, bis in die Indologie hinein: Die Selbstdarstellung der heutigen Abteilung für Indologie am bereits erwähnten „Institut für Orient- und Asienwissenschaften“ (IOA) verknüpft mit dieser Arbeit den Beginn der „,modernen indischen Studien in Bonn“ “25. Dies ist sicherlich gerechtfertigt, denn gleich zu Beginn des Vorworts machen die $\mathrm{Au}-$ toren deutlich, dass ,,[d]as Studium des Hindūstān̄̄ [...] in Deutschland bisher sehr vernachlässigt worden [ist], da die Wissenschaft ein fast ausschließliches Interesse am Altindischen, besonders am Sanskrit, hatte“"26, was wiederum auf die vergleichsweise eher geringen politischen und wirtschaftlichen Beziehungen zwischen Deutschland und Indien zurückgeführt wird. Wozu also dieses Lehrbuch, dessen Erscheinen zu jenem Zeitpunkt, nach Meinung von Spies und Bannerth, „,keinerlei Rechtfertigung “27 bedurfte? Der besondere Wert dieses Buches sollte einmal mehr in der für die deutsche Orientalistik charakteristischen philologischen Systematik und Gründlichkeit liegen und damit der „Flut von Grammatiken, Lehrbüchern und besonders Sprachführern in englischer Sprache, meist von zweifelhaftem Wert“"28 ein den Standards der deutschen Orientphilologie entsprechendes Produkt entgegensetzten. Ob dieses Buch allerdings in der Islamwissenschaft der folgenden Dekaden zur Anwendung gekommen ist, ist schwer nachzuvollziehen, scheint aber - aufgrund des geringen Prestiges, das die Sprache in diesem Bereich genießt - wohl eher zweifelhaft. Nichtsdestotrotz, und das ist hier zu betonen, gelang Spies nicht zuletzt mit dieser Arbeit ein Brückenschlag zur Nachbardisziplin Indologie, und damit darf er durchaus für den Beginn einer Öffnung der Islamwissenschaft stehen, wie sie sich erst in den letzten paar Jahren deutlicher abzeichnete.

Orients in der ersten Hälfte des 20. Jahrhunderts, Wiesbaden: Harrassowitz 2003, S. 178. Ich danke Günter Windhager (Wien) für den Hinweis.

24 Für die heutige - vor allem kommunikationsorientierte - Urdu-Sprachausbildung wird allerdings kaum auf diese Arbeit zurückgegriffen, sondern Gebrauch von einer Reihe neuerer und dem Zweck eher zuträglicher englischsprachiger Lehrbücher gemacht. Die Urdu-Dozentin des SAI, Christina Oesterheld, erarbeitet gegenwärtig ein neues systematisches Urdu-Lehrbuch auf Deutsch. Vgl. C. Oesterheld: Problems of Teaching Urdu, S. 128f. Am Institut für Indische Philologie und Kunstgeschichte der FU Berlin hingegen stand das Lehrbuch von Spies und Bannerth für den UrduAnfängerkurs im Sommersemester 2006 durchaus noch zur Debatte (vgl. KVV SS 2006, LV 13 672).

$25 \mathrm{http} / / / \mathrm{www}$. indologie.uni-bonn.de/indo/start.htm\#Neuindische\%20Sprachen vom 24. Februar 2007.

26 O. Spies/E. Bannerth: Lehrbuch, S. v.

27 Ebd. Es ist auffällig, dass die Autoren hierfür allerdings keinerlei Begründung angeben.

28 Ebd. 
Vorerst aber lag die Beschäftigung mit dem muslimischen Subkontinent weiterhin außerhalb der Islamwissenschaft. Um die Brücke zu dieser zu schlagen bedurfte es möglicherweise tatsächlich eines außerhalb des Faches liegenden Impetus'. Hier ist wohl insbesondere die phänomenologisch arbeitende Religionswissenschaft zu nennen, wie sie in Deutschland insbesondere auch an der PhilippsUniversität Marburg - der einstigen Wirkungsstätte von mit diesem Ansatz in Beziehung stehenden Persönlichkeiten wie dem Philosophen Martin Heidegger und dem evangelischen Neutestamentler Rudolf Bultmann (beide gest. 1976) vertreten wurde. Es ist wohl nicht zuletzt der Einfluss des Marburger Ordinarius für Religionsgeschichte Friedrich Heiler (gest. 1967) gewesen, der in einer seiner bekanntesten Schülerinnen - Annemarie Schimmel (gest. 2003) - das Interesse an der „Nahtstelle zwischen Islam und Hinduismus“ ${ }^{\text {29 }}$ zumindest deutlich untermauert hat. So romantisch nämlich, wie Schimmel den Beginn ihrer Passion für den Subkontinent in ihren zahlreichen Selbstdarstellungen verstanden wissen will, scheint dieser de praxe nicht, zumindest nicht ausschließlich, gewesen zu sein: $\mathrm{Zu}$ deutlich sind die Parallelen zwischen Heilers bekannter Arbeit Das Gebet von 1917 und Schimmels Büchern Denn Dein ist das Reich: Gebete aus dem Islam (1978) und Dein Wille geschehe: Die schönsten islamischen Gebete (1992), oder auch der explizite Bezug auf Heilers religionsphänomenologische Arbeiten in Schimmels recht spätem Deciphering the Signs of God: A Phenomenological Approach to Islam (1994).

Noch kaum ein Jahrzehnt, bevor Annemarie Schimmel 1945 nach Marburg kam, hielt sich am dortigen Theologischen Seminar - das heute dem Fachbereich Gesellschaftswissenschaften und Philosophie zugeordnete Institut für Vergleichende Kultur- und Religionswissenschaft wurde erst kürzlich im Zuge des Bologna-Prozesses etabliert - der indische Muslim Sayyid Waḥ̄d ad-Dīn aus Hyderabad im Dekkan (gest. 1998) auf. Als einer der Letzten promovierte er dort bei Rudolf Otto (gest. 1937), der anderen Ikone der Religionsphänomenologie in Deutschland, über Indisch-Moslemische Werterlebnisse als Parallele zu europäischen Kulturwandlungen und begann nach seiner Rückkehr nach Indien eine akademische Karriere als Professor für (Religions-)Philosophie. Diese Dissertation ist, trotz der wohl dem Zeitgeist geschuldeten gelegentlichen nationalsozialistischen Diktion, von einigem Interesse für unseren Gegenstand, denn im Abschnitt zu „Irrationale[m], Religion und Mystik“ lässt Waḥīd ad-Dīn all jene Șūfīs aufmarschieren, die in Annemarie Schimmels Werk später eine zentrale Position einnehmen sollten: Ğalāl ad-Dīn Rūmī (gest. 672/1273), Farīd ad-Dīn 'Atṭār (getötet 627/1230), Mīr Dard (gest. 1199/1785), oder auch Ġawt 'Alī Šāh (gest. 1297/1880). Auch Schimmels Bezugsfiguren der europäischen Geistesgeschich-

29 Annemarie Schimmel: Auf den Spuren der Muslime. Mein Leben zwischen den Kulturen, hg. von Hartmut Bobzin/Navid Kermani, Freiburg, Basel, Wien: Herder 2002, S. 50. 
te, wie Meister Eckart (gest. 1328) und Johann Wolfgang von Goethe (gest. 1832), kommen hier zur Sprache. ${ }^{30}$ Nicht zuletzt aus diesem Grund ist es gut vorstellbar, dass über das Beziehungsdreieck ,Otto-Wahīd ad-Dīn-Heiler ‘ - Otto hatte sich mit Nachdruck für die Berufung Heilers nach Marburg verwendet - der Bezug der deutschen Religionswissenschaft zum muslimischen Südasien hergestellt worden ist. Auch wenn die autobiographischen Veröffentlichungen von Annemarie Schimmel darüber keinen Aufschluss geben, mag dies keine unwesentliche Rolle dabei gespielt haben, in ihr, die sich über Die Struktur der Militärschicht unter den späten Mamluken (1945-6) habilitierte, ein wissenschaftliches Interesse am südasiatischen Islam zu wecken. Solches ist jedenfalls abzuleiten, wenn man sich Wahīd ad-Dīns stark Sufik-geprägtes Islamverständnis vergegenwärtigt: ${ }^{31}$ Dieses nämlich korrespondiert sehr wohl mit Ottos Das Heilige (1917) und Heilers Die Bedeutung der Mystik für die Weltreligionen (1919), mag darüber hinaus aber zur nicht zuletzt auch durch das Werk Annemarie Schimmels betriebenen Essentialisierung des südasiatischen Islam als nahezu exklusiv von sufischen Tendenzen dominiert geführt haben.

Der religionswissenschaftliche Nexus scheint heute wohl für eine Beschäftigung mit dem muslimischen Südasien nicht mehr zwangsläufig vonnöten. Rückblickend ist er jedoch durchaus verständlich, denn der zu weiten Teilen nicht von arabischen Traditionen geprägte Subkontinent, der letztlich eben doch mehrheitlich von Nichtmuslimen bewohnt ist, stellte für die etablierte deutsche Islamwissenschaft jener Zeit - trotz Otto Spies - auch weiterhin ein mehr als abwegiges Forschungsgebiet dar. So war es schließlich kaum erstaunlich, dass für Annemarie Schimmel - nach einer mehrjährigen Dozentur für Religionsgeschichte in Ankara - in Deutschland lediglich die Stelle einer außerplanmäßigen Lektorin am von Otto Spies ins Leben gerufenen ,Seminar für Orientalische Sprachen bei der Universität Bonn“ bereitstand. Es ist nachvollziehbar, dass diese Situation für eine ausreichend qualifizierte Akademikerin mit einer Passion für indomuslimische Studien unbefriedigend war. So verwundert es schließlich nicht, dass Annemarie Schimmel 1970 einen Ruf auf die Professur für „Indo-Muslim Culture“ an der Harvard University annahm, die mit Geldern des afghanischstämmigen Multimillionärs und Philanthropen Uzai Durrani (gest. 1964) finanziert wurde und wird. Die USA blieben denn auch, ungeachtet ihrer mittlerweile auch in Deutschland reichlich verlegten Publikationen, bis zu ihrer Emeritierung 1992 Schimmels hauptsächliches akademisches Wirkungsfeld. Erst bei ihrer Rückkehr nach Bonn wurde die bis heute fachlich keinesfalls unumstrittene Ge-

30 Vgl. Syed Vahiduddin: Indisch-moslemische Werterlebnisse als Parallele zu europäischen Kulturwandlungen, Leipzig: J. A. Barth 1937, S. 42-55.

31 Vgl. die verschiedenen Beiträge in: ders.: „Islamic Experience in Contemporary Thought“, in: Christian W. Troll (Hg.), Islam in India. Studies and Commentaries, Bd. 3, Delhi: Chanakya Publications 1986. 
lehrte $^{32}$ für ihr Lebenswerk mit einer Honorarprofessur für Islamwissenschaft geehrt.

Die Verschlossenheit der akademischen Islamwissenschaft in Deutschland gegenüber der Erweiterung ihres Objektbereiches nach Osten hin berührte auch noch die nachfolgende Generation derjenigen, die sich mit dem Islam auf dem indischen Subkontinent beschäftigten. Christian W. Troll SJ, dem wir eine bahnbrechende Studie zum religiösen Denken Sir Sayyid Aḥmad Hुāns verdanken, kam erst in Anschluss an seine Hochschulausbildung in Deutschland, sowie intensiven Arabischstudien an der Université St. Joseph in Beirut, an der Londoner „School of African and Oriental Studies“ (SOAS) mit dem muslimischen Indien in Berührung. Dort, wo die philologische Tradition keine solche Ausprägung wie in der deutschen Orientalistik erfahren hatte und zudem - nicht zuletzt aufgrund der eigenen kolonialen Vergangenheit - ein disziplinär weniger strikt reglementierter Umgang mit außereuropäischen Kulturen gepflegt wurde und wird, studierte Troll Urdu, das zu jener Zeit an deutschen Hochschulen noch kaum erlernbar war. Im Jahre 1975 promovierte er dann unter der Aufsicht des namhaften Südasienhistorikers Peter Hardy mit der erwähnten Studie zu Sayyid Aḥmad Hān. Es ist gerade diese 1978 erstmals publizierte Arbeit, die die philologische Kompetenz eines deutschen Orientalisten, insbesondere die solide Kenntnis des Arabischen, mit einem für den deutschen Geschmack doch etwas abwegigen Gegenstand verband, und die darum einer Reihe von im anglophonen Raum hervorgebrachten Arbeiten zur indo-muslimischen Geistesgeschichte des 19. und 20. Jahrhunderts in gewisser Weise überlegen ist.

Trotzdem scheint es nicht zuletzt das Unbehagen der deutschen Islamwissenschaft mit dem Gegenstandsbereich ,muslimisches Südasien“ gewesen zu sein, das dafür verantwortlich war, dass Troll nie den Ruf auf einen islamwissenschaftlichen Lehrstuhl an einer deutschen Universität erhielt. Wie schon Annemarie Schimmel vor ihm, musste auch Troll sein berufliches Fortkommen im Ausland und dazu unter der Ägide der Religionswissenschaft suchen. Letzteres war allerdings auch mit dem Umstand verbunden, dass Troll bereits vor seiner Londoner Zeit der Societas Jesu beigetreten und sein Wirken - nicht allerdings seine akademischen Schriften - der konfessionellen Agenda des Ordens unterworfen war: Von einer langjährigen Professur für Islamische Studien am „Vidyajyoti Institute of Religious Studies“ in Neu Delhi, einer jesuitischen Hochschule, führte sein Weg über eine Senior Lecturership am „Centre for the Study of Islam and Christian-Muslim Relations (CSIS)“ der University of Birmingham zur Professur für Islamische Institutionen am „Pontificio Istituto Orientale“ in Rom. Erst

$32 \mathrm{Zu}$ einer recht massiven und oftmals in unnötiger Weise polemisch vorgetragenen Kritik an Schimmels Arbeiten zur Sufik vgl. Bernd Radtke: „Von des Chisers Händeln und schmutzigen Tricks“, in: Der Islam 81 (2004), S. 96-114; ders.: „Die unerträgliche Nettigkeit des Seins. Auch eine Konfession“, in: Neue kritische Gänge. Zu Stand und Aufgaben der Sufikforschung, Utrecht: Houtsma 2005, S. 1-25. 
nach seiner Emeritierung wurde er zum Honorarprofessor an einer deutschen Hochschule ernannt, allerdings auch hier nicht für Islamwissenschaft an einer staatlichen Einrichtung, sondern für „Islam und christlich-muslimische Begegnung" an der in der Verantwortung des Jesuitenordens stehenden PhilosophischTheologischen Hochschule St. Georgen bei Frankfurt am Main.

Der einzige mir bekannte deutsche Islamwissenschaftler aus der Generation der ,WegbereiterInnen', dessen Forschung bis in jüngere Zeit einen klar und nahezu ausschließlich auf Südasien bezogenen Fokus aufweist und der heute im Besitz eines islamwissenschaftlichen Lehrstuhls ist, ist der im Alter von drei Jahren mit seinen Eltern aus Pakistan eingewanderte Jamal Malik. Allerdings ist auch in diesem Fall die Professur in das Seminar für Religionswissenschaft an der 1994 neugegründeten Universität Erfurt eingebunden und zudem ursprünglich mit einem inhaltlichen Schwerpunkt auf Islam in Europa geschaffen worden. ${ }^{33}$ Sowohl Lehrangebot als auch Forschungsaktivitäten des Lehrstuhls verweisen nichtsdestotrotz auf Maliks ursprüngliche Präferenz für die Islambezogene Südasienforschung, wobei der religiöse Minderheitenstatus der Muslime in Südasien und gleichermaßen im Westen den Bezug zum EuropaSchwerpunkt des Lehrstuhls bildet. Dass die regionale Orientierung auf Südasien jedoch auch weiterhin keine uneingeschränkte Billigung durch insbesondere sich der Arabistik verpflichtet fühlende FachvertreterInnen erfährt, musste Malik auf unangenehme, da alles andere als kollegiale, Art und Weise erfahren, selbst, wenn die Kritik den Anschein erweckt, als bezöge sie sich in erster Linie auf die wenigstens seit den 1990er Jahren tobende innerdisziplinäre Methodendiskussion. ${ }^{34}$

Gerade hierin aber offenbart sich meines Erachtens ein springender Punkt: Durch die oben dargestellte Schwierigkeit, die Islam-bezogenen Südasienstudien einer der beiden in Betracht kommenden Philologien - der Indologie oder der Islamwissenschaft - klar zuordnen zu können, waren ihre ProtagonistInnen gezwungen, nach Alternativen zu suchen, die sie v.a. im anglophonen Raum fanden. Dort sind die Studien zum muslimischen Südasien - wie oben bereits angedeutet - einer ganzen Reihe geistes- und besonders sozialwissenschaftlicher Fä-

33 Vgl. hierzu die Selbstdarstellung des Faches auf der Homepage des Seminars für Religionswissenschaft unter: http://www.uni-erfurt.de > Fakultäten > Philosophische Fakultät $>$ Religionswissenschaft $>$ Profil, vom 24. Februar 2007.

34 Vgl. z.B. die stark polemische, als Rezension von Maliks publizierter Habilitationsschrift (Jamal Malik: Islamische Gelehrtenkultur in Nordindien. Entwicklungsgeschichte und Tendenzen am Beispiel von Lucknow, Leiden, New York, Köln: Brill 1997) getarnte Miszelle von B. Radtke: Von des Chisers Händeln; ebenso vgl. Martin Riexinger: Sanā’ullāh Amritsarī (1868-1948) und die Ahl-i Hadīs im Punjab unter britischer Herrschaft, Würzburg: Ergon 2004, S. 87-93. Auf S. 579-611 (et passim) polemisiert der Autor zudem gegen Aspekte in Maliks 1989 publizierter Dissertation (Islamisierung in Pakistan, 1977-1984. Untersuchungen zur Auflösung autochthoner Strukturen, Wiesbaden: Steiner). 
cher zugeordnet, je nach der konkreten thematischen und disziplinären Ausrichtung der einzelnen WissenschaftlerInnen. Ihren institutionell wohl prägnantesten Ausdruck - dies nur en passant - hat eine solcherart gestaltete disziplinäre Landschaft mit regionalem Bezug auf Asien und Afrika in der bereits erwähnten SOAS an der University of London gefunden. Im Zusammenhang mit der disziplinären Vielfalt der Südasien-bezogenen Studien im anglophonen Raum wird die Nähe der Arbeiten von Jamal Malik zu den heuristischen Angeboten vor allem der Sozialwissenschaften schließlich durchaus verständlich. Wagt man allerdings einen etwas gründlicheren Blick auf die im anglophonen Raum entstandenen Arbeiten zum muslimischen Südasien, die bis heute die Forschungslandschaft dominieren, so sticht eines ins Auge: Die deutsche islamwissenschaftliche Tradition verfügt durchaus über wenigstens eine Besonderheit, an der es - wie oben bereits mehrfach angedeutet - einem nicht geringen Teil der vor allem britischen und US-amerikanischen Arbeiten zum Großkomplex zu mangeln scheint und die zur Begründung der islamwissenschaftlichen Beschäftigung mit Südasien in Deutschland ins Feld geführt werden kann und sollte: eine solide philologische Kompetenz in den relevanten Islamsprachen Arabisch und Persisch, die - gepaart mit einer adäquaten Kenntnis der entsprechenden indischen Sprache(n) - den Zugang zu einer deutlich breiteren Materialbasis und damit einen stärkeren historischen und intellektuellen Tiefgang erlaubt, als dies für einen erheblichen Teil der KollegInnen im anglophonen Raum möglich ist. Es ist denn auch genau diese Stärke, die die gegenwärtige Generation von IslamwissenschaftlerInnen, die sich mit dem muslimischen Südasien befassen, ins Feld führt, und aus der sie deutlich mehr Selbstbewusstsein schöpft, als dies in der Vergangenheit der Fall war.

\section{Die ,Jungen Wilden‘}

Die gegenwärtig zum muslimischen Südasien arbeitende Generation von IslamwissenschaftlerInnen lässt sich - je nach Forschungsrichtung - grob in zwei bis drei Gruppen einteilen. Hier ist zunächst ein Kreis zu nennen, der in enger Beziehung zur Iranistik und (zentralasiatischen) Turkologie steht und sich der weiteren Erforschung des Mogulreiches zwischen dem 16. und 19. Jahrhundert widmet. Damit könnte nach meinem Dafürhalten über kurz oder lang auch das Monopol v.a. indischer Sozial- und WirtschaftshistorikerInnen der AligarhSchule (heute insbesondere der Kreis um Irfan Habib) auf diesen Themenbereich gebrochen werden und diesen Untersuchungen zudem die ihnen gebührende Anerkennung auch in der anglophonen Wissenschaftslandschaft sichern. In mehreren Fällen wurde dies durch frühere islamwissenschaftliche Arbeiten zur religiösen Herrschaftslegitimation im muslimischen Mittelasien angestoßen ${ }^{35}$ und so

35 Vgl. z.B. Jürgen Paul: Die politische und soziale Bedeutung der Naqšbandiyya in Mittelasien im 15. Jahrhundert, Berlin, New York: de Gruyter 1991; Anke von Kü- 
scheint es durchaus plausibel, dass insbesondere der Rolle der Historiographie in diesem Zusammenhang nachgegangen wurde. Aktuelle Forschungsarbeiten erweitern den Gegenstandsbereich nun um ideengeschichtliche Untersuchungen, wobei in erster Linie Projekte wie jenes zur ,Indopersischen Übersetzungsliteratur" an der Martin-Luther-Universität Halle-Wittenberg nicht ohne eine fruchtbare Kooperation mit der Indologie, ergo ohne Transdisziplinarität, auskommen kann. $^{36}$

Als ein zweiter und recht gewichtiger Themenkreis innerhalb der islamwissenschaftlichen Forschung zum muslimischen Südasien in Deutschland, der bereits eine Reihe von monographischen Arbeiten zutage gefördert hat, ist jener zur indo-muslimischen Geistesgeschichte seit dem 18. Jahrhundert zu nennen. Dieser Kreis verdankt seine Existenz zu einem nicht unerheblichen Teil den Impulsen, die von Arbeiten ausgegangen sind, die zu dieser Thematik seit den späten 1970er Jahren insbesondere im anglophonen Raum entstanden sind. Bedeutend stärker als in den v.a. US-amerikanischen Arbeiten zum indo-muslimischen Reformgelehrtentum kommt in den deutschen Studien erneut die philologische Kompetenz, insbesondere im Arabischen, zum Tragen. Dieser Umstand und neue methodische Überlegungen, wie sie z.B. zwischen 1998 und 2004 nachhaltig durch die Nachwuchsforschergruppe „Islamische Bildungsnetzwerke im lokalen und transnationalen Kontext (18.-20. Jahrhundert)“ am Seminar für Orientalistik und Islamwissenschaft der Ruhr-Universität Bochum angestellt wurden, ${ }^{37}$ sind meines Erachtens gut dazu geeignet, den Islam auf dem indischen Subkontinent seiner vermeintlichen Exklusivität zu entkleiden und zu zeigen, dass das ,,islamische Indien [...] trotz seiner regionalen und sozialen Koexistenz mit dem hinduistischen Indien ein integrierender Bestandteil der islamischen Welt gewesen [ist] und [...] sich während seiner Geschichte als zu ihr gehörig betrachtet [hat] “38. Die Einsicht in diese anhaltende wechselseitige Einflussnahme von ,indischem

gelgen: Die Legitimierung der mittelasiatischen Mangitendynastie in den Werken ihrer Historiker (18.-19. Jahrhundert), Würzburg: Ergon 2002.

$36 \mathrm{Vgl}$. http://www.indologie.uni-halle.de/forschung/indop/index.htm vom 24. Februar 2007.

37 Vgl. Michael Kemper (Hg.), Laufende Forschungsarbeiten der Nachwuchsgruppe (Volkswagen-Stiftung) Islamische Bildungsnetzwerke im lokalen und transnationalen Kontext (18.-20. Jahrhundert) am Seminar für Orientalistik und Indologie der Ruhr-Universität Bochum, Bochum: RUB 2000; ders./Bekim Agai (Hg.), Abgeschlossene und laufende Forschungsarbeiten der Nachwuchsgruppe (VolkswagenStiftung) Islamische Bildungsnetzwerke im lokalen und transnationalen Kontext (18.-20. Jahrhundert) am Seminar für Orientalistik und Indologie der RuhrUniversität Bochum, Bochum: RUB 2002; sowie: Roman Loimeier (Hg.), Die islamische Welt als Netzwerk. Möglichkeiten und Grenzen des Netzwerkansatzes im islamischen Kontext, Würzburg: Ergon 2000.

38 Aziz Ahmad: „Indien“, in: G. E. von Grunebaum (Hg.), Fischer Weltgeschichte Band 15: Der Islam II. Die islamischen Reiche nach dem Fall von Konstantinopel, Frankfurt/M: Fischer ${ }^{3} 1976$, S. 226. 
Islam ' und ,nicht-indischem Islam “ - hier sollte durchaus an die einige Dekaden zurückliegenden Einsichten von Otto Spies angeknüpft werden - erscheint mir als ein bedeutender Schritt in Richtung einer Normalisierung des Verhältnisses von Nahost- und Südasien-bezogener Forschung innerhalb der deutschen Islamwissenschaft und somit zum dringend gebotenen Abbau gewisser Vorbehalte auf der einen, und der angeführten latent defensiven Haltung auf der anderen Seite.

Schließlich sollten noch jüngere literaturwissenschaftliche Untersuchungen mit einem Fokus auf Südasien innerhalb einer weiter gefassten deutschen Islamwissenschaft Erwähnung finden, verweisen diese doch deutlich auf einen notwendigen Nexus v.a. zwischen Iranistik und neuindischer Philologie. Erneut ist es - dies nur en passant - der eingangs erwähnte Muhammad Šāh Iqbāl, der hier zum transdisziplinären Bindeglied wird, was nicht zuletzt Annemarie Schimmels intensiver Beschäftigung mit dessen Lyrik zu verdanken ist. Aktuelle Projekte zur Sufik in Südasien, wie eine unmittelbar vor ihrem Abschluss stehende Dissertation zur bisher wenig beachteten Gemeinschaft der Madārìya an der Humboldt-Universität Berlin, berühren hingegen die Schnittstelle von textorientierter Islamwissenschaft und Sozialanthropologie; darüber hinaus tragen sie zunehmend zu einer ausgewogeneren Sicht der Rolle von Sufik für muslimische Kulturen in Südasien bei und helfen so letztlich, mit der hier bisher dominierenden essentialistischen Sicht aufzuräumen. Forschungen zum modernen politischen Islam in Südasien wiederum bedürfen erneut sowohl einer breiten Sprachkompetenz als auch einer multidisziplinären Expertise, wie sie beispielhaft am Berliner Zentrum Moderner Orient (ZMO) zur Verfügung steht.

\section{Wohin soll(te) die Reise gehen?}

Ich habe den wohl nicht unbegründeten Eindruck, als gäben die gegenwärtigen Entwicklungen Anlass zu vorsichtigem Optimismus. Zunehmend wird auch dem muslimischen Südasien in der akademischen Islamwissenschaft in Deutschland eine Beachtung geschenkt, die ihm, wie oben in einiger Ausführlichkeit dargelegt, bislang weitestgehend verwehrt blieb. Diese Entwicklung mag u.a. zwar den hochschulpolitischen Veränderungen geschuldet sein, hat aber nicht zuletzt auch innerdisziplinäre Gründe. Wie immer man sich im islamwissenschaftlichen (vermeintlichen) Methodenstreit ,Philologie vs. Sozialwissenschaften " positionieren mag, fest steht, dass wir dieser mindestens seit den frühen 1990er Jahren zum Teil erbittert geführten Auseinandersetzung auch eine Neubewertung der Untersuchungsgegenstände und -kontexte des Faches zu verdanken haben. In gleichem Maße lassen sich analoge Entwicklungen aber auch in anderen sogenannten ,kleinen Fächern', in unserem Fall der Indologie, ausmachen, so dass - dies meine Hypothese - in einzelnen Bereichen über kurz oder lang eine fruchtbare Kooperation zwischen den einzelnen Disziplinen gang und gäbe sein wird, ohne dass dadurch deren jeweilige Besonderheiten gefährdet würden. Das Beispiel des 
Hallenser Forschungsprojektes zur „Indopersischen Übersetzungsliteratur“ sei in diesem Kontext erneut lobend erwähnt.

Auch der angedeutete Wandel innerhalb der akademischen Indologie, der sich nicht zuletzt in einer zunehmenden Öffnung gegenüber neuindischen Sprachen und den damit verbundenen kulturellen Spezifika manifestiert, wird einen zunehmend wichtigen Beitrag zur Verstärkung und Verbesserung der Studien zum muslimischen Südasien leisten. In diesem Zusammenhang ist insbesondere eine Förderung der Sprachfähigkeiten im Urdu, Bengali, und anderen für gezielte islamwissenschaftliche Forschung relevanten indischen Sprachen zu erwähnen, die mit einer Vermittlung regionalkundlicher Kompetenz verbunden werden sollte, wie sie bevorzugt durch die Indologie bereitgestellt werden kann. Auch dies wird über kurz oder lang zu einer Entmonopolisierung exklusiver Wissensansprüche von denjenigen vergleichsweise wenigen IslamwissenschaftlerInnen führen, die diese Sprachen heute schon beherrschen: Vermehrt werden Materialien in diesen Sprachen nach quellenkritischen Gesichtspunkten einschätzbar und damit bisher getroffene Aussagen auf dieser Basis intersubjektiv nachprüfbar. Apodiktische Aussagen, wie sie gelegentlich bis heute von den VertreterInnen der islamwissenschaftlichen Beschäftigung mit Südasien getätigt werden, können auf diese Weise relativiert und damit Tore zu neuen Untersuchungen auf der Grundlage von bisher Bestehendem - ganz im Sinne des Popper'schen Falsifikationsmodells - aufgestoßen werden.

Als ein institutionelles Novum, das nicht zuletzt auch deshalb von verschiedensten FachvertreterInnen mit großer Aufmerksamkeit bedacht wurde und wird, muss in diesem Zusammenhang auch das oben bereits kurz erwähnte Bonner „Institut für Orient- und Asienwissenschaften“ (IOA) Erwähnung finden. Hervorgegangen aus acht ehemals separat bestehenden Seminaren, knüpft das IOA zum einen an die durch Otto Spies begründete und oben angerissene Tradition interdisziplinärer Forschung und Lehre innerhalb der Regionalwissenschaften an der Rheinischen Friedrich-Wilhelms-Universität an. Zum anderen aber bildet dieses Institut das m. W. einzige Zentrum orientbezogener Lehre und Forschung in der Bundesrepublik Deutschland, das zumindest von seiner inhaltlichen Breite an die SOAS in London erinnert. Vier regionale Masterstudiengänge werden am IOA durch zwei räumlich übergreifende Angebote ergänzt und erweitert, ${ }^{39}$ von denen vor allem der Studiengang „Sprach- und Kulturwissenschaft West- und Südasiens" für die wissenschaftliche Beschäftigung mit Südasien im Allgemeinen und dem muslimischen Südasien im Besonderen von Interesse ist. ${ }^{40}$ Gerade in der Konzeption dieses Studienganges tritt der Bezug zu den wissenschaftspolitischen Bemühungen von Otto Spies in den 1950er Jahren ganz besonders zutage.

39 Vgl. http://www.asien.uni-bonn.de/www/IOA/Studium.html vom 24. Februar 2007.

$40 \mathrm{Vgl}$. http://www.asien.uni-bonn.de/www/IOA/Studium/MA_Westsued.html vom 24. Februar 2007. 
Ziel ist es nämlich, sich den geographischen Großraum, der von Anatolien bis zum indischen Subkontinent reicht und innerhalb dessen sich in einer historischen Perspektive vielfältigste Wechselbeziehungen ausmachen lassen, kulturwissenschaftlich zu erschließen und zugleich durch solide philologische Arbeit zu untermauern. Dabei wird neben dem Islam auch parallel existierenden oder auch zeitlich versetzten sinnstiftenden religiösen Lebensentwürfen, wie dem Buddhismus und Hindu-Religionen, sowie deren wechselseitiger Beeinflussung gebührend Rechnung getragen. Die Besonderheit des Masterstudienganges „Sprach- und Kulturwissenschaft West- und Südasiens“ stellt also - dies darf in meinen Augen durch eine Wiederholung bekräftigt werden - die indologischislamwissenschaftliche interdisziplinäre und zudem methodenoffene Beschäftigung mit dieser geopolitisch wichtigen Region, allerdings auf einer gediegenen philologischen Grundlage, dar.

In diesem Zusammenhang ist auch darauf hinzuweisen, dass der UrduSprachausbildung hier eine gewichtige Rolle zukommt: Integrativer Bestandteil des Masterstudienganges „Sprach- und Kulturwissenschaft West- und Südasiens“, der im Wintersemester 2007/08 anlaufen wird, werden textorientierte Urdumodule sein, die schließlich gezielt die Grundlagen schaffen sollen, im Rahmen eines Ph.D.-Programms Promotionen auf der Basis von urdusprachlichen Materialien durchzuführen. Allerdings muss einschränkend trotzdem erwähnt werden, dass durch die - aus administrativer Sicht völlig plausible - Konzentration auf das Urdu die zeitgenössischen indo-muslimischen Kulturen außerhalb dieses Sprachraumes aus der seriösen Beschäftigung mit dem muslimischen Südasien ausgeklammert sind. In diesem Zusammenhang kommt wiederum dem Fachbereich Südasienwissenschaften in Halle-Wittenberg mit einem inhaltlichen Schwerpunkt auf das muslimische Bengalen grundlegende Bedeutung zu.

Trotzdem belegt nicht zuletzt auch das hier vorgestellte Bonner Beispiel nachdrücklich die mittlerweile wohl recht weit verbreitete Einsicht, dass die Beschäftigung mit dem muslimischen Südasien, ebenso wie jegliche regionalwissenschaftliche Forschung, nicht ohne die generelle Bereitschaft auskommen kann, das ursprünglich ausschließlich philologische Instrumentarium um methodische Angebote anderer - v.a. geistes- und sozialwissenschaftlicher - Disziplinen zu erweitern. Hier kann - und wird bereits - von den KollegInnen im anglophonen Raum gelernt werden. Allerdings wäre es höchst bedauerlich, wenn ein solcher methodischer Eklektizismus zu Einbußen der philologischen Kompetenz als einem Charakteristikum der deutschen Islamwissenschaft führen würde, das in der anglophonen Academia als „Thoroughness“ bekannt, geschätzt, aber auch - möglicherweise aufgrund eigener Ressentiments - gelegentlich belächelt wird. All diese Perspektiven, die die einzelnen Disziplinen sowohl in ihrem jeweiligen Inneren verändern als auch zu einer verstärkten Öffnung aufeinander zuführen werden, werden - davon bin ich fest überzeugt - für die Islam-bezogene Forschung zu Südasien hilfreich sein. In dem Moment, wo diesem Untersuchungsgebiet entsprechende Anerkennung zuteil wird, ohne es als Marginalie sowohl 
negativ als auch positiv zu diskriminieren, wird die aus einer Verteidigungshaltung entstandene Mauer - ausgedrückt zumeist in der Betonung der Einzigartigkeit dieses Gegenstandes - fallen. Letztendlich sind ja, - dies die wohl triviale Einsicht aus einer mikrohistorischen Perspektive heraus - alle Forschungsgegenstände einmalig, seien sie ,klassische“ (arabistische) Objekte islamwissenschaftlicher Betätigung oder solche bisher eher marginalisierter Regionen und Bereiche. 


\section{Iranistik zwischen brennender Aktualität und exotischer Abseitigkeit - Gedanken zur Positionierung eines ,kleinen ${ }^{\text {' orientalistischen Faches }}{ }^{1}$}

BERT G. FRAGNER (WIEN)

„Es ist schon schrecklich, wenn einer so hungrig ist, dass er vor lauter Durst nicht weiß, wo er heute nacht schlafen wird“

(Nestroy)

Erlauben sie mir bitte, eingangs - und später, im weiteren Verlaufe meines Vortrags, immer wieder - in persönlichen Erinnerungen herum zu kramen! Wenn sich Ihnen der Eindruck aufdrängen sollte, ich hätte den Faden meines Narrativs (ein Ausdruck, der im Moment unumgänglich sein dürfte, weshalb ich ihn gleich am Anfang gezielt platziert habe) - wenn Sie also meinen, ich hätte diesen Faden verloren, tröste ich Sie schon jetzt prophylaktisch: Er taucht sicherlich wieder auf, Sie müssen nur aufpassen, wann und wo.

Nun also zu meinen Erinnerungen: In der akademischen Saison 1976/77 habe ich mich mehrere Monate unter anderem zum Behufe des Büchererwerbs in Teheran aufgehalten, um diese Bücher anschließend an das Orient-Institut der Deutschen Morgenländischen Gesellschaft in Beirut, im Libanon, weiter zu transportieren. Das war knappe zwei Jahre vor dem Ausbruch der Islamischen Revolution in Iran und circa anderthalb Jahre nach dem Ausbruch der allerersten Runde des libanesischen Bürgerkriegs. An unseren libanesischen Aufenthalt (meine Frau und unsere damals gerade gut vierjährige Tochter waren mit von der Partie) knüpfen wir viele angenehme und nicht wenige aufregende Erinnerungen. $\mathrm{Zu}$ den angenehmen zählt sicherlich der Umstand, dass wir dort die Gelegenheit hatten, Rotraud Wielandt kennen zu lernen, deren Kollege ich zwölf Jahre später (damals noch ungeahnter Weise) in Bamberg werden sollte. Ganz Beirut war von den Gräueln des Bürgerkriegs gebrandmarkt und durchsetzt. Damals bis vor Kurzem im Libanon, der angeblichen Schweiz des Vorderen Orients, noch bestanden habende Lebensformen, später von Vielen als einzigartig und nahezu paradie-

1 Text der Abschiedsvorlesung von Bert Fragner an der Universität Bamberg am 16. Januar 2006. 
sisch verklärt, waren genau so zusammen gebrochen wie das Ambiente, das sie umgab - die libanesische Kulturlandschaft, vor allem auch die Hauptstadt Beirut mit ihrem einzigartigen levantinischen Flair. Gerade aus Teheran gekommen, einer Stadt, in der ich mich schon während der sechziger Jahre fünf Jahre lang aufgehalten hatte, die mir vertraut war und die gut zu kennen ich überzeugt war, gab ich irgendwann einmal meinen Beiruter Kolleginnen und Kollegen gegenüber den Stoßseufzer von mir: ,Also in Iran - in Iran könnte eine solche Verrücktheit wie dieser Bürgerkrieg hier sicherlich nicht passieren, dort sind die Leute im Schnitt so entspannt und überlegt, die würden sich bestimmt nicht auf solcherlei einlassen!‘

Zwei Jahre später wusste ich: Ich bin nicht gut in Prognostik, und ich gestehe das auch ein. Ich gehe noch einen Schritt weiter und erlaube mir aus metawissenschaftlichen Erwägungen, auch die prognostische Kompetenz vieler anderer wissenschaftlichen Disziplinen anzuzweifeln, selbstverständlich ausgehend von meinem eigenen Defekt: In Beirut 1977 mit dem Brustton der Überzeugung zu verkünden, in Iran werde es keine derartigen Umstürze geben, weil dort die Voraussetzungen dafür nicht gegeben seien, war - jedenfalls retrospektiv - ein stolzes Wort: Etwa zwei Jahre später sollte Khomeini aus der durch alle visuellen Medien berühmt gewordenen Maschine der Fluggesellschaft ,Iranair‘, aus Paris kommend, in Teheran die Gangway hinuntersteigen, begleitet von einer Reihe von revolutionären Mitstreitern, von denen wiederum heute auf dem inzwischen ikonisierten Bild des aussteigenden Ayatollahs nur mehr zwei übrig geblieben sind - die anderen fielen im Laufe der Zeit in politische Ungnade und den Retoucheuren zum Opfer.

Da saß ich also mit meinen naseweisen Aussprüchen - gewissermaßen in guter Gesellschaft mit dem letzten österreichischen Staatssekretär des Äußeren vor dem Ende des Ersten Weltkriegs, der auf ein Exemplar der Neuen Freien Presse vom 8. November 1917 neben die Schlagzeile ,Revolution in Russland!‘ mit Bleistift die Bemerkung kritzelte: Wer soll denn in Russland Revolution machen? Vielleicht der Herr Bronstein, der im Café Zentral immer Schach spielt? Ja, mein lieber Herr, genau der war's! Der Herr Bronstein, in der Welt eher als Lev Trockij bekannt, der hat in Russland Revolution gemacht, und der Experte für die Außenpolitik hat es nicht ahnen können!

Wir waren aber beide in relativ guter Gesellschaft, wenn ich an all die hochseriösen Sozial- und Politikwissenschaftler denke, die nicht in der Lage waren, die Implosion des Sowjetimperiums und den ihr vorangegangenen Sturz von Mauer und Eisernem Vorhang vorher zu sagen, oder auch an all die prognostisch tätigen Ökonomen, die in der Vorhersage der wirtschaftlichen Entwicklung von Jahr zu Jahr oder sogar in noch kürzeren Abständen genauso versagten wie weiland Zeno in dem Gleichnis mit der Schildkröte.

Nun sei aber auch etwas zu meiner Entschuldigung gesagt: Streng genommen war ich gar nicht für derlei Spekulationen ausgebildet worden - mein orientalistisches Studium in Wien und selbst die Fortsetzung meines wissenschaftlichen 
Werdens am Orientalischen Seminar an der Universität Freiburg basierten eher auf der Annahme, unsereins habe mit den Untiefen der Gegenwart überhaupt nichts zu schaffen oder aber seien gegenwärtige Phänomene allenfalls ableitbar von festen historistischen Glaubenssätzen, denen unsereins sich zu verpflichten hatte. Einer meiner Wiener Lehrer sagte uns Studierenden einmal aus tiefer Überzeugung: „Wissen Sie - für mich hört islamische Geschichte mit dem Jahr 1258 auf!" Aus heutiger Sicht: kein weiterer Kommentar! Was die Sprachaneignung betraf, musste ich mir Sätze anhören wie: „Wir Orientalisten sind Philologen und keine Papageien! Studieren Sie erst einmal Arabisch, Persisch und Türkisch von Grund auf (das heißt also, im Wege des Trockenschwimmens), dann können Sie ja irgendwann - etwa nach Ihrer Promotion, auf Urlaub gewissermaßen - dort hinfahren und üben, wie man sich einen Kaffee bestellt!“

Ich konnte persönlich mit solchen Rezepten nichts anfangen: Ich will nicht ausschließen, dass es mir an einer Tugend mangelte, die mir in jungen Jahren als Grundvoraussetzung für eine erfolgreiche orientalistische Karriere gepredigt wurde: an disziplinierter Ausdauer, bar jeglicher nach außen gerichteter sinnlicher Interessen, und an Vermeidung jeglicher Begegnung mit dem real existierenden ,Orient', bevor nicht durch lang andauernde Indoktrination und Selbstvorbereitung ein so fest gezimmertes Orientbild im eigenen Kopf geschaffen war, dass die Wahrnehmung irgendwelcher Realitäten diesem Bild keinen Schaden mehr antun konnte. Ich hatte mich daher schon in jungen Jahren sozusagen nach Iran ,abgesetzt' um mir dort mein eigenes, sicherlich subjektives Bild zu machen, das aber immerhin den Vorzug haben sollte, nicht ausschließlich an trüben Nachmittagen mitteleuropäischer Wintersemester hinter Schreib- und Lesepulten entstanden zu sein ...

Als ich Ende 1970 nach Freiburg kam, wehte mir dort ein anderer Wind entgegen: Die frühe Neuzeit war hier immerhin erklärtes Forschungsthema, und sogar kokette Blicke in die Kulturgeschichte des 20. Jahrhunderts waren erlaubt! Vor allem aber hatten damals die islamwissenschaftlich und arabistisch ausgerichteten jungen Gelehrten Deutschlands seit den sechziger Jahren eine aus der Sicht von Außenstehenden einzigartige Gelegenheit angeboten bekommen, den wissenschaftlichen Umgang mit dem islamischen Orient einem antiquarischen, um nicht zu sagen, den Methoden der Ur- und Frühgeschichte näher stehenden Stil zu entziehen und sozusagen an Ort und Stelle zu üben, zu formen und $\mathrm{zu}$ schärfen: das schon genannte Orient-Institut der Deutschen Morgenländischen Gesellschaft, in den frühen sechziger Jahren von Hans Robert Roemer gegründet, das Jahrzehnte hindurch inzwischen schon in der Dreistelligkeit zu zählenden jungen deutschen Gelehrten die Chance geboten hatte, an den dortigen Referentenstellen wissenschaftlich tätig zu werden (,jung ' ist hier ein differenzialer Begriff: Die ReferentInnen vor vierzig Jahren waren jung, und die heutigen sind es noch immer!). Es ist heute nur noch schwer zu vermitteln, in welch hohem Maße diese Institution noch bis heute als Katalysator für die Aktualisierung der Orientwissenschaft in Deutschland gedient hatte - eine der großartigsten Investitio- 
nen der deutschen Öffentlichkeit, wenn man Aufwand und Ertrag einander gegenüberstellt. Offenbar bildete der durchschlagende Erfolg dieses Instituts, dem heute auch eine blühende Zweigstelle in Istanbul zur Seite steht, den Anlass dafür, dass die seinerzeit für Wissenschaftliches zuständige Bundesministerin Bulmahn letztlich durchsetzte, die beiden Institute aus der wissenschaftlichen Eigenbestimmung durch den zuständigen Gründungs-Fachverband in den direkten $\mathrm{Zu}$ griff einer ministeriell gesteuerten Stiftung zu überführen. Als ich in meiner damaligen Funktion als Erster Vorsitzender der Deutschen Morgenländischen Gesellschaft, also der Fachvertretung deutscher OrientalistInnen, darauf beharrte, dass es den beiden Instituten sicherlich nicht übel täte, unter wissenschaftlicher, orientalistischer Führung zu bleiben, sagte mir der mit uns verhandelnde Ministerialbeamte pikiert: „Herr Professor Fragner, Sie werden doch nicht behaupten wollen, Ihre Kollegenschaft könne derartige Forschungsinstitute besser führen als wir vom Ministerium?" Bravo; wieder kein weiterer Kommentar.

Inzwischen ist das akute Interesse des Ministeriums allerdings wieder abgeklungen, so wie Schnupfen. Das ist durchaus angenehm, wenn der Schnupfen abklingt, aber vergessen wir nicht: Der kommt irgendwann einmal wieder! Vor dem Hintergrund dieser Entwicklungen der Orientalistik in Deutschland führte die Iranistik ein seltsames Randschicksal, vor allem deshalb, weil sie ihrer Herkunft und disziplinären Definition wegen nicht so ohne weiteres in den orientalistischen ,Mainstream“ hineinpasste.

Folgen Sie mir bitte ein paar Minuten durch die Geschichte dieses Faches: Im 19. Jahrhundert war die Iranistik als ,jüngere Schwester der Indologie entstanden, in enger Umarmung mit der Indogermanistik. Ihr Thema waren die zahlreichen Sprachen, die der iranischen Sprachfamilie angehören, und die textlichen Überreste. Auslöser der Konstituierung dieser Disziplin war die Erkenntnis, dass das Altpersische der antiken achämenidischen Königsinschriften und das sogenannte ,Awestische " - die Ritualsprache der Zoroastrier (,Feueranbeter', in Indien auch ,Parsen“ genannt) gemeinsam mit dem Altindischen entwicklungsgeschichtliche Vorgänger des Altgriechischen und mithin sehr frühe Zeugen der indogermanischen Sprachfamilie waren. Einige Zeit lang hielt man das Altpersische sogar für die älteste indogermanische Sprache und ihre Sprecher, für die die Selbstbezeichnung, Arya' belegt ist, für die ältesten Indogermanen. Vor circa hundert Jahren hatte eine sehr intensive Ariomanie eine Vielzahl mitteleuropäischer Hirne erfasst, verbrämt mit allerlei esoterischem Klimbim und - was viel schlimmer war - wie vom Schimmelpilz durchsetzt von aggressiven Formen von rassistischem Antisemitismus. Aus diesen verquasten Vorstellungen ging schließlich eine Reihe unmittelbarer Vorläufer des Nationalsozialismus hervor.

Bleiben wir aber bei den im engeren Sinne, wissenschaftlichen' Betreibungen der Iranistik, soweit sich diese davon trennen lassen! Die Befassung mit den Sprachen der iranischen Verwandtschaft bildete schließlich seit der zweiten Hälfte des 19. Jahrhunderts gemeinsam mit dem Studium ihrer Texte die Substanz des Faches, das als ,Iranistik' bekannt geworden ist. Dabei erwies sich alsbald ein 
eigenartiger Widerspruch: Die in Literatur- und Kulturgeschichte zweifellos bedeutendste aller iranischen Sprachen ist das sogenannte Neupersische, oft einfach auch Persisch genannt, eine Sprache, die im Wesentlichen im 9. Jahrhundert konstituiert worden ist. Aber eben dieses Neupersische ist wiederum von allen iranischen Sprachen diejenige, die aus der Sicht der Erforscher historischer Sprachverwandtschaften über die geringste Attraktivität verfügt. Verschmitzte Dialekte und Restsprachen aus afghanischen Bergdörfern oder von den Hochplateaus des Pamir-Gebirges sind aus historisch-vergleichender Perspektive um ein Vielfaches spannender als das Neupersische, die Sprache mit einem der größten vormodernen Aufkommen an schriftlichen Überresten in der ganzen Welt! Als Kompromiss bürgerte es sich ein, das frühe Neupersische rund um das auf vorislamischen Traditionen fußende, grandiose Epos von Ferdousi, das ,Schahnameh“ (Königsbuch) gerade noch als seriösen Gegenstand der Iranistik zu betrachten; natürlich waren auch die berühmten Dichtungen der großen persischen Lyriker und Mystiker wie Hafez, Sa'di, Jalal ad-Din Rumi etc. nicht zu ignorieren. Schließlich entwickelte sich die Iranistik zweigleisig - einerseits im Gravitationsbereich der Indogermanistik, andererseits (insbesondere in Deutschland) in enger Verschränkung mit der Islamwissenschaft. Wissenschaftler wie Roemer in Freiburg oder Spuler in Hamburg waren der Ansicht, dass die auf das Neupersische konzentrierte Iranistik eigentlich Teil der Islamwissenschaft sei, wogegen aber Persönlichkeiten wie etwa Roemers und zum Teil auch Spulers Lehrer Walther Hinz stets die Meinung vertreten hatten, dass wesentliches Iranspezifisches in der islamwissenschaftlichen Umzingelung verloren gehen oder zumindest marginalisiert werde, weshalb die Aufrechterhaltung dieses Zweiges der Iranistik wichtiger sei denn je. Dazu kommt, dass außerhalb Deutschlands die islamwissenschaftliche Vereinnahmung der ,Neuiranistik“ ohnehin viel weniger drohte als hierzulande.

Dem einstigen langjährigen Vertreter der Iranistik in Hamburg, Wolfgang Lentz, kommt der Ruhm zu, sich in Westeuropa erstmals uneingeschränkt dafür eingesetzt zu haben, die Befassung auch mit dem modernen und modernsten Persischen als eine der Hauptaufgaben der Iranistik zu betrachten. Ähnliche Positionen hatte seit den späten fünfziger Jahren auch der amerikanische Iranist Richard N. Frye offensiv vertreten. Damals hatten solche Positionen den Beigeschmack, Strategien der sowjetischen Iranistik zu ähneln, die übrigens bis in die späten achtziger Jahre hinein im Westen einen sehr hohen Ruf genoss, der seit 1991 allerdings rückläufig ist. Wie auch immer: In diesen heute eher entschärften Streit bin ich vor mehr als dreieinhalb Jahrzehnten mit voller Energie hineingewachsen.

Hatte es sich dabei um einen Streit um des Kaisers Bart gehandelt? Eigentlich nicht, insbesondere, wenn wir das Nestroy'sche Motto recht bedenken, das ich dem Titel meiner heutigen Vorlesung beigesellt habe - aber dazu kommen wir noch!

Lassen Sie mich das bitte näher erläutern: Es gibt heute insgesamt fünf universitäre Institutionen in Deutschland, die das Wort ,Iranistik` in ihren offiziellen 
Bezeichnungen führen. An der FU Berlin (die Iranistik der DDR-HumboldtUniversität ist inzwischen in ,Zentralasienwissenschaften “ umgewandelt worden, ein Fach, das von der einst in Bamberg habilitierten Turkologin Ingeborg Baldauf repräsentiert wird), in Hamburg, in Göttingen, in München und in Bamberg. Berlin stammte aus einer alt- und mitteliranistischen Schule (die Mitteliranistik befasst sich mit Sprachen aus der Zeit zwischen Alexander dem Großen und der islamischen Expansion im 8. Jahrhundert), Göttingen war in den siebziger Jahren gleichfalls von Alt- und Mitteliranisten ,erobert ' worden, und für Hamburg galt das Nämliche. In München hieß der indologische Lehrstuhl bis in jüngste Zeit aus historistischer Sentimentalität ,Indologie und Iranistik', ohne dass Iranistik dort auf irgend eine Weise behandelt worden wäre, und nur Bamberg hatte von Anfang an eine klare neuiranistische Ausrichtung!

Wollten wir mithin diese Art der Iranistik in Deutschland mit der den meisten hier Anwesenden sicherlich eher geläufigen Romanistik vergleichen, entstünde folgendes Bild: An einer dieser fünf namentragenden Einrichtungen würde tatsächlich Französisch respektive Italienisch oder Spanisch betrieben. An zwei weiteren wäre die Romanistik durch klassisches Latein und frühe vulgärlateinische Studien bestimmt, ab und zu mit Ausflügen in die großen rezenten Sprachen der Romania. Das Beispiel FU Berlin wäre ein eigenartiger Ausnahmefall aus dem Zwischenreich, der eines eigenen Essays bedürfte und deshalb hier ausgespart wird. Auffällig wäre der Umstand, dass von den gegenwärtig existierenden Sprachen das für das Fach typische spracharchäologische Interesse eher durch versteckte rätoromanische oder auch aromunische und entlegene walachische Dialekte angesprochen wäre als etwa durch Diderot, Dante oder Cervantes. Schließlich würden vor allem Studierende immer wieder gegen den Widerstand der Altvorderen darauf pochen, dann und wann auch verwegen moderne Autoren wie Lorca, Sartre oder Italo Svevo zu lesen. Im Falle Münchens - immer noch unter der Vorgabe, wir würden den Begriff Iranistik durch Romanistik ersetzen - würde sich die Sache so darstellen, als hieße das dortige Seminar (in natura ,Indologie und Iranistik') ,Gräzistik und Romanistik‘, ohne dass dort irgendetwas Romanistisches betrieben würde!

Einen derartigen Vergleich hatte in den frühen achtziger Jahren der damalige Vorsitzende der Deutschen Morgenländischen Gesellschaft und spätere Ehrendoktor der Universität Bamberg Hans Robert Roemer angestellt - er wurde ihm, nicht zuletzt ob seiner Plausibilität, weithin übel genommen.

Inzwischen hat es sich an den Festungen der Tradition eingebürgert, bei Berufungen stets auch darauf zu achten, dass sich die (in Anführungszeichen) ,klassisch' ausgebildeten Kandidaten auch in irgendeinem Sektor mit Neuerem beschäftigen sollten - wenn wir noch einmal unseren Vergleich mit der Romanistik strapazieren wollen, so hieße das, man erwarte, dass die Spezialisten für Vergil, Horaz und Ovid in ihrem Oeuvre auch einen Beitrag zu Victor Hugo nachzuweisen hätten, vielleicht sogar auch in ihrer Probevorlesung ihre Kompetenz auf die- 
sem schon nahezu ,Heullebecque-haft‘ verwegenen, ,modernen ‘ Seitengleis ihres eigentlichen Faches gefällig vorführen sollten!

Diese Vergleiche mögen Ihnen abstrus vorkommen, sie treffen aber im Prinzip recht gut die lange Zeit gültigen inhaltlichen Standards des Faches Iranistik!

Dabei waren - und sind zum Teil noch heute - diese antiquarischen Konzepte nur eine der beiden schroffen Klippen, zwischen denen die Iranistik zu navigieren hat. Das zweite Problem besteht in dem Umstand, dass gerade in Deutschland das Fach ,Islamwissenschaft" - in deutlichem Kontrast zur ,Islamkunde “ Bamberger Typs! - herkömmlich und oft bis heute nicht eigentlich als eine eher religionswissenschaftliche Disziplin verstanden wird, wie es die Bezeichnung suggerieren würde, sondern als ein Fach, in dem ein großes Areal von Marokko bis wenigstens theoretisch - weit über das Indische hinaus, eben das Verbreitungsgebiet des Islams, auf der Basis der ,philologisch-historischen Methode' geisteswissenschaftlich erfasst werden sollte. So sehr dieses Konzept pragmatisch überzeugend sein mag, enthält es doch auch ernste Probleme, vor allem dieses: Die verbindende Substanz dieser Betreibungen steckt in dem semantischen Element ,Islam': Seit dem 19. Jahrhundert wird dieser - der Islam - als der kulturelle Kitt dieses Kontinente übergreifenden Areals verstanden, und seine Kenntnis sollte auch bei der Erfassung aller nur erdenklichen sozialen oder kulturellen Phänomene das methodische Rüstzeug liefern, auf das man sich zu stützen hatte - eine essentialistische Auffassung, die erstaunlicherweise islamischen Fundamentalisten gar nicht so unvertraut sein mag, und der vor etwa einem Jahr der damalige iranische Staatspräsident eine Absage erteilt hat, indem er hervorhob, dass der Begriff ,Kultur' keineswegs auf den der ,Religion` beschränkt werden dürfe und sich von Letzterem substantiell unterscheide. Davon abgesehen: de facto war, wie nicht anders zu erwarten, niemand in der Lage, die Gesamtheit dieses Gebiets in Raum, Zeit und in Methodenvielfalt zu erfassen, weshalb sich RepräsentantInnen dieser Islamwissenschaften ihre Schwerpunkte nach Neigung, Kompetenz und Fähigkeit setzten: Sprachwissenschaft, Literatur, Geschichte, Religion, Volkskunde, selbst Sozial- und/oder Politikwissenschaftliches bildeten die Themen, die von den Fächervertretern jeweils nach eigenem Gutdünken eingebracht wurden. Diese nicht anzuzweifelnde theoretische Unschärfe hatte über Generationen hinweg auch ihre ebenfalls nicht anzuzweifelnde pragmatische ZweckmäBigkeit, weil dieses nominelle Fach de facto zur nicht mehr steuerbaren Heimstätte für eine ganze Fülle von tatsächlichen Fächern werden konnte! Der lange Zeit verbreitete lässige Umgang mit der Fächertaxonomie konnte zum Beispiel meinen eigenen Ausbildungsgang zur Folge haben: Mein Wiener Promotionsfach (Hauptfach) lautete offiziell ,Turkologie und Islamwissenschaft', mein Habilitationsfach in Freiburg hieß (damals noch), Islamkunde', nach Berlin wurde ich auf eine Professur für ,Iranistik` und nach Bamberg auf eine für ,Neuiranistik` berufen. Letztere war aber die ganze Zeit hindurch der eigentliche Gegenstand meines wissenschaftlichen Tuns. 
Hieraus ergibt sich, dass es unter den ,Islamwissenschaftlerinnen“ und ,Islamwissenschaftlern " eine erkleckliche Reihe von in der Wolle gefärbten iranistischen Gelehrten gibt, die an den vorhin genannten, nominellen iranistischen Stellen kaum Unterkunft gefunden hätten! Das wäre nicht weiter schlimm, wenn nicht derartige islamwissenschaftliche Stellen grundsätzlich nicht zwingend iranistischen Inhalten zugeschrieben werden können! Das heißt, die Vertretung iranistischer Inhalte auf islamwissenschaftlichen Stellen ist ausschließlich an die jeweiligen Individuen gebunden. Als Beispiel diene wieder die einschlägige Professur für (heute) Islamwissenschaft an der Universität Freiburg: Der vor allem iranistisch und hier historisch interessierte, schon mehrmals genannte Hans Robert Roemer musste im Sinne der Denomination seines Faches auch Anderes betreiben: Er entschied sich für das spätmittelalterliche Ägypten, sozusagen sein zweites inhaltliches Standbein. Unter der Ägide seines Nachfolgers Werner Ende verschwanden die iranistischen Aspekte zusehends zugunsten von Forschungen eher religionssoziologischen, gegenwartsbezogenen Inhalts. Dessen Nachfolger wiederum wurde der in Bamberg habilitierte Turkologe Maurus Reinkowski. Etwa gleichzeitig wurde am dortigen Orientalischen Seminar eine islamwissenschaftliche Junior-Professur etabliert, die gemäß ihrer Ausschreibung einen iranistischen Schwerpunkt bedienen sollte - sie ist nunmehr befristet mit dem in Bamberg promovierten Iranisten Christoph Werner besetzt.

Wir erkennen also, dass die - nennen wir sie einmal so - ,Neuiranistik ${ }^{*}$ sich an deutschen Universitäten unter dem Gesichtspunkt inhaltlicher Affinität immer wieder erfolgreich und ganz gut im Rahmen der Islamwissenschaft da und dort und vor allem immer wieder einnisten konnte und immer noch kann. Auch hierfür haben wir ein ganz großartiges Bamberger Beispiel: Die nunmehrige Inhaberin des Bamberger Lehrstuhls für Iranistik, Birgitt Hoffmann, in Bamberg habilitiert, vertrat danach den Lehrstuhl für Islamwissenschaft in Würzburg und wurde dann auf eine gleichfalls islamwissenschaftliche Professur nach Bonn berufen. Ich glaube, dass ich meine Freude darüber nicht verhehlen muss, dass sie jetzt den Bamberger iranistischen Lehrstuhl übernommen hat! Dennoch: Bleiben wir noch ein Moment bei den iranistischen Inhabern islamwissenschaftlicher Professuren: Gelehrte auf solchen Stellen haben nur wenig Aussicht auf dauerhafte Etablierung iranistischer curricularer Nachhaltigkeit auch über ihre persönliche Präsenz hinaus - im Gegenteil: Iranistische Professorinnen und Professoren auf islamwissenschaftlichen Stellen unterliegen oft genug implizit der Nachweispflicht, dass sie auch mit Anderem befasst seien als ausschließlich mit iranistischen Themen und Diskursen. Vor allem aber: Es gibt in allen diesen Fällen keinen inhaltlichen Scheck auf die Zukunft, im Gegenteil: Es ist sogar ziemlich wahrscheinlich, dass die jeweils nachfolgenden Gelehrten die Ausrichtung ihrer Vorgänger nicht weiterführen würden!

Hierin sehen wir die Besonderheit des Bamberger Lehrstuhls für Neuiranistik mit den Feldern ,Sprache, Geschichte, Kultur bzw. Literatur', mit erwünschtem Gegenwarts- und Anwendungsbezug. De facto gibt es an keiner anderen Univer- 
sität in Deutschland eine vergleichbare Einrichtung! Die Frage stellt sich also durchaus legitim - lohnt es sich denn eigentlich, einen solchen Ausnahmefall weiter zu erhalten?

Noch ein weiteres Mal muss ich Sie in die Wissenschaftsgeschichte entführen. Iranistische und persische Studien (letzterer Ausdruck, Persian Studies, ist in Großbritannien heute noch durchaus verbreitet) waren in diversen europäischen Ländern zumindest bis zum Ersten Weltkrieg durchaus populär, zum Teil auch darüber hinaus. Von dem österreichischen Orientalisten Joseph Freiherr von Hammer-Purgstall, dessen Todestag sich heuer zum hundertfünfzigsten Male jährt, stammen nicht nur all die Übersetzungen vor allem aus persischer Lyrik, die Goethe zu seinem West-Östlichen Divan anregten. Mit seiner Rezeption eines bestimmten traditionellen Typus persischer Dichteranthologien - der ,Geschichte der schönen Redekünste Persiens" - schuf er auch einen heute immer noch verbindlichen Prototyp der Abfassung persischer Literaturgeschichte, der längst auch eine Art ,Reflux ‘ zurück nach Iran gefunden hat. Ein anderer Meister der Übersetzung, der Franke Friedrich Rückert, hat darüber hinaus zur Popularisierung orientalischer und darunter wiederum sehr viel persischer Lyrik beigetragen. In England waren die „Persian Studies“ Teil der Kolonialwissenschaft - den Engländern galt das Persische mindestens bis zum Beginn des Zwanzigsten Jahrhunderts als die wichtigste, einheimische‘ Kommunikationssprache Indiens. In der britisch-indischen Kolonialarmee konnten Offiziere den Rang eines ,Colonels' nur durch Nachweis einer erfolgreich abgelegten Persisch-Prüfung überschreiten. Das „India Office“ war das eigentliche Zentrum der Pflege der persischen Sprache in England, gleichermaßen Stätte orientalistischer Gelehrsamkeit und der Kundschafter- und Agentenausbildung. Die allgemeine Begeisterung, die in der anglophonen Welt der Dichter und Orientalist Fitzgerald mit seinen Übertragungen der Vierzeiler Omar Chayyams in den gepflegten Salons bei Jung und Alt ausgelöst hat, ist heute kaum mehr nachvollziehbar. Schließlich wurden die Fitzgerald'schen Verse in eine Fülle weiterer Sprachen übersetzt, darunter auch Arabisch, was dazu führte, dass vor allem in dem britisch stark beeinflussten Ägypten sich die allgemeine Überzeugung einwurzelte, der Genannte sei ein arabischer Dichter von Schrot und Korn gewesen. In Frankreich entfaltete sich seit den zwanziger Jahren ein philosophisch-religionswissenschaftlich angehauchter intellektueller Kult um iranische Geisteskultur islamischer wie auch vorislamischer Provenienz, die auf den iranophilen Kulturphilosophen Henry Corbin zurückgeht und heute noch späte, aber durchaus reichliche Früchte trägt. In Deutschland war die Begeisterung für Iranisches-Arisches nach 1945 in verständlicherweise rückläufig, aber es konnte schon noch geschehen, dass Anfang der fünfziger Jahre der vielseitige Orientalist und (unter anderem auch) Iranist Hans Heinrich Schaeder in einer philologischen Lehrveranstaltung über Ferdousis Königsbuch darauf beharrte, auf dem Grammophon gleichzeitig heroische Wagnerklänge als Begleitmusik abzuspielen, was von einer Reihe von Adepten durchaus goutiert worden sein soll! Eine fabelhafte Vision: Wort für Wort mühsam über- 
setzende Studierende werden von Schaeders Stentorstimme heroisch ermuntert, und dazu erschallt der Walkürenritt von einer nicht kratzfreien 78er-Schellack!

In den sechziger Jahren erkannte die damalige Regierungsriege Irans, das sogenannte ,Schah-Regime“, die Imagepflege, die von der internationalen Iranforschung für die Vermittlung des Bildes von Iran als einem uralten Kulturland weltweit ausging. Als Ergebnis dieser Entwicklung ließ sich alsbald der iranische Staat die großzügige Förderung und Pflege der internationalen Iranistik einiges Geld kosten. Das betraf vor allem ausgewählte thematische Felder wie vergleichend-historische Sprachwissenschaft, Archäologie, Kunstgeschichte, Erforschung der Geisteskultur des alten Persiens, Geschichte von Philosophie und Naturwissenschaften und Literaturgeschichte. Geschichte im engeren Sinn war weniger gefragt, dieses Fach war auch im Lande selbst seit der Mitte der fünfziger Jahre zunehmend zurückgedrängt, da dort selbst Historiker leicht in den Verdacht der Marxismusanfälligkeit geraten konnten. Dennoch: Ende der siebziger Jahre bestand ein weltweites iranistisches Netzwerk, das sicherlich nicht durch das iranische Schah-Regime kontrolliert, aber doch von ihm vielfältig unterstützt und gepflegt worden war.

Und dann kam die Islamische Revolution, und innerhalb kurzer Zeit wurde alles radikal anders.

Es gab keine Einreisevisa mehr für Iranisten. Für das revolutionäre Regime standen sie eine Zeitlang unter dem Generalverdacht der Spionage, der Verfälschung und der Betreibung von Kolonialwissenschaft. Im Westen tendierte der öffentliche Bedarf an Iranisten gegen Null: Fortan wollte über ein so unattraktiv gewordenes Land ohnehin niemand mehr etwas wissen, und über das wenige vermeintlich Wissenswerte, nämlich darüber, was jetzt gerade politisch in Iran los war, konnten die Iranisten am wenigsten Auskunft geben. Journalisten schienen viel besser informiert. Die meisten Islamwissenschaftler waren auch nicht in der Lage, die spezifisch schiitischen Aspekte der Revolution zu kommentieren, weil sich viele von ihnen in ihrer Forschung nicht eben darauf konzentriert hatten. Als besonders schlimm wurde die plötzliche Trennung vom iranischen Büchermarkt empfunden! In der Folge blieb europaweit und auch in den USA das Interesse der Studenten für Iranisches weithin aus, ganze Studiengänge, die sich noch vor wenigen Jahren erheblicher Beliebtheit erfreut hatten, drohten zu kollabieren oder kollabierten.

Diese Entwicklung hatte wiederum zur Folge, dass sich 1983 zum ersten Mal Iranforscher aus diversen (west-)europäischen Ländern in Rom zusammentaten und eine gemeinsame iranistische wissenschaftliche Gesellschaft ins Leben riefen - die „Societas Iranologica Europaea“ (S.I.E.). Nicht nur, dass sich seither die Iranistik, inzwischen um Osteuropa erweitert, ein neues, europäisches Gesicht gab und sich von nun an im Sinne des Subsidiaritätsprinzips auf eigene Ressourcen stellte. Im Rahmen der Societas wurde auch das inhaltliche Tableau dessen, was sich Iranistik nannte, zu definieren versucht. 
Dabei wurde auch zum ersten Mal ausführlich reflektiert, welche unterschiedlichen Felder innerhalb der Iranistik einzurichten seien und wie vor allem die Neuiranistik zu gestalten sei. Und es gab nicht wenige Stimmen, die zwar die Notwendigkeit der Stärkung des ,neuen“ Sektors unterstrichen, dennoch davon ausgingen, dass dieses ,Neue“ als eine Extension des klassischen ,Alten“ zu verstehen sei. Beliebte Themen, die aus diesem Diskurs hervorgingen, zielten auf nachgerade überzeitliche Kontinuität iranischer Grundmerkmale ab, in denen sich gewissermaßen noch bei Chomeini Aspekte uriranischen Dualismusdenkens etc. ablesen ließen. So hießen auch die ersten thematischen Tagungen, die durch die S.I.E. organisiert wurden: „Transition Periods in Iranian Cultures“, „Recurrant Patterns of Religious Life".

Zum Zeitpunkt der Gründung der S.I.E. war ich 41 Jahre alt - nicht eigentlich das, was man spontan als einen ,Nachwuchswissenschaftler' bezeichnen könnte dennoch entwickelte sich alsbald - ausgehend von einer Gruppe von „,founding members“ der S.I.E. - ein intensives Netzwerk von ähnlich Halbjungen, wie ich einer war, aus so gut wie allen europäischen Regionen stammend und alsbald sogar noch von amerikanischen WissenschaftlerInnen (hier ist die feminine Form tatsächlich sachlich mehr als berechtigt, weil damals nur sehr wenige Männer dabei waren). Noch vor der ,Wende“ von 1989 wurden zunehmend auch osteuropäische Fachleute angesprochen, so gut das möglich war. Ein Entwurf für die Beschaffenheit eines Faches ,Neuiranistik` nahm schnell konkrete Gestalt an, in der der philologische Umgang mit der Gegenwartssprache mit kultur-, literatur- und sprachwissenschaftlichen, historischen und gesellschaftswissenschaftlichen Ansätzen vereint werden sollte. Islamwissenschaftliche Aspekte durften nicht fehlen - im Gegenteil: Die Kenntnisse aktueller religionsbezogener Sachverhalte sollten nicht mehr länger durch reflexartige Übertragung antiquarischer Gemeinplätze etwa zoroastrischen oder manichäischen Ursprungs ins Islamische hinein die sachliche Kenntnisse des Letzteren ersetzen, wie es bei so vielen Iranisten vergangener Zeit der Fall gewesen war!

Mir persönlich - alsbald sollte sich herausstellen, keineswegs nur mir allein lag noch ein Aspekt am Herzen: Wir Iranisten neuen Schlages sollten uns auch mehr als bisher davon fernhalten, sozusagen iranische Staats- und Nationalgeschichte bzw. -kultur von außen her zu betreiben. Was wir als Wissenschaftler von außen her als ,iranisch“ bezeichneten, sollte nicht gezwungenermaßen dem entsprechen, was aus inneriranischer, vor allem aus nationalistischer Sicht die gleiche Bezeichnung führte. Diese nationalistische Perspektive hat dort, in Iran, unweigerlich zur Konsequenz, dass alle als ,iranisch“ erkannten Phänomene der modernen iranischen Staatsnation zuzuschreiben seien, woraus wiederum historistische Bilder und Imaginationen von früherer Größe Irans abgeleitet würden, die dann mit der überwiegend als von außen her verschuldet gedachten, gegenwärtigen Misere zu kontrastieren wären. Bei dieser ideologisch motivierten Sichtweise spielte es keine Rolle, ob es sich bei den jeweiligen Nationalisten um einstige Anhänger der Pahlavi-Monarchie, um solche der Islamischen Republik 
oder gar um emigrierte iranische Nationalisten handelte: Endzeitlich träumten und träumen alle davon, durch einen politischen Kraftakt diese einstige Größe wieder herzustellen - was sich übrigens an der derzeit aktuellen Verfolgung der iranischen Atomforschungspläne trefflich illustrieren lässt, die unter Regimeanhängern und Gegnern inner- und außerhalb des Landes erheblichen Zuspruch finden.

Bei dem von mir vertretenen Modell verhält es sich gerade umgekehrt: Die gemeinsame Zugehörigkeit $\mathrm{zu}$ einem größeren, historisch $\mathrm{zu}$ fassenden Kulturverband und zeitweilig auch zu einer viel weiteren Sprachgemeinschaft sollte Iran einen geschichtlich gewachsenen Platz im Kreise anderer Völker und Kulturen zuweisen - aber ohne irgendwelche Dominanzansprüche. Ein Beispiel zur Veranschaulichung: In den Kulturleistungen Indiens zur Mogulzeit (Stichwort: Taj Mahall) wollen meinesgleichen keinen kulturellen Ableger iranischer Einzigartigkeit auf indischem Boden sehen, sondern die Leistungen einer komplexen Zivilisation, die auf vielfältige Weise nicht zuletzt durch die gemeinsame lingua franca, das Persische, mit Vorderasien und Zentralasien kommunikativ verbunden war, ein Zustand der sich gerade im Prozess der Modernisierung (im Gefolge der Kolonialherrschaft etc.) aufgelöst und verflüchtigt hat. Aus einem viele Jahrhunderte bestandenen Kreis eng miteinander verbundener Kulturen sind heute meines Erachtens vereinzelte Nationalkulturen geworden, die mit den anderen eher durch weltweit gemeinsame Globalisierungsprozesse einander wieder nahe rücken als durch die Wiederanknüpfung von inzwischen gekappten, einstigen kulturellen Kompatibilitäten.

Diskussionen über derartige Themen über viele Ländergrenzen hinweg mit Gleichgesinnten zu führen, habe ich stets genossen, und ich genieße die daraus erwachsene internationale Verbundenheit mit so vielen Kolleginnen und Kollegen, von denen nicht wenige Freunde wurden, bis heute. Diese Diskussionen trugen aber auch dazu bei, dass derartige Themen zunehmend zu Fachinhalten wurden, beziehungsweise als solche anerkannt wurden.

Vier Jahre lang habe ich mich mit begrenztem Erfolg um die Etablierung eines solchen Modells an der Freien Universität Berlin bemüht, wohin ich 1985 berufen worden war. Immer noch erschien mir das der Einladung zu diesem Vortrag beigesellte Nestroy-Zitat die hauptsächliche Bedrohung unserer wissenschaftlichen Programmatik zu beschreiben: Wie können wir denn eine zum Teil neue Ausrichtung eines Faches, die international von wachsendem Konsens getragen wird, auch seriös absichern, wenn wir nur von der Hand in den Mund leben, wenn wir auf keine Budget-Sicherheit zurückgreifen können und uns nicht in einer angemessenen disziplinären Einbettung durch die entsprechenden Nachbarfächer aufgehoben fühlen können - wenn wir also, um mit Nestroy zu sprechen: „so hungrig sind, dass wir vor lauter Durst nicht wissen, wo wir heute nacht schlafen werden?“ Dazu bedarf es nicht nur finanzieller Möglichkeiten, sondern auch der organisatorischen Bereitschaft durch eine Universität, für aus- 
reichende Nachhaltigkeit zu sorgen, damit ein derartiges Programm implantiert werden könne.

Während der letzten anderthalb Jahrzehnte hat die Universität Bamberg genau das ermöglicht. Die hier bestehenden organisatorischen und planerischen Rahmenbedingungen erlaubten mir, ,mein“ Iranistik-Programm Zug um Zug umzusetzen. Das wäre selbst unter den günstigsten Verhältnissen nie möglich gewesen, wenn ich nicht zweierlei Glück gehabt hätte: Zum einen das Glück, während meiner Bamberger Jahre mit einer gar nicht so kleinen Anzahl von vor allem Mitarbeiterinnen, aber selbstverständlich auch von Kollegen von der maskulinen Seite zusammen arbeiten zu dürfen, wodurch die nachgerade modellhafte Entfaltung der Bamberger Iranistik erst machbar geworden ist.

Das ,zweite Glück‘ ist sowohl struktureller als auch personeller Natur: Die disziplinäre Zusammensetzung der Bamberger Orientalistik ist optimal konzipiert: drei philologisch determinierte Fächer mit kulturwissenschaftlicher Dimension stehen den Fächern Islamkunde und Islamische Kunstgeschichte und Archäologie zur Seite - ich hätte mir manchmal noch einschlägige Ethnologen, Soziologen und/oder Politikwissenschaftler in diesen Verbund hinein gewünscht, aber das ist eine andere Geschichte. Der personelle Aspekt dieses zweiten Glücks besteht in der hervorragenden zwischenmenschlichen Atmosphäre, die in der $\mathrm{Zu}$ sammenarbeit mit den Fachvertreterinnen und -vertretern dieser Schwesterfächer geherrscht hat. Vielen Dank!

Das alles wäre nicht möglich gewesen ohne eine Universität und innerhalb ihrer einer Fakultät, die dazu bereit waren, sich ein solches unübliches Konglomerat zu wünschen, es planen und implantieren zu lassen und ungeachtet zeitweilig turbulenter Dynamik uns Orientalisten und innerhalb derer wiederum den Iranisten eine verlässliche Heimstatt zu bieten und sich - so hoffe ich - von Zeit zu Zeit sogar darüber zu freuen, dass wir hier sind! Hier ist es so weit, den einleitenden Nestroy einer Antithese zu unterwerfen: Bamberg ist in den letzten zwei Jahrzehnten einer der raren Plätze geworden, wo ein derartiges orientalistisches Konzept ohne permanenten Hunger und Durst gedeihen kann und auch weiß, wo es nachts seinen Kopf zu betten hat. 



\section{Afrika in der deutschen Islamwissenschaft}

ROMAN LOIMEIER (BERLIN)

Als Edward Said im Jahre 1978 seine berühmte Polemik Orientalism veröffentlichte, schloss er den deutschen und, implizit, österreichischen Orientalismus aus seiner Kritik ausdrücklich aus. ${ }^{1}$ Unter ,Orientalismus ‘ verstand Said dabei natürlich nicht nur die akademische Disziplin, sondern auch und insbesondere eine spezifische Art des Denkens, das in essentialistischen Kategorien zwischen dem ,Westen“ oder der ,westlichen (abendländischen) Zivilisation“ und einer Konstruktion des ,Anderen “ unterschied, das unter der Kategorie ,Orient` zusammengefasst wurde. Saids Argumentation, dass nämlich der deutschsprachige Orientalismus nicht auf dieselbe Stufe wie der britische und französische Orientalismus gestellt werden solle, obwohl auch der deutschsprachige Orientalismus immer versucht hätte, ,intellektuelle Autorität“ über den Orient auszuüben, gründete dabei zunächst auf der Annahme, dass das Konzept des ,Orients“ Resultat eines spezifisch britischen und französischen kulturellen Projekts war, das wiederum mit den imperialen Verwicklungen dieser beiden Länder im Orient verbunden war. Zum anderen vertrat Said die Ansicht, dass die islamischen Länder im späten 19. und frühen 20. Jahrhundert fast ausschließlich durch Großbritannien und Frankreich kolonisiert worden waren und seit dem Zweiten Weltkrieg von den politischen Interessen der USA beherrscht wurden.

Nun war der akademische deutschsprachige Orientalismus in der Tat erst seit dem Ende des 19. Jahrhunderts an den zeitgenössischen Gesellschaften des Orients und des islamischen Afrika interessiert und nach dem Ersten Weltkrieg verschwanden das islamische Afrika und der zeitgenössische Orient wieder weitgehend in der Versenkung orientalistischen Desinteresses, bis in den 1960er Jahren im deutschsprachigen Raum eine erneute, wenn auch zunächst marginale Beschäftigung mit dem zeitgenössischen Orient und, noch marginaler, mit dem islamischen (subsaharischen) Afrika begann. Insbesondere in Bezug auf das islamische Afrika muss zudem gesagt werden, dass die deutschsprachige Islamwis-

1 Vgl. Edward Said: Orientalism, Harmondsworth: Penguin 1978/1995, S. 2f.; siehe hierzu auch Sarah Roche-Mahdi: ,The Cultural and Intellectual Background of German Orientalism“, in: Azim Nanji (Hg.), Mapping Islamic Studies. Genealogy, Continuity and Change, Den Haag: Mouton de Gruyter 1997, S. 108-127. 
senschaft zwar immer die Existenz von Muslimen im subsaharischen Afrika registrierte. In den Augen der deutschsprachigen Orientalistik - und ich spreche hier ausdrücklich über die Orientalistik und nicht die Beiträge von Afrikanisten wie Westermann oder Meinhof, ${ }^{2}$ von Missionaren wie Klamroth oder von Ethnologen wie Frobenius und Baumann - spielten die subsaharischen afrikanischen Muslime aber keine nennenswerte Rolle bei der Entwicklung des Islam, weil sie scheinbar nur wenige Texte produziert hatten, die es wert waren, etwa in Carl Brockelmanns Geschichte der arabischen Litteratur aufgenommen zu werden. Diese Annahme kann wohl inzwischen durch die ersten Bände der Arabic Literature of Africa als widerlegt gelten. ${ }^{3}$

Aber selbst wenn in der deutschsprachigen Islamwissenschaft die muslimischen Gesellschaften des Maghrib, des Sudan und des subsaharischen Afrika bis heute als marginal und ,eigentliches' Feld etwa der Ethnologie angesehen wird, stellt sich doch die Frage, warum sich die deutschsprachige Islamwissenschaft zu diesen großen ,islamischen ‘ Regionen (mit der Ausnahme Ägyptens) bis vor kurzem nicht oder kaum äußerte, von einigen wenigen frühen Schriften von Wüstenfeld $^{4}$ und Ignaz Goldziher ${ }^{5}$ einmal abgesehen. Hier kann nur vermutet werden, dass die koloniale Eroberung Nordafrikas und seine Aufteilung in die französischen Kolonialgebiete und Protektorate Mauretanien, Marokko, Algerien und Tunesien, das spanische Marokko und Westsahara-Gebiet und die italienischen Kolonien in Tripolitanien, im Fezzan und der Cyrenaika für die deutschsprachige islamwissenschaftliche Forschung seit dem Ende des 19. Jahrhunderts bis zur Zeit der indépendances dieser Länder in den späten 1950er Jahren eine kontinuierliche Forschung ausschloss. In der Tat erwuchs - aus dieser Zeit der europäischen Kolonialherrschaft in Nordafrika im 20. Jahrhundert - im deutschsprachigen Raum lediglich die Übersetzung von Ibn Haldūns Muqaddima durch Franz Rosenthal, ${ }^{6}$ die freilich erst 1967 im amerikanischen Exil veröffentlicht wurde.

2 Aus Platzgründen ist es leider nicht möglich, das Gesamtwerk der genannten Autoren oder auch nur einen Teil ihres umfangreichen Oeuvres in der Bibliographie zu erfassen. Diese beschränkt sich daher auf die für die Argumentation des Beitrags zentralen Schriften sowie einige weiterführende Werke. Ein umfassender Überblick über die zumindest jüngere deutschsprachige islamwissenschaftliche Literatur zum islamischen Afrika (Maghribländer, Sudan, subsaharisches Afrika) ist in Werner Ende/Udo Steinbach (Hg.), Der Islam in der Gegenwart, München: C.H. Beck 2005, zu finden.

3 Vgl. John Hunwick (Hg.), The Writings of Central Sudanic Africa. Arabic Literature of Africa, Bd. 2, Leiden: Brill 1995 und Sean R. O'Fahey (Hg.), The Writings of Eastern Sudanic Africa. Arabic Literature of Africa, Bd. 1, Leiden: Brill 1994.

4 Ferdinand Wüstenfeld: Geschichte des Fatimiden Chalifates, Göttingen 1880/1881.

5 Ignaz Goldziher: „Muhammad Ibn Toumert et la théologie de 1'Islam dans le Maghreb au XIème siècle“, in: Jean-Dominique Luciani (Hg.), Le Livre de Muhammad Ibn Toumert, Algier 1903.

6 Franz Rosenthal: The Muqaddimah. An Introduction to History, 3 Bde., Princeton: Princeton University Press 1967. 
Bemühungen einer politischen Instrumentalisierung der nordafrikanischen Muslime für den Afrika-Feldzug Rommels zwischen 1941 und 1943 scheiterten nicht nur an der Kurzlebigkeit dieses Unternehmens, sondern auch an dem dünnen Personal- und Wissensstand der nationalsozialistischen Orientalistik, was die Maghribländer anging.

Dagegen entwickelte sich gleichzeitig insbesondere in Frankreich eine sehr umfangreiche Forschungstradition zum islamischen Nord- (und Westafrika), deren inhaltliche Ausrichtung bis in die 1980er Jahre von anerkannten Historikern, Geographen, Orientalisten, Ethnologen und Soziologen wie Ageron, Berque, Bourdieu, Braudel, Brunschvig, Etienne, Gautier, Golvin, Jamous, Julien, LéviProvencal, Le Tourneau, Terasse, Valensi oder Vatin bestimmt wurde und die in der Tat im Saidschen Sinne als ,paradigmen-bildend ' für die französische Sicht und Interpretation des ,französischen Orients ‘ bezeichnet werden kann. Ihre wissenschaftliche und gesellschaftliche Anerkennung war aber nicht nur mit dem französischen kolonialen (und ,zivilisatorischen') Projekt in Nord- und Westafrika verbunden, sondern auch mit der Tatsache, dass sich in Frankreich eine Tradition ,mediterraner' Studien entwickelt hatte, die auch das islamische Nordafrika einschloss. Viele Arbeiten der französischen Orientalisten zum islamischen Nordafrika wie etwa Louis Rinns Marabouts et Khouans ${ }^{7}$ können geradezu als Schlüsseltexte einer weiterführenden Wissenschaftstradition angesehen werden, die auch in anderen französisch-islamischen Kolonialgebieten (zunächst vor allem im Senegal und Mauretanien, später im gesamten ,französischen Soudan“) meinungsbildend war. Nach den indépendances der späten 1950er Jahre etablierte sich aber auch die anglophone Orientalistik im islamischen Nordafrika. Insbesondere die Arbeiten von Brown, Cornell, Dunn, Eickelman, Evans-Pritchard, Geertz, Gellner, Rosen, Stewart und Waterbury wären hier zu nennen.

Erst in den 1960er Jahren hat dagegen die deutschsprachige Orientalistik begonnen, im islamischen Nordafrika, im Sudan und im subsaharischen Afrika Fuß zu fassen, obwohl sich zu diesen Regionen bisher keine wirklich geschlossene Forschungstradition entwickeln konnte, zu unterschiedlich waren bisher die Forschungsinteressen einzelner Schulen. Den Anfang deutschsprachiger Arbeiten zu den islamischen Gesellschaften Nordafrikas (mit Mauretanien und dem Raum der Sahara) machten dabei die Studien von Clausen, Ebert, Haarmann, Johansen, Mattes, Müller, Oßwald, Rebstock, Singer, von Sivers und Spittler, ${ }^{8}$ ebenso die ,algerische (politikwissenschaftliche) Gruppe“ von Elsenhans, Faath, Nestvogel

7 Louis Rinn: Marabouts et Khouans, Étude sur 1'Islam en Algérie, Algier: Adolphe Jourdan 1884.

8 Zahlreiche Arbeiten zu den islamischen Gesellschaften Afrikas stammen in der Tat nicht von ,Islamwissenschaftlern', sondern von Ethnologen, Politikwissenschaftlern oder Geographen. Jedoch ist es auch hier aus Platzgründen nicht möglich, einen umfassenden Überblick über diese Fachliteraturen zu geben, die nur in Teilen Bezüge $\mathrm{zu}$ islamwissenschaftlichen Fragestellungen aufweisen. 
und Ruf, sowie Halms umfangreiche Geschichte der Fatimiden, die weithin Anerkennung, insbesondere auch im anglophonen Raum, gefunden hat. Seit den 1980er Jahren bildete sich zudem an der Universität Bayreuth unter Abun-Nasr ein Forschungsschwerpunkt zum islamischen Nord- und Westafrika heraus, aus dem nicht nur die Arbeiten von Abun-Nasr selbst hervorgingen, sondern auch Studien von Elger und Kogelmann mit einem ausgesprochenen MarokkoSchwerpunkt. In diesem regionalen Kontext wären auch die jüngeren Arbeiten von Dennerlein, Hegasy und Kraus sowie die Arbeiten der ,Erlanger Schule` der Geographie von Eugen Wirth mit Anton Escher zu nennen.

Ähnliches kann wohl für die Entwicklung der deutschsprachigen Forschung zum Sudan gesagt werden, der zwar bereits im späten 19. Jahrhundert romantische Anerkennung in den Schriften von Rudolph Slatin Pascha und Karl May (siehe unten) erfuhr, im 20. Jahrhundert dann aber ebenfalls in der Versenkung wissenschaftlichen Desinteresses an zeitgenössischer Forschung verschwand. Erst seit den 1960er Jahren haben die Forschungen von Beck, Herzog, Hofheinz, Köndgen, Mattes, Oevermann, Seesemann, Streck oder Tetzlaff dafür gesorgt, dass der Sudan in der deutschsprachigen Islamwissenschaft und benachbarten Fächern als nicht ganz abseitiges Forschungsgebiet anerkannt wurde. Auf Grund dieser jüngeren Entwicklungen kann inzwischen gesagt werden, dass sich die deutschsprachige Orientalistik in Bezug auf die Maghrib-Länder und den Sudan aus dem wissenschaftlichen Nichts in eine respektable Regionaltradition verwandelt hat, auch wenn diese Arbeiten häufig noch nicht die Anerkennung erfahren, die ihnen eigentlich gebührt. Aber dies ist wohl ein Schicksal der Orientalistik als solcher. Dennoch leidet die Herausbildung eines Forschungs- und Lehrschwerpunkts, islamisches Afrika' bis heute daran, dass sich in der deutschsprachigen Orientalistik seit dem Ende des 19. Jahrhunderts eine wohl vor allem realpolitische Fokussierung auf das Osmanische Reich, die spätere Türkei, Iran sowie Mittelasien und die sogenannten ,islamischen Kernländer (Ägypten, Syrien, arabische Halbinsel) ergeben hat, welche die Beschäftigung mit anderen Räumen der islamischen Welt immer noch als ,marginal ‘ erscheinen lässt.

Obwohl sich nun zumindest in Bezug auf die Maghrib-Länder und den Sudan so etwas wie eine neuere deutschsprachige Forschungstradition in den Sozialund Geisteswissenschaft im Allgemeinen und der Islamwissenschaft im Besonderen entwickelt hat, gilt dies noch kaum für die islamischen Gesellschaften des subsaharischen Afrika, ${ }^{9}$ obwohl sich gerade zum subsaharischen islamischen Afrika, verbunden mit dem Namen Carl Heinrich Becker (siehe unten), vor dem ersten Weltkrieg tatsächlich Ansätze einer an gegenwartsbewogenen Fragestel-

9 Für das subsaharische Afrika wären für die jüngere Zeit (seit den 1970er Jahren) jedoch die Arbeiten von Abun-Nasr, Desplat, Forstner, Günther, Kogelmann, Kropp, Loimeier, Müller, Muth, Reichmuth, Rotter und Seesemann zu nennen. Auch diese Auflistung kann aus Gründen des Platzmangels nicht den Anspruch der Vollständigkeit erheben. 
lungen interessierten deutschsprachigen Islamwissenschaft herausgebildet hatten, die allerdings nach 1918/1919 zu einem abrupten Ende kamen. Die bis heute wirkende Marginalität des islamischen (subsaharischen) Afrika könnte nun als ein trauriges Symbol der Vernachlässigung der intellektuellen Leistungen der afrikanischen Muslime durch die deutschsprachige Orientalistik gesehen werden. Die marginale Rolle des subsaharischen islamischen Afrika in der deutschsprachigen Islamwissenschaft könnte aber auch als Merkmal einer umfassenderen orientalistischen Grundhaltung gesehen werden, der zu Folge ,wir (die Orientalisten) definieren, wie wir die ,anderen' (in diesem Falle die afrikanischen Muslime) sehen. Ich möchte daher im Folgenden im Rahmen einer kritischen Analyse der Entwicklung der deutschsprachigen Orientalistik seit dem späten 19. Jahrhundert ${ }^{10}$ in Bezug auf das islamische (subsaharische) Afrika einige der zentralen Thesen Edward Saids überprüfen.

Zunächst einmal sollte festgehalten werden, dass eben nicht nur Frankreich und Großbritannien, sondern auch Deutschland Kolonien mit bedeutenden muslimischen Bevölkerungsanteilen im subsaharischen Afrika erworben hatte, nämlich Togo, Kamerun und Deutsch-Ostafrika. Österreich-Ungarn, aber auch Deutschland hatten zudem beträchtliche Einflusszonen im osmanischen Reich und anderen islamischen Ländern wie Marokko, Ägypten oder Sudan kultiviert. ${ }^{11}$ Diese kolonialen bzw. imperialen Interessen fanden durchaus ihren Widerhall in den Schriften der Wissenschaftler. Dabei sollte beachtet werden, dass auch die französische und britische Orientalistik bis zum Ersten Weltkrieg noch kaum mit substanziellen Arbeiten zum zeitgenössischen Islam in Afrika oder zu islamischen Gesellschaften im Allgemeinen hervorgetreten war. Bereits an diesem Punkt muss somit Edward Said widersprochen und betont werden, dass sich der deutschsprachige akademische Orientalismus zumindest bis zu diesem Zeitpunkt kaum vom britischen oder französischen akademischen Orientalismus unterschied, ${ }^{12}$ und zwar in Bezug auf Charakter, Qualität und öffentliche Wirkung. ${ }^{13}$

10 Vgl. Sabine Mangold: Eine „,weltbürgerliche Wissenschaft“ - Die deutsche Orientalistik im 19. Jahrhundert, Wiesbaden: Franz Steiner Verlag 2004.

$11 \mathrm{Zu}$ den österreichisch-ungarischen kolonialen Bestrebungen vgl. Michael Zach: Österreicher im Sudan von 1820 bis 1914, Wien: Veröffentlichungen des Instituts für Afrikanistik und Ägyptologie der Universität Wien 1985 und Dorothea McEwan: Habsburg als Schutzmacht der Katholiken in Ägypten, Kairo: Schriften des österreichischen Kulturinstituts Kairo 1982; zu Deutschland vgl. Hans-Ulrich Wehler: Bismarck und der Imperialismus, Frankfurt/M: Fischer Verlag 1985.

12 Zur französischen orientalistischen Forschung im subsaharischen Afrika vgl. Christopher Harrison: France and Islam in West Africa, 1860-1960, Cambridge: Cambridge University Press 1988; zum britischen Kolonialreich vgl. Michael Crowder: West Africa under Colonial Rule, London: Hutchinson University Library for Africa 1968/82.

13 Vgl. E. Said: Orientalism, S. 3f. und 17f.; zu spezifischen Erscheinungsformen des österreichischen Orientalismus vgl. Andre Gingrich: „Österreichische Identitäten und Orientbilder. Eine ethnologische Kritik“, in: Walter Dostal/Helmuth Nieder- 
Die öffentliche Wirkung nicht-akademisch begründeter orientalistischer Kategorien im deutschsprachigen Raum im 19. Jahrhundert erschließt sich aber auch, wenn wir uns den Einfluss einer Reihe literarischer Arbeiten betrachten, die zwar, was ihre Perzeption des Orients angeht, recht unterschiedlicher Natur sind, die aber die deutschsprachige bürgerliche Kultur des 19. Jahrhunderts maßgeblich geprägt haben. Besonders deutlich wird der öffentliche Einfluss orientalistischer Klischees in Hinblick auf die Werke Karl Mays, die in Nordafrika (Durch die Wüste) oder im Sudan (Im Reiche des Mahdi) spielen und die die Abenteuer des deutsch-österreichischen Helden Kara ben Nemsi und seines trotteligen muslimischen Begleiters Hadschi Halef Omar ben Hadschi Abul Abbas ibn Hadschi Dawud al-Gossarah zum Inhalt haben. ${ }^{14}$ In Zusammenhang mit der Wirkung der Arbeiten von Karl May zum Orient und zum islamischen Afrika ist auf den österreichisch-ungarischen Armeeoffizier Rudolf Slatin Pascha hinzuweisen, der in ägyptischen und später britisch-ägyptischen Diensten im Sudan diente, Gouverneur der Provinz Darfur wurde und schließlich als Gefangener des Mahdī und seines Nachfolgers 'Abdallāh die Entwicklung der Mahdiyya im Sudan prominent miterlebte. Sein zweibändiger Erfahrungsbericht Feuer und Schwert im Sudan ${ }^{15}$ hatte nicht nur großen Erfolg als literarisches Werk, sondern wurde unmittelbar nach der Zerschlagung des mahdistischen Staates im Sudan im Jahre 1898 auch die wichtigste externe Quelle zur Geschichte der Mahdiyya. Feuer und Schwert im Sudan inspirierte nachhaltig Karl May, der, auf den Aufzeichnungen von Rudolf Slatin Pascha aufbauend, seine Sudan-Trilogie unter dem Titel Im Lande des Mahdi veröffentlichte. Orientalisierende Konzepte fanden sich aber auch in den pseudo-orientalischen Salon-Moden des 19. Jahrhunderts oder in der Aufmerksamkeit, die deutschen und österreichisch-ungarischen Entdeckungsreisenden im 19. Jahrhundert zuteil wurde: Heinrich Barth, Gustav Nachtigal, Georg Schweinfurth oder Samuel Graf Teleky. ${ }^{16}$

Schließlich sollten wir nicht vergessen, dass die Auseinandersetzungen im Kontext des Ersten Weltkriegs eine Reihe von Kriegshelden hervorbrachte, die in den 1920er Jahren das Genre des Abenteuerromans anregten und von großer Be-

le/Karl R. Wernhart (Hg.), Wir und die Anderen. Islam, Literatur und Migration, Wien: Wiener Universitätsverlag 1999, S. 29-34.

14 Vgl. Karin Hörner: „Das Islambild der Deutschen: Von Goethe bis Karl May“, in: Gernot Rotter (Hg.), Die Welten des Islam, Frankfurt/M: Fischer Verlag 1993, S. 206-210 und Petra Kappert: Europa und der Orient, in: Jochen Hippler und Andrea Lueg (Hg.), Feindbild Islam, Hamburg: Konkret Literatur Verlag 1993, S. 44-76.

15 Rudolph Slatin: Feuer und Schwert im Sudan, Leipzig: F. A. Brockhaus 1895/1922.

$16 \mathrm{Zu}$ Teleky vgl. Erich Woldan: „Österreichische Forscher in Ostafrika und ihre Publikationen“, in: Abenteuer Ostafrika. Der Anteil Österreich-Ungarns an der Erforschung Ostafrikas, Eisenstadt: Amt der Burgenländischen Landesregierung 1988, S. 125-8 und Günther Hamann: „Ein Überblick über die Geschichte der Erforschung des nordöstlichen und östlichen Afrikas“, in: Abenteuer Ostafrika. Der Anteil Österreich-Ungarns an der Erforschung Ostafrikas, Eisenstadt: Amt der Burgenländischen Landesregierung 1988, S. 81-124. 
deutung für die Verklärung afrikanisch-orientalischer Kriegsabenteuer waren. Wir müssen hierbei nicht nur an den wohl berühmtesten dieser ,Helden “ des orientalischen Wüstenkrieges denken, Lawrence of Arabia, oder den deutschen „Helden“ des Afrika-Krieges par excellence, Paul von Lettow-Vorbeck und seine ,treuen' (muslimischen) Askaris, sondern sollten auch Agenten, Diplomaten und Abenteurer wie den deutschen Konsul Wilhelm Wassmuss in Teheran berücksichtigen, der auf Grund seiner wagemutigen Aktionen in Persien im Ersten Weltkrieg zu einem wichtigen Bezugspunkt deutsch-orientalistischer Folklore in den 1920er Jahren wurde. Wassmuss hatte 1915 erfolgreich den Widerstand einiger Stämme gegen die britische Besetzung des südlichen Persien organisiert, während ein anderes deutsches Kommando unter der Führung von Hauptmann Oskar von Niedermayer ebenfalls 1915 die britischen Linien in Ostpersien durchbrach und das neutrale Afghanistan erreichte, wo von Niedermayer, wenn auch vergeblich, den afghanischen Herrscher dazu zu bewegen ersuchte, den Briten in Indien den ğihād zu erklären. ${ }^{17}$

Wenn wir uns nun wieder dem akademischen deutschsprachigen Orientalismus des späten 19. und frühen 20. Jahrhunderts zuwenden, so könnten wir natürlich zunächst betonen, dass sich dieser Orientalismus, wie auch der französische, niederländische und britische im 18. und 19. Jahrhundert, in Verbindung mit christlichen Bibelstudien und kulturhistorischen Denkmustern im Bereich der Geschichtswissenschaft entwickelt hatte. ${ }^{18}$ Diese, vor allem philologische, Tradition des akademischen deutschsprachigen Orientalismus ist jedoch bereits ausführlich beschrieben worden. Es ist daher nicht nötig, ein weiteres Mal auf die Leistungen herausragender Gelehrter wie Ignaz Goldziher, Julius Wellhausen und Theodor Nöldeke einzugehen. ${ }^{19}$ Der deutschsprachige akademische Orientalismus hat aber auch, wie der britische, niederländische und französische, einige

17 Vgl. Gustav von Grunebaum: Der Islam II: Die islamischen Reiche nach dem Fall von Konstantinopel, Frankfurt/M: Fischer Verlag 1982, S. 201; Christopher Sykes: Wassmuss, the German Lawrence, New York: Longmans, Green\&Co. 1936 und Peter Hopkirk: On Secret Service East of Constantinople, Oxford: Oxford University Press 1994.

18 Vgl. Johann Fück: Die arabischen Studien in Europa bis in den Anfang des 20. Jahrhunderts, Leipzig: Otto Harrassowitz 1955.

19 Vgl. hierzu J. Fück: Die arabischen Studien in Europa; Jacques Waardenburg: The Study of Islam in German Scholarship, in: Azim Nanji (Hg.), Mapping Islamic Studies. Genealogy, Continuity and Change, Den Haag: Mouton de Gruyter, 1997, S. 132; Holger Preissler: Die Anfänge der Deutschen Morgenländischen Gesellschaft, Göttingen 1995 [Erweiterter Sonderdruck aus der ZDMG, Band 145/2]; Rudi Paret: Arabistik und Islamkunde an deutschen Universitäten. Deutsche Orientalisten seit Theodor Nöldeke, Wiesbaden: Otto Harrassowitz 1966; Hichem Djait: L'Europe et l'Islam, Paris: Seuil 1978 oder Josef van Ess: „From Wellhausen to Becker. The Emergence of Kulturgeschichte in Islamic studies“, in: Malcom H. Kerr (Hg.), Islamic Studies: A tradition and its Problems, Malibu: Undena Publications 1980, S. 27-51. 
Forscherpersönlichkeiten hervorgebracht, die sich nicht mehr nur auf einen philologischen und historischen Ansatz konzentrierten, sondern darüber hinaus die Islam- und Kolonialpolitik Deutschlands bzw. Österreich-Ungarns aufmerksam beobachteten, kommentierten und zum Teil von den Erfahrungen deutschsprachiger Kolonialbeamter oder Armeeoffiziere in kolonialen Diensten profitierten und die schließlich eine gegenwartsbezogene Forschung zum Islam in den deutschen und österreichisch-ungarischen Kolonien und Einflusszonen betrieben und daraus die Forderung ableiteten, eine neue, sozialwissenschaftlich orientierte Islamwissenschaft zu entwickeln.

Der eigentliche Durchbruch eines ,modernen“ akademischen, deutschsprachigen Orientalismus, der nicht mehr allein auf philologische und historische Studien ausgerichtet war, sondern auch soziale, politische und wirtschaftliche Entwicklungen der damals gegenwärtigen islamischen Welt berücksichtigte, wird heute allgemein mit dem Namen Carl Heinrich Becker (1876-1933) verbunden. ${ }^{20}$ Becker hatte seit 1908 den neu eingerichteten Lehrstuhl für die „Geschichte und Kulturen des Orients“ am Deutschen Kolonial-Institut in Hamburg inne und publizierte in dieser Funktion zahlreiche Schriften zu den religiösen und aktuellpolitischen Verhältnissen im Osmanischen Reich, in Nordafrika, aber auch in den deutschen Kolonien. ${ }^{21}$ So veröffentlichte er im Jahre 1911 nach einer Reise nach Deutsch-Ostafrika eine Studie zum Islam in Deutsch-Ostafrika, die unter dem Titel Materialien zur Kenntnis des Islam in Deutsch-Ostafrika zunächst in der Zeitschrift Der Islam (Band 2, 1-48) und später in seinen gesammelten Schriften, den Islamstudien (Band II), erschien und bis heute ein wichtiges Referenzwerk zum Islam in Ostafrika darstellt. $^{22}$

Die Materialien zur Kenntnis des Islam in Deutsch-Ostafrika wurden in einem spezifischen Kontext verfasst: $\mathrm{Zu}$ Beginn des 20. Jahrhunderts entstand nämlich in Deutschland die von Missionaren geschürte Befürchtung, dass es in den Kolonien zunehmend ,Probleme mit dem Islam ' gäbe. ${ }^{23}$ Eine Reihe von antikolonialen Aufständen wie Maji-Maji in Deutsch-Ostafrika im Jahre 1904/05, eine Mekka-Brief-Affäre in Togo im Jahre 1905 und später in Deutsch-Ostafrika

20 Vgl. Angelika Hartmann/Konrad Schliephake: Angewandte interdisziplinäre Orientforschung, Hamburg: Deutsches Orient-Institut Hamburg 1991; Hellmut Ritter: „Carl Heinrich Becker als Orientalist“, in: Der Islam 24 (1937), S. 175-85, sowie Cornelia Essner/Gerd Winkelhane: „Carl Heinrich Becker (1876-1933). Orientalist und Kulturpolitiker“, in: Die Welt des Islams 28 (1988), S. 154-77.

21 Vgl. Baber Johansen: „Politics and Scholarship: The Development of Islamic Studies in the Federal Republic of Germany", in: Tareq Y. Ismael (Hg.), Middle East Studies. International Perspectives on the State of the Art, New York: Praeger 1990, S. 71-130, hier S. 88.

22 Carl Heinrich Becker: „Materialien zur Kenntnis des Islam in Deutsch-Ostafrika“, in: Der Islam 2 (1911), S. 1-48.

23 Vgl. Holger Weiss: „German Images of Islam in West Africa“, in: Sudanic Africa 11 (2000), S. 53-94. 
im Jahre 1908, sowie mahdistische Aufstände im nördlichen Kamerun im Jahre 1907 schienen diese Befürchtungen zu bestätigen. In der Folge wurde der Islam bereits beim Deutschen Kolonial-Kongreß im Jahre 1905 in Berlin zu einem zentralen Thema und im Jahre 1908 finanzierte die Deutsche Reichsregierung drei Untersuchungen zum Stand der Dinge in Bezug auf den Islam in den Kolonien. Diese Untersuchungen wurden in der Tat durchgeführt, und zwar von Carl Heinrich Becker in Deutsch-Ostafrika im Jahre 1908/09, von Martin Hartmann in Kamerun im Jahre 1911 und von Dietrich Westermann in Togo im Jahre 1913. ${ }^{24}$ Diese Untersuchungen, insbesondere Beckers Untersuchung in DeutschOstafrika, zeigten, dass der Islam in den deutschen Kolonien in der Tat beträchtlichen Einfluss erlangt hatte. Dennoch erklärte Becker zum Verdruss zahlreicher Missionare, dass der Islam zwar eine Gefahr für die weitere Missionierung, keineswegs aber eine Bedrohung der deutschen Kolonialherrschaft darstelle. ${ }^{25}$ Vielmehr müsse überlegt werden, ob der Islam nicht sogar als ein Weg zur „Förderung der Zivilisation“ der Afrikaner angesehen und entsprechend behandelt werden solle. ${ }^{26}$ Becker wiederholte diese Einschätzung in einer Reihe seiner Beiträge zum Islam in Afrika, wie Staat und Mission in der Islamfrage (1910), wo er zudem erste Ideen bezüglich einer spezifisch deutschen ,Islampolitik' in den Kolonien entwickelte, die wiederum direkt von französischen Überlegungen in dieser Richtung beeinflusst waren: Becker zitierte explizit die Arbeit des französischen Kolonialoffiziers und Orientalisten Alain Quellien. ${ }^{27}$

Unter anderem schlug Becker vor, nach britischem Vorbild die Autorität der einheimischen Herrscher zu stärken, wobei er vor allem an die Sultane, Lamidos und Jumben des nördlichen Kameruns und Deutsch-Ostafrikas dachte. ${ }^{28}$ Des Weiteren betonte er die Notwendigkeit, sich aus religiösen Fragen herauszuhalten, eine genaue Kenntnis des Islam in den Kolonien und, damit verbunden, eine genaue ,wissenschaftliche Aufnahme des Islam und seiner lokalen Gestaltung“ zu erlangen. ${ }^{29}$ Darauf aufbauend sollte dann wiederum eine ,strenge Aufsicht des Islam“ erfolgen. Gleichzeitig sollte den Muslimen aber auch Autonomie in bestimmten Teilen der Rechtsprechung, insbesondere im Ehe- und Familienrecht und in Bezug auf die religiösen Stiftungen zugestanden werden, wobei die Frage der Polygamie ,nach österreichischem Vorbild gelöst werden könnte“ ${ }^{30} \mathrm{Im}$ Be-

24 Vgl. ebd., auch was die deutsche Kolonialpolitik angeht; spezifisch zu DeutschOstafrika vgl. John Iliffe: Tanganyika under German Rule 1905-1912, Cambridge: Cambridge University Press 1969.

25 Carl Heinrich Becker: Islamstudien. Vom Werden und Wesen der islamischen Welt, 2 Bde., Leipzig: Quelle \& Meyer, Band 2, S. 176.

26 Ebd., S. 185.

27 Alain Quellien: La politique musulmane dans l'Afrique Occidentale Française, Paris Emile: Larose 1910; Siehe dazu auch C. H. Becker: Islamstudien II, S. 215.

28 C. H. Becker: Islamstudien II, S. 179.

29 Ebd., S. 186.

30 Ebd., S. 223. 
reich des Erziehungswesens sollte ein staatliches Schulwesen aufgebaut werden, das, dem Einfluss der Missionsorganisationen entzogen, religionslos gehalten sein sollte. ${ }^{31}$ Die Verwaltungspolitik sollte schließlich eine Trennung zwischen islamischen Gebieten und „Missionsgebieten“ anstreben, in denen etwa die „Erbauung von Moscheen und die Niederlassung von Waalimus [religiöse Gelehrte, RL] kurzerhand verboten werden“ sollte, während die Kolonialverwaltung in den islamischen Gebieten wiederum strikte Neutralität wahren sollte, „höchstens ein väterliches, passives Wohlwollen betätigen, ohne aber den Islam anders als durch Zuführung von Bildung und durch Schutz vor Ausbeutung zu fördern“. ${ }^{32}$

Beckers Aktivitäten waren jedoch nicht auf den Islam in Afrika fokussiert, obwohl er zu diesem Thema mindestens dreizehn Beiträge verfasste. Er befasste sich auch ausführlich mit den deutsch-osmanischen (später: deutsch-türkischen) Beziehungen und verfasste so im Jahre 1914, bei Beginn des Ersten Weltkriegs, eine Abhandlung mit dem Titel Deutschland und der Islam, die nicht in die Islamstudien aufgenommen wurde, und in der er einige Perspektiven in Bezug auf mögliche deutsche Kriegsstrategien unter besonderer Berücksichtigung des Islams entwickelte. Insbesondere unterstrich er die Bedeutung eines deutschosmanischen Bündnisses, dessen Inhalt letztendlich die Zerschlagung der französischen, britischen und russischen kolonialen Herrschaft über die Muslime, insbesondere in Französisch-Nordafrika, Ägypten, Britisch-Indien und RussischMittelasien, sein sollte. Diese Idee erweckte den Zorn seines Freundes Snouck Hurgronje und führte zu einer erbitterten Auseinandersetzung zwischen den beiden Islamwissenschaftlern noch im Kriege. ${ }^{33}$ In dem von Becker entwickelten Szenario einer deutsch-osmanisch-muslimischen Allianz spielten jedoch die Muslime Afrikas keine nennenswerte Rolle mehr; die Beziehungen zum Osmanischen Reich genossen Vorrang:

„Der Kernpunkt unserer Beziehungen zum Islam ist unser Verhältnis zur Türkei [...]. Die paar Millionen Mohammedaner, die wir in die Zeit unserer Türkenpolitik schon mit hineinbrachten - in Ostafrika und am Tschadsee -, haben wir natürlich behalten, aber sie spielen als Negermuslime oder als Mohammedaner der Peripherie in dieser großen Frage keine Rolle. Wie richtig unsere auf Kolonialerwerb in Negergebieten, aber reine Wirtschafts- und Kulturpolitik in Islamgebieten abzielende Reichspolitik war, zeigt die in mehrfacher Hinsicht charakteristische Äußerung eines türkischen Journalisten und Abgeordneten, der einst zum Verfasser sagte: ,Deutschland kann deshalb der Freund der Türkei sein, weil es keine mohammedanischen Untertanen in seinen Kolonien hat. “ ${ }^{3} 4$

31 Ebd.

32 Ebd., S. 225.

33 Ebd., S. 281f.

34 Carl Heinrich Becker: Deutschland und der Islam, Stuttgart: Deutsche Verlagsanstalt 1914. 
Neben Carl Heinrich Becker könnten wir aber auch die Namen anderer deutschsprachiger Orientalisten wie Martin Hartmann (1851-1918), Gotthelf Bergsträsser (1886-1933), Eugen Mittwoch (1876-1942), Franz Babinger (1891-1967) und insbesondere Alois Musil (1868-1944) nennen, die sich ebenfalls darum bemühten, eine neue Tradition der Islamwissenschaft zu etablieren, ${ }^{35}$ auch wenn ihre Bemühungen, etwa im Falle Martin Hartmanns, auf weitgehende Ablehnung in der etablierten Orientalistik stießen, was allerdings weniger mit Martin Hartmanns Versuchen, soziologische Denkansätze in die Orientalistik einzubringen, zusammenhing, als vielmehr mit seiner erratischen Persönlichkeit und seinem seltsamen wissenschaftlichen Stil. ${ }^{36}$ In Gegensatz zu den früheren, vor allem historisch und philologisch orientierten Orientalisten, die, mit der Ausnahme Ignaz Goldzihers, die Länder und Menschen ihrer Forschungsinteressen meist nicht aus persönlicher Anschauung kannten, reisten diese jüngeren Islamwissenschaftler ausgiebig in den Ländern des Orients, waren für sozialwissenschaftliche Fragestellungen aufgeschlossen, und arbeiteten zum Teil sogar, wie Eugen Mittwoch, für die Orientabteilung des Deutschen Nachrichtendienstes, wodurch sie aktiv zu den deutschen Kriegsanstrengungen im Ersten Weltkrieg beitrugen. ${ }^{37}$ Insbesondere der bereits oben erwähnte Alois Musil ${ }^{38}$ zeichnete sich durch seine umfangreiche Reise- und Feldforschungsaktivitäten aus, mit denen er für die deutschsprachige Orientalistik neue Maßstäbe setzte.

Musil, ein austro-ungarischer Tscheche aus Olmütz, der seit 1898 in seinen Forschungsarbeiten von der Universität Wien (genauer: der Wiener Akademie) unterstützt wurde, nach dem Ersten Weltkrieg allerdings nach Prag übersiedelte, kann auf Grund seiner ausgedehnten Reisen in den Ländern des Fruchtbaren Halbmonds und insbesondere auf Grund seines einjährigen Forschungsaufenthaltes unter den nordarabischen Rwala-Beduinen im Jahre 1908/09 (seine Aufzeichnungen hierzu erschienen im Jahre 1928 unter dem Titel The Manners and Customs of the Rwala Bedouins) als vermutlich der erste Wissenschaftler angesehen werden, der bewusst moderne ethnologische Feldforschungsmethoden praktizierte, und dies Jahre, bevor ein anderer Bürger der k.u.k. Monarchie, nämlich Bronislaw Malinowski, im Rahmen seiner Internierung auf den Trobriand-Inseln dazu gezwungen wurde, sich die Zeit mit ethnologischen Feldstudien zu vertreiben.

Der eigentliche Bruch des deutschsprachigen akademischen Orientalismus mit ähnlichen Entwicklungslinien des französischen und britischen akademischen

35 Vgl. J. Fück: Die arabischen Studien in Europa und Klaus Kreiser (Hg.), „,The Early Twentieth Century and its Impact on Oriental and Turkish Studies“, in: Die Welt des Islams, Sondernummer 38 (1998).

36 Siehe hierzu die Laudatio Martin Hartmanns durch C. H. Becker: Islamstudien, II, S. 481f.

37 Ludmilla Hanisch: Ausgegrenzte Kompetenz. Porträts vertriebener Orientalisten und Orientalistinnen 1933-1945, Halle: Orientwissenschaftliches Zentrum der MartinLuther Universität Wittenberg-Halle 2001, S. 63.

38 Siehe zu ihm J. Fück: Die arabischen Studien in Europa, S. 260f. 
Orientalismus erfolgte daher erst nach dem Ersten Weltkrieg, als Deutschland seine Kolonien verloren hatte, als die Verbündeten des Deutsches Reiches, insbesondere das Osmanische Reich territorial zerschlagen und in alliierte Einflusszonen aufgeteilt wurden, und als auch Österreich seine historischen Einflusszonen auf dem Balkan, im Osmanischen Reich, in Ägypten und im Sudan verlor. Das Ende der imperialen Pläne Deutschlands und Österreich-Ungarns erwies sich somit als kontraproduktiv für die Bemühungen Carl Heinrich Beckers, eine ,moderne', sozialwissenschaftliche und möglicherweise bereits auch ethnologische und politikwissenschaftliche Tradition innerhalb der deutschsprachigen Orientalistik zu entwickeln: Für eine solche Ausrichtung gab es schlicht und einfach keinen Bedarf mehr. Zynisch gesprochen führte das Ende der deutschen und österreichisch-ungarischen imperialen Bestrebungen also dazu, dass Deutschland und Österreich ihrer historischen Chancen beraubt wurden, einen nach französischem und britischem Vorbild ,normalen', wenn auch zunächst kolonial motivierten, Orientalismus zu entwickeln, der dereinst der Kritik Edward Saids würdig sein sollte.

Es soll hier nun natürlich nicht gesagt werden, dass es besser gewesen wäre, wenn Deutschland und Österreich-Ungarn ihre Kolonien und imperialen Einflussräume behalten und so ihre Chance bewahrt hätten, eine Art von französischen oder britischen Kolonial-Orientalismus zu entwickeln, der sich später durch die Arbeiten eines Evans-Pritchard oder Jacques Berque auszeichnen sollte. Auf der anderen Seite sollte aber auch nicht vergessen werden, dass sich die französischen, britischen und amerikanischen orientalistischen Disziplinen heute von ihrem kolonialen Erbe emanzipiert und sich zu modernen Fächern entwickelt haben, auf die die einst berechtigte Kritik Edward Saids kaum noch zutrifft. In der Tat haben sich die französischen, britischen, amerikanischen und skandinavischen Islamwissenschaften heute zu modernen akademischen Fächern entwickelt, die von Denkern wie Marshall Hodgson, Albert Hourani, Maxime Rodinson, Fredrik Barth oder Talal Asad geprägt sind, deren Ideen und Schriften nicht nur für die orientalistischen Disziplinen von zentraler Bedeutung geworden sind, sondern die über die orientalistischen Fächer hinaus wirken und die Gesellschafts-, Geistes- und Kulturwissenschaften insgesamt beeinflusst haben. Dennoch soll hier nun auch nicht die Meinung vertreten werden, dass der westliche Orientalismus vollkommen überwunden ist: Gerade in Krisenphasen erheben sich alte orientalistische Konzeptionen wie Zombies aus ihren Gräbern und werden Teil neo-orientalistischer Entwürfe, die, wie Samuel Huntingtons Konzept eines ,Clash of Civilisations ', den Islam und die Muslime essentialisieren und für die Konstruktion von Feindbildern politisch instrumentalisieren.

Der deutschsprachige Sonderweg, d.h. der deutsche und österreichische Rückzug in historische und philologische Studien, wurde jedoch unglücklicherweise nach 1933 bzw. nach 1938 verstärkt, als zahlreiche deutschsprachige Orientalisten jüdischer wie auch nicht-jüdischer Abstammung und häufig linker oder liberaler weltanschaulicher Orientierung emigrierten oder in die Emigration ge- 
zwungen wurden, aus ihren Hochschulpositionen entlassen und zum Teil auch durch das Nazi-Regime ermordet wurden. Auf diese Art und Weise verlor die deutsche und österreichische Orientalistik, eine Disziplin, die sowieso nie besonders groß und zudem auf Grund ihrer Beschäftigung mit den ,Semiten“ bei den Nazis nicht besonders populär war, mehr als sechzig herausragende Wissenschaftler wie Joseph Schacht (1902-1969), der bereits erwähnte Eugen Mittwoch (1876-1942), Franz Rosenthal (1914-2003), Karl Wittvogel (1896-1988) oder Gustav von Grünebaum (1909-72), alles Gelehrte, die in ihren neuen Heimatländern, insbesondere Großbritannien und den USA, beträchtlich zur Entwicklung der dortigen Fachdisziplin beitrugen. ${ }^{39}$ Die Politik Nazi-Deutschlands bewog zudem die meisten der verbliebenen Orientalisten im deutschsprachigen Raum zu einem noch konsequenteren, wenn auch verständlichen Rückzug in den Elfenbeinturm philologischer Studien, während eine im Vergleich zu anderen Fächern vergleichsweise kleine Minderheit bereit war, mit dem Nazi-Regime zusammenzuarbeiten oder sogar aktiv an der Nazi-Politik mitzuwirken. ${ }^{40}$ Diese Politik zielte etwa darauf ab, den palästinensischen Führer Hajj Amin al-Husseini gegen die britische Politik im Nahen Osten zu instrumentalisieren und beinhaltete den Aufbau pro-deutscher muslimischer Armeeeinheiten für den Krieg im Balkan wie auch im Osten, wo krimtatarische Einheiten, die sogenannten (sechs), Tatarenbatallione', auf deutscher Seite gegen russische Partisanen auf der Krim kämpften. ${ }^{41}$ Auch nach dem Zweiten Weltkrieg zeichnete sich die deutschsprachige Orientalistik zunächst durch ihre Konzentration auf ,unpolitische“ philologische und historische Studien und ihre heilige Scheu vor jeder Art von Beschäftigung mit den zeitgenössischen Gesellschaften der islamischen Welt aus. Lediglich Walter Braune und später Fritz Steppat in Berlin dürften in dieser Zeit Ausnahmen von der Regel dargestellt haben. Hans Heinrich Schaeder, einer der wenigen überlebenden Schüler Beckers, konnte so berechtigterweise im Jahre 1946 erklären:

„Die orientalischen Studien können leicht so angelegt werden, dass sie sich mit lauter Dingen befassen, die dem täglichen Leben und seinem Anliegen so fern liegen wie möglich. Man betreibt sie für gewöhnlich allein oder im kleinsten Kreise, mit einem Mindestmaß von Gemeinsamkeit und Austausch. Grund genug dafür, dass die Hingabe

39 Siehe dazu L. Hanisch: Ausgegrenzte Kompetenz und K. Kreiser: The Early Twentieth Century.

40 Vgl. Ekkehard Ellinger: Deutsche Orientalistik zur Zeit des Nationalsozialismus 1933-1945, Berlin: deux mondes 2006.

41 Siehe dazu Helga Baumgarten: Palästina: Befreiung in den Staat, Frankfurt/M: Suhrkamp 1991, S. 36; B. Johansen: Politics and Scholarship, S. 91, sowie Ann Sheehy: „Krimtataren und Meschier. Massenbewegung für Rückkehr“, in: pogrom 26 (1974), S. $10 f$. 
an diese Studien einer Flucht aus der Wirklichkeit nahe kommen kann und jedenfalls dazu angetan ist, Sonderlinge zu züchten. “42

Erst die 1960er Jahre brachten eine langsame und bescheidene Veränderung der Entwicklung zunächst der westdeutschen Islamwissenschaft. Bereits im Jahre 1960 hatte ein Bericht der Deutschen Forschungsgemeinschaft zur Lage der deutschen orientalistischen Fächer empfohlen, 32 neue Lehrstühle einzurichten, die von den etablierten ,semitischen Studien“ abgetrennt werden und sich auf ,islamwissenschaftliche Fragestellungen“ konzentrieren sollten und zwar besonders auf die islamischen Gesellschaften der Gegenwart. ${ }^{43}$ Im Jahre 1972 waren aber, wie die Deutsche Morgenländische Gesellschaft zugeben musste, erst 21 dieser neuen Lehrstühle eingerichtet worden und nur drei von ihnen hatten eine Ausrichtung auf die Beschäftigung mit dem Islam in der Gegenwart erhalten. Seither hat sich diese Situation nicht mehr entscheidend verändert, auch wenn Jacques Waardenburg diese Entwicklung etwas weniger drastisch schildert: Seit 1972, so Waardenburg im Jahre 1997, habe die Situation ,improved slightly““ ${ }^{4}$

Die leichten Veränderungen in Aufbau und Ausrichtung des deutschsprachigen Orientalismus waren erneut mit den politischen Entwicklungen seit den 1960er Jahren verbunden: ${ }^{45}$ Zunächst einmal erkannten die westdeutsche wie auch die österreichische Regierung die gewachsene Bedeutung der ölproduzierenden Staaten des Nahen Ostens an. Zum Zweiten versuchten sowohl die westdeutsche SPD unter der Führung von Willy Brandt, wie auch die österreichischen Sozialisten unter der Führung von Bruno Kreisky, neue politische Beziehungen zu den Ländern des Nahen Ostens im Allgemeinen und zu Israel im Besonderen $\mathrm{zu}$ entwickeln. Und schließlich war insbesondere die westdeutsche Regierung daran interessiert, eine politische Strategie zu entwickeln, die es ihr ermöglichen würde, die recht erfolgreiche Politik der DDR, eigenständige und freundschaftliche Beziehungen zu einer Reihe von Nahoststaaten wie Ägypten, Syrien, Irak und Algerien aufzubauen, zu konterkarieren, wobei hier nicht unerwähnt bleiben soll, dass diese Politik der DDR von der ausgezeichneten Ausbildung und Lehre insbesondere an der Universität Leipzig wissenschaftlich getragen wurde.

Die iranische Revolution des Jahres 1978/9 und der Zusammenbruch des Sowjetblockes nach 1989/90 mit der damit verbundenen politischen Emanzipation der rohstoffreichen und strategisch wichtigen muslimischen Staaten Mittelasiens und des Kaukasus-Raumes unterstrich die politische Relevanz des Faches Islamwissenschaft weiter. In der Folge waren die orientalistischen Fächer in Deutschland, Österreich und der Schweiz seit den späten 1960er Jahren eigent-

42 Zitiert in C. Essner/G. Winkelhane: Carl Heinrich Becker (1876-1933), S. 154.

43 Vgl. Fritz Steppat: „Wissenschaftliche Nachrichten: Contemporary Middle East Studies in Germany“, in: ZDMG 126 (1976), S. 8-13.

44 Vgl. J. Waardenburg: The Study of Islam in German Scholarship, S. 9.

45 Vgl. B. Johansen: Politics and Scholarship, S. 96f. 
lich nicht mehr wirklich gezwungen, ihre bloße Existenz öffentlich oder gegenüber der Politik zu rechtfertigen. Man könnte daher annehmen, dass sich die orientalistischen Fächer heute in Deutschland, Österreich und der Schweiz in einer fast paradiesischen Situation öffentlicher Anerkennung, überquellender Fördermittel und blühender Forschungsaktivitäten befinden und dass sich das Fach Islamwissenschaft darüber hinausgehend auf Grund seiner offensichtlichen und anhaltenden politischen Bedeutung in einer privilegierten Situation befindet und zwar in Bezug auf die Diskussion sowohl methodischer Fragen wie auch der Entwicklung sozial-, religions- wie auch politikwissenschaftlicher und ethnologischer Theorien und Perspektiven. Zudem wäre zu erwarten, dass die Islamwissenschaft auf Grund dieser günstigen Rahmenbedingungen - wie in Frankreich, Großbritannien, den skandinavischen Ländern und Nordamerika - entscheidende Anregungen für gesamtgesellschaftliche Auseinandersetzungen und Debatten liefert.

Leider ist genau das Gegenteil der Fall: Von wenigen Ausnahmen wie dem Deutschen Orient-Institut in Hamburg oder dem Zentrum Moderner Orient in Berlin abgesehen, konzentrieren sich nur einige wenige Institute oder Lehrstühle für Islamwissenschaft in Deutschland, Österreich und der Schweiz auf Forschung und Lehre zu den islamischen Gesellschaften der Gegenwart. In den späten 1990er Jahren hatten so, wie ich im Rahmen einer Durchsicht des Lehrprogramms von 55 islamwissenschaftlichen und arabistischen (also nicht iranistischen und turkologischen) Instituten und Lehrstühlen feststellen konnte, immer noch mehr als $80 \%$ dieser Institute und Lehrstühle eine fast ausschließlich philologisch-historische Forschungs- und Lehrausrichtung ${ }^{46}$ auch wenn sich dies heute (2007) etwas weniger drastisch darstellen dürfte. ${ }^{47}$ Zudem konzentrieren sich die meisten Institute und Lehrstühle nach wie vor in ihrer Forschung und Lehre auf die Kernländer der islamischen Oikumene, also die Länder des Nahen Ostens, insbesondere Ägypten, die arabische Halbinsel und die Länder des Fruchtbaren Halbmonds, sowie natürlich die Türkei und Iran, während die überwiegende Mehrheit der Muslime in den Maghrib-Ländern, im Sudan und im subsaharischen Afrika, auf dem indischen Subkontinent, in Mittel- und Zentralasien und Südostasien, aber auch die wachsende Zahl von Muslimen in den Ländern des

$46 \mathrm{Zu}$ ähnlichen Ergebnissen kommt die Studie von Eckehard Rudolph: Bestandsaufnahme. Kultur- und Sozialwissenschaftliche Forschung über die muslimische Welt in der Bundesrepublik Deutschland, Hamburg: Deutsches Orient-Institut 1999.

47 Dies soll keine Kritik an den etablierten Forschungs- und Lehrtraditionen der deutschsprachigen Islamwissenschaft darstellen, sondern vielmehr als Appell an die Islamwissenschaft verstanden werden, mit ihren anerkannten Pfunden zu wuchern und die Einrichtung von zusätzlichen, gegenwartsorientierten Forschungs- und Lehreinrichtungen zu betreiben, die sich vor allem den ,,marginalen“ Räumen widmen sollten. In diesem Zusammenhang sollte auf die Tatsache verwiesen werden, dass die überwiegende Mehrheit der Muslime heute in diesen von der etablierten Islamwissenschaft vernachlässigten Räumen lebt. 
Westens, von der etablierten Orientalistik nach wie vor nicht genügend beachtet wird. Damit werden diese ,marginalen Muslime“ den Ethnologen, Religions- und Politikerwissenschaftlern überlassen, die sich auf diese Art und Weise zunehmend islamwissenschaftliche Kompetenzen aneignen, ohne dass ihnen dies unter diesen Umständen zu verübeln wäre. In Folge haben Disziplinen wie Ethnologie, Religionswissenschaft, Politikwissenschaft oder Soziologie, die sich bereits seit längerem in den von der Orientalistik als marginal behandelten und entsprechend vernachlässigten Räumen etabliert haben, damit begonnen, sich in den Kernbereichen der Islamwissenschaft einzurichten und eigene Forschungen in den arabisch, türkisch und persisch sprechenden Ländern des Mashriq und Maghrib durchzuführen, die islamwissenschaftlichen Forschungsarbeiten häufig in nichts nachstehen. Auch aus diesem Grunde stellt sich die Frage, wie lange sich die deutschsprachige Islamwissenschaft angesichts ihrer selbst auferlegten Fokussierung auf einige wenige Kernthemen und Kernräume noch gegenüber anderen Fächern behaupten kann. 


\section{Islamische Kunstgeschichte und Archäologie: Letztes Fach der Orientalistik?}

LORENZ KORN (BAMBERG)

\section{Ein unübersichtliches Terrain}

Was haben das Taj Mahall im indischen Agra und der Zisa-Palast in Palermo gemeinsam? Welche Verbindung besteht zwischen dem Marmorbecken aus Madinat az-Zahra, das heute im archäologischen Nationalmuseum von Madrid steht, und den Türflügeln der Großen Moschee von Cizre, die sich heute im Museum für türkische und islamische Kunst in Istanbul befinden? Was haben die reich illuminierten mamlukischen Korane in der ägyptischen Nationalbibliothek mit den Buchmalereien einer safavidenzeitlichen Handschrift aus Iran zu tun, die die Erzählungen des Shahname illustrieren? Diese Gegenüberstellungen mögen gewollt erscheinen, sind bei näherem Hinsehen aber nicht ganz abwegig. ${ }^{1}$ Sie sollen hier einen Sachverhalt illustrieren, der je nach Standpunkt als kaum zu erschöpfendes Potential oder als beinahe unüberwindliche Schwierigkeit gewertet werden kann: Die genannten Werke - Bauwerke oder künstlerisch gestaltete Objekte - sind geographisch weit voneinander entfernt, sie stammen aus ganz verschiedenen Kunstgattungen, und sie lösen bei ein und demselben Betrachter ganz unterschiedliche Reaktionen und Assoziationen aus. ${ }^{2}$ Die Frage erscheint auf den ers-

1 Überblicksdarstellungen zur Islamischen Kunstgeschichte vereinen diese konträr wirkenden Beispiele regelmäßig zwischen zwei Buchdeckeln; als rezentes Beispiel vgl. Markus Hattstein/Peter Delius (Hg.), Islam: Kunst und Architektur, Köln: Könemann 2000. Auf den Einzelnachweis von Literatur zu den besprochenen Kunstwerken wird hier verzichtet; vgl. dazu die detaillierten Literaturangaben in: Richard Ettinghausen/Oleg Grabar/Marilyn Jenkins: The Art and Architecture of Islam (6501250), New Haven: Yale University Press 2001; Sheila S. Blair/Jonathan M. Bloom: The Art and Architecture of Islam (1250-1800), New Haven: Yale University Press 1994.

2 Als Beispiel für das Bekenntnis zu einem persönlich gefärbten, wenngleich durchweg wissenschaftlich fundierten Ansatz, vgl. Oleg Grabar: „The Experience of Is- 
ten Blick berechtigt, ob es überhaupt etwas Verbindendes gibt, das die gemeinsame Aufzählung rechtfertigt. Sind diese Schöpfungen, mit denen sich die islamische Kunstgeschichte beschäftigt, nicht zu verschieden, um an ihnen etwas über eine einzelne Kultur ablesen zu können? Stammen sie nicht aus Kontexten, die so weit voneinander entfernt waren, dass sie zu Recht im Plural als „,islamische Kulturen “ ${ }^{3}$ bezeichnet werden? Als der Architekt des Taj Mahall sein Werk schuf, konnte er von der Zisa in Palermo nichts mehr wissen; als religiöses Bauwerk diente das Mausoleum am Yamuna einem gänzlich anderen Zweck als der sizilianische Palast; und so erscheint es folgerichtig, dass auch die gemeinsame Grundlage für die Architektur der beiden Gebäude nur schmal ist, dass gemeinsame Urahnen, an denen sich wichtige Merkmale beider identifizieren lassen, in weiter chronologischer Ferne liegen. Und doch gibt es Gemeinsamkeiten, sowohl auf der Ebene einzelner Bauelemente, wie auch in allgemeineren gestalterischen Prinzipien, die verdeutlichen, dass die beiden Bauten bei aller durch die Gattung und den Zeitstil bedingten Verschiedenheit als Ableger einer künstlerischen Tradition gelten können, die wir als ,islamisch ' bezeichnen. Das gilt für die Verwendung einzelner Bauelemente - beispielsweise Muqarnaszellen an vorkragenden Bauteilen - ebenso wie für übergreifende Gestaltungsprinzipien, zu denen wir die Dominanz der Symmetrie, die Verbindung zwischen Innen- und Außenraum und die Einbeziehung des Gartens zählen können. Dennoch ist zu fragen, ob diese als gemeinsam erkannten Elemente künstlerischer Gestaltung als wesentlich gelten können, ob die Zuordnung der beiden Bauten zu einer gemeinsamen Geschichte der Kunst etwas aussagt, das spezifischer ist als nur die Zugehörigkeit zur Menge menschlicher Hervorbringungen.

Dasselbe ließe sich auch für die anderen zusammengestellten Paare sagen: Das andalusische Marmorbecken mit seinem geometrisch-vegetabilen, in Blendarkaden organisierten Dekor und die Türflügel mit ihrem Sternmuster wirken durchaus verschieden, auch wenn in beiden Fällen noch Tierdarstellungen und Inschriften den nicht-figürlichen Dekor ergänzen. Man kann fragen: Ist die $\mathrm{Zu}-$ sammenstellung von geometrischem, vegetabilem und epigraphischem Dekor, bereichert um figürliche Elemente, ein wichtigeres Merkmal für die Identifizierung dieser Objekte als etwa die Einzelformen der Bögen, Ranken und Blätter, die das Marmorbecken eindeutig als andalusisch kennzeichnen und es damit von Gegenständen aus dem Vorderen Orient abgrenzen? Wahrscheinlich würde man diese Frage bejahen; die Zuordnung zum islamischen Kulturbereich erscheint primär gegenüber der Rolle der beiden Objekte als Vertreter einer ,spanischen “ oder , anatolischen' Kunstgeschichte. Andererseits kann ja gerade aus einer solchen Gegenüberstellung eine Charakterisierung verschieden ausgeprägter regio-

lamic Art“, in: Irene Bierman (Hg.), The Experience of Islamic Art on the Margins of Islam, Reading: Ithaca Press 2005, S. 11-59.

3 Vgl. Ira M. Lapidus: A History of Islamic Societies, Cambridge: Cambridge University Press 1988. 
naler Traditionen erwachsen, die in ihrer Genese und Entwicklung nicht vollkommen unverbunden nebeneinander stehen, sondern Berührungspunkte und Phasen des Austauschs aufweisen.

Vollends erscheint es aber problematisch und willkürlich, die Illustrationen des persischen Nationalepos mit Vertretern einer nicht-figürlichen Buchkunst zusammenzustellen. In den Bildern zum Shahnameh stehen erzählerische Momente so im Vordergrund, dass andere Eigenschaften dieser Malerei demgegenüber in den Hintergrund gedrängt werden: Die Linienführung, die Verteilung von Massen und Farben werden meist in ihrer dienenden Funktion aufgefasst, mit der sie sich der Präsentation einer Handlung oder, allgemeiner, eines poetischen Inhalts, unterordnen. Bei illuminierten Koranblättern liegt die Sache anders. Hier werden Inhalte nicht illustriert, sondern die buchkünstlerische Gestaltung dient zunächst einmal als Fassung des geschriebenen Wortes. Vielleicht bietet aber auch hier der Vergleich zwischen Beispielen verschiedener Gattungen die Möglichkeit, etwas über die Ästhetik einer Buchkunst herauszufinden, die allgemein auf Feinheit größeren Wert legte als auf starken Ausdruck.

\section{Anfang und Ende islamischer Kunstgeschichte}

Diese wenigen Sätze zu einigen Kunstwerken sollen nur anhand von Beispielen andeuten, mit welchen Schwierigkeiten sich eine ,islamische Kunstgeschichte“ auseinandersetzen muss, wenn es um die Definition und die Abgrenzung ihres Gegenstandes geht. ${ }^{4}$ Nach allen Seiten erscheint das Gebiet offen. Wohl ist es möglich, einen Anfangspunkt der Geschichte des Islam zu bestimmen, der dann auch als terminus post quem für die Entstehung einer islamischen Kunst gelten kann. Von welchem Zeitpunkt an wir tatsächlich berechtigt sind, von, islamischer Kunst' zu sprechen, hängt unter anderem davon ab, ob wir in unserer Definition pragmatisch vorgehen, oder ob wir eine gewisse gestalterische Einheitlichkeit zur Voraussetzung für eine einheitliche Benennung machen. Mit Recht sind Kunstwerke der Umayyadenzeit als Ausläufer spätantiker Kunst charakterisiert worden: Nicht nur die selbstverständliche Aneignung und Fortsetzung antiken Erbes in den Kunstgattungen, in der Ikonographie und im Formenschatz laden dazu ein, in den Auftraggebern der umayyadischen „Wüstenschlösser“ syrisch-arabische Fürsten zu sehen, die sich selbst als Nachfolger der Ghassaniden betrachteten wenn sie auch nunmehr auf imperialer Ebene konkurrenzfähig geworden waren. Unter diesen Vorzeichen gehören die Badeanlage von Qusayr 'Amra und die Umayyadenmoschee von Damaskus zur Spätantike. ${ }^{5}$ Noch wichtiger ist aber, wie

4 Vgl. Sheila S. Blair/Jonathan M. Bloom: „The Mirage of Islamic Art: Reflections on the Study of an Unwieldy Field“", in: The Art Bulletin 85 (2003), S. 152-184.

5 Vgl. Garth Fowden: Qusayr 'Amra. Art and the Umayyad Elite in Late Umayyad Syria, London u.a.: University of California Press 2004. 
man die Zäsur zwischen der Kunst des byzantinischen und des umayyadischen Syrien bewertet: War sie weniger scharf als diejenige zwischen der umayyadischen und der abbasidischen Kunst? Oder sind die innovativen Elemente der umayyadischen Kunst so richtungsweisend, verbinden sie sie mit den nachfolgenden Epochen so eng, dass sie die Benennung als ,islamisch“ rechtfertigen? Die Verwaltungsreformen unter 'Abd al-Malik prägten die Kultur der islamischen Welt für mehrere Jahrhunderte. Beinahe gleichzeitig entstanden die ersten großen Schöpfungen umayyadischer Kunst, die uns erhalten sind. Sie sprechen eine verwandte Sprache: Die Adaption ererbter künstlerischer Mittel für eigene Zwecke, das Zusammenstellen in neuer Kombination und das Ausscheiden des Unerwünschten zeigen den Beginn eines neuen Zeitalters an, auch wenn erst in der Abbasidenzeit eine reichsweit nachgeahmte Formensprache voll entwickelt war.

Betrachtet man die Zeitleiste von der anderen Seite, so erscheint die Frage nach dem Ende noch schwieriger zu beantworten als die Frage nach dem Beginn. Dauert die Geschichte der islamischen Kunst bis in die Gegenwart fort, oder ist zu irgendeinem Zeitpunkt ein Ende der, islamischen Kunst' anzusetzen? Haben wir es nicht mit arabischer, persischer und türkischer Kunst zu tun, um nur die augenfälligsten sprachlich-nationalen Einheiten zu benennen? Den Maler Ömer Uluç oder den Architekten Cengiz Bektaş aufgrund ihrer türkischen Herkunft als ,islamische Künstler' zu bezeichnen, ist mehr als fragwürdig. Bei dem Kalligraphen Emin Barın hingegen zögert man weniger, da schon die Gattung, zu der seine Arbeiten zählen, eine lange Tradition und einen hohen Stellenwert in der islamischen Kunst besitzt. In der europäisch-amerikanisch geprägten ,Moderne“ kann sie dagegen bislang nur als Randphänomen existieren. Die gegenwärtige Kunst in den Ländern der islamischen Welt lässt sich nur schwer unter der einheitlichen Bezeichnung ,islamisch“ charakterisieren; schon die Organisation des Kunstbetriebs folgt eher den nationalstaatlichen Grenzen. Mit aller Vorsicht kann gesagt werden, dass die Herausbildung einer indischen, persischen und osmanisch-türkischen Kunst bis in das 16. Jh. zurückzuverfolgen ist. Schwierig bleibt dann die Einordnung von Werken in der arabischen Welt, die bis ins 19. Jh. weitgehend unter osmanischer Herrschaft stand - für eine nationalstaatliche Entsprechung zu einer ,arabischen Kunst' fehlt hier das politische Gegenstück.

Aber auch der Charakter der Kunstwerke selbst spricht gegen eine zu früh angesetzte Einteilung in nationalstaatlichen Kategorien. Ein schlagendes Beispiel ist das Berliner Aleppo-Zimmer, das um 1600 für eine wohlhabende christliche Familie in Aleppo angefertigt wurde. ${ }^{6}$ Vom Typ der Raumausstattung her steht es in der Tradition der Aleppiner Wohnhausarchitektur. Die Malereien auf den

6 Vgl. Julia Gonnella: Ein christlich-orientalisches Wohnhaus des 17. Jahrhunderts aus Aleppo (Syrien). Das „Aleppo-Zimmer“ im Museum für Islamische Kunst, Staatliche Museen zu Berlin - Preußischer Kulturbesitz, Berlin 1996. 
Holzpaneelen speisen sich aber aus den verschiedensten künstlerischen Quellen: Die Motive des floralen Dekors gehen auf den Istanbuler Hofstil zurück, wie er etwa durch die Iznik-Fliesen oder durch Textilien verbreitet worden ist. Die figürlichen Szenen dagegen orientieren sich an Vorlagen aus der persischen Buchmalerei. Die Vorlagen für die Inschriften wurden höchstwahrscheinlich von lokal ansässigen Kalligraphen geliefert (wobei der Hausherr das Programm inhaltlich mitbestimmte); ausgeführt wurden sie aber von einem Maler, dessen Schreibgewohnheiten persisch geprägt waren. Das Aleppo-Zimmer steht somit für eine Kunst, die sich in keiner Weise mit ethnischen oder politischen Kategorien deckt. Der übergreifende, Grenzen überschreitende Charakter ,islamischer ${ }^{6}$ Kunst wird an diesem Werk des beginnenden 17. Jahrhunderts deutlich. Selbst die Etikettierung als ,islamisch“ wirkt angesichts des christlichen Bekenntnisses des Auftraggebers fragwürdig. Andererseits sind die Parallelen zu anderen ,islamischen' Werken mehr als deutlich, sind die Verbindungen zu den Kunstlandschaften des Vorderen Orients um 1600 nach allen Seiten so überzeugend, dass die begriffliche Schöpfung einer christlich-orientalischen Kunst an diesem Beispiel artifiziell und unglücklich wirken würde. Um es mit einem Aufsatztitel Scott Redfords auszudrücken: „How Islamic Is It?“

Derzeit bleibt die pragmatische Grenzziehung, mit der sich die wissenschaftliche Disziplin islamischer Kunstgeschichte meist begnügt hat, ohne Alternative: Als ,islamische Kunst" werden Kunstwerke bezeichnet, die unter islamischer Herrschaft entstanden sind, selbst wenn die Auftraggeber sich nicht zum muslimischen Glauben bekannt haben. Diese Eingrenzung ermöglicht es, Kunstwerke als zusammenhängend zu betrachten, die durch regionalisierte Kunstgeschichtsschreibung auseinandergerissen würden. Am Beispiel Zentralasiens war zu beobachten, wie sowjetische Kunsthistoriker die Bauten von Samarkand und Buchara in eine regionale Kunstgeschichte einordneten, die die Vergleichsbeispiele auf iranischem und afghanischem Staatsgebiet weitgehend ausklammerte. Die Leistung der sowjetischen Wissenschaft soll damit nicht geschmälert werden: Zum einen sorgte sie für die Erschließung eines sehr beachtlichen Materialbestandes. Zum anderen konnte ihr Werk gelingen, weil sie die Realität jenseits der Grenze nicht völlig ignorierte. Außerdem waren die islamischen Kunstwerke Zentralasiens mindestens in der Timuridenzeit, teilweise auch noch danach, eigenständig und qualitativ anspruchsvoll genug, um die künstlerische Entwicklung innerhalb eines regionalen Kontextes zu erklären.

Mit der pragmatischen Eingrenzung ,islamischer Kunst" als ,Kunst unter islamischer Herrschaft' bleiben immer noch die Schwierigkeiten mit moderner Kunst in der islamischen Welt, die nicht als ,islamische Kunst" etikettiert werden kann, und mit Werken, die in der ,Diaspora ' durch muslimische Künstler oder für muslimische Auftraggeber geschaffen wurden, bzw. die aufgrund anderer Merkmale zur ,islamischen Kunst' gezählt werden sollten. Als prominente Beispiele können die Decke der Cappella Palatina in Palermo und der Kaisermantel in der Wiener Hofburg genannt werden, die im Auftrag der christlichen Normannenkö- 
nige Siziliens entstanden, aber deren künstlerischer Hintergrund ganz eindeutig in der islamischen Welt zu sehen ist. Trotz dieser Unklarheiten spricht die Praxis des Faches eine eindeutige Sprache: Wissenschaftler, die sich - nach der Bezeichnung der nordamerikanischen Fachorganisation - als „Historians of Islamic Art" verstehen, beschäftigen sich mit der Kunst des islamischen Orients bis ins 19. Jahrhundert oder gar bis in die Gegenwart und ziehen die Grenzen dabei eher weit. Einige methodische Implikationen sorgen dafür, dass diese Grenzen nicht ins Uferlose verschwimmen. Auf sie wird im Folgenden noch einzugehen sein.

\section{Ist islamische Kunst muslimisch?}

Was bezeichnet der Begriff ,Kunstgeschichte" in der Zusammensetzung, islamische Kunstgeschichte " oder gar ,islamische Kunstgeschichte und Archäologie“? Wenn es einen inneren Zusammenhang zwischen künstlerischen Phänomenen im Bereich der islamischen Kulturen gibt, dann sollte sich dieser auf zwei Wegen darstellen lassen. Nehmen wir die oben angeführten Paare von Kunstwerken wieder als Ausgangspunkt, dann lässt sich zeigen: Das Mausoleum in Agra steht in seinen formalen und funktionalen Aspekten in einer Abfolge von Werken, die sich bis in die Anfänge der islamischen Geschichte hinauf verfolgen lässt. Schon für ein grundlegendes Merkmal des Bauwerks, das achtseitige Schema des Grundrisses mit dem zentralen Kuppelraum, kann eine Kette von Vorläufern zitiert werden, die sich über mehrere Jahrhunderte hinweg durch verschiedene Regionen der islamischen Welt verfolgen lässt. Sie beginnt beim Felsendom in Jerusalem, der für die Gestaltung von Memorialbauten typenbildend wurde. Auf der anderen Seite ist das Taj Mahall seinerseits für zahlreiche indische Mausoleen zum Vorbild geworden, an das sich diese mehr oder weniger getreu anlehnen.

Ganz anders stellt sich die Situation bei der Zisa in Palermo dar. Zwar können auch seine Funktion und seine Bauformen in eine historische Abfolge von Palastbauten (und anderen Werken) gestellt werden. Doch ist diese Folge an vielen Stellen lückenhaft und weist Sprünge auf, die nicht ohne Weiteres erklärt werden können. So besitzen wir aus dem Vorderen Orient kaum Beispiele für einen flächenmäßig beschränkten, aber hoch aufragenden Palastbau, wie ihn die Zisa darstellt. Als mutmaßliches Vorbild sind die fatimidischen Paläste von Kairo postuliert worden, die aber in der Substanz beinahe restlos zerstört sind und nur in der Anlage ihrer Bauteile ungefähr rekonstruiert werden können. Ein kompliziertes Geflecht aus Textbelegen und Parallelen in anderen, zum Teil entfernt liegenden Bauten kann Hinweise darauf geben, dass die Zisa tatsächlich etwas von der verlorenen Pracht der fatimidischen Palastarchitektur in Kairo widerspiegelt. Damit bildet sie einen wichtigen Ersatz für ein ,missing link' der westislamischen Hofkultur, dessen Fehlen aufgrund der eminenten politischen und kulturellen Bedeutung des Fatimidenhofes besondere Schwierigkeiten bildet. 
Die Geschichte der Kunst als eine Abfolge von Phänomenen, die sich in Form einer Entwicklung von Formen (und Funktionen) darstellen lässt, in der nachvollziehbar das eine aus dem anderen hervorgeht, ist für Europa und das weiße Amerika bereits in großem Detailreichtum geschrieben. Fragen der Stilgeschichte, Ikonographie und Ikonologie können hier in den Grundzügen seit längerem als geklärt gelten. Für die islamische Kunstgeschichte ist das nicht in demselben Ausmaß der Fall. Die Ziele bleiben aber dieselben: Vom einzelnen Objekt ausgehend ist nach den Umständen seiner Entstehung zu fragen. Wer waren die Auftraggeber? Durch welche Vorstellungen waren ihre Handlungen geprägt? Welche Künstler schufen die Werke? Wie waren sie ausgebildet, und woher bezogen sie ihre Anregungen? Welche bildnerischen Traditionen, welche technischen Gegebenheiten und funktionalen Anforderungen beeinflussten die Gestaltung der Werke? Umgekehrt kann von einer allgemeinen Fragestellung her die Entwicklung materieller Kultur und künstlerischer Formen beschrieben und interpretiert werden: Welche Gattungen bestimmten das Geschehen, und welche formalen Gesetzmäßigkeiten bildeten sich heraus? Kann die Ästhetik, die die Kunst in einer bestimmten Epoche charakterisiert, bestimmt werden? Steht diese Ästhetik im Zusammenhang mit geistigen Strömungen, zu denen andere Quellen Auskunft geben?

Sollen diese Fragen für die ,islamische Kunstgeschichte "voraussetzungslos beantwortet werden, dann können wir die ,islamische Kunst“ und ihre Geschichte als einen Teil der Weltkunst verstehen. Gemäß diesem Konzept werden verschiedene Kulturräume definiert, innerhalb derer sich kunsthistorische Entwicklung abgespielt hat. Sie stehen nicht in einer hierarchischen Beziehung zueinander, wie sie einem kolonialen Weltbild entspräche. Stattdessen werden historische Abfolgen in den verschiedenen ,Kulturen“ mit demselben Instrumentarium der Stilanalyse und der historischen Einordnung untersucht. Querverbindungen zwischen den Kulturen, die sich in künstlerischen Austauschbeziehungen äußern, bleiben dabei nicht unberücksichtigt.

Nun schließt aber schon die Eingrenzung auf einen ,islamischen “ Kulturraum die erste Voraussetzung mit ein: Es wird davon ausgegangen, dass so verschiedene Werke aus voneinander weit entfernten Regionen, wie sie eingangs in wenigen Beispielen angedeutet wurden, aufgrund ihrer ,islamischen` Prägung zusammengehören. Es ist schon angedeutet worden, dass die Abgrenzung einer Region der Weltkunst und deren Benennung nach der islamischen Religion auch sehr pragmatische Züge trägt. Sie muss also nicht mit einer wesensmäßigen Charakterisierung islamischer Kunst einhergehen; es muss nicht notwendig die islamische Religion als prägende und identitätsstiftende Kraft hinter einer kunstgeschichtlichen Entwicklung stehen. In vielen Fällen sind es ja vorislamische Traditionen, die sich in der islamischen Kunst weiter entwickeln. Viele formale Entwicklungen und künstlerische Errungenschaften werden nicht primär durch islamische religiöse Doktrin oder Praxis bestimmt. Häufig spielten andere kulturelle Prägungen und Bedürfnisse mit. Man könnte zugespitzt sagen: Selbst unter 
islamischen Vorzeichen konnte sich im Iran die Hofmoschee mit Iwanen und Kuppelraum als Regelform durchsetzen - ein Bautyp, der für das Ritual des Gemeindegebets nicht besonders gut geeignet ist. Man könnte postulieren: Die Arabeske hätte sich auch ohne das so genannte ,Bilderverbot' entwickelt.

Wichtiger als die Einzelprobleme, welches einzelne künstlerische Gestaltungselement nun als ,islambedingt ‘ erklärt werden kann oder sollte, scheint mir die Frage, inwiefern die jeweiligen Zeitgenossen ihre Weltregion als zusammengehörigen Kulturraum verstanden haben. Geographen und Reisende geben darüber Auskunft. Ibn Jubair bewegte sich zwischen al-Andalus und der Arabischen Halbinsel ganz selbstverständlich, und so dürfte es vielen Reisenden gegangen sein. Die Sprache, die Religion der Herrscher und der Bewohner eines Landes scheinen die wichtigsten Determinanten zu bilden, nach denen sich die Reisenden fremd oder vertraut fühlten. Eine Zusammengehörigkeit der ,islamischen Welt' kann, gewissermaßen auf der Grundlage von Yaqut, al-Qazvini und Ibn Fadlallah al-'Umari, zumindest bis in die Mamluken- und Timuridenzeit postuliert werden. Diese Zusammengehörigkeit lässt sich auch in der Kunst direkt beobeachten: Bis ins 16. Jahrhundert sorgte die Wanderung von Künstlern zwischen Maghrib und Mashriq, zwischen Iran, Anatolien und Indien dafür, dass Formen und Entwürfe ausgetauscht wurden. Der ,internationale timuridische Stil“", der von etwa 1450 bis 1500 weithin die Entwürfe von Baudekor, Buchkunst und Textildesign bestimmt hatte, konnte sich aufgrund bestehender Verflechtungen zwischen den Regionen fast überall durchsetzen. Am Beispiel des Aleppo-Zimmers wurde bereits gezeigt, wie unbedeutend dabei ethnische und politische Grenzen waren. So bestätigt sich Ernst Herzfelds Lehrsatz, den er auf die Fassade von Mshatta gemünzt hatte, dass die Vereinigung der künstlerischen Elemente aus allen Regionen des Vorderen Orients den Charakter der islamischen Kunst ausmache, auch für spätere Epochen. ${ }^{7}$,Islamische Kunst ${ }^{`}$ lässt sich somit nicht als wesensmäßig durch islamische Religion bestimmte Kunst definieren, sondern als Kunst, die unter den Voraussetzungen eines durch den Islam zusammengebrachten Kulturraumes entstehen konnte.

Das Problem der ,nationalen' Kunstgeschichten scheint sich vor diesem Hintergrund zu verflüchtigen - zumindest was die lange Zeitspanne bis zur Entstehung der ,gunpowder empires ' angeht; für die Jahrhunderte danach wird es wieder interessant. In der Tat hat eine national gefärbte Kunstgeschichtsschreibung zumindest im Falle Irans und der Türkei die Rolle der Nation besonders hochgespielt und damit den Blick für manch andere Zusammenhänge verstellt.

7 Vgl. Ernst Herzfeld: „Die Genesis der islamischen Kunst und das MshattaProblem“, in: Der Islam 1 (1910), S. 27-63, 105-144. 


\section{Eine Geschichte der Spezialisierung}

Als Wissenschaftszweig hat sich die islamische Kunstgeschichte, unter Einschluss der Archäologie, im Wechselspiel zwischen Orientalistik und Kunstwissenschaft entwickelt. ${ }^{8}$ Berlin und Wien bildeten am Anfang des 20. Jahrhunderts besonders wichtige Zentren der kunstgeschichtlichen Forschung und Theoriebildung. Alois Riegl entwickelte seine „Stilfragen“ anhand der Arabeske, weil ihm ein nicht-figürliches Ornament besonders geeignet erschien, Aussagen über formale Entwicklungen zu treffen; auf diese Weise trug er wertvolle Beobachtungen zur islamischen Kunstgeschichte bei. Josef Strzygowski untersuchte die MshattaFassade, deren Zugehörigkeit zur islamischen Kunst damals noch ganz umstritten war, und stellte darin stilistische Einflüsse aus verschiedenen Regionen des Vorderen Orients fest. Friedrich Sarre begründete die Sammlung des Berliner Museums für Islamische Kunst, nicht ohne selbst auf Reisen Material zur Architekturund Kunstgeschichte zu sammeln. Die erste Dokumentation bedeutender Bauten und Kunstwerke wurde sogleich in die allgemeine Kunstgeschichte eingeordnet; Heinrich Wölfflins „Kunstgeschichtliche Grundbegriffe“ waren ja erst im Entstehen begriffen. Fast gleichzeitig mit der Formulierung grundlegender Hypothesen zur islamischen Kunstgeschichte wurde die Kenntnis der Denkmäler drastisch erweitert, was wiederum neue Perspektiven eröffnete: Die Entdeckung von Qusair Amra durch Alois Musil gab dabei wesentliche Impulse.

Die Münchner Ausstellung „Meisterwerke Muhammedanischer Kunst“, welche 1910 stattfand, gibt einen Eindruck vom damaligen Stand der Forschung, der aus heutiger Sicht beeindruckend wirkt, wenn man bedenkt, wie viel Material erst später bekannt geworden ist. Vielleicht ist noch wichtiger zu betonen, wie sehr sich die Ausstellung von früheren Präsentationen islamischer Kunst und materieller Kultur unterschied, die etwa auf den Weltausstellungen zu sehen gewesen waren. In München wurde versucht, den Exotismus zu vermeiden, der nur die orientalistischen Vorurteile bediente. Stattdessen sollten die „Meisterwerke“ wissenschaftlich fundiert präsentiert werden, wenn möglich in einem ihnen angemessenen Kontext, der aber wiederum nicht folkloristisch wirken sollte. Die Musealisierung stellte den ästhetischen Reiz der Objekte heraus, die in Vitrinen vor neutralem Hintergrund lagen, und verfolgte daneben das Ziel, eine Entwicklungsgeschichte der Formen sichtbar zu machen, die mit den damals neu entwickelten stilgeschichtlichen Theorien (z.B. von geschlossener Form zu offener Form) übereinstimmte.

8 Vgl. Stephen Vernoit: „Islamic Art and Architecture. An Overview of Scholarship and Collecting, c. 1850-1950“, in: ders. (Hg.), Discovering Islamic Art. Scholars, Collectors and Collections, 1850-1950, London, New York: I.B.Tauris 2000, S. 161; Annette Hagedorn: „Das Interesse für Islamische Kunst in Deutschland im 19. Jahrhundert", in: Joachim Gierlichs/Annette Hagedorn (Hg.), Islamische Kunst in Deutschland, Mainz: von Zabern 2004, S. 16-20. 
Eine Ausweitung auf neue wissenschaftliche Methoden stellten die Ausgrabungen von Samarra dar, die Ernst Herzfeld ab 1911 durchführte. Zum ersten Mal widmete sich archäologische Forschung dezidiert einer Stätte, an der Funde aus islamischer Zeit dominierten. Die Archäologie stand hier noch weitgehend im Dienst der Kunstgeschichte; Ziel war die Freilegung der Paläste mit ihrem Wandschmuck und die Bergung von Objekten aus der Zeit des Abbasidenkalifats. Damit konnte die Kunst einer der zentralen Epochen islamischer Kulturgeschichte in einem höchst wichtigen Ausschnitt erfasst werden. Auf die Alltagskultur erstreckte sich die archäologische Forschung zu Herzfelds Zeit nur nebenbei.

Ein weiteres Vorhaben, das durch den Ersten Weltkrieg schwere Rückschläge erleiden sollte, war die Erfassung arabischer Inschriften. Max van Berchem regte mit dem „Corpus Inscriptionum Arabicarum“ die flächendeckende Sammlung arabischer Bauinschriften an, die nach Orten publiziert werden sollten. Den ersten Band mit Inschriften aus Kairo verfasste er selbst; weitere Arbeiten waren an deutsche und französische Wissenschaftler in einer Art internationalem Forschungsprojekt verteilt. Verschiedene Verwicklungen führten dazu, dass insbesondere die Inschriften von Damaskus nicht zur Publikation gelangten. Eine Erneuerung der internationalen Kooperation war in den Jahren nach dem Ersten Weltkrieg nicht ohne weiteres denkbar.

Die archäologische Erforschung der islamischen Welt erlebte in den nachfolgenden Jahrzehnten einen Aufschwung. Er lässt sich an eigens begonnenen Grabungen ebenso ablesen wie an der Tatsache, dass bei Vorderasiatischen und Klassischen Archäologen nach und nach der Gedanke reifte, dass die jüngeren Schichten in ihren Grabungsplätzen mehr waren als nur Hindernisse, die es möglichst schnell wegzuschaffen galt. Bis sich diese Erkenntnis allgemein durchsetzt, wird allerdings noch weitere Zeit verstreichen. Auch in der europäischen Archäologie war ja das Interesse am Mittelalter schon lange vorhanden, bevor es sich in der archäologischen Praxis oder gar in einer eigenen Fachrichtung niederschlug. Die archäologische Erforschung von Plätzen, an denen die islamische Zeit einen Schwerpunkt der Siedlungsgeschichte und damit des Forschungsinteresses darstellt, ist unter anderem mit so bedeutenden Städten wie al-Fustat, al-Wasit, Istakhr, Rayy, Nishapur und Afrasiyab verbunden. Auch Residenzen außerhalb städtischer Kontexte wurden ausgegraben: Hierzu zählen - um nur einige zu nennen - Khirbat al-Minya und Khirbat al-Mafjar im Jordantal, die Qal'a der Bani Hammad in Algerien, der Takht-i Sulayman im Hochland Westirans und der Palast von Kubadabad westlich von Konya (die beiden letzteren in der Zeit nach dem Zweiten Weltkrieg). Das Deutsche Archäologische Institut leistete bedeutende Beiträge zur Archäologie der islamischen Zeit. Zwei größere Forschungsprojekte des DAI Damaskus seien hier stellvertretend genannt, die in den 80er90er Jahren durchgeführt wurden: Die Grabungen in Raqqa, der abbasidischen Residenz und Stadtgründung am Euphrat, und die Freilegungsarbeiten und Bauaufnahmen in der südsyrischen Stadt Bosra. An den genannten Projekten lassen 
sich die fördernden und hemmenden Rahmenbedingungen der islamischen Archäologie ablesen: Der an vielen Stellen beachtliche Bestand an architektonischen Resten erleichterte einerseits die Interpretation einer Stätte, zog aber andererseits die Aufmerksamkeit (und Arbeitskraft) von den vielleicht ebenso bedeutenden stratigraphischen Befunden ab. Ambivalent kann man das von außen herangetragene Interesse bewerten: Die Identifikationsmöglichkeit, die islamzeitliche Funde für gegenwärtige Gesellschaften bieten, fördern einerseits das Interesse daran, dass archäologische Forschung überhaupt stattfindet. Auf der anderen Seite bietet sie auch einen Ansatzpunkt für ideologisch gefärbte Vereinnahmungen, die einer unvoreingenommenen Interpretation im Wege stehen. Vielleicht hat es damit zu tun, dass bedeutende Ergebnisse für unsere Kenntnis materieller Kultur und ihres Wandels aus Orten stammen, an denen nicht primär unter islamischen Vorzeichen ausgegraben wurden und die in islamischer Zeit nicht als besonders wichtige Städte hervorgetreten sind: So haben Pella/Tabaqat Fihl und Bet Shean/Baysan im Jordantal anschauliche Befunde zum Wandel der Stadtkultur zwischen Spätantike und Abbasidenzeit geliefert, und die Sequenz südiranisch-irakischer Gebrauchskeramik der ersten islamischen Jahrhunderte wurde in Susa erarbeitet.

Die Entwicklungsgeschichte der islamischen Archäologie zeigt besonders anschaulich, dass Forschung, die sich auf islamische Kulturgeschichte bezieht, seit jeher mit Nachbardisziplinen vernetzt gewesen ist. Häufig sind es Klassische oder Vorderasiatische Archäologen, Architekten und Bauforscher gewesen, die Beiträge zur islamischen Archäologie geleistet haben, und nicht ,Orientalisten . Die Beschäftigung mit dem islamischen Orient war bei vielen eine nachträgliche Wendung, die nicht in ihrer Ausbildung angelegt war. Auf der anderen Seite hat es zwar immer Islamwissenschaftler, Arabisten, Iranisten und Turkologen gegeben, die sich aktiv an der archäologischen Feldforschung beteiligten - man denke etwa an Enno Littmann, der auf den Erkundungen der Princeton University in Syrien mitreiste und Inschriften aufnahm. Den Schritt zu eigenen Feldforschungen, gar archäologischen Ausgrabungen hat dagegen nur eine kleine Minderheit unter den Orientalisten getan.

Innerhalb der akademischen Kunstgeschichte hat die islamische Kunst immer nur eine marginale Rolle gespielt. Dafür sorgte nicht nur das weithin dominierende eurozentrische Weltbild, das nur gelegentlich die Relevanz von Entwicklungen in der benachbarten Weltregion erkennen konnte. Auch die methodischen Anforderungen, die Kombination von Kenntnis der Länder und ihrer Denkmäler, von historischem und philologischem Wissen, haben dafür gesorgt, dass Kunsthistoriker sich nur in geringem Umfang mit der islamischen Welt beschäftigt haben. Am ehesten wurde noch Spanien als europäisches Land wahrgenommen, in dessen künstlerischer Tradition wesentliche islamische Elemente (auch für die Zeit nach der Reconquista) zu berücksichtigen waren. Als zweite Kontaktzone zwischen Orient und Okzident ermöglichten Konstantinopel/Istanbul und der Balkan einen Zugang, nun zur osmanischen Kunst. Dagegen wurden Sizilien und 
die Kreuzfahrerstaaten als Räume des künstlerischen Austauschs lange Zeit kaum wahrgenommen.

Islamische Kunstgeschichte hat unter diesen Umständen einen Standort als akademische Disziplin vor allem in den orientalistischen Abteilungen der Universitäten gefunden. Neben der Forschung, die an Museen, am Deutschen Archäologischen Institut und an einzelnen Architektur-Fakultäten durch die Bauforschung betrieben wurde, waren es immer wieder Orientalisten, die Aspekte der materiellen Kultur und der Kunst in ihrer Lehre behandelten und so für Ansätze einer Ausbildung in der islamischen Kunstgeschichte und Archäologie sorgten. Betrachtet man die Entwicklung innerhalb der deutschen Universitätslandschaft, so ist zu vermerken, dass mit der Einrichtung bzw. Verstetigung der beiden Professuren für islamische Kunstgeschichte in München und Bamberg in den 90er Jahren die Re-Etablierung als eigenständiges Fach geglückt ist. Auf der anderen Seite kann es nur als trauriges Kuriosum gewertet werden, dass in Berlin - als Museumsstandort und durch akademische Strukturen und Traditionen dafür prädestiniert - kein Lehrstuhl für islamische Kunstgeschichte existiert.

\section{Regionale Kunstgeschichte oder Aufgaben für Generalisten?}

Mit der Ausdifferenzierung der Orientalistik in einzelne, zunehmend nach Sprachen und Regionen differenzierte Fächer, stellt sich die Frage nach der Spezialisierung und regionalen Differenzierung auch in der islamischen Kunstgeschichte und Archäologie. Schon die Sprachkenntnisse, die für das Heranziehen relevanter Schriftquellen bei der Interpretation eines Objekts nötig sind, oder die ein Archäologe braucht, um sich bei seinen Feldstudien einigermaßen erfolgreich im Lande zu bewegen, sorgen bei den meisten für eine gewisse thematische und methodische Spezialisierung. Kann also die Entwicklung des akademischen Umfeldes dazu führen, dass es in Zukunft eine Trennung zwischen arabischer, türkischer und iranischer Kunstgeschichte geben wird, ganz zu schweigen von der ohnehin schon weitgehend separat betriebenen indischen und westafrikanischen Kunstgeschichte?

In den jeweiligen nationalen Wissenschaften ist diese Trennung faktisch schon vollzogen, wenigstens teilweise. Kunsthistoriker in der Arabischen Welt beispielsweise beschäftigen sich immer seltener mit Iznik-Fliesen oder mit der Baugeschichte von Isfahan; die Konzentration liegt jeweils auf der eigenen Region. Diese Verengung schafft Probleme: So kennen iranische Studenten, die sich mit Baudekor beschäftigen, die Verwandtschaft zwischen sasanidischen Stuckarbeiten und der Dekoration der Freitagsmoschee von Nayin; den in dieser Hinsicht nicht zu übergehenden Baudekor von Samarra nehmen sie dagegen kaum wahr (ohnehin hat im Iran die Großmachtstellung des Landes in der vorislamischen Geschichte eine passende Folie für modernen Nationalismus abgegeben, der sich auch in einer nationalistisch gefärbten Kunstgeschichtsschreibung geäußert hat). 
Türkische Kunsthistoriker bezeichnen mamlukenzeitliche Bauten im Südosten ihres Landes als ,anatolisch“ geprägt, weil sie ihren Blick nicht über die syrische Grenze auf das nahe Aleppo wenden. Eingeschränkte Reisemöglichkeiten tun das ihre, um die Denkmälerkenntnis zu beschränken. Glücklicherweise wird die Tendenz zur Isolation immer wieder durchbrochen. Der innere Zusammenhang sorgt dafür, dass auch die Geschichte islamischer Kunst weiter geschrieben wird und die breiten Ströme künstlerischer Entwicklung zwischen Marokko und Indien Gegenstand der Diskussion bleiben. Dafür ist es allerdings nötig, einen Überblick über wichtige Kunstwerke zu behalten, Resultate der archäologischen Forschung in diesem Gebiet zu beachten, Quellen und Literatur in den verschiedenen Sprachen heranzuziehen und neuere Erkenntnisse aus der Geschichtsforschung und Islamwissenschaft zu berücksichtigen. Vielleicht werden bei weiter fortschreitender Ausdifferenzierung der Orientfächer die Kunsthistoriker zu den letzten ,Orient-Generalisten ' gehören. In jedem Fall wird ein intensiver Austausch innerhalb der Islam-Kunsthistoriker und Islam-Archäologen nötig sein, um den inhaltlichen Anforderungen gerecht zu werden, und die Vernetzung mit Nachbarwissenschaften wird dabei noch zunehmen. Sollte es weiterhin Islamwissenschaftler im alten Stil geben, die einen generalistischen Ansatz pflegen, werden sie zu den wichtigsten Gesprächpartnern der Islam-Kunsthistoriker zählen.

Im Einzelnen lassen sich die Aufgaben der islamischen Kunstgeschichte und Archäologie leichter formulieren. Für einen großen Teil der islamischen Kunstgeschichte sind die Grundlinien der Stilgeschichte bzw. der Formentwicklung heute überblickbar. Ein Disput um die Einordnung eines Bauwerks, der wie bei der Mshatta-Fassade zwischen römischer und abbasidischer Datierung schwankt, wäre heute kaum noch denkbar. Es bestehen aber deutliche Lücken in mehreren Bereichen der Kunstgeschichte, die durchaus nicht immer als ,entlegen ' bezeichnet werden können. So wissen wir beispielsweise nur wenig über die Kunst des abbasidischen Bagdad im 10. bis 11. Jahrhundert, von der nur geringe Reste überliefert sind. Aber auch in anderen Epochen und Gattungen bedarf die Stilgeschichte noch der Erhellung - man denke etwa an Holz und Stuck.

Im Bereich der Archäologie und materiellen Kultur sind die blinden Flecken, aber auch die potenziellen Erkenntnisse, noch wesentlich größer: So steckt etwa die archäologische Erforschung ländlicher Siedlungen erst in den Anfängen; die Stadtarchäologie hingegen leidet meist darunter, dass die Kontinuität der Nutzung eine Freilegung größerer Flächen unmöglich macht. In manchen Fällen macht sich bemerkbar, dass die professionelle Anwendung archäologischer Techniken für islamzeitliche Strukturen noch nicht überall selbstverständlich ist - saubere stratigraphische Arbeit, die allein zweifelsfreie zeitliche Zuordnungen ermöglicht, leidet unter dem Drang mancher Archäologen, architektonische Strukturen freilegen zu wollen (zumal ja scheinbar in einer durch Schriftquellen ,bekannten“ Epoche keine historischen Nachrichten mehr gebraucht würden!). Noch größer ist der Nachholbedarf bei der Keramik: Die unentbehrlichen Sequenzen von Gebrauchswaren fehlen noch für weite Bereiche. Werden hier Lü- 
cken geschlossen, so sind schon durch die Strukturierung vorhandenen Materials, das punktuell ergänzt werden muss, ganz neue Kenntnisse zur Geschichte der islamischen Welt zu erwarten. Kunstgeschichte und Archäologie können auf diese Weise Beiträge leisten, die unser Verständnis vom Zusammenwachsen der islamischen Welt im 7.-8. Jahrhundert erweitern und unser Bild von der Wirtschaftsgeschichte und -geographie der islamischen Welt von der klassischen Zeit bis in die frühe Neuzeit an vielen Punkten ergänzen. Was wäre vom Silberreichtum der Samaniden in Zentralasien bekannt, gäbe es nicht die Nord- und Osteuropäischen Schatzfunde? Was wüsste man über Bestattungsgebräuche der Fatimidenzeit ohne die entsprechenden Funde aus al-Fustat? Könnte man die Handelsverbindungen zwischen Ostasien und dem Abbasiden- und Buyidenreich ohne die Keramikfunde am Persischen Golf abschätzen? Wie viele kleinere Dynastien und Herrscher, die sich keine Hofgeschichtsschreibung leisteten, sind erst durch numismatische Belege bekannt geworden? Der unersetzbare Quellenwert archäologischer Zeugnisse ist vielleicht an keiner Stelle so deutlich wie für die frühislamische Zeit, für die das umfangreiche chronikalische Material mehr Fragen aufwirft als beantwortet. ${ }^{9}$

Für die inhaltliche Deutung von Werken islamischer Kunst kann ikonographische Arbeit - durch systematische Sammlung von Motiven, aber auch in der Zusammenarbeit mit philologisch basierter Kulturgeschichte - noch vieles beitragen. Für die Erforschung der Selbstvergewisserung islamischer Kultur und der dabei verwendeten Semiotik kann auf kunsthistorische Analyse nicht verzichtet werden.

Für noch wichtiger halte ich die monographische Untersuchung einzelner Werke. Wenn sie auch in einem historischen, kultur- und stilgeschichtlichen $\mathrm{Zu}$ sammenhang entstanden, der ihre Merkmale erklärt, so wurde doch jedes für sich als eine Einheit konzipiert, die in bestimmter Weise auf den Betrachter wirken sollte. Vor allem die Malerei bietet hier ein reiches Betätigungsfeld. Doch auch von den Objekten der ,Kleinkunst" sind viele noch kaum dokumentiert und wenig verstanden. Die Bauforschung schließlich hat in der Erfassung ihrer Objekte mit modernen Methoden an Genauigkeit stark zugenommen. Sie kann für die Dokumentation und Erhaltung von Gebäuden in der islamischen Welt viel leisten, bevor diese Werke durch Abbruch und Überrestaurierung verloren gehen. Es bleibt nicht viel Zeit, um sich einem ,Unbehagen“ über die Identität des Fachs zu ergeben - dafür gibt es zu viel zu tun.

9 Vgl. bereits Albrecht Noth: Quellenkritische Studien zu Themen, Formen und Tendenzen frühislamischer Geschichtsüberlieferung. Themen und Formen (Bonner Orientalistische Studien 25), Bonn 1973. 


\section{Gender Studies - eine Herausforderung zur Standortbestimmung der Islamwissenschaft}

BIRGIT KRAWIETZ (BERLIN)

\section{Westliche Repräsentationen des Orients und Gender Studies}

Bei einem Besuch auf dem Sklavenmarkt in Kairo erwarb Fürst Pückler im Jahre 1837 die entzückende, allerhöchstens zwölfjährige Äthiopierin Machbuba, die er später als Lebensabschnittspartnerin ins kalte Deutschland mit zurücknahm. Wegen einer schweren Erkrankung verstarb sie dort jedoch recht bald. Sie wurde auf seinem Anwesen in Muskau beigesetzt. Längst nicht jeder verfügte über derartige Weltläufigkeit wie Fürst Pückler, aber das Publikum vor Ort konnte sich zumindest am Skandal der Saison ergötzen.

Bereits seit dem 17. und dann vor allem im 18. Jahrhundert war es in Europa zu einer beträchtlichen Nachfrage nach Exotika jedweder Art gekommen. Dies betraf vor allem auch deren wissenschaftliche oder aber literarische Darbietung in Form von Reiseberichten bzw. phantastischen Geschichten. Als ursächlich dafür betrachtet man eine Entwicklung, welche weite Bereiche der außereuropäischen Welt exotisierte und in den Radius westlicher Begehrlichkeiten treten ließ. Diese von Edward Said in seinem berühmten Buch Orientalism von 1978 kritisierte Haltung gilt als eine Begleiterscheinung des kolonialen Ausgreifens nach Asien und Afrika, welches sich vor allem im 19. Jahrhundert manifestierte. Dadurch wurde ein Prozess eingeleitet, den der palästinensisch-amerikanische Literaturwissenschaftler als „,die Orientalisierung des Orients“ bezeichnete, eine Haltung, die er insbesondere der englischen und französischen Orientalistik attestierte. In Abstützung machtpolitischer Interessen wurde der Orient auch im Rahmen der Wissenschaften zu einer gewaltigen Projektionsfläche europäischer Faszination und Abstoßung sowie des Willens, dort gegebenenfalls im Sinne einer ,civilizing mission“ einzugreifen. Eine solche hatte wohl auch Fürst Pückler im Sinn, denn er kaufe Machbuba nicht nur aus der Sklaverei ,frei“, sondern ließ ihr auch Lesen und Schreiben sowie Italienisch beibringen.

Entwicklungen dieser Art bescherten darüber hinaus einen beträchtlichen Schub an Motiven mit heute augenfälligem Gender-Bezug: allerlei Schleiertänze und Anlässe zur Fleischbeschau, mit Löwen kämpfende Araber, dunkelhäutige Wächtersklaven in martialischer Gewandung und vieles mehr gehören seither 
zum kulturellen Gedächtnis der Europäer - vor allem der Museumsbesucher. Den Gipfel solcher durch westliche Malerei (später auch Photographie und Alltagskultur), Architektur, Musik und Literatur ${ }^{1}$ konstruierten Welten bildet die Vorstellung vom Harem als einer Stätte unbeschränkter weiblicher Verfügbarkeit und Sinnlichkeit. Dagegen erscheint der orientalische Mann oft als ungestüm, gefährlich und ohne wirksame Impulskontrolle. Auch durch Opern wie Mozarts 1782 uraufgeführte „Entführung aus dem Serail“ wirkten Orientalia stilbildend. Bei derlei erotisch aufgeladenen Fluchten aus eigenen repressiven Sexualmilieus oder auf der Suche nach anderweitigen Sinnstiftungen offenbarten europäische Literaten, Reisende und Künstler ihre Vorstellungen von angeblich typisch orientalischen Gesellschaftsstrukturen.

Umbrüche in den Naturwissenschaften in den ersten Jahrzehnten des 20. Jahrhunderts und zeitversetzt auch entsprechende geisteswissenschaftliche Entwicklungen haben die Wirklichkeit als feste Größe jedoch zunehmend diskreditiert. Die Wahrnehmungsfähigkeit des erkennenden Subjekts wurde seither massiv in Zweifel gezogen und problematisiert. So betont Michel Foucault, dass jede Gesellschaft fortlaufend Konstruktionen vermeintlich natürlicher Gegebenheiten produziere. Das aktuelle Wissen sei keineswegs neutral, sondern als Ausdruck der jeweils vorherrschenden Machtverhältnisse zu verstehen und müsse deswegen immer wieder aufs Neue einer kritischen Analyse unterzogen werden. Dieses Verständnis wurde gerade von den Postcolonial Studies und der bereits seit den 60er Jahren einsetzenden Bewegung des postklassischen Feminismus aufgegriffen und für deren Zwecke nutzbar gemacht. Angeregt von Simone de Beauvoirs Le deuxième sexe (deutsch: „Das andere Geschlecht“) hatte insbesondere Judith Butlers Gender Trouble von 1989 („Das Unbehagen der Geschlechter“) einen maßgeblichen Einfluss auf die Ausgestaltung der neu eingerichteten Gender Studies. $^{2}$ Die soziokulturelle Konstruktion von Geschlecht (gender) in spezifischen Kontexten im Gegensatz zum biologischen oder anatomischen Geschlecht $(\operatorname{sex})^{3}$ und die längst über reine Geschlechterforschung im engeren Sinne hinausgehende Untersuchung verschiedener Identitätskategorien in Verbindung mit diversen Faktoren sozialer Autorität und Macht wurden zum Gegenstand jenes Studien-

1 Vgl. beispielsweise Ludwig Ammann: Östliche Spiegel. Ansichten vom Orient im Zeitalter seiner Entdeckung durch den deutschen Leser 1800-1850, Hildesheim: Olms 1989, insbs. S. 3-44, 150-155. Mein Dank gilt Ludwig Ammann (Freiburg), Kai Kresse (Berlin, ZMO) sowie den beiden Herausgebern dieses Bandes für ihre kritische Durchsicht dieses Beitrags und hilfreiche Anmerkungen.

2 Stellvertretend für eine ganze Reihe von Einführungen sei Christina von Braun/Inge Stephan (Hg.), Gender@Wissen. Ein Handbuch der Gender-Theorien, Köln u.a.: Böhlau 2005, genannt. Mit Bezug auf den Islam vgl. Leila Ahmed: Women and Gender in Islam. Historical Roots of a Modern Debate, New Haven: Yale University Press, 1992.

3 Sofern man sich nicht der radikalen These Butlers anschließt, welche auch letzteres für kulturell generiert hält. 
gangs Gender Studies, welcher sich in den USA seit den 1970er Jahren konstituierte. Während hierzulande reine Women's, Men's, Gay, Lesbian oder Queer Studies zumindest nicht zu breiterer institutioneller Verankerung im Bildungssystem gelangt sind, gilt dies aber sehr wohl für die seit einiger Zeit beträchtlich prosperierenden Gender Studies. Nach vereinzelten Initiativen seit den 80er Jahren haben aber erst die Umstellung auf die neuen Bachelor- und Master-Studiengänge und in Verbindung damit systematische Anleihen bei anglo-amerikanischen Curricula den derzeitigen Siegeszug nachhaltig befördert. Dies hat Folgen für die bereits etablierten Fächer. Letztere werden aufgefordert, sich einer entsprechenden Wandlung zu unterziehen und müssen sich nach ihrem Nutzen für Nachbardisziplinen fragen lassen. Die Gender Studies haben dabei, wie noch zu zeigen sein wird, einige Defizite in der Islamwissenschaft aufgedeckt, bieten aber auch Impulse für deren weitere Entwicklung.

\section{Stereotype Konstruktionen des Islam als Aufhänger für Gender Studies}

Was die hier einleitend skizzierte Dekonstruktion westlicher Rezeptionen des Orients angeht, so beschränkt sich der Untersuchungsgegenstand nicht allein auf koloniale Selbstermächtigungsstrategien in Bezug auf Asien und Afrika. Er betrifft auch den Islam als Religion. In historischer Perspektive ist der Blick sogar weit zurück bis in die Zeit der Kreuzzüge zu richten. Die Verbreitung des Islams wurde als Gefährdung des „Heiligen Landes“ angesehen. Die Kirche war deswegen bestrebt, Muhammad als unseriösen Lügenpropheten zu diskreditieren. Auch zu Zeiten der „Türkengefahr“ im 15. Jahrhundert waren entsprechende Negativdarstellungen sehr populär. Die Tatsache der gut ein Dutzend Eheschließungen des Propheten, welche deutlich über das für gewöhnliche Gläubige auf maximal vier Gattinnen festgelegte Limit (Koran 33:50-51) hinausgehen, insbesondere seine Eheschließung mit der noch kindlichen Aischa, haben bis heute immer wieder willkommenen Anlass zu scharfer Kritik geboten - bis hin zum Vorwurf der Pädophilie.

Erst mit der Emanzipierung der Orientalistik von der christlichen Theologie im späten 18. Jahrhundert und angeregt durch ihre Übersetzungs- und Vermittlungstätigkeit konnten sich jedoch auch gegenläufige Tendenzen im Sinne einer zunehmenden Würdigung und Wertschätzung des Islams oder orientalischer Lebenswelt respektive dessen, was man dafür hielt, entfalten. $\mathrm{Zu}$ dieser Entwicklung trugen im deutschsprachigen Raum beispielsweise der Dichter und Orientalist Rückert, aber auch Literaten im Range eines Lessing oder Goethe bzw. Philosophen wie Herder bei. Festzuhalten ist, dass sich im Westen für unterschiedliche historische Epochen und Strömungen veränderte Konstruktionen des changierenden Begriffs ,Orient‘ sowie der ,Welt des Islams‘ aufdecken lassen.

Eine wiederum stark polarisierte Situation ergibt sich schließlich heutzutage im zunehmend multikulturellen Europa, welches seit der zweiten Hälfte des 20. 
Jahrhunderts vor allem durch ausländische Arbeitsimmigration geprägt ist. Angesichts dieses „Orients vor der eigenen Haustür“ hegen viele besorgte Bürger eine dezidierte Meinung darüber, was es mit dem Los muslimischer Mädchen und Frauen gemeinhin auf sich hat, worauf man bei orientalischen Männern gefasst sein muss und woran das gesamtgesellschaftliche Zusammenleben mit Muslimen/Orientalen krankt. Besonders verbreitet ist die Vorstellung von der unterdrückten Frau, welcher durch patriarchalische Übermacht ein defizitäres Körperund Selbstwertgefühl eingeimpft und die über diesen Mechanismus - erforderlichenfalls durch körperliche Züchtigung - in Schach gehalten wird. Als Pendant dazu gilt der aufbrausende, gewalttätige Mann, welcher seine Regungen ohne Rücksicht auf Verluste ausagiert. Im schlimmsten Fall hat man bei Letzterem einen dauerhaft narzisstisch gekränkten, radikalisierten Bildungsverlierer vor $\mathrm{Au}$ gen, der sein persönliches Scheitern mit übersteigerter Aggression zu überwinden trachtet. Wissenschaftlich zu differenzieren sind ferner stereotype Vermutungen, wie diejenige, bei Muslimen trete angesichts der Übermacht der Moderne regressiv-fanatisches Verhalten auf und wohlmöglich sogar eine eigene „Kultur des Todes“ - von Tötungen Dritter im „Heiligen Krieg“ bis hin zu Selbstmord(attentaten). Gerade seit dem offiziellen „war on terror“ finden sich solche oder ähnliche Wahrnehmungen von grundsätzlicher kultureller Differenz (othering) ${ }^{4}$ verstärkt in populären Enthüllungs- oder Erfahrungsberichten. Auch für wissenschaftliche Publizistik öffnet sich in dieser Hinsicht ein mittlerweile beachtlicher Markt. Im Kielwasser von Altmeistern wie Bernard Lewis oder Bassam Tibi werden gerade in jüngerer Zeit in gesteigertem Maße fehlende innerislamische Selbstkritik und destruktive Tendenzen angeprangert. ${ }^{5}$ Seit Jahrzehnten dringen unmittelbar Betroffene wie Lehrer, Kindergärtner, Ärzte, Anwälte, Stadtplaner oder Polizisten auf Klärung ihrer Irritationen. Diesem Diskussionsbedarf sind Politiker und Medien allerdings nur selektiv gefolgt. Das gilt auch, wie man selbstkritisch sagen muss, für die westliche Islamwissenschaft, welche es insgesamt jahrzehntelang eher versäumt hat, sich als kompetenter Ansprechpartner für Fragen auch solcher Art zu positionieren. In dieses Beratungsvakuum sind stattdessen vielfach Vertreter anderer Fächer getreten - oft angeregt durch kulturübergreifende Graduierungsarbeiten ihrer eigenen Studenten mit so genanntem Migrationshintergrund.

An der Spitze der Themen, welche der Islamwissenschaft lange Zeit ohne Distinktionsgewinn erschienen, steht der Islam in Europa und die Analyse alternativer Islam-Konzepte in Sachen eines „Euro-Islam“ oder anderer Etikettierun-

4 Martin Sökefeld (Hg.), Jenseits des Paradigmas kultureller Differenz. Neue Perspektiven auf Einwanderer aus der Türkei, Bielefeld: transcript 2004, beklagt in seiner Einleitung, S. 16: „Das Konzept des ,Kulturkonflikts “ dominiert weite Bereiche des wissenschaftlichen Diskurses über Einwanderung.“

5 Vgl. http://www.akte-islam.de/7.html oder den Tenor bei http://europenews.blogg. de, beide vom 27. Februar 2007. 
gen. Eine ganze Reihe von Herausforderungen vertrauter Geschlechter-Attributionen lassen sich jedoch gerade in diesem Feld an einer Reihe von neuralgischen Punkten untersuchen wie z.B. bei Eheschließungen mit Nichtmuslimen, koranisch legitimiertem Züchtigungsrecht, Berufstätigkeit von Frauen, Teilnahme von Mädchen am Schwimmunterricht oder der speziellen Situation von homosexuellen Migranten. Spätestens seit dem ,11. September` sowie nach spektakulären Ehrenmorden und Ausschreitungen randalierender Jugendlicher in der banlieue ist es mit einer solchen vornehmen Meidehaltung jedoch weitgehend vorbei. Die Islamwissenschaft hat das Thema Islam in Europa bzw. im Westen in den letzten Jahren zunehmend für sich entdeckt. Nach jahrzehntelanger Konzentration vor allem auf die Situation von muslimischen Frauen hat sich aber das Interesse der Gender Studies und einiger Sozialwissenschaften gerade in letzter Zeit auch auf junge Männer mit Migrationshintergrund ausgedehnt. ${ }^{6}$ Die Impulse dazu gingen jedoch vor allem von sozialwissenschaftlichen Fächern aus. Das gewachsene Interesse ließ aber auch zu Tage treten, dass die Islamwissenschaft trotz reichhaltiger Quellen ihrerseits bislang wenig Systematisches zu (Re-)Konstruktionen hegemonialer Männlichkeit oder deren möglichen Gegenentwürfen in der Geschichte und Gegenwart islamischer Länder vorgelegt hat. ${ }^{7}$

Auf islamwissenschaftlicher Seite kann es selbstverständlich nicht nur um Auseinandersetzungen mit und gegebenenfalls Korrekturen von westlichen Repräsentationen muslimischer Lebenswelten gehen. Dafür sind ja komplementär auch Germanisten, Anglisten, Romanisten, (Kunst)Historiker, respektive Musikwissenschaftler, Psychologen, Soziologen und Vertreter der (Europäischen) Ethnologie oder Allgemeinen Kulturwissenschaft bzw. der Postcolonial Studies zuständig. Die primäre islamwissenschaftliche Beschäftigung gilt zunächst Diskursen, welche auf Arabisch, Persisch, Türkisch usw. Einblicke in das doing gender in diversen islamisch (mit)geprägten Kontexten gestatten - soziale Wechselwirkungen und Austauschprozesse mit einem (niemals in Reinform zu denkenden) ,Westen' inbegriffen. Auch die sprachlichen Grenzen verschwimmen jedoch in den letzten Jahrzehnten zunehmend, da sich längst viele Muslime im Westen unmittelbar auf Englisch etc. artikulieren. ${ }^{8}$ Das Phänomen der Übersetzung aus orientalischen in westliche Sprachen und umgekehrt ist bereits seinerseits als

6 Beispielsweise Ahmet Toprak: Das schwache Geschlecht - die türkischen Männer. Zwangsheirat, häusliche Gewalt, Doppelmoral der Ehre, Freiburg: LambertusVerlag 2005, S. 13, 169.

7 Vgl. allerdings den Sammelband von Lahoucine Ouzane (Hg.), Islamic Masculinities, London und New York: Zed Books 2006 oder - schon etwas spezieller - Catherine Mayeur-Jaouen (Hg.), Saints et héros du Moyen-Orient contemporain, Paris: Maisonneuve et Larose 2002.

8 Bei einem Workshop in Köln zu „Feminism, Islam and Pluralism in the West“ im Rahmen einer FES-Konferenz zu „Women in Islam“ bezeichnete Margot Badran am 9.3.2007 Englisch als „the global language of the Umma“, als universales Medium der Gemeinde gläubiger Muslime. 
ambivalentes Instrument zur Ausübung sozialer Macht in den Blick der Forschung geraten.

\section{Anatomie des Unbehagens}

Bevor nähere inhaltliche oder methodische Ausgestaltungsmöglichkeiten von Gender- und Islam-Studien erörtert werden, sind zunächst einige - oft unausgesprochene - Dynamiken gegenseitiger Abstoßung zu thematisieren. Das Unbehagen, welches die Islamwissenschaft bei einem so stark transdisziplinär ${ }^{9}$ angelegten Fach wie den Gender Studies zu verspüren mag und vice versa, speist sich aus verschiedenen Quellen. Nach der im ersten Teil skizzierten breiten Palette an stereotypen Vorstellungen, mit denen die Islamwissenschaft immer wieder konfrontiert wird und welche unter verschiedenen wissenschaftlichen Gesichtspunkten zu überprüfen sind, werden an dieser Stelle drei Aspekte herausgegriffen. Es handelt sich um erstens die Relevanz von Sprache, zweitens die traditionelle islamwissenschaftliche Fixierung auf Texte bei gleichzeitiger Vernachlässigung sozialer Kontexte und entsprechender sozialwissenschaftlicher Perspektiven sowie drittens die noch unzulängliche Eigeninitiative und Eigenständigkeit der Islamwissenschaft.

Was die erste Perspektive betrifft, nämlich die unterschiedlichen Dimensionen sprachlicher Kompetenz, so sind sowohl orientalische wie westliche Wissenschafts- und Quellensprachen zu berücksichtigen. Ein Umstand, der das Lesevergnügen für Islamwissenschaftler insgesamt nicht gerade steigert, ist die Tatsache, dass grob geschätzt $95 \%$ der Titel, welche in das Weichbild von Gender und Islam-Studien gehören (sie sind ganz überwiegend von Frauen verfasst!), heutzutage auf Englisch publiziert werden. Das ist auf jeden Fall wesentlich mehr als in den meisten anderen Gegenstandsbereichen der Islamwissenschaft und hat gewisse Folgen. Dieses Phänomen tritt in konzentrierter Form bei der Encyclopedia of Women \& Islamic Cultures ${ }^{10} \mathrm{zu}$ Tage, welche sich jetzt trotz ihres anachronistischen Titels (der sich ausdrücklich auf Frauen beschränkt und dadurch kulturelle Repräsentationen von Männlichkeit ausblendet) als das zentrale Medium von Gender und Islam-Studien etabliert hat. Das Problem besteht jedoch darin, dass, wer sich auf diesem Wege zu einem bestimmten Unterthema einen seriösen Überblick über Quellenlage, wissenschaftliches Schrifttum, Diskussionsstand und sonstige wichtige Aspekte verschaffen möchte, Gefahr läuft, dass ihm - zumindest aus der Sicht kontinentaleuropäischer Islamwissenschaften - teilweise Wichtiges entgeht. Auch ist auf diesem besonderen Wissenschaftsmarkt insge-

$9 \mathrm{Zu}$ Inter- und Transdisziplinarität in der Frauen- und Geschlechterforschung vgl. Sabine Hark: Dissidente Partizipation: Eine Diskursgeschichte des Feminismus, Frankfurt/M: Suhrkamp 2005, S. 363-396.

$10 \mathrm{Vgl}$. http://sjoseph.ucdavis.edu/ewic/index.htm vom 27. Februar 2007. 
samt ein besonders hoher Anteil an Sammelbänden zu verzeichnen, was die empfindlichen Lücken einer soliden thematischen Durchdringung mit Blick auf islamisch geprägte Gesellschaften eher schmerzlich erkennen lässt, als dass er sie erfolgreich überbrückt. Ein großer Teil solcher Darstellungen stammt aus USamerikanischer Feder und profitiert von der dortigen jahrzehntelangen Tradition der Gender Studies. Jedoch werden einschlägige Beiträge oft nicht von umfassend geschulten Islamwissenschaftlern verfasst. Es ist ein großer Gewinn, wenn ,Migranten' ihre Muttersprache, Quellen- und Sachkenntnisse in die Wissenschaft einbringen, aber viele leisten das eben nicht bzw. nur ziemlich unzulänglich. Gerade von den sozialwissenschaftlichen Disziplinen wird einschlägiges Schrifttum zum Islam, insbesondere auch solches aus weiteren europäischen Sprachen oft erst gar nicht berücksichtigt. Ohne die entsprechenden (westlichen und orientalischen) Sprachkenntnisse werden immer öfter monokulturell englische Quellen- und Schrifttumsverzeichnisse vorgelegt. Ein zu hoher Grad der Spezialisierung, etwa in der Medizinethnologie, birgt tendenziell die Gefahr eines gewissen Tunnelblicks. Die Marginalisierung arabischer u.a. Materialien sowie großer Anteile europäischer Islamwissenschaft und die fehlende rückwirkende Einbeziehung von islamwissenschaftlichen Gender Studies avant la lettre ist vor allem deswegen bedenklich, weil aufgrund mangelnder Kenntnisse des Schrifttums „das Rad immer wieder neu erfunden“ wird. Potenziell interessierte Islamwissenschaftler wenden sich deshalb oft mit Verdruss von entsprechenden Publikationen der Gender Studies wieder ab. Neugierde, Lernbereitschaft und Toleranz wären somit auch auf Seiten interessierter Nachbardisziplinen erforderlich und sind nicht bloß von der Islamwissenschaft zu verlangen. Gernot Rotters Dissertationstitel von 1966 „Die Stellung des Negers in der islamisch-arabischen Gesellschaft bis zum 16. Jahrhundert" mag heute manchen als sprachlich degoutant erscheinen. Es wäre jedoch fatal, solche islamwissenschaftlichen Publikationen, wie sie in dieser oder anderer Form insgesamt zu Tausenden vorliegen, gar nicht mehr zur Kenntnis zu nehmen, um sie entsprechend nutzbar zu machen. Die dringende Notwendigkeit profunder Kompetenz in orientalischen Sprachen für Gender und Islam-Forschung wird weiter unten noch aus den Abschnitten vier bis sechs ersichtlich, welche sich zentralen Untersuchungsbereichen von Gender und Islam zuwenden. Hier sei abschließend zunächst nur darauf hingewiesen, dass ca. 60-70 \% der Publikationen auf den großen arabischen Buchmessen des Nahen Ostens religiösem oder schariatrechtlichem Schrifttum zuzuordnen sind. Dieses als unbeachtlich zu betrachten oder nur an den Rändern bzw. in durch Übersetzungen erschlossenen Feldern forschen zu wollen, wäre ein kardinaler Fehler.

Der zweite Aspekt wechselseitigen Unbehagens zwischen den Disziplinen ist die starke Textlastigkeit der Islamwissenschaft. Angesichts der - auch historisch betrachtet - ungeheuren Fülle des Materials ist sie in gewisser Weise verständlich. Es ist ferner zu bedenken, dass die Orientalistik jahrhundertelang in erster Linie als hermeneutisch versierte Zulieferin der christlichen Theologie gefragt 
war. Sie emanzipierte sich dann als Philologie durch Einbeziehung von orientalischen Gegenwartssprachen. Dieses Programm wurde etwa zu Beginn des 20. Jahrhunderts um islamwissenschaftliche Realienkunde erweitert und erlebte erst seit dessen letztem Viertel wie andere Fächer auch einen gewissen „cultural turn“. ${ }^{11}$ Für Interessen der Gender Studies bedeutet die lange islamwissenschaftliche Fixierung auf die offizielle Botschaft von Texten, dass deren hegemonialpatriarchalische Lesart in der Regel gar nicht reflektiert und in Frage gestellt wurde. Auch unterblieben meistens lebensweltliche Gegenproben oder solche aus anderen Quellen. Lange Zeit wurde islamwissenschaftlicherseits auch der Aspekt einer konkreten „diskursiven Tradition“12 übersehen bzw. häufig einfach den Ethnologen überlassen. Hier hat die Islamwissenschaft unstreitig Nachholbedarf.

Andererseits aber werden von Muslimen selbst oder auch von Nichtmuslimen bzw. islamkritischen ,Apostaten“ islamische Begriffe bzw. Konzepte ins Feld geführt oder kritisiert. Somit ist es auch weiterhin geboten, die verschiedenen historischen Traditionen und gewisse Eigenlogik solcher Denksysteme zu untersuchen. In der islamischen Theologie etwa spiegelt sich die Geschlechterordnung üblicherweise in den jeweiligen Repräsentationen des Verhältnisses von Gott und Mensch und nicht in einer fachwissenschaftlich verselbständigten Anthropologie. Wenn die Instrumentalisierung islamischer Doktrinen in spezifischen Lebenswelten untersucht werden soll, könnte eine rein ethnologisch ausgerichtete und stark atomisierende Betrachtung kleinster Wissenseinheiten etwa bezüglich einer Detailfrage des Rituals viel zu kurz greifen und eine nötige geistesgeschichtliche Einbettung vermissen lassen. Islamwissenschaftler hingegen mögen dazu neigen, den Islam (oder auch regionale Besonderheiten wie anatolisches Gewohnheitsrecht) als jeweils mächtigsten Bestimmungsfaktor (z.B. für Ehrenmorde) anzusehen. Ohne zusätzliche Kenntnisse aus Bereichen wie beispielsweise der Migrationsforschung, Bildungssoziologie etc. besteht jedoch die Gefahr, dass gerade Islamwissenschaftler daran gehen, etwa Schwierigkeiten muslimischer Jugendlicher in der westlichen Schul- und Berufswelt oder mit der Justiz rein kulturalistisch zu deuten. Angesichts unzähliger kultureller Rekonfigurationen durch gegenseitige Beeinflussungen und Austauschprozesse haben Islamwissenschaftler allerdings Grund, sich auch mit geeigneten Theoriekonzepten für Konstruktionen von Identität auseinander zu setzen, wie z.B. dem Paradigma der Hybridität. Vehement wendet sich der postkoloniale Theoretiker Homi Bhabha mit seiner Vorstellung eines fruchtbaren ,dritten Raumes“ gegen ,hierarchische Ansprüche auf

$11 \mathrm{Zu}$ den vielen turns, auch wenn sie nicht alle mit voller Macht auf die Islamwissenschaft durchgeschlagen haben, vgl. Doris Bachmann-Medick: Cultural Turns. Neuorientierungen in den Kulturwissenschaften, Reinbeck: Rowohlt 2006.

12 Zur „,discursive tradition“ Talal Asad: „The Idea of an Anthropology of Islam“, in: Washington DC: Center for Contemporary Arab Studies, Georgetown University, Occasional paper, 1986, S. 1-22, hier S. 7, 14-17. 
die inhärente Ursprünglichkeit oder ,Reinheit" von Kulturen““. ${ }^{13}$ Debatten über Hybridität, Diaspora, transnationale Identität, Transkulturalität oder Transdifferenz ${ }^{14}$ wenden sich gegen essenzialisierende Behauptungen von Kultur, welche den Einzelnen auf ein quasi vorbestimmtes Handeln festzulegen versuchen. Falls es überhaupt eine dezidierte weltanschauliche Grundausrichtung von Genderund Islam-Studien geben sollte, dann eher diejenige, was hier dahingestellt bleiben muss, dass Islamwissenschaftler wirksam dem behaupteten Kampf der Kulturen entgegentreten, ${ }^{15}$ als dass sie sich daran beteiligen, etwa einem weltweiten Feminismus von der Stange das Wort zu reden.

Drittens ist zu bemerken, dass die Islamwissenschaft den gewaltigen Herausforderungen nicht dadurch angemessen entgegentritt, indem sie artig alle Hausaufgaben erledigt, welche an sie herangetragen werden bzw. an denen andere Fächer ein gesteigertes Gender-Interesse bekunden. Auch sind manche Fragestellungen aus der Sicht anderer Disziplinen längst ,abgehakt', könnten sich jedoch für Untersuchungen von Gender und Islam als äußerst fruchtbar erweisen. Es ist somit an der Zeit, dass die Islamwissenschaft ihren noch viel zu stark reaktiven Modus überwindet. Sie sollte ihre unerschöpflichen Quellen im Lichte neu gewonnener theoretischer Instrumente und inhaltlicher Anregungen produktiv überdenken und entsprechend auch eigenständige Ansätze und Forschungsinitiativen entwickeln. Wenn sie aber nur das zutage fördert, was andere Fächer vor dem Hintergrund ihrer disziplinären Ausrichtung für relevant halten, wäre es tatsächlich schlecht um sie bestellt. So führt, wie aus den nachfolgenden Punkten deutlich wird, allein schon die aktuelle Nachfrage anderer an den Gender Studies beteiligter Fächer zu signifikanten Ausblendungen ganz bestimmter islamwissenschaftlicher Bereiche: dazu zählen insbesondere vormoderne Geschichte, normativer Islam jenseits staatlich kodifizierter Schrumpfvarianten sowie die Missachtung von Süd-Süd-Dynamiken. Es wäre insgesamt wichtig, dass sich die Islamwissenschaft nicht alle Themen zu Gender und Islam von anderen Disziplinen vorgeben ließe und dabei nicht nur noch (wie schon einmal in ihrer Geschichte wie nämlich lange Zeit gegenüber der christlichen Theologie) als Zulieferer fungierte. ,Agency“ wäre somit auf Seiten der Islamwissenschaft nicht bloß als Gegenstand der Untersuchung erforderlich.

Angesichts des umfassenden, sich immer weiter ausbreitenden Spektrums dessen, was theoretisch an Gender- und Islam-Themen möglich ist, sind im Hin-

13 Homi Bhabha: Die Verortung der Kultur, Tübingen: Stauffenburg Verlag 2000, S. 57.

$14 \mathrm{Zu}$ Letzterer vgl. insb. Lars Allohio-Näcke/Britta Kalscheuer/Arne Manzeschke (Hg.), Differenzen anders denken. Bausteine zu einer Kulturtheorie der Transdifferenz, Frankfurt/M und New York: Campus 2005, 15-25, 443-453.

15 Gegen Religion als kulturelles Alleinstellungskriterium vgl. Amartya Sen: Die Identitätsfalle. Warum es keinen Krieg der Kulturen gibt, München: Beck 2007, S. 8, 2627 et passim. 
blick auf eine mögliche Kooperation von Islamwissenschaftlern mit Vertretern anderer Disziplinen Frustrationen und Konflikte vorprogrammiert. Demgegenüber werden im Folgenden drei wichtige, vielfach miteinander verknüpfte Forschungsbereiche von Gender und Islam in eigenen Abschnitten beleuchtet, nämlich zum einen (zumeist neuzeitliche) Geschichte, des Weiteren Literaturwissenschaft (einschließlich Kulturforschung) und schließlich Untersuchungen zum islamischen Recht, bei dem Norm und Wirklichkeit oft stark auseinander klaffen.

\section{Gender und (moderne) Geschichte islamischer Länder}

Ausweislich der Sekundärliteratur liegt der absolute Schwerpunkt der bisherigen historischen Erforschung von Gender und Islam auf der Moderne oder zumindest neuzeitlicher Geschichte. Das hat damit zu tun, dass Gender Studies und jüngere islamische Geschichte sehr eng mit einer ganzen Reihe von aktuellen Schlüsseldebatten und damit auch diversen weiteren Disziplinen wie z.B. Politikwissenschaft, Soziologie, Ethnologie oder Erziehungswissenschaft zusammenhängen. Neben dem bereits skizzierten Orientalismus sind Unterthematiken wie Kolonialgeschichte mit ihrer Verschiebung überlieferter Geschlechterrollen, der Entmachtung traditioneller und Schaffung neuer Eliten, Einführung westlicher Bildungsinstitutionen oder Herausbildung moderner Nationalstaaten zu nennen. Darunter fallen auch Phänomene wie der Staatsfeminismus eines Atatürk oder Bourghuiba. Ferner geht es um ethnische oder religiöse Bündnisvorstellungen, Verschiebungen von Machtverhältnissen durch ökonomischen Wandel, islamischen Internationalismus, Säkularisierung, Globalisierung, innerislamischen Pluralismus sowie Erinnerungskulturen. Auch handelt es sich um die (Wieder-) Erfindung von Traditionen, um islamische Reformer und Reformbewegungen, neue Medien, Jugendkultur, Umgang mit Alten und Behinderten, Einführung von Gesetzgebungen nach westlichem Muster, Konkurrenz und Vereinbarkeit von religiöser und säkularer Bildung, Neukonstituierung islamischer Normativität und deren weltweite mediale Vermittlung, Rechtspluralismus, Aktivitäten von NGOs, moderne Medizin- und Bioethik, islamischen Fundamentalismus, Heldenkulte, Märtyrer- und Gewalt-Problematik und dergleichen mehr. In geografischer Hinsicht sind die einschlägigen Themen mittlerweile fast unbegrenzt. GenderAspekte der Migrationsforschung und Globalisierung sowie das Wirken von internationalen islamischen Netzwerken und die dortige Beteiligung von Frauen spielen zunehmend eine Rolle. Viele muslimische Reformer oder Feministinnen sind von westlicher Wissenschaftsliteratur bzw. auch Belletristik unterschiedlicher Epochen beeinflusst, was jeweils genau zu rekonstruieren wäre. Muslimische Befreiungstheologen von heute sitzen weniger an altehrwürdigen Stätten islamischer Gelehrsamkeit wie der Azhar-Universität in Kairo, sondern gegenwärtig insbesondere an US-amerikanischen Hochschulen. Die „Queer TV“Aktivitäten der streitbaren kanadischen Lesbierin und Islamkritikerin Irshad 
Manji wären kaum in den 56 Mitgliedstaaten der „Organization of the Islamic Conference" möglich. ${ }^{16}$

Ältere Epochen islamischer Geschichte stoßen demgegenüber auf deutlich weniger Interesse. Selbst diejenigen aber, welche Gender- und Islam-Studien auf jüngere Geschichte beschränkt sehen wollen, kommen nicht umhin, sich immer wieder mit den zahlreichen konkurrierenden Entwürfen einer normstiftenden Urgemeinde von Medina im 7. nachchristlichen Jahrhundert auseinander zu setzen. Die Art, wie dieses präsumtive Gesellschaftsmodell und insbesondere die Rolle der verschiedenen Frauen des Propheten heutzutage imaginiert wird, wirft auch ein entscheidendes Schlaglicht auf die jeweiligen Geschlechterdoktrinen. Über die Geschichte der Islamischen Welt ${ }^{17}$ hinaus werden von der Islamwissenschaft beispielsweise auch noch Auskünfte verlangt zu den vorislamischen Sozialstrukturen im Bereich von Ehe und Familie auf der Arabischen Halbinsel.

Vormoderne arabische usw. Quellen erscheinen insofern als problematisch, als sie in der Regel durch einen dominant männlichen Herrschaftsdiskurs geprägt sind, auch wenn das nicht die tatsächlich gelebte Realität wiedergeben muss. Sie werden deswegen in Gender-Hinsicht weniger bearbeitet, denn gerade die jüngere Forschung hat vor allem die kompensatorische Rekonstruktion einer aktiven Rolle von Frauen in der Islamischen Welt im Sinn. Die Zeugnisse des - häufig aber eher indirekten - Agierens von Frauen, müssen demzufolge oft erst mühsam aus den Quellen rekonstruiert werden. Selbstzeugnisse wie Briefe, Tagebücher, Frauenmagazine oder (Auto-)Biographien liegen in signifikanter Zahl allerdings meist erst ab dem 19. Jahrhundert vor. Bislang konzentriert sich die Aufmerksamkeit noch auf so genannte ,women worthies“"18, also Frauen, welche in besonderer Weise als Individuen von sich reden machten. In deutlich geringerer Zahl werden Untersuchungen angestellt, welche sich mit den mehr oder weniger anonymen Schicksalen von beispielsweise Fabrikarbeiterinnen oder Prostituierten auseinandersetzen.

16 Ihre Ausführungen zum Islam können allerdings von Manjis Website unter http://www.muslim-refusenik.com unentgeltlich auf Arabisch, Persisch und Urdu heruntergeladen werden, eingesehen am 27. Februar 2007.

17 Von der „Islamischen Welt“ ist in diesem Beitrag in Großbuchstaben die Rede, um islamisch geprägte Gesellschaften zu bezeichnen oder solche, in denen Muslime (wie immer es um deren persönliche Gläubigkeit bestellt sein mag) in der Mehrzahl waren oder noch sind. Der Ausdruck „Islamwissenschaft“" wird im Kollektivsingular benutzt, denn es geht um Prozesse der Ausdifferenzierung des Faches und die fortschreitende Verselbständigung von Teilbereichen.

18 Magaret L. Meriwether/Judith E. Tucker (Hg.), Social History of Women and Gender in the Modern Middle East, Boulder Westview Press 1999, S. 3. 


\section{Gender und Islam in Literatur- und Kulturwissenschaften}

Die Entwicklung der Postcolonial Studies mit ihrer Sensibilität gegenüber Klasse und Ethnizität sowie asymetrischen Machtverhältnissen in der Gesellschaft insgesamt hat auch verstärkt Gender- und Islam-Fragen in den Blick treten lassen. Bei englischsprachigen Quellen zögern Islamwissenschaftler jedoch bislang, an deren Bearbeitung mitzuwirken. Ähnliches gilt für frankophone Literatur des Maghreb bzw. auch für lateinamerikanisches Schrifttum, welches bis zu einem gewissen Grad von arabischen oder muslimischen Einwanderern beeinflusst ist. Von wenigen löblichen Ausnahmen abgesehen erfolgt die wissenschaftliche Branchensortierung bislang - wenig inspirierend - in erster Linie formal entlang den Sprachgrenzen der Originalquellen. In arabischer, persischer oder türkischer Literatur der Moderne ist zwar die so genannte ,Frauenfrage“ von großer Bedeutung, wird aber keineswegs mehrheitlich nur von Frauen behandelt. Gerade zu seinem Beginn ist der Feminismus in der Islamischen Welt eher noch Männersache gewesen und ist besonders eng mit dem Bildungsproblem verknüpft. Die genauen Unterschiede zwischen säkularer bzw. stark westlich geprägter Emanzipationsbewegung und verschiedenen Spielarten eines islamischen Feminismus nötigen jedoch auch westliche Frauenrechtlerinnen, über unterstellte kulturelle Prämissen im Sinne eines klar erwartbaren Programms globaler „sisterhood“ nachzudenken. Eine ganze Reihe muslimischer Feministinnen wollen nämlich aus bestimmten Lebenssituationen gar nicht befreit werden, deren Bekämpfung bisher als für den Feminismus essentiell betrachtet worden ist. ${ }^{19}$ Und viele von denen, die durchaus ein stark emanzipatorisches Programm erkennen lassen, lehnen im Übrigen die Bezeichnung ,,islamische Feministin“ für sich selbst dezidiert ab. Die große Erzählung einer ,white woman's burden“, Geschlechtsgenossinnen nach einem klar erkennbaren Katalog bewährter Maßnahmen den gemeinsamen Weg zu einer weltweit fortschreitenden Emanzipierung zu weisen, hat sich als Sackgasse erwiesen bzw. ist unerwartet auf Renitenz der zu Errettenden gestoßen. Unabhängig von genauen Inhalten ist aber allein schon die wachsende Zahl schreibender Frauen im 19. und 20. Jahrhundert gender-relevant. Dies gilt in besonderem Maße für weibliche (Auto-)Biographien. Ob fiktional oder nicht ermöglichen solche Schriften den Zugang zu eindringlichen Binnenperspektiven von Konflikten zwischen familialer Innen- und gesellschaftlicher Außenwelt. Ein weiterer Schwerpunkt islamwissenschaftlicher/arabistischer/iranistischer/turkulogischer etc. Bemühungen im Bereich der Literatur ist es, Verbindungen zwischen dem Ringen um nationale Unabhängigkeit oder Identität und Emanzipation aufzuzeigen. So werden in der palästinensischen Literatur das zu befreiende Land

19 Saba Mahmood: Politics of Piety. The Islamic Revival and the Feminist Subject, Princeton: Princeton University Press 2004, S. 197-199 et passim. 
verschiedentlich als Braut und der Kämpfer als ihr Bräutigam metaphorisiert. ${ }^{20}$ Auch vormoderne Literatur bietet in reichem Maße Anschauungsmaterial für Gender Studies. Mentalitätsgeschichtlich interessante Aspekte arabischer Liebeslyrik $^{21}$ einerseits, aber auch die satirische Schmähung von Gegnern sowie Darstellungen siegreicher, heldenhafter Gestalten gestatten tiefe Einblicke in Strukturen sozialer Verhaltenserwartungen. Für ältere Phasen islamischer Geschichte bietet die Lyrik insgesamt das gegenüber der Prosa reichere Anschauungsmaterial, jedenfalls solange es nur um Belletristik im engeren Sinne geht. Homosexualität ist ein besonders signifikantes Beispiel dafür, dass bestimmte Phänomene in mehreren Genres islamischen Schrifttums sowie diversen sozialen Kontexten ganz unterschiedlich beurteilt werden - von teilweise schärfster schariatrechtlicher Sanktionierung bis hin zur Huldigung in klassischer arabischer und vor allem persischer Dichtung.

Der berühmte Koranexperte und Kenner arabischer Literatur Naṣr Hāmid Abū Zayd charakterisiert die islamische Zivilisation als eine „Kultur des Textes (hadārat al-naṣs) “. ${ }^{22}$ Demgegenüber ist die Bildende Kunst wegen des so genannten (aber nicht allzu strikt eingehaltenen) islamischen Bilderverbots für Belange der Gender Studies vergleichsweise schwach ausgeprägt. ${ }^{23}$ Dieser Befund kann jedoch für die seit der Mitte des 19. Jahrhundert in der Islamischen Welt zunehmende Präsenz von Produkten visueller Kultur im öffentlichen und dann auch privaten Leben nicht mehr gelten. Den Schriften als Gegenstand von Gender- und Islam-Forschung werden deswegen zunehmend Artefakte der Bildenden Kunst bis hin zu Photographie und Film gegenüber gestellt. Inspiriert von Autoren wie Loti oder Flaubert bzw. Malern wie Ingres oder Gérome bestätigte und kommerzialisierte die voyeuristische koloniale Photographie mit ihren neckischen Postkarten-Sujets den europäischen Mythos vom Orient. Auch Muslime selbst haben früh neue Medien wie etwa Portraitmalerei oder Photographie zu eigenen Darstellungszwecken genutzt. ${ }^{24}$ Nobilitierende Inszenierungen des jeweiligen staatlichen Machthabers in Amtsstubenportraits oder durch Denkmäler im öffentlichen Raum sind längst ein verbreitetes Phänomen. Westliche Repräsentationen des orientalischen Mannes reichen von hedonistischen Genre-Bildern im Stile eines „Hafis vor der Schenke““25 bis zur Darstellung des präpotenten, gewaltbereiten

20 Birgit Embaló/Angelika Neuwirth/Friederike Pannewick (Hg.), Kulturelle Selbstbehauptung der Palästinenser. Survey der modernen palästinensischen Dichtung, Würzburg: Ergon 2001, S. 15.

21 So z.B. Thomas Bauer: Liebe und Liebesdichtung in der arabischen Welt des 9. und 10. Jahrhunderts. Eine literatur- und mentalitätsgeschichtliche Studie des arabischen Ġazal, Wiesbaden: Harrasowitz 1998, insbesondere S. 93-149.

22 Mafhūm al-nașs, Beirut: al-Markaz al-țaqāfī al-'arabī 1994, S. 9.

23 Die Segregierung von Frauen durch Architektur ist hier ebenfalls von einschlägiger Bedeutung.

24 Vgl. beispielsweise unter http://www.qajarpages.org, gesehen am 27. Februar 2007.

25 Titel eines Gemälde von Anselm Feuerbach von 1852 in der Kunsthalle Mannheim. 
arabischen Flugzeugentführers im Hollywood-Kino. Schwitzend und mit Dreitagebart tritt er dem Zuschauer auf der Gangway entgegen. Seine neurotische Belastungsstörung, die ihn ständig nervös schreiend mit der Waffe herumfuchteln und ganz unmittelbar die Schwangere in der ersten Reihe malträtieren lässt, droht ständig in die befürchtete Katastrophe umzukippen. Für Einsichten in Einflüsse des Islams und gewohnheitsrechtlicher Praktiken ist gerade der Film von Bedeutung. Er gestattet Einblicke in psychologische und soziale Hintergründe komplexer Problematiken wie beispielsweise auch der weiblichen Beschneidung (z.B. „Moolaadé“ von Ousmane Sembène) oder der im Maghreb bedeutsamen rechtlich-sozialen Fiktion vom schlafenden Embryo (,Das schlafende Kind“ von Yasmine Kassari). Die Verbindung von Literaturforschung und visueller Anthropologie ist gerade für Gender-Aspekte bedeutsam. Sowohl literarische Verarbeitungen wie visuelle Repräsentationen erlauben es, verschiedene Verstöße gegen die normative Ordnung und Rollenerwartungen des Gesetzesislams bzw. die spielerische Auseinandersetzung mit Letzterem zu thematisieren. Gender- und Islam-Studien sollten sich insgesamt nicht als festgefügter Kanon, sondern als eine lernfähige und lernbereite Perspektive verstehen und dabei ein hohes Maß an inhaltlicher Offenheit an den Tag legen. Manche Themenstellungen, wie etwa „Harem als Phantasma"-Inspektionen, dürften mittlerweile ihren heuristischen Zenit überschritten haben.

\section{Gender und Islamisches Recht}

Nichts ist im Überschneidungsbereich von Islam, Recht und Gender so einschlägig wie das Familienrecht in Ländern der Islamischen Welt, ${ }^{26}$ denn dort laufen viele Rollenkonstruktionen zusammen. Gesetzliche Festlegungen als so genanntes Personalstatut (qānūn al-aḥwāl al-šahșiyya) sind verknüpft mit einer ganzen Reihe unterschiedlicher rechtlicher Belange (wie Eheschließung, Polygamie, Scheidung, Erbrecht oder Unterhalt), welche bereits in den traditionellen Werken islamischen Rechts eingehend erörtert werden. ${ }^{27}$ Die (Teil)Kodifizierung islamischen Rechts ist allerdings erst ein Phänomen der Moderne und hängt eng mit der Schaffung von Staaten nach europäischem Muster zusammen. Sie fällt in den einzelnen Nationalstaaten unterschiedlich aus und ist in eine umfassende Bestandsaufnahme der aktuellen rechtlichen Situation einzubetten. Der Islam wird in den Verfassungen verschiedentlich als Staatsreligion und ,die Scharia' als eine

26 Vgl. beispielsweise Andrea Büchler: Das islamische Familienrecht. Eine Annäherung unter besonderer Berücksichtigung des Verhältnisses des klassischen islamischen Rechts zum geltenden ägyptischen Familienrecht, Bern: Stämpfli 2003.

27 Zur Definition vgl. Hans-Georg Ebert: Das Personalstatut arabischer Länder. Problemfelder, Methoden, Perspektiven; ein Beitrag zum Diskurs über Theorie und Praxis des islamischen Rechts, Frankfurt/M u.a.: Lang 1996, S. 11. 
der Quellen oder sogar die zentrale Quelle der Gesetzgebung ausgewiesen. Dies bedeutet jedoch heutzutage in der Regel keine wirkliche Dominanz oder gar Suprematie schariatrechtlicher Normsetzung gegenüber der gesamten staatlichen $\mathrm{Ge}$ setzgebung und führt im Einzelfall zu ganz unterschiedlichen Auswirkungen auf Frauen und Familien. Neben dem Personalstatut sind gender-relevante Formen von Scharia-Recht in einigen Staaten, wie etwa Saudi-Arabien, Iran, Pakistan oder Sudan, auch im Strafrecht anzutreffen, aber auch in sonstigen Rechtsmaterien. Diese Aspekte können nicht allein von der Islamwissenschaft herausgearbeitet werden. Für modernes Gesetzesrecht ist zum einen die Rechtsvergleichung zuständig, flankiert von anderen Disziplinen, wie der Politikwissenschaft. Auch innerstaatlich ergibt sich im Zusammenspiel von Scharia, (islamischem) Gesetzesrecht und gewohnheitsrechtlichen Praktiken ein weites Feld für Rechtspluralismus, der noch zu wenig erforscht ist. Auch die Rechtsethnologie analysiert Strategien, wie sich Frauen und andere soziale Akteure bzw. Gruppen die Justiz oder auch weitere Institutionen der Schlichtung von Disputen zunutze machen, um ihre Interessen durchzusetzen.

Konkret untersuchte originalsprachliche Quellen der Islamwissenschaft sind hier gewöhnlich moderne Gesetzestexte oder - insbesondere für die Frühmoderne bzw. die Neuzeit - häufig auch Gerichtsakten. Besonders ergiebig für Darstellungen von „female agency“ sind dabei Frauen als Stifterinnen oder Begünstigte von waqf-Einrichtungen, d.h. frommen Stiftungen des islamischen Rechts. Bei der Interpretation all solcher Phänomene kommt es auf die komplexen jeweiligen Strukturen an, denn ,,neither secularization nor a return to a Shari'a based society in themselves ameliorate or worsen women's lot.“28

Neben der Domäne des Familienrechts gilt es, auch die im Westen weniger vertrauten, weiteren Bereiche normativen Islams für Erkenntnisinteressen der Gender Studies, aber auch der Islamwissenschaft selbst nutzbar zu machen. Derartige Einsichten werden üblicherweise weitgehend nicht als Recht rezipiert und dementsprechend marginalisiert. Sie machen jedoch den Großteil dessen aus, was in der historischen Entwicklung - in teilweise stark umgestalteter Form - auch heute noch als tradiertes, normativ relevantes Wissen ausführlich erörtert wird. Dies betrifft beispielsweise folgende, aber noch keineswegs vollständig erfasste gender-relevanten Bereiche: Rituelle Reinheit beider Geschlechter, Umgang mit der Leiche, Kleidersemiotik jenseits der extensiv behandelten Frage des Schleiers als Symbol, Gräberbesuch von Frauen, Teilnahme an religiösen Festen oder vergleichbares Auftreten im öffentlichen Raum, Frau und Pilgerfahrt sowie Normierung von Mobilität allgemein, Frau und Heiliger Kampf ( $\breve{g} i h \bar{a} d$ ), Exklusionsstrategien gegenüber Frauen bezüglich bestimmter Funktionen oder Ämter, Regeln der Begrüßung, Bewirtung von Gästen, Reglementierung von Blicken und Be-

28 Ziba Mir-Hosseini: Marriage on Trial. A Study of Islamic Family Law, Iran and Morocco Compared, London und New York: Tauris 2000, S. 198. 
rührungen, Konstruktionen von Kindheit, Unreife oder (Geistes)Krankheit, Umgang mit Dämonen $(\breve{g} \text { inn })^{29}$, Maßnahmen zur Körpergestaltung, medizinische Behandlungen oder Strafausübung gegenüber Frauen. Es gibt noch weitere Genres schariatrechtlicher Stellungnahmen, welche ebenfalls zu berücksichtigen sind. So erlauben Fatwas und Spezialstudien die Behandlung neuartiger Fragen, wie etwa im Bereich der Bio- und Medizinethik, insbesondere moderner Reproduktionsmedizin. Dies geschieht nicht zuletzt aufgrund der durch die vielfältigen Kommunikationsmedien verbreiteten Formen islamischer Normativität, wie insbesondere des Internets und von „Islamic soundscapes, ways of reconfiguring urban space acoustically through the use of Islamic media forms ${ }^{\text {‘30 }}$. Derartige Repräsentationen gebotenen Verhaltens sind nicht notwendigerweise an staatliche Regulierung gebunden und funktionieren in Kombination oder Überlappung mit säkularem Orientierungswissen. Sie sollten von den Gender Studies nicht ignoriert werden, denn Kultur und somit auch normative Kultur ,rückt die menschliche Subjektivität ins Zentrum der Fragestellung und lässt die Vorgänge und Geschehnisse der menschlichen Welt in Raum und Zeit im Lichte der Deutungen verstehen, die ihnen die Betroffenen angedeihen lassen “ ${ }^{31}$ Die konkreten Anteile von islamischem Recht im Bereich der Ethik, Moralität oder auch der Konstruktion von Emotionen, wie beispielsweise von Scham, sind ebenfalls stark unterforscht.

Die Scharia als Invokation und inhaltliche Bezugnahme auf ein in der Praxis wie im Bewusstsein der Gläubigen existierendes, wenn auch für die westliche Islamwissenschaft und Jurisprudenz kognitiv nicht beweisbares, ,vorgegebenes “ Gottesrecht bedarf zu ihrer Repräsentation und Rekonstruktion von Fall zu Fall immer wieder aufs Neue der aktuellen Bestimmung durch islamische Jurisprudenz (fiqh). Auch nach deren Selbstsicht sind aber die wenigsten Belange des Islamischen Rechts ausdrücklich oder gar abschließend von Gott geregelt, so dass sich auch in vielen ,frauenrechtlichen ' Fragen ein beträchtlicher Argumentationsspielraum ergibt. Im weiten Feld der so genannten ,koranischen Wissenschaften wimmelt es von überlieferten, permanent (re)produzierten Exklusions- bzw. Marginalisierungsstrategien gegenüber Mädchen/Frauen, religiös nachlässigen Glaubensbrüdern oder religiösen Minderheiten. Religiös gestiftetes Wissen wird von muslimischen Reformern nicht allein durch feministische Koranexegese, sondern zunehmend auch in umfassender Auseinandersetzung mit juristischer Hermeneutik und praktischer Jurisprudenz kritisch ausgeleuchtet und nach den jeweiligen Regeln der Kunst dekonstruiert. Prominente Fälle akademischer, zu-

29 Der juristische Diskurs ist jedoch bei all diesen Themen nur eine von mehreren wichtigen Dimensionen. Die Untersuchung von etwa Gender und Dschinnen ist bislang vorwiegend von Ethnologen betrieben worden.

30 Charles Hirschkind: The Ethical Soundscape: Cassette Sermons and Islamic Counterpublics, New York: Columbia University Press 2006, S. 6.

31 Jörn Rüsen: Kultur macht Sinn, Köln und Weimar: Böhlau 2006, S. 173. 
gleich aktivistischer Gegenstrategien und von Forderungen nach geschlechtergerechter Partizipation sind in jüngerer Zeit beispielsweise die iranische Juristin und erste muslimische Friedensnobelpreisträgerin Schirin Ebadi oder der ägyptisch-amerikanische Anwalt, Islamwissenschaftler und Feminist Khaled Abou El Fadl. Die amerikanische Koranhermeneutikerin Amina Wadud schließlich nimmt sich die Freiheit, bestimmte juristische Deutungen des Korans wie etwa eines Züchtigungsrecht für Männer (Sure 4:34) aus ihrer persönlichen Glaubensüberzeugung heraus entschieden zurückzuweisen. Sie orientiert sich dabei am universalen Menschenbild des Koran, ,while armed with comparative religious studies in the twentieth and twenty-first centuries",32.

\section{Jenseits der vertrauten Regionalwissenschaft}

Die Verbindung mit Gender Studies fordert die Islamwissenschaft noch in einer weiteren Hinsicht heraus. In den letzten Jahrzehnten stellten Arabisch, Persisch und Türkisch/Osmanisch das unverrückbare Dreigestirn einer islamwissenschaftlichen Ausbildung dar. Subjektiv konnte deshalb der Eindruck entstehen, dadurch sprachlich so etwas wie den relevanten Kernbereich der Islamischen Welt erfasst zu haben. Urdu oder Bahasa Indonesia bildeten dagegen, zumindest in Deutschland, eher eine Ausnahmeerscheinung. Für eine ernsthafte Gender und IslamForschung sind solche Ausgrenzungen des süd(ost)asiatischen Raumes jedoch fatal und stehen in deutlichem Gegensatz allein schon zu den demographischen Befunden. Unter den weltweit 1,4 Milliarden Muslimen stellen die Indonesier mit ca. 215 (Gesamtbevölkerung 245) Millionen das größte nationalstaatliche Kontingent. Es folgen Pakistan, Indien, Bangladesch und frühestens an fünfter Stelle ein arabisches Land, nämlich Ägypten mit ca. 70 Millionen Muslimen. ${ }^{33}$ Gender und Islam-Studien dürfen sich aber nicht nur in besonderem Maße für Bevölkerungsentwicklungen interessieren, sondern müssen dies auch tun im Hinblick auf nationale Identitätsbildung sowie das Zusammenleben in multiethnischen und multireligiösen Staaten wie z.B. auch in Malaysia. Von Interesse ist ferner, wie sich die Erfahrungen mit den ehemaligen atheistischen und sozialistischen Sowjetrepubliken auf deren muslimische Bevölkerungsanteile ausgewirkt haben.

Reformimpulse zu Gender-Fragen gehen heutzutage zunehmend nicht von den traditionellen arabischen Lehrstätten in Kairo, Damaskus oder Medina aus, sondern von der angeblichen Peripherie der Islamischen Welt. Um Entwicklungen in diesen Regionen verstehen zu können, ist es aber wichtig, nicht nur die

32 Vgl. ihre neueste, halbbiographische Monographie ,Inside the Gender Jihad. Women's Reform in Islam', Oxford: Oneworld 2006, S. 192-195.

33 Fast genauso viele haben die Türkei mit ca. $97 \%$ Muslimen oder Nigeria, wo sich allerdings nur die Hälfte der Bevölkerung zum Islam bekennt. 
Einflüsse des Westens oder von Globalisierungsprozessen zu untersuchen, sondern auch die mannigfaltigen Süd-Süd-Beziehungen im Sinne der historischen und gegenwärtigen Verflechtungen von außereuropäischen bzw. nicht westlichen Gesellschaften, Gruppierungen und Individuen untereinander. Im Zuge von ausbildungsbedingter oder ökonomischer Migration kommt es zu höchst unterschiedlichen Prozessen der Rezeption und Diffundierung eines im Wesentlichen normativen Islam. Werden solche Entwicklungen nicht näher studiert, entsteht des Weiteren der fatale Eindruck, bei muslimischen Reformern oder den sozialen Wandel betonenden Stimmen/Akteuren müsse es sich vornehmlich um Leute handeln, die im Westen ausgebildet wurden oder sich an diesem Vorbild orientieren. Die hier vorgenommenen Untersuchungen des Verhältnisses, in dem Gender Studies und Islamwissenschaft zueinander stehen, bieten jedoch Anlass, den sich immer wieder neu figurierenden, allzu oft selbstherrlichen Deutungen westlicher Provenienz näher auf den Grund zu gehen.

\section{Lob des Unbehagens - ein vorläufiges Fazit}

Ein Unbehagen in der Islamwissenschaft, dem diese sich allerdings nicht in offenen Diskussionen stellt, wurzelt darin, dass die Islamwissenschaft mit den normativen und deskriptiven Aspekten ihres Fachs, die einander wechselseitig bedingen, bislang nicht ganz ins Reine gekommen ist. Sie teilt diese Problematik mit der Theologie, der Politikwissenschaft und der Jurisprudenz sowie denjenigen Disziplinen, wie beispielsweise auch der Ethnologie, die es in ihrem Gegenstandsbereich mit dem Verhältnis von Normen und Handeln zu tun haben. Hier wird die These vertreten, dass vor allem die Kombination mit Gender Studies eine inhaltlich und methodisch weit gespannte Islamwissenschaft sinnvoll erscheinen lässt. Problematisch wäre jedoch eine Festlegung auf eine imaginäre Königswissenschaft bzw. eine einzige allein seligmachende Teildisziplin im Rahmen oder in Kombination mit der Islamwissenschaft. Vielmehr dürften fallweise wechselnde Methodenkombinationen oder zumindest doch transdiziplinäre Betrachtungen erforderlich sein.

Der Islam ist zu wichtig, um ihn allein der Islamwissenschaft zu überlassen. Angesichts der für Aspekte der Gender Studies besonders bedeutsamen charakteristischen Verbindung von Religion, Recht und Moral in einer Vielzahl von islamischen Staaten, die auf einer jeweils unterschiedlichen Synthese von religiösem und säkularem (staatlichem) Recht basieren, betrachtet sich die Islamwissenschaft mit Blick auf normativen Islam seit jeher, aber heute ganz besonders nicht als alleinzuständig. Ein Unbehagen der Islamwissenschaft kann nicht darin gesehen werden, dass sie ihr Forschungsfeld arbeitsteilig organisieren und bestellen muss. Es sollte auch nicht dadurch begründet werden, dass neue Problemstellungen, welche islamische Gesellschaften - wie die Weltgesellschaft überhaupt betreffen, auch neue Problemstellungen für die Islamwissenschaft ergeben. An- 
lass zum Unbehagen ist jedoch die Tatsache, dass die beteiligten Öffentlichkeiten die Bedeutung der Islamwissenschaft für derartige Forschungen zwar sehr bejahen, die schon bestehenden Forschungseinrichtungen jedoch nicht in die Lage versetzen, ihren Aufgaben in verantwortlicher Weise nachzukommen. Solange es an europäischen Universitäten für die Sphäre islamisch geprägter Gesellschaften nicht ähnlich viele Stellen gibt, wie für den Bereich ,christlich-europäischer Kultur', sind die Islamwissenschaften strukturell benachteiligt und werden auf Dauer überfordert. Dies gilt insbesondere gegenwärtig, da sich unter dem Druck der Gender Studies u.a. das gesamte Forschungsfeld verändert hat und auch weiterhin fortlaufend verändern wird. 

Teil III

Mediale und politische Ambivalenzen 



\section{Auf dem Marktplatz der Islamgespenster. Die Islamwissenschaft in Zeiten des Erklärungsnotstandes}

MANFRED SING (FREIBURG)

Durch den 11. September 2001 ist das Fach Islamwissenschaft unverhofft in den Mittelpunkt des öffentlichen Interesses gerückt. Diese erhöhte Aufmerksamkeit hat sich, aufs Ganze gesehen, für die Islamwissenschaft zweischneidig ausgewirkt. Einerseits erwartet man sich Beratung von den Islamwissenschaftlern, andererseits stehen diese am Pranger - vor allem dann, wenn sie aktuelle Konflikte gerade nicht unter Bezugnahme auf die islamische Geschichte, Kultur oder Religion erklären. Dies bleibt oftmals fachfremden Experten überlassen, die unbeschwert von der Last der Komplexität des Gegenstands über das Wesen des Islams spekulieren und Linien vom Koran zum Taliban oder vom 11. Jahrhundert zum 11. September konstruieren. Auch im universitären Raum hat das Wissen vom Islam deutlich an Bedeutung gewonnen und ist von der Peripherie ins Zentrum vorgedrungen, wodurch sich die Machtverhältnisse und -strukturen gewandelt haben. Das Wissen vom Islam lässt sich nicht mehr als Monopolgebiet von Spezialisten mit ihrer akademischen Geheimsprache reklamieren. Vielmehr sieht sich die Islamwissenschaft in einen Wettbewerb mit anderen Geistes- und Sozialwissenschaften geworfen, die sich mit den Ursachen sozialer und politischer Konflikte beschäftigen und nun verstärkt im Claim Muhammads wildern.

Für die Islamwissenschaft hat sich deshalb das Rechtfertigungsproblem im politischen und wissenschaftlichen Betrieb nur vordergründig gelöst. Vor 2001 galt die Islamwissenschaft als Orchideenfach und hatte um ihre Existenzberechtigung gegen rein ökonomische Vorbehalte zu kämpfen - ähnlich wie die Indologie oder Sinologie. Seit 2001 hat sie jedoch ihre Existenzberechtigung noch expliziter nachzuweisen, wenn auch nicht mehr allein gegenüber ökonomischen Einwänden. Die Nützlichkeit des Faches bemisst sich nun in erster Linie daran, inwiefern es handfeste, nahe liegende Interessen befriedigen kann. Dass sich die Erwartungshaltung von Politik und Öffentlichkeit, aber auch von Universitäts- 
Rektoren und Studierenden gegenüber der Islamwissenschaft grundlegend gewandelt hat, schlägt sich nicht nur in den Lehrinhalten nieder. War Studienanfängern noch in den 1990er Jahren die Verblüffung ob ihrer Studienfachwahl gewiss, so wird ihnen heute von allen Seiten die hohe Relevanz des Studienfaches bescheinigt. Studierende entscheiden sich heute für das Hauptfach ,Islamwissenschaft" weniger aus einem Interesse für ein etwas abgelegenes Forschungsgebiet als aus handfesten Karriere-Absichten in einem prestigeträchtigen Fach. Obwohl sich die Islamwissenschaft natürlich nicht in ein Massenfach verwandelt hat ${ }^{1}$ und die Quote der Studienabbrecher nach wie vor hoch ist, so erhöhte sich die Zahl der Studienanfänger doch kontinuierlich Jahr für Jahr und lag 2006 um etwa 75 Prozent höher als 2001. ${ }^{2}$ Unter Politik-Studenten ist das einstmals nahezu unbekannte Fach inzwischen eines der beliebtesten Nebenfächer.

Wird ein Problem in der Öffentlichkeit als besonders bedeutsam beurteilt, so kann man sicher sein, dass hinter einem solchen Relevanzurteil vielfältige und starke gesellschaftliche Interessen stehen. ${ }^{3}$ Zeichnet indes die mit dem Problem befasste Wissenschaft ein von den herrschenden Interessen abweichendes Bild, kann der Vertrauenskredit schnell entzogen werden. Zwar ist die Zerstörung öffentlicher Mythen das ureigenste Geschäft der Geistes-, Kultur- oder Sozialwissenschaften, doch wird dieses Geschäft gerade in einem solchen Falle rasch als ideologisch motivierte Verzerrung denunziert. So hat beispielsweise Martin Kramer seinen US-amerikanischen, postkolonial beeinflussten ,Kollegen “ aus der Islam-Forschung vorgehalten, sie hätten nicht nur zur Verharmlosung des islamischen Fundamentalismus beigetragen, sondern die Anschläge vom 11. September durch ihre Islam(ismus)-freundliche Haltung erst möglich gemacht. ${ }^{4}$ Ähnliche Töne werden auch in der europäischen Integrationsdebatte angeschlagen, wenn vor einer Toleranz gegenüber der islamischen Intoleranz gewarnt wird.

Diese Entwicklung gilt es nun nicht mit kulturpessimistischem Gestus zu beklagen. Früher war nicht alles besser. Die Idee der Wissenschaft vom Islam war wahrscheinlich nie frei vom Dünkel der Aufklärung und Überlegenheit - ganz zu

1 Siehe auch Arnfrid Schenk: „1001 Hürde. Nach dem 11. September wuchs das Interesse an den Islamwissenschaften. Warum sie dennoch nicht zum Massenfach werden“, in: Die Zeit vom 21.02.2002, S. 73.

2 In Freiburg erhöhte sich die Gesamtzahl der im Erstfach Islamwissenschaft Studierenden von $64 \mathrm{im}$ Wintersemester 2002/03 auf $115 \mathrm{im}$ Wintersemester 2005/06. Nach Angaben des Statistischen Bundesamtes waren im Wintersemester 2005/06 deutschlandweit fast 3000 Studierende im Erstfach in Islamwissenschaft (1338) oder einem verwandten Fach (Arabistik, Turkologie, Iranistik, Zentralasiatische Sprachen und Kulturen) eingeschrieben.

3 Vgl. Walter M. Sprondel: „Über das Verhältnis der Soziologie zu den Geisteswissenschaften“, in: Florian Keisinger/Steffen Seischab (Hg.), Wozu Geisteswissenschaften? Kontroverse Argumente für eine überfällige Debatte, Frankfurt/M., New York: Campus 2003, S. 163-167, hier S. 166.

4 Martin Kramer: Ivory Towers on Sand. The Failure of the Middle Eastern Studies in America, Washington: Washington Institute for Near East Policy 2001. 
schweigen von kolonialen und imperialen Interessen. Ein Dreh- und Angelpunkt der Islamstudien waren schon immer Eigeninteressen und Eigenerkenntnis. ${ }^{5} \mathrm{Neu}$ ist lediglich, wie sehr das Wissen vom Islam heutzutage aufgrund elementarer Eigenbedürfnisse - vom Kampf gegen Terror bis zur Integration - legitimiert wird. Über diese Veränderungen und Herausforderungen soll hier anhand folgender Fragen nachgedacht werden: Wie definiert die Islamwissenschaft Islam? Welches Profil hat die Islamwissenschaft? Inwiefern hängt das Fehlen einer eigenständigen islamwissenschaftlichen Theorie mit der Frage nach der ,Haltung“ der Islamwissenschaftler sowie dem Vorwurf, ,Orientalismus ‘ zu betreiben, zusammen? Welche Islambilder dominieren in den öffentlichen Medien, und warum stellen diese ein Problem für die Islamwissenschaft dar?

\section{Wie definiert die Islamwissenschaft Islam?}

In den öffentlichen Islam-Debatten lässt sich in doppelter Hinsicht ein Islamverlust diagnostizieren. Die erste Form dieses Islamverlusts tritt auf, wenn islamwissenschaftliche Erkenntnisse nur als schmückendes Beiwerk für politische Analysen dienen, wenn also die ,eigentlichen' Konfliktursachen mit ökonomischen, politischen oder sozialen ,Fakten“ erklärt werden, so als ob Religion und Kultur kein Teil dieser ,Fakten “ wären und als ob die Wahrnehmung der ,Fakten“ durch die Betroffenen keine Rolle in den Konflikten spielte, sondern nur ein folkloristisches Detail bildete. Die zweite Art des Islamverlusts tritt nicht mangels Masse, sondern durch Vervielfältigung auf, wenn eine präzise, zeit- und kontextabhängige Definition von ,Islam“ oder ,Muslim‘ unterbleibt. In diesem Fall werden alle möglichen Probleme auf ,den“ Islam oder auf einen Konflikt zwischen Myriaden miteinander rivalisierender Muslime zurückgeführt: konservative, orthodoxe, neo-orthodoxe, heterodoxe, reformorientierte, liberale, islamistische, terroristische. Islam bildet dann sozusagen den gemeinsamen Nenner aller Konflikte, ohne dass geklärt werden muss, was Islam überhaupt ist.

Solche ungenauen Verwendungen des Begriffs ,Islam" lassen sich in den Massenmedien täglich studieren (siehe unter Punkt 3). Diese Begriffsunschärfe ist deutlich zu unterscheiden von der offenen, kontextabhängigen Verwendung eines vielseitigen ,Islam‘-Begriffs in der Wissenschaft. Unter Islamwissenschaftlern herrscht ein Konsens darüber, dass das Fach keine eigenständige Theorie oder Methode besitze: Islamwissenschaft ist mehr als nur eine Religionswissen-

5 Schon Max Weber diente die Sicht auf den Islam der Selbstkenntnis. Im Islam fand und konstruierte er einen irrationalen Gegenpol zum rationalen Westen, wodurch er zeigen wollte, wie es im Westen zur Ausbildung des Industriekapitalismus und damit zu einer einzigartigen Rationalität trotz vergleichbarer Ausgangsbedingungen im Islam kam. Siehe Georg Stauth: Islam und westlicher Rationalismus. Der Beitrag des Orientalismus zur Entstehung der Soziologie, Frankfurt/M: Campus 1993. 
schaft, eine Philologie oder eine Historiographie. Da Literaturwissenschaftler offenkundig anders vorgehen als Koranwissenschaftler, Rechtswissenschaftler oder Historiker, müssen die entsprechenden Theorie-Baukästen je nach Kontext aus angrenzenden Fächern entlehnt werden. Man bezeichnet es als Charakteristikum und Vorzug des Faches, dass man zu jeder Fragestellung ,das passende Handwerkszeug' wählen müsse. Die theoretische Vielfalt, in der Wissen über den Islam produziert wird, korrespondiert mit der Bandbreite des Gegenstandes, lässt jedoch keine simple Definition mehr von ,Islam‘ zu. Da der ,Islam‘ vielseitig ist, kann die Islamwissenschaft nicht mit einer griffigen Definition von Islam, wohl aber mit einem kontextabhängigen Begriff arbeiten. Daran wird deutlich, dass der Begriff ,Islam‘ ein äußerst komplexes Feld umfasst, wobei nicht immer auf Anhieb ersichtlich sein dürfte, worin die ,islamische' Gemeinsamkeit einzelner Aspekte gründet. Wie in jeder anderen Wissenschaft auch, zeigt sich darin die Tendenz zur Spezialisierung.

Die Selbstbeschreibungen des Faches sind daher meistens hinreichend vage, um alle denkbaren Tendenzen unter einem Dach vereinen zu können. In einer ,Wegleitung ' zum Bachelorstudium an der Universität Basel heißt es im ersten Satz: „Die Islamwissenschaft befasst sich mit der Religion des Islams und sämtlichen Aspekten der islamischen Welt von deren Anfängen im 7. Jahrhundert bis in die Gegenwart."6 Allgemein steht ,Islam“ in solchen Selbstbeschreibungen für eine Religion, Region, Geschichte und Kultur sowie für verschiedene Völker und Gesellschaften und politische Entwicklungen. ,Islam “ umfasst einen Textkorpus religiöser und profaner Literatur ebenso wie die Lebenspraxis von Muslimen in verschiedenen Kontexten. Anhand der meist fremdsprachigen Quellen sollen die Studierenden die „historische Tiefe“ des Islam ebenso kennen lernen wie „das Leben von Muslimen heute in der islamischen Welt und der Diaspora (besonders in Europa)“. 7

In der Regel behelfen sich Islamwissenschaftler bei der Frage ,Was ist Islam?' mit der Aussage, dass sie das untersuchen, was Muslime tun oder schreiben oder für islamisch halten. Die doxa ${ }^{8}$ in der Islamwissenschaft besteht in der Grundannahme, dass entweder Texte oder Praktiken von ,Muslimen` Aufschluss

6 Siehe: philhist.unibas.ch/fileadmin/faculty/user_upload/redaktion/WegleitungenBachelor/Islamwissenschaft.pdf (,Wegleitung für das Studienfach Islamwissenschaft im Bachelorstudium an der Philosophisch-Historischen Fakultät der Universität Basel“) vom 1.3.2007.

7 Siehe die Selbstbeschreibung des Freiburger Fachbereichs unter http://www.orient.uni-freiburg.de/islam vom 1.3.2007.

8 Als doxa bezeichnet Pierre Bourdieu (Homo academicus, Frankfurt/M: Suhrkamp 1988) das Ensemble von Thesen, das von den Akteuren eines Feldes trotz unterschiedlicher Ansichten und Positionen stillschweigend und jenseits allen Fragens postuliert wird, weil es als selbst-evident betrachtet wird. Die dominanten Positionen verstehen sich selbst als universell und objektiv und bilden die Orthodoxie; arrivierte Häretiker vertreten heterodoxe Ansichten. 
über den ,Islam` geben. Diese Grundannahme birgt mehrere Probleme in sich: zum einen ist der Zusammenhang von Texten zum ,Islam“ oder von Praktiken zum ,Islam“ ein angenommener oder behaupteter; zum anderen ist der Zusammenhang von Texten zu Praktiken ein oftmals von außen oder von innen konstruierter; und zum dritten unterliegt der Annahme dieser Zusammenhänge ein je eigener Determinismus. Daher ergibt sich bei der Beantwortung der Frage, was eigentlich Islam oder Muslime ausmacht, die Gefahr eines sozial- oder kulturwissenschaftlichen Determinismus, der die Erklärungslücke zwischen Text und Islam oder zwischen Praxis und Islam auf je unterschiedliche Weise zu überbrücken sucht. In einem ,Reflexionsansatz ' werden reale (soziale, politische, juristische) Zustände als Niederschlag von Vorschriften des ,Islams' aufgefasst. Im Gegensatz hierzu steht die ,Hermeneutik', die versucht eine Art von Ideologie aus Texten oder Handlungen herauszulesen, um eine verborgene islamische Struktur sichtbar zu machen. Hier referiert man über Aussagen bekannter Geistlicher, um das, was Islam in bestimmten Zusammenhängen ausmacht, einzugrenzen.

Die Schwierigkeit liegt darin, dass soziale Praktiken und kulturelle Deutungsmuster von Muslimen in den seltensten Fällen monokausal auf etwas Islamisches zurückzuführen sind. Genauso wenig wie sich die Taten und das Denken von Christen, Rationalisten, Atheisten oder Philatelisten auf ihre Glaubenszugehörigkeit oder eine andere exklusive Identität zurückführen ließen. Sowohl die Welt und die Taten als auch die Glaubenssysteme und Identitäten sind zu komplex für solche eindeutigen Reduktionen. Bei jedem Phänomen kommen allgemeine anthropologische und situative sowie kulturelle (nicht alle Muslime habe eine identische Kultur) und soziale Aspekte mit islamischen zusammen. Die Frage, was genau Islamwissenschaft untersucht, da sie den ,reinen' Islam nicht untersuchen kann, weil sich das Islamische nicht von anderen Faktoren trennen lässt, - diese Frage kann nur durch die wissenschaftliche Praxis in einem konkreten Kontext beantwortet werden.

Was bedeutet dies für die in den Medien diskutierten Streitthemen? Zur Frage beispielsweise, ob Selbstmordattentäter, Staatsislam, Kopftücher oder Antisemitismus ,islamisch ' gerechtfertigt seien, lässt sich antworten: Der Bezug zu einem Text aus der zweifellos langen islamischen Tradition ist immer zugleich überdeterminiert und willkürlich, selbstverständlich und überraschend, dicht und lose. Derjenige verwundete Gefährte des Propheten Muhammad, dem in der Schlacht die Gliedmaßen abgeschlagen werden und der dennoch bis zum letzten Blutstropfen weiterkämpft, ist ein gleichermaßen nahe liegendes wie an den Haaren herbeigezogenes Vorbild für den Selbstmordattentäter. 


\section{Profil und Polarisierung in der Islamwissenschaft}

Die allgemein inserierte Bandbreite der Islamwissenschaft stößt in der Praxis an eine natürliche Grenze, weil Islamwissenschaftler nicht alle Teilbereiche des Islams abdecken können. Die meist sehr kleinen Institute an den Universitäten bilden verschiedene Schwerpunkte, die von den Interessen und Fähigkeiten der Mitarbeiter abhängen. Im Gegensatz zum einzelnen Institut lässt sich jedoch das Profil der Islamwissenschaft in ihrer Gesamtheit schwer eingrenzen. Abträglich auf ein solches Gesamtprofil wirkt sich aus, dass unter den heutigen, veränderten Rahmenbedingungen zwei scheinbar konträre Tendenzen auf das im Kern kulturwissenschaftliche Fach einströmen: Es wird sowohl zu viel als auch zu wenig von ihm verlangt. Folgende Konflikte lassen sich anführen:

(1) Wenn die Islamwissenschaft von anderen Fächern als eine Art Hilfswissenschaft instrumentalisiert wird, erscheinen die Möglichkeiten extrem beschränkt: Entweder die Forschungsresultate tragen zur Deutung des Islams als „Zornsammelstelle“9 im Rahmen der Fundamentalismus- und Terrorismusforschung bei. Oder sie werden für eine grundsätzliche Religions- und Kulturkritik benutzt, wie sie eine konfrontative Aufklärungsindustrie verlangt, die den politischen Missbrauch, die Defizite und Differenzen des Islams analysiert, um dessen mangelnde Demokratiefähigkeit zu beweisen. ${ }^{10}$ Oder die Erkenntnisse werden von einer einfühlenden Dialogindustrie vereinnahmt, die Brücken zwischen Religionen und Kulturen bauen will. ${ }^{11}$ Diese Möglichkeiten stimmen nicht zufälligerweise auch mit den in den Medien vorhandenen drei Hauptrichtungen der Problematisierung von Islam überein (siehe unten).

(2) Die Interessensverengung auf tagesaktuelle Konflikte kann ein Abrücken von der Grundlagenarbeit zur Folge haben. Die islamwissenschaftliche Grundlagenforschung, das Sichten und Auswerten der islamischen Texttradition, ist schon deshalb notwendig, weil in allen Forschungsbereichen noch große Lücken klaffen. Daher müssten die Fachvertreter hervorstreichen, dass die gesellschaftspolitische Relevanz einer Wissenschaft nicht in dem liegt, was täglich in TalkRunden debattiert wird und was eine Mehrheit für relevant hält, sondern darin, dass Wissen abseits des allgemein Gewussten/Debattierten produziert wird, weder als Korrektur noch als Bestätigung der verhandelten Fragestellungen.

(3) Der Ruf nach interdisziplinär verwertbaren Ergebnissen kann sich für die Islamwissenschaft als ambivalent erweisen, da theoriegeleitete Fächer wie Politologie oder Soziologie eine interpretative Oberhoheit beanspruchen. Implizit bil-

9 Peter Sloterdijk: Zorn und Zeit. Politisch-Psychologischer Versuch, Frankfurt/M: Suhrkamp 2006.

10 Bernard Lewis: Die Wut der arabischen Welt. Warum der jahrzehntelange Konflikt zwischen dem Islam und dem Westen weiter eskaliert, Frankfurt/M u.a.: Campus 2003.

11 Hans Küng: Der Islam. Geschichte. Gegenwart. Zukunft, München, Zürich: Piper 2004. 
ligt die Islamwissenschaft, da sie von jeher auf einer interdisziplinären Herangehensweise basiert, durch ihre theoretischen Anleihen bei diesen Fächern deren Anspruch. Eine tatsächlich interdisziplinäre Arbeitsweise erforderte sowohl die selbstkritische Auseinandersetzung mit der eigenen Wissenschaftstradition als auch eine konstruktive Kritik an den Theorieangeboten aus anderen Fächern, die dem Islam übergestülpt werden. Beides hat, von wenigen Ausnahmen abgesehen, ${ }^{12}$ in der Islamwissenschaft bislang keine Fach-Tradition, weil Theoriebildung ein ungeliebtes Stiefkind ist. ${ }^{13}$

(4) Relevanzkriterien werden der Islamwissenschaft nicht nur von außen aufgedrängt, sondern sie existieren auch fachintern. So gab und gibt es eine deutliche Differenz zwischen der ,klassischen “ und ,gegenwartsbezogenen“ Islamwissenschaft. Die Bruchlinie verläuft in etwa entlang der oben erwähnten eher textoder eher sozialwissenschaftlichen Sichtweise, wobei die einen Forscher eher vom Beharrungsvermögen des Islams, die anderen eher vom Veränderungsvermögen der Muslime überzeugt sind. Dieser Bruch zieht sich potenziell durch alle Forschungszweige (Religion, Recht, Literatur, Politik, Gesellschaft) und bedingt unterschiedliche Betrachtungsweisen zur Vereinbarkeit oder Nicht-Vereinbarkeit von Islam und Moderne, Islam und Aufklärung, Islam und Geschlechtergleichheit, Islam und Demokratie. Die inhaltliche Differenz bildet sich auch im Habitus der jeweiligen Vertreter ab: Während die einen Handschriften-Fragmente sichten, beschäftigen sich die anderen potenziell mit islamischem HipHop. Den einen hängt der Ruf an, weltfremd, den anderen, modisch zu sein. Das Kräfteverhältnis im wissenschaftlichen Feld hat sich seit den 1970er Jahren umgekehrt, denn die ,klassische' Richtung hat ihre Dominanz an die ,gegenwartsbezogene" verloren. Wer sich heutzutage dem Studium frühislamischer Quellen oder der Geschichte des islamischen Mittelalters widmet, verspürt selbst innerhalb des Faches einen höheren Legitimationsbedarf als jemand, der zum jihad, zum Irak oder zu alQaida lehrt und forscht. Dennoch betrachten sich die Spezialisten für die ,klassische' Zeit nach wie vor als die eigentlichen Islamwissenschaftler, weil sie sich mit den Grundlagen der islamischen Kultur beschäftigen; diesem (auch von auBen affirmierten) Verständnis liegt die Vorstellung zugrunde, ein Kenner des Frühislams sei ein ausgewiesener Fachmann für das Ursprüngliche und Eigentli-

12 Daniel M. Varisco: Islam Obscured. The Rhetoric of Anthropological Representation, New York u.a..: Palgrave Macmillan, 2005. Marco Schöller: Methode und Wahrheit in der Islamwissenschaft: Prolegomena, Wiesbaden: Harrassowitz, 2000. Armando Salvatore: Islam and the Political Discourse of Modernity, Reading: Ithaca, 1999. Aziz al-Azmeh: Die Islamisierung des Islam. Imaginäre Welten einer politischen Theologie, Frankfurt/M: Campus, 1996. G. Stauth: Islam und westlicher Rationalismus.

13 Eine „kulturtheoretische Neubestimmung“ des Faches hält Reinhard Schulze für dringend geboten, siehe Schulze: „Orientalistik und Orientalismus“, in: Werner Ende/Udo Steinbach (Hg.), Der Islam in der Gegenwart, München: Beck ${ }^{5} 2005$ : S. 755-767, hier S. 767. 
che am Islam. Im Gegensatz hierzu können ,gegenwartsbezogene“ Islamwissenschaftler zwar eine nahe liegende Relevanz für ihre Forschung reklamieren, setzen sich dabei aber nicht direkt mit den Ursprungsmythen auseinander und müssen sogar einräumen, dass ihr Studium des modernen Islams nicht möglich wäre ohne genaue Kenntnis der islamischen Geschichte.

Es ist daher offenkundig, dass die Islamwissenschaft als Ganzes erst im Zusammenspiel der beiden Flügel einen tieferen Sinn ergibt, wenn sie also Einsichten in die Interdependenzen von Frühislam und Gegenwart gewinnt oder die Wandelbarkeit von philologischen, religiösen, sozialen, politischen und ökonomischen Phänomenen aufzeigt. Die Vielzahl möglicher Perspektiven erschwert zwar die Profilierung des Faches, macht sie aber nicht unmöglich. Gleichwohl prägt die Zuordnung zu einem philologisch-historischen (klassischen) oder soziopolitischen (gegenwartsbezogenen) Pol bis heute das Selbstverständnis vieler Fachvertreter. ${ }^{14}$ Dieses divergierende Selbstverständnis hat sogar eine mehr oder weniger institutionalisierte Form angenommen und lässt sich mit einiger Wahrscheinlichkeit an der Mitgliedschaft (von Doppelmitgliedschaften abgesehen) in einer der beiden Standesvertretungen ablesen: der Deutschen Morgenländischen Gesellschaft (DMG) oder der Deutschen Arbeitsgemeinschaft Vorderer Orient (DAVO).

Dass zwischen den beiden Flügeln eine Distanz herrscht, die sogar zu einem unüberbrückbaren Dissens führen kann, zeigte sich in den 1990er Jahren in der These Tilman Nagels, die - als Philologie verstandene - Islamwissenschaft habe sich aus der ,dreißigjährigen Umklammerung durch sozialwissenschaftliche

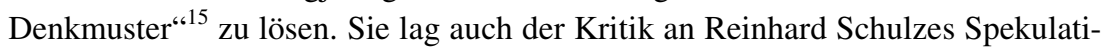
on über eine autochthone Aufklärung im Islam zugrunde, zumal die Kontrahenten diese These auch durch den Nachweis philologischer Mängel zu erschüttern versuchten. ${ }^{16}$ Noch der 28. Orientalistentag 2001 in Bamberg stand unter dem Motto: „Orientalistik zwischen Philologie und Sozialwissenschaft“. Typischerweise versuchte Bert Fragner aber bereits in seinem Eröffnungsvortrag einen Brückenschlag, indem er betonte, dass die ,permanente definitorische Standort-

14 Vgl. M. Schöller: Methode, S. 2.

15 Tilman Nagel: „Die Ebenbürtigkeit des Fremden - Über die Aufgaben arabistischer Lehre und Forschung in der Gegenwart“, in: Zeitschrift der Deutschen Morgenländischen Gesellschaft 148 (1998), S. 367-378.

16 Bernd Radtke: Autochthone islamische Aufklärung im 18. Jahrhundert. Theoretische und filologische Bemerkungen. Fortführung einer Debatte, Utrecht: Houtsma Stichting, 2000. Tilman Seidensticker/Gottfried Hagen: „Reinhard Schulzes Hypothese einer islamischen Aufklärung. Kritik einer historiographischen Kritik“, in: Zeitschrift der Deutschen Morgenländischen Gesellschaft 148 (1998), S. 83-110. Zu einer kritischen Bewertung beider Seiten siehe beispielsweise Albrecht Hofheinz: "Illumination and Enlightenment Revisited, or: Pietism and the Roots of Islamic Modernity", http://folk.uio.no/albrech/Hofheinz_IllumEnlightenment.pdf vom 15.3. 2007. 
beschreibung der orientalistischen Fächer"17 sowohl der philologischen Kompetenz als auch der Rezeption aktueller geisteswissenschaftlicher Debatten bedürfe. Keinesfalls dürfe man sich Einschränkungen der Kompetenzen unterwerfen und auf Antiquarisches oder Modisches reduzieren lassen. Diese Worte stellen angesichts des Fachdissenses den Versuch dar, den Fachkonsen ${ }^{18}$ wiederherzustellen.

Der Dissens drehte sich nur vordergründig um methodische Fragestellungen. Da es einen Konsens über die Methoden-Vielfalt gibt, lag der wirkliche Dissens auf einer anderen Ebene: Der - als zu negativ oder zu positiv bewerteten - ,Haltung' des Wissenschaftlers gegenüber dem Islam. Nahezu unausweichlich sind Islamwissenschaftler mit dem Vorwurf konfrontiert, entweder zu islamkritisch oder zu islamfreundlich zu sein. So lag auch der Kritik Edward Saids am eurozentristischen ,Orientalismus ${ }^{19}$ der Vorwurf einer kolonialen Attitüde von Schriftstellern, Intellektuellen, Politikern und Wissenschaftlern zugrunde. Annemarie Schimmel hingegen musste sich anlässlich der Verleihung des Friedenspreises des Deutschen Buchhandels - nach Meinung ihrer Kritiker - eine allzu naive oder verständnisvolle Haltung gegenüber autoritären Staaten wie Iran und Pakistan und gegenüber der Fatwa gegen Salman Rushdie vorwerfen lassen. ${ }^{20}$ Und die Diskussion um Schulzes Aufklärungs-Hypothese entspann sich, nachdem er den Satz „Der Islam kennt keine Aufklärung“ als eurozentristisch dekonstruiert hatte. $^{21}$

In solchen Auseinandersetzungen steht folglich eher der gegenseitige Vorwurf ideologischer Gesinnung im Raum, als dass es um theoretische oder methodische Grundsatz-Probleme ginge. Wenn Marco Schöller dennoch diese Diskussionen als Ausgangspunkte nimmt, um über theoretische Gegensätze innerhalb des Faches wie Universalismus versus Kulturrelativismus, Rationalismus versus Hermeneutik, Eurozentrismus versus Ethnozentrismus nachzudenken, so nimmt er damit eine theoretische Überhöhung der Polemiken vor. ${ }^{22}$ Dadurch wird den

17 Bert G. Fragner: „Orientalistik zwischen Philologie und Sozialwissenschaft“, http://web.uni-bamberg.de/split/dot/reden_fragner vom 15.3.2007.

18 Die Ansicht, dass Philologie und Sozialwissenschaft nicht gegeneinander ausgespielt werden sollten, wurde seit den 1990er Jahren mehrfach artikuliert (u. a. von Thomas Philipp, Ekkehard Rudolph, Gerhard Endreß), vgl. hierzu M. Schöller: Methode, $116 \mathrm{f}$.

19 Edward Said: Orientalism. New York: Vintage Books 2003 [ $\left.{ }^{1} 1978\right]$.

20 Munir D. Ahmed/Kai Hafez: „Das Orient- und Islambild in Deutschland: Überlegungen zum Friedenspreis des Deutschen Buchhandels und ein Gespräch mit Annemarie Schimmel“, in: Orient 36 (1995), S. 411-428.

21 Reinhard Schulze: „Das islamische achtzehnte Jahrhundert. Versuch einer historiographischen Kritik“, in: Die Welt des Islams 30 (1990), S. 140-159. sowie ders.: „Was ist die islamische Aufklärung?“, in: Die Welt des Islams 36 (1996), S. 276325.

22 M. Schöller: Methode, 1-5, 113-120. Schöller geht davon aus, dass die Islamwissenschaft in zwei gut etablierte Lager geteilt ist. Er hält die plakative Gegenüberstellung von Sozialwissenschaft und Philologie für eine Verengung, da er meint, dass 
Stellungnahmen mehr Plausibilität und Konsistenz zugewiesen, als ihnen zueigen ist. Demgegenüber ist festzuhalten, dass auch Verteidiger einer philologischen Herangehensweise Texte aus dem Umfeld Bin Ladens analysieren und weit reichende kulturtheoretische Schlussfolgerungen daraus ableiten, ${ }^{23}$ während Befürworter einer kulturtheoretisch geleiteten Forschung die „kulturelle Dramatisierung von Konflikten“ äußerst skeptisch beurteilen können. ${ }^{24}$

Dass die Haltung des Islamwissenschaftlers gegenüber dem Islam ein sensibles Thema ist, liegt an der doppelten Asymmetrie ,Westen gegenüber Islam“ sowie ,Wissenschaft gegenüber Religion“. Nach Edward Said gibt es aufgrund dieses doppelten Herrschaftsgefälles eine hohe Wahrscheinlichkeit für ,orientalistische“ Vorurteile: Der Islam und/oder die Muslime sind irrational und rückständig und vermischen Politik, Recht und Religion. In der Medienberichterstattung treten diese Stereotype immer wieder auf, weil das Fremde und Bedrohliche aufgrund eigener Interessen und Ängste erklärt wird; dabei können offensichtlich auch islamwissenschaftliche Erkenntnisse funktionalisiert werden.

Die Islamwissenschaft produziert zwar ebenfalls Fremdzuschreibungen von Menschen anderer Kultur oder Religion und nimmt solche Zuschreibungen von der autoritativen (aber niemals neutralen) Position der Wissenschaft vor; sie ist sich aber in der Regel der herrschenden Asymmetrien bewusst. Daher nimmt sie eine Zwischenstellung zwischen islamischem Selbstverständnis und westlichen Fremdzuschreibungen ein. Sie zielt nicht darauf $a b$, die fremde Religion als unwissenschaftlich zu dekonstruieren; vielmehr interessiert sie sich für die Transformationen einer geistigen, religiösen und kulturellen Tradition, die sie sowohl nach dem Eigen- als auch Fremdverständnis zu deuten versucht. Sie untersucht einen Wahrheitsanspruch, der zugleich weniger und mehr ist als nackte Tatsachen. Je nachdem, wie sie das tut, sieht sie sich dem Vorwurf ausgesetzt, entweder zu islamfreundlich oder zu islamkritisch zu sein. Dieser Vorwurf sollte jedoch eher zu den Rahmenbedingungen als zum Kern der Islamwissenschaft gerechnet werden. In islamwissenschaftlichen Studien finden sich sowohl asymmetrische Erklärungen als auch Relativierungen für ,Defizite‘ im Islam. Die Schwierigkeit liegt nicht darin festzustellen, ob diese Defizite tatsächlich vorliegen (also nur im Auge des womöglich eurozentristischen Betrachters entstanden sind), sondern in der Frage, worin die diagnostizierten Defizite gründen, welcher

der Kontrast „,weitaus grundlegender und weitreichender“ sei. Er bezeichnet ein Lager als „Rationalisten“, das andere als „Kulturalisten“ und behauptet, in der Islamwissenschaft dominierten - anders als im weiten Feld der Geistes- und Kulturwissenschaften - die Rationalisten, deren Einfluss zu wachsen scheine, vgl. ebd. S. 2f.

23 Hans G. Kippenberg/Tilman Seidensticker (Hg.), Terror im Dienste Gottes. Die „Geistliche Anleitung“ der Attentäter des 11. September 2001, Frankfurt/M: Campus 2004.

24 Reinhard Schulze: „Rasse, Klasse und Kultur“, in: Gewerkschaftliche Monatshefte 11-12/2001, S. 670-678. 
spezifisch islamische Anteil in ihnen liegt und welche anderen Faktoren hinzukommen.

\section{Islambilder in den Medien}

Das Fach Islamwissenschaft kann nicht als bloßes Opfer der Entwicklungen gesehen werden. Denn zahlreiche Islamwissenschaftler haben akademisches und berufliches Kapital aus dem Erklärungsnotstand seit dem 11. September geschlagen. Die Zeiten, als Gerhard Konzelmann und Peter Scholl-Latour in den 1980er Jahren sowie Bassam Tibi in den 1990er Jahren den deutschen Islam-Markt beherrschen konnten, sind vorbei. Heute tummelt sich eine Vielzahl jüngerer, auch akademisch ausgebildeter Islam-Experten in der deutschen Medienlandschaft, um dem Publikum zu erläutern, was es mit dem Islam innen- und außenpolitisch auf sich hat. Das Islam-Business stellt ein wachsendes und daher auch stark umkämpftes und polarisiertes Marktsegment dar. Die Gretchenfrage lautet, welches Verhältnis der Islam zur Gewalt, zur Frauenfeindlichkeit oder zur Demokratie hat. Die Antwort darauf hängt von der Haltung und dem Vergleichsmaßstab eines Experten ab. Er kann den Islam im Kern für absolut gewalttätig oder friedlich erklären oder ihn im Vergleich mit den anderen beiden monotheistischen Religionen für gewalttätiger, genauso gewalttätig oder weniger gewalttätig darstellen. Im Grundsatz stehen sich in den Massenmedien drei Lager gegenüber:

(1) So genannte Islamkritiker, die der These vom ,Kampf der Kulturen“ anhängen ${ }^{25}$

(2) Dialogbefürworter, die sich dem Brückenbau zwischen Religionen und Kulturen verschrieben haben; ${ }^{26}$

(3) postkoloniale Kritiker, die die Politik des Westens und das Zerrbild des Islams in den westlichen Medien bemängeln. ${ }^{27}$

Die Experten-Meinungen lassen sich weiter dahingehend differenzieren, ob die Experten den Islam als Religion oder Ideologie auffassen oder ob sie auf den Islam als Erklärungsgrund weitgehend verzichten und stattdessen auf Macht und Rohstoffe als Konfliktursachen verweisen, so dass sich insgesamt neun verschiedene Positionen ergeben (siehe Grafik).

Alle drei Lager sind ihren selbstgesteckten Zielen nicht näher gekommen. Weder ist bewiesen noch widerlegt, dass ,der' Islam das neue Feindbild in der

25 Zum Beispiel: Siegfried Kohlhammer: Die Feinde und die Freunde des Islam, Göttingen: Steidl 1996; ders.: „Die Feinde und die Freunde des Islam“, in: Merkur 55 (November 2001), S. 958-978.

26 Zum Beispiel H. Küng: Islam.

27 Zum Beispiel E. Said: Orientalism. Kai Hafez: Die politische Dimension der Auslandsberichterstattung. Das Nahost- und Islambild der überregionalen Presse in Deutschland, Baden-Baden: Nomos 2002. 
Politik ist. Noch ist definitiv festgestellt worden, dass es sich beim ,Kampf der Kulturen " um eine schlichte Tatsache oder bloße Chimäre handelt. Noch hat sich allseitige Harmonie über die existierenden Konflikte darniedergesenkt.

Nach sechs Jahren des Islam-Hypes sind die Islam-Experten nicht nur den Nachweis schuldig geblieben, dass der Kreislauf der immergleichen Argumente bei der Lösung der bekannten Probleme weitergeholfen habe, ganz zu schweigen von weiterreichenden Zielen (etwa: das Miteinander von Muslimen und Nichtmuslimen zu fördern). Vielmehr lässt sich sogar die These aufstellen, dass die Medienarbeiter an dem kulturellen Graben, den sie vorgeben zu bekämpfen, eifrig mitarbeiten. Illusorisch ist vor allem die Vorstellung, in den Medien auftretende Islamwissenschaftler könnten die stereotypen Islambilder ,korrigieren“. Aufgrund der medialen Mechanismen von Pauschalisierung, Personifizierung und Dramatisierung kann eine solche Korrektur nicht gelingen, weil auch jede Korrektur mit pauschalen Aussagen, personifizierten Beispielen und dramatischen Effekten arbeiten muss.

Grafik: Das mediale Feld der Islam-Debatten

\begin{tabular}{|c|c|c|c|}
\hline & \multicolumn{3}{|c|}{ Positionen der Islam-Experten } \\
\hline $\begin{array}{l}\text { Rolle des Islams in den } \\
\text { Erklärungen }\end{array}$ & 1. Islamkritik & 2. Dialog & 3. Postkoloniale Kritik \\
\hline $\begin{array}{l}\text { 1. Islam als Religion, } \\
\text { Kultur }\end{array}$ & $\begin{array}{l}\text { Der Islam ist als Religion } \\
\text { oder Kultur an der } \\
\text { Modernisierung } \\
\text { gescheitert und hat einen } \\
\text { Minderwertigkeitskomplex } \\
\text { (Bernard Lewis, Bassam } \\
\text { Tibi). }\end{array}$ & $\begin{array}{l}\text { Der Islam versucht eine } \\
\text { Wiederverzauberung der } \\
\text { seelenlosen Moderne; } \\
\text { wir können mit den } \\
\text { gemäßigten Muslimen } \\
\text { einen religiösen Dialog } \\
\text { führen (Hans Küng). }\end{array}$ & $\begin{array}{l}\text { Der Islam wird } \\
\text { aufgrund westlicher } \\
\text { Interessen als } \\
\text { rückständig dargestellt; } \\
\text { Muslime werden durch } \\
\text { die westliche Politik } \\
\text { permanent gedemütigt } \\
\text { (Edward Said). }\end{array}$ \\
\hline $\begin{array}{l}\text { 2. Islam(ismus) als } \\
\text { Ideologie }\end{array}$ & $\begin{array}{l}\text { Islam(ismus) ist eine anti- } \\
\text { westliche, anti- } \\
\text { demokratische, totalitäre } \\
\text { Ideologie (Samuel P. } \\
\text { Huntington, Necla Kelek, } \\
\text { Ayaan Hirsi Ali). }\end{array}$ & $\begin{array}{l}\text { Im Kampf der Kulturen } \\
\text { treffen zwei } \\
\text { Fundamentalismen } \\
\text { aufeinander. Ein Dialog } \\
\text { der Kulturen soll die } \\
\text { ideologischen } \\
\text { Verblendungen } \\
\text { aufbrechen (D. } \\
\text { Senghaas, B. J. } \\
\text { Trautner). }\end{array}$ & $\begin{array}{l}\text { Islam(ismus) } \\
\text { funktioniert als } \\
\text { „Zornsammelstelle“ } \\
\text { (Peter Sloterdijk) der } \\
\text { Zu-kurz-Gekommenen. } \\
\text { Er greift in religiösem } \\
\text { Gewande die } \\
\text { Forderungen des } \\
\text { Nationalismus auf (F. } \\
\text { Burgat). }\end{array}$ \\
\hline
\end{tabular}




\begin{tabular}{|l|l|l|l|}
\hline $\begin{array}{l}\text { 3. Macht- } \begin{array}{l}\text { Rohs } \\
\text { Roffkonflikte }\end{array} \\
\text { Gesellschaften werden } \\
\text { asymmetrisch durch } \\
\text { Terroristen angegriffen. } \\
\text { Wir müssen lernen, für } \\
\text { unsere Werte zu kämpfen } \\
\text { (Herfried Münkler). }\end{array}$ & $\begin{array}{l}\text { anstelle der Diktatoren } \\
\text { oder Islamisten die } \\
\text { demokratischen Kräfte } \\
\text { unterstützen (Michael }\end{array}$ & $\begin{array}{l}\text { Lüders). } \\
\text { Feindbild } \\
\text { Kommunismus durch } \\
\text { dersetzt, um seine neo- } \\
\text { imperialen Interessen } \\
\text { im Mittleren Osten } \\
\text { besser durchsetzen zu } \\
\text { können (Hippler/Lueg). }\end{array}$ \\
\hline
\end{tabular}

Die Debatten zwischen den drei Lagern lassen sich noch am ehesten als eine Form des organisierten Missverständnisses betrachten, weil unablässig verschiedene Ebenen des Islams durcheinander geworfen werden. Im Allgemeinen fehlt jeglicher normative Begriff von Islam. Es wird noch nicht einmal gefragt, welches Wissen vom Islam im Allgemeinen oder in einem besonderen Kontext relevant ist, ja es fehlt gänzlich am Bewusstsein, dass eine solche Frage überhaupt gestellt werden könnte. Schon deshalb werden Terroranschläge, SelbstmordAttentate, Kopfabschneiden, Kopftuch, Parallelgesellschaft, Zwangsehe und Ehrenmord unterschiedslos unter der Rubrik ,Islam‘ abgehandelt, wobei diese Rubrik vollkommen gegensätzlich konnotiert werden kann: Warnen die einen vor einer Verharmlosung des Islams, so warnen die anderen vor einem Feindbild. Sehen die einen das Grundübel in einer anhaltenden Starre, Rückwärtsgewandtheit und Stagnation des Islams, betrachten andere Islamismus und Jihadismus als Bewegungen, die einen fundamentalen Bruch mit der islamischen Tradition vollziehen. Sehen die einen den Islam(ismus) auf dem Vormarsch, meinen die anderen, er sei im Niedergang begriffen. Verstehen die einen den Terror als Konsequenz des Islamismus, analysieren ihn die anderen als seine Zerfallserscheinung. Fast alle beharren auf dem großen Unterschied zwischen Islam und Terrorismus, ohne abstreiten zu wollen, dass es sich bei letzterem um religiös legitimierte Gewalt handelt. Und obwohl niemand den Islam unter Generalverdacht stellen will, plädiert eine Mehrheit dafür, dass Moscheen besser kontrolliert werden müssen. Es ist daher kein Zufall, dass sich die Diskussion zwischen den Lagern oftmals in dem gegenseitigen Vorwurf erschöpft, den Islam falsch zu verstehen, der sich mit dem Hinweis paart, ein falsches Islamverständnis sei Wasser auf die Mühlen der Islamisten. ${ }^{28}$ Die Differenz zwischen öffentlicher Debatte und Islamwissenschaft ist größer als gemeinhin angenommen wird, obwohl es in beidem um den Islam geht. Die Islamwissenschaft fragt nach der ,historischen Tiefe' des Islams und

28 Islamkritiker sind wie Fundamentalisten von der Unvereinbarkeit von Islam und Demokratie überzeugt. Postkoloniale Kritiker begreifen wie Fundamentalisten den Islamismus als Reaktion auf die Gewaltanwendung des Westens. Dialogbefürworter gehen davon aus, dass Fundamentalisten den Islam missbrauchen, klammern aber aus, dass auch andere Akteure den Islam instrumentalisieren. 
beschreibt zusammenhängende Strukturen und Fixpunkte islamischer Kulturen. Im Gegensatz hierzu bewegt sich die mediale Debatte nur auf der Oberfläche der Ereignisse. Daher ist auch der Vorwurf des ,Kulturalismus ‘ oder ,Orientalismus“ an islamkritische Autoren wie Huntington irreführend, weil diese den heutigen Islam gerade nicht aus einer historischen Tiefe oder einer kulturellen Struktur heraus erklären, sondern weil sie ein Sammelsurium beliebig kombinierbarer Elemente als ,islamisch“ betrachten. Bei jedwedem Phänomen - „Islam has bloody borders" - versuchen sie, einen verborgenen islamischen Mechanismus dingfest zu machen. Die gängige Methode besteht darin, Bezüge zum Koran, zur islamischen Geschichte, zu gesellschaftlichen Normen oder zur muslimischen Psyche herzustellen, ohne die Ambivalenz solcher Bezüge in Rechenschaft zu stellen. Auf diese Weise kann alles Mögliche oberflächlich islamisiert werden. Der Einspruch der Huntington-Kritiker besteht kurioserweise meistens darin, dass sie es genauso halten: Sie weisen auf die Vielfalt des Islams hin - also darauf, dass das Islamische noch viel beliebiger konstruiert werden kann. Sie geißeln das Islamverständnis der ,Kulturalisten“ als falsch und einseitig, ohne selbst ein besseres zu haben. Der Islamverlust tritt auf beiden Seiten ein, weil der Bezug zu einer - wie auch immer gedachten - historischen Tiefe oder islamischen Grundstruktur nicht mehr existiert. Während auf der einen Seite alles - vor allem alles Negative - Islam sein kann, ist es auf der anderen Seite im Zweifelsfalle fast nichts mehr: „Dummerweise wissen eben viele Muslime nicht besonders viel über ihre Religion. Das macht das Ganze so gefährlich.“29 Ein solcher Satz spielt mit dem Paar Muslim/Islam - der doxa der Islamwissenschaft - und lässt beide Teile so weit auseinander treten, dass sie nichts mehr verbindet: Wenn selbst Muslime, Mullas und Ayatollahs in der Islamischen Republik nicht wissen, was Islam ist, wie können ,wir' dann den Islam für das verantwortlich machen, was Muslime tun?

Ironischerweise tendieren vor allem die in den Medien agierenden Islamwissenschaftler dazu, das Handeln von Muslimen gerade nicht oder nicht ausschließlich unter Bezug auf einen der genannten islamischen Referenzpunkte zu erklären. Während Islamkritiker das Islamische am Terror durch Verweis auf Koranverse, historische Vorläufer, soziale Normen, Denkkategorien oder durch Hass auf den Westen verständlich machen, so weisen Islamwissenschaftler oftmals nach, dass der jeweilige islamische Bezug fragwürdig konstruiert ist. Als typisches Beispiel für dieses Vorgehen darf ein Vortrag gelten, in dem Navid Kermani alle islamischen Bezüge zu den Attentätern des 11. Septembers solange dekonstruierte, bis ihm nichts anderes mehr übrig blieb, als die Terroranschläge eine Form von Nihilismus ${ }^{30}$ oder Faschismus ${ }^{31}$ zu nennen, welche im übrigen auf

29 Katajun Amirpur: „Prozessiert! Demonstriert! Aber bekennt euch endlich!“, in: Süddeutsche Zeitung vom 10.11.2004.

30 Navid Kermani: Dynamit des Geistes. Martyrium, Islam und Nihilismus, Göttingen: Wallstein 2002. 
dem Rückzug sei. Das Problem an diesem Erklärungsmuster ist, dass islamische lediglich durch nicht-islamische Bezugspunkte ersetzt werden, obgleich die Gewalttäter trotz aller Dekonstruktion Muslime bleiben. Der gewöhnliche Islamkritiker geht davon aus, dass die Attentäter aus ,islamischen' Gründen morden seien diese nun religiös, kulturell oder ideologisch. Hingegen bestreitet sein Kontrahent, der Islambild-Kritiker, dass die Motive der Attentäter rein islamische seien; er bescheinigt den Tätern dadurch ein gerüttelt Maß an Schizophrenie, weil sie von der Islamität ihrer Handlungsweise überzeugt sind und selbst viele Muslime daran glauben, obwohl ihnen die Kritik das Gegenteil nachweisen kann. Dem Publikum werden folglich zwei vollkommen rationale Erklärungen angeboten, warum Muslime gar nicht anders könnten, als vollkommen irrational zu sein und zu handeln. Die kulturalisierte Variante führt das Irrationale auf den irrationalen Islam, die sozialpsychologische auf ein falsches Verständnis des Islams zurück. Terrorismus ist entweder die logische Folge aus pathologischen Verhältnissen oder die wütende Reaktion darauf. Der islamische Irrweg wird entweder durch die Unfähigkeit zur Modernisierung ausgelöst ${ }^{32}$ oder durch eine Abfolge ,demütigender" historischer Ereignisse, verlorener Kriege oder nachteiliger ökonomischer und sozialer Entwicklungen. ${ }^{33}$ Da für diese Demütigungen auch die politische Einmischung des Westens verantwortlich gemacht wird und „die meisten Araber [...] wissen“, dass sie trotz ihrer Sehnsucht nach Rechtsstaat, Wohlstand und Fortschritt ,,vom Westen nichts zu erwarten haben“634, wird oft genug ein paradoxes Fazit nahe gelegt: sei es, dass suggeriert wird, westliche Politik sei nur kurzsichtig an eigenen (materiellen) Interessen ausgerichtet, anstatt auch die Perspektive der Araber zu berücksichtigen, was den eigenen Interessen ,eigentlich“ viel besser nützte; sei es, dass behauptet wird, eine Besserung des „Kranken Mannes am Bosporus" setzte voraus, dass der Westen sich nicht wie bisher „falsch“, sondern endlich einmal ,richtig“ einmische und beispielsweise die demokratischen Kräfte unterstütze - obwohl westliche Unterstützung für arabische Politiker faktisch einem politischen Todesurteil gleichkommen kann und theoretisch die ,demütigende“ Infantilisierung des Hilfe bedürftigen Arabers fortschreibt.

Oft genug führt die Kritik an Huntington nur zum Abbau eines Kulturalismus, an dessen Stelle ein anderer aufgebaut wird. Symptomatisch für diese Problematik ist der Versuch, Patriarchat, Frauen-Unterdrückung, Mädchen-Beschneidung, Zwangsheirat und Ehrenmord als etwas darzustellen, was nicht direkt mit Islam zu tun habe, sondern dort halt auch vorkomme und islamisch gerechtfertigt

31 Interview mit Navid Kermani: „Der islamistische Traum ist aus“, in: die tageszeitung vom 3.11.2001.

32 B. Lewis: Die Wut.

33 Zum Beispiel Sonja Hegasy: „Arabiens Versailles“, in: Die Zeit, 6.5.2004, S. 4.

34 Zum Beispiel Michael Lüders: Im Herzen Arabiens. Stolz und Leidenschaft - Begegnung mit einer zerrissenen Kultur, Freiburg: Herder 2004, S. 25. 
werde; was aber natürlich nicht heiße, dass es islamisch sei. ${ }^{35}$ Während Ayaan Hirsi Ali die Musliminnen aus dem islamischen „Jungfrauenkäfig“ befreien will $^{36}$ und Necla Kelek am Beispiel von Importbräuten pauschal auf Probleme „türkischen Lebens in Deutschland“37 hinweist, deutet Katajun Amirpur „,arrangierte Ehen“ als Praxis eines Unterschichtenmilieus und als Spätwirkung der anatolischen Herkunft der ersten Gastarbeiter-Generation. ${ }^{38}$ Warum diese Erklärung zutreffender oder weniger kulturalistisch sein soll als die ,islamische" von Hirsi Ali und die ,türkische“ von Kelek, ist indes nicht ersichtlich. Unterschiedlich ist lediglich die Wortwahl, weil an Stelle von ,Islam“ oder ,Türken“ ,Anatolien “ eingesetzt wird und irgendwelche sozialen Gründe angeführt werden, als gäbe es diese losgelöst von kulturellen Weltwahrnehmungs- und Weltdeutungsmustern. Ähnlich verhält es sich, wenn ,die“ Iraner als „,völlig unreflektiert proamerikanisch“" und Iran als das eigentlich USA-freundlichste Land im Mittleren Osten dargestellt werden. ${ }^{39}$ Unfreiwillig komisch erscheint es, wenn angesichts des so genannten Karikaturenstreits von 2006 als „entscheidende Frage“ ausgegeben wird, ob ,die‘ Muslime Humor haben und lachen können, - eine Frage, die dann mit dem Verweis auf eine lange, bis ins Mittelalter zurückreichende islamisch-persische Humortradition beantwortet wird. ${ }^{40}$ Während die ,Kulturalismus '-Kritiker den westlichen Medien generell unterstellen, islamophobe Stereotype zu verbreiten und in ahistorischer Weise alle Muslime in einen Topf zu werfen, verfahren sie unter Umständen mit den Christen in gleicher Weise: Auf der einen Seite bezweifeln sie fünf Jahre nach dem 11. September noch immer, ob Gewalt etwas mit dem Islam zu tun habe, und sind sich sogar sicher, dass es sich bei diesem Zusammenhang nur um ein „stolzes Vorurteil“41 handelt. Auf der anderen Seite werden die Papst-Zitate in Regensburg natürlich in den Kontext des

35 Siehe zum Beispiel Katajun Amirpur: „Feindbild Islam“, in: die tageszeitung vom 5.12.2005, S. 11. Sabine Schiffer: „Musliminnen in Deutschland. Von Kronzeugen und Halbwahrheiten“, http://qantara.de/webcom/show_article.php?wc_c=469\&wc_ $\mathrm{id}=501$ vom 1.3.2007.

36 Ayaan Hirsi Ali: Ich klage an. Plädoyer für die Befreiung der muslimischen Frauen, München, Zürich: Piper 2004. Etwas weniger polemisch: Irshad Manji: Der Aufbruch. Plädoyer für einen aufgeklärten Islam, Frankfurt/M: Eichborn 2003.

37 Necla Kelek: Die fremde Braut. Ein Bericht aus dem Inneren des türkischen Lebens in Deutschland, Köln: Kiepenheuer\&Witsch 2005.

38 K. Amirpur: „Feindbild“.

39 Katajun Amirpur: „Iran auf der Achse des Bösen“, www.kas.de/db_files/dokumente/auslandsinformationen/7_dokument_dok_pdf_1225_1.pdf vom 1.3.2007. Katajun Amirpur: „Die Revolutionäre sind müde“, in: Der Tagesspiegel vom 20.6.2003.

40 Katajun Amirpur: „Was Gott will - Es gibt kein islamisches Bilder- und Humorverbot“, in: Frankfurter Rundschau online vom 11.2.2006; abrufbar unter: http://davo. uni-mainz.de/info/060215.htm vom 1.3.2007.

41 Hilal Sezgin: „Stolzes Vorurteil“, in: die tageszeitung vom 20.09.2006, S. 11. 
Blutvergießens im Namen der christlichen Religion gestellt, angefangen von den Kreuzrittern bis hin zur Ausrottung der Indianer. ${ }^{42}$

Oftmals weisen Wissenschaftler in den Medien - im x-ten Aufguss der Thesen Edward Saids - darauf hin, dass das Islambild in den Medien zu einseitig sei und die Ängste der Zuschauer schüre. ${ }^{43}$ In einer aktuellen Untersuchung kritisieren Kai Hafez und Carola Richter einen Kampagnen-Journalismus gegen den Islam. ${ }^{44}$ Sie haben nachgezählt, dass 80 Prozent aller Islam-Beiträge in ARD und ZDF ,gewalt- und konfliktorientiert" seien, was - ohne weitere Inhaltsanalyse bereits als unausgewogen und vorurteilsverstärkend gewertet wird. Nur knapp 20 Prozent der Berichte behandelten Kultur und Alltag der Muslime. Diese Marge entspreche keiner differenzierten Behandlung des Themas und müsse im Sinne des öffentlich-rechtlichen Informationsauftrages weiter ausgebaut werden.

Erstaunlich an dieser Medienschelte sind mehrere Punkte, vor allem aber, dass bereits die Berichterstattung über Konflikte als negativ und unausgewogen bewertet wird: Welche Vorstellung von der Aufgabe der Medien wird hier zugrunde gelegt? Soll etwa eine ,konfliktorientierte“ Berichterstattung durch Friedensprophezeiungen ${ }^{45}$ ersetzt werden? Oder soll jedem Bericht von einem Bombenanschlag einen Reportage über ,die‘ Kultur folgen? Aber über welche Kultur in welchem Alltag - in Bagdad oder in Birmingham? Wenn ernsthaft Hommos als ,die andere Seite" von Hamas angesehen wird, so lässt sich die Gegenfrage stellen, ob hier nicht einem Kulturalismus das Wort geredet wird, der vordergründig kritisiert wird. Offensichtlich sind sich die Medienkritiker noch nicht einmal darüber im klaren, dass Reportagen über ,Alltag und Kultur ' des Islams nicht aufgrund eines genuinen Interesses einen Sendeplatz erhalten, sondern weil sich dahinter bereits das journalistische Gespür für eine ,andere Seite' des Themas und das hohe Publikumsinteresse für alles irgendwie ,Islamische" verbergen. Die 20 Prozent ,Alltag und Kultur' bilden nicht das Potenzial für die Korrektur eines Islambildes, sondern stellen lediglich ein Segment des Islam-Marktes dar.

42 Ebd.

43 Siehe beispielsweise: Sabine Schiffer: Die Darstellung des Islams in der Presse. Sprache, Bilder, Suggestionen. Eine Auswahl von Techniken und Beispielen, Erlangen, Nürnberg 2004. Andreas Pflitsch: Mythos Orient. Eine Entdeckungsreise. Freiburg u.a..: Herder 2003. Jochen Hippler/Andrea Lueg: Feindbild Islam oder Dialog der Kulturen, Hamburg: Konkret 2002 [11993].

44 Kai Hafez/Carola Richter: „Das Gewalt- und Konfliktbild des Islams bei ARD und ZDF. Eine Untersuchung öffentlich-rechtlicher Magazin- und Talksendungen“, www2.kommunikationswissenschaft-erfurt.de/uploads/bericht_islam_in_ard_und_ zdf_2005_2006.pdf vom 1.3.2007. Siehe auch das Interview mit Hafez unter www. sicherheit-heute.de/gesellschaft,255,Islam_Medienberichte_schueren_die_Aengste_ der_Buerger.htm vom 1.3.2007.

45 Kai Hafez: „Der Machtantritt der Hamas birgt die Chance auf ein Ende der Gewalt im Nahen Osten“, in: die tageszeitung vom 28.02.2006. 


\section{Die komplizenhafte Gegnerschaft der Islam-Experten}

Der Schlagabtausch zwischen den verschiedenen Islam-Experten verdeckt grundsätzliche Gemeinsamkeiten, nämlich ihre komplizenhafte Gegnerschaft. Alle Sorten von Islam-Bedrohungs-Aufklärungs-Literatur gehören zum Spiel um die Deutungshoheit, das unterschiedliche Akteure der herrschenden Elite - Akademiker, Politiker, Journalisten - zu ihrem eigenen Vorteil zu spielen versuchen. In einem selbst-referentiellen Diskussions-Zirkel führen sie gegeneinander einen gemeinsamen Kampf um knappe Güter: Aufmerksamkeit, Sendezeit, Verkaufszahlen, Fördermöglichkeiten, Finanztöpfe. Die Forderung, mit Muslimen müsse endlich ,auf gleicher Augenhöhe“ geredet werden, schließt die Verachtung für die „Schleierliteratur“46 und für Kronzeuginnen à la Kelek, Hirsi Ali und Seyran Ateş nicht aus. Vielmehr ist der Gegensatz konstitutiv für die Debatte, weil die Korrekturliteratur nur unter dem Anspruch gedeihen kann, man habe der ,verantwortungslosen Reduktion eines komplexen Sachverhalts“, der ,antiislamischen Leseerwartung“ und den „Halbwahrheiten“ auf dem gemeinhin „reißerischen“ und „sensationslüsternen Buch- und Medienmarkt"“47 etwas Sachliches entgegenzustellen. Erst die Wettbewerbssituation um knappe Güter - die ,richtige' Deutung des Islams und die Aufmerksamkeit des Publikums - erzeugt die notwendige Spannung für weitere Publikationen und Talk-Runden. Die ,Islam“Debatte speist sich nicht nur aus sich selbst heraus, sie erzeugt auch Legitimation für bestimmte Themen und politisches Handeln. Die Vorstellung, Experten könnten durch ihr objektives Wissen die Probleme lösen helfen, ist eine nette, aber keineswegs selbstlose Idee, zumal in Zeiten knapper werdender Mittel und Stellen. Das heißt nicht, dass die Themen unwichtig wären, für die sich die Experten zuständig erklären. Doch sichern sich die Experten ihre Position, indem sie sich am herrschenden Diskurs beteiligen, der auf eine Repression der wenigen gefährlichen Muslime und eine reibungslose Integration der vielen gutmütigen abzielt. Wer nicht gejagt werden muss, soll in einen fruchtbaren Dialog eingebunden werden. Vorausgesetzt, es gibt genügend finanzielle Mittel und den politischen Willen dafür. Weil an beidem jedoch offensichtlich Mangel herrscht, führen die Experten stets Beschwerde, dass das Geld an der falschen Stelle ausgegeben werde, beispielsweise für Geheimdienste anstatt für Dialog. ${ }^{48}$ Das Publikum wird mit dem Hinweis in Aufregung gesetzt, dass sich aufgrund der bisherigen Politik bedrohliche Szenarien am Horizont abzuzeichnen beginnen, und mit dem Hinweis beruhigt, dass es angesichts dieser Bedrohung rationale Gegenstrategien gibt, die allerdings gegenüber dem politischen Gegner durchgesetzt werden müssten.

46 K. Amirpur: „Feindbild“.

47 S. Schiffer: „Musliminnen“.

48 Michael Kiefer/Eberhard Seidel: „Kultur des Ressentiments“, in: die tageszeitung vom 26.11.2005, S. 11. 
Gemeinsam ist den Debattenbeiträgen auch die Überzeugung, dass der drohende oder sich vertiefende kulturelle Graben durch Sozialtechniken (Überwachung, Sprachförderung, Anerkennung) überwunden werden könne und dass deshalb Institutionen der kulturellen Repräsentation ins Leben gerufen werden müssten. So erzeugt die Debatte ein kulturalisiertes Anderes: obwohl jeder Mensch verschiedene Identitäten - Religion, soziale Herkunft, Nationalität, Beruf, Alter, Geschlecht - in sich vereint, die je nach Kontext unterschiedliches Gewicht tragen, werden Muslime vorwiegend über eine exklusive Identität wahrgenommen, die sowohl positiv als auch negativ bewertet werden kann. Denn selbst wer in der Integrationsdebatte die ,Unvereinbarkeit ${ }^{*}$ des Islams mit der deutschen Leitkultur als Glaubenssatz vertritt, muss Leitbilder der Harmonie finden, weil ansonsten die Programme der Umerziehung und Einbürgerung (,Fördern und Fordern') sinnlos wären: Der ,gute Muslim` muss möglichst sicher vom ,bösen Muslim` zu unterscheiden sein. So können während der Fußball-WM Musliminnen mit Kopftüchern in Schwarz-Rot-Gold im Fernsehen auftreten, am Kebab-Stand Deutschlandfahnen schwenken, die Nationalhymne singen und stolz erklären, sie hätten im Gegensatz zu den meisten Deutschen kein Problem mit dem Patriotismus, was ihnen ja auch leichter falle, weil sie zwar Deutsche, aber unbelastet von deutscher Geschichte seien.

Das Schwanken zwischen vollkommener Unverträglichkeit und kompletter Harmonie offenbart nicht nur eine Schwundstufe der Differenzierungsfähigkeit. Vielmehr verstärken die einfältigen medialen Leitbilder bei der Mehrheitsbevölkerung das Gefühl einer Uneinschätzbarkeit, weil die Muslime in Deutschland zwar mehrheitlich keine Terroristen sind, aber dennoch nicht täglich mit deutschen Wimpeln wedeln. Gleichwohl geben sich die Experten erstaunt, dass die Tendenz zur Identitätspolitik auf der einen Seite das identitätsstiftende Verhalten auf der anderen verstärkt, dass also beispielsweise die europaweite Debatte um Kopftuch-Verbote die Zahl der getragenen Tücher eher erhöht, denn verringert hat. Oder dass nicht nur Musliminnen, die freiwillig ein Kopftuch tragen, sich fragen lassen müssen, wie sie's mit der Religion halten und ob sie unterdrückt sind, sondern auch Musliminnen, die kein Kopftuch tragen: sind sie wirklich religiös und kaschieren sie ihre Unterdrückung nur besonders geschickt?

\section{Resümee}

Islam-Experten in den Medien definieren meistens einen Ausschnitt als Islam, um für eine harte Haltung gegenüber islamischer Intoleranz, für einen Dialog auf gleicher Augenhöhe oder für eine Korrektur des Islam-Bildes zu werben. Die Wahl des Ausschnittes hängt in der Regel mit der Haltung eines Experten gegenüber dem zusammen, was er als Islam definiert hat. Mediale Auseinandersetzungen beziehen sich daher nicht allein auf Islam-Bilder (,guter Muslim‘ vs. ,böser Muslim'), sondern auch auf die Haltung der Islam-Experten (,guter Experte‘ vs. 
,böser Experte‘). Daher wird in den Medien fortwährend der ,Orientalismus`Vorwurf von Edward Said recycelt. Dieser Vorwurf wird von allen Seiten erhoben, vor allem aber von jenen Experten, die behaupten, ,die' Massenmedien würden ein falsches Islambild verbreiten - also nicht ,die' Experten, die gebraucht werden, um dieses Bild zu korrigieren. Ziel dieses Beitrages war es deshalb zunächst einmal, die Skepsis der Medienrezipienten gegenüber dieser Expertokratie zu schüren: Islamwissenschaftler treten - wie andere Experten in den Medien auch - im Gewande objektiver Wahrheit und unabhängiger Meinungsäußerung auf. Wenn sie es als ihre Aufgabe ausgeben, das herrschende Islambild differenzieren zu müssen, stellt sich jedoch stets die Frage, im Dienste welcher Interessen diese Differenzierung geschehen solle.

Die weitere Intention dieses Beitrages war es, darauf hinzuweisen, dass eine - wie auch immer geartete - Differenzierung oder Korrektur des Islambildes nicht gelingen kann. Dies liegt zum einen in der Funktionsweise der Medien begründet: Pauschalisierung, Personifizierung, Dramatisierung von Konflikten. Zum anderen haben die Medienbilder enormen Sekundärnutzen für Islamwissenschaftler. Die Klage über ,zu tolerante“ oder „zu einseitige“ Islambilder zielt nicht auf eine ,Lösung' der gegenwärtigen Probleme ab, sondern hilft Experten und Wissenschaftlern lediglich, die eigene ,überlegene“ Position herauszukehren und es sich dadurch im status quo bequem zu machen. Jeder Wissenschaftler, der einen Zeitungsartikel nicht als undifferenziert kritisieren könnte, hätte sein Handwerk nicht gelernt. Das Lamentieren der Wissenschaftler über Medienbilder führt genauso wenig irgendwohin wie das Debattieren der Expertokratie. Zwar suggerieren Islamwissenschaftler gerne, der Kampf gegen Medienbilder sei ein Kampf gegen Windmühlen. Doch gerade dieses Bild von der eigenen Rolle trifft nicht zu; es setzte nämlich voraus, dass es einen wissenschaftlich verbürgten Konsens über das richtige Islambild gäbe, sowie ein gemeinsames Interesse der Islamwissenschaftler, dieses eine Bild durchzusetzen. Doch nicht einmal das gemeinsame Interesse kann vorausgesetzt werden. Denn die finale Korrektur des Islambildes wäre vor allem für diejenigen unangenehm, die derzeit am meisten Nutzen aus dem Korrigieren schlagen; sie läge also gerade nicht im Interesse der sich gegenseitig kritisierenden Islam-Expertokratie. Die Existenzberechtigung der Experten basiert auf der Unübersichtlichkeit der Islambilder, weil aus dieser Unübersichtlichkeit das populäre Bedürfnis nach Orientierung erwächst. Die Deutungskämpfe unter den Experten tragen wiederum zur Verwirrung des Publikums und zur Existenzsicherung der Experten bei.

Eine ,Korrektur' der Islambilder scheitert außerdem am diffusen Objekt der Begierde, denn nicht nur das Orient-Bild ist heutzutage imaginär, sondern auch die Kritik daran. Die von Edward Said beschriebenen Oriente der Imagination der religiöse, der romantische, der kolonisierte, der kulturelle und durch Migration auch der geographische Orient - sind uns mittlerweile abhanden gekommen. Auf den Ruinen dieser Oriente haben sich nun die Islam-Experten versammelt, um Kassandras eines diffuseren Phänomens zu spielen. Der Islam ist zum ge- 
spenstischen Wiedergänger des verlorenen Orients geworden und fungiert als Platzhalter der Imagination. Im Gegensatz zur kolonialen Erzählung über den Orient stellt die Deutung des Islams jedoch keinen klar umrissenen, imaginierten Ort des Anderen, keine bloße Projektionsfläche fremder Wünsche und kein Kolonialprojekt mehr dar. Der Islam, als Ausdruck kultureller Differenz, ist vielmehr mit Formen der Selbstaffirmation und Selbstabgrenzung verknüpft. In ihnen dauern zwar die Obsessionen und Phantasmen des Orientalismus fort, die weiterhin die Imagination gefangen halten. Doch kann der ,Islam' sowohl mit den Stereotypen des Orientalismus als auch mit deren Dekonstruktion angefüllt werden. Der Begriff ,Islam“ ist an Bedeutungen übervoll und entleert - sei es, dass jedes beliebige Phänomen auf einen islamischen Faktor zurückgeführt wird, sei es, dass jegliche Verbindung zu einem islamischen Faktor gekappt wird.

Dass sich die Islamwissenschaft mit den medial vorherrschenden Islambildern auseinandersetzt, ist bis zu einem gewissen Grade unvermeidlich, aber auch vergebene Liebesmüh'. Einerseits gehören die medialen Islambilder zu den Rahmenbedingungen, in denen sich die Islamwissenschaft heutzutage wiederfindet und auf die sie reagieren muss. Andererseits kann es weder Aufgabe noch Ziel der Wissenschaft sein, die in den Medien polemisch verhandelten Fragestellungen zu bearbeiten oder abschließend zu beantworten. Wer für eine stärkere Nutzbarmachung der Islamwissenschaft in der Politik oder Öffentlichkeit plädiert, sollte sich klar machen, dass eine Funktionalisierung oder Popularisierung islamwissenschaftlicher Ergebnisse längst geschieht, weil verschiedene Akteure je nach Interessenslage auf passende Islambilder zurückgreifen.

Was kann, was soll die Islamwissenschaft stattdessen leisten? Die Islamwissenschaft kann und muss die von Muslimen und Nicht-Muslimen verwendeten Begriffe und Kategorien in Frage stellen. Insofern als die Re- und Dekonstruktion von Begriffen, Mythen und Narrativen eine wesentliche Aufgabe von Wissenschaft ist, wird der Islamwissenschaft die Arbeit nicht ausgehen. Sie wird aber eher das Bewusstsein für die Komplexität der Zusammenhänge schärfen, denn zu einfachen Lösungen beitragen.

Das Fach Islamwissenschaft hat sich damit abzufinden, dass der Einfluss der Massenmedien auf die öffentliche Wahrnehmung des Islams größer ist als der Einfluss der Islamwissenschaft. Da Politiker, Journalisten und Öffentlichkeit vom universitären Fach seit dem 11. September eindeutigeres Orientierungswissen einfordern, wird es zwischen diesen Erwartungen auf der einen und den wissenschaftlichen Fragestellungen und Resultaten auf der anderen Seite weiterhin eine Diskrepanz geben. Besonders die Arbeitsteilung zwischen Wissenschaft und Medien ist strukturell nicht aufhebbar, auch wenn sich Islamwissenschaftler in die Mediendebatte einmischen und Teile des Faches unter dem Druck der Öffentlichkeit verändern. Es ist zwar möglich, die Diskrepanz zwischen Wissenschaft und öffentlichem Interesse (und die daraus resultierenden nachteiligen Auswirkungen) differenziert zu analysieren, nicht jedoch, die in den Medien herrschenden Islambilder durch die Wissenschaft zu ,differenzieren`. 
Weiter sollte sich das Fach darauf einrichten, dass es sich mit unkundigen ebenso wie mit kundigen Vorurteilen auseinanderzusetzen hat. Wissen über den Islam, das als ,solide“ daherkommt, mag entweder als banal oder verlässlich gelten; wissenschaftlich gesehen, ist es damit entweder uninteressant oder verdächtig. Eine besonders starke diskursive Macht hat die These vom ,Kampf der Kulturen' entfaltet, weil sowohl deren Befürworter als auch Kritiker oftmals Schwarz-Weiß-Bilder zeichnen und bestehende Konflikte auf simple Gegensätze reduzieren, zwischen zwei oder maximal vier Identitäten: zwei innerhalb jeder Kultur. ${ }^{49}$ Im Gegensatz hierzu muss eine wissenschaftliche Analyse auf die Vielzahl der an einem Konflikt beteiligten internationalen, regionalen und lokalen Akteure hinweisen.

Es ist Marco Schöller zuzustimmen, wenn er fordert, die Islamwissenschaft müsse „Buntheitskompetenz“ fördern oder sie tauge nichts. ${ }^{50}$ Wenig sinnvoll erscheint es jedoch, wenn er die Islamwissenschaftler - teilweise entsprechend ihrem Selbstverständnis - gleichfalls nur in zwei Lager einteilt: rationale Universalisten und hermeneutische Kulturrelativisten. Mit einem derart einfachen Gegensatz wird die farbenblinde These vom ,Kampf der Kulturen“ nur auf einer anderen Ebene reproduziert, nämlich als Haltung der Islamwissenschaftler gegenüber ihrem Studienobjekt. Die wissenschaftliche Praxis ist bedeutend farbenfroher als diese theoretische Rekonstruktion der Praxis, und sie sollte es auch bleiben.

49 Stefan Weidner: „Zum Kampf der Waffen und Begriffe. Über harte und weiche Islamdeutungen“, in: Merkur 662 (2004), S. 500-509.

50 M. Schöller: Methode, S. 125. 


\section{Die Islamwissenschaft und der 11. September}

GUIDO STEINBERG (BERLIN)

Der 11. September hat sich nicht nur für die Weltpolitik, sondern auch für die Islamwissenschaft in Deutschland als ein Wendepunkt erwiesen. Bis dahin hatte die deutsche Gesellschaft nur sporadisch wahrgenommen, dass es ein kleines ,Orchideenfach ' gibt, das sich nicht nur mit dem Islam als religiöser Größe, sondern auch der Kultur, Geschichte und seltener der Politik der islamischen Welt befasst. In der Vergangenheit hatten Krisen wie der Aufruf Ayatollah Khomeinis zum Mord an Salman Rushdie 1989 oder der Golfkrieg 1990/1991 ein kurz aufflammendes, dann aber ebenso schnell wieder nachlassendes Interesse an der Region und denjenigen, die sich hierzulande ihrer Erforschung widmen, hervorgerufen. Nach den Anschlägen auf World Trade Center und Pentagon hingegen geriet die Islamwissenschaft nachhaltiger als bisher in den Fokus einer interessierten Öffentlichkeit und auch der Politik.

Die neue Situation konfrontierte die deutsche Islamwissenschaft mit einer Reihe von Herausforderungen. Erstens schuf das plötzliche große Medieninteresse eine Nachfrage, die die deutschen Islamwissenschaftler kaum befriedigen konnten. Dies lag zum einen an ihrer vergleichsweise geringen Zahl, darüber hinaus jedoch auch daran, dass das Phänomen ,islamistischer Terrorismus “ - der nun das größte Interesse fand - kein Bestandteil des herkömmlichen islamwissenschaftlichen Curriculums (so es ein solches überhaupt gibt) ist und lediglich als Begleiterscheinung des Islamismus behandelt wird. Dies führte dazu, dass sich viele Politikwissenschaftler, Publizisten und Journalisten ohne Regionalerfahrung oder islamwissenschaftliche Ausbildung bemühten, die öffentliche Lücke zu füllen - mit einigem Erfolg, wenn auch bei sehr unterschiedlicher Qualität der Beiträge. Zweitens geriet die Islamwissenschaft in die Kritik. Meist hieß es, sie habe die Bedeutung des islamistischen Terrorismus nicht rechtzeitig erkannt und sich statt den ungleich relevanteren Gegenwartsthemen gänzlich abwegigen Wissensgebieten wie beispielsweise der klassischen persischen und arabischen Lyrik, der Philosophie und Linguistik oder gar der Prosodie gewidmet. Zwar war diese Kritik bei weitem nicht so ausgeprägt wie in den USA, wo Martin Kramer 
mit seinen „Ivory Towers on Sand: Middle Eastern Studies in America“" zum Generalangriff auf die amerikanischen Nahoststudien und Islamwissenschaft blies. Dennoch konnte auch deren deutsches Pendant den Eindruck nicht entkräften, nicht auf der Höhe der Zeit zu sein und sich häufig mit irrelevanten Themen zu befassen. Dies mag dazu beigetragen haben, dass, trotz der offensichtlichen tagespolitischen Bedeutung profunder islamwissenschaftlicher Kenntnisse, die deutsche Islamwissenschaft von Mittelkürzungen und Stellenstreichungen nicht ausgenommen blieb. Drittens - und dies war mindestens ebenso sehr eine Chance wie eine Herausforderung - entstand schlagartig ein Arbeitsmarkt für Islamwissenschaftler, die trotz einer im Detail scheinbar nicht vollkommen adäquaten Ausbildung nun begehrte Spezialisten waren, für die zahlreiche Stellen in der Ministerialbürokratie, bei der Polizei und den Nachrichtendiensten geschaffen wurden. Obwohl dies zunächst eine sehr positive Entwicklung war, musste sie unweigerlich dazu führen, dass die in der deutschen Islamwissenschaft vermittelten Fähigkeiten der Absolventen nun auf breiterer Basis einem Praxistest unterzogen wurden. Soweit dies von außen zu beurteilen ist, fiel dieser Test bisher überwiegend positiv aus, was ein erstes Indiz dafür ist, dass die deutsche Islamwissenschaft ihre Studierenden nicht vollkommen an der Wirklichkeit vorbei ausbildet.

Die Frage, der sich die Islamwissenschaft in dieser Situation dennoch stellen muss, ist, was ihre Funktion außer der meist unbeabsichtigten Ausbildung künftiger Nachrichtendienstler nach dem 11. September 2001 sein kann. Was kann und muss die Islamwissenschaft zur Erklärung von Politik, Wirtschaft, Gesellschaft und Kultur der islamischen Welt beitragen und inwiefern muss sie sich zu diesem Zweck ändern? Soll sie sich etwa aus ihrer philologischen Tradition lösen, um sich unter vermehrter Zuhilfenahme von Methoden aus der Sozialwissenschaft weiterzuentwickeln und Terrorismusspezialisten ausbilden? Oder soll sie philologische Traditionen pflegen und auf die Ausbildung der Studenten in möglichst vielen ,Islamsprachen“ setzen? Gibt es möglicherweise einen Mittelweg? Um diese Fragen zu klären, soll hier am Beispiel des islamistischen Terrorismus untersucht werden, was die deutsche Islamwissenschaft zur Klärung dieser einen wichtigen Gegenwartsfrage leisten kann und inwieweit ihr bisheriger Beitrag darauf schließen lässt, dass die Disziplin Defizite aufweist, die behoben werden sollten.

Man kann den möglichen und notwendigen Beitrag der Islamwissenschaft zur Erforschung des islamistischen Terrorismus vor allem an zwei Problemfeldern verdeutlichen: erstens der Betonung der lokalen Verankerung des transnationalen Terrorismus im Gegensatz zu den in Politikwissenschaft, Politik und Öffentlichkeit verbreiteten Globalisierungstheorien, und zweitens der Erforschung

1 Martin Kramer: Ivory Towers on Sand: Middle Eastern Studies in America, Washington: Washington Institute for Near East Policy 2001. 
militanter islamistischer Ideologien, die nur die Islamwissenschaft leisten kann. In beiden Themenfeldern könnte und sollte die deutsche Islamwissenschaft mehr beitragen. Um zu diesen Themen Substantielles beizutragen, sind profunde Kenntnisse der Geschichte, Kultur und Sprachen der islamischen Welt vonnöten. Die wünschenswerte Rezeption historischer und sozialwissenschaftlicher Methoden ist ohnehin in vollem Gange und erleichtert auch die Vermittlung von Arbeitsergebnissen in Nachbardisziplinen. Sie darf aber keinesfalls die Erlangung sprachlicher Kompetenz und die daran gebundenen historischen und kulturellen Kenntnisse beeinträchtigen. Insofern wird diese Untersuchung möglicher Beiträge der Islamwissenschaft zur Klärung eines wichtigen Gegenwartsproblems zeigen, dass sie auf keinen Fall ihre besondere Stärke, die ausgeprägte philologische Kompetenz, aufgeben darf.

\section{Arabische Bürgerkriege, kein Kampf der Kulturen}

Untersuchungen zum islamistischen Terrorismus, die islam- und regionalwissenschaftliche Forschungsergebnisse nicht berücksichtigen, laufen Gefahr zu übersehen, wie sehr al-Qaida und andere terroristische Organisationen weiterhin durch ihre Heimatländer geprägt sind. Dies betrifft insbesondere, wenn auch nicht ausschließlich, ihre Zielsetzungen, denn es geht der überwiegenden Mehrzahl der Jihadisten weiterhin darum, politische Systeme in ihren Heimatländern zu ändern. Der islamistische Terrorismus war und ist immer noch viel mehr Ausdruck arabischer Bürgerkriege als eines „Kampfes der Kulturen“ gegen den Westen. Um dies festzustellen, genügt oft schon eine recht kursorische Lektüre jihadistischer Literatur und der Abgleich mit der weiterhin stark landsmannschaftlichen Binnenstruktur terroristischer Gruppierungen und ihren konkreten Aktionen. Wenn man allerdings die Darstellungen des islamistischen Terrorismus in Wissenschaft und Medien der letzten Jahre Revue passieren lässt, stellt man schnell fest, dass eine solche Sichtweise, die nicht nur die Wurzeln, sondern auch die Zielsetzungen und die Grundlagen der Organisationsstruktur islamistischer terroristischer Gruppen in ihren Heimatländern sucht, zwar bekannt ist, sich aber nicht durchgesetzt hat. Globale, transnationale Erklärungsmuster dominieren weiterhin. Hier zeigt sich, dass die deutsche Islamwissenschaft insgesamt Nachholbedarf hat, was die Kommunikation ihrer auch zu diesem Thema vorhandenen Forschungsergebnisse nach außen angeht.

Die Anschläge des 11. September 2001 wurden schnell zum Symbol einer Bedrohung, die nach Ansicht vieler Kommentatoren vollkommen neuartig war. Hier hatte erstmals eine terroristische Organisation, die ihr Hauptquartier in Afghanistan aufgeschlagen hatte, Anschläge über drei Kontinente (Asien, Europa und Amerika) hinweg geplant, organisiert und ausgeführt. al-Qa'ida schien der Prototyp eines ,neuen ‘ oder ,transnationalen Terrorismus` zu sein, der nicht mehr an eines oder mehrere Ziele in einem bestimmten Land gebunden war, sondern 
Muslime aus aller Herren Länder vereinte, die den Westen im Allgemeinen und die USA im Besonderen angriffen. Häufig hieß es nun in Politik und Öffentlichkeit, es handele sich bei al-Qaida auch nicht mehr um eine Organisation im herkömmlichen Sinne, sondern um ein Netzwerk. Dementsprechend konnten auch herkömmliche Bekämpfungsweisen nicht mehr genügen. „Netzwerke bekämpft man nur mit Netzwerken“ hieß es und heißt es in Sicherheitskreisen immer noch, ohne dass der Nachweis erbracht worden ist, dass dem wirklich so ist oder dass staatliche Bürokratien tatsächlich in der Lage wären, netzwerkartig zu arbeiten. Glücklicherweise war die dieser ,Netzwerkhysterie“ zugrunde liegende Sichtweise der neuen Bedrohung weitgehend falsch, sonst hätten die neuen, globalen Terrorismusbekämpfer die al-Qa'ida zunächst nicht so erfolgreich eindämmen können. In der verbreiteten Interpretation der al-Qaida als globales, transnationales Phänomen spiegelte sich vielmehr der Einfluss von Globalisierungstheorien auf die westliche Sicht der Welt. Bei al-Qa'ida handelte es sich nämlich vielmehr um eine weitgehend herkömmliche, das heißt stark national geprägte terroristische Organisation, die erst als Reaktion auf die Bekämpfungsmaßnahmen der USA und ihrer Verbündeten lange nach dem 11. September einen stärker netzwerkartigen Charakter annahm.

Islam- und Regionalwissenschaftler vertraten mehrheitlich ein Bild der Terrororganisation, das eher auf ihre lokalen Wurzeln und nationalen Zielsetzungen abhebt. Tatsächlich war die al-Qaida bis 2001 mitnichten eine Vereinigung von Militanten aus allen Teilen der islamischen Welt, sondern vielmehr eine fast ausschließlich arabische Organisation, die von Saudi-Arabern und Ägyptern dominiert wurde und deren Kern außerdem noch einige Jemeniten und Kuwaitis angehörten. Zudem handelte es sich nicht um eine integrierte transnationale Organisation, sondern eher um die Summe nebeneinander fortbestehender nationaler Gruppierungen, die eine gemeinsame Basis in Afghanistan hatten und eng miteinander kooperierten, sich aber oft genug erbitterte Grabenkämpfe um die Kontrolle und die strategische Ausrichtung der Gesamtgruppierung lieferten. Dieses Phänomen wurde meist nur von Autoren erfasst, die sich intensiv mit der politischen Entwicklung der jeweiligen Herkunftsländer und mit den Schriftprodukten der Jihadisten selbst auseinandergesetzt haben. ${ }^{2}$

Wie sehr die Aktionen der al-Qaida von konkreten Zielsetzungen in Ägypten und Saudi-Arabien bestimmt waren, zeigen exemplarisch die Anschläge des

2 Ein Beispiel für eine Publikation mit einem islamwissenschaftlich geprägten Ansatz aus dem angelsächsischen Raum ist: Fawaz A. Gerges: The Far Enemy. Why Jihad went Global, Cambridge: Cambridge University Press 2005. Trotz des Anspruchs, sich mit dem Gesamtphänomen Jihadismus zu befassen, beschränkt sich Gerges fast ausschließlich auf ägyptische Jihadisten. In Deutschland wurde publiziert: Guido Steinberg: Der nahe und der ferne Feind. Die Netzwerke des islamistischen Terrorismus, München: C. H. Beck 2005. Eine sehr gute journalistische Darstellung mit wissenschaftlichem Anspruch ist: Yassin Musharbash: Die neue Al-Qaida. Innenansichten eines lernenden Terrornetzwerks, Köln: Kiepenheuer \& Witsch 2006. 
11. September. Hierbei handelte es sich nicht um einen Angriff auf die,westliche Welt', noch viel weniger auf die westliche Zivilisation und ihre Werte. Vielmehr war der Anschlag Ausdruck des sehr genau kalkulierten Versuchs, die Regime in Kairo, Riad und in anderen arabischen Staaten zu schwächen. al-Qaida griff deren wichtigsten Verbündeten an und forderte ihn auf diese Weise auf, sich aus Saudi-Arabien zurückzuziehen und seine in erster Linie finanzielle Unterstützung für Ägypten einzustellen. Ägyptische und saudi-arabische Terroristen verwirklichten hier eine Strategie, die nicht mehr ausschließlich auf den „,nahen Feind“, also die Regierungen der jeweiligen Heimatländer, sondern nun auch parallel auf den „fernen Feind“, das heißt die USA und die westliche Welt, abzielte. Diese Neuorientierung war Ergebnis eines Lernprozesses, infolgedessen militante Oppositionsgruppen insbesondere in Ägypten ihren Kampf gegen das Heimatregime aufgaben. Sie mussten ab Mitte der 1990er Jahre einsehen, dass substaatliche Gruppierungen nicht in der Lage waren, Regierungen in der arabischen Welt zu stürzen. Hierfür machten sie aber nicht die eigene Schwäche oder die inhärente Stärke des Regimes verantwortlich. Vielmehr identifizierten sie das Bündnis zwischen der Regierung und den USA als Quelle des Beharrungsvermögens arabischer Machteliten. Deshalb gingen sie dazu über, verstärkt diejenigen westlichen Staaten anzugreifen, deren finanzieller und/oder militärischer Unterstützung ihre Heimatregime zumindest gemäß der Interpretation al-Qa'idas ihre Stabilität verdankten. So hofften sie, nach dem Rückzug der Amerikaner eine neue Geschäftsgrundlage für den bewaffneten Kampf in ihrer Heimat schaffen zu können. Genau diesem Zweck dienten die Anschläge in den USA.

Erst infolge dieses Strategiewechsels und des damit einhergehenden Bündnisschlusses zwischen ägyptischen Jihadisten unter der Führung von Aiman azZawahiri und saudi-arabischen Kämpfern, die sich um Usama Bin Laden geschart hatten, entstand in den Jahren 1996/97 die al-Qa'ida in ihrer bekannten Form.

Die Ägypter entstammten mehrheitlich der Jihad-Gruppe (Tanzim oder Jama'at al-Jihad), einer der ältesten militanten islamistischen Organisationen der arabischen Welt. Diese hatte sich bereits Ende der 1970er Jahre gebildet und 1981 den ägyptischen Präsidenten Sadat ermordet. In der Folge sah sie sich verschärfter Repression durch den ägyptischen Staat ausgesetzt, was viele Angehörige und Sympathisanten veranlasste, sich Mitte der 1980er Jahre nach Pakistan und Afghanistan abzusetzen. Dort versuchten sie, ihre stark geschwächte Organisation zu reorganisieren. Die ,ägyptischen Afghanen“wurden von Aiman azZawahiri angeführt, einem Kairener Arzt, der schnell zum Führer der JihadGruppe im Exil aufstieg. Da sie ihren Aufenthalt in Pakistan und Afghanistan lediglich zur Vorbereitung eines Aufstandes in ihrem Heimatland betrachteten, entbrannte ein Konflikt zwischen ihnen und dem damaligen Anführer der arabischen Afghanistankämpfer, dem Palästinenser 'Abdallah 'Azzam (1941-1989). Dieser plante, auf den Kampf gegen die Sowjetunion in Afghanistan eine ganze Reihe von ,Heiligen Kriegen“ überall, allerdings auch ausschließlich nur dort folgen zu 
lassen, wo ,Ungläubige‘ muslimisches Territorium erobert hatten. Primär ging es ihm um Palästina, aber er sah auch die Befreiung der muslimischen Teile Zentralasiens, des Libanon und Tschad, Eritreas, Somalias, der Philippinen, des damals sozialistischen Südjemen und Spaniens vor. ${ }^{3}$ Hiermit schloss er an die klassische Auffassung muslimischer Juristen an, dass einmal von Muslimen erobertes Land im Falle einer Rückeroberung durch Nichtmuslime wieder gewonnen werden müsse. Im Gegensatz zu dieser traditionellen Haltung verlangten die ägyptischen Militanten eine Ausrichtung des Kampfes auf die ,ungläubigen' Regime in der arabischen Welt, vor allem in ihrem Heimatland. Da 'Azzam ihre Interpretation, dass die muslimischen Herrscher arabischer Staaten durch ihre Politik zu Ungläubigen geworden waren, nicht teilte, lehnte er auch ihre Schlussfolgerung, dass diese zu bekämpfen seien, rundheraus ab. Das Verhältnis zwischen beiden Gruppen verschlechterte sich zusehends, bis 'Azzam 1989 ermordet wurde. ${ }^{4}$

1992 brach in Ägypten tatsächlich ein Aufstand aus, an dem auch zurückgekehrte Afghanistankämpfer teilnahmen. Er wurde allerdings von der Islamischen Gruppe (al-Jama'a al-Islamiya) getragen, die zahlenmäßig weitaus stärker war als die Jihad-Gruppe. Diese spielte im Kampfgeschehen nur eine Nebenrolle; sie verübte vereinzelte Anschläge, von denen mehrere scheiterten. Deshalb setzte sich bei der Exilführung der Jihad-Gruppe im Jahr 1995 die Einsicht durch, dass es den Islamisten nicht gelingen würde, den ägyptischen Staat zu destabilisieren. Aiman az-Zawahiri entwarf nun eine neue Strategie, die darauf abzielte, den ,nahen Feind“, also die eigene Regierung, zu schwächen, indem man ihren wichtigsten Verbündeten, den ,fernen Feind“ USA angriff. Terroristische Anschläge sollten Washington zwingen, seine Unterstützung für Kairo aufzugeben. Hierbei handelte es sich um mehr als einen rein pragmatischen Wechsel in der Militanzstrategie einer terroristischen Gruppe. Vielmehr war die Änderung Ergebnis eines Umdenkens insbesondere Aiman az-Zawahiris. Er hat den Wandlungsprozess innerhalb der Jihad-Gruppe selbst beschrieben, abschließend in seinem Buch „Ritter unter dem Banner des Propheten“, das er um den 11. September 2001 herum verfasst hat. ${ }^{5}$

3 Eine entsprechende Liste findet sich in: 'Azzam, 'Abdallah: Basha'ir an-nasr (Frohbotschaften des Sieges), Peschawar 1988 unter http://www.tawhed.ws/a?i=77 vom 15. März 2007. Als 'Azzams Hauptwerk gilt ad-Difac 'an aradi l-muslimin ahamm furud al-ayan (Die Verteidigung der Länder der Muslime ist die wichtigste der individuellen Glaubenspflichten), o.O., o.J. http://www.tawhed.ws/r?i=1594 $\& c=3545$ vom 15. März 2007.

4 'Azzam starb in Peschawar, als eine Bombe unter seinem PKW detonierte. Bis heute ist die Urheberschaft des Anschlags ungeklärt. Einige Autoren halten seine ägyptischen Konkurrenten, andere sogar Usama Bin Laden für den Täter. Eine Aktion sowjetischer Geheimdienste kann allerdings ebenso wenig ausgeschlossen werden.

5 Der Text erschien in der London erscheinenden arabischen Tageszeitung ash-Sharq al-Ausat. „Al-Sharq al-Ausat Publishes Abstracts from Al-Jihad Leader AlZawahiri's New Book", www.fas.org vom 23. Juni 2005. 
Die Saudi-Araber innerhalb der al-Qacida waren weniger straff organisiert, hatten aber eines der zahlenmäßig stärksten Kontingente unter den arabischen Afghanistankämpfern gestellt. Die einflussreichste Persönlichkeit unter ihnen war Usama Bin Laden, der schon seit Beginn der 1980er Jahre Unterstützung aus den Golfstaaten für den Kampf der Afghanen gegen die sowjetischen Truppen organisierte. Er war damals zum wichtigsten Mitarbeiter 'Abdallah 'Azzams geworden, geriet im Zuge der Auseinandersetzungen 'Azzams mit den Ägyptern jedoch zwischen die Fronten. Er scheint zunächst die Visionen seines Mentors 'Azzam geteilt zu haben, dann aber immer mehr von Zawahiris Strategie des Kampfes gegen den ,nahen Feind“ beeinflusst worden zu sein. Inwieweit er sich jedoch schon in den 1980er Jahren für die eine oder die andere Seite entschied, ist unklar.

Zum Oppositionellen in seiner Heimat wurde Bin Laden erst, als die saudiarabische Regierung im August 1990 amerikanische Truppen ins Land rief, nachdem der Irak das Emirat Kuwait besetzt hatte. Riad und Washington befürchteten damals einen Einmarsch der irakischen Truppen in die ölreiche saudiarabische Ostprovinz. In Saudi-Arabien führte der amerikanische Truppenaufmarsch zur Entstehung einer islamistischen Oppositionsbewegung, die die Präsenz der Amerikaner vehement ablehnte. In der Tradition der Wahhabiya betrachteten viele Saudis die Anwesenheit ungläubiger Truppen im „Land der Heiligen Stätten“ Mekka und Medina als Sakrileg und kritisierten ihre Regierung, die trotz des Ölreichtums des Landes nicht in der Lage war, eine effektive Landesverteidigung zu gewährleisten. Bin Laden schloss sich dem Protest an und musste das Land bereits 1991 verlassen, um seiner Inhaftierung zu entgehen. Bis er beschloss, mit Gewalt gegen die saudi-arabische Regierung vorzugehen, dauerte es jedoch noch zwei bis drei Jahre. Anlass war die Verhaftung prominenter oppositioneller Religionsgelehrter - insbesondere von Safar al-Hawali und Salman al-'Auda -, zu denen Bin Laden enge Kontakte unterhalten hatte. Im Spätsommer und Herbst 1993 schien sich die innenpolitische Lage in Saudi-Arabien zuzuspitzen, so dass sich die Herrscherfamilie entschloss, mittels einer breit angelegten Verhaftungswelle für Ruhe zu sorgen. Dies bewog Bin Laden, den bewaffneten Kampf gegen die Familie Saud aufzunehmen. Im Sommer 1995 folgte ein erster großer Anschlag in Riad und im nächsten Jahr ließ Bin Laden einen programmatischen Text veröffentlichen, der mit „Jihad-Erklärung gegen die Amerikaner, die das Land der Heiligen Stätten besetzt halten“ überschrieben war. ${ }^{6}$ Die Erklärung wird in Wissenschaft und Medienöffentlichkeit üblicherweise als „Kriegserklärung an die USA“ bezeichnet und als Auftakt des Kampfes gegen den Westen gewertet. Dies ist korrekt; ein genauerer Blick auf den Text

6 Eine gekürzte englische Übersetzung findet sich in: Barry Rubin/Judith C. Rubin (Hg.), Anti-American Terrorism and the Middle East. A Documentary Reader, Oxford: Oxford University Press 2002, S. 137-142. 
selbst macht jedoch deutlich, dass es Bin Laden in erster Linie um Saudi-Arabien ging. Schon der Untertitel „Vertreibt die Polytheisten von der Arabischen Halbinsel“" macht dies deutlich. Der eigentliche Text ist dann eine ausführliche Abrechnung mit der Herrscherfamilie Saud, in der alle erdenklichen Aspekte der saudi-arabischen Innenpolitik kritisch beleuchtet werden. ${ }^{7}$ Bis heute wird nirgendwo deutlicher als hier, dass Usama Bin Ladens antiamerikanische Ausrichtung eine Reaktion auf das schon seit den 1940er Jahren bestehende Bündnis Saudi-Arabiens mit den USA ist.

Bis Mitte der 1990er Jahre war Bin Laden tatsächlich ein herkömmlicher saudi-arabischer Oppositioneller, der sich von anderen Gegnern der Familie Saud lediglich durch seine Radikalität und Militanz, seine großen finanziellen Ressourcen und seine transnationalen Verbindungen abhob. Dies änderte sich jedoch um 1996/97, als er sich mit Aiman az-Zawahiri, mit dem er bereits seit den 1980er Jahren in Kontakt stand, verbündete. Gemeinsam beschlossen sie, den bewaffneten Kampf auf den „fernen Feind“ und damit amerikanische Ziele auszudehnen. Für die saudi-arabischen Jihadisten bedeutete dieser Strategiewechsel keine so bedeutende Neuerung wie für die Ägypter. Der oppositionelle Islamismus in Saudi-Arabien hatte eine sehr viel ausgeprägtere anti-amerikanische Dimension, die auf die enge sicherheits- und energiepolitische Zusammenarbeit zwischen Riad und Washington, insbesondere aber auf die physische Präsenz amerikanischen Militärs in Saudi-Arabien seit 1990 zurückging. Hinzu kam, dass die islamistische Opposition auch in Saudi-Arabien die Stabilität des politischen Systems nicht hatte erschüttern können, so dass sich ein Strategiewechsel anbot. Wieder besiegelte Bin Laden seine Neuausrichtung, indem er gemeinsam mit Aiman az-Zawahiri im Februar 1998 den Aufruf der „Islamischen Weltfront für den Jihad gegen Juden und Kreuzzügler" veröffentlichte, in der sie ihre gemeinsame antiamerikanische Strategie darlegten. ${ }^{8}$ Die amerikanische ,Besetzung“ Saudi-Arabiens spielte auch in diesem Dokument noch eine wichtige Rolle, wurde nun jedoch in einen regionalpolitischen Rahmen integriert. Die Unterzeichner erklärten den ,Heiligen Krieg ‘ (jihad) gegen die USA und ihren Verbündeten zur individuellen Glaubenspflicht jedes Muslims. Terroristische Anschläge auf amerikanische Ziele sollten die USA zum Rückzug aus Saudi-Arabien bewegen und den Weg zum Kampf gegen die Regierung in Riad freimachen. Diesem Ziel dienten alle Anschläge der al-Qaida in den folgenden Jahren.

7 Der Text ähnelt bis in die Details stark einem älteren Text mit dem Titel „Memorandum des Guten Rates" (Mudhakkirat an-Nasiha) vom Juli 1992, in dem die saudi-arabische islamistische Opposition ihre Forderung nach einer umfassenden Islamisierung des Staates vorbrachte.

8 Der Text der Erklärung wurde am 23. Februar 1998 in der palästinensischen Tageszeitung al-Quds al-Arabi veröffentlicht. Nass bayan al-jabha al-islamiya al'alamiya li-jihad al-yahud wa-s-salibiyin. Eine gekürzte englische Version findet sich in: B. Rubin/J.C. Rubin: Anti-American Terrorism, S. 149f. 
Eine auch nur kursorische Lektüre der grundlegenden Dokumente zur Geschichte der al-Qa'ida verdeutlicht bereits, wie wichtig eine islam- und regionalwissenschaftliche Interpretation ist, will man dem Phänomen islamistischer Terrorismus gerecht werden. Nimmt man die Eigenaussagen ihrer Protagonisten ernst, entdeckt der Beobachter schnell, wie eng die Entwicklung ihrer Ideologien und Strategien mit der Geschichte ihrer Heimatländer verwoben ist. Ein scheinbar globales Phänomen wird dadurch schnell wieder regional. Monolithisch und überlebensgroß scheinende Organisationen wie al-Qaida werden schnell zu stark fragmentierten Einheiten, deren Verständnis an eine intensive Beschäftigung mit den Heimatländern ihrer Aktivisten gebunden ist. Diese Diversität zu vermitteln, zur Differenzierung beizutragen, ist eine Aufgabe der Islamwissenschaft.

\section{Von der Organisation zur Ideologie}

In der Terrorismusforschung, in Politik und Öffentlichkeit ist heute immer häufiger die Rede davon, dass sich al-Qa'ida ,von der Organisation zur Ideologie“, oder zu „einer ideologischen Leitstelle“ entwickelt habe oder entwickele. Während die Organisation selbst weitgehend zerschlagen und ihre Führung in den pakistanischen Bergen isoliert ist, handeln immer mehr Zellen und Gruppen weltweit entsprechend der ideologischen und strategischen Vorgaben Bin Ladens und Zawahiris. Dementsprechend wird es immer wichtiger, die ideologische Entwicklung und die strategisch-taktischen Debatten unter militanten Islamisten nachzuvollziehen, will man den islamistischen Terrorismus verstehen und auch Aufschluss über mögliche Gefährdungen gewinnen. Oft ist heute die ideologische Entwicklung die einzige feste Basis für seine Erforschung. Dies können allerdings nur Forschende mit einer profunden islamwissenschaftlichen Ausbildung leisten. Mehr noch, die hierfür erforderlichen Kenntnisse islamischer Geschichte, Kultur und der für deren Studium relevanten Sprachen eignen sich Studierende vor allem in Studiengängen an, die einen deutlichen Schwerpunkt auf die Beherrschung verschiedener ,Islamsprachen' und vor allem des Arabischen legen. Auch wenn darüber hinaus sozialwissenschaftliche Kenntnisse nützlich sind, ist eine stark philologisch und an der Literatur auch früherer Jahrhunderte orientierte Ausbildung die beste Voraussetzung für eine nachhaltige Beschäftigung mit dem islamistischen Terrorismus nach 2001. Der islamistische Terrorismus ist zwar ein Phänomen der Moderne, doch beziehen sich seine Vordenker immer auf klassische Texte, um ihrer Argumentation Nachdruck zu verleihen. Der Rückbezug auf den Damaszener Gelehrten Taqi ad-Din b. Taimiya (12631328) ist nur das prominenteste Beispiel hierfür. Während ein Politikwissenschaftler mit guten Arabischkenntnissen die Bindung islamistischer Terroristen an ihre jeweiligen Heimatländer gegebenenfalls noch nachzeichnen kann, sind für die Erforschung militanter Ideologie tiefergehende philologische und islamwissenschaftliche Kenntnisse vonnöten. 
Mit der Entwicklung der al-Qaida von der Organisation zur Ideologie beschreibt die Terrorismusforschung einen Trend, der im Herbst 2001 mit der Zerschlagung der Strukturen der alten al-Qaida in Afghanistan einsetzte. Ihre Führungsspitze war in den folgenden Jahren immer weniger in die konkrete Planung und Organisation von Anschlägen eingebunden. Gleichzeitig gewann die von ihr vertretene Ideologie an Bedeutung. Mit Beginn der Luftangriffe auf Afghanistan Anfang Oktober 2001 begannen Bin Laden und Zawahiri, in unregelmäßigen Zeitabständen Audio- und Videobotschaften zu veröffentlichen, in denen sie ideologische, strategische und taktische Fragen des bewaffneten Kampfes diskutierten. Dabei handelte es sich zum einen um allgemeine Standortbestimmungen der al-Qaida beispielsweise hinsichtlich der Frage, welche Staaten oder auch nichtstaatliche Gruppen oder Individuen legitime Ziele terroristischer Gewalt sind. Zum anderen gaben Bin Laden und Zawahiri in diesen Botschaften konkrete Zielvorgaben, auf die in mehreren Fällen entsprechende Anschläge folgten. Meist scheint es sich hierbei mitnichten um Handlungsanweisungen an eine bestimmte Zelle oder Gruppe gehandelt zu haben. Vielmehr nahmen unabhängig von der Mutterorganisation operierende Gruppen die Richtlinien der al-Qa'idaFührung auf und versuchten dann, in ihrem Sinne terroristisch aktiv zu werden. Diese Entwicklung führte dazu, dass terroristische Zellen und Gruppen insbesondere in Europa immer unberechenbarer wurden. Da es immer weniger Kontakte (Brief- und E-Mailkontakte, Telefonate, persönliche Treffen) zwischen terroristischen Zellen und ihren jeweiligen Mutterorganisationen gibt, fällt es Sicherheitsbehörden auch immer schwerer, terroristische Strukturen aufzuspüren. Umso wichtiger wird es seitdem, die Ideologie- und Strategieentwicklung zu beobachten, um auf diese Weise Aufschlüsse über mögliche Gefahren zu erhalten.

Seit 2003 mehren sich die Anzeichen, dass zumindest Teile der al-Qa'ida ganz bewusst auf Dezentralisierung setzen und dabei eine Strategie verfolgen, die der amerikanische Rechtsextremist Louis Beam (geb. 1946) zu Beginn der 1980er Jahre „führerlosen Widerstand“ genannt hat: Er hatte beobachtet, dass herkömmliche, strikt hierarchisch strukturierte militante Organisationen von den Sicherheitskräften moderner Gesellschaften ohne größere Schwierigkeiten entdeckt und zerschlagen werden konnten. Da die Führung mit allen Teilen der Organisation intensiv kommuniziert, müssen Nachrichtendienste und Polizeibehörden lediglich die Kommunikationsstränge identifizieren, um die Gruppierung dann auszuheben. Deshalb sollten die Extremisten direkte Kontakte untereinander vermeiden, und stattdessen ihre Ideologie und Zielvorstellungen verbreiten, so dass es einzelnen Zellen ganz ohne organisatorische Verbindung zu einer zentralen Führung gelingen konnte, unabhängig, aber in Einklang mit einer handlungsleitenden Ideologie zu agieren. Nur so, argumentierte Beam, sei es möglich, eine schnelle Aufdeckung und Zerschlagung der Organisation zu verhindern. Ü- 
ber ihre terroristischen Aktionen würden die Gruppen zueinander finden, um eine landesweite Revolution auszulösen. ${ }^{9}$

Erst in der globalisierten Welt des Internets, das sich seit Ende der 1990er Jahre auch in der arabischen Welt rasant ausbreitete, gewannen Beams Ideen über die USA hinaus an Relevanz und wurden nun von islamistischen Terroristen rezipiert. Seitdem ist es ohne Weiteres möglich, eine handlungsleitende Ideologie ungehindert weltweit zu verbreiten. Zwar ist nicht vollkommen gesichert, dass sich islamistische Terroristen und ihre Anhänger mit dem Text Louis Beams beschäftigt haben. ${ }^{10}$ Dennoch weist ihre Vorgehensweise seit 2003 darauf hin, dass sie auch über die Führung der al-Qa'ida hinaus einer ähnlichen Strategie folgen. In der medialen Praxis war es der saudi-arabische Flügel der al-Qaida, al-Qa'ida im Land der Heiligen Stätten (al-Qa'ida fi Bilad al-Haramain), der seit September 2003 zwei Zeitschriften im Internet veröffentlichte. Die eine war Die Stimme des Jihad (Saut al-Jihad), in der vor allem ideologische Fragen diskutiert wurden und die, obwohl sie seit April 2005 nicht mehr erschienen ist, von Jihadisten weltweit gelesen wird. Ab Dezember 2003 kam eine zweite Publikation namens Das Trainingscamp Yusuf al-'Uyairis (Mu'askar al-Battar) hinzu. ${ }^{11}$ Dabei handelte es sich um eine Art „virtuelles Trainingscamp“, in dem sich die Autoren vor allem Themen terroristischer Taktik widmeten. Die saudi-arabische al-Qa'ida versuchte hier, ihren Anhängern über das Internet alle Informationen zukommen zu lassen, die bis 2001 in den Trainingslagern der al-Qa'ida vermittelt worden waren. In den folgenden Jahren gingen auch unabhängige terroristische Organisationen wie al-Qa'ida im Irak (al-Qa'ida fi Bilad ar-Rafidain), die kurdischirakischen Helfer der Sunna (Ansar as-Sunna) und die algerische Salafistische Gruppe für Predigt und Kampf (Groupe Salafiste pour la Prédication et le Combat, GSPC) dazu über, vor allem ideologisches und strategisches Material in Internetzeitschriften zu verbreiten.

Zum Vordenker dieser Strategie des „führerlosen jihadistischen Widerstands“ wurde jedoch der Syrer Mustafa as-Sitt Mariam (Abu Mus'ab as-Suri), der seit Mitte der 1990er Jahre zu einem wichtigen Strategen des islamistischen Terro-

9 Bruce Hoffman: Terrorismus. Der unerklärte Krieg. Neue Gefahren politischer Gewalt, Frankfurt/M: Fischer-Taschenbuch-Verlag 2002, S. 78-82. Der Originaltext „Leaderless Resistance by Louis Beam, published in the Seditionist 12, February 1992" kursiert heute auf zahllosen Webseiten.

10 Jessica Stern behauptete in einem Artikel in Foreign Affairs von 2003, dass Louis Beams Artikel schon damals von Islamisten intensiv rezipiert wurde. Sie nannte aber keine Belege. Jessica Stern: „The Protean Enemy”, in: Foreign Affairs 82 (July/August 2003), S. 27-40, hier S. 34.

11 ,al-Battar“ war der Kampfname Yusuf al-'Uyairis, eines saudi-arabischen Ideologen der al-Qaida, der 2003 getötet wurde. Seine Publikationen insbesondere zum Krieg der USA im Irak sind bis heute in Jihadistenkreisen weit verbreitet. Vgl. z.B. sein bekanntestes Werk Mustaqbal al-Iraq wa-l-Jazira al-'Arabiya ba'da suqut Baghdad (Die Zukunft des Irak und der Arabischen Halbinsel nach dem Fall Bagdads), o.O., o.D. (2003). 
rismus geworden war. ${ }^{12}$ Im Dezember 2004 veröffentlichte er unter dem Titel „Aufruf zum weltweiten islamischen Widerstand“ eine monumentale Studie zu Geschichte und Zukunft des Jihadismus, die seit ihrem Erscheinen zu einem der wichtigsten ideologischen und strategischen Leitfäden des islamistischen Terrorismus wird. In Anlehnung an Beams „führerlosen Widerstand“ formulierte er: „Wir rufen die Jugend und alle Muslime auf, den individuellen Widerstand zu wählen, wobei der Widerstand sich nicht auf netzwerkartige und hierarchische Strukturen stützt, bei denen die Verhaftung einiger Individuen zu ihrer Zerstörung und Verhaftung aller Angehörigen führt. Dies geschieht durch die Wahl einer Vorgehensweise, die keine Organisationsform im bekannten Sinne ist. Vielmehr trägt jeder Teilnehmer unverbunden zu den Aktivitäten des Widerstands bei und gehört damit zum, weltweiten islamischen Widerstand“ (al-muqawama alislamiya al-'alamiya). ${ }^{13}$ Will man einen genaueren Einblick in die Fortentwicklung militanter Ideologie und Strategie gewinnen, ist Abu Mus'ab as-Suris Buch Pflichtlektüre. Inwieweit seine Vorstellungen in Zukunft allerdings tatsächlich verwirklich werden, ist bisher offen. Dagegen spricht, dass al-Qaida bis 2001 versucht hatte, eine weitgehend herkömmliche, hierarchisch strukturierte Organisation zu schaffen und erst anschließend, aus einer Position der Schwäche, eine Dezentralisierung betrieb. $\mathrm{Zu}$ beobachten ist allerdings, dass eine Strategie des führerlosen Widerstands vor allem in der europäischen Diaspora Anhänger zu finden scheint. Hier macht sich seit Beginn des Irak-Krieges 2003 ein Trend zu immer dezentraleren Organisationsformen terroristischer Gruppierungen bemerkbar, in dem der Ideologievermittlung über das Internet eine besondere Bedeutung zukommt.

Das möglicherweise wichtigste Beispiel hierfür sind die Anschläge von Madrid am 11. März 2004. Usama Bin Laden hatte bereits in einer Audiobotschaft vom Oktober 2003 Attentate auf spanische, italienische und britische Ziele gefordert, weil diese Staaten Truppen in den Irak entsandt hatten. Ungefähr zeitgleich erschien ein Strategiepapier der al-Qaida im Internet, in dem die bis heute unbekannten Autoren die Zielvorgaben Bin Ladens näher erläuterten. ${ }^{14}$ Im Zentrum ihrer Argumentation stand die Forderung, die finanziellen, militärischen und politischen Kosten der Präsenz im Irak für die USA zu erhöhen. Zu diesem Zweck sollten die Truppen der amerikanischen Verbündeten Italien, Spanien und Großbritannien im Irak angegriffen werden, um sie zum Rückzug zu bewegen. Ohne die Unterstützung der damals wichtigsten Alliierten würde die amerikani-

12 as-Sitt Mariam schrieb zahlreiche Texte, in denen er die Erfahrungen militanter Bewegungen in Syrien, Algerien, Zentralasien, Afghanistan und der Arabischen Halbinsel analysierte.

13 Abu Mus'ab as-Suri: Da'wat al-muqawama al-islamiya al-'alamiya (Aufruf zum weltweiten islamischen Widerstand), o.O., 2004, S. 54.

14 Formale und inhaltliche Hinweise verweisen auf saudi-arabische und marokkanische Einflüsse und damit auf mehr als einen Autor. 
sche Präsenz im Irak immer kostspieliger und damit auch ein Rückzug der USTruppen wahrscheinlicher. Spanien wurde als das schwächste Glied in der Kette identifiziert, und folgerichtig forderten die Autoren nicht näher definierte Schläge gegen die spanischen Truppen noch vor den am 14. März 2004 anstehenden Parlamentswahlen:

„Wir müssen es unbedingt nutzen, dass in Spanien die landesweiten Wahlen schon in nächster Zeit - im März 2004 - folgen werden. Wir denken, dass die spanische Regierung nicht einmal zwei oder drei (An-)Schläge (darabat, Sg. darba) aushalten wird, bis sie wegen des öffentlichen Drucks gezwungen sein wird, ihre Truppen zurückzuziehen. Wenn ihre Soldaten jedoch nach diesen Schlägen bleiben sollten, ist ein Sieg der Sozialistischen Partei beinahe garantiert und dann wird der Abzug der spanischen Truppen auf ihrem Wahlprogramm stehen. “15

Die Anschläge in Madrid wurden zu einem der größten Erfolge des islamistischen Terrorismus überhaupt. Das katastrophale Krisenmanagement der Regierung Aznar trug zum Wahlsieg der oppositionellen Sozialisten bei, die bis Sommer 2004 ihr Wahlversprechen wahr machten und sämtliche spanischen Truppen aus dem Irak abzogen. Insofern handelte es sich bei den Anschlägen um eine fast perfekte Umsetzung des Strategiepapiers, in dem die politischen Folgen im Detail vorgezeichnet worden waren. Bei den Tätern handelte es sich um eine Gruppe von mehrheitlich marokkanischen Nordafrikanern, sozioökonomisch unterprivilegierte junge Männer, teils Kleinkriminelle, so dass in Sicherheitskreisen zunächst die Auffassung vorherrschte, dass sie die Anschläge nicht eigenverantwortlich geplant und organisiert haben könnten. Vielmehr glaubten die Ermittler, dass es eine Verbindung zu einem Planer im Hintergrund und/oder einer größeren terroristischen Organisation geben müsse.

Der bisher einzig stichhaltige Beleg für eine solche ,organisatorische“ Anbindung ist das erwähnte Strategiepapier der al-Qa'ida. Es besteht kein Zweifel, dass die Täter es als Anleitung für ihre Aktion genutzt hatten. Unabhängig davon, ob - was wahrscheinlich ist - ein noch direkterer Kontakt zu al-Qa'ida oder zur Organisation des Jordaniers Zarqawi im Irak (damals Jama'at at-Tauhid wal-Jihad) bestand, verdeutlichte dieser Vorgang, wie wichtig die Verbreitung ideologischer und strategischer Traktate im Internet sein kann. Immer häufiger operieren kleine terroristische Gruppierungen eigeninitiativ und in einem ideologisch-strategischen Rahmen, der von Jihadisten im Internet vorgegeben wird.

In dieser Situation wird es immer wichtiger, die ideologische Entwicklung und die strategisch-taktischen Debatten unter militanten Islamisten nachzuvollziehen, will man sie verstehen und auch Aufschluss über mögliche Gefährdungen gewinnen. Da terroristische Gruppen immer dezentraler vorgehen, ist die Beo-

15 „Iraq al-jihad - amal wa-akhtar“, o.O., o.D. http://www.e-prism.org/images/book _-_Iraq_al-Jihad.doc vom 15. März 2007. 
bachtung der Ideologie heute die nahezu einzige Möglichkeit, zumindest einen groben Überblick über ihre Entwicklung zu wahren. Folgerichtig wächst weltweit - in erster Linie in den USA - das Interesse an islamistischer und jihadistischer Ideologie. ${ }^{16}$ Regierungen reagieren darauf seit 2001 (und in Deutschland vermehrt seit den gescheiterten Kofferbombenattentaten im Sommer 2006), indem sie vermehrt Islamwissenschaftler und sonstige Sprachkundige einstellen, um das jihadistische Internet zu überwachen. Ob die zu diesem Zweck eingestellten Islamwissenschaftler dieser Aufgabe gewachsen sind, ist von außen nur schwer einzuschätzen. ${ }^{17}$ Die Anforderungen an Interpreten islamistischer Ideologien sind in jedem Fall hoch. Um die entsprechenden Texte einordnen und interpretieren zu können, sind zunächst profunde Kenntnisse der islamischen Geschichte, insbesondere der Geschichte religiös-politischen Denkens und der Geschichte islamischer Reformbewegungen unabdingbar. Ist es schon anspruchsvoll, Texte wie Abu Mus'ab as-Suris „Aufruf zum weltweiten islamischen Widerstand" zu bearbeiten, haben diese oft eine historische Dimension, da sie ihre Argumentation durch zahlreiche Zitate und Verweise auf Koran, Sunna und angesehene Gelehrte der Vergangenheit zu untermauern suchen. Die wichtigste Gewährsperson ist dabei Taqi ad-Din b. Taimiya. Seine Lehren und Lebensführung machen ihn zur wichtigsten intellektuellen Bezugsperson heutiger islamistischer Terroristen. Für die Jihadisten ist insbesondere Ibn Taimiyas berühmtes ,Mongolenfatwa' wegweisend. Darin lieferte er den mamlukischen Herrschern Syriens eine Rechtfertigung für einen ,Heiligen Krieg' gegen die mongolischen Ilkhane, die damals Syrien bedrohten. Ibn Taimiya argumentierte, dass die Ilkhane zwar zum Islam übergetreten seien, aber dennoch Ungläubige seien, weil sie nicht islamisches Recht, sondern den „yasa“ genannten Gesetzescode des Mongolenherrschers Dschingis Khan anwandten. Für islamistische Terroristen bietet dieses Fatwa die Gelegenheit, sich auf einen gemeinhin anerkannten Religionsgelehrten zu beziehen, wenn sie den ,Heiligen Krieg' gegen die Regierungen ihrer Heimatländer führen. Denn auch hier stellt sich das Problem, dass ein ,Heiliger Krieg' gegen Muslime zunächst generell unzulässig ist. Wenn Islamisten dennoch einen jihad gegen den „,nahen Feind“ führen und dies durch eine religionsrechtliche Argumentation rechtfertigen wollen, müssen sie eine anerkannte Autorität finden, auf die sie sich berufen können. Ein Kopf der Sadat-Attentäter, der Ingenieur Muhammad ,Abdassalam Farag (1954-1982) nutzte denn auch den Rückbezug auf das Mongolenfatwa des großen Damaszeners, um den Mordan-

16 Vgl. z.B. William McCants (Hg.), Militant Ideology Atlas, Combating Terrorism Center, US Military Academy, November 2006 unter http://www.ctc.usma.edu/atlas /Atlas-ResearchCompendium.pdf vom 15. März 2007.

17 Der bekannteste Islamwissenschaftler in Diensten einer Sicherheitsbehörde ist ein Mitarbeiter des Bundesnachrichtendienstes (BND), der ab 2006 im Auftrag des UNGeneralsekretärs einen Gefangenenaustausch zwischen Israel und der libanesischen Hizbullah vermitteln soll. Der Spiegel (23.10.2006) taufte ihn „Mr. Hisbollah“. 
schlag auf den ägyptischen Präsidenten 1981 zu rechtfertigen. ${ }^{18}$ Diese und andere Texte stellen - so wenig originell die neueren unter ihnen oft auch sein mögen hohe sprachliche Anforderungen an den nichtmuttersprachlichen Leser, die dieser in der Regel erst nach mehrjährigem Studium ähnlicher Texte erwirbt. Hinzu kommt, dass allein arabische Sprachkenntnisse für eine umfassende Beobachtung des Themas nicht mehr ausreichen. Immer häufiger publizieren Jihadisten in Europa und der Türkei beispielsweise in türkischer Sprache, wobei sie allerdings arabische jihadistische Literatur intensiv rezipieren. Urdu und Paschtu sind unabdingbar, wenn man sich mit militantem Islamismus in Pakistan und Afghanistan befasst. Betrachtet man diese Anforderungen an den Interpreten jihadistischer Ideologie, so wird hier deutlich, dass er ohne profunde islamwissenschaftliche Kenntnisse scheitern wird.

\section{Die Islamwissenschaft und der islamistische Terrorismus}

Wie die im bisherigen Text angeführten Schlussfolgerungen zeigen, soll es hier keinesfalls darum gehen, die Islamwissenschaft an den Erfordernissen der Terrorismusbekämpfung zu messen. Der islamistische Terrorismus ist aus gutem Grund ein Randthema in der Islamwissenschaft und sollte dies auch bleiben. Vielmehr habe ich versucht, an zwei Beispielen zu zeigen, dass die deutsche Islamwissenschaft in ihrer heutigen Erscheinungsform durchaus wichtige Beiträge zu einer Erforschung des islamistischen Terrorismus leisten und auch entsprechende Spezialisten ausbilden kann, ohne dass sie zu einer reinen Sozialwissenschaft wird. Durch die in den letzten Jahren beschleunigte Annäherung an die Politik- und Geschichtswissenschaft bieten sich interessierten Studierenden ohnehin ausreichende Gelegenheiten, methodische Kompetenzen zu erwerben, die für eine vergleichende Betrachtung des Phänomens vonnöten sind.

Die Islamwissenschaft sollte sich auf ihre Stärken besinnen. Wie oben ausgeführt, ist nur eine islam- und regionalwissenschaftliche informierte Betrachtung des Phänomens geeignet, die Charakteristika des islamistischen Terrorismus richtig, nämlich als Folge- und Begleiterscheinung innerarabischer oder auch innermuslimischer Bürgerkriege zu verstehen und seine Wurzeln in der arabischen und islamischen Welt aufzuspüren. Aufgabe der Islamwissenschaft muss es sein, diesen Aspekt der Politik, einer breiteren Öffentlichkeit und auch denjenigen Terrorismusforschern zu vermitteln, die sich aus politikwissenschaftlichen Perspektiven mit Islamisten und Jihadisten befassen. Zu häufig noch können sich diese mit einigen Plattitüden zur Ideologie Sayyid Qutbs und 'Abdallah 'Azzams aus der Affäre ziehen. Die Voraussetzungen für eine effektivere Kommunikation

18 Dies in seiner Schrift ,die vergessene Pflicht“ (al-Farida al-Gha'iba). Johannes J. G. Jansen: The Neglected Duty: the Creed of Sadat's Assassins and Islamic Resurgence in the Middle East, New York: Macmillan u.a. 1986. 
aus der Islamwissenschaft heraus haben sich nach 2001 verbessert. Sie trifft erstmals auf nachhaltiges Interesse, was ihr ermöglicht, ihre Arbeitsergebnisse einer breiteren Öffentlichkeit als zuvor zur Verfügung zu stellen - und dies ohne dass sie ihre Arbeitsschwerpunkte verändert. Hier sollte sie präsenter sein und für islamwissenschaftlich informierte und regionalwissenschaftlich differenzierte Interpretationen werben.

Die Islamwissenschaft sollte sich darüber hinaus auch verstärkt der Erforschung islamistischer und jihadistischer Ideologien widmen. Während die darauf basierende Interpretation von Gefährdungen getrost den Sicherheitsbehörden überlassen werden kann, deuten zumindest die Veröffentlichungen aus dem angelsächsischen Raum darauf hin, dass, wenn entsprechende Studien mit der philologischen Kompetenz der deutschen Islamwissenschaft erarbeitet würden, durchaus weiterführende Ergebnisse erwartet werden könnten. Darüber hinaus handelt es sich bei den Debatten nicht nur über politische Interpretationen des Islam, sondern auch über militante Ausprägungen des Islamismus um zentrale Themenfelder des politischen Denkens in der islamischen Welt und unter Muslimen weltweit - und damit um einen wichtigen Gegenstand der Islamwissenschaft.

Um diese Beiträge zum Verständnis einer Gegenwartsfrage leisten zu können, muss sich die deutsche Islamwissenschaft nicht grundsätzlich umorientieren. Insbesondere für das Studium islamistischer Ideologien ist eine solide philologische Ausbildung in mindestens einer Sprache unabdingbar. Wenn dann auch noch Erfahrungen mit sozialwissenschaftlichen Methoden hinzukommen, ist dies wünschenswert, aber eben nicht entscheidend. Selbst wenn man sich einem so gegenwartsbezogenen Thema wie dem islamistischen Terrorismus widmet, ist die besondere Stärke des Islamwissenschaftlers seine profunde Kenntnis von Geschichte, Kultur und (mehreren) Sprachen der islamischen Welt. Vor allem dies unterscheidet ihn von Sozialwissenschaftlern und macht ihn auf einem sich internationalisierenden Arbeitsmarkt zu einem begehrten Spezialisten. 


\title{
Von der „Islampolitik“ zum „Dialog mit der islamischen Welt" - Anmerkungen zum Verhältnis zwischen Orientalistik und deutscher (Außen-)politik
}

TIM EPKENHANS (BISCHKEK)

\begin{abstract}
„Da ist es denn eine der Grundfragen, wie man sich zum Islam überhaupt stellt, ob man ihn bekämpft, befördert oder indifferent behandelt $[\ldots]$ ob man sich in die islamischen Verhältnisse einmischen soll, oder ob man die europäische Staatsleitung vollkommen trennen soll von dem islamischreligiösen Leben der Bevölkerung, um sich höchstens auf ein allgemeines Aufsichtsrecht zu beschränken." Carl Heinrich Becker (1915) ${ }^{1}$
\end{abstract}

\section{Einleitung}

Als ich Anfang der 1990er Jahre mein Studium der Islamwissenschaft und Iranistik aufnahm, reagierten Verwandte und Freunde eher mit Unverständnis auf meine Entscheidung, häufig mit dem Hinweis, dass es sich doch wohl um eine brotlose Kunst mit geringen beruflichen Perspektiven handle. Das Interesse am ,Islam`war in der deutschen Öffentlichkeit und Politik marginal und die deutsche Orientalistik forschte und publizierte weitgehend selbstgenügsam in einem kommoden Elfenbeinturm. ,Den Islam“ erklärten der deutschen Öffentlichkeit (und Politik) zumeist selbsternannte Experten (wie etwa der notorische Peter Scholl-Latour), die in öffentlichen Debatten Fachvertretern der Orientalistik regelmäßig den Rang abliefen (und heute noch ablaufen) und sich weitaus effizienter den spezifischen Regeln einer Mediengesellschaft unterwarfen. ${ }^{2}$ Offensicht-

1 Carl Heinrich Becker: „Islampolitik“, in: Die Welt des Islams 3 (1916), S. 101-120, hier S. 108.

2 Vgl. hier etwa die TV-Debatten während des Golfkrieges 1991. Allerdings ist hier anzumerken, dass sich Vertreter der orientalistischen Fachdisziplinen durchaus kritisch gegen Scholl-Latour zu Wort meldeten (vgl. Verena Klemm/Karin Hörner (Hg.), Das Schwert des Experten - Peter Scholl-Latours verzerrtes Araber- und Islambild, Heidelberg: Palmyra 1993). Gernot Rotter hatte zuvor bereits nachgewie- 
lich war und ist es vielen orientalistischen Fachvertretern unangenehm, sich in die profanen Untiefen deutscher Medienöffentlichkeit oder gar der Politikberatung zu begeben. Das Unbehagen in der Islamwissenschaft offenbarte sich nicht zuletzt in der Kontroverse um die Verleihung des Friedenspreises des deutschen Buchhandels 1995 an die Grand Old Dame der deutschen Orientalistik Annemarie Schimmel. Um es mit Stefan Wild zu sagen: „Ein Fach verkriecht sich“3.

Der 11. September 2001 und die folgenden Ereignisse insbesondere in Europa hatten schließlich zur Folge, dass ,Islam‘ zu einem der zentralen Themen in der deutschen Öffentlichkeit und Politik avancierte. Mittlerweile bemüht sich eine Flut von einschlägigen Publikationen um eine Erklärung des ,Islam ‘ und den Absolventen der orientalistischen Disziplinen eröffneten sich zahlreiche berufliche Perspektiven unter anderem in staatlichen Institutionen, wie etwa dem Verfassungsschutz, Bundesnachrichtendienst und dem Auswärtigen Amt. Letzteres initiierte bereits Ende 2001 eine umfangreiche diplomatische Initiative unter dem Titel „Dialog mit der islamischen Welt“ (oder in der Kurzform „Islamdialog“), zu dessen Implementierung auch Orientalisten als Referenten auf befristete Stellen vergleichbar zum höheren Dienst rekrutiert wurden. ${ }^{4}$ Auch der Verfasser dieser Zeilen fand sich - durchaus zu seiner Überraschung - nach seiner Promotion im Frühjahr 2002 als so genannter ,Islambeobachter' an der deutschen Botschaft in Duschanbe, Tadschikistan, wieder - doch dazu später mehr.

Die Anwerbung von Orientalisten im Rahmen einer dezidiert auf die islamische Welt fokussierten Außenpolitik mag unter aufmerksamen Beobachtern der deutschen Orientalistik unangenehme Assoziationen mit einer Zeit evozieren, wo Fachvertreter und dilettantische Laien schon einmal versucht hatten, die deutsche ,Islampolitik‘ zu beeinflussen.

sen, dass Gerhard Konzelmann (Publizist und Nahost-Korrespondent der ARD) in seinem zahlreichen Publikationen wissenschaftliche Arbeiten plagiiert hatte (vgl. Gernot Rotter: Allahs Plagiator. Die publizistischen Raubzüge des „Nahostexperten“ Gerhard Konzelmann, Heidelberg: Palmyra 1992). Dennoch ist Scholl-Latour noch heute einer der erfolgreichsten Sachbuchautoren in Deutschland und auch Konzelmann publiziert weiterhin (wenn auch weniger erfolgreich).

3 Stefan Wild: „Der Friedenspreis und Annemarie Schimmel: Eine Nachlese“, in: Die Welt des Islams 36 (1996), S. 107-122, hier S. 121.

4 Die Einrichtung befristeter Stellen für bestimmte Aufgaben war bis zu diesem Zeitpunkt im Auswärtigen Amt gänzlich unüblich. Seit Einrichtung des AA 1951 wurden gelegentlich auch Absolventen der orientalistischen Fächer in den auswärtigen Dienst berufen. Der auswärtige Dienst untersteht jedoch dem Paradigma des Generalismus, d.h. die fachliche Qualifikation eines Beamten im Auswärtigen Dienst wird nur bedingt in der Stellenplanung berücksichtigt, wobei die amtsinterne Attaché-Ausbildung eine Verwendung in allen Abteilungen des AA gewährleisten soll. 


\section{Der Erste Weltkrieg und die „Revolutionierung“ der islamischen Welt}

Nach der Reichsgründung 1871 und insbesondere während der Regentschaft Wilhelm II. verfolgte das Deutsche Reich eine ambitionierte Außenpolitik, die ihm einen Platz an der Sonne in Form überseeischer Kolonien garantieren sollte. Weder die ,Weltpolitik، von Reichskanzler von Bülow noch die heterogenen Vorstellungen verschiedener Lobbyistengruppen (wie etwa dem Alldeutschen Verband) folgten konsistenten Ideen, wie die koloniale Expansion im Orient und insbesondere die Politik gegenüber dem Osmanischen Reich ausfallen sollte, führte aber zu zunehmenden Rivalitäten mit Russland, Großbritannien und Frankreich. Fachvertreter der orientalistischen Disziplinen, etwa Carl Heinrich Becker, Eugen Mittwoch oder Martin Hartmann, bemühten sich nachhaltig um eine aktive Mitgestaltung der ,Orientpolitik' des Deutschen Reiches bereits im Vorfeld des Ersten Weltkrieges. Obwohl es vor allem ,Laienorientalisten“ wie etwa Max von Oppenheim ${ }^{5}$ oder Konsul Schabinger waren, die sich aktiv um eine „Revolutionierung der islamischen Gebiete unserer Feinde “6 bemühten, hatten sich auch zahlreiche Fachvertreter deutscher Universitäten nur allzu bereitwillig für Pläne der Reichsleitung und des Auswärtigen Amtes einspannen lassen. Dies ist mittlerweile detailliert und kritisch dokumentiert worden. ${ }^{7}$ Allerdings, das En-

5 Max von Oppenheims Karriere war ungewöhnlich für einen Nachkommen der vermögenden Bankiersfamilie Oppenheim. 1860 geboren, trat er 1883 nach seinem Jura-Studium in den preußischen Verwaltungsdienst ein. Das väterliche Vermögen erlaubte ihm bereits frühzeitig die Möglichkeit ausgedehnter Reisen nach Nordafrika und Indien. Oppenheim nutzte einen längeren Aufenthalt in Alexandria, um auf den Spuren des berühmten Richard Francis Burton ,ein Orientale‘ zu werden. Zwischen 1896 und 1910 residierte Oppenheim als Attaché an der deutschen Gesandtschaft in Kairo. Seine nachrichtendienstliche Funktion verpflichtete ihn zu zahlreichen Reisen im Gebiet der Arabischen Halbinsel und der Levante, wo er 1899 die hethitische Siedlung Tell Halaf (im heutigen Syrien) entdeckte. 1910 quittierte er den diplomatischen Dienst und leitete bis 1913 die archäologischen Ausgrabungen in Tell Halaf. Kurz nach Ausbruch des Ersten Weltkrieges berief das Auswärtige Amt Oppenheim zur Bearbeitung der Angelegenheiten die islamische Welt betreffend zurück. Vgl. R. L. Melka: „Max Freiherr von Oppenheim. Sixty Years of Scholarship and Political Intrigue in the Middle East“, in: Middle Eastern Studies 9 (1973), S. 81-93.

6 So der Titel der Denkschrift (1914) Max von Oppenheims. Siehe hierzu die Edition von Tim Epkenhans: „Geld darf keine Rolle spielen“, Teil 1 und Teil 2, in: Archivum Ottomanicum 18 (2000), S. 247-250 und 19 (2001), S. 121-163.

7 Vgl. etwa: Gottfried Hagen: „German Heralds of Holy War: Orientalists and Applied Oriental Studies“, in: Comparative Studies of South Asia, Africa and the Middle East 24 (2004), S. 145-162; Ludmila Hanisch: „Gelehrtenselbstverständnis, wissenschaftliche Rationalität und politische ,Emotionen“: Ein Nachtrag“, in: Die Welt des Islams 32 (1992), S. 107-123; Peter Heine: „C. Snouck Hrugronje versus C. H. Becker. Ein Beitrag zur Geschichte der angewandten Orientalistik“, in: Die Welt des Islams 23 (1984), S. 378-387; Martin Kröger: „Revolution als Programm. Ziele und Realität deutscher Orientpolitik im Ersten Weltkrieg“, in: Wolfgang Michalka (Hg), Der Erste Weltkrieg. Wirkung, Wahrnehmung, Analyse, München, 
gagement von Orientalisten in der Politik ist keineswegs ein deutsches Phänomen: Der eminente russische Orientalist Vitaly V. Barthold wirkte aktiv an der stalinistischen Nationalitätenpolitik in Zentralasien mit, Snouck Hurgronje war in der niederländischen Kolonialverwaltung Indonesiens tätig und die Zahl britischer Orientalisten, die zwischen militärisch-administrativer und akademischer Karriere oszillierten, ist beträchtlich - in den Worten Disraelis: The East was a career. $^{8}$

Carl Heinrich Becker äußerte sich 1904 noch mit deutlichem Unbehagen ge-

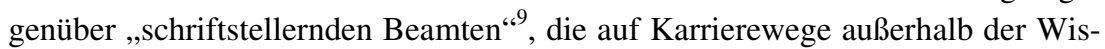
senschaft als Diplomaten oder Verwaltungsbeamten zurückblickten und sich dennoch zu orientalistischen Themen zumeist in einem politischen Kontext äuBerten (wie etwa Max von Oppenheim). Dies soll jedoch nicht bedeuten, dass Becker eine Einmischung in das politische Feld a priori als unwissenschaftlich ablehnte. Im Gegenteil, ab 1908 leitete er das Seminar für Geschichte und Kultur des Vorderen Orients in Hamburg, welches auch mit kolonialpolitischen Funktionen betraut war und äußerte sich - wie das einleitende Zitat zeigt - wiederholt zu dem Themenkomplex Islam und koloniale Politik. Beckers Mahnung, eine „sachkundige Islampolitik“10 zu betreiben, unterstreicht, wie Gottfried Hagen treffend bemerkt, sein Bestreben, ein ,,academic monopoly for authorative interventions in the public sphere ${ }^{\text {"11 }}$ zu verteidigen. Im Kontext des Gelehrtenselbstverständnisses des späten Kaiserreiches rangierten Fragen der Diskurshoheit vermutlich vor Fragen der Relevanz oder praktischen Anwendbarkeit der Orientalistik.

Der Ausbruch des Ersten Weltkrieges und die Einrichtung der Nachrichtenstelle für den Orient durch das Auswärtige Amt gab zahlreichen Orientalisten (aber vor allem auch ,schriftstellernden Beamten“, Dilettanten und gewitzten Betrügern $^{12}$ ) die Gelegenheit, Politik und Form der deutschen ,Orientpolitik' zu gestalten. Die deutsche Begeisterung für die Ausrufung des ğihād gegen die Alliierten durch Mehmet V. am 14. November 1914 verdeutlicht dies und ist zudem Kern einer emotionalen Debatte zwischen Becker und seinem niederländischen Kollegen Snouck Hurgronje. Dieser griff die deutsche Orientpolitik und Becker, der den Aufruf zum ǧihād ausdrücklich unterstützte, in seinem Artikel „Heiliger Krieg made in Germany“ scharf an. ${ }^{13}$ Der Austausch zwischen Becker und Hur-

Zürich: Piper 1994, S. 366-391; Herbert L. Müller: Islam, Ğihād („Heiliger Krieg“) und das Deutsche Reich, Frankfurt/M u.a.: Lang 1991.

8 Vgl. Edward Said: Orientalism, London u.a.: Penguin Books 2003 (Erstausgabe 1978), S. 5.

9 Zitiert nach L. Hanisch, Gelehrtenselbstverständnis, S. 111.

10 Ebd., S. 107.

11 G. Hagen: Applied Oriental Studies, S. 154.

12 Vgl. M. Kröger: Orientpolitik, S. 376f.

13 Vgl. P. Heine: Hurgronje versus C. H. Becker, S. 379f.; Hurgronje verfasste 1915 einen Artikel mit dem Titel „Heilige Oorlog made in Germany“. 
gronje wirft weniger Fragen der wissenschaftlichen Ethik auf, sondern beleuchtet vielmehr Elemente des orientalistischen Diskurses jener Zeit. ${ }^{14}$ Auch wenn verschiedene Auffassungen über das vermeintlich fanatische Potential des ,Islam“ unter deutschen Orientalisten bestanden, unterstreicht das folgende Zitat von Martin Hartmann wesentliche Elemente des Diskurses:

„Es sei hiermit gewarnt, durch Erregung des religiösen Fanatismus Unruhen herbeizuführen. Gegen einen solchen Versuch würden alle Kulturstaaten einmütig zusammenstehen [...]. Islam ist eine Religion von $\mathrm{Ha} ß$ und Krieg. Es darf nicht das herrschende Prinzip in einer Nation der zivilisierten Welt werden. “15

Dass auch die ,sachkundige Islampolitik' eines Carl Heinrich Becker nicht die erwünschten Erfolge zeitigte, belegt die Einschätzung eines weiteren deutschen Orientalisten, Friedrich Rosen (der in der Weimarer Republik kurzzeitig Außenminister werden sollte), der weitaus nüchterner und ohne Verweise auf die vermeintlichen kulturellen Dispositionen ,der Muslime“ die deutschen Ambitionen als ,Wahnvorstellungen' charakterisiert und feststellt:

„[I]m Auswärtigen Amt glaubte man damals ebenso fest an die grüne Fahne des Propheten und den Heiligen Krieg, wie einige Jahre später an den Völkerbund und die Segnungen der Locarno-Politik. [...] So wie Voltaire als der Vater der französischen Revolution angesehen wird, so konnte man Karl May als den Vater unserer Orientpolitik dieser Zeit betrachten. “16

\section{Eine Frage der Qualität oder der Ethik?}

Peter Heine schließt seinen Beitrag zur Auseinandersetzung zwischen Becker und Hurgronje, indem er die Frage der Verantwortung einer ,anwendungsbezogenen Wissenschaft" aufwirft:

„Die Gefahr, in die jede angewandte Orientalistik geraten kann, die Gefahr nämlich, in direkte politische Auseinandersetzungen zu geraten. In solchen Auseinandersetzungen geht es dann um wissenschaftliche Fragen eher am Rande. Solch eine Situation kann auf Kosten der Qualität gehen. [...] Gerade in einer Zeit, in der viele Orientalisten in den Bereichen der angewandten Orientalistik ein berufliches Betätigungsfeld sehen oder sehen müssen, sollte die Kontroverse Snouck Hurgronje/Becker uns ein warnender Hinweis auf die hohe Verantwortung jeder anwendungsbezogenen Wissenschaft sein. “ ${ }^{17}$

14 Said behandelt die deutsche Orientalistik nur am Rande, verweist aber mehrfach auf Hurgronje (vgl. Orientalism, S. 255f.).

15 Vgl. Martin Hartmann: „Das Ultimatum des Panislamismus“, in: Das freie Wort 11 (1911), S. 605-610, hier S. 606.

16 Friedrich Rosen: Aus einem diplomatischen Wanderleben, Bd. 3-4, Wiesbaden: Limes Verlag 1959, S. 54f.

17 P. Heine: Hurgronje versus C. H. Becker, S. 387. 
Obwohl Heine hier implizit eine ethische Dimension aufwirft, stellt sich ihm jedoch vordringlich das Problem des Qualitätsverlustes im Falle einer politischen Kontamination, also um eine eher generelle Ablehnung, dem Fach eine politische Dimension bzw. Funktion zuzuschreiben. Auch Hanisch erwähnt in ihrer Reaktion auf Heine die Webersche Verantwortungsethik im Kontext der gesellschaftlichen Verantwortung innerhalb eines politischen Systems. ${ }^{18}$ Wie Hagen bereits angemerkt hat, verweisen Hanisch und Heine auf die generelle Problematik des Verhältnisses zwischen Wissenschaft und gesellschaftlicher Verantwortung, ohne die spezifischen Charakteristika der Orientalistik zu berücksichtigen, d.h. die diskursive Ethik, die Said in Orientalism thematisiert. ${ }^{19}$

Die Frage der gesellschaftlichen Verantwortung von Wissenschaft ist vor allem dann von erheblicher Relevanz, wenn das politische und gesellschaftliche System, in dem Wissenschaft praktiziert wird, totalitär ist, wie etwa während der NS-Diktatur. Die deutsche Orientalistik hat sich in den vergangenen Dekaden zwar detailliert mit der Rezeption des Faschismus/Nationalsozialismus in der islamischen Welt beschäftigt ${ }^{20}$, aber eine erste ausführlichere Einordnung der Orientalistik in die Wissenschaftsgeschichte des NS-Regimes ließ bis 2006 auf sich warten. $^{21}$ Die zögerliche Aufarbeitung könnte dadurch bedingt sein, dass nicht wenige eminente Orientalisten während der NS-Zeit ihre akademische Karriere begannen und nach dem Zweiten Weltkrieg fortsetzten. Auch zeigt Ellinger in seiner Dissertation auf, dass Orientalisten als Funktionsträger im NS-System agierten. Das Scheitern der Wahrnehmung sozialer Verantwortung von Wissenschaft während der nationalsozialistischen Diktatur mit ihren teils wissenschaftlich legitimierten Perversionen von Rassenauslese ist selbstverständlich kein genuines Problem der Orientalistik, sondern aller Disziplinen, aber wohl mit ein Grund für den Rückzug der Orientalistik in einen wissenschaftlichen Elfenbeinturm und für das große Unbehagen gegenüber einer , angewandten Wissenschaft ${ }^{*}$ nach dem Zweiten Weltkrieg. Ebenfalls ist zu bedenken, dass sich der gesellschaftspolitische Rahmen der Orientalistik in beiden deutschen Staaten veränderte. Die westdeutsche (und bedingt auch die ostdeutsche) Außenpolitik stand unter den Prämissen der deutschen Teilung (Hallstein-Doktrin) und der Konsolidierung der BRD in Europa. Der außenpolitische Diskurs wurde nicht mehr vordringlich im Kontext von nationalstaatlichen Interessen und Zielen formuliert, sondern wechselte auf eine multilaterale (EU und Vereinte Nationen) sowie abstrakte

18 L. Hanisch: Gelehrtenselbstverständnis, S. 107 und $123 \mathrm{f}$.

19 Vgl. G. Hagen: Applied Oriental Studies, S. 155.

20 Vgl. etwa Stefan Wild: „National Socialism in the Arab near East between 1933 and 1939“, in: Die Welt des Islams 25 (1985), S. 126-173.

21 Vgl. Ekkehard Ellinger: Deutsche Orientalistik zur Zeit des Nationalsozialismus 1933-1945, Edingen-Neckarshausen: deux-mondes-Verlag 2006. Siehe auch K. Kreiser: Gotthard Jäschke, S. 406-423. 
Ebene, in der Demokratisierung, Menschenrechte und wirtschaftlich-soziale Entwicklung zentrale Positionen einnahmen. ,Islam“ oder gar eine ,Islampolitik“ stand nicht auf der Agenda deutscher Außenpolitik, zumal ein Großteil der islamischen Welt durch säkulare Regime beherrscht wurde. ,Islam“ erlangte erst wieder mit der Revolution in Iran 1979 und der graduell wachsenden Bedeutung islamischer politischer Gruppen in den 1980er und 1990er Jahren an Bedeutung.

Edward Saids Orientalism erschütterte zwar die Selbstgenügsamkeit der deutschen orientalistischen Forschung und förderte eine anhaltende Diskussion ${ }^{22}$, aber es scheint mir, dass andere Disziplinen die Anregungen und Überlegungen Saids weitaus bereitwilliger aufnahmen:

„Indem die Islamwissenschaft den allgemeinen sozial- und mehr noch den kulturwissenschaftlichen Diskurs weitgehend ignorierte, isolierte sie sich und wurde für andere Forscher, die sich mit verwandten Themen in anderen Sprachen beschäftigen, unattraktiv, häufig unlesbar.“23

\section{Orientalistik nach dem 11. September - Islamdialog und auswärtige Politik}

Die Bundesregierung reagierte nach dem 11. September 2001 umgehend mit der Verabschiedung der so genannten Anti-Terror-Pakete (ATP) I (noch im September 2001) und II (Dezember 2001), die nicht nur eine Reihe von Gesetzesänderungen beinhalteten ${ }^{24}$, sondern verschiedenen Ministerien und Bundesbehörden zusätzliche Haushaltsmittel in Höhe von 1,5 Mrd. Euro bewilligten.

Auch das Auswärtige Amt wurde im Rahmen der ATP mit zusätzlichen Haushaltsmitteln bedacht, mit denen unter anderem der ,Dialog mit der islamischen Welt ${ }^{\star 25}$ finanziert werden sollte (neben anderen Antiterrorismusinitiativen). Das Dialogprojekt sah vor, die Öffentlichkeitsarbeit der deutschen Auslandsvertretungen (inklusive der Goethezentren) in der islamischen Welt zu intensivieren, Islambeobachter an verschiedene Auslandsmissionen zu entsenden und ein eigenes Referat (heute 626) unter der Leitung eines Beauftragten für den Dialog mit der islamischen Welt (bis 2005 Botschafter Dr. Mulack) zu etablie-

22 Vgl. u. a. Reinhard Schulze: „Orientalistik und Orientalismus“, in: Werner Ende/Udo Steinbach (Hg), Der Islam in der Gegenwart. München: C.H. Beck 1995, S. 707-718.

23 Navid Kermani: „Zur Zukunft der Islamwissenschaft“, in: Fikrun wa Fann 81 (2005), S. 3, http://www.goethe.de/mmo/priv/1224466-STANDARD.pdf vom August 2007.

24 Vor allem die Änderungen StGB § 129a („Anti-Terrorismus-Paragraph“), Aufhebung des Religionsprivilegs im Vereinsgesetz (§ 3), Auskunftspflicht der Banken über Konten verdächtiger Organisationen.

25 Vgl. etwa: Auswärtiges Amt (Hg.), Dialog mit der islamischen Welt, Berlin 2006 (www.auswaertiges-amt.de). 
ren. ${ }^{26}$ Laut der Homepage des Auswärtigen Amtes besteht das Ziel des Dialogs darin:

„,...] die Verständigung zwischen dem ,Westen“ und der islamischen Welt sowie innergesellschaftlichen Pluralismus und den Abbau antiwestlicher Feindbilder in islamisch geprägten Gesellschaften zu fördern. Deutschland hat als erstes westliches Land bereits 2002 einen Politikschwerpunkt ,Dialog mit der islamischen Welt“ (kurz: ,Islamdialog *) im Auswärtigen Amt geschaffen. Unter anderem wurde das Amt des Beauftragten für den Dialog mit der islamischen Welt eingerichtet, das derzeit [2007] Botschafter HansGünter Gnodtke innehat. Er berät alle Arbeitsebenen im Auswärtigen Amt und wird von einem Arbeitsstab unterstützt, der ein Netz von sprach- und fachkundigen ReferentInnen an den deutschen Auslandsvertretungen in der islamischen Welt koordiniert. Aufgabe der ReferentInnen ist es, über die Bedeutung von Islam und Islamismus in ihren Gastländern zu berichten, sowie lokale Partner für die Zusammenarbeit zu identifizieren und mit diesen konkrete Projekte auszuarbeiten. “27

Während ein Teil der hier erwähnten ,ReferentInnen` zeitlich befristet (für zwei Jahre) in den vergleichbaren höheren Dienst eingestellt wurden, ${ }^{28}$ erlaubten die ATP eine umfangreiche Konsolidierung des Stellenplans im Auswärtigen Amt. Auch das Auswärtige Amt war in den 1990er Jahren von der Sparpolitik der Bundesregierungen Kohl und Schröder nicht verschont geblieben, was zu sukzessiven Streichungen von Planstellen in Berlin, Bonn und an den Auslandsvertretungen führte. Insbesondere im höheren Dienst ergab sich dadurch ein erheblicher Beförderungsstau. Im Rahmen des ATP konnten erstmals wieder Planstellen in Referaten und Auslandsmissionen designiert werden, die zuvor entweder nicht besetzt oder eingerichtet waren. ${ }^{29}$ Diese Planstellen wurden sowohl für den gehobenen als auch höheren Dienst ${ }^{30}$ für bereits im auswärtigen Dienst tätige Beamte eingerichtet und hatten nicht immer einen unmittelbaren Bezug zu den ATP. Teilweise erfolgte eine Entsendung auf ,Islambeobachter'-Stellen nicht aufgrund der Qualifikation (einer der amtsinternen Islambeobachter teilte mir schmunzelnd mit, seine Qualifikation beruhe wohl auf einer Zwischenlandung in Kabul in den 1960er Jahren - eine offensichtlich hinreichende Erfahrung für die Bedingung, die islamische Welt zu kennen), sondern hatte andere Beweggründe

26 Das Referat 626 untersteht der Abteilung 6 für Kultur und Kommunikation.

27 http://www.auswaertiges-amt.de/diplo/de/Aussenpolitik/Kulturpolitik/DialogIslam/ IslamDialog.html.

28 Wie bereits erwähnt, ist diese Einstellungspraxis für das Auswärtige Amt unüblich, wird aber zurzeit (2007) in begrenztem Umfang weitergeführt.

29 Nach meinen Informationen (und durch Gespräche mit Kollegen) wurden 2002 zunächst 45 externe Referentinnen und Referenten befristet eingestellt, während etwa 200 Planstellen neu eingerichtet bzw. bestehende Planstellen ein zusätzliches Portfolio im Rahmen des ATP erhielten.

30 Für die Organisation des AA vgl. BGB1 I 1990, 1842, Gesetz über den Auswärtigen Dienst (GAD) vom 30. August 1990. 
(wie etwa der bereits erwähnte Beförderungsstau). Auch bei den externen Referentinnen und Referenten handelte es sich nicht ausschließlich um Orientalisten; Juristen, Slawisten oder Chemiker wurden ebenfalls berücksichtigt, da die ATP nicht nur ,Islambeobachtung ' umfassten, sondern auch den Komplex der ,Terrorismusbekämpfung`. Während ein Teil der Referenten in Berlin (vor allem im Islam-Referat) tätig waren, entsandte das Auswärtige Amt Referenten an verschiedene Auslandsmissionen, z.B. in Nigeria, Libanon, Iran und - in meinem Fall Tadschikistan. In der Regel, aber nicht immer, korrespondierte die Entsendung bzw. der Einsatz der Referentinnen und Referenten mit ihrer spezifischen Qualifikation (insbesondere der Sprachkompetenz). Unter welchen Gesichtspunkten das Auswärtige Amt einige der Auslandsstationen auswählte, entzieht sich jedoch meiner Kenntnis.

Neben der konkreten Islambeobachtung durch Referenten initiierte bzw. intensivierte das Auswärtige Amt ab 2002 eine Vielzahl von Dialogprojekten, insbesondere in Form von periodisch erscheinenden Publikationen, Konferenzen und Seminaren, auf die hier nicht weiter eingegangen werden soll, die aber nach wie vor einen integralen Bestandteil des ,Islamdialogs ' darstellen. ${ }^{31}$

\section{Islambeobachtung in Tadschikistan}

Im Nachhinein war ich mehr als (positiv) überrascht, als im Frühjahr 2002 mein Erlass für die Entsendung an die deutsche Botschaft in Duschanbe, Tadschikistan, eintraf. Zwar verfügte ich über rudimentäre Kenntnisse der Landeskunde und Sprache (d.h. des Tadschikischen, einer Form des Farsi), allerdings hatte ich keinerlei Erfahrung mit dem post-sowjetischen Raum. Trotz seiner Nachbarschaft zu Afghanistan ist Tadschikistan von eher nachrangigem Interesse für die deutsche Außenpolitik. Die 1995 eingerichtete Botschaft ist eine so genannte Kleinstvertretung mit 10 Entsandten, wobei konsularische Tätigkeit (Visa-Angelegenheiten, ${ }^{32}$ Betreuung von deutschen - teilweise auch europäischen - Bürgern in Tadschikistan sowie der deutschen Minderheit ${ }^{33}$ ), die Koordinierung der wirtschaftlichen Zusammenarbeit sowie der Bildungsinitiativen die wesentli-

31 So wurde beispielsweise eine arabische Version der Homepage des Auswärtigen Amtes eingerichtet. Siehe auch die Homepage der Online-Zeitschrift www.qantara. de und des deutschen Informationszentrums in Kairo (www.gic.de) sowie die Zeitschrift Fikrun wa Fann.

32 Die deutsche Botschaft in Duschanbe ist - wie in vielen der zentralasiatischen Staaten - die einzige Botschaft, die „Schengen“-Visa ausstellt.

33 In den 1980er Jahren lebten etwa 40.000 Deutsche (zumeist Wolga-Deutsche und deren Nachkommen, die in den 1940er Jahren deportiert wurden) in Tadschikistan, vor allem in Duschanbe. Ein Großteil der deutschen Minderheit verließ Tadschikistan während des Bürgerkrieges; vgl. Kamoludin Abdullaev/Shahram Akbarzadeh (Hg.), Historical Dictionary of Tajikistan, Lanham, MD u.a.: Scarecrow Press 2002. 
chen Aufgabengebiete darstellen. Wie die bereits zitierte Zielvorgabe des Auswärtigen Amtes verdeutlicht, fiel die Erlasslage (d.h. die amtsinterne Definition des Aufgabenbereiches) für die ,Islambeobachtung ' insgesamt vage aus und erlaubte eine recht freie Auslegung durch den Islambeobachter, aber auch durch die Vorgesetzen in der Auslandsvertretung. Zu den Kernaufgaben zählt die Berichterstattung über Ausdrucksformen islamischer Religiosität bzw. islamische Gruppierungen, Kontaktaufnahme zu Regierungsvertretern, die mit islamischen Angelegenheiten betraut sind, und mit offiziellen wie inoffiziellen islamischen Würdenträgern sowie die Identifikation von Projekten im Kontext des ,Islamdia$\log s^{6} .^{34}$

Wie Kollegen aus den ATP berichteten, gelang die Integration des Islambeobachters in eine Auslandsvertretung nicht immer ohne Konflikte. Gelegentlich hatten Vorgesetzte Vorbehalte gegenüber, amtsfremden “ Mitarbeitern, stellten sie als ,Islamisten ' vor, ignorierten die Erlasslage oder standen dem Dialogprojekt kritisch gegenüber. Die vage Erlasslage ergab zudem, dass die Berichterstattung der verschiedenen Islambeobachter kaum einheitlichen Kriterien folgte: Akademische Interessen sowie Vorbildung eines Islambeobachters konnten somit leicht Themen der Berichterstattung beeinflussen. Details bestimmter regionaler Auslegungen islamischer Rechtsvorstellungen füllten umfangreiche Berichte, deren Relevanz für Laien nicht immer nachvollziehbar war. Bei der Identifikation geeigneter Projekte im Rahmen des Islamdialogs ergaben sich ebenfalls Probleme durch die wenig konzisen Vorgaben, wie solche Projekte auszusehen hätten. Eine Haushaltssperre 2003 erschwerte zudem die Realisierung von relevanten Projekten, da nun Mittel nur noch bedingt zur Verfügung standen.

In meinem Fall hatte ich außerordentliches Glück, an eine Auslandsvertretung zu kommen, deren Mitarbeiter mich hervorragend in ein Arbeitsumfeld integrierten, das durch ein hohes Maß kollegialer Solidarität sowie Freundschaft gekennzeichnet war. Formal wiesen mich der Kanzler und Botschafter den Bereichen Kultur sowie Presse und Öffentlichkeitsarbeit zu, so dass sich ausreichend Schnittmengen mit den Vorgaben des Islambeobachtererlasses ergaben. Auch die spezifische Situation in Tadschikistan erwies sich als eine interessante Herausforderung. Tadschikistans Entwicklung nach der unerwarteten Unabhängigkeit 1991 ist überschattet durch einen verheerenden Bürgerkrieg (1992-1997)

34 Im spezifischen Fall Tadschikistans existierte eine Agentur für religiöse Angelegenheiten (bis Januar 2007), die von staatlicher Seite islamische Belange reglementierte. Die derzeitige tadschikische Regierung verfolgt eine äußerst repressive Politik gegenüber Ausdrucksformen islamischer Religiosität mit einem ostentativen Verweis auf den säkularen Charakter der Verfassung. Während der Sowjetzeit haben sich zudem verschiedene Gruppen islamischer Würdenträger herausgebildet, die vereinfacht als ,offizieller' und ,inoffizieller' Islam bezeichnet werden können; vgl. Oliver Roy: The New Central Asia. The Creation of Nations, London: Tauris 2000 und Adeeb Khaleed: Islam after Communism. Religion and Politics in Central Asia, Berkeley: University of California Press 2007. 
und ein fragiles Friedensabkommen, das eine islamische politische Partei zeitweilig in die Regierung integrierte. ${ }^{35}$ Obwohl der ,Islam “ in Zentralasien zumeist als intellektuell wenig anspruchsvoll und institutionell schwach ausgeprägt beschrieben wird, ${ }^{36}$ entwickelte sich in Tadschikistan bereits während der sowjetischen Zeit ein komplexes Geflecht aus offiziellen und informellen islamischen Strukturen sowie Identitätsmustern - doch dies geht über die Grenzen des vorliegenden Beitrags hinaus. ${ }^{37}$

\section{Ein gut gemeinter Dialog?}

Die Konzeption des ,Islamdialogs' seitens des Auswärtigen Amtes zeigt deutlich das Bemühen, ,Islam“ weder essentialistisch noch entlang notorischer Bedrohungsszenarien $\mathrm{zu}$ thematisieren. Auch ist die heutige auswärtige Politik weit entfernt von den ambitionierten und bizarren Vorstellungen einer ,Islam- ' oder ,Orientpolitik', wie sie im Vorfeld und während des Ersten Weltkrieges von deutschen Diplomaten und Orientalisten erträumt wurde. Allerdings spiegelt die Idee des Dialogs der Kulturen bzw. des Dialogs mit der islamischen Welt eine performative Arroganz wieder, denn:

,[t]atsächlich verfestigt das Paradigma des Dialogs der Kulturen genau jene manichäische Wahrnehmung, gegen das es sich scheinbar wendet: Als ob es bei Islam und Westen um zwei Subjekte handelte, die sich nun endlich verstehen müssten. [...] Nein, der Dialog der Kulturen ist eine Karikatur, nicht weniger als der Kampf der Kulturen. Das Problem ist allerdings, dass sich diese Karikaturen in immer mehr Köpfen festsetzen und dann zu politischem oder gar militärischem Handeln führen. Am 11. September sollte offenkundig im Namen ,des' Islams, der' Westen bekämpft werden statt eines konkreten Staats oder einer Regierung, wie Terroristen es bislang vorgaben. Aber auch in Europa wird die eigene Kultur zunehmend essentialisiert, also als eine eigenständige

35 Obwohl der Bürgerkrieg gelegentlich als ein Konflikt zwischen islamischen und post-kommunistischen Fraktionen dargestellt wird, waren es vor allem regionale Identitäten, sozial-ökonomische Faktoren und der Einfluss von Strukturen organisierten Verbrechens, die die wesentlichen Ursachen des Konfliktes darstellen (vgl. O. Roy, New Central Asia, passim). Eine konzise Darstellung des tadschikischen Bürgerkrieges steht allerdings noch aus.

36 Vgl. etwa T. Jeremy Gunn: „Shaping an Islamic Identity: Religion, Islamism, and the State in Central Asia", in: Sociology of Religion 64 (2003), S. 389-410; Vitalij V. Naumkin: Radical Islam in Central Asia: Between Pen and the Rifle (Soviet Bloc and After), Lanham u.a.: Rowman \& Littlefield 2005 oder Martha Brill Olcott: Roots of Radical Islam in Central Asia. (Carnegie Papers, 77), Washington 2007.

37 Vgl. die Überlegungen in: Robert Hefner: „Public Islam and the Problem of Democratization", in: Sociology of Religion 62 (2001), S. 491-514. Für Zentralasien siehe vor allem International Crisis Group (ICG): Central Asia: Islam and the State (ICG Asia Report, 59), Osh, Brussels 2003, sowie idem: Radical Islam in Central Asia: Responding to Hizb ut-Tahrir (ICG Asia Report, 58), Osh, Brussels 2003. 
anthropologische Größe gedacht, die unabhängig vom Menschen existiert und handelt. “38

Betrachtet man die Dialogidee des Auswärtigen Amtes stellt sich letztendlich die Frage, welches die Indikatoren für einen erfolgreichen ,Islamdialog ' sind.

Öffentlichkeitsarbeit, die Einladung islamischer Würdenträger zu diversen Konferenzen und Seminaren, Austausch von Jugendlichen oder die Einbeziehung islamischer Gruppierungen in politische Prozesse sind Initiativen, deren Resultate erst mittel- oder langfristig einzuschätzen sind - und dies ist vielleicht das eigentliche Problem der Konzeption des Auswärtigen Amtes. Der auswärtige Dienst untersteht dem Paradigma des Generalismus, d.h. Beamten des auswärtigen Dienstes sollen in allen Bereichen des Auswärtigen Amtes einsetzbar sein, wobei die Standzeiten von Diplomaten in bestimmten Bereichen sowie Auslandsvertretungen in der Regel 3 bis 4 Jahre betragen. Eine Spezialisierung wird im diplomatischen Dienst bis auf wenige Ausnahmen weder unterstützt noch ermutigt, auch der Bildungsweg spielt nur eine untergeordnete Rolle - ein Erbe aus der Frühzeit des Auswärtigen Amtes, in der Loyalitätskonflikte im Falle von langen Standzeiten oder Spezialisierungen antizipiert wurden. Die Herausforderungen an die Außenpolitik nach dem 11. September 2001 und vielleicht auch die Personalpolitik im Rahmen der ATP führte zu einer internen Diskussion im Auswärtigen Amt, inwieweit Spezialisierungen (und damit längere Standzeiten bzw. Konzentration auf bestimmte Aufgabengebiete) im auswärtigen Dienst eine sinnvolle Ergänzung zu der bestehenden Personalpolitik darstellen könnten. Die Reforminitiative wurde im Frühjahr 2004 zurückgewiesen. Letztendlich hatte dies zur Folge, dass die ,Islambeobachtung ' vor allem in den Auslandsmissionen nach zwei oder drei Jahren aufgrund von Versetzung bzw. Vertragsende entweder endete oder zumindest unterbrochen wurde. Angesichts der mangelnden Kontinuität ist es zweifelhaft, ob der ,Islamdialog' mittel- oder langfristige Auswirkungen zeitigen wird. Die Vermutung liegt nahe, dass das Auswärtige Amt den ,Islamdialog ' vor allem als eine Chance in der Personalpolitik sah, Planstellen zu schaffen, die in den Jahren zuvor finanziellen Zwängen zum Opfer gefallen waren.

\section{Das Für und Wider einer angewandten Orientalistik}

Die Frage nach der gesellschaftlichen Verantwortung von Wissenschaft ist von ungebrochener Aktualität, dies gilt nach dem 11. September insbesondere für die Orientalistik, wobei diese Verantwortung zwei Ebenen hat: Zum einen betrifft sie das Verhältnis zum politischen Feld und zum anderen die Ebene des spezifischen Diskurses (d.h. der ,Repräsentation“ im Sinne Saids) über den islamischen Kul-

38 N. Kermani: Zur Zukunft der Islamwissenschaft, S. 8. 
turraum. Die öffentliche Debatte über ,Islam‘ wird auf absehbare Zeit ihre hohe Relevanz bewahren und die Orientalistik herausfordern - dies betrifft vor allem die vermeintlich , angewandte Orientalistik' mit unmittelbaren politischen Bezügen. Der so genannte ,Krieg gegen den Terror “ mit all seinen diffusen Gefahrendiskursen, Doppelstandards und rechtlichen Grauzonen (bis hin zu gravierenden Verletzungen essentieller Menschenrechte) ist in diesem Zusammenhang vielleicht die größte Herausforderung, da zunehmend auch Orientalisten auf verschiedenen Ebenen involviert sind. Dies schließt nicht nur die Wortführer eines Zivilisationskonfliktes ein, die aus der sicheren Distanz ihrer Washingtoner Büros eine vermeintlich ,sachkundige Islampolitik' propagieren, sondern zunehmend auch Mitarbeiter staatlicher wie nicht-staatlicher Institutionen, die with boots on the ground politisch motivierte ,Islamprojekte' implementieren. ${ }^{39}$

Die gegenwartsbezogene Beschäftigung mit der islamischen Welt bedeutet vor allem auch die Auseinandersetzung mit überwiegend säkularen autoritären Staaten, die die Menschenrechte ihrer Bürger massiv verletzen, aber aufgrund politisch-militärischer Erwägungen im ,Krieg gegen den Terror' von den USA oder den EU-Staaten hofiert werden. Die Verantwortungsethik der Wissenschaft wird hier gleich in zweierlei Hinsicht strapaziert: Zum einen in Bezug auf das ,Forschungsobjekt', d.h. wie führt man in einem autoritären politischen System Forschungsprojekte durch, ohne dass man entweder Kollegen oder Kontaktpersonen gefährdet (,Do no Harm!“) bzw. von dem Regime vereinnahmt wird?

39 Neben Deutschland verfolgen auch die USA und Großbritannien so genannte „Muslim Outreach" Projekte, die im Bereich der Öffentlichkeitsarbeit angesiedelt sind. Einige dieser Projekte zielen jedoch auf eine direkte Einflussnahme auf Gesellschaften in islamischen Ländern ab bzw. haben eine militärische, sicherheitsorientierte Komponente. Das US State Department stellt in diesem Zusammenhang umfangreiche Finanzmittel für eine ,Demokratisierung ' bzw. einen Regimewechsel in Iran zur Verfügung. Die New York Times berichtete am 5.10.2007 (David Rohde: „Army Enlists Anthropolgy in War Zones“), dass US-Truppen in Afghanistan von Zivilisten mit einschlägiger Ausbildung in Anthropologie und Landeskunde begleitet werden.

40 Usbekistan ist in diesem Zusammenhang ein trauriges Beispiel, insbesondere hinsichtlich der Niederschlagung des Aufstandes in Andijan im Mai 2005 mit vermutlich Hunderten von getöteten Zivilisten. Eine Reihe von gut dokumentierten Berichten bemüht sich um eine Rekonstruktion der Ereignisse in Andijan vgl. etwa Human Rights Watch: Bullets Were Falling Like Rain. The Andijan Massacre, May 13, 2005; New York, Juni 2005; ICG: Uzbekistan: The Andijon Uprising (Asia Briefing No. 38); Bischkek, Brüssel 2005; Organisation for Security and Co-operation in Europe (OSCE)/Office of Democratic Institutions and Human Rights (ODIHR): Preliminary Findings on the Events in Andijan, Uzbekistan, 13 May 2005; Warschau 2005. Während usbekische und russische Medien die Niederschlagung des Aufstandes als einen Sieg im Krieg gegen den Terror feierten, war die westliche Berichterstattung gekennzeichnet von Schock und Abscheu. Das usbekische Regime fand nur wenige Fürsprecher, unter denen allerdings Shirin Akiner vom SOAS die vielleicht lautstärkste ist. Akiner besuchte Andijan 12 Tage nach dem gescheiterten Aufstand in Begleitung hochrangiger Vertreter des usbekischen Regimes und ver- 
Zum anderen in Bezug auf die politische Agenda, d.h. inwieweit steht insbesondere die orientalistische Forschung im Dienst des ,Kriegs gegen den Terror ‘. Diesen Herausforderungen muss sie sich stellen.

fasste einen Bericht, der sich kritisch mit der westlichen Berichterstattung auseinandersetzt und die Sichtweise des usbekischen Regimes unterstützt (vgl. Shirin Akiner: Violence in Andijan, 13 May 2005: An Independent Assessment; Silk Road Paper, 2005 auf http://www.silkroadstudies.org/new/inside/publications/0507Akiner.pdf). Grundsätzlich ist an einer kritischen Auseinandersetzung mit den Medien nichts auszusetzen, allerdings ist die apologetische Darstellung von Akiner extrem einseitig und verzichtet gänzlich auf eine Einordnung der Ereignisse in einen breiteren Kontext. Insbesondere ihre enge Kollaboration mit Vertretern des usbekischen Regimes (inklusive eines Interviews im usbekischen Staatsfernsehen) ist im Sinne einer Wissenschaftsethik höchst problematisch. 


\section{Die Täter zu Opfern, die Opfer zu Tätern machen - Räume und Grenzen islamwissenschaftlicher Politikdeutung}

UDO STEINBACH (HAMBURG)

Die große Annemarie Schimmel - doch wer kannte sie schon in einer breiteren Öffentlichkeit, bevor sie im Oktober 1995 den Friedenspreis des Börsenvereins des Deutschen Buchhandels erhielt? Eine Islamwissenschaftlerin allzu reinen Wassers, fanden viele Kritiker der Entscheidung. Dies schien sie auch noch durch einen Lapsus zu bestätigen: Als Anfang Mai 1995 bekannt wurde, dass sie die nächste Preisträgerin sein würde, trat sie am Abend in den Tagesthemen des Ersten auf. Von Sabine Christiansen nach ihrer Einschätzung der „Fatwa Ayatollah Khomeinis gegen Salman Rushdie“ gefragt, war sie sichtlich überfordert. Ihr Zögern und ihre ausweichende Antwort waren geeignet, den Eindruck zu erwecken, als hege sie wie immer geartete Sympathien mit dem Verdikt des Ayatollah. ${ }^{1}$

Dass Frau Schimmel den Preis nach heftiger Kampagne doch erhielt, war die bislang wichtigste Anerkennung der Tatsache, dass der islamwissenschaftliche Beitrag zum ,Dialog der Kulturen“ und mithin zur Gestaltung der Beziehungen zwischen der islamischen Welt und dem Westen heute als wichtiger politischer Beitrag zum Frieden gewertet werden kann. Tatsächlich hat kein anderes geisteswissenschaftliches Fach in den letzten zwei Jahrzehnten eine derart tiefgreifende Revolution seines politischen und gesellschaftlichen Stellenwertes durchgemacht wie die Islamwissenschaft (bzw. Orientalistik). In Deutschland geboren im 18. Jahrhundert als Magd der Theologie hat sie bis weit nach dem Zweiten Weltkrieg - Ausnahmen bestätigen die Regel - als Orchideenfach im Verborgenen geblüht: interessant, aber für das Leben in dieser Welt nicht essentiell. Nicht wenige deutsche Islamwissenschaftler taten das Ihre, um diese Einschätzung zu

1 Annemarie Schimmel ist auch in ihrer Dankesrede anlässlich der Preisverleihung noch einmal auf die Situation zurückgekommen, die sie offenkundig bewegt hat. Die Rede A. Schimmels zum Thema „Dem stillen Dialog verpflichtet“ ist vom Börsenverein des Deutschen Buchhandels im Rahmen der Publikation „Friedenspreis des Deutschen Buchhandels 1995“, Frankfurt/M 1995, im Verlag der MVB veröffentlicht worden. 
bestätigen; sie wandten sich bewusst von der Gegenwart der islamischen Welt ab. Sie wollten ihr Bild von der so hohen Kultur der Vergangenheit nicht durch eine ziemlich ernüchternde Gegenwart verdunkeln lassen.

Der Verfasser dieses Beitrags erinnert sich noch, wie unverhohlen die Zunft die Nase rümpfte, als er Anfang der siebziger Jahre begann, an einem Think Tank der Bundesregierung (Stiftung Wissenschaft und Politik) das NahostReferat aufzubauen: So etwas tat ein Orientalist nicht, der sich mit höchstem akademischem Prädikat an einem mittelalterlichen arabischen Volksroman versucht hatte. ${ }^{2}$ Es bedurfte eines Visionärs wie des Institutsdirektors Klaus Ritter, ${ }^{3}$ um nicht nur zu erkennen, dass die islamische Welt Gegenstand eines politischen Think Tank der Regierung werden sollte, sondern dass es bei qualifizierter Befassung mit ihr eines Islamwissenschaftlers bedürfen würde. Demgegenüber waren andere führende Mitarbeiter am Institut so frei zu bekennen, dass der soeben eingestellte Islamwissenschaftler überflüssig sei und erst dann von Nutzen sein werde, wenn er über die NATO arbeite.

Die Masse der Islamwissenschaftler hatte mit der politischen Wirklichkeit nicht viel zu tun und diese (in Gestalt der Politiker) nicht viel mit den Islamwissenschaftlern. Als ein Geistlicher einen Massenaufstand entfesselte und in Teheran einen Freund des Westens vom Thron stürzte, stand die Politik vor einer von den Weltstrategen nicht erwarteten Herausforderung. Khomeini hat der unpolitischen Annemarie Schimmel vor der Kamera Sabine Christiansens Gewissensbisse bereitet, er hat aber zugleich die Islamwissenschaft zu einer Schlüsseldisziplin für das Verständnis grundlegender, den ,Westen“ betreffender Entwicklungen werden lassen. Aber - mancher wird sich noch erinnern - auch längst nicht alle Orientalisten/Islamwissenschaftler wussten, was ein Ayatollah und wer Khomeini war.

In den 28 Jahren seit dem Erfolg der Islamischen Revolution in Iran ist die islamische Religion zu einer Bewegung geworden, die weltweit unmittelbar und mittelbar auf ganz unterschiedliche Weise im politischen und gesellschaftlichen Raum wirksam geworden ist. Der Islam ist gegenwärtig wohl die einzige geistigpolitische Kraft, die weltweit Menschen betroffen macht. Unübersehbar haben breiteste Teile von Menschen in der islamisch geprägten Welt ein Problem der Akzeptanz mit Blick auf eine vom ,Westen' und insbesondere der Supermacht USA politisch, wirtschaftlich, kulturell, zivilisatorisch (und militärisch) geprägten Welt.

Hinter der Wahrnehmung eines Großteils von Öffentlichkeit, Medien und Politik steht seit etwa anderthalb Jahrzehnten das Paradigma vom ,clash of civiliza-

2 Udo Steinbach: Dhat al-Himma. Kulturgeschichtliche Untersuchungen zu einem arabischen Volksroman, Wiesbaden: Steiner 1972.

3 Klaus Ritter gründete die als politischen Think Tank konzipierte „Stiftung Wissenschaft und Politik“" (SWP) 1965 und war bis 1988 ihr erster Direktor. Er ist Neffe des Islamwissenschaftlers Hellmut Ritter (1892-1971). 
tions ' d.h. einer auf Konflikt weisenden Grundtönung vor allem der Beziehungen zwischen der islamischen Welt und dem Westen. Der 11. September 2001, der Kampf gegen den Terrorismus und die gewalttätigen Eruptionen seither, die vor allem in Palästina und im Irak (aber auch in Afghanistan) ihre Epizentren haben und deren Auswirkungen zwischen Madrid und Bali zu verzeichnen sind, drohen den ,clash of civilizations' zu einer self-fulfilling prophecy zu machen. Vor diesem Hintergrund kann sich die Islamwissenschaft nicht länger verweigern, in den öffentlichen Raum zu treten. Wo der Islam zur Rechtfertigung oder Mobilisierung von Konflikten bemüht wird, ist der Islamwissenschaftler/Orientalist herausgefordert zu erklären, und das heißt ipso facto zu differenzieren. Im schlimmsten Fall muss er erläutern, warum und mit welcher Zielsetzung im Namen von Religion Menschen getötet werden. Wo es aber Tote gibt, sind in hohem Maße Emotionen freigesetzt; er muss den Grund für diese Emotionen ermitteln. Deshalb läuft der Islamwissenschaftler von Anfang an Gefahr, zwischen die Fronten zu geraten - denn beide Seiten fühlen sich als Opfer: Ein getöteter Amerikaner oder Europäer stärkt die Wahrnehmung, ,der Westen ' werde angegriffen. Der Extremist im Irak oder Palästina handelt aus der tiefsitzenden Überzeugung, die islamische Welt ihrerseits sei einmal mehr Opfer westlicher Aggression. Jeder Versuch, zu erklären und zu differenzieren, kann als Bemühung wahrgenommen werden, zu verharmlosen bzw. das Opfer zum Täter und den Täter zum Opfer zu machen.

Die Fragen, die zu stellen sind, sind nicht zuletzt deshalb schwierig, weil die Antworten in den meisten Fällen nur Annäherungen an die ,Wahrheit' sein können. Welche Rolle spielt die Religion wirklich - ist sie die treibende Kraft oder wird sie zur Erreichung persönlicher/politischer Ziele instrumentalisiert? In jedem Falle ist die Frage nach dem Wesenskern der islamischen Religion gestellt; aber zugleich gilt es, deutlich zu machen, dass auch der Islam - wie jede andere Religion - in unterschiedlichen gesellschaftlichen und politischen Kontexten unterschiedliche Erscheinungsformen annimmt. Damit richtet sich die Frage auf die Gesellschaft, ihre politische und geistige Verfasstheit. Entscheidend ist auch der internationale Kontext: Wer sind die Akteure; was sind ihre Ziele und ihre Wirkungsweise? Welche Verletzungen sind entstanden und entstehen weiterhin? Am Ende richtet sich der Blick auf jeden einzelnen Täter; darauf, die Tat zu hinterfragen.

\section{Der Blick vom Elfenbeinturm}

In seiner Dankesrede anlässlich der Verleihung des Friedenspreises des Deutschen Buchhandels am 6. Oktober 2006 kommt der Soziologe Wolf Lepenies auf diese Art der ,Forschung', die er „Gegnerforschung“ nennt, zu sprechen. Sie müsse es nach Lage der Dinge auch geben: Es wäre selbstmörderisch, auf „Gegnerforschung“ zu verzichten. Notwendig sei es, der Militanz wehrhaft zu begeg- 
nen - auch mit den Mitteln der Wissenschaft. Um das Phänomen von Militanz und Terror, das sich mit einem religiösen Mäntelchen umgibt, an seiner Wurzel $\mathrm{zu}$ verstehen, bedürfe es eines komplexeren Ansatzes. Hier reichten kulturelle Zuweisungen nicht nur nicht aus, sondern seien auch Teil des Problems. Wenn wir glaubten, die Ursachen des Terrors einzig in den Kulturideologien fremder Völker finden zu können, seien wir längst Kombattanten im ,Krieg der Kulturen“, den die Fundamentalisten herbeibomben wollen.

„Die Islamwissenschaft muss sich mit anderen Wissenschaften zusammentun: der Geschichte, den Politik- und Gesellschaftswissenschaften. Immerhin - der Befund bleibt gültig: Heute gewinnt die Orient- oder Islamwissenschaft eine neue Bedeutung. Der Elfenbeinturm reicht in die politische und gesellschaftliche Aktualität: Es gibt Elfenbeimtürme, von denen aus man weit sieht. “4

Dass die im weiteren Sinne auf den ,Orient' gerichteten Wissenschaften objektiv seien, ist spätestens seit der von dem Palästina-stämmigen amerikanischen Literaturwissenschaftler Edward Said in dem Buch Orientalism losgetretenen Debatte in Frage gestellt. Seine Kernthese, dass die westliche Orientalistik ein Bild von der islamischen Welt entworfen habe, das von europäischen kolonialen und imperialen Interessen geleitet gewesen sei - die Wissenschaft als ancilla der Politik -, hat das Selbstverständnis des Faches tief erschüttert. ${ }^{5}$ Auch wenn Said selbst seine These an englisch- und französischsprachiger Literatur festmacht, so haben neuere Untersuchungen auch deutsche Wissenschaftler ausgemacht, deren Arbeitsergebnisse politische Bezüge erkennen lassen. ${ }^{6}$ Um Saids These ist es im Laufe der Zeit stiller geworden; doch hat sie auch im Zusammenhang mit der Greater Middle East Initiative des amerikanischen Präsidenten George W. Bush, dem expliziten Versuch, die Region des Nahen und Mittleren Ostens - gegebenenfalls mit gewalthaftem Nachdruck wie im Irak - nach westlichem Vorbild zu demokratisieren, nichts an Aktualität verloren. Zahlreiche Wissenschaftler haben ihre Expertise hergegeben, zu beweisen, dass derartige Bemühungen legitim, machbar und erfolgreich sein können. Zahlreiche Wissenschaftler haben aber auch klar gemacht, dass dies nach Lage der Dinge eine gefährliche Illusion sei. Kaum ein Thema ist in den letzten Jahren derart prominent hervorgetreten, wie das Thema ,Islam und Demokratie‘. An der Diskussion waren Islam- wie Politikwissenschaftler (in zahlreichen Fällen sind beide Ansätze in einer Person vereint) beteiligt.

4 Dankesrede anlässlich der Verleihung des Friedenspreises des Deutschen Buchhandels am 8. Oktober 2006 in der Frankfurter Paulskirche. In: Berliner Journal für Soziologie 17/1 (2007), S. 131-136.

5 Edward Said: Orientalism, New York: Pantheon Books 1978.

6 Alexander Haridi: Das Paradigma der ,,islamischen Zivilisation“ - oder die Begründung der deutschen Islamwissenschaft durch Carl Heinrich Becker (1876-1933), Würzburg: Ergon 2005. 


\section{Fragwürdiger ,Universalismus“}

Die Frage nach der Objektivität der Politikwissenschaft und den ihr zugrunde liegenden Kriterien bei der Beurteilung politischer Tatbestände mit Blick auf den Nahen Osten ist beispielhaft an der Beurteilung der Gestalt eines der Führer des palästinensischen Widerstandes gegen die zionistische Besiedlung Palästinas, des Mufti Hajj Amin al-Husaini, akut geworden. In jüngster Zeit sind ihm mehrere Untersuchungen gewidmet worden. ${ }^{7}$ Die Arbeit von Klaus Michael Mallmann und Martin Cüppers erschließt neues Archivmaterial. ${ }^{8}$ Eine der gegenüber früheren Arbeiten schärfer hervortretende Erkenntnis ist, dass die nationalsozialistische Politik im Vorderen Orient, stärker als bisher deutlich gemacht, auf die Vernichtung des Yishuv, des jüdischen Siedlungsraums in Palästina, ausgerichtet gewesen sei. Der seit 1941 in Berlin residierende Mufti, der von der in Europa angelaufenen Vernichtungsaktion gegen die Juden Kenntnis gehabt habe, sei an diesen Aktivitäten als Spiritus rector maßgeblich beteiligt gewesen. In dem aufschlussreichen ,Epilog' setzen sich die Autoren kritisch mit den einschlägigen Untersuchungen der Geschichts- und Islamwissenschaften auseinander. „Gerade innerhalb der Geschichts- und Islamwissenschaften fand die Nähe zwischen Nationalsozialismus und der arabischen Welt bis in die jüngste Vergangenheit eine eher nur sehr zweifelhafte Beachtung." Von einem Standpunkt, der die Kollaboration des Mufti mit dem nationalsozialistischen Regime bei der mehr oder minder wissenschaftlich belegten Intention zur Vernichtung des Yishuv in den Vordergrund rückt und zu einer völlig negativen Bewertung der persönlichen wie politischen Qualitäten des Mufti kommt, erscheinen die angeblich so differenzierten Einschätzungen von Geschichts- und Islamwissenschaftlern bestenfalls blauäugig, wenn nicht bewusst schönfärberisch. Diese hätten versucht, den Mufti im Licht einer gezielten Diffamierungskampagne Englands und Israels als Realpolitiker („Der Feind meines Feindes ist mein Freund“) ja schlicht als Patrioten zu sehen. Den Vorwurf des Eurozentrismus lassen Mallmann und Cüppers nicht gelten; es führe an der Sache vorbei, ,,in einem derartigen Zusammenhang als faktische Absolution der arabischen Seite den Hinweis auf andersartige kulturelle Umgangsformen einzuführen“. Ein solcher Einwand bedeute nichts anderes, als Individuen und ihr Tun auf diverse eherne Kulturkreise zu reduzieren und damit zu entschuldigen sowie den Subjekten von vornherein faktisch jegliche Reflektion menschlichen Handelns zu verwehren. „Die Kritik an solcherlei leichtfertigen Zuschreibungen gar noch mit dem Vorwurf ,eurozentrischen` Denkens zu kon-

7 Gerhard Höpp u.a. (Hg.), Blind für die Geschichte? Arabische Begegnungen mit dem Nationalsozialismus, Berlin: Klaus Schwarz 2004; Gerhard Höpp (Hg.), MuftiPapiere. Briefe, Memoranden, Reden und Aufrufe Amin al-Husainis aus dem Exil, 1940-45, Berlin: Klaus Schwarz 2001.

8 Klaus-Michael Mallmann/Martin Cüppers: Halbmond und Hakenkreuz. Das Dritte Reich, die Araber und Palästina, Darmstadt: WBG 2006. 
tern, kommt einem katastrophalen Denkverbot gleich. Die Autoren reklamieren die Position eines ,Universalismus“, ,,der [...] für die Formulierung eines Urteils über die Kollaboration von Arabern mit dem nationalsozialistischen Deutschland von unverzichtbarer Bedeutung ist. " ${ }^{\text {9 }}$ Mit dieser , universalistischen “ Position ziehen sich die beiden Autoren jedoch auf einen Punkt zurück, der der zionistischen Bewegung eine nicht mehr zu hinterfragende Rechtfertigung verleiht und ignoriert, dass durch sie die Lebensrechte palästinensischer Araber einseitig in Frage gestellt wurden.

\section{Die Beteiligten der ,Islamischen Revolution‘ in Iran}

Der Konflikt zwischen einem Universalismus (der von Mallmann und Cüppers als „abendländisches Denken“ im Gefolge der „Errungenschaften der Aufklärung“ gepriesen wird) ${ }^{10}$ und einer Sichtweise, die tatsächlich kulturelle und religiöse Elemente bei der Erklärung politischer Phänomene in Betracht zieht, ist spätestens mit der Revolution in Iran (1978/79) aufgebrochen. Es war ein (schiitisch) islamischer Geistlicher, der einer verbreiteten Protestbewegung schließlich mit dem Islam entlehnten religiösen Konzepten ihre Durchschlagskraft verlieh, sie zur Revolution eskalieren ließ und beim Sturz der alten Ordnung Regie führte. Nicht viele Orientalisten/Islamwissenschaftler gab es damals, die den Namen Khomeini kannten; und nur wenige hatten seine Schrift von der hukumat-e isla$m i$, der ,islamischen Regierung“, der die vilayat-e faqih, die Amtsführung des anerkannten Gottesgelehrten, zugrunde liegen würde, gelesen. Die gegenwartsbezogene Islamwissenschaft war in Deutschland noch wenig entwickelt und nur unzureichend vorbereitet und willens, aktuelle politische Entwicklungen zu kommentieren - schließlich hatte es dazu noch keine wirklich nachhaltigen Anlässe gegeben. Das sollte sich ändern. Die Islamwissenschaft/Orientalistik trat aus einem Schattendasein ins Rampenlicht der Öffentlichkeit. Sie sollte Phänomene erklären, die für die Politik, Medien und Öffentlichkeit irritierend waren. Dabei waren Konflikte programmiert. Der ,universalistische common sense, in dem sich der ,abendländische', die Aufklärung hochhaltende Bürger eingerichtet hatte, würde mit einer Sichtweise in Konflikt geraten, die in dem Geschehen eine Logik sui generis erkennen würde; die rechtfertigen würde, wo aus der Sicht westlicher Interessen, eines westlichen Werteverständnisses, krasse Mittelalterlichkeit und Verletzungen eines modernen Verständnisses von Demokratie und Menschenrechten geschehen würden. Sie würde allerdings zugleich deutlich machen müssen, an welchen Punkten die Erklärung ihre Grenzen haben würde und wo im Namen der Religion Geschehenes und Getanes vom Standpunkt ,universaler' Werte aus nicht mehr akzeptabel sein und Kritik, ja Verurteilung, ausge-

9 Vgl. ebd., S. 243-258, Zitate auf den S. 253, 257 und 258.

10 Ebd., S. 258. 
sprochen werden müsste. Sie würde also konfliktbereit sein müssen - gegenüber der eigenen Gesellschaft ebenso wie gegenüber den Akteuren, die im Namen der islamischen Religion Werte verletzten, die in der zweiten Hälfte des 20. Jahrhunderts Grundlage des globalen Zusammenlebens geworden waren.

Die Revolution im Iran bedeutete eine dramatische Herausforderung für das Selbstverständnis und die gesellschaftliche Relevanz der Islamwissenschaft/Orientalistik. Angesichts der Gewalthaftigkeit des Geschehens und der großen Zahl der Opfer stellte sich die Frage nach der Rechtfertigung der Revolution als eines Phänomens tiefgreifenden politischen Wandels: Wie stand es um die Legitimität der ,Islamischen Republik' im Lichte der augenfälligen Abweichungen des Systems der vilayat-e faqih von modernen Demokratiestandards? Wie stand es um die Menschenrechte angesichts der Übergriffe an und Verfolgungen von Menschen, die die islamischen Grundlagen des Systems nicht akzeptierten? Das Dilemma lag auf der Hand: Würden Werte, deren universale Geltung im Westen gefordert wurde, uneingeschränkt gelten müssen; oder würde das System eine eigene Legitimation aus ihren reklamierten Wurzeln heraus haben und somit über der Kritik vom Standpunkt westlicher Werte aus stehen? Wie Muhammad Khatami, Staatspräsident Irans von 1997 bis 2005, noch im Jahre 2000 anlässlich der Einweihung des ,Denkmals des Dialogs der Kulturen“ im Schlosspark von Weimar feststellte: Er spricht zunächst von der Notwendigkeit der Kritik von Tradition und der Moderne; ,wir können uns weder der Tradition, noch der Moderne unterwerfen, aber auch nicht die eine der anderen opfern“. Die Errichtung der Islamischen Republik sieht er im Licht der Lösung des Spannungsverhältnisses von Tradition und Moderne: „Die neue religiös-gesellschaftliche Ordnung wurde im Iran etabliert, um auf die sich immer erneuernden Bedürfnisse und Fragestellungen des heutigen Menschen Antworten zu finden." Imam Khomeini habe sowohl auf der Erhaltung der Grundlagen der Religion als auch auf der Erhaltung der Rolle des Volkes bestanden. Es gehe um die Etablierung der Volksherrschaft im Einklang mit den traditionellen geistig-religiösen Grundlagen der Gesellschaft bei gleichzeitiger Entwicklung einer modernen Zivilgesellschaft. ${ }^{11}$

Das Dilemma, das sich der Orientalistik/Islamwissenschaft stellte, lag auf der Hand: Wie war das Geschehen zu erklären, ohne zu rechtfertigen, was vom Standpunkt universaler Werte nicht zu rechtfertigen war? Denn das Geschehen hatte eine eigene, nachvollziehbare Logik: Die Ursprünge der Revolution lagen in dem vom CIA im August 1953 unterstützten Putsch gegen die gewählte säkulare Regierung von Muhammad Musaddegh. Ein direkter Faden ließ sich von dessen Sturz zur Machtübernahme Khomeinis Anfang 1979 ziehen. Ayatollah Khomeini war ein Revolutionär in dem Sinne, dass er eine Massenbewegung ge-

11 Weimarer Gespräch von Präsident Seyed Mohammad Khatami und Bundespräsident Johannes Rau am 12. Juli 2000 im Schloss zu Weimar. In: Seyed Mohammed Khatami: Religiosität und Moderne, Heidelberg: deux mondes, 2001, o.S. 
gen eine Ordnung in Gang setzte, die von der Masse der Iraner nicht gewollt war, vom Ausland jedoch im Namen von dessen eigenen Interessen nachhaltig unterstützt wurde. Die Mobilisierung war nicht auf der Grundlage säkularer ,linker“ Denk- und Handlungsparadigmen erfolgt, die offensichtlich in Iran eine breite Masse nicht zu erreichen vermochten. Khomeini war es gelungen, Elementen des in Iran tief verwurzelten schiitisch-islamischen Glaubens eine Dynamik zu verleihen, von der sich Millionen von Iranern mitgerissen fühlten. Und von der Islamischen Republik sagte Muhammad Khatami nach sieben Jahren gescheiterter Anläufe, das System in der Weise zu verändern, dass politischer Pluralismus, Rechtstaatlichkeit und Menschenrechte respektiert würden, anlässlich der Feiern zum 25. Jahrestag der Revolution am 11. Februar 2004 (etwa eine Woche vor den Parlamentswahlen, vor denen der Wächterrat etwa 3.000 Kandidaten des Khatami-Lagers aus dem Rennen geworfen hatte): Demokratie in einem islamischen Rahmen sei der beste Kurs für das Land.

„Diejenigen, die einem westlichen Stil von Säkularismus folgen, werden nicht nur die Unabhängigkeit, sondern auch die historische Identität der iranischen Nation aufs Spiel setzen. Und diejenigen, die die Demokratie unter dem Deckmantel des Islams untergraben, stellen eine ähnliche Bedrohung dar und riskieren, die junge Generation zu entfremden [...]. Wofür ich immer gestanden habe und fürderhin stehen werde, ist die dritte Option: Demokratie im Rahmenwerk der Religion vereinbar mit unserer Geschichte und Religion. “12

Damit brachte Khatami zum Ausdruck, dass er das Prinzip der vilayat-e faqih als Grundlage des politischen Systems in Iran akzeptiere. Die Islamwissenschaft war zu erklären bemüht, in welcher Weise ,der Islam“ in dem Geschehen wirksam war. Das politische Dilemma des Widerspruchs zwischen einem westlich geprägtem universalen Demokratieparadigma und der gesellschaftlichen und politischen Wirklichkeit in Iran hat sie naturgemäß nicht zu lösen vermocht. Dass die noch immer anstehende politische und gesellschaftliche Modernisierung von Teilen der islamischen Welt aber nicht ausschließlich gemäß aus dem Westen entnommenen Blaupausen verlaufen wird, ist eine zentrale Einsicht, die durch die Ergebnisse der Wissenschaft untermauert worden ist. Die Herausforderung der islamischen Welt mit Blick auf Entwicklung und Modernisierung würde darin liegen, universale Standards mit dem Rückgriff auf Kultur und Religion zu einer Synthese zu bringen. Dass dies im ,Westen“ akzeptiert wird, ist eine Vorbedingung für die Gestaltung der Beziehungen zur islamischen Welt.

Wohin Versuche führen, westliche Demokratiemodelle tel quel in die islamische Welt zu transplantieren, haben der durch die USA gewaltsam herbeigeführte Sturz des irakischen Diktators Saddam Husain und das Scheitern der amerikanischen (aber auch von der Europäischen Union übernommenen) Greater Middle

12 Weekly Press Digest (Teheran), Nr. 7, 7.2.-13.2.2004. 
East Initiative gezeigt. Die Orientalistik/Islamwissenschaft hat sich intensiv an der Diskussion zu Themen wie ,Islam und Demokratie“ und ,Islam und Menschenrechte' beteiligt, die auch in der islamischen Welt in den letzten zwei Jahrzehnten nicht zuletzt im Zusammenhang mit den Bemühungen um demokratische Reformen in Iran geführt worden sind. Naturgemäß sind die Ergebnisse kontrovers. Ganz grundsätzlich aber ist deutlich geworden, dass die vorstehend genannten Begriffspaare einander nicht ausschließen. In welcher Weise die Begriffe miteinander kompatibel gemacht werden können, ist Gegenstand zahlreicher islamwissenschaftlicher Arbeiten gewesen.

\section{Der ,Dialog der Kulturen‘}

Die Auflösung des Dilemmas muss im politischen Raum erfolgen. Der Ausweg aus dem Spannungsverhältnis von Universalität der Geltung grundlegender politischer und gesellschaftlicher Werte auf der einen, und der Legitimität der Gründung jeweils eigener Ordnungen auf der Grundlage von Tradition, Kultur und Religion auf der anderen Seite lag in dem, was vage und bisweilen missverständlich der ,Dialog der Kulturen“ genannt wurde. Nach Lage der Dinge war es kein Zufall, dass dieses Thema mit der Gründung und Konsolidierung der Islamischen Republik an Aktualität gewann. Mit dem Abschluss des irakisch-iranischen Krieges durch den Waffenstillstand vom 20. August 1988 und dem Tod Khomeinis (3. Juni 1989) galt es zu ermitteln, auf welcher Grundlage sich künftig das Zusammenleben ,westlicher' Ordnungen und der Islamischen Republik Iran gestalten würde. Dass Deutschland im Rahmen der Europäischen Union dabei seit 1988 eine Vorreiterrolle annahm, war vor dem Hintergrund der Geschichte der deutsch-iranischen Beziehungen kein Zufall. Symbolisch für diese Qualität der Beziehungen war die Einweihung des Denkmals des Dialogs der Kulturen in Weimar anlässlich des Staatsbesuchs Khatamis in Deutschland im Juli 2000 durch die beiden Staatspräsidenten Muhammad Khatami und Johannes Rau. Auf zwei unbesetzten Sesseln aus Granit wird durch Zitate aus ihren Dichtungen die Gegenwart von Goethe und Hafiz imaginiert. Am Vorabend des Ereignisses hatten die beiden Staatsoberhäupter mit dem Theologen Hans Küng und dem Islamwissenschaftler Josef van Ess über philosophische und theologische Aspekte der Beziehungen zwischen der islamischen Welt und dem Westen ,dialogisiert . ${ }^{13}$

Der ,Dialog der Kulturen“ ist - anders als es der Begriff suggeriert - kein rein kulturelles Ereignis. Er umfasst zwar eine kulturelle Dimension, ist aber in seiner Reichweite politisch zielorientiert und richtet sich auf die Zukunft einer internationalen Ordnung, in der ,culture matters‘. Deshalb wurden die Menschenrechte in den Mittelpunkt des ,Dialogs der Kulturen“ mit Iran gestellt. Die Teilnehmer

13 S.o. Anm. 14. 
auf beiden Seiten kamen aus dem akademischen wie aus dem politischdiplomatischen Raum. Die Gegenwart der Islamwissenschaft war notwendig, um die deutsche (,westliche") Delegation für die Legitimation von Rückfragen aus dem iranischen (,islamischen') Raum zu sensibilisieren; so wie intime Kenner Deutschlands (,des Westens') auf der anderen Seite den iranischen Teilnehmern verdeutlichen mussten, wo die essentiellen Anliegen der deutschen (westlichen) Position lagen. Anliegen wie Anlage dieses ,Dialogs der Kulturen' aber reichten weit über die Kompetenzgebiete von Islamwissenschaft/Orientalistik und WestKennerschaft/Okzidentalistik hinaus. Das Ergebnis musste ein politisches sein und damit das Selbstverständnis der Akteure, aber auch die Grundlage des globalen Ordnungssystems berühren. So war die Wirkung des Dialogs der Kulturen von Anfang an nur in langfristiger Perspektive zu sehen. War es ein Zufall, dass Mitte der neunziger Jahre eine breite Bewegung in Iran Veränderungen in der demokratischen Verfasstheit und vertiefte Achtung der Menschenrechte einforderte und 1997 Muhammad Khatami an die Macht wählte? Auf deutscher Seite war es Bundespräsident Roman Herzog, der die Logik des ,Dialogs der Kulturen“ unter den veränderten Bedingungen des ,culture matters ' hervorhob. ${ }^{14}$

Er hielt auch die Laudatio bei der Verleihung des Friedenspreises des Deutschen Buchhandels im Oktober 1995 an die Islamwissenschaftlerin Professor Annemarie Schimmel. Ohne auch nur ein Jota von der Geltung von Werten abzugehen, auf die sich die internationale Gemeinschaft als ,global' geltend verständigt hat (u.a. in der Menschenrechtserklärung der UNO von 1948) stellt Herzog fest, dass die political correctness ,,keine legitime Schranke der verfassungsrechtlich verbürgten Meinungsfreiheit sein kann." Am Beispiel amerikanischer, britischer und russischer Literaturwissenschaftler macht er deutlich, dass die Befassung mit deutscher Literatur und Kultur während der Nazi-Barbarei geeignet war, ein anderes, gültigeres Verständnis der Deutschen zu vermitteln, ohne die Furchtbarkeit des Regimes der Nazis zu relativieren. Die Aufgabe auch der Islamgelehrten sieht er darin, jene Kenntnisse des Islams zu vermitteln, die die Gesellschaft instand setzen, zu differenzieren und die Vielfalt von Religion und Kultur zum Ausdruck zu bringen. Damit habe die Preisträgerin zum Frieden beigetragen und erhalte den Friedenspreis des Deutschen Buchhandels zu Recht. ${ }^{15}$

Roman Herzog und Muhammad Khatami haben bis zum Ende der Amtszeit des Bundespräsidenten einen immer wieder öffentlich gemachten Dialog der Kulturen geführt. ${ }^{16}$ Der Verfasser dieses Beitrags hatte die Ehre, gemeinsam mit

14 Roman Herzog (Hg.), Dialogue of Cultures - the Future of Relations between Western and Islamic Societies (Report on a Conference held at the initiative of the German President Roman Herzog), Berlin 1999.

15 Die Laudatio von Bundespräsident Roman Herzog ist zu finden unter: httpllwww. bundespraesident.deldokumentel-2.12136\Redeldokument.htm.

16 Sayed Mohammed Khatami: „Auch die Tradition ist nicht ewig“, in: FAZ, 1. August 1998; idem: „Keine Religion ist im Besitz der absoluten Wahrheit“, in: FAZ, 
den engsten Mitarbeitern des Bundespräsidenten eine Sequenz von Projekten und Veranstaltungen zu erarbeiten, in der der wissenschaftliche und politische Raum auf westlicher wie muslimischer Seite aufs engste miteinander kommunizieren sollten. Auf der Seite der Wissenschaft würde die Islamwissenschaft/Orientalistik den anderen beteiligten Wissenschaften von der Politik- über die Erziehungsund Naturwissenschaften bis hin zu den Ingenieurwissenschaften das Feld ebnen, indem sie kenntlich machte, wo deren Stellenwert für eine auch kulturell relevante Dimension an Gemeinsamkeiten mit Vertretern der entsprechenden Disziplinen aus dem islamischen Raum liegen würde. Die am 23. April 1999 verabschiedete ,Berliner Erklärung' sollte Wegweisung für den weiteren Gang der Dinge sein. ${ }^{17}$ Die Entwicklungen haben dann eine andere Richtung eingeschlagen. Auf die Gründe dafür kann an dieser Stelle nicht eingegangen werden. Mit dem 11. September 2001 war schließlich eine Situation entstanden, in der zwar viel von Dialog geredet wurde. Aber nunmehr hatten politische Extremisten das Wort und das Heft des Handelns auf ihrer Seite. Ein christlicher Fundamentalist im Weißen Haus, der sich auszuziehen anschickte, in erklärtermaßen religiöser Dimension dem ,Greater Middle East` das Gute in Form westlich verstandener Demokratie und Freiheit zu bringen; und Extremisten, die sich rüsteten, über ,islamische“ Konzepte wie den $d$ schihad Widerstand zu leisten und die islamische Welt von den ,Kreuzfahrern` zu befreien. Der wirkliche Dialog blieb dabei auf der Strecke. Die Wahl von Mahmud Ahmadineschad als Nachfolger Khatamis im Juni 2005 war nur eines - und noch eines der harmloseren - Ergebnisse dieser Entwicklung. Khatami, nach den Gründen befragt, warum der Prozess der Demokratisierung in Iran nicht vorangekommen sei, sieht einen der Gründe in der Politik Washingtons: Beim Kampf gegen die Taliban im Gefolge des 11. September habe Iran doch die Nordallianz in Afghanistan unterstützt und sei somit an der Seite der USA gewesen. Wenig später aber, am 29. Januar 2002, habe Präsident George W. Bush in seiner ,State of the Union“ Botschaft Iran auf der ,Achse des Bösen' festgemacht. Dies habe diejenigen in Iran bestärkt, die Demokratisierung mit Amerikanisierung gleichgesetzt hätten. Dem Demokratisierungsprozess sei mithin die Legitimität verlorengegangen.

Dieses mag man als einen weiteren Beleg für das sattsam bekannte Argumentationsmuster in der islamischen Welt werten, ,dem Westen' alle Probleme der islamischen Welt anzulasten. ${ }^{18}$ Die Flucht vor der Wirklichkeit sollte auch kei-

26. September 1998; Roman Herzog: „Warum der Westen lernen muss, skeptisch zu werden“, in: FAZ, 30. April 1999; Sayed Mohammed Khatami: „Dialog der Zivilisationen - östliche Spiritualität und westliche Rationalität“, in: Die Welt, 7. August 1999.

17 Zur Berliner Erklärung und der einschlägigen Konferenz, aus der sie hervorgegangen ist, s. Heiner Bielefeld in Orient 37 (1999), S. 38-47.

18 Bassam Tibi: Die Verschwörung. Das Trauma arabischer Politik, Hamburg: Hoffmann und Campe 1993. 
neswegs kleingeredet oder entschuldigt werden. Eine der Herausforderungen an die islamische Welt ist, sich der Moderne und der Auseinandersetzung mit dieser ohne Tabus zu stellen. Aber der Westen und seine Politik tragen eben Mitschuld an den Verkrampfungen gegenüber dem Modernisierungsprozess weithin in der islamischen Welt. Zu Recht fordert deshalb Roman Herzog, dass wir für ,unsere Vorstellungen von Menschenwürde und Menschenrechten kämpfen und werben“ müssen, aber wir könnten das in Frieden tun - ,niemand müsste mehr befürchten, dass hier eine Fortsetzung alter kolonialistischer Herrschaftsmethoden mit ideologischen Mitteln stattfindet“. Vor dem Hintergrund einer sich selbst erfüllenden Prophezeiung eines ,Kampfes der Kulturen“ sieht Herzog den interkulturellen Dialog als „Teil einer rationalen Friedensstrategie“. Und deshalb begrüßte er die Verleihung des Friedenspreises an Annemarie Schimmel: „Und für diesen Dialog braucht man Menschen, die zwischen Kulturen wandern und die über sie Wissen vermitteln, die bereit und imstande sind, sich auch in fremde Begrifflichkeiten und Erfahrungen hineinzudenken und so das Gelernte weiter zu vermitteln, die auf diese Weise Brücken des Vertrauens bauen“. 19

\section{Der ,islamische Terrorismus - Täter zu Opfern machen?}

Das Verbrechen des 11. September 2001 hat es weiter erschwert, das Selbstverständnis der Islamwissenschaft/Orientalistik als Brücke zu bestimmen. Die Lesarten islamistisch begründeter Gewalt lagen in der deutschen Öffentlichkeit weit auseinander. Die einen sahen sich im Kriegszustand. Die Brutalität des 11. September und nachfolgender Terrorakte bestätigte ihnen einmal mehr, dass sich der Terrorismus gegen fundamentale Wertvorstellungen richtete, die dem weltweiten menschlichen Zusammenleben im 21. Jahrhundert zugrunde liegen. Tatsächlich ist nach dem Terrorakt des 11. September die Dimension des Konflikts in die Nähe eines ,Dritten Weltkrieges“ gerückt worden. Dieser Einschätzung einer ,islamistischen Herausforderung' standen jene diametral gegenüber, die in Terror und Gewalttätigkeit im Wesentlichen eine Antwort auf eine Politik des Westens - und insbesondere seiner Vormacht, der USA - sehen, die ihrerseits von rücksichtsloser Durchsetzung wirtschaftlicher Interessen, politischer - auch militärischer - Dominanz und der Praktizierung doppelter Standards gekennzeichnet sei. Islamistische Gewalttäter werden so zu einer islamischen Variante von Verlierern der Globalisierung.

Man muss nicht notwendig zu letzterer Spezies gehören, um in den Ruch der Blauäugigkeit, der Verharmlosung oder der ,Terroristen-Versteher` zu kommen. Wer aber hat die Deutungshoheit? Wenn es der Islam ist, der von Gewalttätern instrumentalisiert wird, dann können diejenigen nicht abtauchen, aber auch nicht

19 S.o. Anm. 18. 
überhört werden, die sich mit dieser Religion, ihren theologischen, historischen, kulturellen und aktuellen politischen Erscheinungsformen, vertieft befassen. Die Wissenschaft vom Islam und der islamisch geprägten Welt muss riskieren, ihre Unschuld zu verlieren, und die Studierstube/den Hörsaal zu verlassen, in dem sie sich lange eingerichtet hatte; und sie muss sich der Herausforderung stellen, in der Öffentlichkeit die Geschehnisse zu erklären - ganz im Sinne jenes Elfenbeinturms von Wolf Lepenies, von dem aus man weit sieht.

Varianten der Deutung anzubieten, geschieht mit zwei interdependenten Zielsetzungen: Der Differenzierung und der Öffnung von Räumen politischen Handelns als Reaktion auf ein Phänomen, das nicht wegdiskutiert werden kann: die Instrumentalisierung von Religion für politische Zwecke und zur Rechtfertigung von Gewalt und Terror. Essentiell ist die Erkenntnis, dass es in der gewalthaften Begegnung nicht um einen Zusammenstoß von Kulturen oder Religionen geht. Die Herausforderung bleibt in ihrem Kern eine politische; und die Lösung des Problems liegt im politischen Raum. Nach dem Ende des Ost-West-Problems sind politische Erblasten schärfer hervorgetreten als im internationalen System vergangener Jahrzehnte. Neue politische Herausforderungen sind hinzugekommen. Im Nahen und Mittleren Osten treten sie mit besonderer Dramatik zutage. Es liegt in bestimmten Wesenszügen von Religion, dass sich der Islam für die Mobilisierung durch Konfliktparteien besonders ,wirksam' instrumentalisieren lässt. Deshalb ist es auch wenig förderlich, das Konfliktgeschehen in der Gegenwart in die Dimension des ,Dritten Weltkrieges' zu stellen. Denn auf diese Weise tritt man in die Falle jener extremistischen Minderheit unter Muslimen, die sich ihrerseits in einer globalen Auseinandersetzung mit ,dem Westen' sehen. Die Weltkriegsdimension verwischt die dringend notwendige Differenzierung. Sie verstellt auch die Tatsache, dass die überwältigende Mehrheit der über einer Milliarde Muslime zwischen dem Atlantik und dem Pazifik dringlich selbst die Lösung der Konflikte und Krisen und nicht zuletzt auch die Befreiung von politischen Regimen wünscht, die im 21. Jahrhundert unzeitgemäß geworden sind.

Die nahezu globale Eskalation gewalthafter Entwicklungen seit dem Beginn des Aufmarsches der USA gegen Saddam Husain Anfang 2002 und dem Fall des baathistischen Regimes in Bagdad hat es unabdingbar gemacht, dass die Islamwissenschaft/Orientalistik noch weiter an die Politik- und Gesellschaftswissenschaften rücken, als dies ohnehin bereits der Fall gewesen ist. Der diffuse Terrorismus im Irak und im islamisch geprägten Raum zwischen Casablanca und Bali, der spätestens mit den Terrorakten in Madrid (März 2004) und London (Juli 2005) auch nach Europa herübergekommen ist, bedarf eines komplexen wissenschaftlichen Ansatzes. Das bezieht sich umso mehr auf jene Elemente des ,Dschihadismus', die Selbstmordattentate als ,normale" Waffe des Kampfes zur Erreichung welcher Ziele auch immer einsetzen. 
Das Ergebnis muss ein sozialpsychologischer Befund sein, zu dem die Islamwissenschaft/Orientalistik einen Beitrag leisten kann - ohne jedoch den Anspruch zu erheben, ihrerseits das Phänomen erschöpfend erklären zu können. ${ }^{20}$ Die Überwindung des Phänomens wird denn auch nicht aus sich selbst heraus und von selbst erfolgen; sie wird vielmehr nur das Ergebnis einer umfassenden Änderung von Politik sein. Dies gilt mit Blick auf Teile der islamischen Welt, d.h. ihre politische, wirtschaftliche und gesellschaftliche Verfasstheit. Dies gilt aber auch mit Blick auf die Gestaltung der Beziehungen zwischen dem Westen und der islamischen Welt, nicht zuletzt beim Umgang mit den Konflikten in der Region des Nahen Ostens. Dass der Lösung des Nahostkonflikts dabei eine Schlüsselrolle zukommt, braucht hier nicht einmal mehr wiederholt zu werden. Aufgabe der Islamwissenschaftler ist es, deutlich zu machen, dass es ,den Islam“ nicht als unwandelbares theologisches System und schon gar nicht als verbindliches politisches oder gesellschaftliches Konzept gibt. Mit Blick auf das Phänomen der Gewalt, die sich auf den Islam beruft, haben sie zu Recht immer wieder darauf hingewiesen, in welcher Weise und in welchen Zusammenhängen im 20. Jahrhundert aus einer Religion im Sinne des Glaubens an Gott eine Ideologie im Sinne der Ausrichtung des Handelns an selektiv und subjektiv vorgenommenen Interpretationen von Elementen des Islams gemacht worden ist.

\section{Der Islam in unserer Gesellschaft}

Differenzierung aber tut auch Not, um den Frieden in unserer eigenen Gesellschaft nicht zu gefährden. Unabweisbar wird der Islam zu einer immer nachhaltiger sichtbaren Facette der gesellschaftlichen Wirklichkeit in Deutschland (und Europa). Dabei leben alle Erscheinungsformen von Muslimen, welche die islamische Welt selbst kennzeichnen, auch unter uns. Dazu gehören Extremisten; die überwältigende Mehrheit aber sucht - jedoch ohne auf eine islamische Identität zu verzichten - an einer freiheitlichen Ordnung und den Chancen einer liberalen Wirtschaftsordnung teilzuhaben. Auch in diesem Falle ist die Islamwissenschaft nur eine Stimme in einer komplexen Antwort auf zahlreiche Fragen. Im Mittelpunkt ihres Parts steht die Erörterung darüber, ob und in welcher Weise sich der Islam als Religion, aber insbesondere als religiös-gesellschaftliches und religiöspolitisches Phänomen verändern muss und kann, um auch Muslimen in den säkularen, liberalen, demokratisch verfassten und auf die Menschenrechte ausgerichteten Gesellschaften Europas ihren Platz zu geben. Dass dies keine leichte Aufgabe ist, ist angesichts des ,Unbehagens am Islam“ in breitesten Teilen der Bevölkerung nachvollziehbar. Und an keinem anderen Punkt der Gegenwart des Islams und der Muslime ist die Islamwissenschaft derart verführt, sich zur Bestäti-

20 Vgl. etwa Olivier Roy: Globalized Islam. The Search for a New Ummah, London: Hurst 2004. 
gung weltanschaulicher und politischer Konzepte, ja Vorurteile und Klischees, instrumentalisieren zu lassen. So schießen denn auch ,Islamwissenschaftler“ wie Pilze aus dem Boden, die man als ,selbsternannt` zu qualifizieren geneigt ist. Aber wo ist die Grenze zwischen genuinem und selbsternanntem Expertentum? Sie ist um so schwerer zu ziehen, als die Medien eher geneigt sind, den ,Bauch“ zu bedienen; d.h. jenen Gefühlen Nahrung zu geben, für die der Islam per definitionem eine Religion ist, die mit der Moderne und damit auch mit modernen politischen und gesellschaftlichen Systemen inkompatibel ist. In dieser konfrontativen und polarisierten Situation erscheinen diejenigen Islamwissenschaftler, die auf die Vielfalt der Erscheinungsformen des Islams, die zahlreichen Ansätze der Modernisierung überall in der islamischen Welt verweisen und mithin zu dem Ergebnis kommen, dass es der islamischen Welt möglich sein wird, einen eigenen Weg in eine mittlerweile globale Moderne zu gehen, als blauäugig.

Der Islamwissenschaftler/Orientalist muss heute - nach seiner Entscheidung für sein Fach - noch eine andere Entscheidung treffen: Wo er seine wissenschaftliche Tätigkeit ansiedelt - im Elfenbeinturm oder auf dem Elfenbeinturm. Wenn er sich für letzteres entscheidet, ist er sichtbar und sieht vieles. Er ist Teil der Gesellschaft; dieser muss er vermitteln, was er tut und ermittelt. Er benötigt heute wer hätte das Anfang der siebziger Jahre gedacht, als Moderne und Gegenwart auch für die Islamwissenschaft/Orientalistik zum Thema wurden - Zivilcourage. In seiner Arbeit sieht er sich mit Lobbies und Interessengruppen konfrontiert, die politisch und gesellschaftlich besser vernetzt sind als er, der seine Unabhängigkeit bewahren muss. Im Gefolge des 11. September 2001 hat sich die Spannung zwischen Vorurteilen und Interessen auf der einen und der Expertise des Islamwissenschaftlers/Orientalisten auf der anderen Seite verschärft. Wie ist das Verhältnis von Islam und Gewalt? Wo liegt der Übergang von islamischer Frömmigkeit zu islamistischem Extremismus? Hier tun sich nicht selten unterschiedliche Einstellungen zu jenem Establishment auf, das für die innere Sicherheit zuständig ist. Ist der Islam in einer Weise modernisierbar, dass Muslime sich als europäische Bürger islamischen Glaubens in den europäischen Gesellschaften integrieren? Gibt es also einen europäischen Islam, der mit dem Grundgesetz und der Wertordnung kompatibel ist, auf dem das Grundgesetz beruht? Oder ist ,die Scharia‘ ein unumstößlich festes Rechtssystem, das unabdingbar eine Kluft zwi-

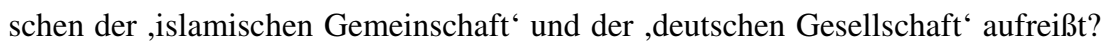
Hier legt sich der Islamwissenschaftler mit jenem breiten, hoch emotionalisierten Strom in der deutschen Bevölkerung an, der ,den Islam‘ als das Gegenstück schlechthin zu den europäischen Errungenschaften, die durch Renaissance und Aufklärung erreicht wurden, wahrnimmt. Sie hatten ihre Hochgefühle im Zusammenhang mit dem ,Karikaturenstreit ‘. ${ }^{21}$,Muslime‘ seien unfähig, Bürgerrech-

21 Karikaturen in der dänischen Zeitung ,Jyllands-Posten“, die islamistische Gewalt mit dem Propheten Muhammad in Verbindung brachten, führten 2005 zu teils hefti- 
te im europäischen Sinne zu akzeptieren, zu denen das Recht auf freie Meinungsäußerung gehöre. Den Fundamentalisten der Meinungsfreiheit ist selbstverständlich, dass die hohen Güter, die Europa durch die Geschichte der letzten Jahrhunderte geschaffen hat, nicht nachvollziehbar sind für die Angehörigen einer Religion, die nach weitest verbreiteten Einschätzungen das Mittelalter noch immer nicht hinter sich gelassen hat.

An dieser Stelle treten Fronten mit Blick auf politische Herausforderungen auch außerhalb der eigenen Gesellschaft ins Bild. So etwa in der Frage nach der Zukunft der Beziehungen zwischen der Türkei und der Europäischen Union. Die ,Abendländer', die - wie in der Debatte um die Migration von Muslimen nach Deutschland - unter sich bleiben wollen, sehen eine derartige Andersartigkeit der Identitäten zwischen ,Muslimen“ und ,Europäern“, dass die Mitgliedschaft der Türkei in der EU „,das Projekt der politischen Einheit Europas torpedieren“ würde. $^{22}$ Diese unhistorisch apodiktische und populistische Feststellung durch Untersuchungen zu korrigieren, die sich der Instrumente und Methoden der Turkologie (als einer Kulturwissenschaft) bedienen, wird als ,kulturalistisch“ abgetan.

Politisch besonders brisant können die gegensätzlichen Wahrnehmungen werden, wenn Israel ins Bild tritt. Die Kritik an Israels Politik in den besetzten Gebieten - welcher Islamwissenschaftler/Orientalist könnte sich ihrer enthalten wird nicht nur allzu leicht in die Ecke des Antisemitismus geschoben. Die Argumentationskette pflegt vielmehr diese kritische Einstellung mit der in der Grundhaltung konstruktiven und differenzierten Position des Zeitgeschichtlers/ Islamwissenschaftlers/Orientalisten gegenüber dem Islam in einen Zusammenhang zu bringen: Zwischen Islam und Islamismus sowie sich islamisch rechtfertigender Militanz nicht mehr differenzierend wird der Islamwissenschaftler/Orientalist zum Parteigänger eines ,Islams“ abgestempelt, dessen Ziel die Vernichtung Israels sei. Dabei wird die psychologische Dimension des PalästinaProblems mit Blick auf den islamisch geprägten Nahen Osten, ja die islamische Welt jenseits desselben, bewusst ausgeklammert. Die anhaltende Besatzung und ihre gewalthaften Begleiterscheinungen wird von Arabern als tiefe Demütigung auch im Horizont der islamischen Religion wahrgenommen. Aus dieser Demütigung erwächst Gewaltbereitschaft. Wer vermöchte diesen Zusammenhang besser zu verstehen als der Islamwissenschaftler? In einer polarisierten politischen und gesellschaftlichen Konstellation - sowohl mit Bezug auf Israel als auch auf den Islam - kann es im Extrem zu existenzbedrohlichen Kampagnen kommen. Sie

gen und gewalttätigen Protesten unter den Muslimen in Europa und in der islamischen Welt. In Europa selbst standen sich zugleich kompromisslose Vertreter der Meinungs- und künstlerischen Freiheit auf der einen und einer gebotenen Zurückhaltung angesichts muslimischer Empfindlichkeiten auf der anderen Seite gegenüber.

22 Hans-Ulrich Wehler: „Verblendetes Harakiri. Der Türkei-Beitritt zerstört die EU“, in: Aus Politik und Zeitgeschichte (APuZ), Nr. 33-34, 9. August 2004. 
finden in der lapidaren Drohung: „Und so einer wird aus Steuermitteln bezahlt“, gleichermaßen ihren Brennpunkt und ihr Totschlagargument. Damit aber ist zum Ausdruck gebracht, welchen hohen gesellschaftlichen Stellenwert die Islamwissenschaft/Orientalistik heute einnimmt. Dass er kontrovers sein muss, liegt in der Natur der Sache. 



\section{Teil IV}

REORIENTIERUNGEN 



\title{
Ist das Tor des, lğtihād' in der Islamwissenschaft geschlossen?
}

ABBAS POYA (FREIBURG)

\author{
Meine Meinung ist richtig, \\ kann aber auch falsch sein. \\ Die Meinung des Anderen ist falsch, \\ kann aber auch richtig sein. \\ Ist seine Meinung besser begründet, \\ akzeptiere ich sie. \\ (Arabische Gelehrtenweisheit)
}

Von dem Gelehrten 'Ubaidallāh b. Ḥasan al-'Anbarī (st. 168/785), der in der Abbasidenzeit fast zehn Jahre lang das Amt des Kadi und Vorbeters beim Freitagsgebet in Bașra innehatte, wurde der Satz zitiert: „kull muğtahid musīi”“ (jeder Sachkundige hat Recht). ${ }^{1}$ Der Satz zeigt den Versuch auf, die vielen Meinungsverschiedenheiten jener Zeit zu legitimieren und damit die damaligen religiös begründeten Feindseligkeiten zu entkräften. Ob al-'Anbarī mit dieser Aussage auch theologische und weltanschauliche Divergenzen anerkennen wollte, oder, wie später der Begriff Iğtihād verstanden wurde, nur die Meinungsunterschiede im Bereich der Jurisprudenz zu legitimieren versuchte, darüber kann nur spekuliert werden. Der Terminus Iğtihād entwickelte sich allerdings im Laufe der Zeit zum zentralen Begriff im islamischen Rechtsdiskurs und diente als theoretische Grundlage dafür, unterschiedlichste Meinungen in der Scharia zu vertreten, zahlreiche Rechtsschulen zu bilden und Pluralität im Rahmen der islamischen Jurisprudenz zu etablieren. Wie es auch aš-Šahrastānī (st. 1153) und Ibn Haldūn (st. 1406) beschrieben, steckte hinter der Praxis des Iğtihād eine pragmatische Überlegung: Man wisse, dass sich bei profanen wie auch sakralen Angelegenheiten immer wieder aufs Neue Fragen ergeben, und man wisse auch, dass nicht alle diese Fragen durch den Koran oder die Sunna beantwortet werden könnten, da die Aussagen im Koran und in den Überlieferungen begrenzt seien, stetig jedoch neue Fragen entstünden. Daher hätte man es für wichtig und sogar notwendig gehalten, qualifizierten Sachkundigen die Möglichkeit einzuräumen, gemäß neu-

1 Vgl. Josef van Ess: Theologie und Gesellschaft im 2. und 3. Jahrhundert Hidschra, Band II, Berlin, New York: Walter de Gruyter 1992, S. $153 f$. 
en Gegebenheiten und Umständen zu neuen praktischen Urteilen zu kommen, eben den Iğtihād zu praktizieren. ${ }^{2}$

Ohne Zweifel führte der Iğtihād zu einer großen Entfaltung und ergo zu einem ,Pluralismus“ im Rahmen des islamischen Rechts - dies gilt insbesondere etwa in der Zeit zwischen dem 8. und dem 10. Jahrhundert. Diese Periode gilt auch als die ,Blütezeit' der islamischen Zivilisation, die freilich nicht nur durch geistige Freiheit im Bereich des Rechts entstanden war, sondern auch durch eine solche in allen anderen Disziplinen wie der Philosophie, Medizin, Mathematik, Übersetzungstätigkeit, etc. Die These vom Ende der Iğtihād-Zeit, mit der der Anfang der Stagnation zumindest im Bereich der Jurisprudenz erklärt wird, ist umstritten. Der Begriff Iğtihād an sich blieb jedoch in der islamischen Geistesgeschichte bis in die Gegenwart eine Metapher für Meinungsvielfalt, wissenschaftliche Pluralität und geistige Dynamik. Als solche soll er auch in diesem Beitrag verstanden werden. Vorher möchte ich aber noch auf einige Merkmale dieser Praxis des Iğtihād hinweisen.

Es ist beeindruckend, mit welcher Präzision die Gelehrten die theoretischen Rahmenbedingungen für den Iğtihād beschrieben haben: Die Notwendigkeit des Iğtihād-Praktizierens wurde, wie ich bereits anlehnend an aš-Šahrastānī und Ibn Haldūn darlegte, pragmatisch erklärt: Neue Gegebenheiten führen zu neuen Fragen und diese erzwingen neue Antworten, welche von qualifizierten Wissenschaftler/innen zu erarbeiten sind. Damit aber jede wissenschaftliche Beliebigkeit vermieden wird, darf man erst dann die Fähigkeit zum Iğtihād für sich beanspruchen, wenn man gewisse Voraussetzungen erfüllt hat. Zu diesen Voraussetzungen gehören u.a. die fachspezifische Kompetenz, nämlich die Kenntnis der Quellen, und die sprachliche Kompetenz, nämlich die Beherrschung der arabischen Sprache und Grammatik. ${ }^{3}$ Das wissenschaftliche Bemühen ist erst dann als vollkommener Iğtihād zu bezeichnen, wenn man mit neuen methodischen Ansätzen arbeitet, d. h. entweder in Form einer völlig neuen Methodik oder eines Eklektizismus. Das bloße Rezipieren von Meinungen verschafft dem IğtihādPraktizierenden eine gewisse Autorität gegenüber den absoluten Laien, gilt jedoch nicht als Iğtihād im eigentlichen Sinne. ${ }^{4}$ Daher spricht man auch von der Schließung des Tors des Iğtihād, nachdem in einigen Rechtsdiskursen die metho-

2 Vgl. M. Abū al-Fatḥ aš-Šahrastānī: al-Milal wa an-niḥal, Bd. 1, Beirut o. J., S. 199; 'Abd ar-Raḥmān M. Ibn Hुaldūn: al-Muqaddima, ediert von 'Alī 'Abd al-Wāhid Wāfì, Kairo 1981, S. 1062.

3 Vgl. Abū Ḥāmid M. al-Ġazālī: al-Mustaṣfā min 'ilm al-uṣūl, ediert von Ḥamza b. Zuhair Hāfiz, Bd. 4, Medina o. J., S. 4-14.

4 Vgl. Šams ad-Dīn Ibn Qayyim al-Ğauziyya: I'lām al-muwaqqi'īn 'an rabb al'ālamīn, ediert von M. M. 'Abd al-Hamīd, Bd. 4, Kairo 1955, S. 212 f. 
dologische Entwicklung im Bereich des Rechtsfindungssystems ab dem 10. Jahrhundert in Frage gestellt wurde. ${ }^{5}$

Grundsätzlich steht der Begriff Iğtihād also für diskursive Offenheit und epistemische Neuerung, während die Schließung des Tors des Iğtihād als erkenntnistheoretische Stagnation angesehen wird. In einer kritischen und (selbst-) reflexiven Betrachtung wenden wir nun den Begriff des Iğtihād auf die Islamwissenschaft an, um zu erkunden, inwieweit in der Islamwissenschaft von epistemischer Offenheit gesprochen werden kann.

\section{,Iğtihād’ in der Islamwissenschaft}

Die islamwissenschaftliche Forschung in Europa ganz allgemein und in Deutschland bis zur Machtübernahme des Nationalsozialismus (1933) im Besonderen kann sich grundsätzlich nicht über den Mangel an ,Iğtihād“ beklagen. Es gab unterschiedliche Forschungsmotivationen und dementsprechend auch verschiedene Forschungsansätze: theologische, philologische, historische, sozialpolitische und kulturphilosophische - auch wenn sie oft im Zeichen der Gewalt standen. Die frühe europäische Beschäftigung mit dem Islam fand erst im Geiste der Kreuzzüge und dann der Reconquista statt. Die Koranübersetzungen und Muhammadbiographien damaliger Zeit hatten größten Teils dazu gedient, gegen den Islam zu polemisieren. Auch Übersetzungen medizinischer, naturwissenschaftlicher und philosophischer Texte aus dem Arabischen führten nicht zu Verständnis und Respekt gegenüber den muslimischen Kulturen. Sie dienten vielmehr dazu, eine Brücke zu den ,eigenen' kulturellen Wurzeln, zur Antike, zu konstruieren. Die osmanischen Eroberungszüge auf dem Balkan gaben wieder Anlass, dem Islam gegenüber skeptisch zu sein und ihn als Religion des Schwertes und des Blutes darzustellen. Vor allem wollten die christlichen Kirchenmänner die arabische Sprache und Grammatik beherrschen, um erfolgreich zu missionieren und die arabischen Glaubensbrüder besser zu unterstützen, aber auch, um nach ursprünglichen Quellen des eigenen Glaubens zu suchen. Die ersten Lehrstühle für arabische Sprache an den europäischen Universitäten wurden von Professoren mit theologischem Hintergrund besetzt. Aber die akademische Beschäftigung mit dem Islam und vor allem die Aufklärung führten auch dazu, mit einigen Vorurteilen über die islamische Kultur aufzuräumen, die religiösen Texte der Muslime ,objektiver' zu behandeln und letztendlich die Arabistik auch unabhängig von der Theologie zu betreiben. Im deutschsprachigen Raum war es Johann Jacob Reiske (1716-74), der entgegen der traditionellen, theologisch motivierten Beschäftigung mit der arabischen Sprache versucht hat, die arabische Philologie als eine

$5 \mathrm{Zu}$ der gesamten Iğtihād- bzw. Rechtsthematik bietet das Buch von Birgit Krawietz einen umfangreichen Überblick: Hierarchie der Rechtsquellen im traditionellen sunnitischen Islam, Berlin: Duncker \& Humblot 2002. 
selbständige Wissenschaftsdisziplin $\mathrm{zu}$ etablieren. Sein Versuch hat Reiske „Missgunst“, „Misstrauen“ und den Vorwurf der „Freigeisterei“ eingebracht und seine Berufung auf einen Lehrstuhl an der Leipziger Universität verhindert. Sein Forschungsansatz trug jedoch zu einer neuen Qualität des islamwissenschaftlichen Diskurses bei und wurde in späteren Islamstudien anerkennend gewürdigt. ${ }^{6}$

Als Begründer der modernen Arabistik und Vater der ,Orientalistik“ im engeren Sinne als akademische Disziplin ging Antoine Isaac Silvestre de Sacy (17581838) in die Geschichte ein. Als Sprachgenie - er beherrschte u.a. Aramäisch, Hebräisch, Arabisch, Persisch, Türkisch, Deutsch, Englisch, Italienisch und Spanisch - und bester Kenner der arabischen Sprache und Grammatik seiner Zeit bildete er zahlreiche Wissenschaftler aus allen Teilen Europas aus, die dann selbst in ihren jeweiligen Herkunftsländern zu großen Orientalisten wurden. Aus Deutschland zählten u.a. Wilhelm Freytag, Gustav Flügel und Heinrich Lebrecht Fleischer zu seinen Schülern. Mit dieser neuen Ausrichtung hatte sich zwar die Beschäftigung mit dem Islam von der kirchlichen bzw. theologischen Zweckgebundenheit befreit, jedoch war es nun den kolonialen Interessen in arabischislamischen Ländern, in Afrika und Asien, sowie dem Versuch einer Eindämmung des osmanischen Einflusses auf dem Balkan geschuldet, dass das Studium der arabischen, türkischen und persischen Sprache intensiver betrieben wurde. ${ }^{7}$

Im 19. Jahrhundert war die vorherrschende Idee in der Geisteswissenschaft der Historismus. Er führte in der Kunst zu der Einsicht, die Architekturformen anderer Epochen als historisch bedingte und gleichwertige Formen anzuerkennen und sie damit eklektizistisch in die neuen Bauten $\mathrm{zu}$ integrieren. In der Geschichtswissenschaft betonte der Historismus im Gegensatz zur Idee der Aufklärung das irrationale, historisch geprägte und in seiner Vergangenheit verwurzelte Wesen des Menschen. Man sah die Aufgabe einfach darin, möglichst ,objektiv ‘ zu zeigen, ,wie es gewesen ist“. Diese geistige Haltung führte, trotz einer starken philologischen Orientierung des Faches, in der Islamforschung zu historischkritischer Auseinandersetzung mit dem Islam und seiner Frühgeschichte. In dieser Periode sind herausragende Werke mit historischem Ansatz wie die Geschichte der Chalifen (5 Bd. 1846-62) von Gustav Weil (1808-89) oder die Geschichte des Qorāns (1860) von Theodor Nöldeke (1836-1930) entstanden. Gleichzeitig wurden die philologischen Texteditionen weitergeführt, welche nicht nur für die historischen Arbeiten innerhalb der Islamwissenschaft als

6 Gerhard Endreß: Der Islam. Eine Einführung in seine Geschichte, München: C.H. Beck 1997, S.13-20; Annmarie Schimmel: „Der islamische Orient - Wege seiner Vermittlung nach Europa“, in: Jochen Golz (Hg.), Goethes Morgenlandfahrten. West-östliche Begegnungen, Frankfurt/M: Insel 1999, S. 16-28, hier S. 18-22; Sabine Mangold: Eine „weltbürgerliche Wissenschaft“ - Die deutsche Orientalistik im 19. Jahrhundert, Stuttgart: Steiner 2004, S. 29-34.

7 Vgl. G. Endreß: Der Islam, S. 21-22; A. Schimmel: Der islamische Orient, S. 22-23; S. Mangold: Eine „,weltbürgerliche Wissenschaft“, S. 38-39. 
Grundlage dienten, sondern darüber hinaus auch von anderen Disziplinen in $\mathrm{Zu}$ sammenhang mit Islam-bezogenen Themen rezipiert wurden. Parallel zu diesen Arbeiten wurden religionswissenschaftliche Studien betrieben. $\mathrm{Zu}$ den letzteren zählen Muhammedanische Studien (1889-90) von Ignaz Goldziher (1850-1921), die über die Grenzen Europas hinaus auch in der islamischen Welt Beachtung fanden. ${ }^{8}$

Als dann Ende des 19. und Anfang des 20. Jahrhunderts die historistische Haltung in der akademischen Landschaft massiv kritisiert wurde und soziologische Ansätze, vor allem die von Max Weber, an Bedeutung gewannen, beobachten wir wieder eine Neuausrichtung in den islamwissenschaftlichen Forschungen. Hier sind es nun Martin Hartmann (1851-1918) und insbesondere Carl Heinrich Becker (1876-1933), die mit sozialwissenschaftlichen und kulturphilosophischen Forschungsmethoden das Fach prägen. Becker, der auch hochschulpolitisch aktiv war und eine Demokratisierung der Universität betreiben wollte, entlehnt die Schlüsselbegriffe seiner Theorie wie „Kultur“, „Zivilisation“, „Bildung“, „Humanismus" und „Volk“ den damaligen deutschen Diskursen in den Geisteswissenschaften und verwendet sie in seinen Forschungsarbeiten über den Islam. ${ }^{9}$ Auch die Untersuchungen Beckers insbesondere zum Islam in den kolonisierten Gebieten Afrikas, im sogenannten Deutsch-Ostafrika, sind von den damaligen politischen Gegebenheiten geprägt und im Rahmen der deutschen Kolonialpolitik in Afrika zu begreifen. ${ }^{10}$ Gleichzeitig führte seine Herangehensweise an den Forschungsgegenstand auch zu neuen Erkenntnissen und einer anderen Haltung in Bezug auf den Islam. Er lehnte die vornehmlich theologische Betrachtung des Islam ab, plädierte für ,gemeinsame Grundlagen und Interaktionen von Christentum und Islam“ und sprach von ,islamischer Zivilisation“ statt von „islamischer Religion“." Dieser neue Forschungsansatz konnte aber nicht lange weiter verfolgt werden. Mit der Machtergreifung der Nationalsozialisten (1933) endete die wissenschaftliche Freiheit und Vielfalt, auch in der Islamforschung.

Die oben skizzierte Geschichte der Islamwissenschaft bis 1933 zeigt eine ambivalente Pluralität an Ideen, Ansätzen und Methoden auf. Der Forschungsgegenstand - ,Islam“ bzw. ,Muslime“ - blieb zwar immer konstant, aber zwei sich ständig ändernde Faktoren führten zu einer gewissen Forschungsdynamik. Zum einen der Faktor des sozialen bzw. politischen Zeitgeists: Je nachdem, ob die Auseinandersetzung mit dem Islam in der Zeit der Kreuzzüge, der Reconquista,

8 Vgl. G. Endreß: Der Islam, S. 22-27; S. Mangold: Eine „weltbürgerliche Wissenschaft", S. 103f.

9 Alexander Haridi: Das Paradigma der „,islamischen Zivilisation“ - oder die Begründung der deutschen Islamwissenschaft durch Carl Heinrich Becker (1876-1933), Würzburg: Ergon 2005, S. 11.

10 Roman Loimeier: „Edward Said und der deutschsprachige Orientalismus: Eine kritische Würdigung“, in: Stichproben. Wiener Zeitschrift für kritische Afrikastudien 2 (2001), S. 63-85, hier S. 68-69.

11 Vgl. A. Haridi: Das Paradigma der ,islamischen Zivilisation“ S. 19-24. 
der Konfrontation mit den Osmanen oder der Kolonialisierung stattfand, sind auch unterschiedliche Forschungsansätze und -schwerpunkte zu beobachten. Der andere Faktor ist der wissenschaftliche Zeitgeist: Die Islamwissenschaft verfolgte die zeitgenössischen Diskurse innerhalb der Geisteswissenschaften aufmerksam und adoptierte sie in ihre eigene Wissenschaftspraxis.

Ein wichtiger und von den Beteiligten meist übersehener Grund dafür, dass man sich in Islam-bezogenen Diskursen immer einen größeren Spielraum gönnte und es sich dadurch hin und wieder leisten konnte, die wissenschaftlichen Spielregeln und Geflogenheiten außer Acht zu lassen und dem Islam gegenüber Polemik und Agitation zu betreiben, war allerdings die Annahme und ja die Überzeugung, dass man sich mit etwas ,Fremdem“ beschäftigte, von dem die ,eigenen“ gesellschaftlichen Empfindlichkeiten und wissenschaftlichen Diskurse nicht direkt betroffen waren. Mehr sogar, es entsteht teilweise der Eindruck, dass dieses ,Fremde' gelegentlich absichtlich instrumentalisiert und stellvertretend verunglimpft wurde, um ,eigene‘ Missstände an den Pranger zu stellen. Voltaire (16941778), um nur ein Beispiel zu nennen, der das Bild des Islam in Europa nachhaltig geprägt hat, beschrieb in seinem 1742 verfassten Drama Mahomet den Propheten Muhammad ,als einen skrupellosen Anführer, der das vorislamische Mekka in Anarchie stürzt". Hinter diesem feindseligen Angriff auf den Islam standen jedoch wohl andere Absichten. Angeblich habe er damit den christlichen Fanatismus seiner Zeit kritisieren wollen. ${ }^{12}$ Zum gleichen Zweck lobte man aber auch manchmal das ,Islamische“ euphemistisch, wie es im positiven Entwurf der Person des Saladin bei Lessing oder in Goethes Darstellung des Islam als „Inbegriff eines lauteren, durch keinerlei historische Ausprägung belasteten Monotheismus" zu beobachten ist. ${ }^{13}$

Dieses fortwährend ambivalente Bild des Islam $^{14}$ zeigt aber auch ein ständiges, umkämpftes Bemühen (Iğtihād) um neue Erkenntnisse. Auch wenn keines dieser Bilder den Islam widerspiegeln vermag, vermitteln sie uns doch die Einsicht, dass wir uns den neuen Erkenntnissen und Ideen in den Geisteswissenschaften und den politischen und sozialen Gegebenheiten und Veränderungen unserer Zeit nicht verschließen können.

Die Zeit des Nationalsozialismus (1933-1945) war eine einschneidende Zäsur auch in der Geschichte der Islamforschung. Durch die Gleichschaltungs- und Rassenpolitik hat die deutschsprachige Islamforschung zahlreiche herausragende Wissenschaftler/innen verloren. Sie gingen in die Emigration oder wurden zur

12 Vgl. Tilman Nagel: Islam. Die Heilsbotschaft des Korans und ihre Konsequenzen, Westhofen: WVA 2001, S. 9.

13 Vgl. ebd., S. 10-13.

$14 \mathrm{Zu}$ unterschiedlichen Islambildern in Europa vgl. Maxime Rodinson: Die Faszination des Islam, München: C.H. Beck 1991; Albert Hourani: Der Islam im europäischen Denken, Frankfurt/M: Fischer 1994; T. Nagel: Islam, S. 9-22. 
Emigration gezwungen. Einige von ihnen wurden ermordet. ${ }^{15}$ Die im Lande verbliebenen Orientforscher/innen und die orientalistischen Institutionen waren der Willkür des Terrorregimes ausgeliefert und wurden zum Teil in die Nazipolitik einverleibt bzw. fügten sich bereitwillig in diese ein. Eine neue historische Untersuchung über die Orientalistik in der Nazizeit kommt zum folgenden ernüchternden Ergebnis:

„Betrachtet man die orientalistischen Wissenschaftsinhalte und das orientalistische Netzwerk der Jahre 1933-45 in ihrer Gesamtheit, so stellt sich die deutsche Orientalistik dieser Jahre als Wissenschaftsdisziplin dar, die sich durch einen hohen Identifikationsgrad mit dem NS auszeichnete. Die Orientalisten hatten es vermocht, sich persönlich, organisatorisch, institutionell und inhaltlich fest im NS zu verankern. Parteimitgliedschaften, formale pro-nationalistische Bekenntnisse und inhaltlich differenzierte Stellungnahmen definierten das persönliche Verhältnis zum NS im Allgemeinen und zur NSDAP im Besonderen. “"16

Zum Zweck des Selbstschutzes versuchten zahlreiche Orientalist/innen, sich auf Themen zu beschränken, die mit der Gegenwart und mit der Politik augenscheinlich wenig zu tun hatten, nämlich auf philologische und zum Teil historische Themen.

Nach dem Zweiten Weltkrieg hat sich die deutsche Islamwissenschaft schwer damit getan, an die frühere dynamischere Tradition anzuknüpfen. Der Rückzug auf die ,sichere' und politisch nicht heikle philologische und historische Forschung, mit dem schon in der Zeit des Nationalsozialismus begonnen wurde, setzte sich fort. Ein Grund war sicherlich die in den 1930er Jahren gesäte und später immer noch lebendige Scheu vor jeglichen Themen, die einen zeitgenössischen oder politischen Bezug hatten. Der andere Grund kann aber sicherlich auch darin gesehen werden, dass der Islamwissenschaft nach den Verlusten, die sie in den Jahren 1933-1945 erlebt hatte, die personelle Grundlage zur Ideenvielfalt fehlte. Die zahlreichen und zum größten Teil herausragenden deutschsprachigen Orientalist/innen, die aus Deutschland flohen, waren häufig jüdischer Abstammung oder linker und liberaler Gesinnung. So mangelte es nun der deutschen Orientalistik bzw. Islamforschung an Internationalität und Überkonfessionalität, die die orientalistischen Organisationen wie die DMG vor 1933 ebenfalls ausgezeichnet hatten. Daher war weder die Möglichkeit noch das Interesse vorhanden, andere Schwerpunkte in der Forschung zu setzen und der Islamwissenschaft neue Perspektiven zu öffnen. ${ }^{17}$

$15 \mathrm{Zu}$ Porträts einzelner Betroffener vgl. Hanne Schönig (Hg.), Ausgegrenzte Kompetenz. Porträts vertriebener Orientalisten und Orientalistinnen 1933-1945, Halle/ Saale: OWZ 2001.

16 Ekkehard Ellinger: Deutsche Orientalistik zur Zeit des Nationalsozialismus 19331945, Berlin: deux mondes 2006, S. 419.

17 R. Loimeier: Edward Said und der deutschsprachige Orientalismus, S. 73-74. 
Die arabische Philologie, die seit 1933 bis in die Gegenwart die islamwissenschaftliche Forschung beherrscht, hatte immer einen besonderen Stellenwert. Man empfand allgemein, dass jedwede islamwissenschaftliche Forschung, ganz gleich mit welchem Ansatz, von dieser abhängig ist. Dies trifft aber nur bedingt zu. Philologische Kompetenz im Sinne von Beherrschung des Arabischen und je nach Schwerpunkt des Persischen oder Türkischen oder anderer afrikanischer und asiatischer Sprachen sowie die kritische Auseinandersetzung mit den Textquellen sollte eine Selbstverständlichkeit sein, wenn man sich mit Islambezogenen Themen beschäftigt. Man kann sich aber, hat man dieses ,Werkzeug ‘ erst einmal zur Hand, auch mit anderen Wissenschaftstheorien seinem Thema nähern - und tut dies ohnehin, auch wenn es dann unbewusst verläuft. Demgegenüber kann es auch für einen Philologen sehr dienlich sein, wenn er mit den neusten Wissenschaftstheorien vertraut ist und sie in seine Forschung einfließen lässt - dies insbesondere angesichts der Tatsache, dass in den geisteswissenschaftlichen Fächern vielfach von einem linguistic turn und cultural turn die Rede ist. Gerade für ein Fach wie die Islamwissenschaft, welches in den aktuellen politischen und gesellschaftlichen Debatten immer mehr an Relevanz gewinnt und zur medialen Ansprechpartnerin geworden ist, ist es sehr wichtig, sich z.B. auch mit Orientalismus- und Rassismuskritiken, mit Kulturalismus bzw. Kulturrelativismus und mit Postmodernismus und Postkolonialer Kritik auseinanderzusetzen. Wie in früheren Phasen muss die Islamwissenschaft auch gegenwärtig sowohl auf den politisch-sozialen Zeitgeist als auch auf den wissenschaftlichen Zeitgeist reagieren, zumal in den letzten Jahrzehnten diesbezüglich große Veränderungen festzustellen sind.

\section{Der Schock der Orientalismuskritik}

Zwei Annahmen haben Edward Said dazu geführt, die deutsche Orientalistik ausdrücklich von seiner Orientalismuskritik auszunehmen: a) die deutsche Orientalistik weise eine sehr starke philologische Tradition auf; und das sei auch ein Beweis dafür, dass b) Deutschland im Vergleich zu Großbritannien und Frankreich weniger koloniale Verwicklungen im Orient aufweise. ${ }^{18}$ Wie aber oben dargestellt, wurde auch in der deutschen Orientalistik trotz einer starken Präsenz der Philologie immer wieder mit anderen Forschungsansätzen gearbeitet. Darüber hinaus blieb sie trotz einer in der Tat geringeren kolonialen Verwicklung nie von kolonialistischen Tendenzen, wie sie insbesondere in der britischen und französischen Orientalistik herrschten, unberührt. Vor allem im Zeitraum zwischen dem Ende des 19. Jahrhunderts und dem Ende des 1. Weltkriegs, welcher gleichzeitig als Entstehungszeit einer modernen Islamwissenschaft in Deutsch-

18 Eward Said: Orientalism, London: Penguin Books 1995, S. 2-4. 
land gelten kann, beobachtet man eine ausgeprägte koloniale Ausrichtung des Faches. ${ }^{19}$ Saids Zurückhaltung ist hier also zu revidieren.

In den muslimischen Ländern gab es die Auseinandersetzung mit orientalistischen bzw. islamwissenschaftlichen Forschungen lange bevor das Buch Orientalism im Jahre 1978 erschien. In allen politischen Lagern hatte man sich mit diesem Phänomen befasst. Die Linken, die Nationalisten, die Islamisten und sogar die liberalen Kräfte beschäftigten sich im Rahmen ihrer Auseinandersetzung mit den sozialpolitischen Missständen ihrer Gesellschaften intensiv mit Kolonialismus, Imperialismus und deren ,Wegbereiter' und ,Gehilfen', nämlich den Orientalisten. Im ,Orient' bzw. in weiten Teilen Afrikas und Asiens existierte zwar nicht ausschließlich ein negatives Bild vom Westen, diese Bewertung überwog aber, nicht zuletzt, weil viele politische Kräfte aus der Instrumentalisierung des Westens als ,Alleinschuldigen ' für die herrschenden Missstände in ihren Gesellschaften politisches Kapital schlagen und von ihrer eigenen Verantwortung ablenken wollten. Davon zu unterscheiden sind aber intellektuell herausragende Arbeiten und berechtigte Kritiken, welche in der Islamwissenschaft, wenn überhaupt, dann nur eine marginale Rolle spiel(t)en. Die zentrale Kritik war, dass sich die Orientalist/innen nicht aus rein wissenschaftlichem Interesse mit dem Islam und den Muslimen befassten; sie täten es vielmehr im Dienste einer hegemonialen Politik des Westens gegenüber den muslimischen Ländern. Kritik an der Orientalistik also gab es auch schon vor dem Erscheinen von Saids Werk; und die Orientalisten waren sich dessen ebenfalls bewusst und daran gewöhnt, ${ }^{20}$ ohne sie jedoch weiter zu beachten.

Mit Saids Orientalism wurden dieselben Anschuldigungen nun plötzlich, jedoch viel prägnanter formuliert, in einer Weltsprache und von einem wissenschaftlich anerkannten Fachmann vorgetragen, der mit der abendländischen Geistesgeschichte bestens vertraut war und sich in seiner Argumentation auf die neusten Wissenschaftstheorien wie die von Foucault berief. Saids Arbeit erzeugte in den akademischen und insbesondere in den orientalistischen Kreisen einen Schockeffekt und hat ,dazu beigetragen, die Ideologie der europäischen (vor allem der anglofranzösischen) Orientalistik im 19. und 20. Jahrhundert und ihre Verwurzelung in den politischen und wirtschaftlichen Zielen des damaligen Europa besser zu erfassen. “21 Dieser Schockeffekt führte in geringem Maße auch dazu, dass sich die Orientalist/innen kritischer als bisher mit ihrer eigenen Vergangenheit beschäftigten. Man hatte sich zwar schon im 19. Jahrhundert, aber vor

19 Vgl. R. Loimeier: Edward Said und der deutschsprachige Orientalismus, S. 63-65.

20 Vgl. Reinhard Schulze: „Orientalistik und Orientalismus“, in: Werner Ende/Udo Steinbach (Hg.), Der Islam in der Gegenwart, 5. Aufl., München: C.H. Beck 2005, S. 755-767, hier S. 761-763; vgl. auch Ekkehard Rudolph: Westliche Islamwissenschaft im Spiegel muslimischer Kritik. Grundzüge und aktuelle Merkmale einer innerislamischen Diskussion, Berlin: Klaus Schwarz 1991.

21 M. Rodinson: Die Faszination des Islam, S. 13-14. 
allem seit Mitte des 20. Jahrhunderts mit der Geschichte der Orientalistik befasst. $\mathrm{Zu}$ kritischen und gar anklagenden Auseinandersetzungen führte allerdings erst die sogenannte Orientalismusdebatte, in deren Folge sich die Einsicht bei den Orientalist/innen durchsetzte, dass sie womöglich ,nicht so unschuldig sind, wie sie meinen. “22

Auch wenn Said die deutsche Orientalistik in seiner Untersuchung ausklammerte, fühlte diese sich dennoch von den Vorwürfen betroffen. Arbeiten zu Saids Orientalismuskritik wurden veröffentlicht, und gleichzeitig entstanden eine Reihe von Studien über die Entstehungs- und Entwicklungsgeschichte der Orientalistik bzw. der Islamwissenschaft in Deutschland. Als Effekt wurde damit aber auch nun ein Fach, das sich mit der „Kultur und der Geschichte des Vorderen Orients“ beschäftigte, selbst historisiert, und man hinterfragte mit kulturhistorischen Methoden, inwieweit seine Geschichte von dem jeweiligen Zeitgeist und den politischen Umständen beeinflusst war. In neueren Untersuchungen wird z.B. darauf hingewiesen, dass sich die Pioniere der neueren Islamwissenschaft, Martin Hartmann und Carl Heinrich Becker, ausdrücklich dazu bekannten, ,praktische Wissenschaft im Dienste deutscher auswärtiger Interessen zu betreiben. “23 Dass die Paradigmen, mit denen Becker als Gründer der Islamwissenschaft arbeitete, sehr stark von den herrschenden wissenschaftlichen Termini und Ideen geformt wurden, versteht sich ohnehin von selbst. ${ }^{24}$ Zentral für Untersuchungen über Islamwissenschaft ist die Auseinandersetzung mit ihrer Geschichte während des Dritten Reiches. Auch hier bestätigt sich die Vermutung, dass die Islamforschung institutionell, personell und auch schwerpunktmäßig von der zeitgenössischen politischen Lage geprägt war. ${ }^{25}$

Selbst die These Reinhard Schulzes über die ,,islamische Aufklärung“ des 18. Jahrhunderts, die zu der lebhaftesten Debatte innerhalb der deutschen Islamwissenschaft der letzten Jahrzehnte und zu einer erstaunlich großen Polarisierung unter den Fachkolleg/innen geführt hat, kann als eine Reaktion auf Saids Generalkritik gelesen werden. Indem die europäische Historiographie das 18. „,christliche“ Jahrhundert der islamischen Geschichte mit Attributen wie „Stagnation“, „Niedergang“, ,Unterdrückung“, „Geistlosigkeit“ und „Imitation“ beschreibe, so Schulze, wolle man den Muslimen jener Epoche jegliches Bemühen um Aufklärung und geistige Erneuerung absprechen. Schulze sieht zwar ebenfalls die von Said angeregte Orientalismuskritik als einen Beitrag zur „Dekomposition“ des westlichen Bildes vom Orient an, ohne sie weiter für hilfreich zu halten, um den Okzident und seine „,machtvolle historische Identität“ zu entzaubern. Letztendlich pflichtet er mit seiner Schlussfolgerung jedoch Said bei: „dass der ,Westen“

22 Ebd., S. 15.

23 S. Mangold: Eine „,weltbürgerliche Wissenschaft“, S. 294.

24 Vgl. A. Haridi: Das Paradigma der ,islamischen Zivilisation“, S. 11.

25 Vgl. E. Ellinger: Deutsche Orientalistik zur Zeit des Nationalsozialismus, S. 420. 
sich den ,Orient" historisch geschaffen und zu eigen gemacht hat und nun über das ,Material “ verfügt, der Geschichtskritik Form und Inhalt zu verleihen.“26

Die Orientalismuskritik richtet sich zwar auf die zu Recht kritisierte koloniale Vergangenheit des Faches - vor allem in seiner französischen und britischen Tradition. Doch Orientalisierungen gehören nicht allein der Vergangenheit an. Orientalisierungen spielen - auch heute noch und auch in ihrer deutschen Variante - eine nicht zu unterschätzende Rolle, denn ,gerade in Krisenphasen erheben sich nämlich alte orientalistische Konzeptionen wie Zombies aus ihren Gräbern und werden Teil neoorientalistischer Entwürfe, die, wie Samuel Huntingtons Konzept eines ,Clash of Civilizations', den Islam und die Muslime erneut als den Inbegriff des Bösen darstellen. ‘27

Trotz kontrovers geführter Diskussionen über die islamwissenschaftliche Methodik als Folge der Orientalismuskritik blieb ein Paradigma in der Islamwissenschaft unbestritten, nämlich dass ohne ausreichende philologische Ausbildung insbesondere in der arabischen Sprache oder - je nach Schwerpunkt - in anderen afrikanischen, asiatischen Sprachen kaum eine qualifizierte Aussage in Bezug auf den Islam oder die Muslime getroffen werden könne, auch, oder gerade, wenn es sich um aktuelle Themen wie etwa ,muslimische Extremisten" handele. Das allerdings schließt natürlich die entgegengesetzte Aussage nicht aus, dass man nämlich trotz ausreichender sprachlicher Ausbildung Polemik betreiben und offen Orientalisierungen nachhängen kann. Gerade davon legt ja die Geschichte der Islamwissenschaft Zeugnis ab. Aber wissenschaftliche Aussagen über Islambezogene Themen ohne entsprechende Sprachkompetenz bleiben zumindest fragwürdig. Abgesehen von diesem gemeinsamen Nenner zeichnen sich in den gegenwärtigen Islamforschungen zwei Tendenzen ab: ${ }^{28}$ Die eine Richtung sieht die Philologie nicht nur als ein Werkzeug islamwissenschaftlicher Forschung, sondern auch als deren einzigen Forschungsrahmen. Sie vertritt die Meinung, dass man nur durch eine philologische Herangehensweise zum einen zu einer ,objektiv' kritischen Beurteilung der muslimischen Textquellen gelangen und zum anderen die Eigenständigkeit des Faches bewahren könne. Diese Schule betont nicht nur die Wichtigkeit der sprachlichen Kompetenz, die auch ihre Gegner/innen an sich nicht bestreiten, sie lehnt darüber hinaus vehement die Anwendung vor allem sozialwissenschaftlicher Methoden in der Islamwissenschaft ab. Somit sieht sie ihre Aufgabe darin, ,,die umsichtige und zielstrebige Herauslösung des Faches aus der [...] Umklammerung durch sozialwissenschaftliche Denkmuster, die auf westliche Verhältnisse ausgerichtet sind und zu Unrecht

26 Vgl. Reinhard Schulze: „Das islamische achtzehnte Jahrhundert. Versuch einer historiographischen Kritik“, in: Die Welt des Islams 30 (1990), S. 140-159, hier S. 147.

27 R. Loimeier: Edward Said und der deutschsprachige Orientalismus, S. 73.

28 R. Schulze: Orientalistik und Orientalismus, S. 767. 
universale Geltung beanspruchen“, ${ }^{29}$ zu betreiben. Die andere Deutungsrichtung sieht zwar ein, dass man in den islamwissenschaftlichen Forschungen ohne philologische Fähigkeit nicht weiter kommt, will aber gegenüber anderen geistes- und sozialwissenschaftlichen Erkenntnissen, Ideen und Methoden offen sein.

Die Frage, welche dieser beiden Richtungen sich unter Umständen durchsetzen wird, kann noch nicht beantwortet werden. Die Diskussionen haben auf jeden Fall der Islamwissenschaft gut getan und zu ihrer Vitalität beigetragen. Nicht zu leugnen ist auch, dass in jüngster Zeit zahlreiche islamwissenschaftliche Arbeiten entstanden sind, die sowohl thematisch als auch methodisch nicht der Philologie zuzuordnen sind.

\section{Das Verschwinden des ,Fremden“}

Trotz einer bewegten Geschichte der wissenschaftlichen Beschäftigung mit dem Islam und ungeachtet aller Auseinandersetzungen über die Methoden und Theorien bezüglich der Islamforschung sind einige Konstanten in den bisherigen islamwissenschaftlichen Arbeiten zu beobachten. Eine erste ist der Gegenstand der Untersuchung, nämlich der Islam oder die Muslime, ganz gleich, ob hierbei die Kultur(en) oder Geschichte(n) oder Menschen oder Sprachen der ,islamischen“ Welt im Mittelpunkt stehen. Ob angesichts der unbestrittenen kulturellen Vielfalt in der islamischen Welt und angesichts der unterschiedlichen Forschungsschwerpunkte innerhalb der Disziplin die Bezeichnung, ,Islamwissenschaft“ im Singular für das universitäre Fach berechtigt und zeitgemäß ist, wurde bereits thematisiert und dabei für den Plural „Islamwissenschaften“ plädiert, ${ }^{30}$ was sich jedoch bisher noch nicht durchgesetzt hat.

Eine weitere Konstante ist die Annahme, dass der Islam und die Muslime als Gegenstand des Faches etwas ,Fremdes“ darstellen. Als Synonym zu ,fremd“ wird auch das Wort ,anders` gebraucht. Während ich im Folgenden den Gebrauch des Begriffes ,fremd“ im Zusammenhang mit dem Islam und den Muslimen als hierarchisierend und wirklichkeitsfern in Frage stelle, verstehe ich die Bezeichnung ,anders“ nicht im Sinne des ,Fremden“, sondern als Ausdruck gesellschaftlicher Vielfalt und individueller Differenzen. Die Annahme der früheren Islamforscher/innen, dass es sich bei dem Islam oder den Muslimen um etwas ,Fremdes ' handelt, mag im Rahmen der damals herrschenden Denkmuster nachvollziehbar erscheinen. Die vorherrschenden biologistischen naturwissenschaftli-

29 Tilman Nagel: „Die Ebenbürtigkeit des Fremden - Über die Aufgabe arabistischer Lehre und Forschung in der Gegenwart“, in: ZDMG 148 (1998), S. 367-378, hier S. 377.

30 Vgl. Ludwig Ammann: „Islamwissenschaften“, in: Klaus E. Müller (Hg.), Phänomen Kultur. Perspektiven und Aufgaben der Kulturwissenschaften, Bielefeld: transcript 2003, S. 71-96; siehe auch seinen Beitrag „Islamwissenschaften. Ein Fächer von Fächern im Wettbewerb um Mittel und Macht“ in diesem Band. 
chen, kultur- und sprachwissenschaftlichen Theorien, von denen auch die Islamwissenschaftler/innen beeinflusst waren, gingen einst von fixen menschlichen Kategorien aus. Auch Becker, der Begründer der deutschen Islamwissenschaft, sprach von „Rassenbeschaffenheit wie Arier, Semiten und Neger“ oder vom „Geist“ des „Ostens“ und „Europas“ oder sogar von „,rassenpsychologischen Tatsachen“. ${ }^{31}$ So hat man sich über viele Jahrzehnte im Rahmen des Faches mit einer Religion, Kulturtradition und mit Sprachen und offensichtlich mit ,Rassen“ beschäftigt, die der eigenen Gesellschaft, Religion, Kultur, Sprache und ,Rasse“ fern lagen und so dem ,Eigenen“ ,fremd“ waren. Dass man das ,Islamische“ als ,fremd“ ansah, lag nicht nur an der Unkenntnis der heutigen Kulturtheorien, die inzwischen von einer Hybridität ${ }^{32}$ nicht nur der menschlichen ,Rassen“, sondern auch der menschlichen Kulturen ausgehen. Es mag auch daran gelegen haben, dass es noch keine nennenswerte Einwanderung von Muslimen in die westlichen Länder gab. Nun hat sich aber die Welt in den letzten Jahrzehnten stark verändert: Globalisierung, Migration, das Internetzeitalter sind nur einige Stichwörter, um die heutige Zeit zu charakterisieren. Durch die Globalisierung haben sich Individuen, Gesellschaften und Staaten immer mehr miteinander verflochten. Gleichzeitig haben die Globalisierung und Einwanderung dazu geführt, dass die deutsche Gesellschaft in den letzten Jahrzehnten immer ,bunter' geworden ist. Menschen mit einem islamisch-kulturellen Hintergrund bilden inzwischen einen festen Bestandteil der deutschen Gesellschaft. In Deutschland leben nach Schätzungen etwa 3,5 Mio. Muslime. Von den Muslimen deutscher Staatsangehörigkeit sind ungefähr 80.000 deutschstämmig. Hinzu kommen weit mehr als 200.000 in den letzten Jahren eingebürgerte Muslime. Eine ähnliche Situation wie in Deutschland findet sich in Frankreich, Spanien, dem Vereinigten Königreich, den Niederlanden, Belgien und Österreich. Insgesamt leben etwa 15 bis 16 Millionen Muslime in der Europäischen Union. Der Islam stellt die größte Minderheitenreligion in Europa dar. „Es gibt im protestantischen Nordeuropa mittlerweile mehr Muslime als Katholiken, sowie mehr Muslime als Protestanten im katholischen Südeuropa. “33 Die türkischen Gemüse- und Dönerläden, die Moscheen an dieser und jener Ecke der Stadt, die muslimischen Studierenden und Mitarbeiter/innen an den Universitäten und Forschungsinstituten und einige Abgeordnete in den Landesparlamenten und sogar im Bundestag sind heute Teil der vielfältigen deutschen Gesellschaft. Diese ,Buntheit' beobachtet man ebenfalls in den islamwissenschaftlichen Seminaren. Fast alle Lektorinnen und Lektoren und

31 Carl Heinrich Becker: Islamstudien. Vom Werden und Wesen der islamischen Welt, Hildesheim: Georg Olms Verlagsbuchhandlung 1967, Bd. 1, S. 2, 247.

$32 \mathrm{Zu}$ dem Begriff Hybridität und seinen historischen Bedeutungsschichten vgl. Kien Nghi Ha: Hype um Hybridität. Kultureller Differenzkonsum und postmoderne Verwertungstechniken im Spätkapitalismus, Bielefeld: transcript 2005.

33 Iytte Klausen: „Europas neue muslimische Elite“, in: Aus Politik und Zeitgeschichte 20 (2005), S. 15-22, hier S. 17. 
einige wenige Dozent/innen haben einen kulturislamischen Hintergrund. In manchen Großstädten werden die islamwissenschaftlichen Kurse fast zur Hälfte von Studierenden mit muslimischem Hintergrund besucht - und viele von ihnen sind Deutsche.

Angesichts dieser Gesellschaftswirklichkeit kann der Islam kaum mehr als etwas ,Exotisches“ und ,Fremdes“ betrachtet werden, er gehört mittlerweile zum deutschen Alltag. Somit beschäftigt sich die Islamwissenschaft nicht mehr mit Themen, die ausschließlich in anderen Regionen zu verorten sind, ganz gleich, ob die Untersuchungsgegenstände historischer, philologischer oder rechtlicher Natur sind; von diesen Themen ist die Weltsicht bzw. die Lebensvorstellung eines Teils der deutschen Gesellschaft geprägt. Hält man sich an die Dichotomie des ,Eigenen“ und des ,Fremden“, so führt sie allein in den orientalischen Seminaren zu einer reichlich bizarren Situation: Dort sitzen Studierende mit einem islamischen Hintergrund und bekommen von - nach der gängigen Kategorisierung Islam-/Orient-fremden Professor/innen ihre ,eigene‘ Geschichte und Kultur als etwas ,Fremdes‘ unterrichtet. Noch grotesker und fast schizophren erscheint es, wenn die Dozierenden selbst islamischer bzw. orientalischer Herkunft sind. Dann würden sowohl die Lehrenden als auch die Studierenden das ,Eigene“ als etwas ,Fremdes' diskutieren.

Der Islamwissenschaft fällt aber noch immer schwer, sich von der traditionellen Dichotomie des ,Eigenen“ und des ,Fremden“ zu verabschieden. Tilman Nagel, ein bekennender Arabist, hält in seiner programmatischen Rede an der Beschreibung des ,Islamischen“ als etwas ,Fremdes“ vehement fest und spricht von der „Illusion eines Verschwindens des Fremden“. Nagel will dem ,Anderen“ gegenüber Respekt, Achtung und „Ebenbürtigkeit“ erweisen, indem er es als ,Fremdes' anzusehen sucht. ${ }^{34}$ Aber auch Marco Schöller, der vom traditionell gepflegten, rein philologischen Forschungsansatz wegkommen will und für die Öffnung der islamwissenschaftlichen Methodik eintritt, kann sich nicht so recht von der Dichotomie des ,Eigenen“ und des ,Fremden“ verabschieden. Im Sinne der Hermeneutik spricht er von einem Zwischenstadium der ,Fremdheit und Vertrautheit“ und urteilt über die Arbeiten ,,anderer“, „,islamisch“ oder „orientalisch“ geprägter Wissenschaftler/innen nach der Annahme, dass sie „nicht europäische“ und „aus islamischen Ländern stammende“ Wissenschaftler/innen sind. Als ob sie nicht wie die ,europäischen“ Forscher/innen möglichst ,objektiv“ arbeiten könnten, sondern „,bei ihrer Erforschung und Deutung der islamischen Kultur oft von der Vorstellung geleitet [sind], grundlegende Elemente des Islam in die Sphäre des Rationalismus ,heimholen` zu müssen, einerseits um dadurch die islamische Kultur als der europäischen ebenbürtig zu kennzeichnen, andererseits

34 T. Nagel: Die Ebenbürtigkeit des Fremden, S. 371. 
um sie als zukunftsträchtig im Sinn westlich-aufklärerischer Kriterien darzustellen. “35

Hier geht es um die Frage, ob angesichts der heutigen Lebenswirklichkeiten in der deutschen Gesellschaft die pauschale Bezeichnung des Islam und der Muslime als etwas ,Fremdes“ haltbar ist. Nach den einschlägigen etymologischen Wörterbüchern beschreibt das ,Fremde“ das, was dem eigenen Land oder Volk nicht angehört, sondern von anderer Herkunft ist; so spricht man von „fremden Arbeitskräften im Land“. ,Fremd“ ist das, was unbekannt und nicht vertraut ist; so spricht man vom „Leben mit fremden Menschen“. Der oder die ,Fremde“ ist jemand, der aus einer anderen Gegend, einem anderen Land stammt, der an einem Ort fremd ist, an dem Ort nicht wohnt; und so sagt man: „Ein Fremder hat es hier schwer, heimisch zu werden“ “. ${ }^{36}$ Ist der Islam oder sind die Muslime in diesem Sinne ,fremd'?

Der Versuch, zum Forschungsgegenstand möglichst ,Distanz ${ }^{\star} \mathrm{zu}$ bewahren, ist eine alte und gute wissenschaftliche Sitte; diese erreicht man aber nicht, indem man seinen Forschungsgegenstand als etwas ,Fremdes 'bezeichnet. Nach etlichen Jahren Beschäftigung mit der islamischen Text- und Kulturtradition ist sie für Islamforschende eher vertraut und bekannt und sogar manchmal vertrauter und bekannter als womöglich für viele Muslime. Einige wollen mit der Bezeichnung des ,Islamischen“ als ,Fremden“ vielmehr die „Einzigartigkeit“ des ,Fremden“ und die „Unvergleichbarkeit“ des ,Islamischen“ mit dem ,Eigenen“ zum Ausdruck bringen ${ }^{37}$ - ,eine Aussage, die uns in ihrer Weltsicht auf kulturhistorische Interpretationen des 19. Jahrhunderts verweist.“38

Indem man den Begriff des ,Fremden“ dichotom zum Begriff des ,Eigenen“ verwendet, hebt man das ,Eigene“ gegenüber dem ,Fremden“ ab. Das ,Eigene“ ist das Vertraute, das Bekannte, das man besitzt, über das man verfügt. Und das ,Fremde“ ist das Unbekannte, das das ,Eigene“ potenziell gefährdet und bedroht. Das ,Fremde' soll daher auch möglichst fern und ergo ,fremd' bleiben. Das ,Fremde“ ist ,etwas, das beobachtbar bleiben, aber mich nicht sehen soll, etwas, das ich mir handhabbar machen könnte und das dennoch keinen Einfluss auf mich ausüben darf.“39 Damit herrscht zwischen mir und dem ,Fremden“ ein ,vertikales“ Verhältnis, in dem ich die Grenzen zwischen mir und dem ,Fremden` bestimme. In diesem Bezugssystem bin ich der Referenzpunkt, von dem ausgehend definiert wird, was ,eigen“ und was ,fremd“ ist. Im Gegensatz zu dem Begriff des

35 Marco Schöller: Methode und Wahrheit in der Islamwissenschaft. Prolegomena, Wiesbaden: Harrassowitz 2000, S. 3, 109.

36 Definitionen und Beispiele übernommen aus: DUDEN, Das große Wörterbuch der deutschen Sprache, 3. Aufl., Mannheim u.a.: DUDEN 1999.

37 Vgl. T. Nagel: Die Ebenbürtigkeit des Fremden, S. 376.

38 R. Loimeier: Edward Said und der deutschsprachige Orientalismus, S. 73.

39 René Reinshagen: „Soziologisches Denken des Fremden“, in: Jennifer Wasmuth (Hg.), Zwischen Fremd- und Feindbildern. Interdisziplinäre Beiträge zu Rassismus und Fremdenfeindlichkeit, Münster: LIT 2000, S. 162-197, hier S. 170. 
,Fremden“ stellt der Begriff des ,Anderen“ ein ,horizontales‘ Verhältnis dar. Ein ,Anderer" ist per Definition ,anders‘ als ich, wie ich auch für ihn. Er kann mich als ,anders` bezeichnen, so wie ich ihn. Also sind wir ebenbürtig. Wir unterscheiden uns zwar, sind ,aber nicht grundlegend voneinander verschieden“. Der ,Andere“ empfindet zu mir keine trennende Grenze, sondern kulturelle Nähe. „Im Bild vom ,Anderen“ ist so der ,Andere “ immer schon im Bereich des ,Ichs“ und dort ist er vertraut". Das ,Fremde“ assoziiert jedoch das ,Unvertraute“, das ,Unbekannte“ und das ,Unvergleichbare‘. Das Bild des ,Anderen“ lebt von „symmetrischer Kommunikation“, von „kultureller Nähe“ und von „Reziprozität“, während dem Bild des ,Fremden“ die „Asymmetrie“, „fehlende Reziprozität“" und „kulturelle Unvergleichbarkeit“ angeheftet ist. ${ }^{40}$ „Fremdes ist nicht Anders, sondern eine Steigerung des Anderen, da es über die bloße Differenz des Andersseins hinausgeht. “ ${ }^{41}$

Ist es angesichts der veränderten europäischen bzw. deutschen Gesellschaftswirklichkeit nicht an der Zeit, sich als Islamwissenschaftler/in ernsthaft die Frage zu stellen, ob es sich bei dem Untersuchungsgegenstand tatsächlich um etwas ,Fremdes“ handelt oder um etwas ,Anderes', das einem ,fremd“ erscheint, „weil ich dessen Andersheit kaum als Erfahrung zulasse.“42 Als Islamwissenschaftler/in den Islam als ,fremd“ zu bezeichnen, ist im Sinne von ,Unbekanntem ‘ paradox und führt im Sinne von ,Unvergleichbarem‘ zu einer asymmetrischen Kommunikation. In beiden Fällen ist es obendrein realitätsfern, denn die ,Fremdheit‘ des Islam ist schon längst obsolet.

\section{Die Welt nach dem 11. September 2001}

Man mag unterschiedlicher Meinung darüber sein, ob die Ereignisse des 11. Septembers 2001 tatsächlich eine Wende in der Weltgeschichte eingeleitet haben oder nicht. Tatsache ist aber, dass diesen Ereignissen in der Weltpolitik und damit in der Öffentlichkeit ein großes Gewicht beigemessen wurde. Unzählige Titel von Büchern, Beiträgen und Dokumentarfilmen wurden mit dem Zusatz „,nach dem 11. September“ gekennzeichnet und suggerier(t)en eine Welt, die nicht mehr so ist wie vor diesem Datum: „Die Welt nach dem 11. September“, „Islamische Welt nach dem 11. September“, „Religion nach dem 11. September“, „Menschenrechte nach dem 11. September“, „Zentralasien nach dem 11. September“, „Digitale Technologien nach dem 11. September“, etc. Viele welt- und regionalpolitische Entscheidungen - rechtmäßig oder unrechtmäßig - und viele folgenreiche Aktionen bzw. Reaktionen - maßvoll oder maßlos - wurden mit den Er-

40 Vgl. ebd., S. 171-173.

41 Korbinian Spann: Der, Die, Das Fremde. Juden und jüdische Religion als Paradigma einer Philosophie des Fremden, Berlin: LIT 2006, S. 16.

42 Vgl. R. Reinshagen: Soziologisches Denken des Fremden, S. 191. 
eignissen des 11. Septembers 2001 gerechtfertigt. Auch die Islamwissenschaft musste und muss noch immer diesen Geschehnissen und deren Folgen Rechnung tragen. Genau diese Ereignisse nimmt Martin Kramer zum Anlass und rechnet in seiner Studie über die US-amerikanischen Nahoststudien mit den Islamwissenschaftler/innen des Landes ab. Er wirft ihnen kollektives Versagen vor, denn sie hätten insbesondere durch den Einfluss der Orientalismuskritik realitätsferne Forschungsansätze betrieben, die muslimischen Zivilgesellschaften und die islamischen Reforminitiativen herbeigeredet, so dass sie die herannahenden islamistischen Gefahren nicht mehr sehen konnten. ${ }^{43}$ Kramers Kritik hört sich so an, als ob man denjenigen deutschen Sozialwissenschaftler/innen, die Kapitalismuskritik betrieben, vorhalten müsste, dass sie wegen ihrer Kapitalismuskritik nicht in der Lage gewesen seien, die aus der linken Bewegung hervorgehende Gefahr in Form der RAF richtig einzuschätzen und rechtzeitig herannahen zu sehen; oder als ob man von den Kriminologen erwarten müsste, die Aufgabe der Geheimdienstler oder der Polizei wahrzunehmen.

Unbestritten ist auf jeden Fall, dass die Ereignisse des 11. Septembers 2001 die Islamwissenschaft verstärkt ins Blickfeld der Politik und der Öffentlichkeit gerückt haben. Eine Wissenschaftsdisziplin, die traditionell so angelegt ist, dass sie sich mit Texten und historischen und kulturellen Fragen befasst, die der westlichen Realität und Gegenwart angeblich sehr weit fern liegen, wurde auf einmal mit Fragen und Themen konfrontiert, wie sie für die hiesige Gesellschaft nicht aktueller und brisanter sein konnten. Dabei fungieren die drei Begriffe ,Islam', ,Fundamentalismus' und ,Terrorismus' als Bindeglieder dieses neuen Diskurses. Es versteht sich von selbst, dass die Islamwissenschaft als das Fach, das sich mit dem Islam auseinandersetzt, alle fragenden Blicke auf sich zieht.

So ist es nicht mehr zu übersehen, dass die Islamwissenschaft, die in ihrer Vergangenheit eher im Dienste der deutschen Außenpolitik, missionarischer Ambitionen oder theologischer Selbstfindung eingesetzt wurde, nun bei innenpolitischen Fragen und Themen gefragt ist. Damit werden auch andere Erwartungen und Berufsfelder mit dem Fach in Verbindung gebracht. Gleichzeitig hat dies zur ,Entfremdung' des ,Fremden“ beigetragen. So paradox es auch klingen mag, haben die Ereignisse des 11. Septembers einerseits zur abermaligen Dämonisierung der Menschen muslimischer Herkunft in den westlichen Gesellschaften geführt, andererseits trugen sie dazu bei, dass dem ,Fremden ' Zugang in das ,Eigene ' gewährt wurde. Bei der Bekämpfung terroristischer Bedrohungen sitzen inzwischen viele Fachleute mit einem islamischen Hintergrund in wichtigen staatlichen Organen, wie im Bundesnachrichtendienst, im Landeskriminalamt und beim Bundesverfassungsschutz. Damit hat sich auch im Bezug auf den ,Absatzmarkt' für Absolvent/innen von islamwissenschaftlichen Seminaren eine weitere Beschäfti-

43 Martin Kramer: Ivory Towers on Sand. The Failure of the Middle Eastern Studies in America, Washington: Institute for Near East Policy 2001. 
gungsmöglichkeit eröffnet. Während vorher die meisten Islamwissenschaftler/innen, die keine universitäre Kariere anstrebten, mit dem Gedanken spielten, in den diplomatischen Dienst einzutreten, was viele auch in die Tat umsetzten, wird nun eine beträchtliche Anzahl von ihnen von den im Inland tätigen Diensten angeworben.

Inzwischen stellen tatsächlich der Islam und die Muslime innerdeutsche oder anders ausgedrückt, eigene“ Themen dar. Daher wurde auch im Koalitionsvertrag zwischen der CDU/CSU und der SPD vom November 2005 festgelegt, dass der interreligiöse und interkulturelle Dialog, insbesondere der Dialog mit dem Islam eine „,bedeutende Rolle“ bei der Integrationspolitik, aber auch bei der „Bekämpfung von Rassismus“ spiele. ${ }^{44}$ Dabei sehen die Politiker/innen die Muslime als „einen festen Teil“ der deutschen Gesellschaft an. ${ }^{45}$ Islam-bezogene Fragen beschäftigen tagtäglich die deutsche Politik und Öffentlichkeit: die Integrationsfrage, der Islamunterricht, das Verhältnis zwischen der Scharia und dem deutschen Recht, die Kopftuchdebatte etc. sind nur einige Dauerthemen, von denen sich die gesamtdeutsche Gesellschaft betroffen fühlt. Diese Fragen wurden schon vor dem 11. September 2001 diskutiert, sie haben aber danach viel stärker an Brisanz gewonnen. Bei der Beantwortung solcher Fragen sind mehr Politikwissenschaftler/innen, Soziolog/innen, Religionswissenschaftler/innen und die so genannten Islamexpert/innen aus dem journalistischen Genre öffentlich präsent als Islamwissenschaftler/innen. Ohne Zweifel kann ein Islamwissenschaftler oder eine Islamwissenschaftlerin nicht in allen Bereichen des Islam und schon gar nicht für alle Themen, die mit dem Islam im weitesten Sinne zu tun haben, Kompetenzen beanspruchen, und es muss sich auch nicht jeder Islamwissenschaftler bzw. jede Islamwissenschaftlerin für aktuelle Fragestellungen interessieren. Indem sich die Islamwissenschaft aber anderen Forschungsansätzen - seien es politik- sozialoder kulturwissenschaftliche - öffnet, kann sie durch ihre philologischen Kompetenzen einerseits qualifizierte Antworten anbieten und darf andererseits diese öffentlichkeitswirksamen Felder nicht den anderen Fächern überlassen und die Chance auf eine kritische Beurteilung und Richtigstellung der an sie herangetragenen politischen Fragen und Statements verspielen.

Aber abgesehen von diesen ,marktwirtschaftlichen ' Kalkulationen sind die Islamwissenschaftler/innen angesichts aktueller und gesellschaftlich brisanter Themen dazu aufgerufen, sich zu positionieren und ihre fachliche Kompetenz in die Diskussionen einzubringen. Islamwissenschaftler/innen sind letztlich diejeni-

44 Koalitionsvertrag vom 11.11.2005, a.a.O., S. 117f., zitiert nach Heiner Bielefeldt: Menschenrechte in der Einwanderungsgesellschaft. Plädoyer für einen aufgeklärten Multikulturalismus, Bielefeld: transcript 2007, S. 119.

45 So Wolfgang Schäuble im Interview mit dem SPIEGEL: „Im Land leben rund drei Millionen Muslime, aber wir haben keine Beziehung zur vielfältigen muslimischen Gemeinschaft, obwohl sie ein fester Teil unserer Gesellschaft ist", in: SPIEGEL 38 (18.09.06), S. 85f., zitiert nach H. Bielefeldt: Menschenrechte, S. 119. 
gen, die beide Kompetenzen in sich vereinen: Sie sind einerseits mit der islamischen Text- und Kulturtradition vertraut, und sie kennen sich andererseits mit den gesellschaftlichen und kulturellen Gegebenheiten im Westen aus - oder sollten dies zumindest tun. Wenn nicht sie zu den insbesondere nach dem 11. September 2001 verstärkt thematisierten Fragen wie ,Islamunterricht in den Schulen', ,Kopftuch“ oder ,Scharia' gefragt werden sollen, wer sonst? Es ist schwierig, sich der Verantwortung zu entziehen und zu behaupten, dass man sich als ,westliche/r" Wissenschaftler/in nicht in ,theologische" oder ,innermuslimische" Diskussionen einmischen wolle. Denn die Einteilung in westliche Wissenschaftler/innen und islamische Fragestellungen ist nicht mehr aufrechtzuerhalten. Diese Fragen und Probleme betreffen inzwischen nicht nur die Muslime, sondern die gesamtdeutsche Gesellschaft. Des Weiteren trifft man mit islamwissenschaftlichen Studien oft auch theologisch relevante Aussagen, ob man es beabsichtigt oder nicht. Indem man in einer wissenschaftlichen Untersuchung die Anfänge der islamischen Jurisprudenz nicht, wie in der traditionellen muslimischen Vorstellung, in der Zeit des Propheten, sondern erst im 8. Jahrhundert verortet, ${ }^{46}$ und indem man dem Islam Rassismus im spezifisch europäischen Sinne abspricht ${ }^{47}$ und seiner Geschichte eine bessere Bilanz des „,gelebten Pluralismus“ und der ,angewandten Toleranz“ im Vergleich zu „Europa vom Mittelalter bis in die Moderne“ ausstellt, ${ }^{48}$ oder indem man anhand verschiedener Methoden der Ḥadīt-Kritik ${ }^{49}$ die Glaubwürdigkeit vieler Überlieferungen in Frage stellt, trifft man theologisch wichtige und politisch richtungweisende Aussagen, die für die aktuellen Debatten wie die Kopftuch- oder die Karikaturenfrage von großer Bedeutung sind. Eine komplexfreie, selbstreflektierte und offene Diskussionskultur kann zum Abbau vieler Vorurteile auf allen Seiten führen und eine ,ebenbürtige' Begegnung mit dem Islam und den Muslimen fördern.

\section{Fazit}

Die Tradition der ,Iğtihād'-Praxis in der Islamwissenschaft kann und soll weiter beibehalten werden, indem man sich den neuen Anforderungen und Gegebenhei-

46 Harald Motzki: Die Anfänge der islamischen Jurisprudenz. Ihre Entwicklung in Mekka bis zur Mitte des 2./8. Jahrhunderts, Stuttgart: Steiner 1991.

47 Gernot Rotter: Die Stellung des Negers in der islamisch-arabischen Gesellschaft bis zum XVI. Jahrhundert, Bonn: Rheinische Friedrich-Wilhelms-Universität 1966, S. 182-183.

48 Gudrun Krämer: Islam, Menschenrechte und Demokratie: Anmerkungen zu einem schwierigen Verhältnis, Ladenburg: Gottlieb Daimler- und Karl Benz-Stiftung 2003, S. 32.

49 Einen Überblick über den Hadīt-Diskurs liefert der folgende Beitrag: Harald Motzki: „Dating Muslim Traditions: A Survey“, in: Arabica. Journal of Arabic and Islamic Studies 52 (2005), S. 204-253. 
ten öffnet. Ein intellektueller Zeitgeist, der die Orientalismuskritik kaum mehr ignorieren kann, eine Gesellschaftswirklichkeit, in der der Islam nicht mehr pauschal als ,fremd' angesehen werden kann, und ein politisches Zeitalter im Zeichen des 11. Septembers 2001 erfordern andere Ansätze, eine andere Sichtweise und eine andere Sprache bei der Er- und Vermittlung des Islam. Dass islamwissenschaftliches Arbeiten die philologisch kompetente Auseinandersetzung mit der islamischen Text- und Kulturtradition voraussetzt, steht außer Debatte. Es geht jedoch darum, anderen Forschungsmethoden und -ansätzen gegenüber Toleranz zu zeigen und sich der neuen Gesellschaftswirklichkeit und den anderen Wissenschaftserkenntnissen zu öffnen; es geht im Sinne von Habermas darum, dass man sich nicht auf die Verallgemeinerung der eigenen Untersuchungsmethode und der eigenen Untersuchungsergebnisse versteift, ,dass man gerade nicht das davon Abweichende ausgrenzt, dass die Toleranzbereiche unendlich viel größer werden müssen. “50 Und je toleranter Islamwissenschaft betrieben wird, umso weiter dürfte sich das Tor des ,Iğtihād‘ in ihr öffnen.

50 So begründet Habermas seine These, dass „es zu universalistischen Wertorientierungen keine Alternative mehr gibt". Die Aussage gilt jedoch, nach meinem Dafürhalten, genauso für die Kontroverse in der Islamwissenschaft. Vgl. Jürgen Habermas: Die nachholende Revolution, Frankfurt/M: Suhrkamp 1990, S. 153. 


\section{Unterscheiden und Verstehen: Über Nutzen und Missbrauch der Islamwissenschaft ${ }^{1}$}

GUDRUN KRÄMER (BERLIN)

Warum sollten wir uns mit dem Islam beschäftigen, und wie sollten wir dies tun? Die Frage mag auf den ersten Blick leicht erscheinen, stellt uns aber, wie so häufig der Fall, vor erhebliche Probleme. Verglichen mit dem ,Wie' ist die Antwort auf das ,Warum' recht einfach: Kultur ist in Mode gekommen, und das schon seit geraumer Zeit. Nicht nur in den Geisteswissenschaften, sondern auch in den Sozialwissenschaften wird der sogenannte cultural turn intensiv diskutiert. Das gilt im Besonderen für das Fach, in dem ich zuerst ausgebildet wurde und dem ich mich bis heute verbunden fühle: der Geschichtswissenschaft. Der cultural turn hat die Soziologie und die Politikwissenschaft erfasst, in geringerem Ausmaß auch die Wirtschafts- und Rechtswissenschaften. Seine Anziehungskraft hat unter anderem politische Gründe, denn der Zerfall der Sowjetunion und die Verschärfung ethnischer Konflikte in vielen Teilen der Welt haben die Themen ,Kultur' und ,Identität' in den Vordergrund treten lassen. Der Zusammenhang zwischen Politik (und ich möchte gleich hinzufügen, dass ich keine Anhängerin monokausaler Erklärungen bin) und dem Interesse an Kultur und Identität, die ihrerseits sehr unterschiedlich und oft genug unscharf definiert werden, muss nicht zwingend bedeuten, dass dieses Interesse suspekt wäre oder gar illegitim: Politik, Gesellschaft, Recht und Wirtschaft mit größerer Aufmerksamkeit und Sensibilität gegenüber kulturellen Normen und Bestrebungen in den Blick zu nehmen, kann nicht falsch sein. Manches muss allerdings beunruhigen, vor allem, wenn die Beschäftigung mit Kultur geradezu zur Obsession wird. Das gilt zum einen für aggressive Strategien der Macht- und Selbstbehauptung unter dem Vorzeichen der Identitätspolitik, zum anderen für die Rede von einem möglichen, wenn nicht gar unausweichlichen ,Kampf der Kulturen“. Gerade sie hätte wohl nie so fruchtbaren Boden und ein so breites Publikum gefunden, hätte es nicht den cultural turn in der Wissenschaft und in dem, was man gemeinhin als das ,wirkliche“ Leben bezeichnet, gegeben.

1 Dieser Beitrag ist die ins Deutsche übersetzte und überarbeitete Version eines Vortrages, den die Verfasserin anlässlich der ISIM Annual Lecture am 15. März 2000 in Utrecht, Niederlande, gehalten hat. 
Der Reiz des cultural turn für den Wissenschaftler ist offensichtlich: Versteht man Kultur nicht als einen eigenständigen Lebensbereich, als abgrenzbares Feld oder gar als eigenes System, das die Literatur, die Musik und die schönen Künste umfasst (,gute' Literatur zumindest und ,ernste‘ Musik), sondern als veränderbare Konfiguration von Wahrnehmungen, Darstellungen und Handlungsweisen, die unser Lebensweise individuell und in der Gemeinschaft mit anderen lenkt und inspiriert, so lässt sich aus der sorgfältigen Untersuchung dieser Konfigurationen viel lernen über ihr Entstehen und Vergehen, ihr komplexes Zusammenspiel, ihre Bedeutung für unterschiedliche Personen in unterschiedlichen Kontexten, ihre Vieldeutigkeit und Widersprüche, ihre Wandlungen über Zeit und Raum. Die Risiken einer solchen Fokussierung auf Kultur - anstelle von sozialer Ordnung, Macht oder dem internationalen politischen System - sind offensichtlich: Allzu leicht tritt an die Stelle eines ökonomischen Reduktionismus, wie ihn nicht so sehr Marx selbst als vielmehr einige seiner schlichteren Anhänger vertreten, ein kultureller Determinismus, der die Wahlmöglichkeiten, Veränderungen und Konflikte innerhalb einer Kultur übergeht oder verleugnet. Die Gefahr besteht vor allem, wenn Kultur als einförmige, zeitlose und allumfassende Größe verstanden wird, die klar unterscheidbare, vollkommen in sich geschlossene und nach außen wasserdicht abgeschlossene Einheiten schafft. Wir können uns allerdings um etwas mehr Anspruch bemühen. Würde etwa die häufig benutzte Analogie zur ,Persönlichkeit‘ ernster genommen (und wir haben viel über ,die deutsche“ oder ,die ägyptische“ Persönlichkeit gehört), ließe sich der reduktionistischen Versuchung schon widerstehen: Keine Persönlichkeit ist vollkommen in sich geschlossen und frei von Widersprüchen, noch entwickelt sie sich in splendid isolation. Um zu wachsen, bedarf sie der äußeren Anregungen. Das Phänomen Kultur muss ernst genommen werden, von Wissenschaftlern wie von Politikern. Kulturalismus dagegen ist eine Falle, die es sorgfältig zu vermeiden gilt.

Am Beispiel der Islamwissenschaft lässt sich dies verdeutlichen: Die Beschäftigung mit dem Islam erfordert die Beschäftigung mit Kultur, Zivilisation und Religion, um die Parameter islamischer Kultur(en) oder Zivilisation(en) bestimmen zu können - unabhängig davon, ob wir diese Begriffe im Singular oder im Plural verwenden. Die Islamwissenschaft untersucht kein abgegrenztes geographisches Gebiet, wie dies Regionalwissenschaften wie etwa die Sinologie, Indologie oder Nordamerikanistik tun, denn der Islam ist global und beschränkt sich nicht auf eine bestimmte Region. Auch wenn dies möglicherweise anstößig klingen mag. Der Islam hat durchaus Zentren und Peripherien, aber der Nahe und Mittlere Osten ist nicht länger sein einziges Zentrum, wenigstens nicht in intellektueller Hinsicht und erst recht nicht in demographischer. Die größte Ähnlichkeit zur Islamwissenschaft weist meines Erachtens die Judaistik auf. Umso bedauerlicher ist es, dass so wenige Studien sich vergleichend mit Entwicklung, Methoden und innerer Organisation dieser beiden Fachrichtungen beschäftigen, wenn es diese Studien denn überhaupt gibt. Man muss nicht Dekonstruktivist 
sein, um ein besonderes Interesse dafür aufzubringen, wie die beiden Fächer Fragen stellen, welchen Fragen sie ausweichen oder welche sie tabuisieren.

\section{Orientalismus - neu betrachtet}

Innerhalb der Islamwissenschaften (dieser Begriff soll hier sehr weit gefasst werden und verschiedene Regionalwissenschaften wie die Turkologie, Iranistik oder Südostasienwissenschaft einschließen, insoweit sie sich auch mit dem Islam bzw. einzelnen Aspekten des Islam beschäftigen) wurden die Gefahren des Kulturalismus - hier bekannt unter dem Signum des ,Orientalismus ‘ - ausführlich diskutiert. Orientalismus ist in der Tat etwas Schlimmes. Es ist unangenehm genug, von Laien immer wieder als ,Islamist“ statt als ,Islamwissenschaftler' bezeichnet zu werden. Immerhin gibt es einen Unterschied zwischen einem politischen Aktivisten, der sich auf den Islam beruft, und dem Forscher, der sich mit dem Phänomen Islam auseinandersetzt. Aber ein Wissenschaftler, der etwas auf sich hält, möchte heutzutage doch eher nicht als ,Orientalist' bezeichnet werden.

Orientalismus ist, wie wir gelernt haben, ein Projekt, das den Islam als eine abgegrenzte, homogene und zeitlose Einheit darstellt oder - wie viele sagen würden - ,konstruiert' bzw. ,repräsentiert'. Aus orientalistischer Sicht konstituiert sich der Islam im Wesentlichen über seine normativen Texte, das heißt den Koran als göttliche Rede und die Sunna als die Tradition des Propheten Muhammad. Muslime sind für den traditionellen Orientalisten allein dadurch hinreichend definiert, dass sie Muslime sind, wobei es wenig Unterschied macht, ob sie in Kuala Lumpur, Kairo oder Karachi leben. Sie sind durch ihre Zugehörigkeit zum Islam determiniert. Das ist natürlich Kulturalismus in Reinkultur. Der Orientalismus geht seinen Kritikern zufolge aber noch weiter: Er ,konstruiert' den Islam als das schlechthin Andere und benutzt ihn als Negativfolie, auf der die Errungenschaften der westlichen Zivilisation, die auf den drei Säulen des frühen Judentums, der griechisch-römischen Antike und des christlichen Glaubens ruhen, in umso hellerem Licht erstrahlen. Im Gegensatz dazu fehlen dem Islam nach orientalistischer Lehre die Idee der Freiheit und der Verantwortung, und zwar sowohl der individuellen als auch der staatsbürgerlichen, es fehlten ihm die Forscherlust und der wissenschaftliche Geist, eine unabhängige Mittelschicht und jegliche Art anerkannter Gemeinschaft mit Ausnahme der umma, der Gemeinschaft der Gläubigen. Folgt man dieser Logik, so ist der Islam nicht viel mehr als ein Mängelpaket. Bryan S. Turner, der, um möglichen Missverständnissen vorzubeugen, diese Sichtweise nicht teilt, sprach von einem „cluster of absences“. Es lohnt sich nicht, die Liste dessen ,was wir haben und was dem Islam fehlt" im Einzelnen durchzugehen, obgleich es nicht schwierig wäre, ein nuancenreicheres Bild zu zeichnen. Hier geht es um Orientalismus und um Orientalismuskritik, die ihrerseits einige Blindstellen aufweist. Ihr zufolge ist der unverbesserliche Orientalist seinerseits durch ein ganzes Bündel an Mängeln und Schwächen gekennzeichnet, 
namentlich einen schockierenden Mangel an Sensibilität. Der Orientalist verfolgt darüber hinaus ein politisches Projekt, das sich damals wie heute mit dem Kolonialismus verbindet und aufgrund seiner kruden Schlichtheit umso machtvoller wirkt. Schlichtheit ist bekanntlich nicht gleichbedeutend mit Unschuld.

Das gilt allerdings ebenso für die Kritik am Orientalismus oder ganz allgemein an denjenigen, die den Islam als ,Außenseiter`studieren. Es wäre eine große Erleichterung und Ermutigung für alle diejenigen, die sich mit dem Islam beschäftigen, wenn das innerhalb und außerhalb der islamischen Welt betriebene Orientalisten-bashing allmählich außer Mode käme. Anstatt anklagend mit dem Finger auf die immer gleichen Wissenschaftler zu zeigen (die meisten von ihnen tot oder hochbetagt), würde es sich lohnen, zur Kenntnis zu nehmen, was sich derzeit auf dem weit gefassten Gebiet der Islamwissenschaft tut, und zwar nicht nur in englischer Sprache. Vieles ruht hier auf strenger Selbstbefragung, die jedem Puritaner oder praktizierendem Sufi Ehre machen würde. Das Dilemma, wie man Kultur ernst nehmen kann, ohne sie als die treibende Kraft der Geschichte darzustellen, wird nicht durch rituelle Anklagen gegen den Orientalismus aufgehoben. Noch wird das Problem dadurch gelöst, dass man alle heiklen Begriffe in Anführungszeichen setzt und also ,Islam“ anstelle von Islam schreibt, ,islamische Kultur' anstelle von islamische Kultur und ,Differenz' anstelle von Differenz, oder immer den Plural benutzt und so konsequent Islame schreibt, oder, um auf der ganz sicheren Seite zu stehen, ,Islame‘. Auch das belässt noch immer die Möglichkeit, dass es doch so etwas geben könnte, das legitimer Weise als Islam bezeichnet wird oder als Kultur oder als Differenz. Und wie kann man überhaupt etwas in den Plural setzen, das es im Singular nicht gibt, zumindest nicht für den Wissenschaftler?

\section{Einheit/Vielfalt}

Um sich vom primitiven Orientalismus zu distanzieren (und das muss natürlich geschehen), erscheint es vielversprechender, der dynamischen und pluralen Natur des Islams mehr Aufmerksamkeit zu schenken - wobei es hierbei keinen Unterschied macht, ob wir den Singular oder den Plural benutzen. Dies entspricht einer erkennbaren Tendenz in den Geistes- und Sozialwissenschaften, stärker auf Akteure denn auf Systeme zu achten und sich auf Handlungsfähigkeit (agency), Praktiken und Prozesse zu konzentrieren, die zwischen den Akteuren auf der einen Seite und Strukturen oder Systemen auf der anderen vermitteln. ,Aushandlung' ist hier das Schlüsselwort, das uns direkt zum Marktplatz führt. Dazu gleich mehr. Wissenschaftler betonen heute die Offenheit historischer Prozesse, die weder linear noch einförmig verlaufen (das Wort ,Kontingenz' ist hier angesagt), und konzentrieren sich auf Kräfte und Bewegungen, die Megatrends wie Industrialisierung, Modernisierung und Globalisierung entgegenstehen. Sie heben innerkulturelle Vielfalt anstelle von Einheitlichkeit hervor, innergesellschaft- 
lichen Konflikt anstelle von Harmonie, Fragmentierung anstelle von Kohärenz. Die Gender Studies haben zu diesem Perspektivwechsel viel beigetragen. Historiker haben von Anthropologen gelernt und umgekehrt. Dekonstruktivisten sprechen gelegentlich von der ,Kakophonie“ des Diskurses bzw. der Diskurse. Für unsere Zwecke sollten wir vielleicht eher von einer ,Polyphonie' muslimischer Stimmen sprechen, denn obgleich sie zahlreich sind, müssen sie das Ohr doch nicht kakophon quälen.

Selbst wenn wir in erster Linie auf Pluralität, Polyphonie und Variation abheben, bleiben doch große Herausforderungen, und zwar auf mehreren Ebenen. Islamwissenschaftler können auf der Pluralität des/r Islam(e) beharren, sie können Anführungszeichen setzen, um ihr Unbehagen gegenüber essentialisierenden Begriffen deutlich zu machen, sie können sogar bestreiten, dass es so etwas wie den Islam, das islamische Recht, die islamische Kunst oder Architektur gibt. Sie können über islamische Geschichtsdiskurse sprechen statt über islamische Geschichte und damit nahe legen, dass Geschichte im Sinne eines realen historischen Geschehens nicht rekonstruiert werden kann, ganz gleich ob in einem islamischen oder einem nicht-islamischen Zusammenhang. Dennoch bleibt die Tatsache, dass für zahllose Muslime der Islam genau das zeitlose, homogene und einzigartige Ganze ist und die Summe aller göttlich bestimmten Normen, Werte und Bestrebungen, die Islamwissenschaftler mit so viel Aufwand dekonstruieren möchten. Es entbehrt nicht der Ironie, dass Islamwissenschaftler gerade mittels der Dekonstruktion den Islam und die Muslime (keine Anführungszeichen) gegenüber jenen Kritikern zu verteidigen suchen, die nicht zwischen den Taliban in Afghanistan, der Islamischen Republik Iran, einem Mullah in Köln und dem Verständnis der prophetischen Lehre durch Muslime in Deutschland oder den Niederlanden zu unterscheiden vermögen. Wie also kann und soll ein Islamwissenschaftler mit den festen Überzeugungen eines gläubigen Muslimen (also nicht einfach irgendeines Muslims) umgehen? Die Antwort kann kaum lauten, diese Überzeugungen als Ausdruck eines falschen Bewusstseins abzutun.

\section{Kultur auf dem Marktplatz}

Ein möglicher Weg, den Anspruch intellektueller Integrität mit der Anerkennung der festen Überzeugungen derjenigen in Einklang zu bringen, die letzten Endes die wichtigsten Partner der Islamwissenschaft sind und nicht das bloße Objekt ihrer Forschung, besteht darin, den Islam als ein Repertoire von Texten, visuellen und anderen Bezügen zu verstehen, die auf verschiedene Weise vermittelt werden können, die aber unter allen Umständen der Interpretation bedürfen, um Wirkung zu erlangen - und dies von Anbeginn der islamischen Geschichte an (ich zögere nicht, den Begriff der islamischen Geschichte zu benutzen). Interpretation wird von denkenden Menschen unternommen, oder um es im aktuellen wissenschaftlichen Jargon auszudrücken: Interpretation beruht auf agency. Es hat 
etwas Befreiendes, von einem Repertoire an Bezügen zu sprechen, die ständig neu interpretiert, definiert und häufig auch umkämpft werden, ohne damit ihre Verbindlichkeit für die Betroffenen zu verlieren. Unter anderem entbindet es die Islamwissenschaft von der Notwendigkeit, zu überaus sensiblen Themen wie etwa der Frage, ob der Koran tatsächlich Gottes Wort ist und Muhammad sein Prophet, Stellung zu beziehen. Wichtig ist, dass muslimische Gläubige sie als solche betrachten und verehren. In Anbetracht der Brisanz dieser Themen ist dies gerade heute ein nicht zu unterschätzender Vorteil.

Einfach gesagt ist es nicht Aufgabe der Islamwissenschaft, für den gläubigen Muslim den Islam zu definieren, seine Grenzen abzustecken und deren Überschreitung zu vermessen. Ungeachtet der Faszination modischer Konzepte wie ausgehandelter Raum, bewegliche Grenzen und vorgestellte Gemeinschaften gibt es Grenzen, die nicht ohne Weiteres verhandelbar sind. Gerade der bereits mehrmals verwandte Begriff des Repertoires ist ja dadurch gekennzeichnet, dass es begrenzt und erschöpfbar ist. Von ausgehandeltem Raum zu sprechen, ist nicht gleichbedeutend mit einem anything goes. Der Islam ist, wie Sayyid Qutb gesagt haben soll, flexibel, aber nicht flüssig. Aufgabe des Islamwissenschaftlers ist es zu klären, wie in einem gegebenen Kontext die normativen Bezüge ausgewählt, benutzt und kombiniert werden - und zwar von wem, zu welchem Zweck und mit welcher Wirkung. Dabei sollte man mit der Metapher des Marktplatzes vorsichtig umgehen: Nicht jedem ist es möglich, die Referenzen, die den eigenen Sichtweisen und Interessen dienen könnten, auf dem freien Markt zu beschaffen. Interessant ist vielmehr heraus zu finden, welche Bezüge bestimmten Personen in bestimmten Situationen verfügbar sind und welche nicht. In vielen Fällen dürften die Wahlmöglichkeiten begrenzter sein, als es dem Wissenschaftler mit seinem breiten Zugang zu Ideen, Quellen und Ressourcen zunächst erscheinen mag.

Zugleich sollte man um einiges vorsichtiger mit der Unterscheidung zwischen inneren und äußeren Sichtweisen sein: Häufig ist diese Trennung nicht so eindeutig wie angenommen. Jedenfalls gibt es keinen Grund, warum ein städtischer Mittelklasseakademiker muslimischen Glaubens Phänomene seiner eigenen Geschichte, Kultur und Gesellschaft grundsätzlich (kompetent und richtig), verstehen' sollte, wohingegen ein städtischer Mittelklasseakademiker mit hinduistischem, christlichem oder sonstigem Hintergrund sie lediglich ,interpretiert ${ }^{\text {` }}$ - andernfalls hätten europäische Mittelalterhistoriker nicht solche methodologischen Probleme, mittelalterliche Geschichte zu verstehen.

\section{Über Differenz und Bescheidenheit}

Wenn es so schwierig ist, Kultur(en) zu ,verstehen', und wenn der Islam so schwer zu fassen ist, unabhängig davon, ob man ihn von innen oder von außen betrachtet, warum machen wir uns dann überhaupt die Mühe? Natürlich gibt es praktische Gründe, dies zu tun: die zunehmende Präsenz von Muslimen in west- 
lichen Gesellschaften, die in ihnen nicht als Migranten oder Besucher leben, sondern als integraler Teil dieser Gesellschaften; der Aufstieg des politischen Islams; die Forderung nach einer Anwendung der Scharia, einer Islamisierung des Wissens usw. Diese praktischen Fragen und Anliegen verbinden sich, wie bekannt, allzu häufig mit einem Gefühl der Bedrohung, die vom Islam ausgeht, oder zumindest mit einem Gefühl der Herausforderung, vor die man gestellt ist. Daneben aber gibt es eine andere Dimension, die wenig oder gar nichts mit Angst und Konfrontation zu tun hat. Sie beruht auf Neugier, sei sie intellektueller oder ganz gewöhnlicher Natur. Neugier setzt Differenz voraus - ein Konzept, das in der Anthropologie und in den Orientwissenschaften so in Verruf geraten ist, dass viele es nicht wagen, das Wort ohne alle Zeichen des Widerwillens auszusprechen. Im schriftlichen Gebrauch lockt einmal mehr das Anführungszeichen. Meine ursprüngliche Motivation, mich mit dem Islam zu beschäftigen, war genau die Annahme, dass er irgendwie anders sei als das Leben, mit dem ich vertraut war. Ich wollte wissen, inwiefern dies der Wahrheit entsprach, ja, ob es überhaupt richtig war. Romantik spielte dabei kaum eine Rolle: Weder faszinierte mich der Orientalismus in der Malerei noch hatte ich das Bedürfnis, als Beduinin mit Beduinen in der Wüste zu leben. Mich interessierte die Möglichkeit, anders zu denken, anders zu leben oder die Gesellschaft in anderer Weise zu organisieren, ohne nun gleich selbst diese andere Denk- und Lebensart zu übernehmen, und ich vermute, dass es vielen unserer Studenten ebenso geht (außer natürlich, sie sind auf der Suche nach ihren Wurzeln).

Wir werden ständig mit Fragen konfrontiert, die nicht, oder wenigstens nicht notwendigerweise, auf einem Gefühl der Distanz oder Überlegenheit beruhen, das so oft mit der Vorstellung von Differenz in Zusammenhang gebracht wird. Wenn Muslime glauben, dass es so etwas wie islamische Werte gibt, welche sind es? Wenn Islamisten eine ,islamische Ordnung ' propagieren, was ist so besonders oder möglicherweise einzigartig an ihr? Sie muss ja nicht, wie viele Islamisten meinen, einzigartig sein, um Aufmerksamkeit zu verdienen. Wenn die Kritiker der Modernisierungstheorie (einer vereinfachten, einlinigen Modernisierungstheorie) die Möglichkeit unterschiedlicher Modernisierungspfade diskutieren und von der Existenz ,multipler Modernen ' ausgehen, die sich nicht auf das westliche Modell beschränken (von dem es wiederum mehrere gibt), worin besteht dann die Vielfalt der Pfade und inwieweit sind sie alle modern? Kann man einen festen Kern des Islams, der sein Wesen und sein Fundament ausmacht, von leichter formbaren Elementen unterscheiden, die sich an die verschiedensten Umstände anpassen können, um den Islam - wie die bekannte Formel lautet - für alle Zeiten und alle Orte geeignet zu machen? Und wie lässt sich dies mit der vertrauten Behauptung vereinbaren, der zu Folge ,Techniken` ohne Beschränkung aus nicht-islamischen Quellen übernommen werden können, wohingegen die islamischen ,Werte ' unter allen Umständen zu bewahren sind? Sicher ist die Funktion derartiger Annahmen und Überzeugungen zu analysieren, darüber hinaus interessieren jedoch auch die Inhalte. Menschenrechte, gute Regierungsfüh- 
rung oder soziale Gerechtigkeit bieten exzellente Beispiele für das, was auf dem Spiel steht.

All dies sind große Fragen, denen man sich in Bescheidenheit nähern sollte. Bescheidenheit bildet, um eine moralische Bemerkung an den Schluss meiner Ausführungen zu stellen, überhaupt eine wesentliche Voraussetzung, wenn wir den Islam weiterhin in all seiner Vielfalt studieren möchten, ohne in die Falle des Kulturalismus zu treten. Die Bescheidenheit, die hier gefragt ist, gilt nicht nur für Frauen, und sie beschränkt sich nicht auf Nichtmuslime: Den Islam zu verstehen ist ein Gemeinschaftsprojekt. Wir alle teilen die Risiken, die Erträge und die Zweifel. 


\section{Islamwissenschaften: Ein Fächer von Fächern im Wettbewerb um Mittel und Macht ${ }^{1}$}

LUDWIG AMMANN (FREIBURG)

Konkurrenz belebt das Geschäft. Unbehaglich ist das nur dann, wenn man glaubte, sich im Schutz eines Deutungsvorrechts als Gelehrter hinter Büchern und Handschriften verschanzen zu können. Dazu verführt nicht zuletzt die Selbstbezeichnung des Fachbereichs als ,Islamkunde' oder ,Islamwissenschaft", die Allzuständigkeit einer Disziplin für einen Gegenstand namens ,Islam“ suggeriert. Diese Einzahl ist in zwei Hinsichten trügerisch. Erstens umfasst der mit ,Islam“ bezeichnete Gegenstand der Untersuchung weit mehr als nur ein Land, eine Sprache, eine Gesellschaft usf., nämlich die ganze ,Welt des Islam‘. Diese Welt besteht aus einer Vielzahl von regionalen Kulturen und Gesellschaften, die nur einen gemeinsamen Nenner haben: Alle wurden sie im Lauf ihrer Geschichte auch - aber keineswegs nur! - vom Islam geprägt. Für diese Vielzahl zuständig ist zweitens nicht nur eine Disziplin, am Ende gar die Islamwissenschaft, zuständig ist eine Vielzahl von Disziplinen mit einer Vielzahl von Fragen an ihren jeweiligen Gegenstand, nämlich die Geschichts-, Politik-, Gesellschafts- und Rechtswissenschaft, Geographie und Ethnologie, verschiedene Sprach- und Literaturwissenschaften usf.

Wir haben es also in Wirklichkeit mit einem Fächer von Fächern zu tun, die allenfalls die unterstellte Prägung des in einzelnen Aspekten untersuchten Ganzen durch den Islam verbindet. Diese Auffächerung legt die Mehrzahl ,Islamwissenschaften“ nahe. Allerdings ist auch das noch missverständlich. Denn man könnte meinen, und viele tun es, dass alle Aspekte der untersuchten Regionalkulturen gleichermaßen stark vom Islam geprägt seien. Das ist mitnichten der Fall,

1 Stark vereinfachte, abgekürzte und um neue Aspekte erweiterte Fassung des gleichnamigen Essays in: Klaus E. Müller, Klaus E. (Hg.), 2003: Phänomen Kultur. Perspektiven und Aufgaben der Kulturwissenschaften, Bielefeld. S. 71-96. Zum dortigen ausführlichen Literaturverzeichnis ergänze die hellsichtige und leider noch immer aktuelle Bestandsaufnahme von Eugen Wirth (1977): „Orientalistik und Orientforschung. Aufgaben und Probleme aus der Sicht der Nachbarwissenschaften“, in: Zeitschrift der Deutschen Morgenländischen Gesellschaft. Supplement. 
es gibt vermutlich mehr Aspekte, die nur teilweise, kaum oder gar nicht religiös geprägt sind, so die Sprachen, Dichtungen, politischen und gesellschaftlichen Geschichten. Der Name ,Islamwissenschaften ' benennt eine wichtige formative und mehr noch symbolisch integrative Komponente ,islamischer' Kulturen; doch man hüte sich, das Studium der islamischen Welt so zu betreiben, als sei Islam das, was alles erklärt!

Leider erwartet die Öffentlichkeit, vom Namen verleitet, genau das vom Islamwissenschaftler: dass er 9/11 schnurstracks aus dem Islam erklärt, weil es im Koran Verse gibt, die zum Dschihad aufrufen, statt nach den politischen und gesellschaftlichen Ursachen einer Radikalisierung zu fragen, die sich des Koran bedient. Oder schlimmer noch: dass IslamexpertInnen gleich welcher fachlichen Qualifikation das Verhalten von Deutschtürken aus ihrer religiösen Prägung erklären, wiewohl mindestens ein Viertel davon so weltlich ist, dass sich ein derartiges Kurzschlussverfahren von selbst verbietet. Hier sollten Islamwissenschaftler entweder die Allzuständigkeitserwartung enttäuschen und den Grenzen ihres Wissens eingedenk schweigen oder aber dazulernen, um kulturalistische Annahmen mit substantiellen Argumenten zu entkräften.

Die Mehrzahl ,Islamwissenschaften“ kann manche Missverständnisse ausräumen, zu denen der Kollektivsingular einlädt, doch eine Täuschung bleibt bestehen. Wenn nämlich ,Islam“ in dieser Selbstbezeichnung mehr sein wollte als eine schwache und vielfach nur nominelle Klammer für Disparates, dann müsste Religionswissenschaft unsere Schlüsseldisziplin sein. In Wirklichkeit kommt gerade die Religionswissenschaft im Denkhorizont der Islamwissenschaften nicht vor. Dies ist der blinde Fleck in unserem Selbstverständnis, eine fundamentale und häufig fatale Wissenslücke. Dass sich ein Fachbereich so nennen kann, ohne wenigstens beiläufig von religionswissenschaftlichen Erkenntnissen Notiz zu nehmen, erklärt sich daraus, dass sich seine Vertreter in der Regel mit allem möglichen, nur nicht mit dem Islam beschäftigen... Tun sie es doch, ist das Fehlen religionswissenschaftlicher Expertise oft mit Händen zu greifen.

,Fächer von Fächern“ ist eine idealistische Metapher. Sie suggeriert, dass sich die Fächer um Zusammenarbeit bemühen, um im Forschungsverbund eine Leistung zu erbringen, die dem Einzelnen allein nicht möglich wäre. Die Realität sieht oft anders aus, denn da konkurrieren die Fächer um knappe Mittel, und darum bricht periodisch Streit aus über die Frage, welche Methode, sprich welches fachmännische Besteck dem Gegenstand am angemessensten sei. Man wird solcher Debatten rasch überdrüssig, wenn sie allein zu dem Zweck geführt werden, andere von den Fleischtöpfen auszuschließen; wenn also zum Beispiel einzelne Fachvertreter ihre Ansprüche auf Deutungsvorrechte kundtun. Ein prominenter Fall sei angeführt: Tilman Nagel hat in seiner Programmrede über die Aufgaben arabistischer Lehre und Forschung in der Gegenwart 1998 gefordert, das Fach ,aus der etwa dreißigjährigen Umklammerung durch sozialwissenschaftliche 
Deutungsmuster“ zu lösen und ,das unvergleichbar Fremde vor allem des islamischen Orients“ zu beschreiben. ${ }^{2}$ Mit anderen Worten: Der Philologe fordert ein Deutungsmonopol der Arabistik und Islamistik auf Kosten der Sozialwissenschaften. Das ist in dreifacher Hinsicht falsch. Erstens kann von einer „dreißigjährigen Umklammerung durch sozialwissenschaftliche Deutungsmuster" in den deutschen Islamwissenschaften beim besten Willen nicht die Rede sein. Zweitens stellt sich die Frage, wie zum Beispiel eine Literaturwissenschaft zu vernünftigen Ergebnissen gelangen soll, die nur das unvergleichbar Fremde beschreiben will, statt durch Vergleiche Gemeinsamkeiten und Unterschiede herauszuarbeiten und so die Begriffe zu schärfen. Drittens erlaubt das Monopol den Begünstigten, trotz unstreitiger Gelehrsamkeit an gravierenden Irrtümern festzuhalten, die echte Konkurrenz rasch zu Fall brächte. Ein Beispiel dafür bietet Tilman Nagels Sicht des islamischen Rechts. Seine Einführung beginnt in enger Anlehnung an ein ganz bestimmtes, keineswegs von allen Muslimen geteiltes Islamverständnis mit dem Satz: „Sich zu dieser Religion bekennen, ohne das Gesetz in seiner Gänze zu bejahen und als unbezweifelbaren und stets gültigen Maßstab für jegliches Tun und Lassen zu befolgen, ist unmöglich; denn das Gesetz ist ein wesentlicher Teil der islamischen Heilsbotschaft."3 In seiner Gänze zu bejahen? Unbezweifelbar und stets gültig? Für jegliches Tun und Lassen? Unmöglich? So sehen das nur zwei Sorten Mensch: Buchstabengläubige Rechtsgelehrte - und auf ihre Art nicht minder buchstabengläubige Islamwissenschaftler, die sich für allzuständig halten und ihr Wissen ausschließlich aus normativen Quellen schöpfen. Es ist ein Jammer, dass solche weltfremden Experten ausgerechnet das reaktionäre Islamverständnis konservativer und radikaler Muslime bestätigen, längst säkularisierten Gesellschaften wie der türkischen und arabischen Reformern wie Abdullahi anNacim in den Rücken fallen und damit zunehmend bewusst einer fremdenfeindlichen Islamkritik in die Hände spielen, die von der Vielfalt der Deutungen aus politischen Gründen nichts wissen will. Um es deutlich zu sagen: In der Türkei, dem für Deutschland und Europa mit Abstand wichtigsten Land mit muslimischer Bevölkerungsmehrheit, gilt seit 1926 weltliches Recht europäischer Herkunft und nicht etwa die von Nagel für unabdingbar erklärte Scharia. Selbstverständlich sind die Türken dennoch gute Muslime; es ist ein Skandal, dass ausgerechnet ein Islamwissenschaftler sie als ungläubig, nämlich vom Glauben abgefallen erscheinen lässt, weil sie ein modernes Verständnis der Heilsbotschaft entwickelt haben. ${ }^{4}$ Wie fragwürdig und politisch folgenschwer das von Nagel

2 Tilman Nagel: „Die Ebenbürtigkeit des Fremden - Über die Aufgaben arabistischer Lehre und Forschung in der Gegenwart“, in: ZDMG 148 (1998), S. 367-378.

3 Tilman Nagel: Das islamische Recht. Eine Einführung, Westhofen: WVA-Verlag 2001, S. 3.

4 Die verschmähte Sozialforschung kann sogar erfassen, wie es um die gesellschaftliche Akzeptanz der von oben verordneten Depotenzialisierung der Scharia zur Ethik steht: Laut Umfrage hielt 1999 nur noch jeder fünfte Türke an einem prinzipiellen 
verfochtene Programm einer Verweigerung sozialwissenschaftlicher Erkenntnisse etwa durch Umfragen ist, stellen seine halb- und ganzseitigen Darlegungen zum Dschihad in Leitmedien wie der Neuen Zürcher Zeitung und Süddeutschen Zeitung unter Beweis: Erörtert wird hier ausschließlich der Angriffsdschihad vergangener Jahrhunderte. Dass heute die meisten Muslime, gewöhnliche Gläubige ebenso wie führende Gelehrte den Dschihad als Verteidigungskrieg und gewaltlose Missionspflicht deuten, ist Nagel keine Zeile wert. Vielmehr erweckt er im Gegenteil den Eindruck, als gelte das frühere militante Verständnis bis heute ungebrochen fort. „Die damals erarbeiteten [rechtlichen] Konzepte sind bis auf den heutigen Tag von keiner muslimischen Autorität widerrufen oder auch nur ernsthaft in Frage gestellt worden“. 5 Das ist falsch, ein Schlag ins Gesicht aller Reformkräfte und wirft die Frage auf: Ist das bloß Selbstverblendung oder bereits gezielte Desinformation eines nicht urteilsfähigen Massenpublikums?

In seiner Gänze unbezweifelbar und stets gültig - das ist essentialistischer Stuss wie ihn Edward Said in seiner Karikatur orientalistischer Textproduktion der Forschung nachsagte. Um einige Jahrzehnte jünger und damit Vertreter einer künftigen Generation ist Marco Schöller. Sein Plädoyer für Hermeneutik und Diskursanalyse beim Verstehen fremder Sinnwelten ist zu begrüßen, auch wenn es offene Türen einrennt. ${ }^{6}$ Misslich hingegen ist das Verbot kulturvergleichender Forschungsprogramme, das er damit verknüpft. Warum kann, wer feinsinnige werkimmanente Gedichtanalysen schätzt, nicht auch den anthropologisch informierten Blick auf die Qaside gelten lassen? Ohnehin verliert der vermeintliche Zielkonflikt zwischen hermeneutischem und szientistischen Zugang an Bedeutung, wenn wir zur Kenntnis nehmen, dass ,Regional'-Wissenschaften ja nicht ein Privileg derer sind, welche eine fremde Region von außen für sich entdecken, historisch gesprochen der Europäer, sondern zunehmend auch von denen betrie-

Bekenntnis zur Scharia als wünschenswertem Recht fest; ein Bekenntnis, das nur vor die konkrete Wahl zwischen säkularem und schariatförmigen Ehe-, Scheidungsund Erbrechtsregelungen gestellt werden musste, um auf 10-14\% zu sinken. Es sind genau diese Einblicke in das tatsächliche Schariaverständnis der Gläubigen, die Nagel kategorisch verweigert (S. IXf.). Zur Umfrage vgl. Ali Carkoglu: „Religion and Public Policy in Turkey”, in: ISIM Newsletter 8 (2001), S. 29.

5 Tilman Nagel: „Kämpfen bis zum endgültigen Triumph. Über Gewalt im Islam“, in: Neue Zürcher Zeitung vom 25./26. 11. 2006, S. 71. Vgl. ders.: „Dschihad von Anfang an. Der Londoner Nahostforscher Efraim Karsh über die aggressive Dynamik des Islam“, in: Süddeutsche Zeitung vom 4.5.2007, S. 16. - Man vergleiche dagegen die herausragende Überschau von Patricia Crone, die mit Blick auf die Gegenwart fairerweise festhält: „The Muslims have not practised missionary jihad since the decline of the Ottoman empire, at least not under the sponsorship of states, and to my knowlege there are no serious calls for its return.“, Patricia Crone: ,Jihad". Idea and history“, in: www.opendemocracy.net/faith-europe_islam/jihad_4579.jsp (Abruf am 30.10.2007).

6 Marco Schöller: Methode und Wahrheit in der Islamwissenschaft. Prolegomena, Wiesbaden: Harrassowitz 2000. 
ben werden, die in der untersuchten Region leben oder aus ihr stammen. Das wird der albernen Fixierung auf das ,unvergleichbar Fremde“ als Revier von Xenologen hoffentlich bald den Garaus machen. Die von Wolf Lepenies ausgegebene Devise für Islamwissenschaften trifft ins Schwarze: „Forschung mit statt Forschung über."

Wir sollten anderen andere Fragen nicht verbieten. Und vielleicht auch zur Kenntnis nehmen, dass es eine Vielzahl von Gegenständen gibt, bei denen sich die unterschiedlichsten Herangehensweisen bestens ergänzen. ${ }^{8}$ Zum Beispiel der islamische Aktivismus: Phänomene wie die Reislamisierung verlangen geradezu danach, im interdisziplinären Verbund erforscht zu werden. Hier kann die Philologie die geistesgeschichtliche Genealogie der Programme aufdecken - und die Soziologie aufzeigen, was islamische Bewegungen mit anderen sozialen Bewegungen wie der Frauen- und Schwarzenbewegung gemeinsam haben. Alle Beteiligten können von einer solchen Zusammenarbeit nur profitieren, nämlich voneinander lernen - man sollte sich diese einmalige Chance nicht durch Denkverbote ausreden lassen!

Die wichtigste Polarität ist allerdings nicht die - auch im Motto des Orientalistentags 2001 angesprochene - von Philologie und Sozialwissenschaften. Konstitutiv für unser Tun ist vielmehr das Zusammenspiel von regionaler und disziplinärer Expertise, also zum Beispiel von Sprach- und Landeskenntnissen einerseits und Sozial- oder Literaturwissenschaft andererseits. Erforderlich ist immer eine Doppelqualifikation - es geht nicht um ein Entweder-Oder, es geht um ein Sowohl-Als auch! Man wird kein wirklich guter Islamhistoriker, wenn man sich nicht mit den Grundlagen der Geschichtswissenschaft als Disziplin vertraut macht. Das gilt natürlich auch umgekehrt: Man ist kein guter Literaturwissenschaftler, wenn man seinen Begriff von Gedicht nur am deutschen Erlebnisgedicht ausgebildet hat und Phänomene wie die altarabische Qaside ignoriert. Und gravierender noch: Man ist heute, im globalisierten 21. Jahrhundert, als Soziologe unglaubwürdig, wenn man Gesellschaftstheorie mit universalem Geltungsanspruch produziert allein auf Basis von europäischen Daten. Wessen Horizont am Mittelmeer endet, obwohl das weiterreichende Wissen längst von Fächern wie den Islamwissenschaften bereitgestellt wurde, ist schlicht ein unbelehrbarer Eurozentrist!

7 Wolf Lepenies: „Arbeitskreis Moderne und Islam. Empfehlungen für eine zukünftige Forschungsförderung der Islamwissenschaften“, in: Ekkehard Rudolph (Red.), Bestandsaufnahme. Kultur- und sozialwissenschaftliche Forschung über die muslimische Welt, Hamburg: Deutsches Orient-Institut 1999, S. 5-14.

8 Zur Komplementarität der Zugänge aus ethnologischer Sicht Justin Stagl: „Szientistische, hermeneutische und phänomenologische Grundlagen der Ethnologie“, in: Wolfdietrich Schmied-Kowarzik/Justin Stagl (Hg.), Grundfragen der Ethnologie. Beiträge zur gegenwärtigen Theorie-Diskussion, Berlin: Reimer 1993, S. 15-49; zum logischen Primat der Kulturalität vor der Sozialität dort und Michael Landmann. Fundamental-Anthropologie, Bonn: Bouvier 1984, S. 81, 147, 321. 
Soviel zu blinden Flecken da wie dort und fragwürdigen Versuchen, den $\mathrm{Zu}$ gang zum Wissen zu monopolisieren. Dabei neigen im Wettbewerb um Mittel und Deutungsmacht auch die zum Foul, die dem Eurozentrismus den Kampf angesagt haben. Das beste Beispiel dafür ist der Mann, der das OrientalistenKlatschen erfunden hat: der Wahl-Newyorker protestantisch-palästinensischer Herkunft Edward Said. Seine spektakuläre These in ,Orientalism“ (1978) lautete: „Essenz des Orientalismus“ sei die unausrottbare Unterscheidung zwischen westlicher Überlegenheit und orientalischer Minderwertigkeit; ,,jeder Europäer“ sei in dem, was er über den Orient sagen konnte, ein Rassist, ein Imperialist und fast vollkommen ethnozentrisch. ${ }^{9}$ Das ist selbstredend auch nur essentialistischer Stuss, wenngleich mit umgekehrtem Vorzeichen. Allsätze über ,die Orientalen ‘ und ,die Orientalisten“ sind gleichermaßen falsch. Sie enthalten vielleicht ein Körnchen Wahrheit - und dazu eine gehörige Portion Propaganda. Die tatsächliche Doppeldeutigkeit der Orientbilder und auf der Gegenseite der Okzidentbilder - ein blinder Fleck Saids! - wurde ein Jahrzehnt vor ihm auf höherem Reflexionsniveau von Tayyib Salih in seinem postkolonialen Klassiker „Zeit der Nordwanderung“ (1969) gültig vorgeführt.

Dennoch ist es zugegebenermaßen ein Segen, dass uns seit Saids Fundamentalkritik essentialistische Aussagen über ,die Muslime“ und ,den Islam“ nicht mehr wie selbstverständlich über die Lippen gehen. Nur sollte man bei aller gebotenen Vorsicht das Kind nicht mit dem Bad ausschütten. Denn wer Islamwissenschaft im emphatischen Sinn als Wissenschaft vom Islam und der islamischen Zivilisation betreiben will, der kommt um die aufgeklärt essentialistische Frage nach dem ,keimträchtigen Kern "10 dieses Fächers von Kulturen nicht herum. Das hierbei zugrunde gelegte Kulturkonzept sollte allerdings der außerordentlichen Komplexität eines raumzeitlich derartig ausgedehnten Kulturkreises gerecht werden, der Binnenunterschiede von Völkern und Schichten ebenso wie der fortwährenden Umgestaltung durch Neuschöpfungen und Kulturkontakte, deren Ergebnis mitnichten apriorisch als ,stimmige [...] Gegebenheit“"11 bezeichnet werden kann. Kultur ist Struktur und Prozess wie Licht Teilchen und Welle ist. Ernstzunehmende Islam-als-Kultur/Zivilisation-Konzepte müssen darum gerade die Vorläufigkeit und Fragwürdigkeit jeder Wesensbestimmung ernst nehmen, den nicht vorhersagbaren Wandel jeder Ausprägung von islamischer Kultur, ihre Vielstimmigkeit und nicht selten Unstimmigkeit, mit einem Wort: ihre Lebendigkeit. Das gibt es. Zum Beispiel bei Marshall G.S. Hodgson in seinem Klassiker „The Venture of Islam: Conscience and History in a World Civilization“ von 1974. Für Hodgson ist die fortdauernde Präsenz formativer Ideale der Wesenskern, der den

9 Edward Said: Orientalism, New York: Pantheon Books 1978, S. 204.

10 Klaus E. Müller: „Ethnicity, Ethnozentrismus und Essentialismus“, in: Wolfgang Eßbach (Hg.), wir/ihr/sie. Identität und Alterität in Theorie und Methode, Würzburg: Ergon 2000, S. 317-343.

11 T. Nagel: Das islamische Recht, S. XIII. 
Zusammenhang zwischen den islamischen Regionalkulturen stiftet. Es geht um den nicht abreißenden Dialog aufeinander folgender Generationen von Muslimen mit den Idealen der Offenbarung - ein Dialog, der bedeutsame Neuerungen hervorbringt und nicht etwa auf der Stelle tritt. Ähnlich hat Gudrun Krämer letzthin in einer wegweisenden Programmrede gefordert, Islam als Repertoire textueller und visueller Bezüge zu verstehen, die fortlaufend neu gedeutet werden. ${ }^{12}$ Auch das heißt letztlich, islamische Kulturen als Geschichte der Deutungen ihrer kulturbildenden Ideale zu studieren.

Was bedeutet das Gesagte für den Kampf der Islamwissenschaften um Mittel und Macht? Noch zählt eine sich überwiegend singularistisch verstehende Islamwissenschaft philologisch-historischer Prägung zu den Kriegsgewinnlern: Die Öffentlichkeit glaubt, dieses Fach habe zu den gegenwärtigen Islamdebatten etwas beizutragen. Doch der Wettbewerb wird härter, und so wird den mit der Verteilung knapper Mittel befassten Ministerien bald auffallen, dass weite Teile des Fachs zu den existentiellen Fragen der Gegenwart trotz des Versprechens, das im Namen ,Islamwissenschaft' anklingt, schweigen - und mithin entbehrlich sind. Es droht die Abwicklung. Erforderlich ist daher eine aggressive Selbstvermarktung.

Voraussetzung erfolgreicher Selbstpositionierung ist Selbsterkenntnis. Hier steht die klassische Islamwissenschaft vor einem Dilemma: Je stärker sie ihr Profil schärft, also den Unique Selling Point hervorhebt, desto weniger hat sie auf den ersten Blick zu verkaufen; denn die Öffentlichkeit interessiert sich weder für altarabische Qasiden noch für das abbasidische Hofzeremoniell. Überdies erweist sich der Kollektivsingular als Mogelpackung - denn gerade die Religion kommt an den meisten ,islam'wissenschaftlichen Seminaren zu kurz. Es ist daher aussichtsreicher - und sachlich ohnehin zutreffender! - sich als Fächer von Fächern zu positionieren: die Summe der Disziplinen, die sich mit - unter anderem! vom Islam geprägten Regionalkulturen beschäftigen, also Islamwissenschaften im Plural. Wer erklärtermaßen vieles bietet, kann zumindest manchem etwas bieten.

Das für unser Tun grundlegende Zusammenspiel von regionaler und disziplinärer Expertise ist im Wettbewerb mit Konkurrenten wie der Soziologie durch Nachrüstung und Abwerbung der besten Köpfe zu stärken und im innerfachlichen Wettbewerb gegen Vertreter disziplinblinder Expertise gleich bornierter Selbstbeschränkung durchzusetzen. In der wissenschaftlichen Öffentlichkeit ist der wohlfeile Essentialismus-Vorwurf der Orientalismus-Kritik offensiv zu kontern: Es handelt sich schon lange nicht mehr um die notwendige Korrektur eines irreführenden Sprachspiels (,der Islam', ,die Muslime'), sondern erkennbar um eine arbeitsbeschaffende Maßnahme für Vertreter von Postcolonial Studies, die

12 Gudrun Krämer: „On Difference and Understanding. The Use and Abuse of the Study of Islam”, in: ISIM Newsletter 5 (2000), S. $6 f$. 
sich lästige Konkurrenten durch Orientalisten-Bashing vom Hals schaffen wollen.

Umgekehrt wird ein Schuh daraus: Es ist gerade die aufgeklärt essentialistische Suche nach dem keimträchtigen Kern islamischer Kulturen, welche die Islamwissenschaften auszeichnet. Zum Unique Selling Point kulturwissenschaftlich akzentuierter Islamforschung wird daher das Angebot, den bis heute andauernden kognitiven Eurozentrismus der Disziplinen zu korrigieren. Nur so wird aus Sonderwissen, das sich selbst genügt und darum anderen gleichgültig ist, also einer bedrohten Spielwiese für Sonderlinge, ein allgemein nachgefragtes Gut. Um die Notwendigkeit islamwissenschaftlicher Expertise vor Augen zu führen, empfiehlt es sich, das Nichtwissen universalistisch argumentierender Fächer beherzt zu kritisieren. Es gilt, die unzulässige Verallgemeinerung aus dem europäischen Beispiel abgeleiteter Begriffe und Theorien da zurückzuweisen, wo es weh tut: auf Konferenzen, durch Rezensionen jenseits der Fachzeitschrift und in öffentlich ausgetragenen Debatten. So hätte die Islamwissenschaft Einiges beizutragen zur Korrektur einer Säkularisierungstheorie, die inzwischen weithin als Fehldeutung eines europäischen Sonderwegs gilt - wenn sie es denn endlich als eine ihrer Aufgaben begriffe, sich in solche dem Anspruch nach interdisziplinären wissenschaftlichen Auseinandersetzungen einzumischen. Es böte die Chance, sich durch Übersetzung des über Generationen angesammelten Wissens in anschlussfähige Deutungsvorschläge zu profilieren und dadurch im arbeitsteilig organisierten Wissenschaftsbetrieb nützlich zu machen.

Erst recht gilt es, in den gegenwärtigen Islamdebatten nachdrücklich Stellung zu beziehen und insbesondere solche Debattenbeiträge in der breiteren Öffentlichkeit erbarmungslos in ihrer ganzen Dürftigkeit bloßzustellen, die das Publikum mit angemaßter Expertise hinters Licht führen. Es ist unerträglich, dass ein Deutschlandhistoriker wie Hans-Ulrich Wehler in Leitmedien mit haltlosen Urteilen über ,den Islam“ und ,die Türkei ‘ Politik macht, ohne dass ihn führende Vertreter unseres Fachs für seine Kompetenzüberschreitung zur Rechenschaft ziehen. Kein seriöser Redakteur käme auf den Gedanken, einen Islamhistoriker ganzseitig über die Europawürdigkeit von Russland spekulieren zu lassen. Es liegt an uns dafür zu sorgen, dass es in Zukunft ebenso unmöglich wird, mit irrelevantem Professorentitel ausgestattete Dilettanten wie Wehler über die Europawürdigkeit der Türkei mutmaßen zu lassen. Zu diesem Zweck empfiehlt es sich, einen für Journalisten und andere nutzbaren elektronischen Pranger im Internet einzurichten, der entsprechende Verfehlungen kontinuierlich dokumentiert und zeitnah richtig stellt. Mit anderen Worten: Unser Fach braucht eine professionelle Öffentlichkeitsarbeit, die gerade an solchen publikumswirksamen Beispielen aufzeigt, was wir besser können als alle anderen, und damit unsere erstrangige $D e$ battenkompetenz unter Beweis stellt. Wenn wir diese einmalige Gelegenheit zur Profilierung versäumen, wird schon bald kein Hahn mehr nach der Islamwissenschaft krähen - und das vermutlich zu Recht. Hier einige Beispiele aus den letzten Monaten, die deutlich machen, wie wenig die Öffentlichkeit der deutschen Is- 
lamwissenschaft zutraut: Als führende Expertin in Sachen Islam und nicht etwa nur Einstellungen deutsch-türkischer MigrantInnen gilt vielen Leitmedien die Soziologin Necla Kelek, die bis heute nicht erklären konnte, warum ihre Dissertation das genaue Gegenteil von dem nachweist, was sie nun lautstark vertritt und warum wir ihren jetzigen journalistischen Arbeiten mehr Vertrauen schenken sollen als der wissenschaftlichen Arbeit, der sie ihren fachliche Expertise suggerierenden Doktortitel verdankt. ${ }^{13}$ Wie kann es geschehen, dass die F.A.Z. unter ihrem Namen veröffentlichten Thesen über ,den ' Islam in Geschichte und Gegenwart und namhafte Schulen und Vertreter eines neuen Islamverständnisses unwidersprochen eine volle Seite einräumt, obwohl sie von islamischer Theologie und Geschichte und schon gar von traditioneller wie auch historischkritischer Koranexegese nicht mehr versteht als ein Schaf vom Bellen? ${ }^{14}$ Wo bleiben die Stimmen aus dem Fach, die solche Scharlatanerie einer auf qualitative Interviews spezialisierten Soziologin unverzüglich entlarven? Würden wir uns das Christentum und Grundzüge der Bibelhermeneutik von Claudia Roth erklären lassen, nur weil sie aus dem christlichen Kulturkreis stammt?

Als Luther der Islamwissenschaft gilt der F.A.Z. der emeritierte katholische Religionswissenschaftler Karl-Heinz Ohlig, dessen „Appell für eine neue Islamwissenschaft" ihr eine halbe Seite wert ist. Darin darf er, der sich damit brüstet, kein Wort Arabisch zu verstehen, dem Fach einmal mehr auf Grundlage bislang völlig unbewiesener und teils schon von zuständigen Fachwissenschaftlern wie führenden Semitisten ätzender Kritik unterzogener Thesen vorwerfen, mit Blick auf die Entstehung des Islam einem Ammenmärchen aufgesessen zu sein: Der

13 Necla Kelek: Islam im Alltag. Islamische Religiosität und ihre Bedeutung in der Lebenswelt von Schülerinnen und Schülern türkischer Herkunft, Münster: Waxmann 2002. „Die Jugendlichen [...] partizipieren größtenteils selbstverständlich an den vielen Möglichkeiten, die die Moderne bietet. Ihre Lebensentwürfe sind, wenn auch in unterschiedlicher Spannweite, auf Deutschland, auf die Moderne bezogen. Was ihre familiären Vorstellungen angeht, orientieren sie sich mehr oder minder an Modellen der modernen Kleinfamilie mit überwiegend emanzipativem Verhältnis zwischen Mann und Frau und liberaler Kindererziehung. Zusammenfassend ist perspektivisch eine weitgehende Anpassung an die Lebensweisen der westlichen Moderne festzustellen." So das Fazit ihrer Dissertation (S. 180). Ganz anders die nur drei Jahre später publikumswirksam vertretenen Thesen in: Necla Kelek: Die fremde Braut, Köln: Kiepenheuer \& Witsch 2005, S. 234f.: „Dieses Menschen- und Weltbild wird nicht hinterfragt, es ist ,fraglos gegeben', es kann auch gar nicht infrage gestellt werden, weil der Islam als Gesetzesreligion gottgegeben ist. Dieses Kulturmuster prägt das Handeln der muslimischen Migranten in Deutschland bis in den letzten Winkel ihres Alltags - ihr Leben, ihr Verhalten, die Erziehung ihrer Kinder. Und diese Werte haben mit den Werten und Normen der deutschen Mehrheitsgesellschaft nicht viel gemein. Wer glaubt, dass sich diese Haltung im Laufe der Generationen gleichsam ,auswächst', der irrt.“

14 Necla Kelek: „Und bist du nicht von uns, dann bist du des Teufels. Was Integration heißt, das kann nicht allein der Islam definieren. Die Gebote des Koran und Europa“, in: FAZ vom 25.4.2007, S. 36. 
Koran basiere auf einer syrischen Grundschrift, der Islam sei nicht in Arabien entstanden usf. ${ }^{15}$ Nun ist es an sich höchst erfrischend, wenn der wissenschaftliche Konsens von Außenseitern in Frage gestellt wird. Aber es sollte uns nach-

15 Karl-Heinz Ohlig: „Wir müssen uns wehren. Appell für eine neue Islamwissenschaft", in: FAZ vom 21.11.2006, S. 41 und 43. - Immerhin erfolgte (nach einer ersten Entgegnung von Nicolai Sinai) dann im Frühjahr die überfällige Klarstellung durch den Semitisten und Numismatiker Heidemann, der die Amateure Ohlig und Popp mit wünschenswerter Deutlichkeit der Ahnungslosigkeit überführt; Stefan Heidemann: „Münzen sind konservativ“, in: FAZ vom 2.3.2007. Vgl. auch die Rezension des von Ohlig herausgegebenen Bands „Der frühe Islam“ durch den Semitisten Daniel Birnstiel auf www.qantara.de vom 7.8.2007 sowie dessen ausführliche Widerlegung Popps auf dem 30. Deutschen Orientalistentag in Freiburg, 24.28.9.2007, Revisionist Concepts on the Origin of Islam and their Meaning in the Wider Socio-political context; Veröffentlichung demnächst. - Ehre wem Ehre gebührt: Am 21. September 2007 hat nun ausgerechnet Tilman Nagel in einem Rezensionsessay das unter Ohligs Anleitung in Saarbrücken betriebene Geschichtsfälschungsprojekt in aller Öffentlichkeit als Unfug entlarvt; vgl. Tilman Nagel: „Befreit den Propheten aus seiner religiösen Umklammerung! Plädoyer für eine säkulare Islamwissenschaft: Wie muss eine Leben-Mohammeds-Forschung aussehen, die den Koran nicht vergewaltigt, sondern historisch-kritisch erhellt?“, in: FAZ vom 21.9.2007, S. 39. - Und ein letztes Kuriosum: Ohlig führt in seinem Artikel Patricia Crone als Kronzeugin für seine Behauptung an, dass man Muhammad erst im 8. Jahrhundert zum Stifter erklärt und die Geschehnisse von Ostmesopotamien in die Heimat der Araber verlegt habe: „So kommt auch Patricia Crone in einem gerade erschienen Aufsatz zu der Überzeugung, die Anfänge des Islam stammten nicht von der Arabischen Halbinsel“. Hier ist, was die führende Historikerin, die ihre vor Jahrzehnten in „Hagarism“ aufgestellten Thesen heute als „,rubbish“ bezeichnet, tatsächlich zum Stand der Forschung mitteilte: „There is no doubt hat Mohammed existed, occasional attempts to deny it notwithstanding. His neighbors in Byzantine Syria got to hear of him within two years of his death at the latest. [...] If such a revised date is accurate, the evidence of the Greek text would mean that Mohammed is the only founder of a world religion who is attested in a contemporary source. But in any case, this source gives us pretty irrefutable evidence that he was an historical figure. [...] The evidence that a prophet was active among the Arabs in the early decades of the $7^{\text {th }}$ century, on the eve of the Arab conquest of the middle east, must be said to be exceptionally good. [...] we can be reasonably sure that the Qur'an is a collection of utterances that he made in the belief that they had been revealed to him by God." Den von Ohlig als semitistischer Gewährsmann protegierten Luxenberg bezeichnet sie als Amateur; und wenn sie die Lokalisierung - nicht aber Zeit und Urheberschaft! - der Offenbarung in Mekka anzweifelt, so nicht etwa, um sie nach Ostmesopotamien zu verlegen, wie Ohlig es tut, vielmehr erwägt sie alternativ sowohl Nordwest- als auch Südarabien - beides gehört zur Arabischen Halbinsel! sowie die Gegend des Toten Meers. Mit anderen Worten: Ohligs Rekurs auf die berühmte Expertin verfälscht ihre Aussagen aufs Dreisteste. In den Naturwissenschaften würde man einen solchen Betrug mit dem Ausschluss aus der scientific community ächten. Es ist ärgerlich, dass die FAZ einem Propagandisten wie Ohlig blind Vertrauen schenkt, ohne seine radikalen These einem Minimum an fact checking zu unterwerfen. Vgl. Patricia Crone: „What do we actually know about Mohammed?“, www.opendemocracy.net/faith-europe_islam/mohammed_3866.jsp (Abruf am 30. 10.2007). 
denklich stimmen, dass eine hochgradig spekulative Geschichtsfiktion einer nicht urteilsfähigen Öffentlichkeit als einzig glaubwürdige Avantgarde im Kampf mit einer verschnarchten Fachwissenschaft vorgestellt wird. Halten die Angegriffenen die öffentliche Arena für unter ihrer Würde, den Kontrahenten für nicht satisfaktionsfähig, ihre Stellung für uneinnehmbar?

DIE ZEIT fasst den Anspruch und die Enttäuschung der Öffentlichkeit so zusammen:

„Eigentlich obliegt es der Wissenschaft, Licht ins Dunkel zu tragen und steile Thesen durch empirisch abgesicherte Fakten zu ersetzen. Doch die zuständigen Universitätsgelehrten haben sich für den heimischen Islam lange kaum interessiert - vor allem die Islamwissenschaftler nicht. Der Glaube der Migranten galt als rückständig und intellektuell anspruchslos. Zudem verstehen sich die Orientalisten eher als Philologen denn als Sozialwissenschaftler [...]. Zugespitzt formuliert: Schön alt und möglichst weit weg musste das Forschungsobjekt sein. So kommt es, dass die deutschen Islamgelehrten mehr über Sufi-Dichter im alten Persien zutage gefördert haben als über Vorbeter in Deutschland. Wer sich dennoch mit dem hiesigen Islam beschäftigte, wurde nicht ernst genommen [...]. Bis heute gibt es keinen ausgewiesenen Islamwissenschaftler, dessen Forschungsschwerpunkt in Deutschland liegt. “16

Das Ergebnis dieser Versäumnisse: Als auf www.perlentaucher.de eine vielbeachtete internationale Islam-und-Multikulti-Debatte geführt wurde, nahmen daran auf deutscher Seite teil: der Politologe Bassam Tibi, die Publizistin Ulrike Ackermann und die Soziologin Necla Kelek. Und kein einziger Islamwissenschaftler!

All dies sind Symptome einer weit reichenden Marginalisierung der klassischen Islamwissenschaften im öffentlichen Diskurs und sollten als Krisensymptom ernst genommen werden. Die zu erringende Debattenkompetenz wird uns nicht in den Schoß fallen. Die erforderlichen Sachkenntnisse und die Fähigkeit, medienwirksam aufzutreten, sollten daher schon im Studium erworben werden. Für unser Selbstverständnis und unsere Selbstdarstellung unerlässlich ist zudem, dass Muslime und Nichtmuslime gemeinsam auftreten: Islamwissenschaften erforschen nicht das ,unvergleichbar Fremde“, weil Wissen kein Privileg verweltlichten Westchristentums ist und weil das ,Fremde“ hier längst heimisch geworden ist.

Stark vereinfachte, abgekürzte und um neue Aspekte erweiterte Fassung des gleichnamigen Essays in: Klaus E. Müller, Klaus E. (Hg.), 2003: Phänomen Kultur. Perspektiven und Aufgaben der Kulturwissenschaften, Bielefeld. S. 71-96. Zum dortigen ausführlichen Literaturverzeichnis ergänze die hellsichtige und leider noch immer aktuelle Bestandsaufnahme von Eugen Wirth (1977): „Orientalistik und Orientforschung. Aufgaben und Probleme aus der Sicht der Nachbar-

16 Martin Spiewak: „Meinungsstark, aber ahnungslos“, in: Die Zeit, 19.4.2007. 
wissenschaften“, in: Zeitschrift der Deutschen Morgenländischen Gesellschaft. Supplement. 


\section{Gaze - Jenseits vom Orient und von Zivilisierungsmissionen}

MARIAM POPAL (HAMBURG)

„In the absence of a critical awareness of colonialisms ideological
effects, reading of counter-discourses can all too easily serve an
institutional function of securing the dominant narrative. None of
us escapes the legacy of a colonial past and its traces in our
academic practice $[\ldots]^{\text {“1 }}$

„One must learn to read how desire for neutrality and/or desire for the Other articulates itself. One must learn to read the text - the narrative, the historical and institutional structures - in which desire is written. "2

\section{Un-Behagliches}

Das Unbehagen in der Islamwissenschaft deutet auf eine behagliche Lage hin. Denn im Behaglichen ist die Angst vorhanden, vielleicht das Ahnen, dass das Unbehagen verdrängt wird. Das (Un-)Behagen mag aus dem un-heimlichen Wissen um die Konstruiertheit hegemonialer, heteronormativer Neutralität herrühren und ist daher von großem analytischem Wert. Beachtenswert ist es zum Beispiel, dass es eine Konferenz gibt, die sich noch immer ,Orientalistentag ' nennt. Die Frage stellt sich, ob nicht eine Tagung wünschenswert und längst überfällig ist, die andere Aspekte dieser ,Regionalstudien“ mindestens mitberücksichtigt, wie etwa die Jewish Studies, Postcolonial Studies, Black European Studies und die Critical Whiteness Studies. Es sind diese Forschungsstränge, die die Sicht der Anderen in der westlichen Forschungslandschaft sichtbar machen (wollen), um dadurch einen eindimensionalen, dichotom gesetzten Blickwinkel zu entkräften und aktiv in die Wissenschaft(-ssprache) einzudringen. Édouard Glissants Worte

1 Jenny Sharpe: „Figures of Colonial Resistance“, in: Bill Ashcroft/Gareth Griffiths/Helen Tiffin (Hg.), The Post-Colonial Studies Reader, London, New York: Routledge 2004, S. 99-103, hier S. 99.

2 Sarah Harasym (Hg.), Gayatri Chakravorty Spivak. The Post-Colonial Critic - Interviews, Strategies, Dialogues, London: Routledge 1990, S. vii. 
machen die Notwendigkeit eines solchen Denkprozesses folgendermaßen deutlich:

„Denn tatsächlich geht es um eine arrogante und tödliche Auffassung, welche die Völker Europas und die westlichen Kulturen der Welt vermittelt haben, nämlich, dass eine Identität aus einer einzigen Wurzel stammen müsse, die den Anderen ausschließt. Diese Sicht der Identität steht im Gegensatz zu der heute in den komplexen Kulturen [cultures composites] verwirklichten Auffassung von der Identität als einem Faktor, der die Kreolisierung zum Ergebnis hat, das heißt, die Auffassung von der Identität als einem Rhizom, einem Wurzelgeflecht. Die Identität speist sich nicht mehr aus einer einzigen Wurzel, sondern ihre Wurzel vernetzt sich in der Begegnung mit anderen.“3

Repräsentation im Sinne von darstellen und vertreten scheint aber das naturalisierte Muster geworden zu sein, nach dem ,Europa ' sich vor allem selbst als WeiBer und christlicher Kontinent mit einer abgrenzbaren (Geistes-)Geschichte und Identität zu mythologisieren und damit zu re-konstruieren versucht. ${ }^{4}$ Daher sind der Einbezug und die Perspektiven der erwähnten Forschungsdisziplinen unerlässlich. Erst im Rahmen solch ausgeweiteter Blickwinkel ist es möglich den Orientalismus - der nicht nur in der Orientalistik, sondern in der gesamten westlichen Epistemologie existent ist - kritisch zu reflektieren und aus seinem dichotomen, hierarchisierenden Blickwinkel herauszubrechen. Denn während sich das Behagliche oft aus dem Heim(l)i(s)chen und Altvertrautem (Denken) ergibt, ergibt sich das Unbehagliche aus dem Unheim(l)i(s)chen, dem (Un-)Denklichen, dem Marginalisierten und Unterdrückten. Im Sinne eines ermächtigenden, emanzipatorischen Prozesses ist das Ausbrechen aus dem (Un-)Behagen vor allem für People of Color ${ }^{5}$ von gravierender Bedeutung. Denn hier erwächst das Unbeha-

3 Édouard Glissant: Kultur und Identität - Ansätze zu einer Poetik der Vielheit, Paris: Wunderhorn 1996, S. 19.

4 Vgl. dazu z.B. Eske Wollrad: Weißsein im Widerspruch. Feministische Perspektiven auf Rassismus, Kultur und Religion, Königstein/Taunus: Ulrike Helmer Verlag 2005; Susan Arndt: „Weißsein. Die verkannte Strukturkategorie Europas und Deutschlands“, in: Maureen Maisha Eggers u.a. (Hg.), Mythen, Masken und Subjekte. Kritische Weißseinsforschung in Deutschland, Münster: Unrast Verlag 2005, S. 24-28.

5 Zum Begriff People of Color im deutschsprachigen Raum und seiner Geschichte vgl. Kien Nghi Ha: „People of Color - Koloniale Ambivalenzen und historische Kämpfe“, in: ders./Nicola Lauré al-Samarai/Sheila Mysorekar (Hg.), re/visionen. Postkoloniale Perspektiven von People of Color auf Rassismus, Kulturpolitik und Widerstand in Deutschland, Münster: Unrast-Verlag 2007, S. 31-40. Der Begriff beinhaltet einen solidaritätsstiftenden Sinn, so heißt es auf S. 37: „Als gemeinsame Plattform für grenzüberschreitende Bündnisse wendet er sich gleichermaßen an alle Mitglieder rassifizierter und unterdrückter Communities. People of Color bezieht sich auf alle rassifizierten Menschen, die in unterschiedlichen Anteilen über afrikanische, asiatische, lateinamerikanische, arabische, jüdische, indigene oder pazifische Herkünfte oder Hintergründe verfügen. Er verbindet diejenigen, die durch die 
gen aus dem ambivalenten Wissen um die Fremdbestimmung und das Verdinglichtsein und aus dem gleichzeitigen Wissen eigener Erfahrungen und des Verwurzeltseins in der Welt, die neben dem hegemonialen (Un-)Behagen hin und her pendelt - und es unwillkürlich herausfordert. Entscheidend ist diese Sichtweise jedoch gleichermaßen für die Bewusstmachung und Dekonstruktion von Weißsein als privilegierte Position und in diesem Sinn für Weiße, die die dichotome, hierarchisierte Anordnung im Sinne einer Verantwortung und Verpflichtung für alle mit umgestalten wollen.

Statt einer Orientalistentagung plädiere ich daher für eine Okzidentalismustagung. Okzidentalismus beinhaltet dabei drei Punkte, die für die Konstituierung wie auch Dekonstruierung von Orientalisierungen von zentraler Bedeutung sind. Er weist erstens sowohl auf die historische Entstehung der Orientalistik hin als auch auf ihre gegenwärtige umkämpfte Bedeutung. Dies sei kurz erläutert. Es gibt in der Islamwissenschaft die Tendenz, den Begriff Okzidentalismus in ein angebliches Machtinstrument des ,Orients “ umzufunktionieren. Dies ist aus vier Gründen problematisch. Erstens ist ein ,Okzidentalismus‘ als komplementäres Gleichgewicht zum Orientalismus überhaupt nicht vorhanden, auch wenn es das Wissen, im Sinne eines ,Wissensarchivs` of Color, um europäische Hegemonie und Überlegenheitswillen gibt, auf die reagiert wird. ${ }^{6}$ Zweitens verdeckt diese Aneignung die Tatsache, dass es eine hegemoniale Asymmetrie gibt, die einen Okzidentalismus im binären Sinn eines Orientalismus faktisch unmöglich macht. Drittens ist die dichotome Asymmetrie Okzident/Orient selbst Teil des diskursiven hegemonialen Konstrukts und keine naturgegebene Realität. Viertens bleibt die Islamwissenschaft damit mehr dem (narzisstischen?) Bemühen verpflichtet, sich und ,den (christlichen) Westen?` von orientalisierenden Vorwürfen durch eine imaginierte Umkehrung frei zu sprechen, und sich gar als Opfer eines Okzidentalismus zu präsentieren. Glaubwürdiger und für ein epistemologisches Weiterkommen in der Forschung unabdingbar wäre es, sich mit den Erkenntnissen der Orientalismus-Debatte und Postkolonialer Kritik argumentativ und selbstreflektiert auseinander zu setzen und zu positionieren - will die Orientalistik überhaupt in der Forschungslandschaft überleben, denn an ihnen vorbei kommen, wird sie ohnehin nicht mehr können. Gespiegelt wird dieser Gedanke eines Gegendiskurses auch im Okzidentalismusbegriff von Hassan Hanafi, der jedoch in den asymmetrischen Machtverhältnissen verfangen bleibt, und sich nur im Bewusstsein über diese Ordnung entfalten kann. Seine weitreichende Ausgestaltung findet dieses Verständnis des Okzidentalismus aber, und dies macht seine zweite Dimension aus, in der von der afrikanisch-amerikanischen Literaturnobelpreisträgerin Toni Morrison eingeforderten Idee der Analyse weißer Perspektiven. In

Weiße Dominanzkultur marginalisiert sowie durch die Gewalt kolonialer Tradierungen und Präsenzen kollektiv abgewertet werden."

6 Vgl. hierzu den anregenden Beitrag von Maureen M. Eggers: „Ein Schwarzes Wissensarchiv“, in: ders. u.a. (Hg.), Mythen, Masken und Subjekte, S. 18-21. 
ihrem viel beachteten Buch Playing in the Dark machte Toni Morrison deutlich, „dass es ihr entgegen dem gewohnten Under the [white] Gaze um eine Veränderung der Perspektive geht, den kritischen Blick vom rassischen Objekt zum rassischen Subjekt zu wenden; von den Beschriebenen und Imaginierten zu den Beschreibenden und Imaginierenden; von den Dienenden zu den Bedienten. ${ }^{77}$ Inzwischen konnte diese Erkenntnis im akademischen Bereich in die Critical Whiteness Studies beziehungsweise im deutschsprachigen Raum in die Kritische Weißseinsforschung münden und scheint einen Paradigmenwechsel einzuleiten. ${ }^{8}$ Zum Dritten benutzt der postkoloniale Wissenschaftler Fernando Coronil den Begriff des Okzidentalismus, um auf das Werden eines Europa aufmerksam zu machen. Mit dem Begriff wird darauf hingewiesen, dass jede Aussage über den Orient eine Aussage über den Okzident beinhaltet: Die Beschreibung der Anderen geschieht stets vor dem Hintergrund der eigenen Selbstwahrnehmung und gestaltung als Okzident. Nach diesem Verständnis macht der Begriff Okzidentalismus im Sinne einer diskursiven Realismusproduktion die historische, geographische, religiöse, ethnische und ethnisierende Konstruktion des Orients erfassbar. Somit liegt der Orient in den hegemonialen Diskursen eines ebenso konstruierten weißen, christlichen Okzidents. ${ }^{9}$

\section{Wer spricht? Wer wird gehört?}

„Then if you think about Asia - and I notice you didn't mention that I was an Asian in your introduction; now let me say that I am one - there are intellectualls in Asia but there are no Asian intellectuals. I would stand by that rather cryptic remark. From this point of view I think the first question about the intellectuals, as indeed we are - as to who asks the question about the intellectual and the specific intellectual, the universal intellectual, is to see that the specific intellectual is being defined in reaction to the universal intellectual who seems to have no particular nation-state provenance. [...] I

7 Toni Morrison: Playing in the Dark: Whiteness and the Literary Imagination, 1992 (im Deutschen unter dem Titel Im Dunkeln spielen. Weiße Kultur und literarische Imagination, Reinbek b. Hamburg: Rowohlt 1994) hier zitiert nach URL: http://de.wikipedia.org/wiki/Wei\%C3\%9Fsein vom 27.09.07.

8 Vgl. Susan Arndt: „,The Racial Turn“. Kolonialismus, Weiße Mythen und Critical Whiteness Studies“, in: Marianne Bechhaus-Gerst u.a. (Hg.), Koloniale und postkoloniale Konstruktionen von Afrika und Menschen afrikanischer Herkunft in der deutschen Alltagskultur, Frankfurt/M: Peter Lang 2005 sowie Maureen M. Eggers u.a. (Hg.), Mythen, Masken und Subjekte.

9 In diesem Sinn verstand sich auch die Internationale Konferenz „De/Konstruktionen von Okzidentalismus. Eine geschlechter-kritische Intervention in die Herstellung des Eigenen am Anderen“ des Graduiertenkollegs „Geschlecht als Wissenskategorie“, die vom 21.-23. Juni 2007 an der Humboldt-Universität zu Berlin stattfand. Vgl. http://www2.hu-berlin.de/gkgeschlecht/okzidentalismus/index2.php vom 12.11.2007. 
would say that the tendency not to look at the margins, at what escapes the things with proper titles, is in itself caught within this definition of the intellectual." ${ }^{\prime 10}$

Diese Aussage der postkolonialen Kritikerin Gayatri Chakravorty Spivak weist auf die historische Kontextualität unseres Denkens und unserer Sprache hin, die stark eurozentristisch ausgerichtet sind. ${ }^{11}$,Intellektuelle“ wird stillschweigend mit Ideen der europäischen Moderne in Verbindung gebracht und die historische und kontextuelle, provisorische Bedeutung von Worten, je nach Zusammenhang, wird dabei aus den Augen verloren. Die europäische Moderne wiederum wird als eine homogene Weltepoche kodiert, nicht etwa als widersprüchliche Momente einer bestimmten historischen Gegebenheit unterschiedlichst erlebter Erfahrungen und Diskurse. Darüber hinaus wird paradoxerweise die europäische Moderne als europainterne Geschichtserfahrung definiert, obgleich die Moderne im Zuge der Kolonisierungsgeschichte und dem Beginn des Kapitalismus erst entstand. ${ }^{12}$ Spivak hinterfragt den Mechanismus des Sprechens, hinterfragt, wer eine Frage wonach stellen darf - wer diese Kodierungen dekodieren kann -, was das wiederum unhinterfragt bedeutet und damit schließlich, wer nicht gehört wird, obwohl er/sie spricht, und was das bedeutet. Bezogen auf unser Thema möchte ich die Frage nach den sprechenden und schreibenden Subjekten stellen. Wer spricht in der Islamwissenschaft? Und was wird besprochen? Und - wer wird nicht gehört?

Dazu müssen wir das wir in der Orientalistik einer Analyse unterziehen - und damit betreten wir bereits das Feld der postkolonialen Kritik und der Kritischen Weißseinsforschung. ${ }^{13}$

10 S. Harasym (Hg.), Gayatri Chakravorty Spivak, S. 3-4.

11 Die Effekte der Kolonisierung auch auf - vermeintlich - kolonisierte Subjekte machte schon Franz Fanon deutlich, deren Analyse er in seinen Werken Schwarze Haut - Weiße Masken und Die Verdammten dieser Erde aufnimmt.

12 Hierzu z.B. Tzvetan Todorov: Die Eroberung Amerikas. Das Problem des Anderen, Frankfurt/M: Suhrkamp 2005 (Erstdruck auf Deutsch 1985) und kritisch zur modernen europäischen Geschichtsinterpretation Robert Young: White Mythologies. Writing History and the West, London, N.Y.: Routledge 1990 insbesondere S. 1-20; Dipesh Chakrabarty: Provincialising Europe. Postcolonial Thought and Historical Difference, Princeton, New Jercey: Princeton UP 2000 und Rosa Amelia PlumelleUribe: Weisse Barbarei. Vom Kolonialrassismus zur Rassenpolitik der Nazis, Zürich: Rotpunkt-Verlag 2004. Für den innerdeutschen Kontext vgl. Peggy Piesche: „Der ,Fortschritt‘ der Aufklärung. Kants ,Race“ und die Zentrierung des weißen Subjekts“, in: Maureen M. Eggers u.a. (Hg.), Mythen, Masken und Subjekte, S. 3039; unabdingbar als theoretische Grundlage hin zu dieser Thematik vgl. Maureen M. Eggers: „Ein Schwarzes Wissensarchiv“, in: ders. u.a. (Hg.), Mythen, Masken und Subjekte, S. 18-21 sowie Kien Nghi Ha: „Deutsche Integrationspolitik als koloniale Praxis“, in: ders. u.a. (Hg.), re/visionen, S. 113-128.

13 Vgl. Zu den Begriffen im deutschen Kontext Kien Nghi Ha: „Postkoloniale Kritik und Migration. Eine Annährung“, in: ders. u.a. (Hg.), re/visionen, S. 41-54 sowie Peggy Piesche: „Das Ding mit dem Subjekt, oder: Wem gehört die Kritische Weiß- 
Sowohl die Postkoloniale Kritik als auch die Kritische Weißseinsforschung sind interdisziplinär angelegte Theorie- und Forschungsansätze, die aber nicht auf akademische Disziplinen eingeschränkt sind, sondern ebenso auf künstlerischer und aktivistischer Ebene vertreten werden. Beide Ansätze haben eine lange Tradition, doch konnten sie sich erst seit den 1990er Jahren in der westlichen Forschung Geltung verschaffen - und werden immer mehr en vogue, was nicht unproblematisch ist. ${ }^{14}$ Sie fokussieren auf unterschiedlichsten Ebenen westliche Epistemologien und Wissensproduktionen und die darin enthaltenen Weißen Selbstentwürfe. Diese Selbstentwürfe gestalten sich in Abgrenzung zu Aussagen über die Anderen. Im deutschen Kontext waren es oftmals Menschen jüdischer Herkunft, die Gegendiskurse produzieren konnten, jedoch in der Regel marginalisiert wurden. Auch die deutsche Islamwissenschaft ist von dieser Geschichte rassistischen Ausschlusses geprägt. ${ }^{15}$

In beiden Ansätzen geht es nicht darum, an biologistischen Konzepten von ,Rassen" festzuhalten oder sie zu essentialisieren. Weißsein wird vielmehr als eine politische, soziale und akademische Kategorie begriffen und analysiert. Rassifizierte Konstruktionen sind zwar unabdingbarer Teil des europäischen hegemonialen Weltbilds, die ihre Hegemonie von Anbeginn an erst definierte. Jedoch werden bis dato die Anderen bezeichnet und beschrieben, während Weiße Epistemologien und Blicke, von welchen diese Schau ausgehen und auf deren Grundlage die Anderen erst ,erschaffen " und markiert werden, als unsichtbar, neutral und in auktorialer Erzählperspektive normiert und institutionalisiert erscheinen. Solche Weißen Rassifizierungen aber prägen durch imperiale, ökonomische, politische, kulturelle und ökologische Hegemonialstrukturen die realen Lebensumstände von Menschen weltweit. Ihre epistemische, politische und soziale Funkti-

seinsforschung?“, in: Maureen M. Eggers u.a. (Hg.), Mythen, Masken und Subjekte, S. 14-17 und Susan Arndt: „Weißsein und Kritische Weißseinsforschung“, in: http://www.unrast-verlag.de/unrast,3,0,261.html vom 16.09.2007.

14 Dazu David Scott: „The Construction of Postcolonial Studies“, in: Ania Loomba u.a. (Hg.), Postcolonial Studies and Beyond, Durham, London: Duke UP 2005, S. 385-400. Scott elaboriert hier unter anderem anhand von Thomas Kuhns Theorien den Forschungsstand und -blick der Postcolonial Studies als revolutionäres Paradigma, das immer mehr durch Institutionalisierung in eine Methode ohne kritisches Potenzial abdriften könnte und erörtert, wie das verhindert werden kann.

15 Vgl. dazu z.B. John M. Efron: „Orientalism and the Jewish Historical Gaze“, in: Ivan Davidson Kalmar/Derek J. Penslar (Hg.), Orientalism and the Jews, Hanover, London: UP New England 2005, S. 80-93. Efron weist auf den anderen, veranderten und oftmals nach den eigenen Wurzeln suchenden Blick von Islamwissenschaftler/-innen jüdischer Herkunft hin. Herausragendes Beispiel ist für ihn Ignaz Goldziher, dessen Können, Leistungen und Ansätze aufgrund rassistischer Blickwinkel in den akademischen und gesellschaftspolitischen Institutionen nie seine volle Entfaltungskraft entwickeln konnte. Siehe auch den anregenden Artikel von Susannah Heschel: „Revolt of the Colonized. Abraham Geiger's Wissenschaft des Judentums as a Challenge to Christian Hegemony in the Academy“, in: New German Critique 77 (1999), S. 61-86. 
on besteht in der Privilegierung Weißer Sichtweisen über Normalisierungen und Normierungen. ${ }^{16}$ Weiße Epistemologien erhalten dadurch Immunität, sie werden zu unsichtbaren Maßstäben, an denen die Anderen gemessen werden. Dies ist eine alte Erkenntnis Schwarzer Wissensarchive, da es den Blick zurück natürlich immer gegeben hat. Um diesem Blick zu entweichen und den kolonialen Blick aufrecht erhalten zu können, werden Stereotypisierungen über People of Color ebenso fortwährend reproduziert wie Überlegenheitsrituale. Eine zentrale, stets (ab-)wertende Ritualisierung ist die Klassifikation von ,Rassen“ - oder inzwischen auch ,Kulturen“ als (post-)moderne Codes derselben Denktradition - als fixe, unveränderliche und der westlichen Epistemologie inferiore Entitäten. Auch wenn es wissenschaftlich nie belegt werden konnte, dass es menschliche ,Rassen“ gibt, dies inzwischen ohnehin widerlegt ist, und vielmehr von ,Rasse“ als sozialem Konstrukt gesprochen wird, welches Produkt und nicht Grundlage des Rassismus selbst ist, ${ }^{17}$ gibt es auch heute noch ein rassifizierendes (Un-)Bewusstsein, das rassialisierte Vorstellungen beinhaltet und das Sprechen und die Sprechpositionen bestimmt, mit denen Politik und Wissenschaft betrieben wird. ${ }^{18}$ In der Kritischen Weißseinsforschung werden diese Markierungen und Kategorisierungen von Menschen durch Begriffe der Natur und solche, die sich auf äußerliche Merkmale wie Hautfarbe beziehen, abgelehnt. ${ }^{19}$ So wird Weißsein, wie bereits erwähnt, als politisches Konstrukt der Analyse unterzogen. Zu Weißsein als Analysekategorie muss aber auch die Weiße christliche Religiosität gezählt werden. Sie war seit Beginn der kolonialen Eroberungen 1492 Motivationsquelle für Eroberung und Ausschluss - und ist es bis heute geblieben. ${ }^{20}$

Für die Islamwissenschaft und weitere Regionalstudiengänge bedeutet die Übertragung postkolonialer Theorien eine kritische Reflexion und Überprüfung bisheriger Standpunkte und vor allem ihrer Untersuchungsgegenstände - und somit einen Paradigmenwechsel. Ein zentraler Begriff dabei ist die Kritik der Repräsentation, also die Situation eines angeblich wissenden Subjekts, das betrachtet und eines betrachteten, nichtwissenden Objekts.

16 Vgl. hierzu Isabell Lorey: „Weißsein und Immunisierung. Zur Unterscheidung zwischen Norm und Normalisierung“, in: http://ranslate.eipcp.net/strands/03/loreystrands01de vom 10.10.2007.

17 Vgl. etwa Wulf D. Hund: Rassismus, Bielefeld: transcript Verlag 2007, S. 9.

18 Siehe dazu den aufschlussreichen Beitrag von Maureen M. Eggers zur Analyse von Weißen Diskursen als rassifizierendes Ordnungsprinzip, Maureen M. Eggers: „Rassifizierte Machtdifferenz als Deutungsperspektive in der Kritischen Weißseinsforschung in Deutschland“, in: ders. u.a. (Hg.), Mythen, Masken und Subjekte, S. 5672.

19 Siehe http://de.wikipedia.org/wiki/Wei\%C3\%9Fsein\#_note-19 vom 27.09.07.

20 So z.B. Tzvetan Todorov: Die Eroberung Amerikas. Das Problem des Anderen, Frankfurt/M: Suhrkamp 2005; siehe auch Susan Arndt: Weißsein, S. 24-28 und Ivan Davidson Kalmar/Derek J. Penslar: „Orientalism and the Jews. An Introduction“, in: ders. (Hg.), Orientalism and the Jews, S. XXI. 
Dass viele Forschungsansätze bezüglich der nicht-europäischen Welt im Allgemeinen und der islamischen hier im Besonderen stark mit der Kolonisierung in Zusammenhang stehen, wurde nach dem Erscheinen von Edward W. Saids Orientalism vermehrt untersucht und wird nicht mehr bezweifelt. Auch beschäftigten sich viele islamwissenschaftliche Abhandlungen mit Saids Ergebnissen, zumeist aber in defensiver Natur und ohne auf den theoretischen Rahmen seiner Arbeiten zu achten. ${ }^{21}$ Obgleich Saids Werke als wichtige Meilensteine in der Forschung angesehen werden und fruchtbar waren, werden sie in den Regionalfächern, auch in der Islamwissenschaft, geradezu ausgeblendet. ${ }^{22}$ So gibt es beispielsweise kaum Seminare zu den Thesen Saids oder bezüglich poststrukturalistischer Theorien, die Said für seine Forschungen benutzt und ausweitet. Dies ist inzwischen insofern beachtlich, als dass postkoloniale Theorien zum einen in sämtlichen anderen geistes-, kultur- und sogar geschichtswissenschaftlichen Disziplinen längst erörtert werden und Thema von Tagung sind; zum anderen stellen sie explizit die Frage nach der Darstellung/Repräsentation des (europäischen) Anderen und des eigenen Selbst, die Frage nach der Forschungsperspektive und nach der Subjektwerdung. Dies sind Kernpunkte islamwissenschaftlicher Fächer, da hier sämtliche Aspekte ,der Muslime ‘ und ,des Islam“ von immer noch zumindest zu 90\% Weißen Wissenschaftler/-innen, zumeist christlicher Herkunft, als fremde Religion und Sitten und Bräuche untersucht, erforscht und dargestellt werden. Um Said zu bemühen, beanspruchen Weiße Wissenschaftler/-innen christlicher Herkunft nach wie vor die Autorität der Wahrheit über ,die Muslime“ und ,den Islam‘. Dies geschieht daher auch nicht in einem diskursiven Austausch mit ,den Muslimen“. Vielmehr wird über ,die Muslime“ und ,den Islam“ gesprochen und weite Teile der Welt damit verdinglicht. Obwohl dieser Umstand der Schwerpunkt von Saids Kritik gewesen ist, hat sich bis dato nichts daran geändert. Er wird weiterhin, weil es nachgerade keine Auseinandersetzung mit den Erkenntnissen postkolonialer Ansätze gegeben hat, reproduziert. Auf diese Weise werden ,subalterne Kategorien, Personen und Gruppen mit Eigenschaften belegt. Es wird ein ,Wissen“ über ihr Wesen erzeugt. In diesem Wissen besteht die Hauptaussage in der Artikulation ihrer ,Differenz، in Relation zu der hegemonialen weißen Gruppe. In einer dichotomischen Anordnung werden ihnen Eigenschaften zugeschrieben, die in Opposition zu den (vermeintlichen) Eigenschaften der weißen Gruppe stehen. “23

21 Siehe dazu Alexander Lyon Macfie: Orientalism. A Reader, New York: New York UP 2000 sowie ders., Orientalism.

22 Der renommierte an der Universität Hamburg lehrende Islamwissenschaftler Albrecht Noth gehörte wohl zu den wenigen Orientalisten, die nachdrücklich Saids Buch als unabdingbare Lektüre für ein islamwissenschaftliches Studium empfahlen. So hängt das Kennen von Saids Thesen allein von der Progressivität und dem kritischem Vermögen einzelner Professor/-innen ab, denen Studierende das Glück haben müssen zu begegnen. Eine Selbstverständlichkeit ist es bisher leider nicht.

23 Maureen M. Eggers: Rassifizierte Machtdifferenz, S. 57. 
Inzwischen gehört zum islamwissenschaftlichen Publikum eine große im weitesten Sinne muslimischstämmige Studentenschaft und ist ,der Islam“ in Europa eine nicht zu verkennende Größe mit einer Überzahl an muslimischen Communities, Lebensstilen und interkulturellen und internationalistisch ausgerichteten (künstlerischen) Vernetzungen. Gleichzeitig ist in den letzten Jahren mit dem ,war on terror' und den politisch brisanten Kriegen und kriegerischen Unternehmungen in vielen muslimischen Ländern nicht nur ein mediales und oftmals islamophob geprägtes Interesse an ,dem Islam ‘ und den ,Muslimen“ zu verzeichnen. Auch die Zahl von Konvertiten unterschiedlichster Herkunft in Europa, Lateinamerika und USA wie auch die Zahl der Menschen muslimischer Herkunft, die sich immer mehr zum ,Islam ‘ bekennen und ihre kulturellen oder historischen Wurzeln betonen, wächst - eine Bewegung, die weit über eine antiimperialistische Haltung hinausgeht. ${ }^{24}$ Diesen Veränderungen ist die Islamwissenschaft bisher in keinster Weise gerecht geworden. Ein wichtiger Grund liegt meines Erachtens wiederum darin, dass sie sich neuen theoretischen Ansätzen und philosophischen Überlegungen nicht geöffnet hat und in gewisser Hinsicht gelinde gesagt ,altertümlich“ wirkt. Schwerwiegender jedoch ist, dass sie sich damit auch ihrer politischen und wissenschaftlichen Verantwortung entzieht, zutreffende Aussagen zu machen und Denkräume zu öffnen, sowohl gegenüber der Weißen Bevölkerung christlicher Herkunft, zu der sie selbst mehrheitlich zählt, als auch gegenüber der muslimischstämmigen Bevölkerung und den People of Color in Deutschland, die sie zu ihrem Untersuchungsfeld zählt.

Die Fragestellungen und Ausgangspositionen Postkolonialer Kritik und der Kritischen Weißseinsforschung in Deutschland sind komplex und umfassen vielschichtige Ansätze zur Dekonstruktion hegemonialer Diskurse. Der Beitrag hebt sprachbezogene und geschichtsbezogene Aspekte heraus, um sie skizzenhaft vorzustellen.

Denn es kann und sollte aus den oben genannten Gründen zur Aufgabe der Islamwissenschaft werden, insbesondere angesichts der Tatsache, dass auch People of Color immer mehr einen beachtlichen Teil der Student/-innen und Forschenden in allen ,orientalistischen' Fächern ausmachen, Okzidentalismen und Orientalisierungen zu entlarven und ihre Wirkungsweisen und Darstellungspraktiken zu analysieren.

24 Hisham D. Aidi: Let Us Be Moors. Islam, Race, and ,Connected Histories', in: Souls. A Critical Journal of Black Politics, Culture, and Society 7/1 (2005), S. 3651. Vgl. außerdem ders.: „,Jihadis in the Hood. Race, Urban Islam and the War on Terror", in: Middle East Report Online, http://www.merip.org/mer/mer224/224_ aidi.html vom 16.09.2007. 


\section{Geschichtsbilder als Narration - Alexander der Große, Columbus und ,die Muslime‘}

„When I recall the shame I felt seeing those images, of the Indian and the ,great" white men, I recognize that there is also rage there. I was not only angry at these images, which did not feel right in my heart, I felt that being forced to look at them was like being forced to witness the symbolic reanactment of a colonizing ritual, a drama of white supremacy. The shame was feeling powerless to protest or intervene.

We are not powerless today. “25

Eine wichtige (und mächtige) Disziplin in der westlichen Forschung stellt die Geschichtswissenschaft dar. In der modernen Geschichtswissenschaft, wie sie im 19. Jahrhundert institutionalisiert wurde, wurden nationale Mythen und ein eurozentristischer Blickwinkel und Begriffe etabliert. Auch Universalgeschichten gehen von dieser Interpretation der Geschichte aus und sind somit Europas Geschichte(n) über die Welt. ${ }^{26}$ Weit davon entfernt eine ,objektive ' Wissenschaft zu sein, stellt die ,eurozentrierte Historiographie die koloniale Verdinglichung des Anderen nicht in Frage“, sondern setzt sie auch heute noch fort. ${ }^{27}$ Dies gilt für geschichtswissenschaftliche Arbeiten im Rahmen der Islamwissenschaft wie auch in den Geschichtswissenschaften selbst. Islamwissenschaftliche Arbeiten bleiben oftmals nicht nur in einem dichotomen Blickwinkel verfangen, sie essentialisieren auch unbescheiden eine ,muslimische Geschichte“ nach dem Muster der schon von Said kritisierten europäischen panoptischen Erzählperspektive. Monika Tworuschka etwa lässt ihren Beitrag in dem Band Der islamische Ori$e n t^{28}$ mit folgenden Worten beginnen: „Dem Islam und Muslimen gegenüber begegnen wir [sic! Wer?] in unserer Umgangs-, Bildungs- ja selbst Wissenschafts-

25 bell hooks, Outlaw Culture. Resisting Representations, New York, London: Routledge 1994, S. 205.

26 Siehe dazu Dipesh Chakrabarty: Provincializing Europe. Postcolonial Thought and Historical Difference, Princeton: Princeton University Press 2000 und Sebastian Conrad/Shalinie Randeria (Hg.), Postkoloniale Perspektiven in den Kultur- und Geschichtswissenschaften, Frankfurt/M: Campus 2002; auch Hayden Whites postmodernistische Kritik an Geschichtsschreibung bestätigt die Machtbezogenheit moderner (europäischer) Geschichtsschreibung als integralem Teil der Erzählung. Denn Geschichtsschreibung betrachtet das Vergangene aus der „öffentlichen Gegenwart“ (S. 43) der Machtverteilung auf der Grundlage eines bestimmten Systems der Sinngebung. Daher schlägt White auch vor, die „Politik als mögliches Forschungsobjekt einer wissenschaftlichen Historiographie“ (S. 47) zu verwenden. Soweit entfernt von Foucault ist dies nicht, wenn wir ,Politik' durch den Begriff der ,Macht' ersetzen. Vgl. Hayden White: Die Bedeutung der Form. Erzählstrukturen in der Geschichtsschreibung, Frankfurt/M: Fischer-Verlag 1990, S. 23, 43f.

27 K. Nghi Ha: Postkoloniale Kritik und Migration, S. 47.

28 Albrecht Noth/Jürgen Paul (Hg.), Der islamische Orient. Grundzüge seiner Geschichte, Würzburg: Ergon-Verlag 1998. Dieses Buch wird hier exemplarisch herangezogen. Bemerkenswert ist in diesem Zusammenhang, dass es sich der Geschichte des ,islamischen Orients` aus einer kritischen Perspektive annähern will. 
sprache mit verschiedenen Urteilsformen, die ein richtiges Verstehen dieser Kultur erschweren.“ ${ }^{، 2}$ Die kategorial gebrauchten Wörter ,Islam“ und ,Muslime“ werden als statische Größen verwendet und ,westlichen` Betrachtungen entgegengesetzt, betrieben von einer ,Westlerin` für ein ,westliches‘ Publikum. Hier werden die komplexen Geschichten moderner (Meta-)Erzählungen und Formen des Othering nicht weiter in Betracht gezogen und die Auseinandersetzung mit Mechanismen von Orientalisierungen unterlassen, obwohl gerade dies den Anspruch des Buches ausmacht, nämlich die Repräsentation von ,Muslimen“ kritisch zu überprüfen. ${ }^{30}$ Gudrun Krämers Artikel Die islamische Welt im 20. Jahrhundert veranschaulicht ebenfalls bereits von Beginn an eine orientalisierende, willkürlich gesetzte kartographische Visualität ,der islamischen Welt im 20. Jahrhundert“. Hier wird der Orient geographisch und ideell mit Deskriptionen und Zuschreibungen essentialisiert und dadurch ein Realismus geschaffen, der keinen Raum lässt für kritische Fragen bezüglich etwa von Subjektivität und Forschung, Geschichtskonstruktionen und -methoden, und die eigentlich, nach all der Orientalismuskritik, in dieser allumfassenden, positivistischen Form so gar nicht mehr dastehen dürften: „Das letzte Ereignis, das Muslime in der gesamten islamischen Welt von Marokko bis Java aufrüttelte, dürfte die Abschaffung des Kalifats im Jahre 1924 gewesen sein. “31 Woher nimmt die Verfasserin die Gewissheit über ihre nicht belegte Aussage über die Gruppe ,Muslime"? Woher etwa weiß die Autorin was ,Muslime', geschlechter-, herkunfts-, alters- und schichtübergreifend über ein so weites Gebiet zur gleichen Zeit gemeinsam fühlen können - und dass sie etwas gemeinsam fühlen? Dass solche Aussagen ,die Muslime' essentialisieren, liegt auf der Hand. Und ist es womöglich nicht vielmehr so, dass die Abschaffung des Kalifats für das Selbstverständnis europäischer Mächte und die europäische Geschichtsschreibung von großer Relevanz gewesen ist und entsprechend in ihr tradiert wird, weshalb die Forscherin sie hier reflexartig auf ,die Muslime ' projiziert? An anderer Stelle heißt es:

„Sie [,die Gesellschaften des islamischen Orients'] leiden alle unter den Folgen letztlich von außen induzierter sozioökonomischer Umwandlungsprozesse, die nicht nur in die Strukturen innerhalb der einzelnen Staaten und Gesellschaften eingriffen und weiterhin

29 Monika Tworuschka: „Islam und Vorurteile. Vorurteile und andere Urteilsformen“, in: A. Noth/J. Paul (Hg.), Der islamische Orient, S. 15-24, hier S. 15.

30 Vgl. Vorwort des gleichen Buches; obwohl das Werk von den Arbeiten und Ansichten des Iraners Abdoljavad Falaturi und seiner ,Islamwissenschaftlichen Akademie“ inspiriert ist, die der Unkenntnis und den Rassismen in Schulbüchern zu begegnen bestrebt waren, und damit indirekt Orientalisierungen thematisieren, versäumt es die islamwissenschaftliche Perspektive, hier theoretische und methodische Fragen explizit zu problematisieren. Vgl. ebd., S. 439-504, hier S. 440.

31 Gudrun Krämer: „Die islamische Welt im 20. Jahrhundert“, in: A. Noth/J. Paul (Hg.), Der islamische Orient, S. 440. 
eingreifen, sondern auch die Gewichte zwischen den einzelnen Staaten und Regionen verändern oder zumindest neu akzentuieren. ${ }^{\text {(32 }}$

Dies ist eine ebenso vage wie allgemeine Aussage, die grundsätzlich für jegliche menschliche Gemeinschaft zutrifft. Interessant in diesem Rahmen ist der Ausdruck „letztlich von außen induzierter“. Zunächst atmet die Formulierung das Bild eines unveränderlichen, passiven ,Orients‘, der sich erst durch europäische ,Induktionen' in Bewegung gesetzt hat (und dann wohl auch noch in die falsche Richtung?). Außerdem erscheint damit das ,Außen', und damit die gewaltvolle Kolonisierungsgeschichte Europas, wie ein natürlicher Geschichtsprozess und ,Europa' als aktive und handelnde Macht. Damit reiht sich diese moderne Erzählperspektive in die bisherigen Okzidentalismen ein.

Es müssen neue Zugänge der Erkenntnis erkundet werden, um solchen Fallstricken zu entgehen. Dafür ist es als Erkenntnisbasis unerlässlich, Kultur und Identität als die instabilen, formbaren und stets im Wandel begriffenen Größen zu begreifen, die sie sind.

„Kultur, Identität und natürlich auch Herkunft existieren. Sie bestimmen in einem gewissen Grade die Handlungsweisen und die Wahrnehmung des Menschen, aber sie sind komplexe, veränderbare, in vieler Hinsicht wählbare und von vielen Faktoren bestimmte Parameter - und damit individuelle Größen. [...] Die antirassistische Auseinandersetzung muss also bereits in die vorgelagerten Debatten eingreifen. Kultur, Identität und Herkunft sind als konstruierte Begriffe zu entlarven, die in Form der Fremdzuschreibung zurückgewiesen und als Eigenbestimmung neu geprägt werden [müssen]. ${ }^{\text {‘33 }}$

Es gibt sicherlich auch kritische Ansätze in der Islamwissenschaft. So hat Reinhard Schulze in seinen Arbeiten auf die Monopolstellung eurozentristischer Wahrheitserzählungen hingewiesen: „Mein grundsätzliches Argument ist, dass der Ausschluss der islamischen Welt aus der europäischen Begriffsgeschichte ein Ergebnis der europäischen Historiographie des 19. Jahrhunderts ist. Hierdurch wurde der globale Aspekt der Kulturgeschichte der Neuzeit verdeckt und auf ein europäisches (westliches) Niveau reduziert. “34 Schulze ist bestrebt, die ,muslimische' Geschichte mit Begriffen zu erfassen, die für die europäische Geschichtsschreibung reserviert sind. Auch dieser Ansatz vermag jedoch nicht die binären dichotomen Vorstellungen von ,europäisch“ und ,muslimisch`zu überbrücken. Er dezentriert nicht die Dominanz eurozentristischer Definitionsbestimmungen und -macht, sondern bestätigt sie im Gegenteil umso mehr. Gewinnbringender mag es

32 Vgl. ebd., S. 441.

33 Sascha Zinflou: „Entwurfsmuster des deutschen Rassismus. Ein theoretischer Überblick“, in: K. Nghi Ha u.a. (Hg.), re/visionen, S. 55-64, hier S. 64.

34 Reinhard Schulze: „Die islamische Welt in der Neuzeit (16.-19. Jahrhundert)“, in: A. Noth/J. Paul (Hg.), Der islamische Orient, S. 333-405, hier S. 333. 
daher sein, die Begriffe selbst zu dekodieren, zu historisieren und auf diese Weise eine interdependente globale Historiographie zu entwickeln.

Doch solche eurozentristischen Kanonisierungen von (Welt-)Geschichte sind nicht allein islamwissenschaftlichen Arbeiten eigen (nur sollten sie dort vielleicht am wenigsten auftauchen). Dies soll noch beispielhaft an dem Band Zivilisierungsmissionen - Imperiale Weltverbesserung seit dem 18. Jahrhundert ${ }^{35}$ gezeigt werden. Interessant sind hier bereits die bildliche Darstellung und sprachliche Untermauerung dieser naturalisierenden Realismusproduktion. Im einführenden Text zum Sammelband von Boris Barth und Jürgen Osterhammel werden trotz der Zentralität der Thematik Postkoloniale Theorien nicht erörtert und Fragen der Hegemonie nicht problematisiert, sondern diskutiert, wann das Eingreifen westlicher Mächte, im Sinne einer zivilisierenden Mission sinnvoll erscheint. Zunächst einmal ahistorisieren die beiden Historiker ihr eigenes Forschungsfeld und die Fragestellung. Denn sowohl die Begriffe ,Zivilisation“ und ,Zivilisierungsmissionen' als auch die (militärische) Intervention westlicher Mächte stehen in einem historischen Kontext. ${ }^{36}$ Der Hype um Themen des Empire in der Geschichtsforschung scheint sich ohnehin nicht zuletzt dem Anwachsen postkolonialer Theorien zu verdanken. Doch die Herausgeber entziehen sich dieser Fragestellung, indem sie sie stillschweigend übergehen. Auf dem Coverbild des Buches wird auch wenn dies eigentlich, ironisch ' gemeint sein mag und es uns in der Tat amüsiert - sogar einer hegemonialen Sicht Genüge getan. Darauf ist ein Weißer Mann, offensichtlich eine Mischung aus ,Alexander der Große', ,Columbus ‘ und ,Napoleon' zu sehen, welcher in herrschaftlicher Pracht, mit breiter Brust und erhobenen Hauptes, sein Schwert in Schulterhöhe mit ausgestrecktem Arm hält. Auf dem Gürtel seiner prachtvollen Rüstung ist in großen verzierten Lettern das Wort Europa geschrieben. Vor ihm sind zwei eher grimmig und böse aussehende afrikanisch-asiatische männliche Figuren in zivilen Kleidungen abgezeichnet, die in starkem Kontrast stehen zur Rüstung des Weißen Eroberers; dass beide perspektivisch unter ihm gezeichnet sind, verstärkt noch den Eindruck ihrer Niederlage. Frauenperspektiven sind hier ausgelöscht. Da fragen wir uns gerade auch als Women of Color in der Tat, was Europa sich ohne viel Aufsehens nach wie vor alles erlauben kann. Die Perspektive entspricht einem Weißen patriarchalischen Männlichkeitsbild; ${ }^{37}$ darüber hinaus zeigt das Bild eine polarisierte Auftei-

35 Hrsg. von Boris Barth und Jürgen Osterhammel, Konstanz: UVK Verlagsgesellschaft mbH 2005.

36 Vgl. dazu und insbesondere zum Begriff Zivilisation auch im deutschen Kontext Robert Young: Colonial Desire. Hybridity in Theory, Culture and Race, London, N.Y.: Routledge 1996, S. 30f.

37 Sandra Maß: Weiße Helden - Schwarze Krieger. Zur Geschichte kolonialer Männlichkeit in Deutschland 1918-1964, Köln u.a.: Böhlau-Verlag 2006. Siehe außerdem die dritte Tagung des Arbeitskreises für interdisziplinäre Männer- und Geschlechterforschung (AIM Gender) 24.-26. Juni 2004 zum Thema Hegemoniale Männlich- 
lung zwischen dem siegreichen Weißen Mann (Singular) und den besiegten Men of Color (Plural). Auch dieses Bild steht damit in der Tradition europäischer Geschichtsschreibung seit dem 19. Jahrhundert, die die Rolle eines starken Weißen Mannes als verdient siegreichen tapferen Eroberer beansprucht und gleichzeitig Men of Color als inferior zeigt. Was dieses Bild wohl vollkommen gemacht hätte, wären noch verschleierte und aufreizend gezeichnete Women of Color gewesen, die der große Weiße Mann vor ihren barbarischen, dunklen Männern rettet. ${ }^{38}$ In dem Bild werden gegenderte Weiße rassisch-kulturelle Geschichtsverständisse aus dem europäischen 18. Jahrhundert wiederholt. Das Bild zeigt, dass ,Europa ‘ die Repräsentation der Anderen als Unterlegene betreibt, um sich selbst als überlegen darstellen zu können. ${ }^{39}$

Obwohl die Umstrittenheit eines Begriffs wie ,Zivilisierungsmission“ den Herausgebern nicht entgangen ist, heißt es: „Wir sind nicht auf eine flache Weise ,für' oder ,gegen' Zivilisierungsmissionen in der Gegenwart. Niemand mit einem um historischen Abstand zu herrschenden Ideologien bemühten Urteil wird bestreiten, dass sich die Probleme nicht mit einem schlichten Entweder-Oder lösen lassen. Zivilisierungsmission ist nicht dasselbe wie ein Kreuzzug oder Angriffskrieg [...].“40 Was aber ist der genaue Unterschied zwischen einer ,Zivilisierungsmission“, einem ,Kreuzzug ' oder ,Angriffskrieg ' und wer ist ermächtigt, über ihre Definitionen und Abgrenzungen zu entscheiden? Es entsteht der Eindruck als würden hier Begriffe willkürlich anachronistisch und sinnentraubt neben einander gestellt, um letztlich einer hegemonialen Betrachtung zu dienen. Der pädagogische Unterton lässt darauf schließen, dass hier gegen jene polemisiert wird, welche der Rhetorik dominanter Diskurse und Sprache widersprechen. Haarsträubender wird das Vorwort noch durch weitere Behauptungen: „Ein Ausdruck gedankenloser politischer Korrektheit ist es, zugleich die Respektierung und Verbreitung der Menschenrechte zu fordern und die Idee der Zivilisierungsmission zu verdammen. “41 Warum? Dies würde bedeuten, dass ohne europäische ,Zivilisierungsmissionen“ (also westliche Gewalt?) Menschenrechte nicht durchzusetzen sind. Setzt der Satz so formuliert nicht ein absolutes Kriegsrecht der über die Menschenrechte Verfügenden (und wir wissen, wen wir zu diesen zählen dürfen) fest und macht die Menschenrechte zur modernen Bürde des Weißen Mannes? Der koloniale Bezug ist hier zumindest nicht ausgeräumt. Die Sprechpositionen sind hier klar an Weiße Westler/-innen vergeben. Gesprochen wird

keit(en), http://www.ruendal.de/aim/tagung04/index.php3 vom 03.11.2007 sowie http://hsozkult.geschichte.hu-berlin.de/tagungsberichte/id=641 vom 03.11.2007.

38 Vgl. Gayatri Chakravorty Spivak: „Can the Subaltern Speak?“, in: Cary Nelson/Lawrence Grossberg (Hg.), Marxism and the Interpretation of Culture, London, Hampshire: MacMillan Education 1988, S. 271-313, insbesondere S. 294f.

39 R. Young: Colonial Desire, S. 35.

40 B. Barth/J. Osterhammel (Hg.), Zivilisierungsmissionen, S. 8.

41 Vgl. ebd. 
aus der Position des hegemonialen Diskurses. Im Gegensatz zum Wort ,Zivilisierungsmission“ wird hier zum Beispiel das Wort ,imperialistisch“ in Anführungszeichen gesetzt (warum?), jedoch nicht einmal mit einem Verweis definiert oder problematisiert. Dabei hängt doch ,Zivilisierungsmission“ mit der Ausübung von Gewalt und mit Machtverhältnissen zusammen. Das tief im imperialen westlichen Denken verankerte Wort ,Zivilisiertheit ' dürfte sich jedenfalls kaum für universalistische Wertmaßstäbe eignen. ${ }^{42}$ Das Recht, ,,um kritischen Abstand zu herrschenden Ideologien bemühte Historiker und Historikerinnen“ zu sein, scheinen außerdem ausschließlich Weiße, westliche Historiker und Historikerinnen zu besitzen, ${ }^{43}$ denn nicht ein/e einzige/r Wissenschaftler/-in afrikanischer, asiatischer oder lateinamerikanischer Provenienz und postkoloniale/r Wissenschaftler/in ist hier vertreten. Das spricht für sich genommen Bände. Auf diese Haltung trifft auch die Analyse Zinflous zum Entwurfsmuster des deutschen Rassismus zu, in welcher es heißt: „Der rassistische Blick auf die Peripherie erlaubt es, die gewalttätigen Konflikte weltweit nicht als Folge und als Instrument der herrschenden globalen Machtverhältnisse zu verstehen, sondern als ,barbarischen Urzustand', angesichts dessen sich die Machtverhältnisse als bessere Alternative durchsetzen müssen. “44

Der aus dem Rahmen fallende Artikel von Andreas Eckert ${ }^{45}$ im selben Band macht deutlich, dass die Analyse und Überwindung imperialer Wissenschaftsperspektiven und -produktionen durchaus möglich ist. Sein Ansatz spiegelt eine Weiße Objektivität und Verantwortlichkeit wider, die die Perspektiven von allen Menschen in Betracht zu ziehen bemüht ist. So gebraucht Eckert den Begriff $\mathrm{Zi}$ vilisierungsmission ,eher in einem Austausch- und Aneignungsprozess“. ${ }^{46}$ Eckert ist sich des imperialen Gebrauchs und rassistischen Anklangs von ,Zivilisierungsmission“ durchaus bewusst, setzt das Wort durchgängig in Anführungszeichen und macht seine Kritik zunächst mit folgenden Worten deutlich:

„Zunächst atmet der Begriff für meinen Geschmack zu stark das Parfum einer altmodischen Imperialismusgeschichte, die vorwiegend die Kolonisierenden im Blick hat und an den kolonisierten Afrikanern wenig oder kein Interesse zeigt. Nach einem genaueren Blick auf verschiedene afrikanische Lokalitäten erwies sich ,Zivilisierungsmissionen“

42 Siehe zu dieser Thematik z.B. Rosa Amelia Plumelle-Uribe, Weiße Barbarei, Gudrun Hentges, Schattenseiten der Aufklärung. Die Darstellung von Juden und ,Wilden' in philosophischen Schriften des 18. und 19. Jahrhunderts, Schwalbach: Wochenschau-Verlag 1999.

43 B. Barth/J. Osterhammel (Hg.), Zivilisierungsmissionen, S. 8f.

44 Sascha Zinflou: „Entwurfsmuster des deutschen Rassismus. Ein theoretischer Überblick“, in: K. Nghi Ha u.a. (Hg.), re/visionen, S. 55-64, hier S. 62.

45 Andreas Eckert: „Die Verheißung der Bürokratie. Verwaltung als Zivilisierungsagentur im kolonialen Westafrika“, in: B. Barth/J. Osterhammel (Hg.), Zivilisierungsmissionen, S. 269-283.

46 Vgl. ebd., S. 276. 
[...] in meinen Augen zudem letztlich als rhetorische Strategie, die nur schlecht rassistische Vorurteile und gradlinige ökonomische Interessen $\mathrm{zu}$ verbergen vermochte. Schließlich schien ,Zivilisierungsmission“ nicht besonders hilfreich, um die Dialektik von universalen Ansprüchen, die mit Kolonialherrschaft verknüpft waren, und spezifischen Machtstrukturen in verschiedenen Teilen Afrikas herauszuarbeiten. ${ }^{* 47}$

Dann wendet Eckert die Bedeutung des Begriffs für seinen Arbeitsansatz um, indem er die Perspektive auf die Handlungsmacht und Subversion der Kolonisierten lenkt, und damit selbst eine subversive Strategie der Umdeutung der hegemonialen Fragestellung betreibt:

„Und siehe da, es erwies sich als durchaus nützlich, um einige der zentralen Aspekte kolonialer Herrschaft in Afrika zu beleuchten. Ich möchte mich der Frage widmen, welche Handlungsspielräume die europäische Kolonialherrschaft der afrikanischen Bevölkerung eröffnete. Dabei werde ich [...] betonen und darlegen, wie afrikanische Verwaltungsmitarbeiter [...] die Absichten der Kolonialadministration unterlaufen und ihre [eigenen] Interessen stärken konnten [sic!]““. 48

\section{Don't ask for the meaning, ask what's the point ${ }^{49}$}

„It is rather a question of repositioning European systems of knowledge so as to demonstrate the long history of their operation as the effect of their colonial other, a reversal encapsulated in Fanon's observation: ,Europe is literally the creation of the Third World'. We should not assume either that the anti-colonialism has been confined to ower own age: sympathy for the oppressed other, and pressure for decolonization, is as old as European colonialism itself. What has been new in the years since the Second World War during which, for the most part, the decolonization of the European empire has taken place, has been the accompanying attempt to decolonize European thought

47 Vgl. ebd., S. 269.

48 Ebd.; interessant ist im Weiteren der Artikel von Sebastian Conrad: „Die Zivilisierung des ,Selbst“ - Japans koloniale Moderne“, S. 245-268; hier wird der Begriff des Kolonialismus nicht undifferenziert auf außereuropäische Gebiete übertragen, wie häufig in der bisherigen Forschung, wobei oft der europäische, Weiße Kolonialismus als ,natürliches', ,menschliches' Phänomen konstruiert und enthistorisiert wird. Vielmehr werden die Effekte des Weißen Kolonialismus auf Japans politisches Innen- und Außenbild in den Blick genommen. Dabei wird der Begriff der ,Selbstkolonisierung' gebraucht. Die Frage aber ist, inwieweit dies eine japanische Ausnahmesituation darstellt und ob dies nicht die Regel kolonialer Begegnungen ist, nach der kolonisierte Andere (meist elitärer Schichten) sich selbst nach den vorgegebenen Maßstäben der hegemonialen, westlichen Herrschaft neu messen und definieren mussten.

49 Jan Hacking zitiert nach D. Scott: The Construction of Postcolonial Studies, S. 385. 
and the forms of its history as well. It thus marks that fundamental shift and cultural crisis currently characterized as postmodernism. “50

Nicht die lückenlose Konstruktion von Geschichte(n) und die lineare Betrachtung von Phänomenen können mehr im Blickfeld stehen. Vielmehr müssen Erzählungen, sollen sie kohärent sein, Spuren folgen, ${ }^{51}$ Spuren, die sich verwandeln, zu neuen Ganzheitlichkeiten führen und sich wieder in vielfältige Abzweigungen verlieren. Eine Sicht, die nach der Vollkommenheit einer (wissenschaftlichen) Erzählung strebt, muss den Verlust und die Brüche mitdenken, Stimmen zulassen, und sei es auch in ihrer Unauffindbarkeit, in ihrer Tonlosigkeit, die fortbestehen, außerhalb hegemonialer Erfassbarkeit und vielleicht außerhalb des tradierten, verschriftlichten Wissens eines Weißen und hetero-patriarchalischen hegemonialen Kanons, denn sonst - und das charakterisiert die westliche Epistemologie - ist die angestrebte Ganzheitlichkeit selbst nur ein Bruchstück. Beginnen können wir damit jedoch nur mitten in der Welt, in der wir sind. Die Welt, die wir kennen, oder vielmehr zu kennen glauben, wird durch die Sprache (hegemonialer Diskurse) konstituiert. In Abgrenzung zu ihnen entwickeln sich auch widerständige Diskurse (counter-discourses). Das komplexe Feld Postkolonialer Theorien und der Kritischen Weißseinsforschung kann als Ausgangspunkt für interdisziplinäre und interdiskursive (emanzipatorische) Betrachtungen genommen werden, die sich der Darstellung islambezogener Themen annehmen. Eine Betrachtung,der Muslime“ ist jedoch nicht von den Betrachtungen ,der Anderen“ schlechthin, die im europäischen Kontext insbesondere ,die Juden“ darstellten, zu trennen.

Damit wird die Forschungsperspektive geändert, nicht positivistische, fixierende Aussagen über ,die Muslime \%,die Anderen'stehen mehr im Vordergrund, sondern der Kontext der Fragen, der Fragenden und Aussagen über ,die Anderen'. Auf diese Weise kann eine diskursive Unabhängigkeit erreicht werden und können etwa Menschen muslimischer Herkunft Subjekte ihrer Betrachtungen und Lebensarten sein, denn sie sind weder geographisch noch künstlerisch, weder religiös noch ethnisch, weder sprachlich noch epochal eine ausmachbare Größe, sondern eine stets im Wandel begriffene inter- und trans- geographische, künstlerische, religiöse, ethnische, sprachliche und epochale Mannigfaltigkeit. Das gibt uns auch die Möglichkeit, Fragen nach Rassismen in den muslimischen Gesellschaften und Communities zu stellen, indem wir die Effekte Weißer Rassismusvorstellungen dabei überprüfen. ${ }^{52}$ Auch können auf diese Weise zum Beispiel

50 R. Young: White Mythologies, S. 119.

51 Vgl. zum Ausdruck und Idee des Denkens der Spur É. Glissant: Kultur und Identität.

52 So beispielsweise die Selbstdarstellungen iranischer Hegemonialansprüche, die stark nach dem Muster von Weißsein in seiner Entsprechung des Arianischsein aufgebaut sind und sich auch im politischen Alltag, so in der iranischen Flüchtlingspo- 
historische Schnittstellen und gemeinsame Erfahrungen zwischen Menschen jüdischer und muslimischer Herkunft oder hinduistischer und muslimischer Herkunft untersucht werden, die einem Teilen-und-Herrschen-Mechanismus zuwiderlaufen und neue Wege gemeinsamen Handelns ermöglichen. ${ }^{53}$ Jede Aussage allerdings über ,die Muslime“ oder ,die Juden' und ,die Anderen' beinhaltet Aussagen über die Weißen Sprechenden und ihre Blickwinkel. Dort liegt der Orient (begraben) und der Hase im Pfeffer. Es ist möglich, seinen Spuren auf allen Ebenen nach zu gehen und neue Sprache(n) und Subjektivitäten wiederzufinden, um andere Referenzwelten bilden zu können - im Sinne von dekolonisierender humanistischer Wissensproduktion und Ökonomie.

litik in Rassismen gegenüber Menschen afghanischer Herkunft niederschlagen. Vgl. zu deren Widerspieglung in der Forschung kritisch Wali Ahmadi: „Exclusionary Poetics. Approaches to the Afghan ,Other' in Contemporary Iranian Literary Discourse“, in: Iranian Studies 37/3 (2004), S. 407-429, online Publikation: http://dx. doi.org./10.1080/00286042000287514 vom 18.08.2007. Wichtig in diesem Zusammenhang wäre es etwa die Effekte des ,Arianismus' im post-kolonialen farsisprachigen Raum zu dekonstruieren. Bezogen auf den indischen Raum gibt es bereits erste Untersuchungen. Vgl. Tony Ballantyne: Orientalism and Race. Aryanism in the British Empire, Houndsmills, N.Y. u.a.: Palgrave 2002.

53 Erste Ansätze hin zu einer solchen Betrachtung gibt es bereits. Vgl. I. Davidson Kalmar/D. J. Penslar (Hg.), Orientalism and the Jews. 


\section{Zur Zukunft der Islamwissenschaft ${ }^{1}$}

NAVID KERMANI (KÖLN)

Das Fach, das sich der Erforschung der islamischen Welt widmet, ist ein Ungetüm. Das Spektrum der Themen, Disziplinen, Methoden und historischen Epochen, das es abzudecken sich vornimmt, ist um vieles zu weit, um sinnvoll in einem einzigen Zusammenhang erforscht und gelehrt zu werden. Die Absurdität ihres Anspruches erweist sich sofort, wenn man sich zur Islamwissenschaft ein Pendant vorstellt: ein einziges Fach, das die Religion, Kultur, Geschichte, Sprache, alte wie neue Literatur, Philosophie, die heutige politische Wirklichkeit, ja die Musik, das Theater, das Recht, die Geschichte der Naturwissenschaften sowie alle anderen für die Geistes- und Sozialwissenschaften relevanten Aspekte nicht nur der europäischen, sondern weltweit aller christlichen Konfessionen, Kontinente, Nationen und ethnischen Minderheiten behandelt, und dies ausgerechnet unter einem Titel wie ,Christliche Wissenschaft" oder ,Christenwissenschaft", also mit der impliziten Annahme, dass alle diese Phänomene einen Bezug zur Religion hätten und mit Blick auf diese studiert werden sollten. Mochte am Ausgang des 19. Jahrhunderts ein Gelehrter die Quellentexte und Forschungsarbeiten des Faches noch einigermaßen übersehen, kann heute kein Islamwissenschaftler das gesamte Spektrum abdecken, und nur wenige versuchen es noch.

Die Problematik, die dem Fach Islamwissenschaft - ähnlich wie anderen Regionalwissenschaften, die allerdings in der Regel nicht zusätzlich mit dem Ballast beschwert sind, den Bezug zur Religion im Namen zu führen - eingeschrieben ist, dürfte von kaum jemanden noch bestritten werden. Reflektiert worden ist auch und vor allem, wie fatal sich das religiös-theologische Vorzeichen, unter dem das Fach betrieben wird, auf das öffentliche Bild der Kulturen ausgewirkt hat, die vom Islam mitgeprägt worden sind. Seit die frühe Orientalistik den Islam als autonome anthropologische Größe behandelte, welcher der Muslim willenlos ergeben sei, und die Religion der Muslime zur Ursache ihrer Unterlegenheit und strukturellen Reformunfähigkeit erklärte, wurde die muslimische Urgeschichte zum Deutungsmuster auch der Gegenwart. In verblüffender Analogie zu heutigen

1 Der Text basiert auf meinem Aufsatz „Moderne und Islam”, erschienen in: Dieter Grimm: (Hg.), 25 Jahre Wissenschaftskolleg zu Berlin 1981-2006, (Akademie Verlag), S. 229-242. 
islamistischen Auffassungen nahm man einen islamischen Urzustand an und betrachtet die Geschichte und die Kultur vorrangig unter der Frage, inwiefern sie der frühislamischen Norm entspreche bzw. zu einem Abweichen von ihr geführt habe. Nicht religiös determinierte Phänomene, Diskurse und Strömungen wurden so fast automatisch als heterodox gedeutet, anstatt in jener Autonomie wahrgenommen zu werden, die etwa Shakespeare, dem Zweiten Weltkrieg oder der Phänomenologie des Geistes zukäme, die eine religiöse Dimension wohl haben, jedoch unmöglich auf diese zu reduzieren oder gar allein von der Bibel aus zu verstehen sind. Dieser essentialistische Blick ist zwar innerhalb der Islamwissenschaft längst in Frage gestellt, beherrscht aber noch immer weite Teile der öffentlichen Darstellung. Der Islamwissenschaftler Aziz al-Azmeh sieht hier „fast eine Art Komplizenschaft zwischen westlichen Kommentatoren und islamistischen Ideologen", da auf beiden Seiten die Urbegründung jedes Phänomens in der islamischen Welt in den religiösen Quellentexten angesiedelt werde. ${ }^{2}$ Eine Betrachtung von solcher Normativität würde sich in Bezug auf die Geschichte und Gegenwart der ,christlichen Welt‘ von selbst diskreditieren.

Die Obsession des Westens, den Orient durch seine Religion zu verstehen, macht sich bis heute in den Lehrplänen, ja bis in die Fächeraufteilung bemerkbar, die in die Erforschung eines gemeinsamen Kulturraums konfessionelle Schneisen schlägt. An vielen großen Universitäten in Deutschland gibt es Seminare für Islamwissenschaft, für Judaistik und einige wenige für die Wissenschaft vom christlichen Orient. Eine Verbindung zwischen diesen Seminaren besteht in der Regel nicht - eine Folge auch des Nationalsozialismus, der die Tradition herausragender jüdischer Orientalisten in Deutschland und die häufig mit ihnen korrespondierende Wissenschaft des Judentums abgebrochen hat. Heute lernen nur wenige Studenten, die sich mit der islamischen Theologie, Philosophie oder Mystik beschäftigen, die Werke jüdischer oder christlicher Autoren kennen, obwohl diese zur gleichen Zeit, in der gleichen Stadt, ja, in der gleichen Gasse entstanden sein könnten wie der Traktat, über den sie sich gerade beugen. Von der klassischen Poesie der arabischsprachigen Juden etwa hören Studenten der Arabistik kaum mehr, als dass sie existiert. Dabei ist diese Dichtung in ihren Motiven und Gedanken selten spezifisch jüdisch, sondern weltlich ausgerichtet - wie die Werke vieler muslimischer Dichter auch. Sie ist in unmittelbarer Nachbarschaft zur arabischen Dichtung und ihren Genres entstanden und teilt mit ihnen den islamisch gefärbten Hintergrund der arabischen Hofkultur. Umgekehrt lernen nur die wenigsten Studenten der Judaistik die arabische Sprache, obwohl wesentliche Werke der jüdischen Philosophie, Poesie oder Mystik von Autoren verfasst worden sind, die Arabisch sprachen, schrieben und sich an eine arabischsprachige Öffentlichkeit wandten.

2 Vgl. Aziz Al-Azmeh: Die Islamisierung des Islam. Imaginäre Welten einer politischen Theologie, Frankfurt/M u.a.: Campus 1996. 
Die Literaturen, die Künste und die religiösen Traditionen des arabisch geprägten Kulturraums sind historisch so eng miteinander verflochten - oft bis zur Ununterscheidbarkeit -, dass sie nur im Zusammenhang studiert und dargestellt werden können. So setzt sich die islamische Theologie zu einem beträchtlichen Teil aus Antworten auf Fragen zusammen, die vom Judentum und vom Christentum an sie herangetragen worden sind - an den Höfen und in den Gelehrtenstuben von Bagdad oder Cordoba. Ohne diese Fragen bleiben die Antworten unverständlich. Nicht viel anders steht es mit dem Judentum: Nicht nur das christliche Europa, auch die Philosophen unter den rabbinischen Gelehrten wie der in Ägypten geborene Saadiya ha-Gaon (st. 942), Abraham ibn Daud aus Toledo (st. 1180) oder Moses Maimonides (st. 1204) empfingen das antike Erbe zum großen Teil in seiner Prägung durch die arabisch-islamische Kultur. Ohne Kenntnis dieser Kultur lässt sich nicht verstehen, wie das Judentum nicht nur auf den Islam, sondern später der Islam auch auf das Judentum zurückgewirkt hat, in der Theologie und deutlicher noch in der Mystik sowie in der Literatur. In der arabischislamischen Kulturgeschichte spielten dabei orientalische Christen als Übersetzer und Bearbeiter griechischer Texte eine entscheidende Rolle. Der Prozess wechselseitiger Beeinflussungen verlief selten konfliktfrei - auch nicht im heute gerne verklärten Andalusien der Mauren. Muslime, Juden, Christen und Agnostiker, Araber, Perser, Türken und andere Völker verfolgten und unterdrückten einander und grenzten sich gegeneinander $\mathrm{ab}$ - blieben aber in der entscheidenden Phase ihrer Kulturentwicklung im arabisch geprägten Raum eng aufeinander bezogen.

In der Formationsphase des Judentums wie des Islams (genauso wie des Christentums) waren Identitäten kaum so eindeutig festgelegt, wie es heute scheint. Das „Wir“ etwa in der arabischen Philosophie oder der arabischen Dichtung ist oft genug kein „Wir Muslime“, „Wir Juden“ oder „Wir Christen“; es ist ein „Wir Philosophen“, dem das „Ihr“ etwa der Mystik oder der Rechtswissenschaft entgegengesetzt wird, seien diese islamisch oder jüdisch. Genauso wie Maimonides sich auf die Werke muslimischer Autoren bezog, hatte er selbst wiederum muslimische Leser, darunter Dozenten, die einem jüdischen Publikum die Philosophie Maimonides' erklärten. Ein muslimischer Philosoph wie alFarabi (st. ca. 950) hat, ohne dass es weiter bemerkenswert gefunden worden wäre, einen großen Teil seiner Ausbildung bei dem nestorianischen Lehrer Ibn Yunus (st. 940) erlangt, der wiederum christliche und muslimische Lehrer gehabt hatte. Dies und unzählige andere Beispiele der Interaktionen waren möglich und selbstverständlich, weil die jüdische, christliche und muslimische Intelligenz des arabisch geprägten Kulturraums sich mit denselben Grundfragen beschäftigte, ohne notwendig dieselben Antworten zu geben oder die sozialen und rechtlichen Unterschiede zwischen den Gruppen aufzuheben. Von manchen religionsphilosophischen Texten lässt sich bis heute nicht einmal mit Bestimmtheit sagen, ob sie von einem Juden oder einem Muslim geschrieben worden sind. Die Durchlässigkeit jenes arabisch geprägten Kulturraums ist vielleicht nicht so sehr anders zu denken als jene der heutigen westlich geprägten Literatur, an der auch Autoren 
wie Adonis, Orhan Pamuk oder Haruki Murakami teilhaben, ohne ihre eigene Herkunft und nationale Bindung zu leugnen, sich als westlich oder auch nur verwestlicht bezeichnen zu müssen. Ein Studium arabischer, hebräischer oder persischer Texte jener Jahrhunderte aus einem ausschließlich judaistischen bzw. islamwissenschaftlichen Blickwinkel führt zu einer Beschränkung der Sinnebenen, zu einem Übergewicht religiös-konfessioneller Momente in der Deutung: So werden Autoren, die sich ursprünglich längst nicht so eindeutig auf eine einzelne Identität bezogen, sondern allgemeine theologische, poetische oder philosophische Themen behandelten, nachträglich auf ihre Konfession hin gelesen.

Gelegentlich explizit, jedenfalls aber implizit versuchen die meisten deutschen Islamwissenschaftler heute der religiösen Determinierung des Faches, die in seinem Namen angelegt ist, zu entkommen, indem sie sich als bloße Regionalwissenschafter des Nahen und Mittleren Ostens begreifen. Die islamischen Quellentexte werden im Grundstudium - häufig en passant - behandelt, spielen aber danach nur noch für jene Studenten und Lehrer eine hervorgehobene Rolle, die sich auf theologische Fragestellungen konzentrieren. Die daraus resultierende Spezialisierung auf einzelne, weitgehend selbstständige Bereiche innerhalb der Islamwissenschaft, die mit dem Islam selbst häufig nichts mehr zu tun haben, erscheint schon aus arbeitsökonomischen Gründen unausweichlich, vollzog sich allerdings bis vor einigen Jahren noch weitgehend unreflektiert. Sie war keinem Konzept, sondern den begrenzten Kapazitäten an den einzelnen Seminaren geschuldet.

Dass die islamwissenschaftliche Forschung in ihren verschiedenen Ausrichtungen heute vorwiegend als Regionalstudium betrieben wird, lässt in Deutschland - mit einiger Verspätung gegenüber den Vereinigten Staaten - den Problemhorizont der area studies aufziehen. Während sich die - in ihrem Selbstverständnis universalen - systematischen Disziplinen wie die Geschichte, die Literaturwissenschaft, die Theologie oder die Rechtswissenschaft gemessen an ihrem empirischen Repertoire zu partikularen westeuropäischen Regionaldisziplinen entwickelt haben, wird die Forschung zur restlichen Welt an institutionell schwach ausgestattete und methodisch überforderte Disziplinen wie die IslamAfrika- oder Asienwissenschaften delegiert. Die Folgen dieser Entwicklung sind in doppelter Hinsicht bedenklich: Islamwissenschaftler nahmen lange Zeit die zentralen Veröffentlichungen, die innerhalb der entsprechenden Hauptdisziplin Aufsehen erregen, allenfalls am Rande zur Kenntnis und hinkten in ihrer Methodik, Fragestellung und sogar im Stil oft um Jahrzehnte zurück: Sammelbände, die sich methodisch in ostentativer Naivität mit arabischer oder persischer Literatur beschäftigen, ohne sich auch nur in Fußnoten auf gegenwärtige Diskussionen innerhalb der allgemeinen Literaturwissenschaft zu beziehen, gehörten und gehören ebenso zum Bild wie die Philologen des klassischen Arabisch, die in den Medien zu aktuellen politischen Vorgängen Stellung nehmen müssen, nur um jenen journalistischen ,Experten“ nicht gänzlich das Feld zu überlassen, die ihre mangelnden sprachlichen und historischen Kenntnisse mit aufbrausenden Vorur- 
teilen aufwiegen. Am ehesten noch ist es der sozialwissenschaftlich orientierten Islamwissenschaft gelungen, Anschluss zu finden an die Diskussionen innerhalb der entsprechenden Hauptdisziplinen; die zunehmende Attraktivität der sozialwissenschaftlichen Islamforschung, die sich in der Lehrstuhlvergabe und der Zahl der Studenten manifestiert, dürfte einen Grund auch darin haben, dass sie ihre eigene Relevanz über das eigene Fach hinaus zu vermitteln begonnen hat.

Indem die Islamwissenschaft den allgemeinen sozial- und mehr noch den kulturwissenschaftlichen Diskurs weitgehend ignorierte, isolierte sie sich und wurde für andere Forscher, die sich mit verwandten Themen in anderen Sprachen beschäftigen, unattraktiv, häufig unlesbar. Tatsächlich werden islamwissenschaftliche Forschungsarbeiten außerhalb ihres eigenen, eng umgrenzten Gebietes noch immer zu selten wahrgenommen. Allgemeine historische, kulturgeschichtliche oder politikwissenschaftliche Studien namhafter Autoren zeugen immer wieder von eklatanter Unkenntnis, sobald sie den islamischen Kulturkreis streifen (wenn sie ihn nicht einfach ignorieren). Diese Situation ist bedauerlich für die Islamwissenschaften, weil sie sich damit die Möglichkeit nimmt, auf die großen Disziplinen wie die Literatur-, Politik- oder Geschichtswissenschaft einzuwirken, sie ist vor allem aber für die übrigen Disziplinen bedenklich, insofern sie zu einseitigen und eingeschränkten Wahrnehmungen führt. Andalusien liegt immerhin im Westen Europas, und die Osmanen waren eine zentraleuropäische Großmacht, um nur zwei Stichwörter für die vielfältigen Verflechtungen zwischen dem Nahen Osten und Europa anzudeuten, die durch den Ausschluss islamwissenschaftlicher Kompetenz in der Geschichtswissenschaft oder der Philosophie kaum angemessen wahrgenommen werden. Ähnlich wäre für die europäische Literaturgeschichte oder die Philosophie zu argumentieren. Das Anliegen, die Islamwissenschaft als Regionalwissenschaft exemplarisch in die allgemeinen Kultur- und Sozialwissenschaften einzubringen, ist also nicht ein fachspezifisches Desiderat, sondern zielt auch und vor allem auf die Weiterentwicklungen der, großen“ Disziplinen.

Die Aufgabe, die Islamwissenschaft in einen allgemeinen kultur- und sozialwissenschaftlichen Diskurs einzubringen, ist auch vor dem Hintergrund der gegenwärtigen gesellschaftlichen und kulturellen Situation in Europa zu sehen. Projekte, die die religiöse Determination von Phänomen innerhalb der islamischen Welt nicht mehr nur implizit, sondern offen und konsequent hinterfragen und beispielsweise die Literatur als autonome Größe und nicht in ihrer Abhängigkeit von der Religion behandeln, stellen sich quer zur Erwartungshaltung einer breiteren Öffentlichkeit, die im Orient exemplarisch den Ort der Religion sieht. Eine säkulare Wahrnehmung würde die religiöse Dimension von Vorgängen und Entwicklungen innerhalb der islamischen Welt nicht übersehen, sie jedoch mit denselben Begründungszusammenhängen konfrontieren und damit erst rational erklärbar machen, wie sie in Bezug auf andere Regionen selbstverständlich sind.

Zum gesellschaftlichen und kulturellen Hintergrund der heutigen Islamwissenschaft gehört aber nicht nur die Wahrnehmung des Islams in der europäischen Öffentlichkeit, sondern ebenso das eigene europäische Selbstverständnis, das die 
eigenen jüdischen und islamisch mitgeprägten Traditionen jedenfalls im breiten öffentlichen Bewusstsein ignoriert und heute außerdem die - durch die Migration entstandene - faktische Teilhabe an zahlreichen weiteren Kulturen verkennt. Damit wird ein Wesensmerkmal und das eigentliche Erfolgsgeheimnis des europäischen Projektes, wie es sich in der Französischen Revolution normativ herausgebildet hat, ins Gegenteil verkehrt: seine radikale Offenheit, sein ebenso anmaßender wie utopischer Universalismus. Auf der expliziten Glaubensneutralität des Projektes zu beharren, bedeutet nicht, den religiösen (allerdings keineswegs ausschließlich christlichen) Ursprung vieler europäischer Werte zu verleugnen. Aber es sind Werte, die säkularisiert, also im Laufe der Zeit innerweltlich begründet worden sind. Von nichts anderem sprechen die muslimischen Reformdenker, die sich zum Beispiel nicht mehr mit der Frage aufhalten, ob die Menschenrechte islamisch sind oder nicht, sondern sie aus der menschlichen Vernunft ableiten und also implizit oder explizit deutlich machen, dass es Lebensbereiche außerhalb des Religiösen gibt. Gerade weil die europäischen Werte säkular sind, sind sie an keine bestimmte Herkunft oder Religion gebunden, sondern lassen sich prinzipiell übertragen. In allen Kulturen gibt es führende geistige Bewegungen, die genau diese Übersetzung immer wieder neu angehen, etwa indem sie die Demokratie oder die Menschenrechte in ein chinesisches, schwarzafrikanisches oder eben islamisches Vokabular überführen.

Wer heute als Historiker die Muslime wegen ihres Glaubens zu ,Uneuropäern' erklärt, verkennt nicht nur die europäische Geschichte, die mit dem Osmanischen Reich einen zentralen Akteur hatte und zu immerhin zwei muslimischen Ländern auf europäischen Boden geführt hat. Er macht aus Europa eine Religion, beinah eine Rasse und stellt damit das Vorhaben der europäischen Aufklärung auf den Kopf, das seine Spezifität gerade dadurch gewinnt, dass es eine weltliche, prinzipiell allen Bürgern offene Willensgemeinschaft darstellt. Ein wirklich säkulares Europa würde sich nicht religiös-genealogisch definieren, sondern durch Ideen, zu denen man sich ungeachtet seines Glaubens oder seiner Abstammung bekennen kann oder eben nicht bekennt (auch zweiteres ist Europäern, wie nicht nur die deutsche Geschichte, sondern auch die Ereignisse der letzten Jahre auf dem Balkan oder innerhalb der ehemaligen Sowjetunion lehren, sehr wohl möglich).

Erst wenn die außereuropäischen und speziell die islamisch geprägten Kulturen in einem Zusammenhang mit der eigenen Vergangenheit und Gegenwart studiert, wenn sie nicht länger als Exotikum begriffen werden, das positiv in seiner faszinierenden Kuriosität, negativ in seiner Bedrohlichkeit zu studieren ist, finden die Geisteswissenschaften zu einem angemessenen Verständnis auch der eigenen, europäischen Geschichte, Literatur und Kultur; gleichzeitig würden sie jene Entwicklung einholen, die sich durch die Migration der letzten Jahrzehnte längst vollzogen hat, ohne sich allerdings im öffentlichen Bewusstsein niedergeschlagen zu haben. Wegen ihrer engen Verflechtung mit der europäischen Kultur und Geschichte ist die Erforschung der islamischen Welt in besonderer Weise 
geeignet, die Dominanz zu brechen, die der Mechanismus der Exklusion in der Beschäftigung mit nicht christlich oder nicht westlich geprägten Traditionen weiterhin ausübt. Damit könnte die Erforschung der nahöstlichen Kulturen, wäre sie in die übrigen Kulturwissenschaften integriert, eine Vorreiterrolle auch für andere Regionalwissenschaften spielen. Die religiösen Traditionen, Literaturen, performativen und bildenden Künste aus dem Nahen Osten würden in einem solchen Diskurs der europäischen Kultur nicht entgegengesetzt, sondern als Bestandteil einer Kultur verstanden, die den Nahen Osten und Europa gemeinsam prägt. Das häufig beschworene, nicht selten zur Floskel erstarrte Wort vom ,Dialog ' würde sich dann schon deshalb relativieren und zugleich neu beleben, weil man wahrnimmt, dass die Trennungslinien quer durch die Kulturen und Religionen verlaufen und ,man selbst" immer auch schon zu, den anderen' gehört. Bisher verfestigt das Paradigma des Dialogs der Kulturen eher eben jene manichäische Wahrnehmung, gegen die es sich scheinbar wendet. 



\section{Bibliographie}

Abdel-Malek, Anouar: „L'orientalisme en crise“, Diogène 44/1983, S. 103-140.

Abdullaev, Kamoludin/Akbarzadeh, Shahram (Hg.): Historical Dictionary of Tajikistan, Lanham, MD u.a.: Scarecrow Press 2002.

Abū Zayd, Naṣr Ḥāmid: Mafhūm an-naṣṣ, Beirut: al-Markaz al-taqāfī al-'arab̄̄ 1994.

Agai, Bekim/Kemper, Michael (Hg.): Abgeschlossene und laufende Forschungsarbeiten der Nachwuchsgruppe (Volkswagen-Stiftung) Islamische Bildungsnetzwerke im lokalen und transnationalen Kontext (18.-20. Jahrhundert) am Seminar für Orientalistik und Indologie der Ruhr-Universität Bochum, Bochum: RUB 2002.

Ahmad, Imtiaz/Reifeld, Helmut (Hg.): Lived Islam in South Asia. Adaption, Accomodation \& Conflict, New Delhi: Social Science Press 2004.

Ahmad, Aziz: „Indien“, in: G. E. von Grunebaum (Hg.): Fischer Weltgeschichte, Band 15: Der Islam II. Die islamischen Reiche nach dem Fall von Konstantinopel, Frankfurt/M: Fischer 1976, S. 226-287.

Ahmadi, Wali: „Exclusionary Poetics. Approaches to the Afghan 'Other' in Contemporary Iranian Literary Discourse“, in: Iranian Studies 37 (2004), S. 407429.

Ahmed, Leila: Women and Gender in Islam. Historical Roots of a Modern Debate, New Haven: Yale UP 1992.

Ahmed, Munir D./Hafez, Kai: „Das Orient- und Islambild in Deutschland. Überlegungen zum Friedenspreis des Deutschen Buchhandels und ein Gespräch mit Annemarie Schimmel“", in: Orient 36 (1995), S. 411-428.

Aidi, Hisham D.: „Jihadis in the Hood. Race, Urban Islam and the War on Terror", in: Middle East Report Online, http://www.merip.org/mer/mer224/ 224_aidi.html vom 16.09.2007.

Aidi, Hisham D.: „Let Us Be Moors - Islam, Race, and 'Connected Histories'“, in: Souls. A Critical Journal of Black Politics, Culture, and Society 7 (2005), S. 36-51. 
Akiner, Shirin: Violence in Andijan, 13 May 2005. An Independent Assessment, Silk Road Paper 2005 (http://www.silkroadstudies.org/new/inside/publications/0507 Akiner.pdf).

Al-Azmeh, Aziz: Die Islamisierung des Islam. Imaginäre Welten einer politischen Theologie, Frankfurt/M u.a.: Campus 1996.

Allohio-Näcke, Lars/Kalscheuer, Britta/Manzeschke, Arne (Hg.): Differenzen anders denken. Bausteine zu einer Kulturtheorie der Transdifferenz, Frankfurt, New York: Campus 2005.

Amirpur, Katajun: „Die Revolutionäre sind müde“, in: Der Tagesspiegel vom 20. 6.2003, www.tagesspiegel.de/kultur/archiv/20.06.2003/620334.asp vom 1. 3.2007 .

Amirpur, Katajun: „Feindbild Islam“, in: die tageszeitung vom 5.12.2005, S. 11.

Amirpur, Katajun: „Iran auf der Achse des Bösen“, www.kas.de/db_files/dokumente/auslandsinformationen/7_dokument_dok_pdf_1225_1.pdf vom 1.3.2007.

Amirpur, Katajun: „Was Gott will - Es gibt kein islamisches Bilder- und $\mathrm{Hu}-$ morverbot", in: Frankfurter Rundschau online vom 11.2.2006, http://davo.uni-mainz.de/info/060215.htm vom 1.3.2007.

Ammann, Ludwig: „Islamwissenschaften“, in: Klaus E. Müller (Hg.): Phänomen Kultur. Perspektiven und Aufgaben der Kulturwissenschaften, Bielefeld: transcript 2003, S. 71-96.

Ammann, Ludwig: Östliche Spiegel. Ansichten vom Orient im Zeitalter seiner Entdeckung durch den deutschen Leser 1800-1850, Hildesheim: Olms 1989.

Arkoun, Muhammad: „The study of Islam in French scholarship“, in: Azim Nanji (Hg.): Mapping Islamic studies. Genealogy, continuity and change, Berlin, New York: de Gruyter 1997.

Arndt, Susan: „'The Racial Turn'. Kolonialismus, Weiße Mythen und Critical Whiteness Studies“, in: Marianne Bechhaus-Gerst/Sunna Gieseke/Rein-hard Klein-Arendt (Hg.): Koloniale und postkoloniale Konstruktionen von Afrika und Menschen afrikanischer Herkunft in der deutschen Alltagskultur, Frankfurt/M: Peter Lang 2005, S. 11-26.

Arndt, Susan: „Weißsein und Kritische Weißseinsforschung“, in: http://www. unrast-verlag.de/unrast,3,0,261.html vom 16.09.2007.

Arndt, Susan: „Weißsein. Die verkannte Strukturkategorie Europas und Deutschlands“, in: diess. u.a. (Hg.): Mythen, Masken und Subjekte. Kritische Weißseinsforschung in Deutschland, Münster: unrast-Verlag 2005, S. 24-28.

Asad, Talal: „The Idea of an Anthropology of Islam“, in: Washington DC: Center for Contemporary Arab Studies, Georgetown University. Occasional paper 1986, S. 1-22.

Bachmann-Medick, Doris: Cultural Turns. Neuorientierungen in den Kulturwissenschaften, Reinbeck: Rowohlt 2006.

Baljon, J. M. S.: Religion and Thought of Shāh Wal̄ Allāh Dihlawī, 1703-1762, Leiden: Brill 1986. 
Ballantyne, Tony: Orientalism and Race. Aryanism in the British Empire, Houndsmills, New York u.a.: Palgrave 2002.

Bälz, Kilian: „Submitting faith to judicial scrutiny through the family trial: the Abū Zayd case“, in: Die Welt des Islams 37 (1997), S. 135-55.

Bannerth, Ernst/Spies, Otto: Lehrbuch der Hindūstān̄̄-Sprache, Leipzig, Wien: Harrassowitz 1945.

Barth, Boris/Osterhammel, Jürgen (Hg.): Zivilisierungsmissionen. Imperiale Weltverbesserung seit dem 18. Jahrhundert, Konstanz: UVK Verlagsgesellschaft mbH 2005.

Bauer, Thomas: Liebe und Liebesdichtung in der arabischen Welt des 9. und 10. Jahrhunderts. Eine literatur- und mentalitätsgeschichtliche Studie des arabischen Gazal, Wiesbaden: Harrasowitz 1998.

Baumgarten, Helga: Palästina. Befreiung in den Staat, Frankfurt/M: Suhrkamp 1991.

Bechert, Heinz/Simson, Georg von (Hg.): Einführung in die Indologie. Stand Methoden - Aufgaben, Darmstadt: WUG 1979.

Beck, Martin: „Globalisierung als Bedrohung. Die Globalisierungsresistenz des Vorderen Orients als Ausdruck rationaler Reaktionen der politischen Eliten auf die neuen Entwicklungen im internationalen System“, in: Henner Fürtig (Hg.): Islamische Welt und Globalisierung. Aneignung, Abgrenzung, Gegenentwürfe, Würzburg: Ergon 2001, S. 53-85.

Becker, Carl Heinrich: „Die orientalischen Wissenschaften. A. Der vordere Orient und Afrika", in: Siegfried Körte/Friedrich Wilhelm von Loebel (Hg.): Deutschland unter Kaiser Wilhelm II., Bd. 3, Berlin: Hobbing 1914, S. 11831188.

Becker, Carl Heinrich: „Gedanken zur Hochschulreform (1918/19) (Auszüge)“, in: Guido Müller (Hg.): Carl Heinrich Becker. Internationale Wissenschaft und nationale Bildung, Köln: Böhlau 1997, S. 180-223.

Becker, Carl Heinrich: „Islampolitik“, in: Die Welt des Islams 3 (1916), S. 101120.

Becker, Carl Heinrich: „Materialien zur Kenntnis des Islam in Deutsch-Ostafrika“, in: Der Islam 2 (1911), S. 1-48.

Becker, Carl Heinrich: Deutschland und der Islam, Stuttgart: Deutsche Verlagsanstalt 1914.

Becker, Carl Heinrich: Islamstudien, Leipzig: Quelle \& Meyer 1924.

Becker, Carl Heinrich: Islamstudien. Vom Werden und Wesen der islamischen Welt, Hildesheim: Georg Olms Verlagsbuchhandlung 1967.

Bhabha, Homi: Die Verortung der Kultur, Tübingen: Stauffenburg Verlag 2000.

Bielefeldt, Heiner: Menschenrechte in der Einwanderungsgesellschaft. Plädoyer für einen aufgeklärten Multikulturalismus, Bielefeld: transcript 2007.

Blair, Sheila S./Bloom, Jonathan M.: „The Mirage of Islamic Art: Reflections on the Study of an Unwieldy Field“, in: The Art Bulletin 85 (2003), S. 152-184. 
Blair, Sheila S./Bloom, Jonathan M.: The Art and Architecture of Islam 12501800 (Pelican History of Art), New Haven/London: Yale UP 1994.

Bobzin, Hartmut: „Geschichte der Arabischen Philologie in Europa bis zum Ausgang des achtzehnten Jahrhunderts“, in: Wolfdietrich Fischer ( $\mathrm{Hg}$.): Grundriß der Arabischen Philologie, Bd. 3, Wiesbaden: Reichert 1992, S. 155-187.

Bobzin, Hartmut: Der Koran im Zeitalter der Reformation. Studien zur frühen Geschichte der Arabistik und Islamkunde in Europa, Stuttgart: Steiner 1995.

Bourdieu, Pierre: Homo academicus, Frankfurt/M: Suhrkamp 1988.

Braun, Christina von/Stephan, Inge (Hg.): Gender@Wissen. Ein Handbuch der Gender-Theorien, Köln u.a.: Böhlau 2005.

Brettell, Caroline B.: „Introduction Fieldwork, Text, and Audience“, in: diess. (Hg.): When They Read what We Write. The Politics of Ethnography, Westport u.a.: Bergin \& Garvey 1993, S. 1-24.

Brockelmann, Carl: „Die morgenländischen Studien in Deutschland“, in: ZDMG 76 (1922), S. 1-17.

Büchler, Andrea: Das islamische Familienrecht. Eine Annäherung unter besonderer Berücksichtigung des Verhältnisses des klassischen islamischen Rechts zum geltenden ägyptischen Familienrecht, Bern: Stämpfli 2003.

Büren, Rainer: Gegenwartsbezogene Orientforschung in der Bundesrepublik Deutschland. Gegenstand, Lage und Förderungsmöglichkeiten, Göttingen 1974 (Schriftenreihe der Stiftung Volkswagenwerk).

Burgat, François: „Ein anderer Blick auf den Islamismus. Eine Polemik“, in: Informationsprojekt Naher und Mittlerer Osten 31 (2002), S. 4-8.

Carkoglu, Ali: „Religion and Public Policy in Turkey“, in: ISIM Newsletter 8 (2001).

Chakrabarty, Dipesh: Provincialising Europe. Postcolonial Thought and Historical Difference, Princton, New Jercey: Princeton UP 2000.

Conrad, Lawrence (Hg.): The world of Ibn Tufayl. Interdisciplinary perpectives on Hayy Ibn Yaqzāan, Leiden: Brill 1996.

Conrad, Lawrence u.a. (Hg.): The Byzantine and early Islamic Near East, Princeton: Darwin Press 1992.

Conrad, Sebastian/Randeria, Shalini (Hg.): Jenseits des Eurozentrismus. Postkoloniale Perspektiven in den Geschichts- und Kulturwissenschaften, Frankfurt/M: Campus 2002.

Conrad, Sebastian: „Die Zivilisierung des 'Selbst' - Japans koloniale Moderne“, in: Boris Barth/Jürgen Osterhammel (Hg.): Zivilisierungsmissionen. Imperiale Weltverbesserung seit dem 18. Jahrhundert, Konstanz: UVK Verlagsgesellschaft mbH 2005, S. 245-268.

Crone, Patricia: „Islam, Judeo-Christianity and Byzantine iconoclasm“, in: Jerusalem Studies in Arabic and Islam 2 (1980), S. 70.

Crowder, Michael: West Africa under Colonial Rule, London: Hutchinson University Library for Africa 1968/82. 
Denffer, Dietrich von: „Theoretischer Ansatz und Methode in der Islamwissenschaft“, in: XIX DOT, ZDMG Supl. III 1 Wiesbaden 1977, S. 342-345.

Djait, Hichem: L'Europe et l'Islam, Paris: Seuil 1978.

Dupret, Baudouin: „A propos de l'affaire Abu Zayd, universitaire poursuivi pour apostasie; le procès: l'argumentation des Tribunaux“, in: Maghreb-Mash-rek (1996), S. 18-22.

Ebert, Hans-Georg u.a. (Hg.): Johann Jacob Reiske - Leben und Wirkung. Ein Leipziger Byzantinist und Begründer der Orientalistik im 18. Jahrhundert, Leipzig: Evangelische Verlagsanstalt 2005.

Ebert, Hans-Georg: Das Personalstatut arabischer Länder. Problemfelder, Methoden, Perspektiven. Ein Beitrag zum Diskurs über Theorie und Praxis des islamischen Rechts, Frankfurt/M u.a.: Peter Lang 1996.

Eckert, Andreas: „Die Verheißung der Bürokratie. Verwaltung als Zivilisierungsagentur im kolonialen Westafrika“, in: Boris Barth/Jürgen Osterhammel (Hg.): Zivilisierungsmissionen. Imperiale Weltverbesserung seit dem 18. Jahrhundert, Konstanz: UVK Verlagsgesellschaft mbH 2005, S. 269-283.

Édouard Glissant: Kultur und Identität. Ansätze zu einer Poetik der Vielheit, Paris: Wunderhorn 1996.

Efron, John M.: „Orientalism and the Jewish Historical Gaze“, in: Ivan Davidson Kalmar/Derek J. Penslar (Hg.): Orientalism and the Jews, London: Brandeis UP 2005, S. 80-93.

Eggers, Maureen Maisha/Kilomba, Grada/Piesche, Peggy/Arndt, Susan (Hg.): Mythen, Masken und Subjekte. Kritische Weißseinsforschung in Deutschland, Münster: unrast-Verlag 2005.

Eggers, Maureen Maisha: „Ein Schwarzes Wissensarchiv“, in: diess. u.a. (Hg.): Mythen, Masken und Subjekte. Kritische Weißseinsforschung in Deutschland, Münster: unrast-Verlag 2005, S. 18-21.

Eggers, Maureen Maisha: „Rassifizierte Machtdifferenz als Deutungsperspektive in der Kritischen Weißseinsforschung in Deutschland“, in: diess. u.a. (Hg.): Mythen, Masken und Subjekte. Kritische Weißseinsforschung in Deutschland, Münster: unrast-Verlag 2005, S. 56-72.

Eisenstadt, Shmuel N.: „Multiple Modernities“, in: Daedalus 129 (2000), S. 1-29.

Eisenstadt, Shmuel N.: Die Vielfalt der Moderne, Weilerswist: Velbrück Wissenschaft 2000.

Ellinger, Ekkehard: Deutsche Orientalistik zur Zeit des Nationalsozialismus 1933-1945, Edingen-Neckarhausen: deux mondes 2006.

Embaló, Birgit/Neuwirth, Angelika/Pannewick, Friederike (Hg.): Kulturelle Selbstbehauptung der Palästinenser. Survey der modernen palästinensischen Dichtung, Würzburg: Ergon 2001.

Ende, Werner/Steinbach, Udo (Hg.): Der Islam in der Gegenwart, München: Beck ${ }^{5} 2005$.

Endreß, Gerhard: Einführung in die islamische Geschichte, München: Beck 1982. 
Epkenhans, Tim: „Geld darf keine Rolle spielen“, Teil 1 und Teil 2, in: Archivum Ottomanicum 18 (2000), S. 247-250 und 19 (2001), S. 121-163.

Epple, Angelika: „'Global History’ und ‘Area History'. Plädoyer für eine weltgeschichtliche Perspektivierung des Lokalen“, in: Birgit Schäbler (Hg.): Area Studies und die Welt. Weltregionen und neue Globalgeschichte, Wien: Mandelbaum Verlag 2007, S. 90-116.

Ess, Josef van: „From Wellhausen to Becker: The Emergence of 'Kulturgeschichte' in Islamic Studies“, in: Malcolm H. Kerr (Hg.): Islamic Studies: A Tradition and its Problems, Malibu: Undena Publications 1980, S. 27-51.

Ess, Josef van: Theologie und Gesellschaft im 2. und 3. Jahrhundert Hidschra, Band II, Berlin, New York: Walter de Gruyter 1992.

Essner, Cornelia/Winkelhane, Gerd: „Carl Heinrich Becker (1876-1933). Orientalist und Kulturpolitiker“, in: Die Welt des Islams 28 (1988), S. 154-77.

Ettinghausen, Richard/Grabar, Oleg/Jenkins, Marilyn: The Art and Architecture of Islam 650-1250 (Pelican History of Art), New Haven: Yale UP 2001.

Fowden, Garth: Qusayr 'Amra. Art and the Umayyad Elite in Late Umayyad Syria, Berkeley u.a.: California UP 2004.

Fragner, Bert G.: „Aktuelle Fragen der historischen Erforschung der islamischen Welt“, in: Saeculum 40 (1989), S. 161-165.

Fragner, Bert G.: „Iranistik in Europa: Gestern, heute und morgen“, in: Heiner Eichner u.a. (Hg.): Iranistik in Europa: Gestern, heute, morgen, Wien: Verlag der Österreichischen Akademie der Wissenschaften 2006, S. 7-25.

Fragner, Bert G.: „Orientalistik zwischen Philologie und Sozialwissenschaft“, http://web.uni-bamberg.de/split/dot/reden_fragner vom 15.3.2007.

Freitag, Ulrike: „Herausforderungen an die Geschichtswissenschaft im Zeitalter der Globalisierung“, in: Lothar Gall (Hg.): 25 Jahre Historisches Kolleg, Rückblick - Bilanz - Perspektiven, München: Oldenbourg 2006, S. 271-275.

Fück, Johann: Die arabischen Studien in Europa bis in den Anfang des 20. Jahrhunderts, Leipzig: Harrassowitz 1955.

Gabin, Annemarie von (Hg.): Turkologie, Leiden, Köln: Brill 1963.

Gahlings, Ute: Hermann Graf Keyserling. Ein Lebensbild, Darmstadt: Justusvon-Liebig-Verlag 1996.

Gangolf Hübinger: „Geschichtskonstruktion und Gedächtnispolitik. Ernst Troeltschs Berliner Historik“, in: Graf, Friedrich Wilhelm (Hg.): 'Geschichte durch Geschichte überwinden'. Ernst Troeltsch in Berlin, Gütersloh: Gütersloher Verl.-Haus 2006.

al-Ğauziyya, Šams ad-Dīn Ibn Qayyim: I'lām al-muwaqqi'īn 'an rabb al-'ālamīn, ediert von M. M. 'Abd al-Hamīd, Bd. 4, Kairo 1955.

al-Ġazālī, Abū Ḥāmid M.: al-Mustaṣfā min 'ilm al-uṣūl, ediert von Hamza b. Zuhair Hāfiz, Bd. 4, Medina o. J.

Gerges, Fawaz A.: The Far Enemy. Why Jihad went Global, Cambridge: Cambridge UP 2005. 
Gingrich, Andre: „Österreichische Identitäten und Orientbilder. Eine ethnologische Kritik“, in: Walter Dostal/Helmuth Niederle/Karl R. Wernhart (Hg.): Wir und die Anderen. Islam, Literatur und Migration, Wien: Wiener Universitätsverlag 1999, S. 29-34.

Goitein, Shlomo Dov Fritz: „Nachruf auf Josef Horovitz“, in: Der Islam 22 (1935), S. 122-127.

Goldziher, Ignaz: „Muhammad Ibn Toumert et la théologie de 1’Islam dans le Maghreb au XIè siècle“, in: Jean-Dominique Luciani (Hg.): Le Livre de Muhammad Ibn Toumert, Algier 1903.

Gonnella, Julia: Ein christlich-orientalisches Wohnhaus des 17. Jahrhunderts aus Aleppo (Syrien). Das „Aleppo-Zimmer“ im Museum für Islamische Kunst, Staatliche Museen zu Berlin - Preußischer Kulturbesitz, Mainz: von Zabern 1996.

Grabar, Oleg: „The Experience of Islamic Art“, in: Irene Bierman (Hg.): The Experience of Islamic Art on the Margins of Islam, Reading: Ithaca Press 2005, S. 11-59.

Grunebaum, Gustave E. von: „The problem of cultural influence“, in: Dunning S. Wilson (Hg.): Islam and medieval Hellenism. Social and cultural perspectives, London: Variorum Reprints 1976, S. 86-99.

Grunebaum, Gustave E. von: Der Islam II. Die islamischen Reiche nach dem Fall von Konstantinopel, Frankfurt/M: Fischer 1982.

Gunn, T. Jeremy: „Shaping an Islamic Identity. Religion, Islamism, and the State in Central Asia“, in: Sociology of Religion 64 (2003), S. 389-410.

Ha, Kien Nghi: „Deutsche Integrationspolitik als koloniale Praxis“, in: ders. u.a. (Hg.): re/visionen. Postkoloniale Perspektiven von People of Color auf Rassismus, Kulturpolitik und Widerstand in Deutschland, Münster: unrastVerlag 2007, S. 113-128.

Ha, Kien Nghi: „People of Color. Koloniale Ambivalenzen und historische Kämpfe“, in: ders. u.a. (Hg.): re/visionen. Postkoloniale Perspektiven von People of Color auf Rassismus, Kulturpolitik und Widerstand in Deutschland, Münster: unrast-Verlag 2007, S. 31-40.

Ha, Kien Nghi: „Postkoloniale Kritik und Migration. Eine Annährung“, in: ders. u.a. (Hg.): re/visionen. Postkoloniale Perspektiven von People of Color auf Rassismus, Kulturpolitik und Widerstand in Deutschland, Münster: unrastVerlag 2007, S. 41-54.

Ha, Kien Nghi: Hype um Hybridität. Kultureller Differenzkonsum und postmoderne Verwertungstechniken im Spätkapitalismus, Bielefeld: transcript 2005.

Haarmann, Ulrich: „Die islamische Moderne bei den deutschen Orientalisten“, in: Friedrich H. Kochwasser/Hans R. Roemer (Hg.): Araber und Deutsche. Begegnungen in einem Jahrtausend, Tübingen u.a.: Erdmann 1974.

Habermas, Jürgen: Die nachholende Revolution, Frankfurt/M: Suhrkamp 1990.

Haddad, Robert M.: „Iconoclasts and Mu'tazila“, in: Greek Orthodox Theological Review 27 (1982), S. 287-305. 
Hafez, Kai/Richter, Carola: „Das Gewalt- und Konfliktbild des Islams bei ARD und ZDF. Eine Untersuchung öffentlich-rechtlicher Magazin- und Talksendungen“, www2.kommunikationswissenschaft-erfurt.de/uploads/bericht_ islam_in_ard_und_zdf_2005_2006.pdf vom 1.3.2007.

Hafez, Kai/Höpp, Gerhard: „Gegenwartsbezogene Orientwissenschaft in der DDR und in den neuen Bundesländern: Kontinuität oder Neubeginn?“ in: Wolf-Hagen Krauth/Ralf Wolz (Hg.): Wissenschaft und Wiedervereinigung. Asien- und Afrikawissenschaften im Umbruch. Studien und Materialien der Interdisziplinären Arbeitsgruppe Wissenschaften und Wiedervereinigung, Berlin: Akademie Verlag 1998, S. 95-163.

Hafez, Kai: „Der Machtantritt der Hamas birgt die Chance auf ein Ende der Gewalt im Nahen Osten“, in: die tageszeitung vom 28.02.2006; http://www. taz.de/pt/2006/02/28/a0189.1/text.ges, 1 vom 1.3.2007.

Hafez, Kai: Die politische Dimension der Auslandsberichterstattung. Das Nahost- und Islambild der überregionalen Presse in Deutschland, Baden-Baden: Nomos 2002.

Hagedorn, Annette: „Das Interesse für Islamische Kunst in Deutschland im 19. Jahrhundert“, in: Joachim Gierlichs/Annette Hagedorn (Hg.): Islamische Kunst in Deutschland, Mainz 2004, S. 16-20.

Hagen, Gottfried: „German Heralds of Holy War: Orientalists and Applied Oriental Studies“, in: Comparative Studies of South Asia, Africa and the Middle East 24 (2004), S. 145-162.

Hagen, Gottfried/Seidensticker, Tilman: „Reinhard Schulzes Hypothese einer islamischen Aufklärung. Kritik einer historiographischen Kritik“, in: Zeitschrift der Deutschen Morgenländischen Gesellschaft 148 (1998), S. 83-110.

Hamann, Günther: „Ein Überblick über die Geschichte der Erforschung des nordöstlichen und östlichen Afrikas“, in: Abenteuer Ostafrika. Der Anteil Österreich-Ungarns an der Erforschung Ostafrikas, Eisenstadt: Amt der Burgenländischen Landesregierung 1988, S. 81-124.

Hanisch, Ludmila: „Gelehrtenselbstverständnis, wissenschaftliche Rationalität und politische 'Emotionen': Ein Nachtrag“, in: Die Welt des Islams 32 (1992), S. 107-123.

Hanisch, Ludmila: Die Nachfolger der Exegeten. Deutschsprachige Erforschung des Vorderen Orients in der ersten Hälfte des 20. Jahrhunderts, Wiesbaden: Harrassowitz 2003.

Hanisch, Ludmilla: „Akzentverschiebung. Zur Geschichte der Semitistik und Islamwissenschaft während des 'Dritten Reichs'“, in: Berichte zur Wissenschaftsgeschichte 18 (1995), S. 217-226.

Hanisch, Ludmilla: Ausgegrenzte Kompetenz. Porträts vertriebener Orientalisten und Orientalistinnen 1933-1945, Halle: Orientwissenschaftliches Zentrum der Martin-Luther Universität Wittenberg-Halle 2001.

Hans-Robert Roemer: Deutsche Orientalistik der siebziger Jahre. Thesen, Zustandsanalyse, Perspektiven, Deutsche Morgenländische Gesellschaft 1972. 
Harasym, Sarah (Hg.): Gayatri Chakravorty Spivak. The Post-Colonial Critic Interviews, Strategies, Dialogues, London: Routledge 1990.

Haridi, Alexander: Das Paradigma der ,islamischen Zivilisation“ - oder die Begründung der deutschen Islamwissenschaft durch Carl Heinrich Becker (1876-1933), Würzburg: Ergon 2005.

Harrison, Christopher: France and Islam in West Africa, 1860-1960, Cambridge: Cambridge UP 1988.

Hartmann, Angelika (Hg.): Angewandte interdisziplinäre Orientforschung. Stand und Perspektiven im westlichen und östlichen Deutschland; Ergebnisse eines Kolloquiums an der Universität Würzburg im Juni 1990, Hamburg: Deutsches Orient-Institut 1991.

Hartmann, Angelika/Schliephake, Konrad: Angewandte interdisziplinäre Orientforschung, Hamburg: Deutsches Orient-Institut Hamburg 1991.

Hartmann, Martin: „Das Ultimatum des Panislamismus“, in: Das freie Wort 11 (1911), S. 605-610.

Hattstein, Markus/Delius, Peter (Hg.): Islam. Kunst und Architektur, Köln: Könemann 2000.

Heck, Gene W.: Charlemagne, Muhammad and the roots of capitalism, Berlin: de Gruyter 2006.

Hefner, Robert: „Public Islam and the Problem of Democratization“, in: Sociology of Religion 62 (2001), S. 491-514.

Hegasy, Sonja: „Arabiens Versailles“, in: Die Zeit, 6.5.2004, S. 4.

Heine, Peter: „'Nur wer Hafiz liebt und kennt...'. Berliner Islamwissenschaft. Ein wissenschaftsgeschichtlicher Überblick“, in: Gerhard Höpp/Norbert Mattes (Hg.): Berlin für Orientalisten, Berlin: Klaus Schwarz 2002, S. 45-58.

Heine, Peter: „C. Snouck Hrugronje versus C. H. Becker. Ein Beitrag zur Geschichte der angewandten Orientalistik“, in: Die Welt des Islams 23 (1984), S. 378-387.

Heine, Peter: Kulturknigge für Nichtmuslime. Ein Ratgeber für alle Bereiche des Alltags, Freiburg: Herder 2001, S. 158.

Hentges, Gudrun: Schattenseiten der Aufklärung. Die Darstellung von Juden und „Wilden“ in philosophischen Schriften des 18. und 19. Jahrhunderts, Schwalbach: Wochenschau-Verlag 1999.

Herzfeld, Ernst: „Die Genesis der islamischen Kunst und das Mshatta-Problem“, in: Der Islam 1 (1910), S. 27-63, 105-144.

Herzog, Roman (Hg.): Dialogue of Cultures - the Future of Relations between Western and Islamic Societies (Report on a Conference held at the initiative of the German President Roman Herzog), Berlin 1999.

Heschel, Susannah: „Revolt of the Colonized. Abraham Geiger's Wissenschaft des Judentums as a Challenge to Christian Hegemony in the Academy“, in: New German Critique 77 (1999), S. 61-86.

Hippler, Jochen/Lueg, Andrea: Feindbild Islam oder Dialog der Kulturen, Hamburg: Konkret 2002. 
Hirschkind, Charles: The Ethical Soundscape. Cassette Sermons and Islamic Counterpublics, New York: Columbia UP 2006.

Hirsi Ali, Ayaan: Ich klage an. Plädoyer für die Befreiung der muslimischen Frauen, München, Zürich: Piper 2004.

Hoenerbach, Wilhelm: Der Orient in der Forschung. Festschrift für Otto Spies zum 5. April 1966, Wiesbaden: Harrassowitz 1967.

Hoffman, Bruce: Terrorismus. Der unerklärte Krieg. Neue Gefahren politischer Gewalt, Frankfurt/M: Fischer 2002.

Hofheinz, Albrecht: „Illumination and Enlightenment Revisited, or: Pietism and the Roots of Islamic Modernity“, http://folk.uio.no/albrech/Hof-heinz_IllumEnlightenment.pdf vom 15.3.2007.

hooks, bell: Outlaw Culture. Resisting Representaions, New York, London: Routledge 1994.

Hopkirk, Peter: On Secret Service East of Constantinople, Oxford: Oxford UP 1994.

Höpp, Gerhard (Hg.): Mufti-Papiere. Briefe, Memoranden, Reden und Aufrufe Amin al-Husainis aus dem Exil, 1940-45, Berlin: Klaus Schwarz 2001.

Höpp, Gerhard u.a. (Hg.): Blind für die Geschichte? Arabische Begegnungen mit dem Nationalsozialismus, Berlin: Klaus Schwarz 2004.

Höpp, Gerhard: Bereich Orientforschung im Institut für Allgemeine Geschichte, Typoskript, Berlin 1991, S. 1. ZMO, Nachlass Höpp, Karton 5.9.

Hörisch, Jochen: Die ungeliebte Universität. Rettet die Alma mater!, München, Wien: Hanser 2006.

Hörner, Karin: „Das Islambild der Deutschen: Von Goethe bis Karl May“, in: Gernot Rotter (Hg.): Die Welten des Islam, Frankfurt/M: Fischer 1993, S. 206-210.

Hörner, Karin/Klemm, Verena (Hg.): Das Schwert des Experten. Peter SchollLatours verzerrtes Araber- und Islambild, Heidelberg: Palmyra 1993.

Horstmann, Axel: Antike Theoria und moderne Wissenschaft. August Boeckhs Konzeption der Philologie, Frankfurt/M: Peter Lang 1992.

Hourani, Albert: Der Islam im europäischen Denken, Frankfurt/M: Fischer 1994.

Hübinger, Gangolf/Terwey, Andreas: „Ernst Troeltsch: Fünf Vorträge zu Religion und Geschichtsphilosophie für England und Schottland. Der Historismus und seine Überwindung (1924)/Christian Thought. Its History and Application (1923)“, Berlin, New York: Walter de Gruyter 2006.

Hübinger, Gangolf: Gelehrte, Politik und Öffentlichkeit. Eine Intellektuellengeschichte, Göttingen: Vandenhoeck \& Rupprecht 2006, S. 190.

Huntington, Samuel P.: Der Kampf der Kulturen. Die Neugestaltung der Weltpolitik im 21. Jahrhundert, München: Europaverlag 1996.

Huntington, Samuel: The clash of civilizations and the remaking of world order, New York: Simon \& Schuster 1996.

Hunwick, John (Hg.): The Writings of Central Sudanic Africa. Arabic Literature of Africa, Bd. 2, Leiden: Brill 1995. 
Ibn Hुaldūn, 'Abd ar-Raḥmān M.: al-Muqaddima, ediert von 'Alī 'Abd al-Wāhid Wāfī, Kairo 1981.

Iliffe, John: Tanganyika under German Rule 1905-1912, Cambridge: Cambridge UP 1969.

Inden, Ronald: Imagining India, Oxford u.a.: Blackwell 1990.

Jäger, Friedrich/Rüsen, Jörn: Geschichte des Historismus. Eine Einführung, München: Beck 1992.

Jäger, Wolfgang: Die islamische Welt und Europa. Begegnung - Zusammenprall - Dialog? Zur Geschichte des islamischen und des christlichen Kulturkreises, Berlin: Cornelsen 2002.

Jansen, Johannes J. G.: The Neglected Duty. The Creed of Sadat's Assassins and Islamic Resurgence in the Middle East, New York: Macmillan u.a. 1986.

Johansen, Baber: „Politics and Scholarship: The Development of Islamic Studies in the Federal Republic of Germany“, in: Tareq Y. Ismael (Hg.): Middle East Studies. International Perspectives on the State of the Art, New York: Praeger 1990, S. 71-130.

Justin Stagl: „Szientistische, hermeneutische und phänomenologische Grundlagen der Ethnologie“, in: Wolfdietrich Schmied-Kowarzik/Justin Stagl (Hg.): Grundfragen der Ethnologie. Beiträge zur gegenwärtigen Theorie-Diskussion, Berlin: Reimer 1993, S. 15-49.

Kalmar, Ivan D./Penslar, Derek J.: „Orientalism and the Jews. An Introduction“, in: ders. (Hg.): Orientalism and the Jews, Hanover, London 2005, S. xiii-xl.

Kalmar, Ivan Davidson/Penslar, Derek J. (Hg.): Orientalism and the Jews, Hanover, London: UP New England 2005.

Kampffmeyer, Georg: „Plane perspicere“, in: Die Welt des Islams 1 (1913), S. 16.

Kappert, Petra: „Europa und der Orient“, in: Jochen Hippler/Andrea Lueg (Hg.): Feindbild Islam, Hamburg: Konkret Literatur Verlag 1993, S. 44-76.

Keisinger, Florian/Berger, Roland (Hg.): Wozu Geisteswissenschaften? Kontroverse Argumente für eine überfällige Debatte, Frankfurt, New York: Campus 2003, S. 17-28.

Kelek, Necla: „Und bist du nicht von uns, dann bist du des Teufels. Was Integration heißt, das kann nicht allein der Islam definieren. Die Gebote des Koran und Europa“, in: FAZ vom 25.4.2007, S. 36.

Kelek, Necla: Die fremde Braut. Ein Bericht aus dem Inneren des türkischen Lebens in Deutschland, Köln: Kiepenheuer \& Witsch 2005.

Kelek, Necla: Islam im Alltag. Islamische Religiosität und ihre Bedeutung in der Lebenswelt von Schülerinnen und Schülern türkischer Herkunft, Münster: Waxmann 2002.

Kemper, Michael (Hg.): Laufende Forschungsarbeiten der Nachwuchsgruppe (Volkswagen-Stiftung) Islamische Bildungsnetzwerke im lokalen und transnationalen Kontext (18.-20. Jahrhundert) am Seminar für Orientalistik und Indologie der Ruhr-Universität Bochum, Bochum: RUB 2000. 
Kermani, Navid: „Der islamistische Traum ist aus“, in: die tageszeitung vom 3.11.2001; http://www.taz.de/pt/2001/11/03/a0106.1/text vom 1.3. 2007.

Kermani, Navid: „Moderne und Islam“, erschienen in: Dieter Grimm: (Hg.): 25 Jahre Wissenschaftskolleg zu Berlin 1981-2006, Berlin: Akademie Verlag, S. 229-242.

Kermani, Navid: „Zur Zukunft der Islamwissenschaft“, in: Fikrun wa Fann 81 (2005), S. 3, http://www.goethe.de/mmo/priv/1224466-STANDARD. pdf vom August 2007.

Kermani, Navid: Dynamit des Geistes. Martyrium, Islam und Nihilismus, Göttingen: Wallstein 2002.

Keyserling, Hermann Graf: Das Reisetagebuch eines Philosophen, Band I, Darmstadt: Reichl 1923.

Keyserling, Hermann Graf: Das Reisetagebuch eines Philosophen, ungekürzte Ausgabe, Frankfurt, Berlin: Ullstein 1990.

Khaleed, Adeeb: Islam after Communism. Religion and Politics in Central Asia, Berkeley: University of California Press 2007.

Khatami, Seyed Mohammed: Religiosität und Moderne, Heidelberg: deux mondes 2001.

Kiefer, Michael/Seidel, Eberhard: „Kultur des Ressentiments“, in: die tageszeitung vom 26.11.2005, S. 11.

Kippenberg, Hans G./Seidensticker, Tilman (Hg.): Terror im Dienste Gottes. Die „Geistliche Anleitung“ der Attentäter des 11. September 2001, Frankfurt/M: Campus 2004.

Kittsteiner, Heinz Dieter: „Zum Aufbau der europäischen Kulturgeschichte in den Stufen der Moderne", in: Graf, Friedrich Wilhelm (Hg.): 'Geschichte durch Geschichte überwinden'. Ernst Troeltsch in Berlin, Gütersloh: Gütersloher Verl.-Haus 2006.

Klausen, Iytte: „Europas neue muslimische Elite“, in: Aus Politik und Zeitgeschichte 20 (2005), S. 15-22.

Kohlhammer, Siegfried: „Die Feinde und die Freunde des Islam“, in: Merkur 55 (November 2001), S. 958-978.

Koselleck, Reinhart: Vergangene Zukunft. Zur Semantik geschichtlicher Zeiten, Frankfurt/M: Suhrkamp 1979.

Kracht, Klaus Große: Die zankende Zunft. Historische Kontroversen in Deutschland nach 1945, Göttingen: Vandenhoeck \& Ruprecht 2005.

Krämer, Gudrun: „Die islamische Welt im 20. Jahrhundert“, in: Albrecht Noth/ Jürgen Paul (Hg.): Der islamische Orient. Grundzüge seiner Geschichte, Würzburg: Ergon 1998, S. 439-502.

Krämer, Gudrun: „On Difference and Understanding. The Use and Abuse of the Study of Islam“, in: ISIM Newsletter 5 (2000).

Krämer, Gudrun: Islam, Menschenrechte und Demokratie: Anmerkungen zu einem schwierigen Verhältnis, Ladenburg: Gottlieb Daimler- und Karl BenzStiftung 2003. 
Kramer, Martin: Ivory Towers on Sand. The Failure of the Middle Eastern Studies in America, Washington: Washington Institute for Near East Policy 2001.

Krawietz, Birgit: Hierarchie der Rechtsquellen im traditionellen sunnitischen Islam, Berlin: Duncker \& Humblot 2002.

Kreiser, Klaus (Hg.): „The Early Twentieth Century and its Impact on Oriental and Turkish Studies“, in: Die Welt des Islams, Sondernummer 38 (1998).

Kremer, Alfred von: Geschichte der herrschenden Ideen des Islams. Der Gottesbegriff, die Prophetie und Staatsidee, Hildesheim: Georg Olms 1961.

Kröger, Martin: „Revolution als Programm. Ziele und Realität deutscher Orientpolitik im Ersten Weltkrieg“, in: Wolfgang Michalka (Hg), Der Erste Weltkrieg. Wirkung, Wahrnehmung, Analyse, München, Zürich: Piper 1994, S.366-391.

Kügelgen, Anke von: Die Legitimierung der mittelasiatischen Mangitendynastie in den Werken ihrer Historiker (18.-19. Jahrhundert), Würzburg: Ergon 2002.

Küng, Hans: Der Islam. Geschichte. Gegenwart. Zukunft, München, Zürich: Piper 2004.

Küttler, Wolfgang/Rüsen, Jörn/Schulin, Ernst (Hg.): Geschichtsdiskurs, Band 5, Frankfurt/M: Fischer 1999.

Lapidus, Ira M.: Islamic Societies, Cambridge: Cambridge UP 1988.

Lepenies, Wolf: „Arbeitskreis Moderne und Islam. Empfehlungen für eine zukünftige Forschungsförderung der Islamwissenschaften“, in: Ekkehard Rudolph (Red.), Bestandsaufnahme. Kultur- und sozialwissenschaftliche Forschung über die muslimische Welt, Hamburg: Deutsches Orient-Institut 1999, S. 5-14.

Lewis, Bernard: „Orientalism. An Exchange“, in: New York Review of Books 29, Nr. 13 (1993), S. 46-48.

Lewis, Bernard: „The Question of Orientalism“, in: New York Review of Books 29, Nr. 11 (1993), S. 49-56.

Lewis, Bernard: Die Wut der arabischen Welt. Warum der jahrzehntelange Konflikt zwischen dem Islam und dem Westen weiter eskaliert, Frankfurt/M u.a.: Campus 2003.

Lockman, Zachary: Contending Visions of the Middle East. The History and Politics of Orientalism, Cambridge: Cambridge UP 2004.

Loimeier, Roman (Hg.): Die islamische Welt als Netzwerk. Möglichkeiten und Grenzen des Netzwerkansatzes im islamischen Kontext, Würzburg: Ergon 2000.

Loimeier, Roman: „Edward Said und der deutschsprachige Orientalismus: Eine kritische Würdigung“, in: Stichproben. Wiener Zeitschrift für kritische Afrikastudien 2 (2001), S. 63-85.

Lorey, Isabell: „Weißsein und Immunisierung. Zur Unterscheidung zwischen Norm und Normalisierung“, in: http://translate.eipcp.net/strands/03/loreystrands01de vom 10.10.2007. 
Lüders, Michael: Im Herzen Arabiens. Stolz und Leidenschaft. Begegnung mit einer zerrissenen Kultur, Freiburg: Herder 2004.

Macfie, Alexander Lyon: Orientalism. A Reader, New York: New York UP 2000.

Mahmood, Saba: Politics of Piety. The Islamic Revival and the Feminist Subject, Princeton: Princeton UP 2004.

Malik, Jamal: Islamische Gelehrtenkultur in Nordindien. Entwicklungsgeschichte und Tendenzen am Beispiel von Lucknow, Leiden, New York, Köln: Brill 1997.

Malik, Jamal: Islamisierung in Pakistan, 1977-1984. Untersuchungen zur Auflösung autochthoner Strukturen, Wiesbaden: Steiner 1989.

Mallmann, Klaus-Michael/Cüppers, Martin: Halbmond und Hakenkreuz. Das Dritte Reich, die Araber und Palästina, Darmstadt: WBG 2006.

Mangold, Sabine: Eine ,weltbürgerliche Wissenschaft“. Die deutsche Orientalistik im 19. Jahrhundert, Wiesbaden: Franz Steiner Verlag 2004.

Manji, Irshad: Der Aufbruch. Plädoyer für einen aufgeklärten Islam, Frankfurt/M: Eichborn 2003.

Marzolph, Ulrich: „Islamische Kultur als Gedächtniskultur. Fachspezifische Überlegungen anhand des Fallbeispiels Iran“, in: Der Islam 75 (1998), S. 296-317.

Maß, Sandra, Weiße Helden - Schwarze Krieger. Zur Geschichte kolonialer Männlichkeit in Deutschland 1918-1964, Köln u.a.: Böhlau-Verlag 2006.

May, Carola: Die Kopftuchdebatte in Frankreich, Hamburg: Magisterarbeit 2005.

Mayeur-Jaouen, Catherine (Hg.): Saints et héros du Moyen-Orient contemporain, Paris: Maisonneuve et Larose 2002.

McCants, William (Hg.): Militant Ideology Atlas, Combating Terrorism Center, US Military Academy, November 2006.

McEwan, Dorothea: Habsburg als Schutzmacht der Katholiken in Ägypten, Kairo: Schriften des österreichischen Kulturinstituts Kairo 1982.

Meier, Christian: Die Welt der Geschichte und die Provinz des Historikers. Drei Überlegungen, Berlin: Wagenbach 1989.

Melka, R. L.: „Max Freiherr von Oppenheim. Sixty Years of Scholarship and Political Intrigue in the Middle East“, in: Middle Eastern Studies 9 (1973), S. 81-93.

Meriwether, Magaret L. und Judith E. Tucker (Hg.): Social History of Women and Gender in the Modern Middle East, Boulder Westview Press 1999.

Michael Landmann: Fundamental-Anthropologie, Bonn: Bouvier 1984.

Mir-Hosseini, Ziba: Marriage on Trial. A Study of Islamic Family Law Iran and Morocco Compared, London, New York: Tauris 2000.

Morrone, Giovanni: Incontro di civiltà. L'Islamwissenschaft di Carl Heinrich Becker, Napoli: Liguori 2006.

Motzki, Harald: „Dating Muslim Traditions: A Survey“, in: Arabica. Journal of Arabic and Islamic Studies 52 (2005), S. 204-253. 
Motzki, Harald: Die Anfänge der islamischen Jurisprudenz. Ihre Entwicklung in Mekka bis zur Mitte des 2./8. Jahrhunderts, Stuttgart: Steiner 1991.

Müller, Friedrich Max: Indien in seiner weltgeschichtlichen Bedeutung. Vorlesungen gehalten an der Universität Cambridge, übers. v. C. Capeller, Leipzig: Engelmann 1884.

Müller, Guido (Hg.): Carl Heinrich Becker. Internationale Wissenschaft und nationale Bildung, Köln: Böhlau 1997.

Müller, Herbert L.: Islam, Ğihād (,Heiliger Krieg“) und das Deutsche Reich, Frankfurt/M u.a.: Peter Lang 1991.

Müller, Klaus E.: „Ethnicity, Ethnozentrismus und Essentialismus“, in: Wolfgang Eßbach (Hg.): wir/ihr/sie. Identität und Alterität in Theorie und Methode, Würzburg: Ergon 2000, S. 317-343.

Münkler, Herfried: Die neuen Kriege. Reinbeck: Rowohlt ${ }^{5} 2002$.

Musharbash, Yassin: Die neue Al-Qaida. Innenansichten eines lernenden Terrornetzwerks, Köln: Kiepenheuer \& Witsch 2006.

Nagel, Tilman: „Die Ebenbürtigkeit des Fremden. Über die Aufgaben arabistischer Lehre und Forschung in der Gegenwart", in: Zeitschrift der Deutschen Morgenländischen Gesellschaft 148 (1998), S. 367-378.

Nagel, Tilman: Das islamische Recht. Eine Einführung, Westhofen: WVAVerlag 2001.

Nagel, Tilman: Islam. Die Heilsbotschaft des Korans und ihre Konsequenzen, Westhofen: WVA 2001.

Naumkin, Vitalij V.: Radical Islam in Central Asia. Between Pen and the Rifle (Soviet Bloc and After), Lanham u.a.: Rowman \& Littlefield 2005.

Noor, Farish A.: Writings on the War on Terror, New Delhi: Global Media Publications 2006.

Noth, Albrecht/Paul, Jürgen (Hg.): Der islamische Orient. Grundzüge seiner Geschichte, Würzburg: Ergon 1998.

Noth, Albrecht: Quellenkritische Studien zu Themen, Formen und Tendenzen frühislamischer Geschichtsüberlieferung. Themen und Formen, Bonn 1973. (Bonner Orientalistische Studien 25)

Oesterheld, Christina: „Problems of Teaching Urdu in Germany: A Foreigner's Reflections on the Status of Urdu“, in: The Annual of Urdu Studies 17 (2002), S. 125-137.

O'Fahey, Sean R. (Hg.): The Writings of Eastern Sudanic Africa. Arabic Literature of Africa, Bd. 1, Leiden: Brill 1994.

Ohlig, Karl-Heinz: „Wir müssen uns wehren. Appell für eine neue Islamwissenschaft", in: FAZ vom 21.11.2006, S. 41 und 43.

Olcott, Martha Brill: Roots of Radical Islam in Central Asia. (Carnegie Papers 77), Washington 2007.

Ouzane, Lahoucine (Hg.): Islamic Masculinities, London, New York: Zed Books 2006. 
Paret, Rudi: Arabistik und Islamkunde an deutschen Universitäten. Deutsche Orientalisten seit Theodor Nöldeke, Wiesbaden: Otto Harrassowitz 1966.

Patricia Crone: „'Jihad'. Idea and history“, in: www.opendemocracy.net/faitheurope_islam/jihad_4579.jsp vom 30.10.2007.

Patricia Crone: „What do we actually know about Mohammed?“, www.opendemocracy.net/faith-europe_islam/mohammed_3866.jsp vom 30.10.2007.

Paul, Jürgen: Die politische und soziale Bedeutung der Naqšbandiyya in Mittelasien im 15. Jahrhundert, Berlin, New York: de Gruyter 1991.

Pernau, Margrit: „Global history. Wegbereiter für einen neuen Kolonialismus“, in: geschichte-transnational 2004, http://geschichte-transnational.clioonline. et $/$ forum $/ \mathrm{id}=572 \&$ count $=26 \&$ recno $=25 \&$ type $=$ diskussionen $\&$ sort $=$ datum\&order=down\&segment=16 vom 16.9.2007.

Pernau, Margrit: „Transkulturelle Geschichte und das Problem der universalen Begriffe. Muslimische Bürger im Delhi des 19. Jahrhunderts“, in: Birgit Schäbler (Hg.): Area Studies und die Welt. Weltregionen und neue Globalgeschichte, Wien: Mandelbaum 2007 (im Druck).

Pflitsch, Andreas: Mythos Orient. Eine Entdeckungsreise. Freiburg u.a.: Herder 2003.

Philipp, Thomas: „Geschichtswissenschaft und die Geschichte des Nahen Ostens“, in: Saeculum 1 (1994), S. 166-178.

Piesche, Peggy: „Das Ding mit dem Subjekt, oder: Wem gehört die Kritische Weißseinsforschung?“, in: diess. u.a. (Hg.): Mythen, Masken und Subjekte. Kritische Weißseinsforschung in Deutschland, Münster: unrast-Verlag 2005, S. 14-17.

Piesche, Peggy: „Der 'Fortschritt' der Aufklärung. Kants 'Race' und die Zentrierung des weißen Subjekts“, in: diess. u.a. (Hg.): Mythen, Masken und Subjekte. Kritische Weißseinsforschung in Deutschland, Münster: unrast-Verlag 2005, S. 30-39.

Plumelle-Uribe, Rosa Amelia: Weisse Barbarei. Vom Kolonialrassismus zur Rassenpolitik der Nazis, Zürich: Rotpunktverlag 2004.

Pollock, Sheldon: „Deep Orientalism? Notes on Sanskrit and Power Beyond the Raj“, in: Carol Breckenridge/Peter van der Veer (Hg.): Orientalism and the Postcolonial Predicament. Perspectives on South Asia, Philadelphia: Pennsylvania UP 1993, S. 76-133.

Preissler, Holger: Die Anfänge der Deutschen Morgenländischen Gesellschaft, Göttingen 1995 [Erweiterter Sonderdruck aus der ZDMG, Band 145/2].

Pritsch, Erich: „Georg Kampffmeyer“, in: Die Welt des Islams 18 (1936), S. 111.

Quellien, Alain: La politique musulmane dans l'Afrique Occidentale Française , Paris: Emile Larose 1910.

Radtke, Bernd: „Von des Chisers Händeln und schmutzigen Tricks“ in: Der Islam 81 (2004), S. 96-114. 
Radtke, Bernd: Autochthone islamische Aufklärung im 18. Jahrhundert. Theoretische und filologische Bemerkungen. Fortführung einer Debatte, Utrecht: Houtsma Stichting 2000.

Radtke, Bernd: Neue kritische Gänge. Zu Stand und Aufgaben der Sufikforschung, Utrecht: Houtsma 2005.

Reinshagen, René: „Soziologisches Denken des Fremden“, in: Jennifer Wasmuth (Hg.): Zwischen Fremd- und Feindbildern. Interdisziplinäre Beiträge zu Rassismus und Fremdenfeindlichkeit, Münster: LIT 2000, S. 162-197.

Richter-Bernburg, Lutz: „Islamwissenschaft“, in: Florian Keisinger/Roland Berger (Hg.): Wozu Geisteswissenschaften? Kontroverse Argumente für eine überfällige Debatte, Frankfurt, New York: Campus 2003, S. 124-130.

Riexinger, Martin: Sanāullāh Amritsarī (1868-1948) und die Ahl-i Hadīs im Punjab unter britischer Herrschaft, Würzburg: Ergon 2004.

Rinn, Louis: Marabouts et Khouans, Étude sur I'Islam en Algérie, Algier: Adolphe Jourdan 1884.

Ritter, Hellmut: „Carl Heinrich Becker als Orientalist“, in: Der Islam 24 (1937), S. $175-85$.

Roche-Mahdi, Sarah: „The Cultural and Intellectual Background of German Orientalism“, in: Azim Nanji (Hg.): Mapping Islamic Studies. Genealogy, Continuity and Change, Den Haag: Mouton de Gruyter 1997, S. 108-127.

Rodinson, Maxime: Die Faszination des Islam, München: Beck 1991.

Rohe, Mathias: Der Islam. Alltagskonflikte und Lösungen, Freiburg u.a.: Herder 2001.

Rosen, Friedrich: Aus einem diplomatischen Wanderleben, Bd. 3-4, Wiesbaden: Limes Verlag 1959.

Rosenthal, Franz: „Die Krise der Orientalistik“, in: Fritz Steppat (Hg.): XXI. Deutscher Orientalistentag vom 24. bis 29. März 1980 in Berlin. Vorträge, Wiesbaden: Steiner 1983, S. 10-21.

Rosenthal, Franz: The Muqaddimah. An Introduction to History, 3 Bde., Princeton: Princeton UP 1967.

Rotter, Gernot: Allahs Plagiator. Die publizistischen Raubzüge des „Nahostexperten“ Gerhard Konzelmann, Heidelberg: Palmyra 1992.

Rotter, Gernot: Die Stellung des Negers in der islamisch-arabischen Gesellschaft bis zum XVI. Jahrhundert, Bonn: Rheinische Friedrich-Wilhelms-Universität 1966.

Roy, Olivier: The New Central Asia. The Creation of Nations, London: Tauris 2000.

Roy, Olivier: Globalized Islam. The search for a new ummah, London: Hurst 2004.

Rubin, Barry/Rubin, Judith C. (Hg.): Anti-American Terrorism and the Middle East. A Documentary Reader, Oxford: Oxford UP 2002. 
Rudolph, Eckehard: Bestandsaufnahme. Kultur- und Sozialwissenschaftliche Forschung über die muslimische Welt in der Bundesrepublik Deutschland, Hamburg: Deutsches Orient-Institut 1999.

Rudolph, Ekkehard: Westliche Islamwissenschaft im Spiegel muslimischer Kritik. Grundzüge und aktuelle Merkmale einer innerislamischen Diskussion, Berlin: Klaus Schwarz 1991.

Rüsen, Jörn: Kultur macht Sinn, Köln, Weimar: Böhlau 2006.

Sabine Hark: Dissidente Partizipation. Eine Diskursgeschichte des Feminismus, Frankfurt/M: Suhrkamp 2005.

Sachau, Eduard: Bericht über die Eröffnung des Seminars für Orientalische Sprachen an der königlichen Friedrich-Wilhelms-Universität zu Berlin und einige auf das Seminar bezügliche Schriftstücke, Berlin: Im Comm.-Verlag bei A. Asser 1888.

Safranski, Rüdiger: Nietzsche. Auswahl seiner Texte, München: dtv 1999.

aš-Šahrastān̄̄, M. Abū al-Fatḥ: al-Milal wa an-nihal, Bd. 1, Beirut o. J.

Said, Edward: Orientalism. New York: Vintage Books 2003 [ $\left.{ }^{1} 1978\right]$.

Salvatore, Armando: Islam and the Political Discourse of Modernity, Reading: Ithaca 1999.

Schäbler, Birgit: „Das Studium der Weltregionen (Area Studies) zwischen Fachdisziplinen und der Öffnung zum Globalen: Eine wissenschaftsgeschichtliche Annäherung“, in: diess., Area Studies und die Welt. Weltregionen und neue Globalgeschichte, Wien: Mandelbaum Verlag 2007, S. 11-44.

Schäbler, Birgit: „Konstruktionen des Selbst als Wissenschaft. Anmerkungen einer Nahost-Historikerin zu Leben und Werk Edward Saids“, in: Alf Lüdtke/Rainer Prass (Hg.): Gelehrtenleben. Wissenschaftspraxis in der Neuzeit, Göttingen: Böhlau 2007 (im Druck).

Schäbler, Birgit: „Vorwort“, in: diess., Area Studies und die Welt. Weltregionen und neue Globalgeschichte, Mandelbaum Verlag: Wien 2007, S. 7-10.

Schäbler, Birgit: Area Studies und die Welt. Weltregionen und neue Globalgeschichte, Wien: Mandelbaum Verlag 2007.

Schäbler Birgit: „Civilizing Others: Global Modernity and the Local Boundaries (French/German, Ottoman, and Arab) of Savagery“, in: diess./Leif Stenberg (Hg.): Globalization and the Muslim World. Culture, Religion and Modernity, Syracuse UP 2004, S. 3-29.

Schäbler, Birgit/Stenberg, Leif (Hg.): Globalization and the Muslim World. Culture, Religion and Modernity, with a Foreword by Roy Mottahedeh, Syracuse: Syracuse UP 2004.

Schenk, Arnfrid: „1001 Hürden. Nach dem 11. September wuchs das Interesse an den Islamwissenschaften. Warum sie dennoch nicht zum Massenfach werden“, in: Die Zeit vom 21.02.2002, S. 73.

Schiffer, Sabine: „Musliminnen in Deutschland. Von Kronzeugen und Halbwahrheiten“, http://qantara.de/webcom/show_article.php?wc_c=469\&wc_ $\mathrm{id}=501$ vom 1.3.2007. 
Schiffer, Sabine: Die Darstellung des Islams in der Presse. Sprache, Bilder, Suggestionen. Eine Auswahl von Techniken und Beispielen, Erlangen, Nürnberg (Dissertation) 2004.

Schild, Hartmut/Wild, Stefan (Hg.): Norm und Abweichung. Akten des 27. Deutschen Orientalistentages (Bonn, 28. September bis 2. Oktober 1998), Würzburg: Ergon 2001.

Schimmel, Annemarie: Auf den Spuren der Muslime. Mein Leben zwischen den Kulturen, hg. von Hartmut Bobzin/Navid Kermani, Freiburg, Basel, Wien: Herder 2002.

Schimmel, Annmarie: „Der islamische Orient. Wege seiner Vermittlung nach Europa“, in: Jochen Golz (Hg.): Goethes Morgenlandfahrten. West-östliche Begegnungen, Frankfurt/M: Insel 1999, S. 16-28.

Schöller, Marco: Methode und Wahrheit in der Islamwissenschaft: Prolegomena, Wiesbaden: Harrassowitz 2000.

Schönig, Hanne (Hg.): Ausgegrenzte Kompetenz. Porträts vertriebener Orientalisten und Orientalistinnen 1933-1945, Halle/Saale: OWZ 2001.

Schulin, Ernst: Die weltgeschichtliche Erfassung des Orients bei Hegel und Ranke, Göttingen: Vandenhoeck \& Ruprecht 1958.

Schulze, Reinhard: „Das islamische achtzehnte Jahrhundert. Versuch einer historiographischen Kritik“, in: Die Welt des Islams 30 (1990), S. 140-159.

Schulze, Reinhard: „Die islamische Welt in der Neuzeit (16.-19. Jahrhundert)“, in: Albrecht Noth/Jürgen Paul (Hg.): Der islamische Orient. Grundzüge seiner Geschichte, Würzburg: Ergon 1998, S. 333-405.

Schulze, Reinhard: „Orientalistik und Orientalismus“, in: Werner Ende/Udo Steinbach (Hg.): Der Islam in der Gegenwart. München: Beck ${ }^{5} 2005$, S. 755767.

Schulze, Reinhard: „Rasse, Klasse und Kultur“, in: Gewerkschaftliche Monatshefte 11-12/2001, S. 670-678.

Schulze, Reinhard: „Was ist die islamische Aufklärung?“, in: Die Welt des Islams 36 (1996), S. 276-325.

Schütte, Hans-Wilm: Die Asienwissenschaften in Deutschland. Geschichte, Stand und Perspektiven, Hamburg: IFA 2002.

Scott, David: „The Construction of Postcolonial Studies“, in: Ania Loomba u.a. (Hg.): Postcolonial Studies and Beyond, Durham, London: Duke UP 2005, S. 385-400

Seiffert, Helmut: Einführung in die Wissenschaftstheorie, 2. Bd., München: Beck 1970.

Sen, Amartya: Die Identitätsfalle. Warum es keinen Krieg der Kulturen gibt, München: Beck 2007.

Senghaas, Dieter: „Schluss mit der Fundamentalismus-Debatte! Plädoyer für eine Reorientierung des interkulturellen Dialogs“, in: Blätter für deutsche und internationale Politik 40 (1995), S. 180-191. 
Sezgin, Hilal: „Stolzes Vorurteil“, in: die tageszeitung vom 20.09.2006: 11; www.taz.de/pt/2006/09/20/a0138.1/text vom 1.3.2007.

Sharpe, Jenny: „Figures of Colonial Resistance“, in: Bill Ashcroft/Gareth Griffiths/Helen Tiffin (Hg.): The Post-Colonial Studies Reader, London, New York: Routledge 2004, S. 99-103.

Sigmund Freud: Das Unbehagen in der Kultur. Und andere kulturtheoretische Schriften, Frankfurt/M: Fischer 1996.

Slaje, Walter: „Was ist und welchem Zweck dient Indologie? Tractatus irae“, in: ZDMG 153 (2003), S. 311-331.

Slatin, Rudolph: Feuer und Schwert im Sudan, Leipzig: F. A. Brockhaus 1895/ 1922.

Sloterdijk, Peter: Zorn und Zeit. Politisch-Psychologischer Versuch, Frankfurt/M: Suhrkamp 2006.

Sökefeld, Martin (Hg.): Jenseits des Paradigmas kultureller Differenz. Neue Perspektiven auf Einwanderer aus der Türkei, Bielefeld: transcript 2004.

Sösemann, Bernd: „Das 'erneuerte Deutschland'. Ernst Troeltschs politisches Engagement im Ersten Weltkrieg“, in: Horst Renz/Friedrich Wilhelm Graf (Hg.): Troeltsch-Studien, Bd. 3, Protestantismus und Neuzeit, Gütersloh 1984, S. 120-144.

Spann, Korbinian: Der, Die, Das Fremde. Juden und jüdische Religion als Paradigma einer Philosophie des Fremden, Berlin: LIT 2006.

Spivak, Gayatri Chakravorty: „Can the Subaltern Speak?“, in: Cary Nelson/Lawrence Grossberg (Hg.): Marxism and the Interpretation of Culture, London, Hampshire: MacMillan Education 1988, S. 271-313.

Sprondel, Walter M.: „Über das Verhältnis der Soziologie zu den Geisteswissenschaften“, in Florian Keisinger/Steffen Seischab (Hg.): Wozu Geisteswissenschaften? Kontroverse Argumente für eine überfällige Debatte, Frankfurt, New York: Campus 2003, S. 163-167.

Stauth, Georg: Islam und westlicher Rationalismus. Der Beitrag des Orientalismus zur Entstehung der Soziologie, Frankfurt/M: Campus 1993.

Steinbach, Udo: „Neuere Entwicklungen in der deutschen gegenwartsbezogenen Nahost-Wissenschaft", in: Marion Gebhardt (Hg.): Institutionen der gegenwartsbezogenen Orient-Forschung und -Information in der Bundesrepublik Deutschland und Berlin (West), Hamburg: Deutsches Übersee-Institut 1991, S. IV-XXIV.

Steinbach, Udo: Dhat al-Himma. Kulturgeschichtliche Untersuchungen zu einem arabischen Volksroman, Wiesbaden: Steiner 1972.

Steinberg, Guido: Der nahe und der ferne Feind. Die Netzwerke des islamistischen Terrorismus, München: Beck 2005.

Steppat, Fritz: „Wissenschaftliche Nachrichten: Contemporary Middle East Studies in Germany“, in: ZDMG 126 (1976), S. 8-13.

Subrahmanyam, Sanjay: „Connected histories. Notes towards a reconfiguration of early modern Eurasia“, in: Modern Asian Studies 31 (1997), S. 735-62. 
as-Sūrī, Abu Mus'ab: Da'wa al-muqāwama al-islāmīya al-'ālamīya (Aufruf zum weltweiten islamischen Widerstand), o.O., 2004.

Sykes, Christopher: Wassmuss, the German Lawrence, New York: Longmans, Green\&Co. 1936.

Tibi, Bassam: Die Verschwörung. Das Trauma arabischer Politik, Hamburg: Hoffmann und Campe 1993.

Tibi, Bassam: Krieg der Zivilisationen. Politik und Religion zwischen Vernunft und Fundamentalismus, Hamburg: Hoffmann und Campe 1995.

Todorov, Tzvetan: Die Eroberung Amerikas. Das Problem des Anderen, Frankfurt/M: Suhrkamp 2005.

Toprak, Ahmet: Das schwache Geschlecht - die türkischen Männer. Zwangsheirat, häusliche Gewalt, Doppelmoral der Ehre, Freiburg : Lambertus Verlag 2005.

Trautner, Bernhard J.: Der interkulturelle Dialog unter dem Druck des Fundamentalismus-Paradigmas, in: Orient 36 (1995), S. 228-241.

Troeltsch, Ernst: Der Historismus und seine Probleme, Tübingen: Mohr 1922.

Turner, Bryan: Orientalism, postmodernism and globalism, London: Routledge 1994.

Tworuschka, Monika: „Islam und Vorurteile. Vorurteile und andere Urteilsformen“, in: Albrecht Noth/Jürgen Paul (Hg.): Der islamische Orient. Grundzüge seiner Geschichte, Würzburg: Ergon 1998, S. 15-24.

Vahiduddin, Syed: „Islamic Experience in Contemporary Thought“, in: Christian W. Troll (Hg.): Islam in India. Studies and Commentaries, Bd. 3, Delhi: Chanakya Publications 1986.

Vahiduddin, Syed: Indisch-moslemische Werterlebnisse als Parallele zu europäischen Kulturwandlungen, Leipzig: J. A. Barth 1937.

Varisco, Daniel M.: Islam Obscured. The Rhetoric of Anthropological Representation, New York u.a.: Palgrave Macmillan 2005.

Vasilev, Aleksandr A.: Byzance et les Arabes, Bd.1: La Dynastie d'Amorium, Brüssel: Inst. de Philologie et d'Histoire Orientales 1935.

Vernoit, Stephen: „Islamic Art and Architecture. An Overview of Scholarship and Collecting, c. 1850-1950“, in: Stephen Vernoit (Hg.): Discovering Islamic Art. Scholars, Collectors and Collections, 1850-1950, London, New York 2000, S. 1-61.

Voigt, Wolfgang (Hg.): Deutscher Orientalistentag: Vorträge. Vom 21. bis 27. Juli 1968 in Würzburg, Teil 1. 1969, Zeitschrift der Deutschen Morgenländischen Gesellschaft: Supplement; 1, S. XXXI.

Waardenburg, Jacques: „The Study of Islam in German Scholarship“, in: Azim Nanji (Hg.): Mapping Islamic Studies. Genealogy, Continuity and Change, Den Haag: Mouton de Gruyter, 1997, S. 1-32.

Wadud, Amina: Inside the Gender Jihad. Women`s Reform in Islam, Oxford: Oneworld 2006. 
Wehler, Hans-Ulrich: Geschichte und Soziologie, Köln: Kiepenheuer \& Witsch, 1976.

Wehler, Hans-Ulrich: „Verblendetes Harakiri. Der Türkei-Beitritt zerstört die EU“, in: Aus Politik und Zeitgeschichte (APuZ), Nr. 33-34, 9. August 2004.

Wehler, Hans-Ulrich: Bismarck und der Imperialismus, Frankfurt/M: Fischer 1985.

Weidner, Stefan: „Zum Kampf der Waffen und Begriffe. Über harte und weiche Islamdeutungen“, in: Merkur 662 (2004), S. 500-509.

Weiss, Holger: „German Images of Islam in West Africa“, in: Sudanic Africa 11 (2000), S. 53-94.

White, Hayden: Die Bedeutung der Form. Erzählstrukturen in der Geschichtsschreibung, Frankfurt/M: Fischer 1990, S. 23, 43-44.

Wild, Stefan: „Der Friedenspreis und Annemarie Schimmel. Eine Nachlese“, in: Die Welt des Islams 36 (1996), S. 107-122.

Wild, Stefan: „National Socialism in the Arab Near East between 1933 and 1939“, in: Die Welt des Islams 25 (1985), S. 126-173.

Windisch, Ernst: Geschichte der Sanskrit-Philologie und Indischen Altertumskunde, Reprint von 1917-21, Berlin, New York: de Gruyter 1992.

Wittkau, Annette: Historismus. Zur Geschichte des Begriffs und des Problems, 2. Aufl., Göttingen: Vandenhoeck \& Ruprecht 1994.

Woldan, Erich: „Österreichische Forscher in Ostafrika und ihre Publikationen“, in: Abenteuer Ostafrika. Der Anteil Österreich-Ungarns an der Erforschung Ostafrikas, Eisenstadt: Amt der Burgenländischen Landesregierung 1988, S. 125-8.

Wollrad, Eske: Weißsein im Widerspruch. Feministische Perspektiven auf Rassismus, Kultur und Religion, Königstein/Taunus: Ulrike Helmer Verlag 2005.

Wunsch, Cornelia (Hg.): XXV. Deutscher Orientalistentag, vom 8. bis 13.4.1991 in München. Vorträge, Stuttgart: Steiner 1994.

Wüstenfeld, Ferdinand: Geschichte des Fatimiden Chalifates, Göttingen 1880-81 u. 1890.

Young, Robert: White Mythologies. Writing History and the West, London, New York: Routledge 1990.

Young, Robert: Colonial Desire. Hybridity in Theory, Culture and Race, London, New York: Routledge 1996.

Zach, Michael: Österreicher im Sudan von 1820 bis 1914, Wien: Veröffentlichungen des Instituts für Afrikanistik und Ägyptologie der Universität Wien 1985.

Zinflou, Sascha: „Entwurfsmuster des deutschen Rassismus. Ein theoretischer Überblick“, in: Kien Nghi Ha/Nicola Lauré al-Samarai/Sheila Mysorekar (Hg.): re/visionen. Postkoloniale Perspektiven von People of Color auf Rassismus, Kulturpolitik und Widerstand in Deutschland, Münster: unrastVerlag 2007, S. 55-64. 


\section{Autorinnen und Autoren}

Ludwig Ammann, geb. 1961, ist Filmverleger, Publizist und Islamwissenschaftler in Freiburg/Breisgau. Zuletzt erschienen Was stimmt? Islam - Die wichtigsten Antworten, Freiburg 2007, und Der Islam am Wendepunkt: Liberale und konservative Reformer einer Weltreligion (hg. mit Katajun Amirpur), Freiburg 2006.

Tim Epkenhans, geb. 1972, ist Leiter der OSZE-Akademie in Bischkek, Kirgisistan. Zurzeit forscht er im Rahmen eines Oral History-Projektes zu den Ursachen des Bürgerkrieges in Tadschikistan. Zuletzt erschien The OSCE's Dilemma in Central Asia (OSCE Yearbook 2006), Baden-Baden 2007.

Bert G. Fragner, geb. 1941, ist Professor für Iranistik und leitet zurzeit das Institut für Iranistik der Österreichischen Akademie der Wissenschaften. Seine Forschungsschwerpunkte sind u.a. die Kultur-, Wirtschafts- und Gesellschaftsgeschichte Irans, Afghanistans, des islamischen Indiens und Mittelasiens vom späten Mittelalter bis zum 20. Jahrhundert; zu seinen zahlreichen Veröffentlichungen gehören: Die „Persophonie “: Regionalität, Identität und Sprachkontakt in der Geschichte Asiens, Berlin 1999, und Zentralasien, 13. bis 20. Jahrhundert. Geschichte und Gesellschaft (hg. mit A. Kappeler), Wien 2006.

Ulrike Freitag, geb. 1962, ist Direktorin des Zentrum Moderner Orient in Berlin und Professorin für Islamwissenschaft an der FU Berlin. Ihre zuletzt erschienene Monographie ist Indian Ocean Migrants and State Formation in Hadhramaut, Leiden 2003. Zurzeit arbeitet sie über die Stadtgeschichte von Jidda. Weitere Forschungsinteressen sind moderne arabische Historiographie und die globalgeschichtliche Verortung des Vorderen Orients.

Jan-Peter Hartung, geb. 1969, ist seit Herbst 2007 Lecturer for the Study of Islam an der School of Oriental and African Studies in London. Zuletzt erschienen 
Viele Wege und ein Ziel. Leben und Werk von Sayyid Abū l-Hasan 'Alī al-Hasañ̄ Nadwī (1914-1999), Würzburg 2004, und Islamic Education, Diversity, and National Identity. Dīnī Madāris in India Post 9/11 (hg. mit H. Reifeld), London 2006.

Benjamin Jokisch ist seit Februar 2006 als Privatdozent für Islamwissenschaft an der Universität Hamburg tätig. Seine Forschungen konzentrieren sich derzeit auf die Entwicklung des islamischen Rechts in transkulturellen Kontexten. Die jüngste Veröffentlichung trägt den Titel Islamic Imperial Law. Hārūn al-Rashīd's Codification Project, Berlin/New York 2007.

Navid Kermani, geb. 1967, ist habilitierter Islamwissenschaftler und war bis 2003 Long Term Fellow am Wissenschaftskolleg zu Berlin. Heute lebt er als freier Schriftsteller in Köln. Zuletzt erschien von ihm die Monographie Der Schrecken Gottes. Attar, Hiob und die metaphysische Revolte, München 2005, und der Roman Kurzmitteilung, Zürich 2007.

Lorenz Korn, geb. 1966, ist Professor für Islamische Kunstgeschichte und Archäologie an der Universität Bamberg. Forschungsschwerpunkte sind Architektur und Baudekor in den Kerngebieten der islamischen Welt (11.-16. Jh.), Metallarbeiten, Epigraphik und Numismatik. Zuletzt erschienen Ayyubidische Architektur in Ägypten und Syrien, Heidelberg 2004, Governing the Holy City (hg. mit J. Pahlitzsch), Wiesbaden 2004, und Bosra - Islamische Architektur und Archäologie (Hg.), Rahden/Westf. 2005.

Gudrun Krämer, geb. 1953, ist Professorin für Islamwissenschaft an der Freien Universität Berlin. Forschungsschwerpunkte sind Geschichte, Politik und Gesellschaft des Modernen Vorderen Orients, islamische Bewegungen und islamischpolitische Theorie. Zuletzt erschienen Geschichte des Islam, München 2005, und Speaking for Islam: Religious Authorities in Muslim Societies, Leiden 2006.

Birgit Krawietz ist habilitierte Islamwissenschaftlerin und arbeitet gegenwärtig als wissenschaftliche Mitarbeiterin am Berliner Zentrum Moderner Orient. Von ihr sind u.a. erschienen: Die Hurma: Schariatrechtlicher Schutz vor Eingriffen in die körperliche Unversehrtheit nach arabischen Fatwas des 20. Jahrhunderts, Berlin 1991, und Hierarchie der Rechtsquellen im tradierten sunnitischen Islam, Berlin 2002.

Roman Loimeier, seit kurzem Professor am Department of Religions (Islamic Studies), University of Florida, Gainesville, studierte Ethnologie, Religionswissenschaft, Soziologie und Islamwissenschaft an den Universitäten Freiburg, London (SOAS) und Bayreuth. Seit 1981 umfangreiche Forschungen in Afrika (Se- 
negal, Nigeria, Tansania) und zahlreiche Veröffentlichungen zum Themenfeld 'Geschichte und Entwicklung islamischer Gesellschaften in Afrika'.

Mariam Popal, Freie Wissenschaftlerin und Lehrbeauftragte an der AlbertLudwigs-Universität Freiburg. Promotion an der Universität Hamburg über die Konstruktion der Scharia als religiöses Recht im Rahmen postkolonialer Theorien. Zuletzt erschien „Kopftücher HipHop - Körper sprechen schweigend (andere) Geschichten“ in: Kien Nghi Ha u.a. (Hg.), re/visionen. Postkoloniale Perspektiven von People of Color auf Rassismus, Kulturpolitik und Widerstand in Deutschland, Münster 2007.

Abbas Poya, geb. 1967, ist wissenschaftlicher Assistent am Lehrstuhl Islamwissenschaft an der Universität Freiburg. Von ihm sind u.a. erschienen: Anerkennung des Iğtihād - Legitimation der Toleranz. Möglichkeiten innerer und äußerer Toleranz im Islam am Beispiel der Iğtihād-Diskussion, Berlin 2003, und $\breve{S}$ kībāȳi, dimūkrāsī wa ḥuqūq-i bašar (Toleranz, Demokratie und Menschenrechte), Teheran 2007.

Maurus Reinkowski, geb. 1962, ist Professor für Islamwissenschaft an der Universität Freiburg. Seine Forschungsschwerpunkte sind die neuere Geschichte des Nahen Ostens und des östlichen Mittelmeerraums, Libanon und Palästina, Konversion und Nationalismus. Zuletzt erschienen Die Dinge der Ordnung. Eine vergleichende Untersuchung über die osmanische Reformpolitik im 19. Jahrhundert, München 2005, und Rechtspluralismus in der islamischen Welt: Gewohnheitsrecht zwischen Staat und Gesellschaft (hg. mit Michael Kemper), Berlin 2005.

Birgit Schäbler, Professorin für Westasiatische Geschichte an der Universität Erfurt, ist z.Zt. Fellow am Max Weber-Kolleg. Zuletzt erschienen Globalization and the Muslim World. Culture, Religion and Modernity (hg. mit Leif Stenberg), Syracuse University Press 2004, und Area Studies und die Welt. Weltregionen und neue Globalgeschichte, Wien 2007.

Manfred Sing, geb. 1966, ist wissenschaftlicher Mitarbeiter am Orientalischen Seminar in Freiburg/Breisgau. Zurzeit erforscht er in einem DFG-Projekt die Neuorientierung arabischer Kommunisten nach 1989. Zuletzt erschien Progressiver Islam in Theorie und Praxis. Die interne Kritik an hegemonialen islamischen Diskurs durch den „roten Scheich“ 'Abdallāh al-'Alāyilī (1914-1996), Würzburg 2007.

Udo Steinbach, geb. 1943, war von 1976 bis 2007 Direktor des Deutschen Orient-Instituts. Schwerpunkte seiner Arbeit sind Politik und Gesellschaft des arabischen Raums, Irans und insbesondere der Türkei sowie der Nahe Osten in der internationalen Politik. Zuletzt erschienen Zentralasien - Geschichte, Politik, Wirt- 
schaft, (hg. mit Marie-Carin von Gumppenberg), München 2004, und Autochthone Christen im Nahen Osten. Zwischen Verfolgungsdruck und Auswanderung, Hamburg 2006.

Guido Steinberg arbeitet zurzeit für die Stiftung Wissenschaft und Politik (SWP) in Berlin. In seiner Forschung beschäftigt er sich mit der Golfregion, dem Irak sowie islamistischen Terroristen und hat zahlreiche Bücher und Artikel zur saudi-arabischen und irakischen Geschichte und Politik, zu Islamismus und Terrorismus publiziert. Zuletzt erschienen Der nahe und der ferne Feind. Die Netzwerke des islamistischen Terrorismus, München 2005. 


\section{Globaler lokaler Islam}

Abbas Poya,

Maurus Reinkowski (Hg.)

Das Unbehagen in der

Islamwissenschaft

Ein klassisches Fach

im Scheinwerferlicht

der Politik und

der Medien

März 2008, 322 Seiten,

kart., $30,80 €$,

ISBN: $978-3-89942-715-8$

Georg Stauth

Ägyptische heilige Orte II:

Zwischen den Steinen des

Pharao und islamischer

Moderne. Konstruktionen,

Inszenierungen und

Landschaften der

Heiligen im Nildelta:

Fuwa - Sa al-Hagar (Sais)

Mit ägyptologischen Studien von Silvia Prell. Fotografische Begleitung von Axel Krause

März 2008, 250 Seiten,

kart., zahlr. farb. Abb., ca. 25,80 €,

ISBN: $978-3-89942-432-4$

Schirin Amir-Moazami

Politisierte Religion

Der Kopftuchstreit in

Deutschland und Frankreich

2007, 294 Seiten,

kart., $28,80 €$,

ISBN: $978-3-89942-410-2$

Johann P. Arnason,

Armando Salvatore,

Georg Stauth (eds.)

Islam in Process

Historical and Civilizational

Perspectives

(Yearbook of the Sociology

of Islam 7)

2007, 332 Seiten,

kart., $36,80 €$,

ISBN: $978-3-89942-491-1$
Gerdien Jonker,

Valérie Amiraux (eds.)

Politics of Visibility

Young Muslims in

European Public Spaces

2006, 226 Seiten,

kart., $27,80 €$,

ISBN: 978-3-89942-506-2

Irka-Christin Mohr

Islamischer Religionsunterricht in Europa

Lehrtexte als Instrumente muslimischer Selbstverortung im Vergleich

2006, 310 Seiten,

kart., 28,80 €,

ISBN: 978-3-89942-453-9

Georg Stauth

Ägyptische heilige Orte I:

Konstruktionen,

Inszenierungen und

Landschaften der

Heiligen im Nildelta:

'Abdallah b. Salam

Fotografische Begleitung

von Axel Krause

2005, 166 Seiten,

kart., zahlr. Abb., 24,80 €,

ISBN: 978-3-89942-260-3

Nilüfer Göle,

Ludwig Ammann (Hg.)

\section{Islam in Sicht}

Der Auftritt von Muslimen

im öffentlichen Raum

2004, 384 Seiten,

kart., 26,80 €,

ISBN: 978-3-89942-237-5

Leseproben und weitere Informationen finden Sie unter: www.transcript-verlag.de 


\section{Globaler lokaler Islam}

Georg Stauth (ed.)

On Archaeology of

Sainthood and Local

Spirituality in Islam

Past and Present Crossroads

of Events and Ideas

(Yearbook of the Sociology

of Islam 5)

2004, 228 Seiten,

kart., $26,80 €$,

ISBN: $978-3-89942-141-5$

Mechthild Rumpf, Ute Gerhard,

Mechtild M. Jansen (Hg.)

Facetten islamischer Welten

Geschlechterordnungen,

Frauen- und Menschenrechte in der Diskussion

2003, 319 Seiten,

kart., $24,80 €$,

ISBN: $978-3-89942-153-8$

Heiner Bielefeldt

Muslime im säkularen

Rechtsstaat

Integrationschancen

durch Religionsfreiheit

2003, 146 Seiten,

kart., $13,80 €$,

ISBN: $978-3-89942-130-9$

Levent Tezcan

Religiöse Strategien der

"machbaren" Gesellschaft

Verwaltete Religion und

islamistische Utopie

in der Türkei

2003, 232 Seiten,

kart., $26,80 €$,

ISBN: $978-3-89942-106-4$

Gerdien Jonker

Eine Wellenlänge zu Gott

Der »Verband der Islamischen

Kulturzentren in Europa "

2002, 282 Seiten,

kart., $25,80 €$,

ISBN: 978-3-933127-99-0
Georg Stauth

Politics and Cultures

of Islamization in

Southeast Asia

Indonesia and Malaysia

in the Nineteen-nineties

2002, 302 Seiten,

kart., 30,80 €,

ISBN: 978-3-933127-81-5

Sigrid Nökel

Die Töchter der Gast-

arbeiter und der Islam

Zur Soziologie alltagswelt-

licher Anerkennungspolitiken.

Eine Fallstudie

2002, 340 Seiten,

kart., $26,80 €$,

ISBN: 978-3-933127-44-0

Leseproben und weitere Informationen finden Sie unter: www.transcript-verlag.de 